Southern Methodist University

SMU Scholar

Fall 12-16-2017

\title{
Common Goods in Uncommon Times: Water, Droughts, and the Sustainability of Ancestral Pueblo Communities in the Jemez Mountains, New Mexico, AD 1100-1700
}

Michael Aiuvalasit

Southern Methodist University, maiuvalasit@smu.edu

Follow this and additional works at: https://scholar.smu.edu/hum_sci_anthropology_etds

Part of the Archaeological Anthropology Commons

\section{Recommended Citation}

Aiuvalasit, Michael, "Common Goods in Uncommon Times: Water, Droughts, and the Sustainability of Ancestral Pueblo Communities in the Jemez Mountains, New Mexico, AD 1100-1700" (2017).

Anthropology Theses and Dissertations. DOI: https://doi.org/10.25172/td/11216826

https://scholar.smu.edu/hum_sci_anthropology_etds/2

This Dissertation is brought to you for free and open access by the Anthropology at SMU Scholar. It has been accepted for inclusion in Anthropology Theses and Dissertations by an authorized administrator of SMU Scholar. For more information, please visit http://digitalrepository.smu.edu. 
COMMON GOODS IN UNCOMMON TIMES: WATER, DROUGHTS,

AND THE SUSTAINABILITY OF ANCESTRAL PUEBLO

COMMUNITIES IN THE JEMEZ MOUNTAINS,

NEW MEXICO, AD 1100-1700

Approved by:

Christopher I. Roos, Associate Professor Southern Methodist University

Michael Adler, Associate Professor Southern Methodist University

Matthew Liebmann, Associate Professor Harvard University

David J. Meltzer, Professor

Southern Methodist University 


\title{
COMMON GOODS IN UNCOMMON TIMES: WATER, DROUGHTS, AND THE SUSTAINABILITY OF ANCESTRAL PUEBLO \\ COMMUNITIES IN THE JEMEZ MOUNTAINS, NEW MEXICO, AD 1100-1700
}

\author{
A Dissertation Presented to the Graduate Faculty of \\ Dedman College \\ Southern Methodist University \\ in \\ Partial Fulfillment of the Requirements \\ for the degree of \\ Doctor of Philosophy \\ with a \\ Major in Anthropology \\ by
}

Michael J. Aiuvalasit

B.A., Anthropology, Archaeological Studies, and History, University of Texas, Austin M.A., Anthropology, Texas A\&M University, College Station

M.A., Anthropology Southern Methodist University, Dallas

December 16, 2017 
Copyright (2017)

Michael J. Aiuvalasit

All Rights Reserved 


\section{ACKNOWLEDGMENTS}

I have too many to acknowledge in too little space. Twenty years ago I took my first anthropology class at the University of Texas at Austin. Dr. Jim Neely introduced me to interdisciplinary approaches to studying water, and he continues to be my mentor. The late Dr. Karl Butzer inspired me to pursue geoarchaeology, while Dr. Stephen Black taught me that there’s more than one way to be an archaeologist. While at Texas A\&M, Dr. Michael Waters’ training made me a geoarchaeologist and in my cohort I found people as excited about archaeology as I was. From Janet McVickar introducing me to New Mexican archaeology to the incomparable Dr. Joe Schuldenrein, the best archaeologists I've worked with were in CRM.

SMU has been good to me. Support from the Anthropology Department, Dedman College, the ORGS, ISEM, the Clements Center, and the DCII got me in the field, to conferences, and time to write. Analyses were funded by the National Science Foundation and professional societies (SAA, GSA, and NMAC). Through Dr. Chris Roos all things dissertation-related were possible. Thank you. I thank the researchers of the FHiRE project, my SMU cohort, my committee, SMU faculty and staff, Drs. Charles Frederick and Barbara Winsborough, supportive Southwestern archaeologists, and resource managers at Bandelier National Monument, Los Alamos National Labs, and the Santa Fe National Forest. I thank the descendant communities, and particularly Jemez Pueblo, for their interest and involvement. Finally, I must acknowledge my family, particularly Leslie and Simon, for their encouragement, understanding, and love. 
Aiuvalasit, Michael J. $\quad$ M.A., Anthropology, Southern Methodist University, Dallas, 2012

Common Goods in Uncommon Times: Water, Droughts, and the Sustainability of Ancestral Pueblo

Communities in the Jemez Mountains,

New Mexico, AD 1100-1700

Advisor: Professor Christopher I. Roos

Doctor of Philosophy conferred December 16, 2017

Dissertation completed September 29, 2017

Adapting our infrastructure and institutions to climate change is a crucial dilemma for modern society. Archaeologists should be well positioned to address this issue with examples from the past. Yet, too often when we find that cultural changes are synchronous with climate variation, such as abandonment of a region during a drought, we advance causal arguments to what may merely be correlations. I argue that identifying proxies for resource management in the archaeological record, particularly for resources managed by collective action and vulnerable to climate change, can help to address this problem. To test this approach I studied water management practices of Ancestral Pueblo communities living on the highland mesa-tops of the Jemez Mountains of New Mexico. Between AD 1100-1700 cultural histories across this region diverged. Ancestral Towa communities of the Jemez Plateau sustained high populations until Spanish removal in the 17th century. The adjacent Pajarito Plateau was nearly completely depopulated by ancestral Tewa and Keres communities by the early 16th century. Archaeologists hypothesize that droughts were a factor in pushing people off the Pajarito Plateau, yet the endurance of communities on the Jemez Plateau is unconsidered. Mesa-top communities in both regions constructed artificial water reservoir features, which historical Pueblo communities 
managed as common pool resources. I hypothesize that these archaeological features reflect collective action decision-making for managing water, a resource vulnerable to scarcity on these mesa-tops during droughts, and that decisions made about water management influenced the long-term sustainability of Ancestral Pueblo communities.

Through diachronic socio-hydrological modeling, I identify how climate variation influenced feedbacks between resource users, water infrastructure, and hydrological systems. I conducted modeling of paleohydrological system responses to droughts, direct geoarchaeological investigations of fifteen reservoirs at nine Ancestral Pueblo villages, and geospatial analyses of water access. My hydrological modeling found that the Pajarito Plateau is more vulnerable to hydrological droughts than the Jemez Plateau. My geoarchaeological investigations found that communities on the Jemez Plateau built reservoirs before droughts when populations were low, and that reservoirs were used and maintained through their entire occupation histories. By contrast, communities of the Pajarito Plateau built reservoirs in the early 1300s when hamlets were coalescing into villages at the peak of regional populations. All of the reservoirs on the Pajarito Plateau, as well as many of the villages with reservoirs, were then abandoned by the mid-1400s. Through least cost analyses from hundreds of water sources to thousands of archaeological sites I found that water costs became much higher during droughts on the Pajarito Plateau, which was further exacerbated by the pooling of resources (and risks) in aggregated communities. Therefore, it cannot be ruled out that an over-reliance on collective action approaches to water management made communities on the Pajarito Plateau more vulnerable to hydrological droughts than communities on the Jemez Plateau. My work shows how archaeological research into resource management, employing earth science methods and common pool resource theory, contributes to dialogs surrounding adaptations to climate change. 


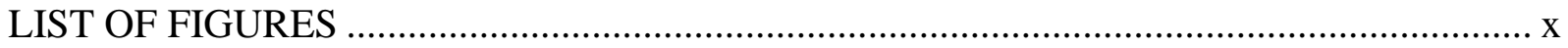

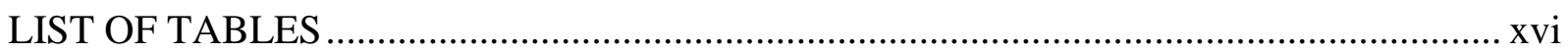

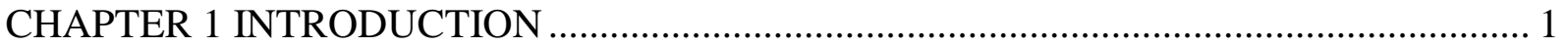

1.1 Droughts, Infrastructure, and Sustainability in the Jemez Mountains .............................. 3

1.2 Research Questions ........................................................................................................ 8

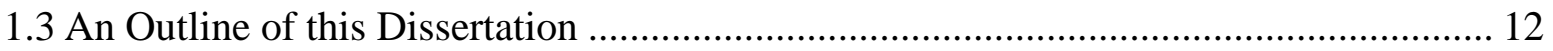

CHAPTER 2 AN ARCHAEOLOGY OF THE COMMONS..................................................... 15

2.1 Sustainability as an Analytical Framework for SES Investigations in Archaeology...... 15

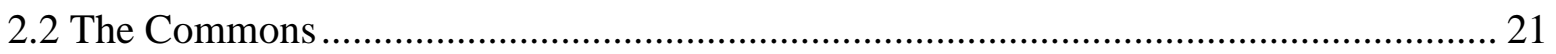

2.3 Archaeological Studies of the Commons........................................................................ 26

2.4 A Future for the Archaeology of the Commons .............................................................. 31

CHAPTER 3 PALEOPRECIPITATION RECORDS AND ARCHAEOLOGICAL CONTEXTS OF THE JEMEZ MOUNTAINS .............................................................. 35

3.1 A Review of Socio-ecological Research in the Jemez Mountains ................................. 35

3.2 Paleoprecipitation Reconstructions of the Jemez Mountains .......................................... 39

3.3 Comparative Ancestral Pueblo Cultural Histories of the Jemez and Pajarito Plateaus .. 45

3.4 Early Developmental Period/San Ysidro Phase (AD 600-1050) ................................... 49

3.5 Late Developmental Period/San Ysidro Phase (AD1050-1200)...................................... 51

3.6 Early Coalition Period/Vallecitos Phase (AD1200-1280) ………………………............ 52

3.7 Late Coalition Period/Vallecitos Phase (AD 1280-1350)................................................. 56

3.8 Early to Middle Classic Period/Paliza Phase (AD 1350-1450) ......................................... 58

3.9 Late Classic/Jemez Period (AD 1450-1600).................................................................. 63

3.10 Historic Period/Guadalupe Period (AD 1600-1760)........................................................ 65 
3.11 Summary 66

CHAPTER 4 AN ETHNOLOGICAL STUDY OF COMMON POOL WATER RESOURCES

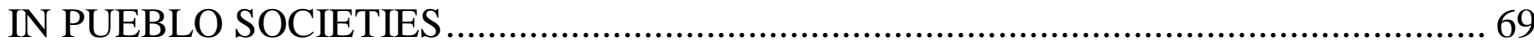

4.1 The Challenges of Applying Ethnographic Analogies to Archaeology............................ 71

4.2 Collective Action and Social Institutions for Pueblo Water Management ....................... 76

4.3 Pueblo Water Management During Periods of Water Scarcity ........................................ 89

4.4 Pueblo Uses of Water Reservoirs and Geoarchaeological Expectations ........................ 94

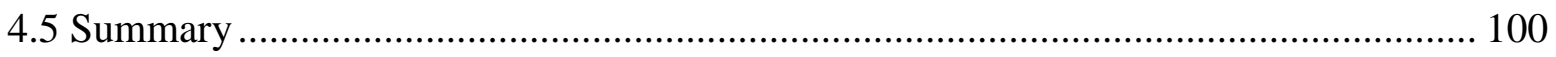

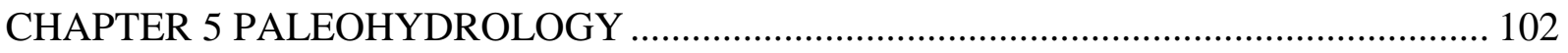

5.1 Hydrology, Paleohydrology, and Traditional Pueblo Hydrological Knowledge........... 102

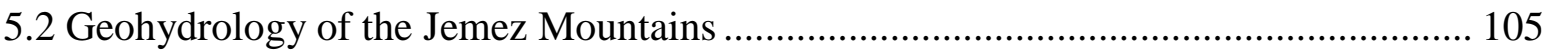

5.3 The Influence of Late Holocene Landform Evolution on Hydrological Conditions .... 121

5.4 Modern Climate and Stream Flow Analogs.................................................................... 124

5.5 Paleohydrological Models ............................................................................................... 136

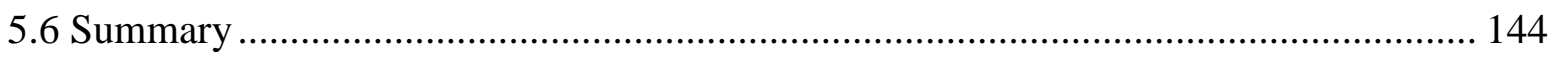

CHAPTER 6 RESEARCH DESIGN FOR TESTING RESERVOIR FEATURES................ 146

6.1 Previous Archaeological Research of Ancestral Pueblo Reservoirs.............................. 146

6.2 Behavioral Geoarchaeology as Research Design.......................................................... 152

6.3 Geoarchaeological Methods and Analyses .......................................................... 157

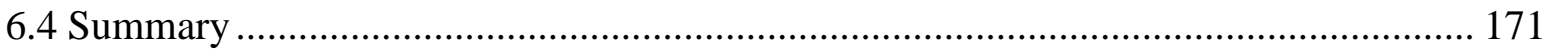

CHAPTER 7 RESULTS OF GEOARCHAEOLOGICAL INVESTIGATIONS..................... 172

7.1 The Jemez Plateau Reservoirs...................................................................................... 172

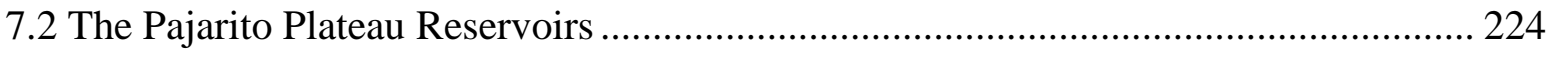

7.3 Inter-regional Comparisons of Ancestral Pueblo Water Management Strategies ........ 273

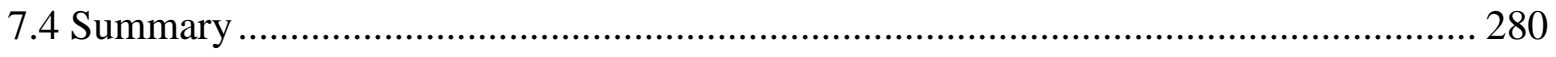

CHAPTER 8 MODELING ANCESTRAL PUEBLO WATER ACQUISITION COSTS .... 282

8.1 Developing Least Cost Analyses of Ancestral Pueblo Water Acquisition .................... 282 
8.2 Least Cost Analysis of the Jemez Plateau.......................................................................... 290

8.3 Least Cost Analysis of the Pajarito Plateau ................................................................... 298

8.4 Comparing Ancestral Pueblo Water Acquisition Costs between the Jemez and Pajarito

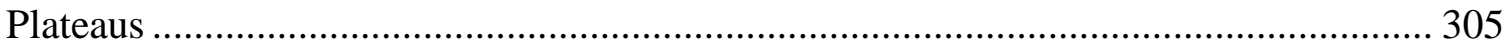

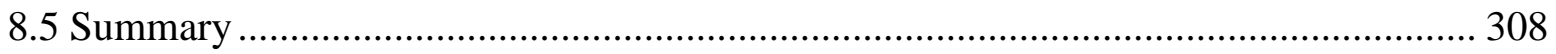

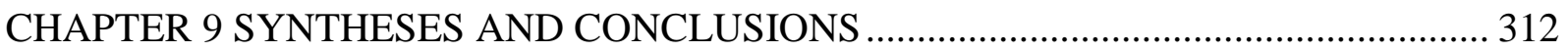

9.1 Diachronic Socio-hydrological Systems Models......................................................... 312

9.2 Recognizing Sustainability in the Archaeological Record ............................................. 339

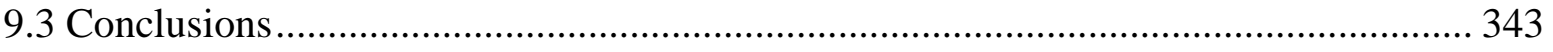

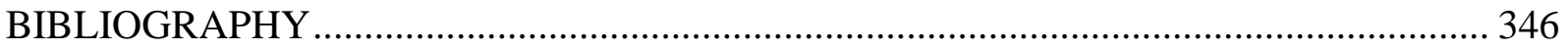

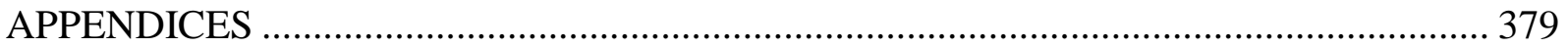

A.Inventory of Spring and Stream Data for the Southern Jemez Mountains ..................... 379

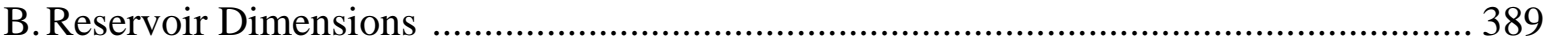

C. Compilation of Reports on Diatom Analysis by Dr. Barbara Winsborough ................... 390

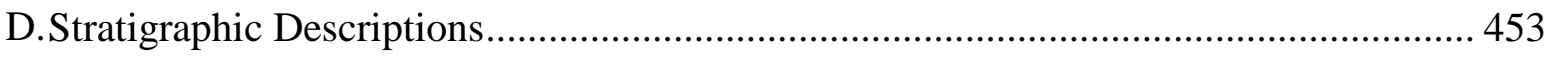

E. Reservoir Hydrological Analyses ............................................................................. 482

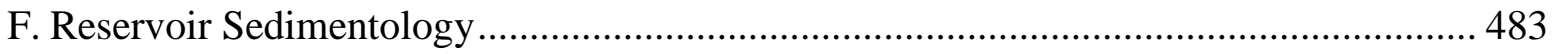

G. Micromorphological Sample Inventory ......................................................................... 487

H. Results of Radiocarbon Dating .................................................................................. 489 


\section{LIST OF FIGURES}

Figure 1.1 Map of the Jemez Mountains, with study areas. 4

Figure 1.21910 photo of the reservoir feature at Amoxiumqua (LA 481) ............................. 7

Figure 1.3 Socio-hydrological systems model of water management in the Jemez Mountains.. 12

Figure 2.1 A generalized framework for analyzing socio-ecological systems ......................... 16

Figure 2.2 A conceptual model of a socio-ecological system ........................................... 20

Figure 2.3 Diachronic models of Hohokam irrigation socio-ecological systems ...................... 32

Figure 3.1 Precipitation reconstructions from between AD 1101-1700 …............................. 42

Figure 3.2 Nine year moving averages of precipitation z-scores between AD 1101-1700 ........ 42

Figure 3.3 Documented Ancestral Pueblo archaeological sites in each project area.................. 46

Figure 3.4 Northern Rio Grande and Jemez chronologies.................................................... 47

Figure 3.5 Jemez and Pajarito Plateau momentary mean population estimates with intervals of hydrological droughts identified between AD 1100-1700 ............................................... 48

Figure 3.6 Distribution of aggregated sites on the Pajarito Plateau during the Developmental

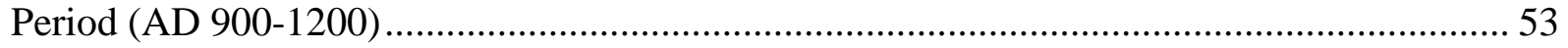

Figure 3.7 A comparison of Vallecitos Phase/Coalition Period (AD 1200-1350) aggregatde site distributions between the Jemez and Pajarito Plateaus. ....................................................... 55

Figure 3.8 A comparison of Paliza Phase/Early Classic Period (AD 1350-1450) aggregated site distributions between the Jemez and Pajarito Plateaus ..................................................... 60

Figure 3.9 An intra-regional comparison of momentary mean population histories in the Northern Rio Grande, with drought periodicities between AD 1100-1700 63

Figure 3.10 A comparison of Jemez Phase/Late Classic Period (AD 1450-1600) aggregated site distributions between the Jemez and Pajarito Plateaus 65 
Figure 3.11 A comparison of Guadalupe Phase/Historic Period (AD 1600-1760) archaeological site distributions between the Jemez and Pajarito Plateaus....................................................... 67

Figure 4.1 Pueblo communities and archaeological sites discussed in this chapter ..................... 70

Figure 4.2 Acoma Pueblo Water Cistern, ca. 1920-1940 …………....................................... 73

Figure 4.3 Acoma cistern after a monsoon rain storm, 2010 …………………………............... 74

Figure 4.4 Hopi water carriers, c. 1900, by Edward S. Curtis ........................................................ 99

Figure 5.1 The scientific model of the hydrological cycle and Puebloan channels of communication with the spirit world....................................................................................... 106

Figure 5.2 Surface geology of the Southern Jemez Mountains ................................................. 108

Figure 5.3 Surface geology and hydrology of the Jemez Plateau .............................................. 111

Figure 5.4 Hydrogeological cross section of the Jemez Plateau................................................ 112

Figure 5.5 Surface geology and hydrology of the Pajarito Plateau ............................................ 115

Figure 5.6 Hydrogeological cross section of the Pajarito Plateau .............................................. 116

Figure 5.7 Mean annual precipitation map of the Southern Jemez Mountains .......................... 127

Figure 5.8 A comparision of standardized z-scores of annual precipitation between the Jemez Springs and Bandelier weater stations, 1936-1975 ……………………………………….... 128

Figure 5.9 Jemez River discharge, 1936-2016....................................................................... 135

Figure 5.10 Frijoles Creek discharge, 1983-2014 ..................................................................... 135

Figure 5.11 Jemez Plateau paleohydrological model, normal and wet periods......................... 139

Figure 5.12 Jemez Plateau paleohydrological model, dry periods ........................................... 140

Figure 5.13 Pajarito Plateau paleohydrological model, normal and wet periods ....................... 141

Figure 5.14 Pajarito Plateau paleohydrological model, dry periods........................................... 142

Figure 5.15 Archaeological periods when hydrological systems were vulnerable to droughts 145

Figure 6.1 Locations of documented reservoir features across the North American Southwest148

Figure 6.2 Standard dimensions of catchment basins ............................................................... 163 
Figure 6.3 Locations of tested stock ponds. 164

Figure 6.4 Coring using the ESP and the Oakfield probe 164

Figure 6.5 Equations used in hydrological calculations ..... 166

Figure 7.1 Locations of reservoir features tested in this study 173

Figure 7.2 Map of coring locations, GPR survey areas, and catchment area of the Amoxiumqua (LA481) reservoir. 175

Figure 7.3 Chronostratigraphic cross section of the Amoxiumqua (LA481) reservoir feature 176

Figure 7.4 Photomicrographs of Amoxiumqua (LA481) reservoir soil samples. 178

Figure 7.5 Multi-proxy evidence for a stratigraphic unconformity and post abandonment forest regeneration at Amoxiumqua (LA481).... 182

Figure 7.6 Map of coring locations, pith date of a snag, and catchment area of the Boletsakwa (LA136) reservoir. 186

Figure 7.7 Chronostratigraphic cross section of the Boletsakwa (LA136) reservoir feature .... 188

Figure 7.8 Photomicrographs of Boletsakwa (LA136) reservoir soil samples ........................ 189

Figure 7.9 Age-depth model of Boletsakwa (LA136) basin sedimentation 191

Figure 7.10 Map of coring locations and catchment area of the reservoir at LA25092 ............ 195

Figure 7.11 Chronostratigraphic cross section of the LA25092 reservoir feature.................... 196

Figure 7.12 Age-depth model of LA25092 basin sedimentation. 197

Figure 7.13 Map of coring locations and catchment area of the Kwastiyukwa (LA482) reservoir feature 201

Figure 7.14 Chronostratigraphic cross section of the Kwastiyukwa (LA482) reservoir .......... 202

Figure 7.15 Map of coring locations and catchment area of the LA61641 reservoir feature .... 206

Figure 7.16 Photograph of a snag in the breach of the LA61641 berm being sampled by Josh Farella in June 2015. 207

Figure 7.17 Chronostratigraphic cross section of the LA61641 reservoir feature. 208

Figure 7.18 Photomicrograph of a LA61641 soil sample. 210 
Figure 7.19 Age-depth model of LA61641 basin sedimentation. 214

Figure 7.20 Map of coring locations and catchment area of the Wabakwa (LA478) reservoir feature 216

Figure 7.21 Chronostratigraphic cross section of the Wabakwa (LA478) reservoir feature ..... 217

Figure 7.22 Jemez Plateau village occupation and reservoir chronologies with modeled periods of hydrological droughts and paleoprecipitation records

Figure 7.23 Momentary mean population estimates of the four village sites on the Pajarito Plateau with tested reservoir features.

Figure 7.24 Map of coring locations and catchment areas of the Haatze/San Miguel and LA3834 reservoir features

Figure 7.25 Chronostratigraphic cross sections of the Haatse/San Miguel and LA3834 reservoir features

Figure 7.26 Map of coring locations and catchment areas of the Tsankawi (LA211) reservoir features 235

Figure 7.27 Chronostratigraphic cross sections of the Tsankawi (LA211) reservoir features .. 236

Figure 7.28 Photographs of reservoir TK-3 at Tsankawi (LA211) 244

Figure 7.29 Map of coring locations and catchment area of the Tsirege (LA170) reservoir feature.

Figure 7.30 Photographs of the Tsirege (LA170) reservoir. 250

Figure 7.31 Chronostratigraphic cross section of the Tsirege (LA170) reservoir feature..... 251

Figure 7.32 Age-depth model of Tsirege (LA170) basin sedimentation 254

Figure 7.33 Map of coring locations and catchment areas at Yapashi (LA250) and its associated reservoir features (YAP, LA70790 and LA70798) ........................................................... 256

Figure 7.34 Photographs of the Yapashi (LA250) reservoir feature .................................... 257

Figure 7.35 Chronostratigraphic cross sections of the Yapashi (LA250), LA70798, and LA70790 reservoir features.................................................................................... 258

Figure 7.36 Age-depth model of the Yapashi (LA250) reservoir basin sediments .................. 262

Figure 7.37 Pajarito Plateau village occupation and reservoir chronologies with modeled periods of hydrological droughts and paleoprecipitation records ..... 271 
Figure 7.38 Relationships between reservoir catchment areas and basin storage volumes....... 275

Figure 7.39 Reservoir use-life histories for all tested features, village occupation spans, and

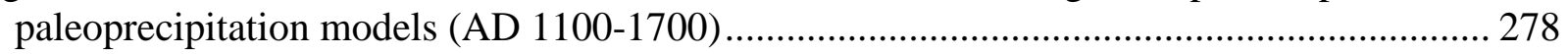

Figure 8.1 Workflow of a least cost analysis ................................................................. 284

Figure 8.2 Spatial distributions of random points used for the control LCA study................. 287

Figure 8.3 Map of sub-regions used to break-out least cost analyses.................................. 288

Figure 8.4 Cost paths and travel times from nearby water sources to Amoxiumqua (LA481) 288

Figure 8.5 Box plots of travel time between water sources and 500 control samples on the Jemez

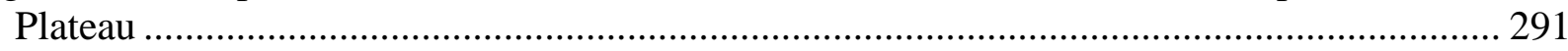

Figure 8.6 Box plots of one-way travel times between water sources and small Ancestral Pueblo sites of the Jemez Plateau region................................................................................... 292

Figure 8.7 Intra-regional comparison of small site water acquisition costs across the Jemez

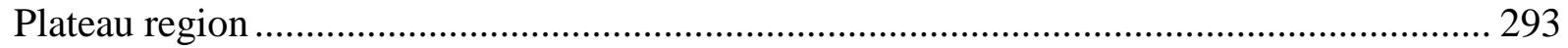

Figure 8.8 Box plots of one-way travel times between water sources and big Ancestral Pueblo sites of the Jemez Plateau region.................................................................................. 294

Figure 8.9 Box plots of one-way travel times between water sources and big Ancestral Pueblo sites with reservoirs in the Jemez Plateau region .......................................................... 295

Figure 8.10 Chronological model of Jemez Plateau water acquisition costs and maximum

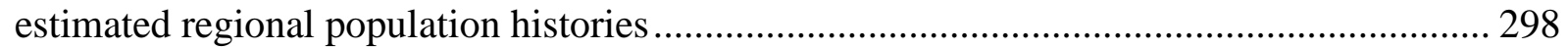

Figure 8.11 Box plots of travel times between water sources and 500 control samples on the Pajarito Plateau. 299

Figure 8.12 Box plots of one-way travel times between water sources and small Ancestral Pueblo sites of the Pajarito Plateau region 300

Figure 8.13 Box plots of one-way travel times between water sources and big Ancestral Pueblo

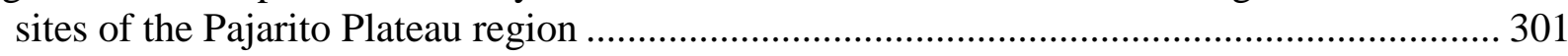

Figure 8.14 Box plots of one-way travel times between water sources and big Ancestral Pueblo sites with reservoirs of the Pajarito Plateau region ........................................................... 303

Figure 8.15 Chronological model of Pajarito Plateau water acquisition costs and maximum estimated regional population histories. 304

Figure 9.1 The socio-hydrological system model of the Jemez Plateau during the San Ysidro Phase (AD 1100-1200) 
Figure 9.2 The socio-hydrological system model of the Pajarito Plateau during the Late Deveopmental Period (AD 1100-1200)

Figure 9.3 The socio-hydrological system model of the Jemez Plateau during the Vallecitos Phase (AD 1200-1350)

Figure 9.4 Momentary mean population estimates of the Pajarito Plateau as a percentage of maximum population with the percentage of population living in aggregated communities 322

Figure 9.5 The socio-hydrological system model of the Pajarito Plateau during the Coalition Period (AD 1200-1350)....

Figure 9.6 The socio-hydrological system model of the Jemez Plateau during the Paliza Phase (AD 1350-1425) 327

Figure 9.7 The socio-hydrological system model of the Pajarito Plateau during the Early Classic Period (AD 1350-1425).... 329

Figure 9.8 The socio-hydrological system model of the Jemez Plateau during the Jemez Phase (AD 1425-1600) 332

Figure 9.9 The socio-hydrological system model of the Pajarito Plateau during the Middle-Late Classic Period (AD 1425-1600) 334

Figure 9.10 The socio-hydrological system model of the Jemez Plateau during the Early Historic Period (AD 1600-1700). 337

Figure 9.11 The socio-hydrological system model of the Pajarito Plateau during the Early Historic Period (AD 1600-1700). 


\section{LIST OF TABLES}

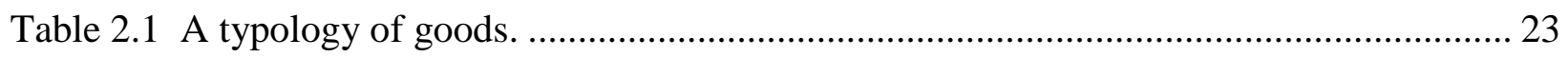

Table 3.1 Dry periods identified from z-scores of paleoprecipitation reconstructions............... 43

Table 3.2 Wet periods identified from z-scores of paleoprecipitation reconstructions. ............. 43

Table 3.3 Chronology and momentary mean population estimates for the Pajarito Plateau project

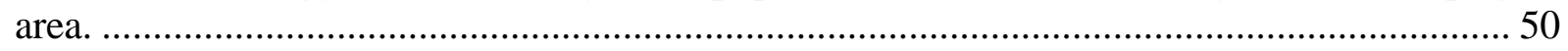

Table 4.1 Ethnographic practices of reservoir use and possible geoarchaeological correlates. .. 96

Table 5.1 Summary precipitation data from weather stations in the Jemez Mountains. ........... 127

Table 5.2 A comparison of mean intra-annual precipitation between Jemez Springs and Bandelier weather stations....................................................................................... 131

Table 5.3 Annual comparisions of rainfall intensities from historical weather station data...... 132

Table 5.4 Elevations and mean annual precipitation of tested Ancestral Pueblo sites............. 133

Table 5.5 Water types of the Jemez Plateau. .................................................................. 138

Table 5.6 Water types of the Pajarito Plateau................................................................. 138

Table 5.7 Results of water resource density analysis. .................................................... 143

Table 5.8 Results of water resource average nearest neighbor analysis............................... 144

Table 6.1 Behavioral model of site formation processes................................................. 158

Table 7.1 Modeled community water budgets and reservoir storage potential for Amoxiumqua (LA481) 180

Table 7.2 Modeled community water budgets and reservoir storage potential for Boletsakwa (LA136). 190

Table 7.3 Modeled community water budgets and reservoir storage potential for LA25092... 198 
Table 7.4 Modeled community water budgets and reservoir storage potential for Kwastiyukwa (LA482).

Table 7.5 Modeled community water budgets and reservoir storage potential for Tovakwa and the LA61641 reservoir

Table 7.6 Modeled community water budgets and reservoir storage potential for Wabakwa (LA478).

Table 7.7 Modeled community water budgets and reservoir storage potential for Haatse/San Miguel (LA370).

Table 7.8 Modeled community water budgets and reservoir storage potential for Haatse/San Miguel and LA3834.

Table 7.9 Modeled community water budgets and reservoir storage potential for Tsankawi-1 reservoir (TK-1).

Table 7.10 Modeled community water budgets and reservoir storage potential for the Tsankawi2 reservoir (TK-2)..

Table 7.11 Modeled community water budgets and reservoir storage potential for Tsankawi-3 reservoir (TK-3).. 246

Table 7.12 Modeled community water budgets and reservoir storage potential for Tsirege (LA170)..

Table 7.13 Modeled community water budgets and reservoir storage potential for Yapashi (LA250).

Table 7.14 Modeled community water budgets and reservoir storage potential for Yapashi (LA250) and LA70798..

Table 7.15 Modeled community water budgets and reservoir storage potential for Yapashi (LA250) and LA70790.

Table 7.16 Estimates of daily village water requirements and the number of days water stored in a reservoir from a 1-year maximum rainfall event could provide. 276

Table 8.1 Regional comparisons of descriptive statistics and means testing of LCA results.... 306 
This is dedicated to John and Amanda. Thank you for raising me to pursue my dreams. 


\section{CHAPTER 1. INTRODUCTION}

Between AD 1100-1700 the cultural histories of Ancestral Pueblo people in the Jemez Mountains of New Mexico diverged. Ancestral Towa communities of the Jemez Plateau sustained high populations living in mesa-top villages until Spanish removal in the $17^{\text {th }}$ century (Liebmann et al. 2016). By contrast, the adjacent Pajarito Plateau was nearly completely depopulated by ancestral Tewa and Keres communities by the early $16^{\text {th }}$ century (Powers and Orcutt 1999). Most archaeological sites are on mesa-tops, with water sources often far below in canyon bottoms. Ancestral Pueblo villages in both regions have infrastructure for water storage. These features, referred to as reservoirs and hypothesized to be domestic water sources, suggest that communities took collective action to confront water insecurities. Beginning in the $15^{\text {th }}$ century, precipitation became less predictable and droughts became more frequent (Touchan et al. 2011). Archaeologists associate these droughts with declining populations on the Pajarito (Orcutt 1991; Kohler 2004), yet archaeologists have not considered the resilience of Jemez populations under analogous conditions.

In this dissertation I assess whether water management strategies enabled the long-term sustainability of Ancestral Pueblo communities during droughts in the Jemez Mountains. I take a comparative approach by modelling the sensitivity of water availability to climate change, reconstructing the use-life histories of reservoirs, and estimating water acquisitions costs. I synthesize these findings within a socio-ecological framework (Anderies et al. 2004). This serves 
as a long term archaeological example of how communities faced the challenges of managing resources sensitive to climate change.

Archaeologists and anthropologists have long linked climate fluctuations to culture change (e.g., historical summaries in Dove 2013; Trigger 2006). Yet, often our linkages are too vague or ill-defined (Rowland 2010), or we mistake correlation for causation when changes in climate align with societal changes (Hudson et al. 2012; Kohler et al. 2007; Roos 2011; van der Leeuw et al. 2002). To contribute to dialogs on modern climate change (e.g., Davies and M'Mbogori 2013; Mitchell 2008; Van de Noort 2011) and make archaeology “matter” to contemporary society (sensu Sabloff 2016) we must leverage the assets we have that others do not: long-term perspectives on behavioral responses to climate change.

To utilize our strengths, we need to understand the vulnerabilities of resources to climate change, and investigate decision-making for their sustainable management (e.g., Tompkins and Adger 2004). Common pool resource theory (CPR) provides a framework for analyzing these relationships (Ostrom 2009). CPR theory examines the relationships between social institutions for collective action, resource management, and community-level sustainability (Ostrom 2014). Researchers investigating these topics use theoretical experiments using game theory and compile cross-cultural studies of both successful and unsuccessful resource arrangements. A key finding is that self-governing local communities with robust social institutions for collective action are critical for sustainably managing resources, especially through periods of climate change (Berkes et al. 1989; Dietz et al. 2003).

Archaeologists could be providing the long-term case studies that CPR researchers need to test their theories on sustainable resource management. Yet, archaeological applications of the study of CPR theory are few. This is probably because of how hard it is to identify rules, norms, 
and social institutions for resource management in the archaeological record. Those who do study the commons (e.g., Bayman and Sullivan 2008; Carballo et al. 2012; Eerkins 1999; Lindholm et al. 2013) focus on the anthropogenic impacts of resource management practices, changing settlement patterns, and political economy. This study advances CPR research by identifying archaeological proxies for resource management in reservoirs and settlement locations, and by integrating my findings into long-term models of socio-ecological systems.

\subsection{Droughts, Infrastructure, and Sustainability in the Jemez Mountains}

Water is often a limiting factor to permanent settlement in the prehistoric North American Southwest (e.g., Adler et al. 1996; Dean et al. 1994; Tainter and Tainter 1996). Dry periods, identified in long-term dendroclimatological reconstructions, routinely triggered region-wide social upheavals, such as the migrations and abandonments in the Four Corners region between the $12^{\text {th }}$ and late $13^{\text {th }}$ centuries (e.g., Benson et al. 2007; Dean 1996; Kohler et al. 2010; and in Doyel and Dean 2006). Recent investigations use concepts of robustness-vulnerability tradeoffs from resilience theory to assess whether dry periods induced resource insecurity at regional levels (e.g., see in Fisher et al. 2009; Nelson et al. 2016). These approaches can also identify intra-regional variability (e.g., Nelson et al. 2006; Schwindt et al. 2016), including examples where dry periods do not correlate to abandonment (Ingram 2010; Ingram and Hunt 2015).

These studies are good at identifying feedbacks between changes in climate and society, but present few direct archaeological proxies for institutional responses to climate-induced resource scarcity. To explore these dynamics, I investigate the adjoining Jemez and Pajarito Plateaus along the southern and eastern margins of the Southern Jemez Mountains in Northern New Mexico (Figure 1.1). Both regions share a robust paleoclimate record (Touchan et al. 2011), and 
potential archaeological proxies for managing resources vulnerable to climate change (Elliott 1982; Allen 2004), yet have divergent cultural histories during dry periods (Crown et al. 1996;

Liebmann et al. 2016).

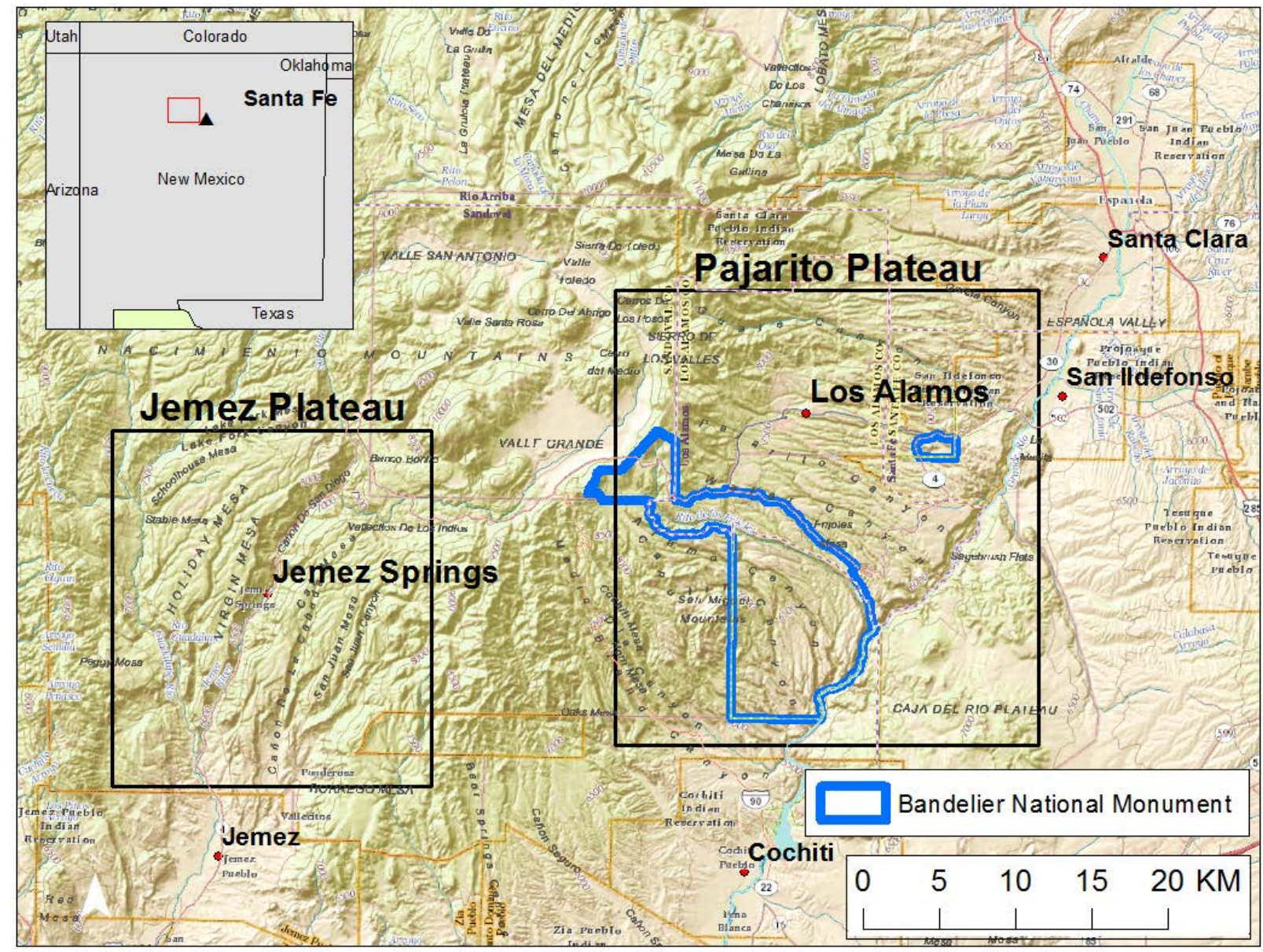

Figure 1.1. Map of the Southern Jemez Mountains, with study areas.

In a recent paper, Bocinsky and Kohler (2014:4) model the high elevation mesa-tops of the Southern Jemez Mountains as one of the prime "maize agricultural niches” of the prehistoric Southwest. By approximately AD 1100, Ancestral Pueblo people began dry-land farming the mesa-tops. Starting in the late AD 1200s there was unprecedented population growth across both regions. Dispersed households and hamlets coalesced into increasingly aggregated communities. 
Likely due in part to an influx of immigrants from other highland contexts, beginning in early 1300s the region had some of the densest populations of Ancestral Pueblo communities in the North American Southwest (Liebmann et al. 2016; Ortman 2012). This type of settlement pattern in highland settings was unique within the broader Northern Rio Grande region, and such high populations in upland settings were rare across the prehispanic North American Southwest (Kulisheck 2005:247-248).

Mesic conditions may have "pulled" people to the mesa-tops, but the southern Jemez Mountains are also vulnerable to droughts. Decadal scale dry periods beginning in the late $14^{\text {th }}$ century hit the Jemez Mountains (Grissino-Mayer 1996; Touchan et al. 2011). These dry periods correlate to the divergence population histories between the Pajarito and Jemez Plateaus (Towner and Salzer 2013). Populations of the Pajarito Plateau fell precipitously in the late 1300s and through 1400s. Only a few aggregated communities near perennial water sources remained by the time of Coronado's entrada into the region in 1541. Archaeologists and Pueblo oral histories both identify climate as a factor in the population decline on the Pajarito (Bandelier 1892:77; Crown et al. 1996; Hewett 1993:90-92; Orcutt 1991). Archaeologists hypothesize that droughts "pushed" communities off the mesa-tops, while emerging market economies and well-watered valleys "pulled" the ancestors of modern Tewa and Keres speakers towards the Rio Grande Valley and its tributaries (Kohler et al. 2004b; Gabler 2009). By contrast, populations of the Jemez Plateau continued growing through these dry periods. Multiple Ancestral Jemez pueblos had more than a thousand inhabitants in the $15^{\text {th }}$ and $16^{\text {th }}$ centuries (Kulisheck 2005; Liebmann et al. 2016).

This context sets up a classic dilemma identified in resource management studies. Robust solutions to one resource management problem often lead to vulnerabilities in other resource 
arrangements (Anderies et al. 2007: 15194). The maize agricultural niche model and the success of the Jemez suggest that dryland maize agriculture is well suited to this region, even during droughts. But could decisions focused on agricultural production have made Ancestral Pueblo communities vulnerable to climate induced insecurities in other resources, like domestic water? Was there something different about the environmental context or water management on the Jemez Plateau that made them seemingly resilient to droughts when compared to the Pajarito?

Acquiring water, a critical resource for consumption and domestic use in these highland settings, presents a logistical challenge. Tourists visiting Bandelier National Monument on the Pajarito Plateau usually just come to see the impressive Ancestral Pueblo cavate structures and the ancient village of Tyounyi along the perennial stream of the Rito de Frijoles in Frijoles Canyon. They may leave with the impression that well-watered canyons with large villages are typical for the region. That isn't true. The majority of villages and agricultural localities are on mesa-tops, not in canyon bottoms (Kohler 2004). There are few natural water sources on these mesa-tops. Daily descents into canyon-bottoms to get water from streams, many of which are intermittent and vulnerable to periods of little to no discharge (Allen 2004), would be a daily occurrence for mesa-top villagers.

Ancestral Pueblo communities built catchment basins, or reservoirs, at many of the largest aggregated villages in both regions (Elliott 1982; Powers et al. 1999) (Figure 1.2). Archaeological investigations from across the Southwest show that reservoirs collect surface runoff and can store an appreciable volume of water for domestic use (e.g. Bayman et al. 2004; Crown 1987; Scarborough 1988; Wilshusen et al. 1997; Wright 2006). These features may have reduced two water related vulnerabilities associated with mesa-top living: water insecurity and high acquisition costs. Water insecurity is the insufficient access by all members of a community 
to safe and abundant water (Wutich et al. 2014). Ethnohistorical and ethnographic observations of Pueblo water use show that social institutions developed for using water as a common pool resource (e.g., Beaglehole 1937; White 1973; Whiteley 1988). In the Jemez Mountains we don’t know anything about these features besides their locations and sizes. Could understanding how Ancestral Pueblo people used reservoirs and other water sources help us understand if water management contributed to the resiliency of Jemez communities to droughts, while leaving those of Pajarito communities seemingly vulnerable?

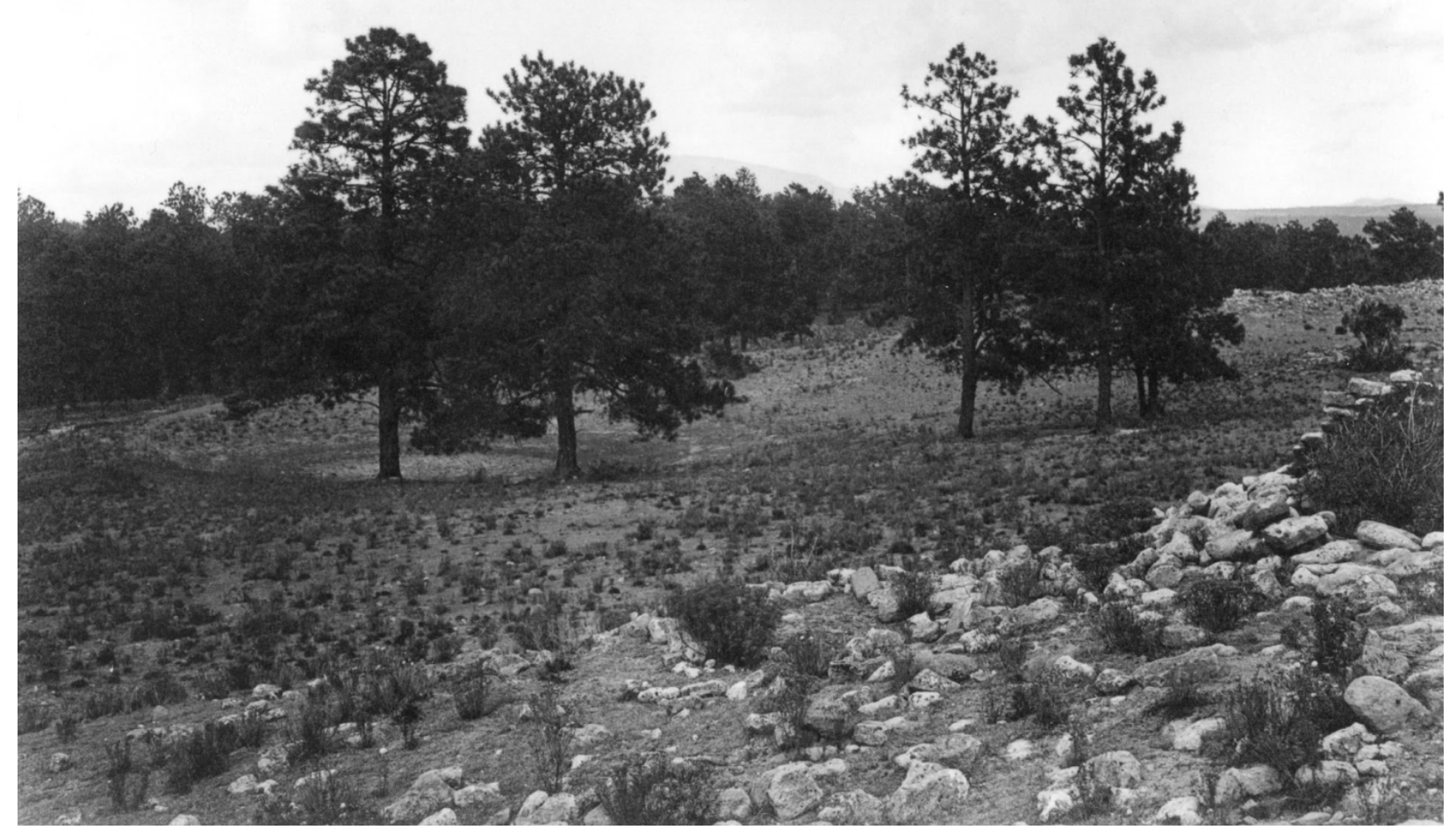

Figure 1.2. 1910 photo of the reservoir feature at Amoxiumqua (LA 481). Courtesy of the Bruan Research Library Collection, Autry National Center, Los Angeles; Photo \#24544. 


\subsection{Research Questions}

A series of research questions drive my investigation. The questions build upon each other. I present each question below, with justifications and summations for how I address these questions through the rest of my dissertation.

1) In what ways is the hydrological system of the Jemez Mountains sensitive to droughts, and how would water availability be affected by droughts in the past?

Paleohydrological models of the sensitivity of hydrological systems to dry periods can address this question. Paleohydrology is the study of past hydrological systems (Baker 1998). Reports from geothermal energy prospecting, environmental remediation projects at Los Alamos National Labs, and Critical Zone Observatory (CZO) research have generated relevant geohydrological data (Enquist et al. 2009). The Village Ecodynamics Project (VEP) used a

paleohydrological approach to address similar questions in the Mesa Verde region (Kolm and Smith 2012; Smith 2008). Kolm and Smith (2012) developed a quantitative model of hydrological systems, and found that droughts reduced discharges at timescales relevant to settlement histories. In Chapter 5, I take a similar approach. I synthesize geohydrological contexts with modern hydrological datasets and paleoprecipitation reconstructions. I then develop qualitative diachronic models of surface water availability for both the Jemez and Pajarito Plateaus through the time period of this study.

2) Were water reservoir features built as a form of collective action to buffer against the risks of water resource scarcity and to reduce domestic water acquisition costs at large Ancestral Puebloan villages on both the Pajarito and Jemez Plateaus? 
Archaeologists investigating prehispanic reservoirs infer that building and maintaining these features required extra-kin cooperation (Haase 1985; Wilshusen et al. 1997). If so, they may serve as proxies for collective action decision-making (Kohler and Van West 1996; Kohler et al. 2012). The ethnological record of Pueblo water management presented in Chapter 4 supports this hypothesis. Archaeologists have recorded reservoirs at large aggregated sites on both the Jemez and Pajarito Plateaus (Elliott 1982; Powers and Orcutt 1999). Because these features are small, some question if they were instead watery shrines (Snead 2006, 2008) or were perhaps never designed to hold water (Benson et al. 2014). We do not know how they functioned, or whether they held enough potable water to contribute to community water budgets. We also do not know when communities built these features in relationship to occupation histories, or if they would reduce insecurities to droughts.

Geoarchaeological investigations make reconstructing the use-life histories of these features possible (e.g., MacWilliams et al. 2009; Murrell 2006; Scarborough 1988). I undertook geoarchaeological studies of fifteen reservoirs at nine sites across both the Jemez and Pajarito Plateaus.By collecting multi-proxy evidence from sedimentological and paleoecological indicators of water storage (Murrell 2006), as well as direct chronometric dating of sediments or charcoal (Aiuvalasit et al. 2010), and hydrological modeling (e.g., Benson et al. 2014; MacWilliams et al. 2009) I was able to reconstruct when and how Ancestral Pueblo used developed and managed their water infrastructure.

\section{3) Did droughts lead to periods of water insecurity and greater water acquisition costs for Ancestral Puebloan communities?}


Travel time to water resources should increase if droughts reduced natural water availability. Collective action responses, such as reservoir construction or settlement relocation, could buffer the impacts of droughts by reducing water costs. The VEP model found that droughts reduced natural water availability. Yet, it did not reduce water availability below community demands. Water was also not so scarce that acquisition costs exceeded how far their agent-based simulations were willing to travel (Kolm and Smith 2012). They did identify a potential collective action response to the decline in water availability in the archaeological record. Settlements concentrated around reliable water sources during dry periods in the 13th century, suggesting water insecurities did factor into decisions about settlement locations and aggregation (Kolm and Smith 2012; Smith 2008). Distance to water was likely a consideration in settlement location.

Existing models of settlement patterns on the Pajarito Plateau suggest changes in site locations and sizes due to droughts. These models consider drought impacts to agriculture and not domestic water (Powers and Orcutt 1999; Kohler 2004; Gabler 2009). In this study, I model the cost of water acquisition (in travel time) across a range of paleohydrological scenarios. I use Spatial Analyst tools in ArcGIS software, and computer scripts built in Python to run cost path analyses. I undertook these analyses from hundreds of water sources (springs and streams) to thousands of archaeological sites (field houses, hamlets, villages, towns). I use the results, presented in Chapter 8, to model regional strategies of water acquisition. From this I identify how water management may or may not have exacerbated vulnerabilities to water insecurity during hydrological droughts. 


\section{4) Did collective action responses to water insecurity enhance, reduce, or seemingly have no effect on the sustainability of mesa-top communities of both the Jemez and Pajarito Plateaus?}

For a social commons to persist, the benefits of cooperation must outweigh the costs of contributing to maintain a resource (e.g. Hooper et al. 2010). Hazards researchers find that resilient communities typically have robust examples of cooperative water management strategies preceding droughts. Vulnerable communities either take action during periods of resource insecurity, when costs of collective action are higher and payoffs potentially lower, or abandon collective strategies altogether (Wilhite and Buchanan-Smith 2005). Either way, impacts to resource cost or availability by climate change to individuals can introduce fragilities in social institutions. This aligns with CPR theory, which identifies collective action as easier to undertake when social institutions are most robust, and each individual's cost for action is low (Adger 2003).

In Chapter 9, I integrate the results of my studies within diachronic socio-ecological systems (SES) frameworks (Figure 1.3). This allows me to model the relative costs of collective action for building water reservoir infrastructure in relationship to the benefit of reduced water acquisition costs. It also allows me to consider other archaeological data, and the implication for socio-political contexts. This makes it possible to assess the effectiveness of social institutions for collective action through periods of climate change, and how droughts impact the sustainability of these systems. 


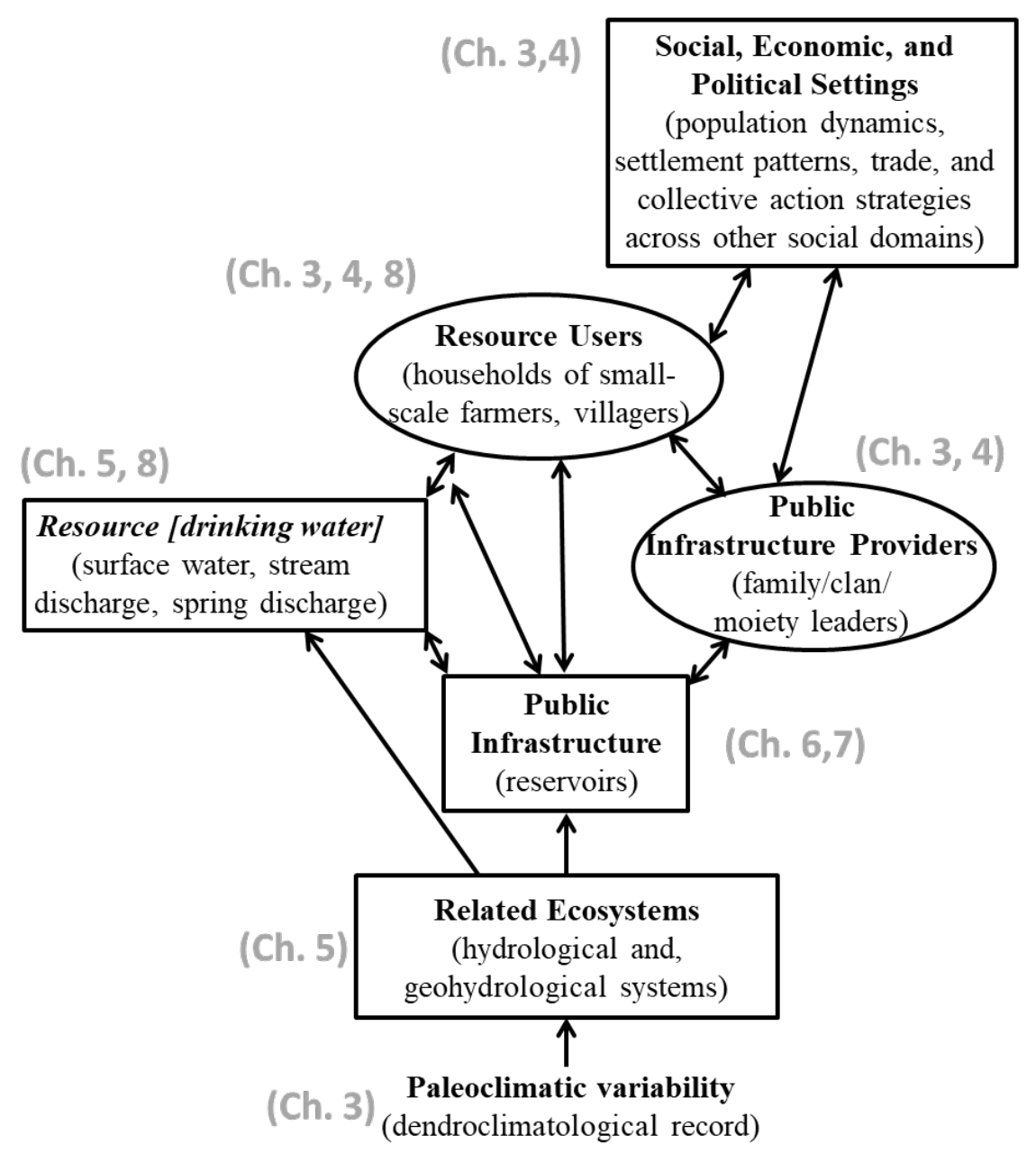

Figure 1.3. Socio-hydrological systems model of water management in the Jemez Mountains. Chapters addressing each component are identified.

\subsection{An Outline of this Dissertation}

I try to answer these questions by synthesizing interdisciplinary geoarchaeological approaches in a SES framework (Figure 1.3). Chapters 2-4 provide the background for this study. In Chapter 2, I argue for the archaeological potential for studying common pool resources, and the applicability of using SES models. I present background information on sociohydrological systems in Chapter 3. I use local tree-ring-based precipitation reconstructions by Touchan et al. (2011) to identify periods of hydrological droughts. I focus my review of the 
cultural history of the Jemez Mountains on population histories, settlement patterns, and archaeological evidence for collective action. In Chapter 4, I present ethnographic and ethnohistorical records of Pueblo domestic water management. The examples show that Puebloan water management practices are embedded in robust social institutions, and often managed as commons. These findings support the inference that archaeological reservoir features are proxies for collective action decision-making. I also use the ethnographic record of reservoir use to identify potential geoarchaeological correlates.

Chapters 5-7 provide the original results of my geoarchaeological analyses. In Chapter 5, I synthesize geological, hydrological, and climatological data to develop a paleohydrological model. The diachronic model spans AD 1100-1700. Natural water resources have different distributions between the Jemez and Pajarito Plateaus. These differences may have resulted in increased vulnerabilities to water scarcity during dry periods, particularly on the Pajarito Plateau. In Chapter 6, I present the research design for the geoarchaeological investigations of reservoir features. I summarize the archaeological record of water storage features across the North American Southwest. To adjudicate between alternative hypotheses of feature use I present a site formation model for reconstructing use-life histories. Field and laboratory methods are also presented. In Chapter 7, I present the results of geoarchaeological investigations of reservoir features. I show that there were significant differences in feature use-life histories between the Jemez and Pajarito Plateaus. In Chapter 8, I develop a diachronic economic model of water acquisition costs using least cost path analyses between water sources and sites. Unsurprisingly, I find that reservoirs reduce water acquisition costs when compared to costs to natural sources. Modeling the impacts of drought on water acquisition times shows how differences in settlement strategies affected community’s vulnerabilities to water insecurity. 
In Chapter 9, I synthesize the results of my analyses with the existing archaeological data. I present five diachronic socio-hydrological systems models for each region. With these models, I evaluate whether water management practices were robust during droughts, or introduced fragilities. Droughts increased water acquisition costs in both study areas, but moreso on the Pajarito. This made communities subject to increasingly higher water costs, especially as households coalesced into villages. This occurred while emerging market economies likely placed greater time demands on households as well. Strong collective action approaches to settlement organization, food sharing, and water management on the Pajarito suggests that social organization structures seen in modern Tewa began as early as the middle to late 1300s. Yet, these social institutions may have formed a rigidity trap (Gunderson and Holling 2002), which made communities vulnerable to climate induced resource scarcity. Fortunately for the Ancestral Pueblo of the Pajarito, the well-watered valley bottoms of the nearby Northern Rio Grande were a place where social institutions for collective action could flourish.

Ancestral Jemez shared many of the same infrastructures to those on the Pajarito Plateau. Yet, a hydrological system less vulnerable to droughts, and the continued assumption of risk at the household level contributed to the endurance of the Ancestral Jemez, even during periods of hydroclimatological variability. The continuation of dual residence patterns and less reliance on water storage features by the Ancestral Jemez proved to be a more robust response to droughts than those practiced on the Pajarito Plateau. The Ancestral Jemez may have been less integrated into regional networks of exchange, and demonstrated less centralized social hierarchies than Ancestral Pueblo communities of the Pajarito Plateau (Liebmann 2012), but they persisted. I conclude by identifying ways to make this study relevant to discussions about sustainability and climate change, research into the commons, and new approaches to socio-hydrological studies. 


\section{CHAPTER 2: AN ARCHAEOLOGY OF THE COMMONS}

In this chapter, I propose that archaeologists investigate the effects of climate change on societies using theory from the study of resource management. I argue for using a socioecological systems framework developed by Anderies et al. (2004). It identifies relationships between social institutions and natural resources, particularly those held in common (i.e., the commons), as a way to conceptualize sustainability. I review Elinor Ostrom's (1990, 2009) common pool resource theory (CPR), as well as existing applications of CPR theory in archaeology. This review demonstrates its usefulness, and highlights the unrealized potential of CPR theory for our discipline. Finally, I outline a future for the archaeology of the commons, which serves as the theoretical framework for this dissertation.

\subsection{Sustainability as an Analytical Framework for SES investigations in Archaeology}

The political scientist Elinor Ostrom proposed a framework to study the relationships between social institutions, resource management, and the environment. Her socioecological systems (SES) framework conceptualizes feedback relationships between social and ecological variables. The framework is a-theoretical, in that it is applicable to different interpretive approaches (McGinnis and Ostrom 2014). SES models consider ecological and socio-political organizations as exogenous drivers influencing the dynamics between resources, users, and governance. Social institutions emerge through collective action 
decision-making. Institutions are broadly conceived as "the prescriptions that humans use to organize all forms of repetitive and structured interactions” (Ostrom 2005:3), and can range from social norms to formal governance. Exogenous shocks or endogenous factors generate feedbacks, which introduce fragilities into systems. Decisions surrounding resource allocation in response to these feedbacks then lead to new outcomes. The goal is to not just conceptualize systems, but to give "a diagnosis of why some SES are sustainable whereas others collapse” (Ostrom 2009:420).

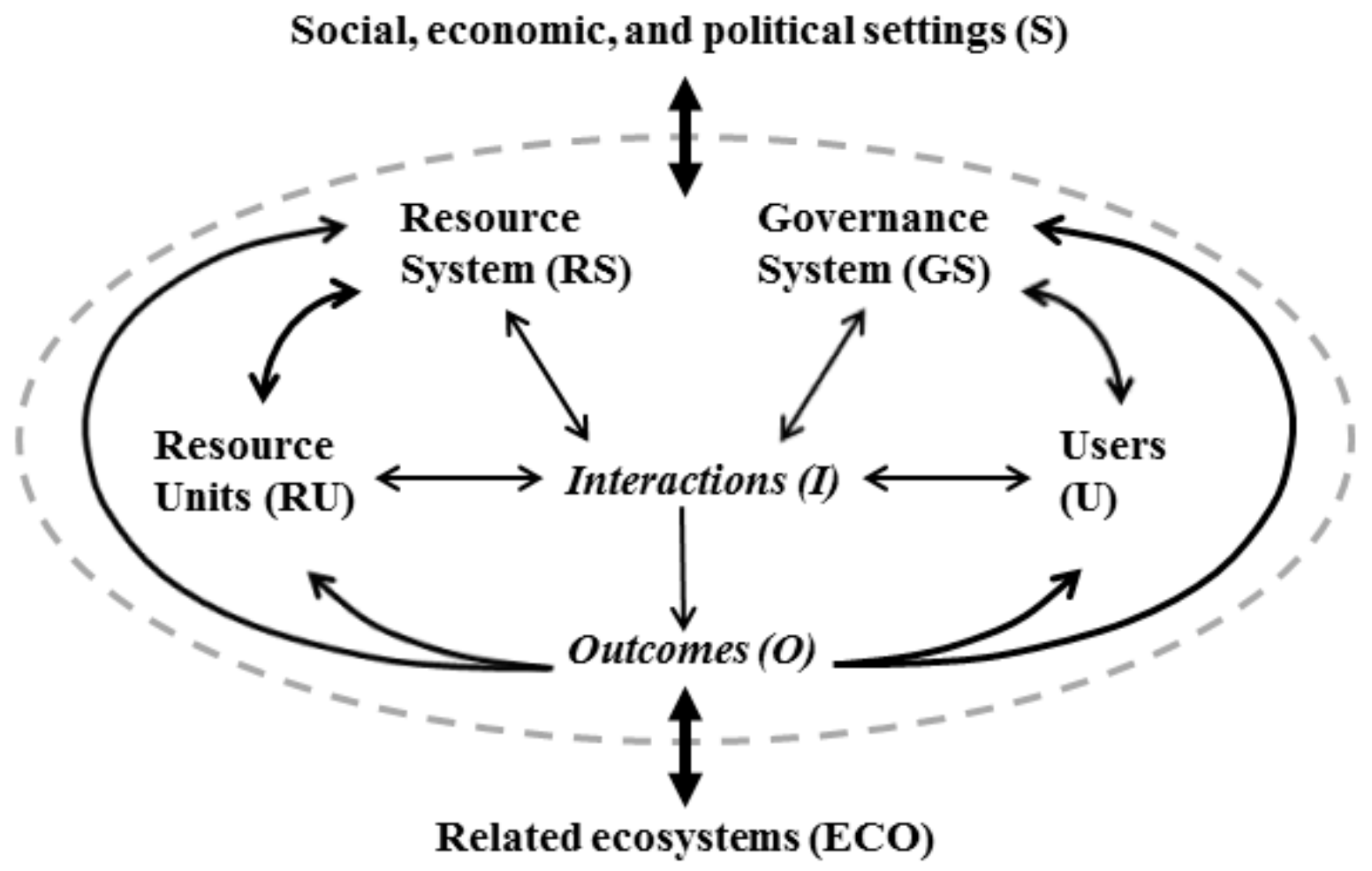

Figure 2.1. A generalized framework for analyzing socio-ecological systems (based on Ostrom 2009: Figure 1). 
Researchers use the concept of sustainability to evaluate socio-ecological systems. Sustainability has many uses across our common vernacular, policy realms, and academic research. Fundamentally, it relates to maintaining the welfare of people, resources, and/or ecosystems over a period of time. The sustainability sciences conceive of sustainability as "an analytical framework to guide actions across all levels of organization related to the way human societies operate and interact with their environment” (Anderies et al. 2013:8). The SES framework is useful because it conceptualizes the social and environmental contexts for collective action decision-making, as well as performance measures (as feedbacks) for how each component of the system functions. Decision making contexts refers to the ways in which resource users make decisions about resource allocation. The contexts for decision making are where collective action problem solving occurs. Feedbacks (like new rules of resource use) and the inherent fragilities which develop, generate change (Anderies et al. 2013).

Resilience theory helps to conceptualize sustainability in socio-ecological systems. Resilience refers to the capacity of a self-organizing system to cope with shocks and maintain its structure and function (Folke et al. 2010). Specific variables within systems respond to specific shocks as trade-offs between robustness and vulnerability. The concepts of robustness and vulnerability originated with control-systems research in engineering for the study of linear systems (Zhou and Doyle 1998), and they are analogous to "specified resilience" when studying complex dynamical SESs (Anderies et al. 2007; Folke et al. 2010). Robustness refers to the sensitivity of a system's outputs to shocks, while vulnerabilities refer to the state of its fragilities (Anderies et al. 2007). In social systems the decisions people make about resources (considered as policies, rules, and norms) generate feedbacks as well. Robustness-vulnerability trade-offs 
impact resilience when fragilities, which inevitably develop in complex systems, exceed the capacity for the system to cope, leading to change.

Researchers identify performance measures for robustness by identifying if the response of a component enhances, reduces, or has no effect on other aspects of the system. Feedbacks, such as intensification of food production or new rules of use in response to competition, impact both resource availability and social relationships. Yet, policies and strategies robust to high frequency, low amplitude disturbances (such as intra-annual seasonality in precipitation), may be vulnerable to disturbances with low frequencies but high amplitudes (such as once in a generation floods or droughts). Researchers find that, "policies robust to uncertainty in one group of parameters are necessarily vulnerable to uncertainty in another group” (Anderies 2007:15194). Stated in another way, a robust response to managing one resource can have unintended consequences for others, which can in turn trigger a cascade of responses to other components of the socio-ecological system. Hazards researchers studying droughts find that resilient communities typically have robust management strategies preceding droughts, while vulnerable communities that respond ad hoc to droughts usually do not (Wilhite and Buchanan-Smith 2005). Therefore, collective action approaches to resource management can greatly impact the resilience of communities to environmental shocks.

Anderies et al.’s (2004) socio-ecological systems model is a framework for evaluating robustness-vulnerability tradeoffs. It identifies key variables, feedbacks, and recognizes the importance of infrastructure to mediate relationships between people and the bio-physical environment (Figure 2.2). Linkages reflect feedbacks between variables, and provide opportunities to evaluate robustness-vulnerability tradeoffs. Ostrom's design principles (which I discuss in the next section) help to conceptualize dynamics of these linkages. Researchers do 
both experimental modeling of thresholds for system change, as well as quantifying performance measures in real systems (Anderies et al. 2004; Anderies and Jassen 2011). Anderies (2006) used this framework to conceptualize feedback relationships in prehistoric Hohokam irrigation systems, which I discuss in a subsequent section. Water infrastructures, particularly irrigation systems, are often the subject of SES research (e.g., Kamran and Shivakoti 2010; Lansing 2009; Ostrom 1993; Schlager and Ostrom 1992). This is because irrigation serves to control, transfer, and distribute a key natural resource at in quantities and across spatial scales where it is most effectively treated as a commons.

Anthropologists and archaeologists have a tradition of taking systems approaches to studying socio-ecological systems. Systems-based, interdisciplinary research was central to the development of the New Archaeology in the 1960s. Growing out of cultural ecology and functionalism (Trigger 2006:419-425), proponents, such as Kent Flannery, applied concepts from General Systems Theory and cybernetics (O’Brien et al. 2005:76-77) to archaeology. They attempted to identify the processes underlying culture change using evolutionary and ecological frameworks. These approaches benefited from a general optimism towards positivistic research in the 1950s and into the 1960s (Trigger 2006), as well as methodological advancements in data collection and analyses (Hill 1970; Meltzer 1979). However, these approaches were poor at handling change in what are inherently dynamic cultural systems (O’Brien et al. 2005:78-79). Interest waned as environmental archaeologists turned towards middle-range research beginning in the 1970s (Binford 1977). Systems-based approaches reemerged in archaeology during the late 1990s and 2000s (Redman 1999). New work incorporated more dynamic approaches to systems, larger datasets, and greater analytical capabilities. Now, research aim to develop models to "be not a universal scientific truth but [to] fit some portion of the real world reasonably well, 


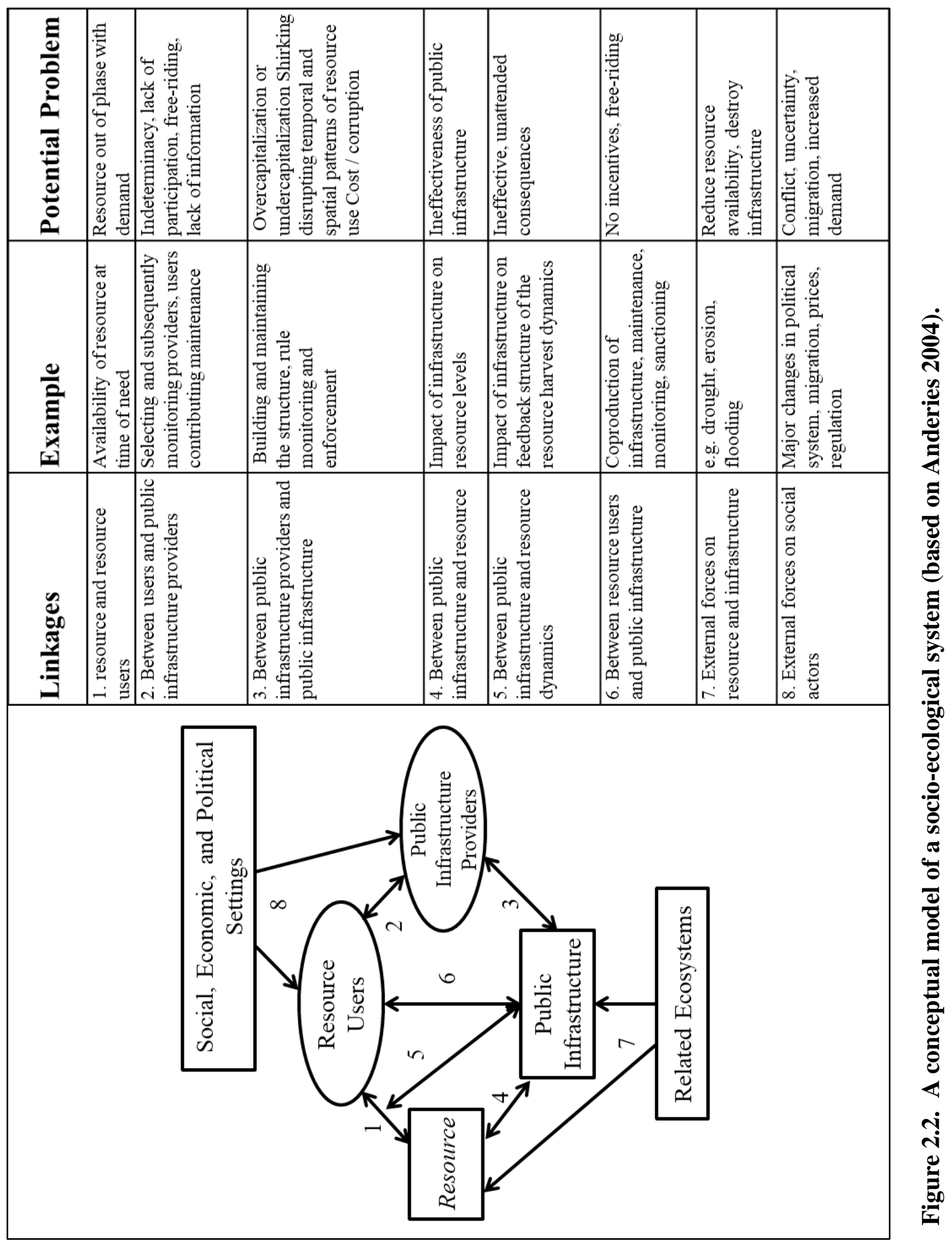


in certain respects and for some specific purpose” (Kohler and van der Leeuw 2007:3). Recent SES archaeogical research in the North American Southwest ranges from evolutionary approaches (e.g., Kohler and Varien 2012), studies of anthropogenic impacts on ecological resilience (e.g., Swetnam et al. 2016), to studies of robustness-vulnerability trade-offs associated with irrigation (Nelson et al. 2011).

\subsection{The Commons}

Anthropologists have long studied the commons, even if we rarely use the term (see Acheson 2011). Through the late $20^{\text {th }}$ century, the study of the commons was most associated with the ecologist Garrett Hardin’s article, The Tragedy of the Commons (1968). He presented a hypothetical scenario of a commonly held pasture falling victim to over-grazing. As each herder makes the economically rational decision to maximize their individual return by placing as many cattle to graze on the pasture as possible, the irrational outcome is the destruction of the commonly held pasture (Hardin 1968). For Hardin, commonly held resources pose an inherent dilemma susceptible to Malthusian catastrophes, with unchecked population growth invariably leading to the overexploitation and ultimately the collapse of both resources and societies. To avert the tragedy of the commons, Hardin and many others use the vulnerability of traditional commonly held resources to justify dismantling locally developed arrangements of commonly held property, and instituting to new property regimes of either private property (Smith 1981) or Hobbes’ Leviathan of state-level control (Ophuls 1973).

Since Hardin’s essay was published, a tremendous amount of research into the relationship between resource management, property rights, and governance has taken place to evaluate the 
arguments behind the tragedy of the commons. In particular, political scientists and economists working within what has come to be called the New Institutionalist approach have refocused their attention to the relationships between individuals and social institutions (Peters 2011). Elinor Ostrom’s work studying the commons aimed to test Hardin’s hypothesis by combining empirical observations with the results of experimental studies based on game theory. Her approach to testing hypotheses related to resource arrangements is a bottom-up approach, which is summarized in "Ostrom’s Law” whereby, "A resource arrangement that works in practice can work in theory” (Fennell 2011:10). Ostrom and her colleagues compiled cross-cultural observations of collective action strategies to resource management from hundreds of cooperatively managed systems (Ostrom 1990). Their field and experimental research found numerous examples of local communities developing long-standing arrangements to sustainably manage resources as commons. Examples included communal tenure of meadows in the Swiss Alps (Netting 1981), Japanese forests (McKean 1992), and Spanish irrigation systems (Maass and Anderson 1986). These examples refute the assertion that only privatization or state controls are options for sustainable resource management (Ostrom 2014).

Commons are resources held collectively by all members of a society or community (Ostrom 2000). Ostrom critiqued Hardin's argument largely because of the simple dichotomy he made between public and private goods. Hardin treated public goods as open access resources (i.e., resources without rules of use). Based on compilations of cross-cultural examples, Ostrom argued that open access resource arrangements are atypical. Instead, Ostrom categorizes resources, broadly conceived as any goods or services, into four basic types of goods based on their inherent subtractability and excludability (Ostrom 1990) (Table 2.1). Subtractability refers to how the use of a resource by one reduces the amount available to others. For example, the 
withdrawal of water from a reservoir by one user necessarily reduces the amount available to others. Rules surrounding allocation are typically needed for highly subtractable goods. Excludability refers to whether access to a resource can be restricted. Some goods cannot be restricted, even to members of a group who did not contribute to the provisioning of the good. This leads to the free-rider problem where those who did not contribute to the creation or maintenance of the resource receive benefits from it. Economists see this as the fundamental dilemma of collective action as a strategy for managing resources (Olson 2009). Mechanisms for establishing excludability involve costs, sanctioning, or embedding the goods in nested institutions to align individual preferences with collective action. Societies come to highly variable and contingent arrangements in how to handle different goods (i.e., a good considered public at a given time may be a private good in another).

Table 2.1. A typology of goods (adapted from Ostrom 2005: Figure 1.3).

\begin{tabular}{|l|l|l|l|}
\hline \multicolumn{2}{|l|}{} & Subtractability \\
\cline { 3 - 4 } \multicolumn{2}{|l|}{} & High & Low \\
\hline \multirow{2}{*}{ Excludability } & Difficult & $\begin{array}{l}\text { Common-pool resources } \\
\text { [CPR] } \\
\text { (fisheries, water reservoir) }\end{array}$ & $\begin{array}{l}\text { Public goods } \\
\text { (a pretty sunset, broadcast } \\
\text { television) }\end{array}$ \\
\cline { 2 - 4 } & \multirow{2}{*}{ Easy } & $\begin{array}{l}\text { Private goods } \\
\text { (my candy bar, my laptop) }\end{array}$ & $\begin{array}{l}\text { Toll or club goods } \\
\text { (day-care center, country club) }\end{array}$ \\
\hline
\end{tabular}

Of these types of goods, common pool resources are particularly interesting because they represent instances where societies developed institutions to confront conflicts over access and 
use. Common pool resources (CPR) are natural or human-made resources that are abundant and yet finite, potentially costly, but from which other potential users can be excluded (Ostrom 2005:79). Rules, norms, and institutions surrounding common pool resources develop to maintain equity and to keep "free-riders" from exploiting the resource. Commons researchers do not deny that resource arrangements can succumb to the tragedy of the commons. Examples of degraded common pool resources and failed institutional arrangements in modern society run the gamut from the collapse of fishing stocks after a change from local to state-level control (Wilson et al. 1994) to trans-boundary air pollution impacts on public health in down-wind polities (Bergin et al. 2005). In these examples social institutions were not able to control socioecological feedbacks in order to avert socio-ecological systems converting into new, degraded stable states.

Yet, empirical evaluations of common pool resources show that not all resource arrangements succumb to tragic outcomes. Small, community-based arrangements for resource management often are sustainable (Ostrom 2000). Common pool resource (CPR) theory developed out of observations of both extant systems of commons management and experimental work in game theory. CPR theory articulates relationships between institutions, resources, and sustainability, and it hypothesizes that sustainable socio-ecological systems share many attributes (Schlager 2004). At its core is the Institution Analysis and Development (IAD) framework. This framework conceptualizes how decision-making generates feedbacks. These feedbacks influence social institutions and system sustainability (Ostrom 2005). Researchers subsume the IAD framework within the Interactions and Outcomes spheres of the SES framework (Figure 2.1) (Ostrom 2009). 
CPR theorists also hypothesize that there are "design principles” common to robust CPR arrangements. The design principles are based on extensive observations of long-standing, selfgoverning CPR systems (Ostrom 1990). They are: 1) clearly defined boundaries; 2) proportional equivalence between benefits and costs; 3) collective-choice arrangements; 4) monitoring; 5) graduated sanctions; 6) conflict-resolution mechanisms; 7) self-determination of the community recognized by higher-level authorities; and 8) nested enterprises (Ostrom 2005: 259). Ostrom also identified five threats to sustainable governance systems: 1) rapid exogenous changes; 2) transmission failures from one generation to the next of the operational principles on which community governance is based; 3) programs relying on blueprint thinking and easy access to external funds; 4) corruption and other forms of opportunistic behavior; and 5) lack of largescale supportive institutions (Ostrom 2005:272). In the decades since their original proposal in 1990, research has shown the utility of these principles across a range of diverse institutional arrangements (Ostrom 2005). However, Ostrom cautions that these principles are not "blueprints", that no system exhibits all principles, and that analyzing a complete SES (much less designing a robust system capable of mitigating all disasters) would be folly (Ostrom 2005:255). Instead, the utility of design principles ranges from providing general heuristics to frameworks for quantifiable observations, usually of specific resource arrangements.

A concept central to CPR theory related to the final design principle deserves more attention. The concept of nested enterprises relates to governance systems referred to as polycentric. Polycentric systems have multiple governing organizations, operating at different scales, developing rules, norms, and institutions relating to aspects central to each (Ostrom 2005). The political jurisdictions of cities, counties, states, and federal government in the United States are a prime example of polycentricism because each inter-related governance system limits the 
centralization of power and expands representation. Polycentric systems create interdependences across a society and reduce centralization, which spreads knowledge and decision-making authority across a society. Yet they also generate conflict, can respond slowly to exogenous inputs, and in their complexity, can be very hard to research. The importance of polycentricity in relationship to Pueblo forms of resource management and social organization will be discussed further in Chapters 4 and 9.

\subsection{Archaeological Studies of the Commons}

In Ostrom's work she speaks of the "evolution of the commons" (Ostrom 2014), without ever really considering the role of historical or archaeological research. The historical depth of commons research is quite shallow. Instead, the attributes of long-standing CPR arrangements form the basis of the design principles for sustainable socio-ecological systems. Labroda-Pemán and de Moor (2016) presented the first summary of the state of historical research into the commons. They identify key challenges to applying theory about the commons to historical research, many of which are relevant to archaeology. Labroda-Pemán and de Moor (2016:520) find that identifying socio-political contexts (and their attributes) as exogenous drivers of CPR relationships doesn't appreciate the reciprocal relationship between the formation of institutions for resource management and emergent socio-political systems. Instead, socio-political contexts should be considered endogenous variables in relationship to participants interacting with institutions and resources. A related problem raised by historians is that there has been too little focus on appreciating the workings of broader contextual variables, regardless of whether these are bio-physical resources (e.g., the vulnerability of resources to climate change) or cultural practices (e.g., religious values) not explicitly tied to socio-political realms. Recent proposals for 
a socio-hydrology, a research tract focused specifically on the dynamics between water and society, also raise these concerns with SES models, and hold great promise in water-focused systems studies (Pande et al. 2017). Socio-hydrology is applied to archaeological datasets (Pande and Ertsen 2014), and like the proposal for a hydroarchaeology (French et al. 1012), further endogenizes important social factors in relationship to water management. More recent applications of SES frameworks address critiques by expanding the number of variables in these frameworks (Ostrom et al. 2009). In the conclusion of my dissertation I discuss how sociohydrology can contribute to future archaeological studies of water management.

Not a single article in the ten volumes that makeup the International Journal of the Commons (IJC), the journal for the International Association for the Study of the Commons, addresses its potential application to archaeology. For archaeology's long tradition of relating systems of resource management to the development of socio-political development, such as archaeological applications of Wittfogel's hydraulic hypothesis (Scarborough 2003), or Boserupian models of agricultural intensification (Morrison 2004), there are few studies explicitly addressing the commons. To better understand the range of archaeological approaches to studying common pool resources, and the potential that more direct applications of CPR theory could provide, I summarize key archaeological publications focused on the commons.

Studies of land tenure and territoriality in association with commons theory have focused on prehistoric hunter-gatherers, foragers, and transitional farmers in western North America (Eerkins 1999; Kohler 1992; Bayman and Sullivan 2008). Eerkins (1999), for example, explores whether there was inter-tribal collective management of resources by prehistoric hunter-gatherers in the Fort Irwin region of the Mohave Desert in Southern California, by testing CPR theory against ethnographic and archaeological data. Using ethnographic analogy, patterns of natural 
resource availability, and artifact distributions, he argues that while this resource-scarce area was unsuitable for year-round habitation, concentrations of floral and faunal resources in early spring would have made it attractive for seasonal use by hunter-gatherers from surrounding areas. The archaeological record suggests corresponding short-term occupations utilizing early season resources, with diverse material culture at the sites tied to adjacent regions. Eerkins suggests comanagement of commonly held territory as the most likely explanation for land-tenure pattern in the Fort Irwin region and that the diverse material culture suggests the development of land tenure and use-strategies to accommodate multiple groups utilizing the same area, at the same time.

Kohler's seminal study Field Houses, Villages, and the Tragedy of the Commons in the Early Northern Anasazi Southwest (1992) addresses land tenure, ownership, and agricultural intensification in the archaeological record of early Ancestral Pueblo people in the northern Southwest. Framed as a "tragedy of the commons” scenario, although not explicitly using CPR theory, Kohler hypothesizes that the development of a seasonal-residence system of field houses reflects the transition from open access agricultural lands to territorial ownership during a period of agricultural intensification, which he tests against diachronic models of population estimates, agricultural productivity, and site distributions.

Bayman and Sullivan (2008) use CPR theory to examine the emergence of prehistoric property rights and identity in the hinterlands of the Papagueria region of Southwestern Arizona and in the Grand Canyon. These regions are relatively marginal, yet multiple cultural groups utilized the landscape simultaneously. Similar to Eerkins, they argue that common pool resource strategies for land tenure and management developed and persisted because these regions could not support permanent occupations. In their comparative study, Bayman and Sullivan identify 
archaeological evidence for the shift from CPR regimes to one with property rights in the Papagueria. This shift occurred in association with limited agricultural intensification due to the adoption of water storage features to overcome inherent water scarcity and increased throughtrade of shell and obsidian to be manufactured into prestige goods by nearby Hohokam communities. By contrast, they argue that CPR regimes endured in the Grand Canyon because of the limited potential for agricultural intensification. Again, these arguments largely rest on relating underlying ecological and environmental resource productivity to socio-economic conditions rather than identifying properties of enduring social institutions for resource management.

Studies of the role of cooperation and collective action in relationship to the emergence of complex societies have also utilized aspects of CPR theory. Blanton and Fargher (2016) recently synthesized how collective action theory can be tested against cross-cultural archaeological examples, and it will surely be influential in future studies. Carballo (2013a, 2013b) articulates how commons research relates to long-standing archaeological research into the role of cooperation in the evolution of social complexity. He also identifies that the commons can serve as a loci for research on natural and social environments, and particularly for how societies respond to problems surrounding resources, vis-à-vis the "tragedy of the commons." For example, he hypothesizes that Ostrom's observation that large decentralized, cooperative systems of water management can be successful due to mutual monitoring and cross-drainage social networks, is applicable to the successful development of irrigation systems and communities in highland contexts of the Formative Period in Central Mexico (Carballo 2013b).

Some European researchers study the pre-historic origins of common property regimes within traditions of landscape archaeology and longue durée approaches of historical ecology 
(Lindholm et al. 2013; Oosthuizen 2013a, 2013b). These studies are important because they focus on identifying correlates in the archaeological record for the commons. Lindholm et al. (2013) identified archaeological commons in pre-industrial boreal forests of Northern Sweden. Using ethnohistorical records of forest CPRs and then conducting spatial analyses of analogous archaeological features such as pastures, roads, dams, game traps, and mills, they identify “hidden commons” from the Iron Age through medieval periods. Oosthuizen’s (2013a, 2013b) work on town commons in England tests the hypotheses that commonly held lands between villages have their origins in the Neolithic and were not a medieval invention developed after the Roman Period. Using a landscape approach, she correlates the continuity of archaeological manifestations of pre-Roman property boundaries, roads, and features associated with pasturage with their subsequent use as commons to reflect the endurance of common property regimes, albeit with significant changes through time relative to regional differences in English history. These approaches demonstrate the ways by which archaeologists can identify archaeological proxies for resource management within the framework of CPR theory.

The final examples relate the study of commonly managed resources within socio-ecological system theory. Campbell and Butler (2010) argue that the management of salmon in the indigenous Pacific Northwest contributed to the resiliency of fisheries. They integrate archaeological data of faunal remains, settlement patterns, and ethnographic evidence to show a long tradition of extensively relying on non-salmon resources, even though it was likely they could have relied more on salmon. Anderies (2006) directly applied a socio-ecological systems framework to analyze Hohokam culture history. He evaluated whether or not the Hohokam commitment to public infrastructure (i.e., irrigation canals and social institutions) to buffer against short-term resource stress made them vulnerable to rare high magnitude climatic events, 
like mega-droughts or flooding (Figure 2.3). Tradeoffs between robustness and vulnerability were identified in how the Hohokam's engineering of large, but costly irrigation systems introduced fragilities. Communities became highly dependent on these systems, which were costly to repair when damaged by floods. These inherent fragilities led to changes when high magnitude flooding increased while increasing populations made communities ever more dependent upon them. They model bio-economic aspects of food demands at different population levels to identify hypothetical thresholds for shifting from wild resources to irrigation agriculture, and how high populations introduce fragilities to even low-intensity droughts. Anderies identifies diachronic changes in population, subsistence, and the emergence of infrastructure as a series of tradeoffs between buffering against vulnerabilities and enhancing robustness, with one response to a resource and institutional challenge leading to new challenges, which in turn influence culture histories.

These studies demonstrate the potential of an archaeology of the commons, despite of the limited direct application of common pool resource theory. Taken together, these studies show a way forward for the study of the commons. Methodological approaches for identifying commons in the archaeological record (Lindstrom et al. 2013) combined with detailed intra-regional settlement pattern data (Eerkins 1999; Kohler 1992), and regional cultural histories identifying the significance of collective action and property regimes (Bayman and Sullivan 2008; Carballo 2013b), could provide the contextual data to analyze within a SES framework (Anderies 2006).

\subsection{A Future for the Archaeology of the Commons}

Applying CPR theory to archaeology will allow us to ask better questions about the relationship between resource management, social institutions, and culture change. CPR theory 


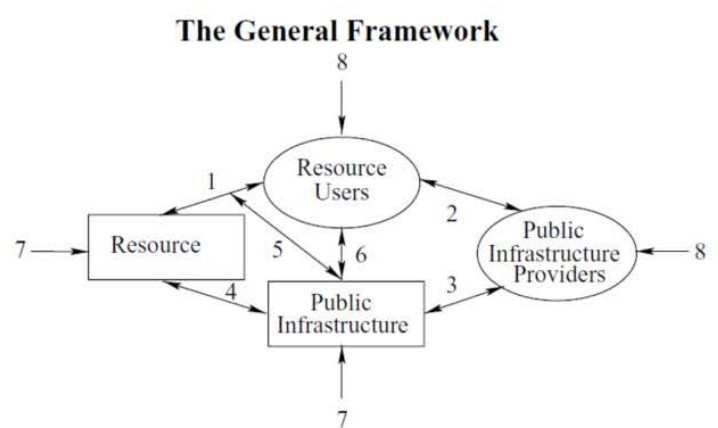

Late Pioneer through middle Sedentary Period (700-1070 A.D.)

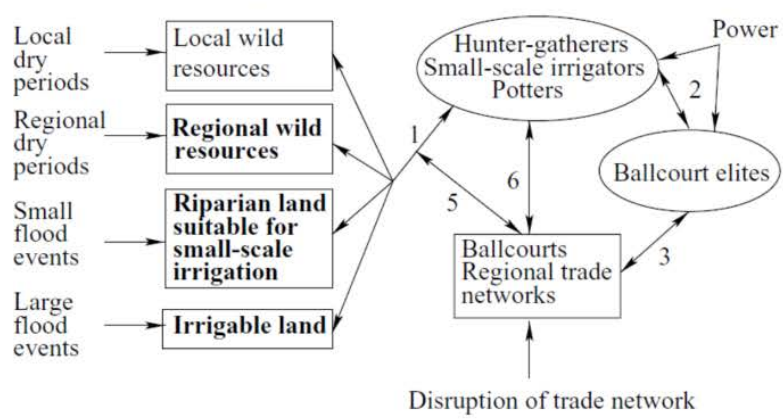

Pioneer Period (1-750 A.D.)

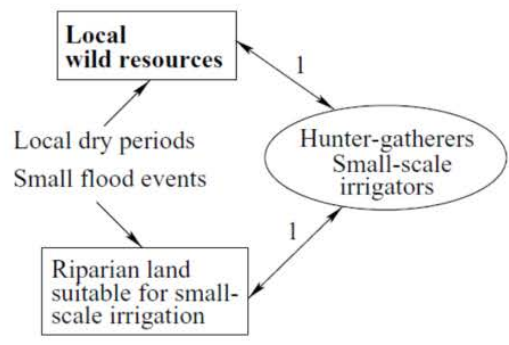

Late Sedentary through Classic Period (1070-1450 A.D.)

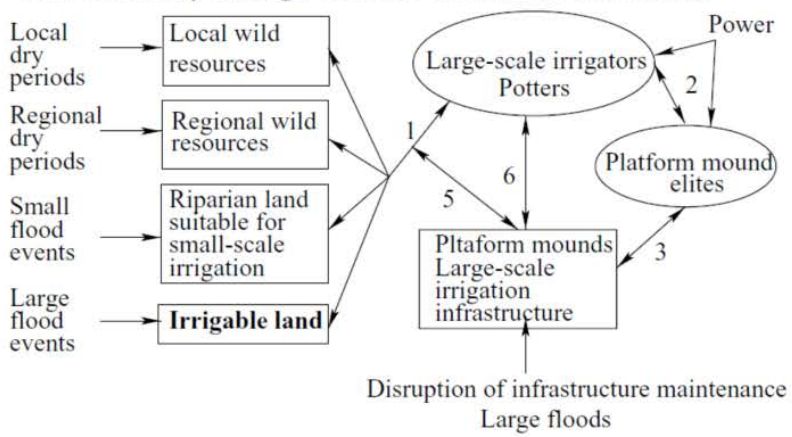

Figure 2.3. Diachronic models of Hohokam irrigation socio-ecological systems (Anderies, M., Robustness, institutions, and large-scale change in social-ecological systems: the Hohokam of the Phoenix Basin, Journal of Institutional Economics, 2(2): Figure 2, reproduced with permission).

includes a conceptual framework to structure investigations, a way to identify CPR regimes, and a series of hypothesized principles commonly seen in successful cooperative arrangements. It may also provide a better way to understand the relationship between climate and culture if we can identify concomitant changes to institutions and common pool resources sensitive to climate change, such as water.

Accordingly, I envision a CPR-informed archaeology with two elements. First, we need archaeological, paleoecological, and in some cases ethnological, investigations. Interdisciplinary researchers should study both natural resources and infrastructures for resource management. These studies are necessary to understand the distribution, management practices, and their sensitivity of to both environmental and cultural factors. In this dissertation, I identify 
archaeological proxies of collective action for water management. Infrastructure, such as a reservoir, is likely to be the most direct archaeological correlate of collective action. Therefore, reconstructing the use-life histories of these features is essential. Geoarchaeological investigations of water reservoir features, presented in Chapter 7, provide evidence for their uselife histories. I use these histories to model relationships between infrastructure, user demands, and climate impacts on resource availability.

Developing proxies for resource distribution, as well as an appreciation for resource sensitivity to both climate change and human use will require multiple analytical domains. Some analyses may fall outside of archaeology, necessitating interdisciplinary collaborations. In my study I use annual paleoprecipitation reconstructions from dendroclimatological records to identify hydrological droughts. In Chapter 5, I model the related ecosystem and resource variables of the SES model through paleohydrological investigations and resource acquisition cost studies.

Properties of resource users, infrastructure providers, and social, economic and political settings are derived from other archaeological lines of evidence. Cultural historical evidence provides the broader socio-economic contexts of particular resource arrangements. Regionspecific data, such as population estimates, site distributions, and intra-village markers of social hierarchies help to identify the decision-making contexts for how resource users and providers (who can be individuals who fill both roles) allocate resources. The background data for these variables are provided in Chapter 3, and incorporated into subsequent analyses and interpretations.

Ethnographic, ethnohistorical evidence and experimental studies of resource management will be essential for applying commons analytical frameworks to archaeology, since many 
attributes of social institutions surrounding resource management will be hard to identify in the archaeological record. Ostrom's design principles (Ostrom 2005) could be used as a rubric to mine ethnographic records or develop ethnographic analogs of CPR systems. Oral histories, mythologies, and folktales can also serve as sources of cultural rules and norms that relate to the management of commons. Groundbreaking work by Chwe (2009) on analyzing African American folktales with rational choice models from game theory shows social norms and rules reflecting values for decision-making surrounding resource allocation can be embedded in oral traditions. Approaches such as these may help archaeologists better appreciate the range of potential resource management relationships and institutions, and ask new questions of the archaeological record. In Chapter 4, I explore the Puebloan ethnographic and ethnohistorical record to demonstrate the existence of traditional CPR regimes and to suggest that these regimes probably originated in prehistory.

The second component for an archaeology of the commons is using socio-ecological systems frameworks to conceptualize the relationships between resource management decision-making in relationship to socio-environmental histories. In this study, I develop diachronic sociohydrological models for both the Pajarito and the Jemez Plateaus. I use these models to assess whether or not resource management strategies would impact the sustainability of these societies (Chapter 9). I presented an example of this framework in Figure 1.3.These models identify when common property regimes were initiated, their duration, and their effectiveness in managing resources. As such, they allow an assessment of the robustness and vulnerabilities of infrastructure and associated institutions to buffer insecurities in water availability and water acquisition costs, particularly in relationship to population histories and climate variation. 


\section{CHAPTER 3. PALEOPRECIPITATION RECORDS AND ARCHAEOLOGICAL CONTEXTS OF THE JEMEZ MOUNTAINS}

In this chapter I review the existing archaeological and paleoecological literature to populate four key variables in my socio-hydrological models. First, I provide a brief historical overview of socio-ecological research relevant to my study. Next, I identify wet and dry periods in the paleoprecipitation record using a local dendroclimate model (Touchan et al. 2011). These trends serve as the paleoclimate drivers for the paleohydrological model. I then use the existing archaeological record to develop a comparative cultural history of the Jemez and Pajarito Plateaus. I devote my attention to the Late Coalition, Classic, and early Historical Periods, between AD 1100-1700. I review broad trends in socio-political and economic culture histories, and focus on attributes of resource users, infrastructure providers, and collective action strategies.

\subsection{A Review of Socio-ecological Research in the Jemez Mountains}

Records of socio-ecological relationships in the Jemez Mountains from before the late $19^{\text {th }}$ century are reflected in Pueblo traditional ecological knowledge and early historical records from Spanish and American military expeditions. Pueblo oral histories and ethnographies document Pueblo traditional ecological knowledge of the Jemez Mountains (e.g., Harrington 1916; Sando 1982; Weslowski 1981) and reflect the deep history and appreciation of these environments by its Jemez, Tewa, and Keres inhabitants. Early historical documents of the Jemez Mountains serve 
as base-line historical record of the natural and cultural resources of the region. They begin with records from the earliest Spanish incursions into the region (discussed in Elliott 1986: 33-34), later U.S. army expeditions by Lieutenant James Simpson in 1842 (Simpson 1852), and geological observations by Dr. Oscar Loew in 1874 as part of the Wheeler Survey by the Army Corps of Engineers (Wheeler 1875).

Scientific research focusing on the relationships between the environment, people, and climate change in the Jemez Mountains began the late $19^{\text {th }}$ century. Adolph Bandelier identified dynamic relationships between precipitation, hydrology, and Ancestral Pueblo culture history. He hypothesized that prehispanic culture histories were sensitive to climate change (Bandelier 1892:13-15). Henderson and Robbins (1912) summarized early observations on this subject and made prescient recommendations for future research. For example, they hypothesized that in contrast with the few remaining modern Pueblos in the area, the abundant archaeological record reflected wetter conditions in prehistory (Henderson and Robbins 1912:47). Because early EuroAmerican researchers saw dryland maize farming on mesa-tops as impossible, they argued that conditions must have been wetter in prehistory to support such large archaeological populations (Henderson and Robbins 1912:58). Overly broad generalizations aside, they outlined a research agenda not dissimilar from what has developed over the last century (Henderson and Robbins 1912:68-70). They called for more archaeological studies, acknowledged the limitations of instrumental records and paleoclimate proxies, and advocated for deeper understandings of local ecology and hydrology in order to address questions about the impact of climate change on Ancestral Pueblo societies.

Archaeological research in the Jemez Mountains began with observations in the late $19^{\text {th }}$ century by Adolf Bandelier (1892) and excavations by Edgar Lee Hewett at Puyé on the Pajarito 
Plateau starting in 1907 (Hewett 1938). The rich archaeological record of the region was recognized immediately and Bandelier National Monument was formed in 1916 along the southern portion of the Pajarito Plateau. At the same time archaeological sites of the Jemez Plateau were also being documented (Bandelier 1892; Holmes 1905; Loew 1879:343-344). Fredrick Webb Hodge did field research on the Jemez in 1907, beginning decades of sporadic excavations in the region (Reiter 1938). More detailed histories of the contributions of these early researchers are synthesized by others (e.g., Elliott 1986; Mathien et al. 1993; Mathien 2004).

The bulk of our archaeological knowledge of these regions comes from relatively recent inventory surveys by federal archaeologists, as summarized by Elliott (1986) and Powers and Orcutt (1999). Beginning in the 1970s, major surveys on the Pajarito Plateau include the Pajarito Archaeological Research Project (PARP) (Hill and Trierweiler 1986; Hill et al. 1996), the Bandelier Archaeological Survey (BAS) (Powers and Orcutt 1999), and the Land Conveyance and Transfer Project (Hoagland et al. 2000). As of 2016, 97\% of Bandelier National Monument (Jamie Civitello, 2015, pers. communication) and approximately 90\% of Los Alamos National Labs (LANL) (LeAnn Purtzer, 2015, pers. communication) has been surveyed for archaeological resources, which totals approximately 54,000 acres. Kulisheck (2005) reported that 81,250 acres ( 38\%) of the Jemez Plateau has been surveyed for archaeology. More recent surveys, focused on the Valles Caldera National Monument (e.g., Anschuetz and Merlan 2007), along with regional syntheses (Vierra and Schmidt 2008), continue to expand this rich archaeological database. As substantial as this dataset is, there are two major limitations. First, survey data from private lands are incomplete and most information from tribal lands is not available. Second, in 
contrast to the abundant survey data, only a tiny fraction of these archaeological sites are excavated (Vierra and Schmidt 2008), thereby limiting archaeological interpretations.

These compliance-based studies are a boon for researchers of Ancestral Pueblo prehistory. Researchers use these data to address anthropological questions like the rise and fall of aggregated communities (Kohler et al. 2004b); ethnogenesis (Ortman 2012); and cultural resistance and revitalization (Liebmann 2012). These types of questions are typically investigated as part of multi-disciplinary projects, such as the National Science Foundation funded Jemez Fire \& Humans in Resilient Ecosystems (FHiRE) project (Swetnam et al. 2016) and the Village Ecodynamics II Project (VEP II) (Bocinsky and Kohler 2014), or in dissertation research (e.g., Curewitz 2008; Duwe 2011; Gabler 2009; Kulisheck 2005; Liebmann 2006; Van Zandt 2006).

Environmental research in the region focuses on studies of forests, water, and game. Rich paleoenvironmental records of forest histories, fire ecology, and paleoclimate are preserved in tree-rings and sediments (summarized in Allen 2004). Sophisticated understandings of local geology (e.g., Broxton and Vaniman 2005) come from generations of researchers studying volcanism, geothermal development, and geohydrology (e.g., Kelly and Anspach 1913). Teams of interdisciplinary researchers focusing on the "critical zone" of biota, soils, and landscapes in the Jemez continue to synthesize these studies (e.g., Chorover 2011). Finally, environmental remediation studies, associated primarily with Los Alamos National Labs on the Pajarito Plateau, provide a wealth of information relevant to SES modeling on climate and weather (Bowen 1990), geomorphology (Drakos and Reneau 2013), and hydrology (Purtyman 1995). 


\subsection{Paleoprecipitation Reconstructions of the Jemez Mountains}

Tree-ring derived paleoprecipitation records provide the opportunity to develop high resolution models of climatic variability. Dendroclimatology uses variation in the radial growth of trees to mathematically model properties of past climates, such as precipitation (Nash 1999). Recent tree-ring studies in the Jemez Mountains expand both our understanding of local variation in paleoprecipitation within the region (Towner and Salzer 2013) and the fidelity of the record (Touchan et al. 2011). For this study, I use Touchan et al.’s (2011) paleoprecipitation model. It is based on local tree-ring records from Pseudotsuga menziesii (Douglas-fir), Pinus strobiformis (Southwestern white pine) and Pinus ponderosa (Ponderosa pine). It spans the time period from AD 824-2007. These data are preferred to those reported by Towner and Salzer (2013) because Touchan et al. (2011) did not rely upon archaeological wood samples. Therefore, the composite ring-width record is not as vulnerable to uncertain proveniences and short segment lengths of individual records. Towner and Salzer's (2013) record is a useful point of comparison to Touchan et al.’s (2011), and I reference it throughout.

There are multiple ways to identify dry and wet periods in paleoclimate records. Drought, which is defined most simply as a deficiency in precipitation over a given time (Wilhite and Glantz 1985), is a multi-faceted concept. Drought conditions are always relative to the "normal” conditions of an environment (Wilhite and Buchanan-Smith 2005). Hazards researchers identify four types of drought: meteorological, agricultural, hydrological, and socio-economic (Wilhite and Buchanan-Smith 2005). Therefore, drought means different things in reference to different components of a socio-ecological system. In fact, Scott Ingram (2010; and in Ingram and Hunt 2015), who has conducted some of the most recent and intensive studies of prehistoric vulnerabilities to drought in the North American Southwest, argues that we do away with the 
concept of drought because its multi-faceted nature is inherently imprecise. Ingram instead uses the expression "dry period" to refer to intervals of reduced precipitation.

I only use the term of droughts to describe dry periods of magnitudes and durations that influence geohydrological systems. The geohydrological cycle typically has time-lags between precipitation and discharge; therefore for a dry period to influence hydrology it must be both protracted and basin-wide. Hydrological droughts are roughly equivalent to "mega-droughts" which are defined by Stahle et al. (2007:140-144) as droughts of both long duration (longer than a decade) and large distribution (regional to continental scale) based on the Palmer Drought Severity Index. Therefore, decadal patterns in rainfall variability are more relevant for understanding the impact of climate change to hydrological systems as opposed to meteorological and agricultural droughts, which are tied to annual and intra-annual variability in precipitation, or socioeconomic droughts, which incorporate a broader suite of natural and social factors. Dean (1988) developed a widely used framework for identifying magnitude, severity, and duration of dry periods in dendroclimatological records. To model Ancestral Pueblo social responses to climate changes on the Colorado Plateau, Dean hypothesized that cultures are largely well adapted to high frequency processes (annual to seasonal variability in climate) but vulnerable to low frequency climate fluctuations (on a $~ 25$ year cycle). To identify these low frequency processes, Dean identified 10- and 20-year running averages of annual precipitation in the dendroclimatological record and used departures from the mean of standard deviation units greater than 1.1 to identify dry and wet periods (Dean 1988: 136-138). Such approaches have been used in the Jemez in the past. Orcutt (1991), using a prior generation of tree-ring data, used the Palmer Drought Severity Index (PDSI) with a 5-year running mean to identify nineteen dry periods of durations 5 years or longer, through the Classic Period (AD 1350-1600). Similarly, 
Towner and Salzer (2013) use a 20-year smoothing spline to visually identify low frequency periods of dry and wet conditions across the three study areas, the Jemez, Chama, and Arroyo Hondo. I used the standard deviation approach of Dean (1988), with modifications following Ingram's (2010) recent summary of approaches to identify dry periods in climate and streamflow reconstructions. These approaches systematically identify thresholds for registering both dry and wet periods. First, I extracted yearly (October to June) precipitation reconstructions from Touchan et al. (2011) for the time period of interest (AD 1100-1700) and plotted with the 9-year moving average, which is a typical interval used (Figure 3.1). Next I calculated z-scores for the entirety of Touchan et al.'s record (2011) (Figure 3. 2). The mean for the entire record is 23.42 $\mathrm{cm}$ of precipitation per year, with a standard deviation of $4.61 \mathrm{~cm}$. Then, I visually identified periods of nine years or greater with z-scores less than zero for more than $70 \%$ of the years within the period. From these periods I further winnowed down the dry periods to intervals where yearly precipitation was below one standard deviation of the mean for more than $20 \%$ of the interval to register dry periods of not just long durations, but also high intensity. Using this approach I identified seven dry periods over the 600 year timespan as low-frequency, longduration dry periods most likely to affect hydrological systems (Table 3.1). Four wet periods were identified using the same criteria but with 1 standard deviation above average precipitation (Table 3.2). Major low-frequency droughts occur approximately once a century, except for the 1400s when there were two. Low frequency wet periods occur less frequently, with wet periods bookending the $12^{\text {th }}$ century, the early $14^{\text {th }}$ century and the beginning of the late $16^{\text {th }}$ century (Table 3.2). 


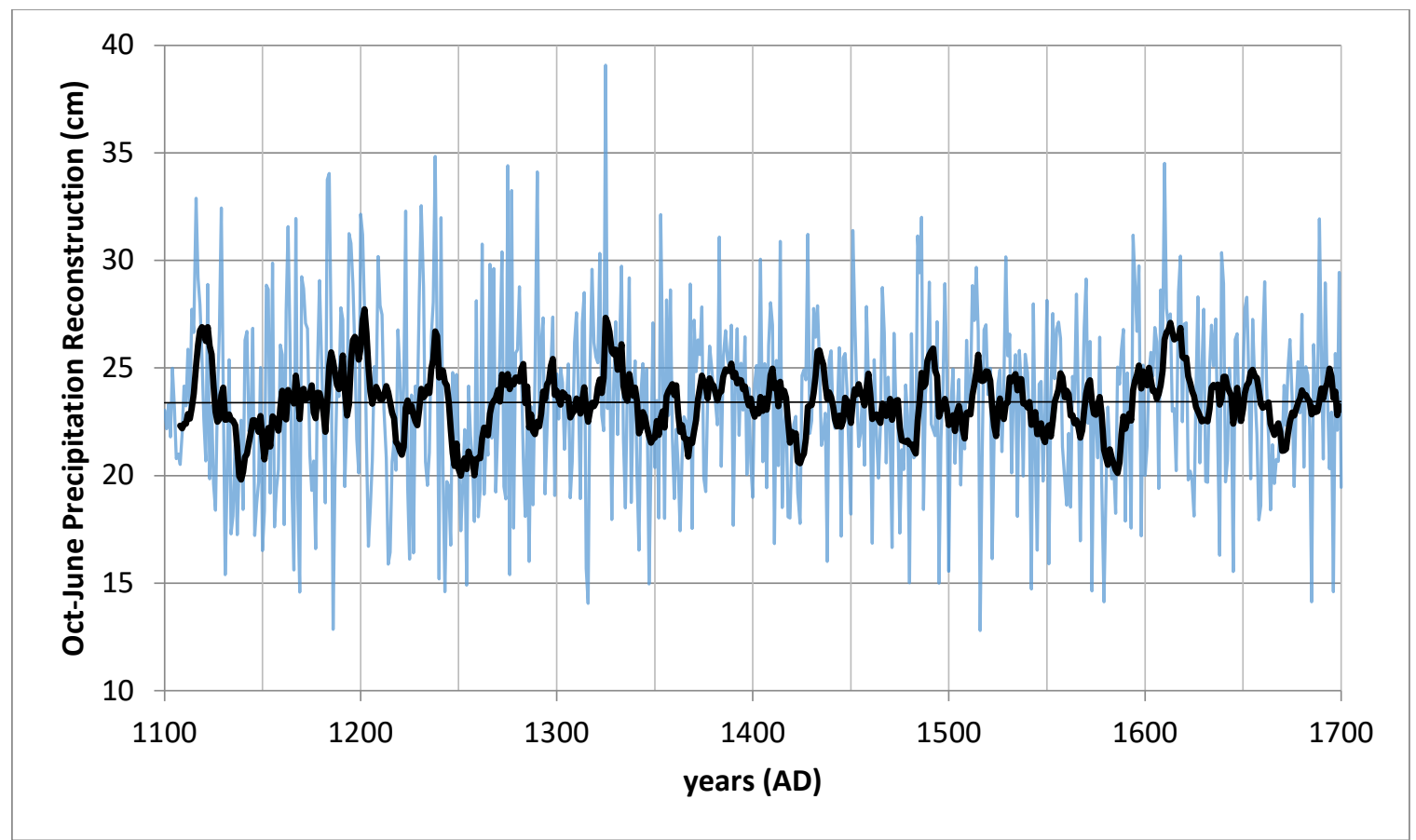

Figure 3.1. Precipitation reconstructions from between AD 1101-1700 (Touchan et al. 2011). Nine year moving average highlighted in black, and trend line with mean precipitation.

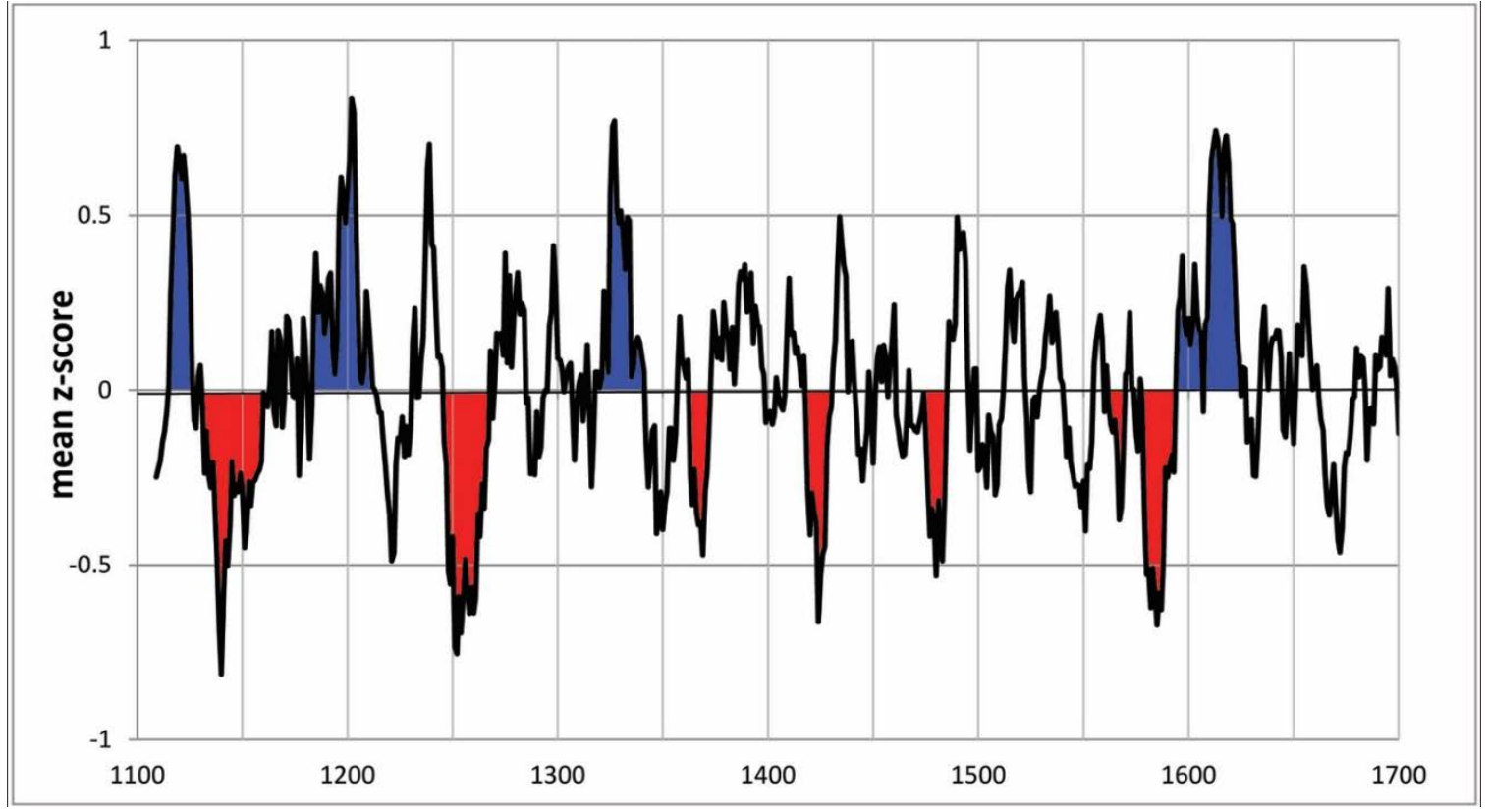

Figure 3.2. Nine year moving average of precipitation z-scores between AD 1101-1700 (Touchan et al. 2011). Dry periods are highlighted in red, and wet in blue. 
Table 3.1. Dry periods identified from z-scores of paleoprecipitation reconstructions (Touchan et al. 2011).

\begin{tabular}{|l|c|c|c|c|c|}
\hline Dry Period & $\begin{array}{c}\text { Period } \\
\text { Duration (yrs) }\end{array}$ & $\begin{array}{c}\text { Years } \\
\text { z-score }<0\end{array}$ & $\begin{array}{c}\text { Years } \\
\text { z-score }<-1\end{array}$ & $\begin{array}{c}\text { \% of years } \\
\text { z-scores }<0\end{array}$ & $\begin{array}{c}\text { \% of years } \\
\text { z-scores }<-1\end{array}$ \\
\hline $1131-1158$ & 28 & 20 & 10 & 71 & 50 \\
\hline $1240-1270$ & 31 & 23 & 7 & 74 & 30 \\
\hline $1359-1369$ & 11 & 10 & 2 & 91 & 20 \\
\hline $1413-1424$ & 12 & 12 & 4 & 100 & 33 \\
\hline $1473-1483$ & 11 & 9 & 2 & 82 & 22 \\
\hline $1558-1568$ & 11 & 8 & 3 & 73 & 38 \\
\hline $1573-1583$ & 13 & 12 & 3 & 92 & 25 \\
\hline
\end{tabular}

Table 3.2. Wet periods identified from z-scores of paleoprecipitation reconstructions (Touchan et al. 2011).

\begin{tabular}{|l|c|c|c|c|c|}
\hline Wet Period & $\begin{array}{c}\text { Period } \\
\text { Duration (yrs) }\end{array}$ & $\begin{array}{c}\text { Years } \\
\text { z-score }>0\end{array}$ & $\begin{array}{c}\text { Years } \\
\text { z-score }>1\end{array}$ & $\begin{array}{c}\text { \% of years } \\
\text { z-scores }>0\end{array}$ & $\begin{array}{c}\text { \%of years } \\
\text { z-scores }>1\end{array}$ \\
\hline $1110-1119$ & 10 & 8 & 2 & 80 & 20 \\
\hline $1183-1202$ & 20 & 14 & 7 & 70 & 50 \\
\hline $1317-1333$ & 17 & 12 & 4 & 71 & 33 \\
\hline $1594-1613$ & 20 & 16 & 5 & 80 & 31 \\
\hline
\end{tabular}

Wet and dry periods identified by this approach show both similarities and differences with regional climate trends and Towner and Salzer's (2013) intra-regional analysis. The dry period identified between AD 1131-1158 falls within the "Chaco Drought” from AD 1130-1180 (Dean 1988). The "Great Drought” (1276-1299) in the Four Corners region (Ahlstrom et al. 1995), was not registered in the Jemez Mountains as a severe event, although there was a major dry period in the Jemez Mountains immediately before this, between AD 1240-1270. The relatively minor effect of the Great Drought in the Jemez Mountains and the greater Northern Rio Grande region (Towner and Salzer 2013) is considered to be a possible contributing factor to the attractiveness of this region to immigrants from the Four Corners region. 
Regional records confirm a relatively drought-free and wet early $14^{\text {th }}$ century (GrissinoMayers 1996; Stahle et al. 2007; Towner and Salzer 2013), and the 89-year interval between dry periods (1270-1359) in the Touchan et al. (2011) record is the longest mesic period in the Jemez until the $17^{\text {th }}$ century. This interval corresponds to archaeological periods with the highest total populations on the Pajarito Plateau. The drought in the mid- $14^{\text {th }}$ century ends a period of above normal precipitation in the Southwest extending back into the $11^{\text {th }}$ century (Grissino-Meyers 1996) and it begins a period characterized by drier than average conditions associated with the onset of the Little Ice Age (Peterson 1994). These conditions are registered in the Jemez Mountains by the increasing frequency of decadal-scale droughts. After the end of the second drought (AD 1483 in the Jemez Mountains) precipitation patterns become highly variable, with both wet periods and dry periods. In particular, the extreme “mega-drought” of the late $16^{\text {th }}$ century, which is observed in dendroclimatological records across North America (Stahle et al. 2007) and on the Colorado Plateau, is identified as a "perfect drought" with both low winter and monsoonal precipitation (Stahle et al. 2009). A long dry period occurred at end of the $17^{\text {th }}$ century as well; however because it lacked high magnitude drought years I did not consider it a hydrological drought. Spanish historical records from New Mexico document this dry period (Hackett 1937). Van West et al. (2013) hypothesize that it contributed to the Pueblo Revolt by causing crop failures. I discuss the implications of hydrological droughts in relationship to culture history throughout the remainder of the chapter only briefly, but in more detail through the remainder of the dissertation. 


\subsection{Comparative Ancestral Pueblo Cultural Histories of the Jemez and Pajarito Plateaus}

In the following sections I present comparative cultural histories of Ancestral Pueblo of the Jemez and Pajarito Plateaus. A total of 5,282 Ancestral Pueblo archaeological sites are recorded in the study areas (Figure 3.3). Chronological frameworks in both regions are based on Wendorf and Reed's (1955) reconstruction of the Northern Rio Grande cultural sequence. Intra-regional cultural chronologies of the Pajarito Plateau are more refined than that of the Jemez Plateau (Figure 3.3). This is largely due to the paucity of locally produced, time-sensitive local glazewares at Jemez archaeological sites (Shepard 1938; Kulisheck 2005; Liebmann et al. 2016). The dominant ceramic type of the Jemez, Jemez Black-on-White, underwent very little stylistic change through time, which makes developing high resolution cultural chronologies challenging (Kulisheck 2005). Accordingly, efforts to develop Jemez-specific typologies are few (see summary in Elliott 1986). The most extensive effort to synthesize ceramic typologies and chronologies of Ancestral Pueblo time periods in the Jemez has been undertaken by Kulisheck (2005). By contrast, the Pajarito Plateau benefits from overlapping, time diagnostic ceramic types (Tewa Biscuitwares and Rio Grande Glazewares), from which more finely divided cultural chronologies are possible (e.g., Orcutt 1991,1999; Ortman 2016) (Figure 3.4). As a consequence the Jemez Plateau culture area receives less attention in regional syntheses of culture history than surrounding areas (e.g., Crown et al. 1996; Snead et al. 2004) and there are no direct comparative studies of archaeological culture histories between these regions.

These problems impact our efforts to develop population estimates of the Jemez. Because Jemez sites can only be attributed to very broad periods, making site-specific estimates of population dynamics is problematic (Kulisheck 2005). Recent efforts at Jemez population estimates have found success by approaching the problem from the historical period back into 


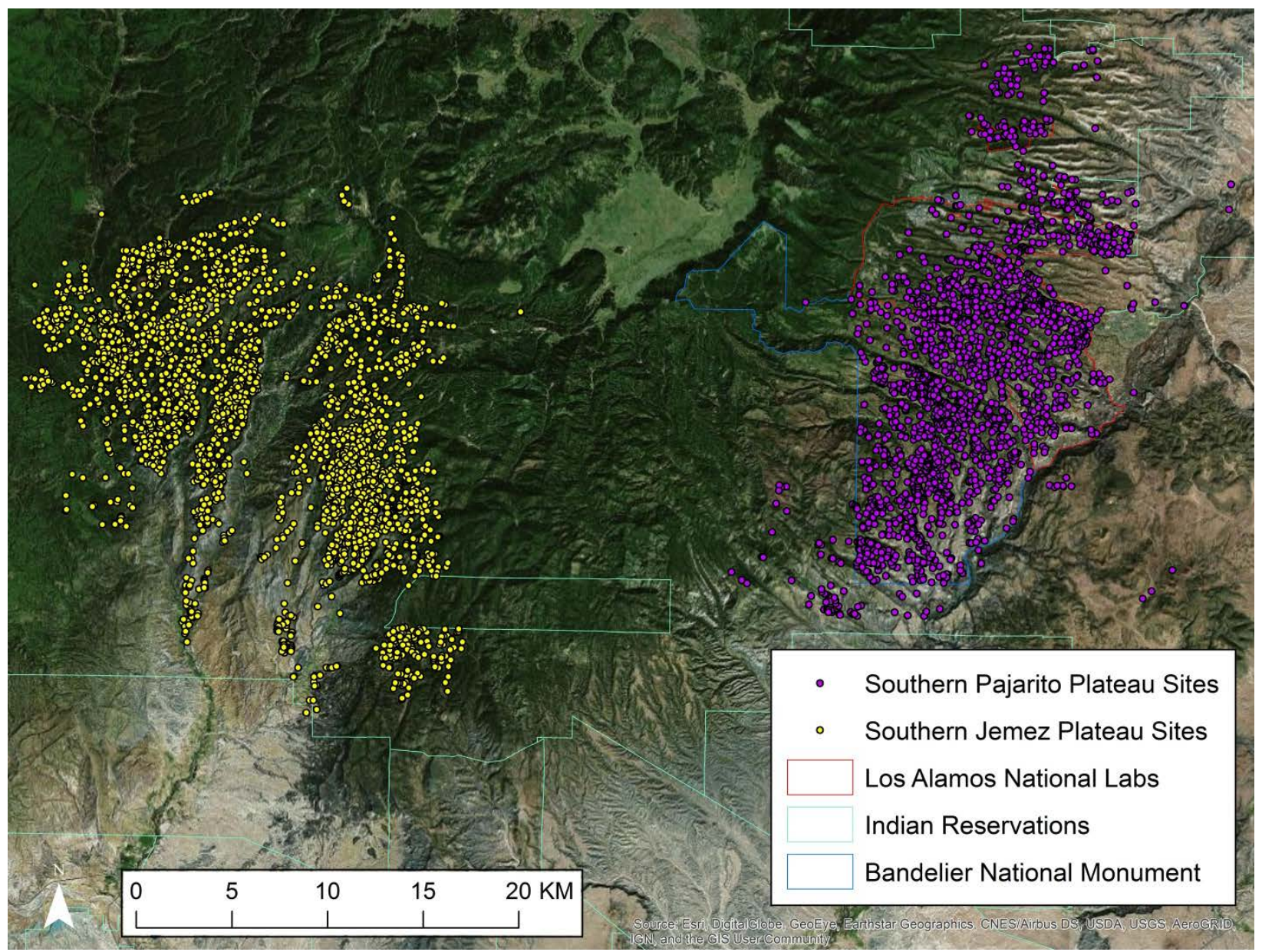

Figure 3.3. Documented Ancestral Pueblo archaeological sites in each project area.

the prehispanic era. Liebmann et al. (2016) use terminus ante quem dating of ponderosa pine recruitment on Ancestral Pueblo sites as a novel proxy for dating site abandonment, new archaeological surveys focused on recovering historical tradewares, and rubble mound volume estimates to model contact period populations at large villages of the Jemez Plateau. Their reconstruction spans from roughly AD 1500 to the 1620s, and they argue, as does Kulischeck (2005), for sustained high populations (5-8,000 persons) from the late $15^{\text {th }}$ century through the early/mid-17 ${ }^{\text {th }}$ century (Figure 3.5). These population estimates can be projected before AD 1500 


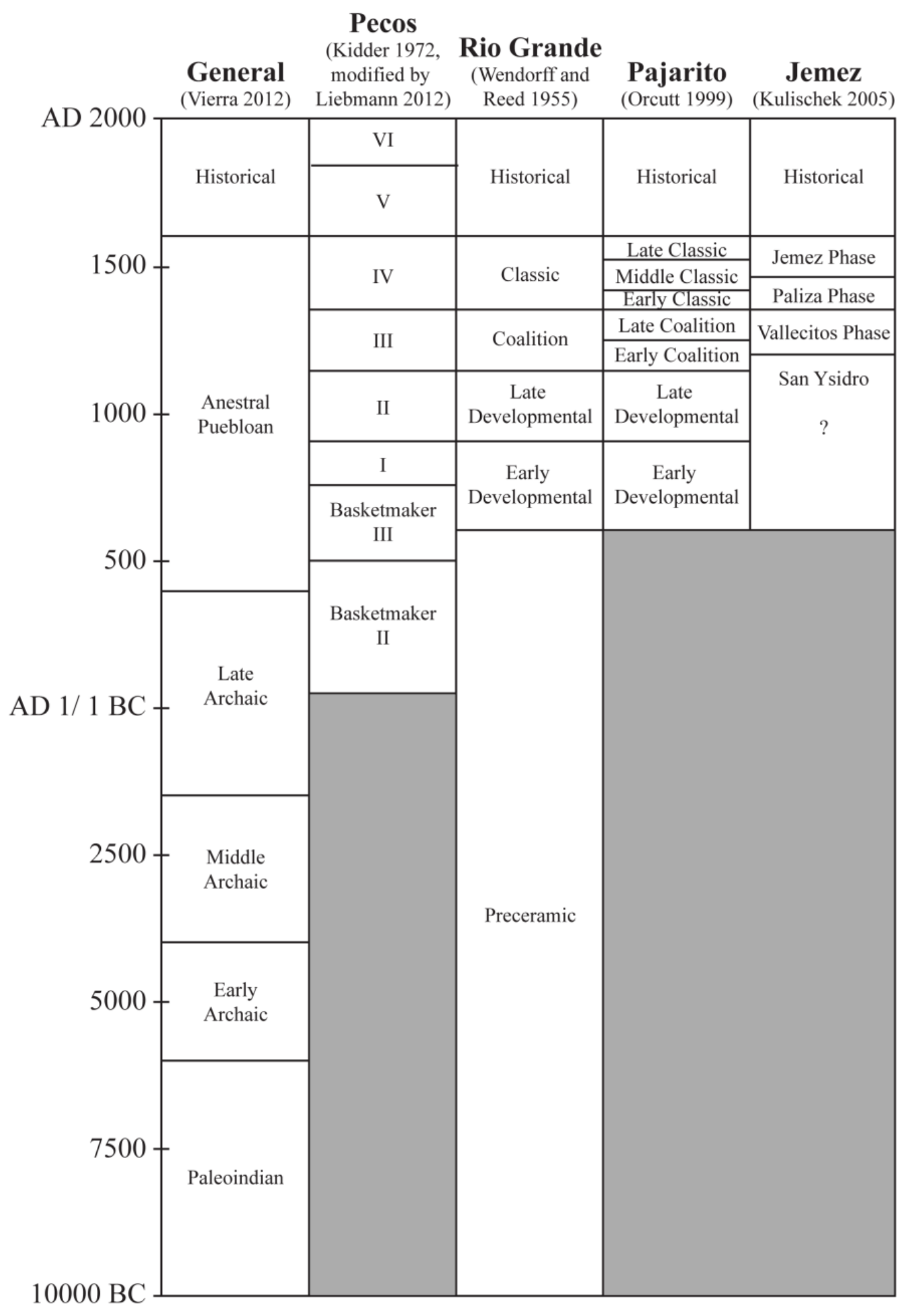

Figure 3.4. Northern Rio Grande and Jemez chronologies. 
based on the densities of earlier artifact types, but with decreasing certainty the further back in time (Liebmann et al. 2016). The consequence of this uncertainty is that only generalized interpretations of population dynamics are possible for Ancestral Pueblo communities of the Jemez Plateau.

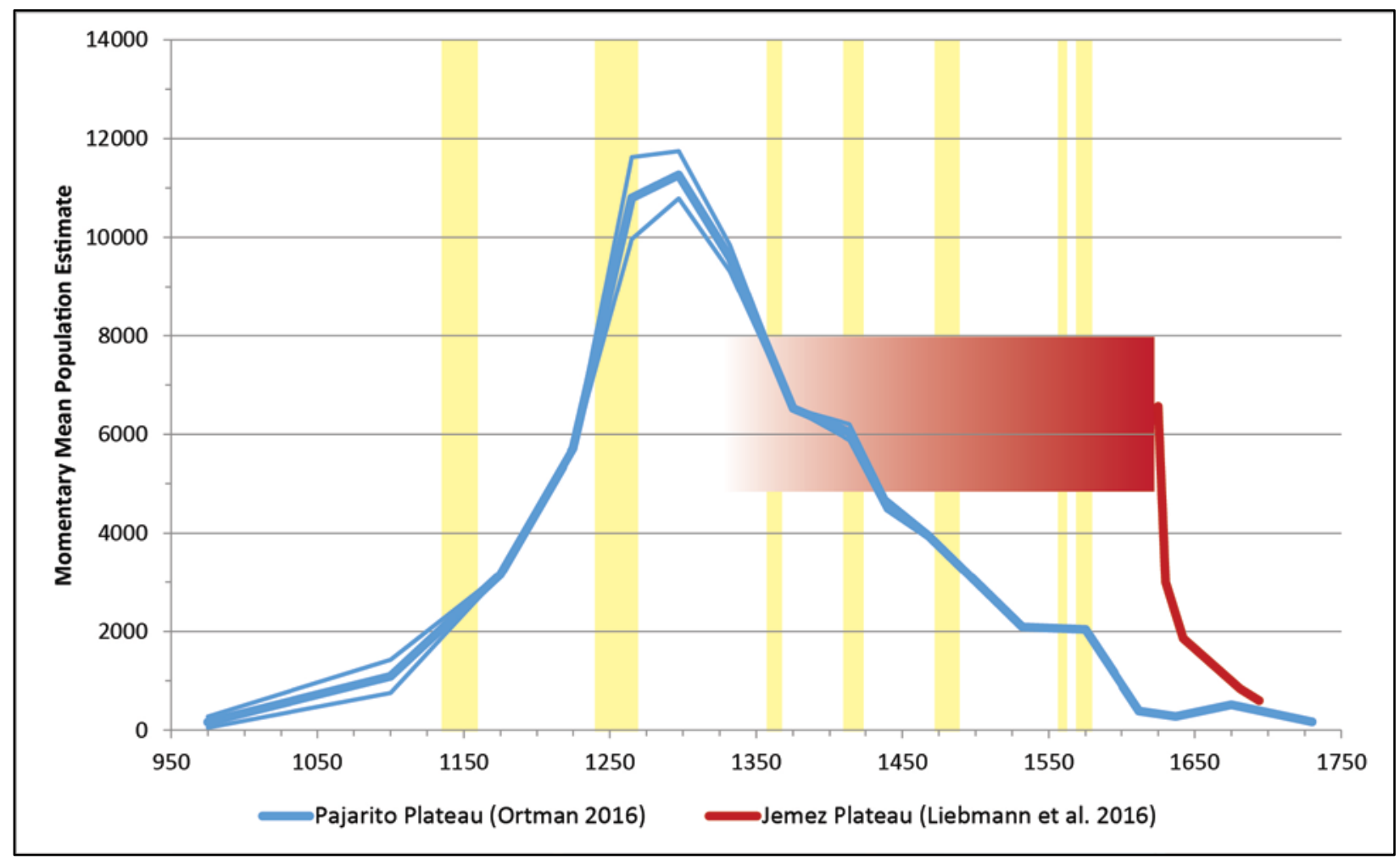

Figure 3.5. Jemez and Pajarito Plateau momentary mean population estimates with intervals of hydrological droughts identified between AD 1100-1700.

Culture histories of the Pajarito Plateau benefit from more long term academic research projects and a material culture more amenable to population reconstructions. Recently, Ortman (2016) synthesized architectural, ceramic, and ethnohistorical data from the Northern Rio Grande region to develop diachronic population histories for Ancestral Tewa communities. His dataset 
included the entirety of the Pajarito Plateau, which includes half of my study area. A 17-period chronology from AD 900-1760 anchors the settlement history. Table 3.3 presents Ortman’s scheme, with site counts and population estimates by time period for the portions of the Pajarito Plateau within the project area. Ortman's more finely divided sequence falls within Orcutt’s broader framework. I should note that the Ancestral Pueblo components of these chronologies are based largely on ceramic cross-dating and tree-ring data, with relatively few radiometric ages. Ortman (2016) analyses total ceramic counts recovered from each site that are apportioned through a uniform probability density analyses to develop a series of probabilities for the number of rooms occupied per site, through time (Ortman 2016). Momentary mean population estimates of these sites are based on apportioning inhabitants to site-specific room counts. Estimates of occupied rooms by site are then summed by time period (with a probability error) to generate a regional momentary mean population within the project area of the Pajarito Plateau (Figure 3.5, Table 3.3). This allows population estimates by time periods at both the site and regional level for the Pajarito Plateau, as well as for adjoining regions of the Northern Rio Grande in his study area, such as the Chama and Santa Fe areas.

\subsection{Early Developmental Period/San Ysidro Phase (AD 600-1050)}

The expansion of agriculturalists living in permanent residences occurred in both regions during what is locally known on the Jemez Plateau as the San Ysidro Phase (Kulisheck 2005) and the Early Developmental Period on the Pajarito Plateau. The constellation of attributes characteristic of the Developmental Period includes the use of ceramics and living in pithouses. Both regions have little archaeological evidence for the early portion of this period, which is not surprising as this period did not develop as quickly in the Northern Rio Grande as it did in 
Table 3.3. Chronology and momentary mean population estimates for the Pajarito Plateau project area (based on Ortman 2012, 2016).

\begin{tabular}{|l|l|l|c|c|c|c|c|}
\hline $\begin{array}{l}\text { Period } \\
\text { Number }\end{array}$ & Period Name & $\begin{array}{l}\text { Dates } \\
\text { (AD) }\end{array}$ & $\begin{array}{c}\text { Period } \\
\text { Length }\end{array}$ & $\begin{array}{c}\# \\
\text { Sites }\end{array}$ & $\begin{array}{c}\text { Mom. } \\
\text { Mean } \\
\text { Pop. Est. }\end{array}$ & $\begin{array}{c}\text { Mean \# } \\
\text { Persons } \\
\text { per site }\end{array}$ & $\begin{array}{c}\text { Pop. } \\
\text { Density } \\
\text { (per/km }{ }^{2}\end{array}$ \\
\hline 1 & $\begin{array}{l}\text { Early } \\
\text { Developmental }\end{array}$ & $900-1050$ & 150 & 109 & 165 & 1.5 & 0.2 \\
\hline 2 & $\begin{array}{l}\text { Middle } \\
\text { Developmental }\end{array}$ & $1050-1150$ & 100 & 341 & 1088 & 3.2 & 1.3 \\
\hline 3 & $\begin{array}{l}\text { Late } \\
\text { Developmental }\end{array}$ & $1150-1200$ & 50 & 575 & 3160 & 5.5 & 3.8 \\
\hline 4 & Early Coalition & $1200-1250$ & 50 & 1215 & 5722 & 4.7 & 6.9 \\
\hline 5 & Middle Coalition I & $1250-1280$ & 30 & 1336 & 10798 & 8.1 & 13 \\
\hline 6 & Middle Coalition II & $1280-1315$ & 35 & 1220 & 11267 & 9.2 & 13.6 \\
\hline 7 & Late Coalition & $1315-1350$ & 35 & 604 & 9579 & 15.9 & 11.5 \\
\hline 8 & Early Classic & $1350-1400$ & 50 & 507 & 6524 & 12.9 & 7.9 \\
\hline 9 & Middle Classic I & $1400-1425$ & 25 & 400 & 6042 & 15.1 & 7.3 \\
\hline 10 & Middle Classic II & $1425-1450$ & 25 & 351 & 4584 & 13.1 & 5.5 \\
\hline 11 & Late Classic & $1450-1515$ & 65 & 335 & 3948 & 11.8 & 4.8 \\
\hline 12 & Terminal Classic & $1515-1550$ & 35 & 308 & 2087 & 6.8 & 2.5 \\
\hline 13 & Contact & $1550-1600$ & 50 & 175 & 2040 & 11.7 & 2.5 \\
\hline 14 & Early Colonial & $1600-1625$ & 25 & 14 & 387 & 27.6 & 0.5 \\
\hline 15 & Pre-Revolt & $1625-1650$ & 25 & 9 & 279 & 31 & 0.3 \\
\hline 16 & Revolt & $1650-1700$ & 50 & 11 & 514 & 46.7 & 0.6 \\
\hline 17 & Reconquest & $1700-1760$ & 60 & 6 & 167 & 27.9 & 0.2 \\
\hline
\end{tabular}

other regions of the Southwest (Reed 2000; Vierra 2005). In the Jemez Plateau region, no mesatops sites date to this period. A few possible pithouse sites are found along river terraces below the confluence of the Rio Guadalupe and Jemez Rivers, down to the confluence of the Jemez with the Rio Salado (Kulisheck 2005). The Jemez Cave site, located in San Diego Canyon near the Soda Dam, has archaeological materials deposited stratigraphically above the Archaic horizons, which should date to this period. The archaeological remains are interpreted to represent only seasonal occupations in the uplands, with evidence of maize horticulture to supplement wild flora and fauna (Ford 2013). 
Populations were small on the Pajarito Plateau as well. Pithouses are confined to nearby lower elevations off of the Pajarito (Van Zandt 2006: 71). Ortman’s database identifies 109 sites to the latter portion of the Early Developmental (AD 900-1050) and he estimates a momentary mean population of only 165 persons for the entirety of the Pajarito Plateau. Both cultural and natural site formation processes likely serve to obscure these early components (Drakos and Reneau 2013), but under these conditions with such limited populations it is no surprise that neither evidence for water management, nor politically integrative architecture are identified during the Developmental Period.

\subsection{Late Developmental Period/San Ysidro Phase (AD 1050-1200)}

The Late Developmental Period (AD 1050-1200) sees the first appreciable increase in occupations on the mesa-tops of the Pajarito Plateau. The lack of refinement within the Jemez chronology precludes differentiating between the Early and Late Developmental on the Jemez Plateau. On the Pajarito we see the first examples of masonry architecture and mesa-top habitation sites with extended or multiple households (Van Zandt 2006). Figure 3.6 depicts the distribution of large archaeological sites (> 12 rooms) on the Pajarito Plateau. Ortman (2016) classifies three aggregated site types based on room counts: hamlets (>12 rooms), villages (>50 rooms), and towns (>500 rooms). His size designation is based on a site's maximum population, none of the towns (i.e., Pueblo Cañada, Otowi, and Guaje) achieved their maximum population by the Late Developmental Period. Ortman (2016) apportions 341 sites on the Pajarito Plateau to AD 1050-1150 and he estimates a momentary mean population of 1,088. Towards the end of this period, Ortman estimates 3,160 persons living at 575 sites across the Pajarito Plateau between AD 1150-1200 (Table 3.3). This corresponds to Van Zandt's (2006) interpretation that most of 
the population increase during the Developmental occurred during the last 50 years of this occupation span. Architecture consists of small adobe structures and a few sites with what are possibly roomblocks. Subsistence still appears to be mixed foraging and horticulture, with no reliance on maize (Vierra and Ford 2006). There are no reported water management features for this time period and occupation sizes are small hamlets with little evidence for political differentiation or hierarchies.

\subsection{Early Coalition Period/Vallecitos Phase (AD 1200-1280)}

The archaeological records of both regions expanded significantly during the Coalition Period. This period is called the Vallecitos Phase on the Jemez and it is broadly analogous to the Coalition Period of the Pajarito (Kulisheck 2005). Populations increase and there is archaeological evidence for year-round habitation on mesa-tops in above ground structures. During the Early Coalition (AD 1200-1280) these structures are small linear to rectangular roomblocks, typically with 10 rooms or less, but with a few larger communities (Preucel 1990; Kulisheck 2005). In Figure 3.7 I compare the distributions of aggregated communities in both regions, using the same site size criteria. The Jemez data comes from Kulisheck (2005: Table A.1) and it is based on room counts, just like Ortman's dataset (2016).

Jemez sites identified as villages and towns likely were not at their maximum population during the Vallecitos Phase and instead were likely being first established. Excavations of Early Coalition roomblocks of hamlets in Bandelier (Kohler and Root 2004a, b) find that resource intensification was occurring, with increased reliance on domesticates, but with wild game resources still an appreciable part of the diet. The more productive 12-14 row maize varieties developed during this time period, to which increased maize production can be inferred (Vierra 


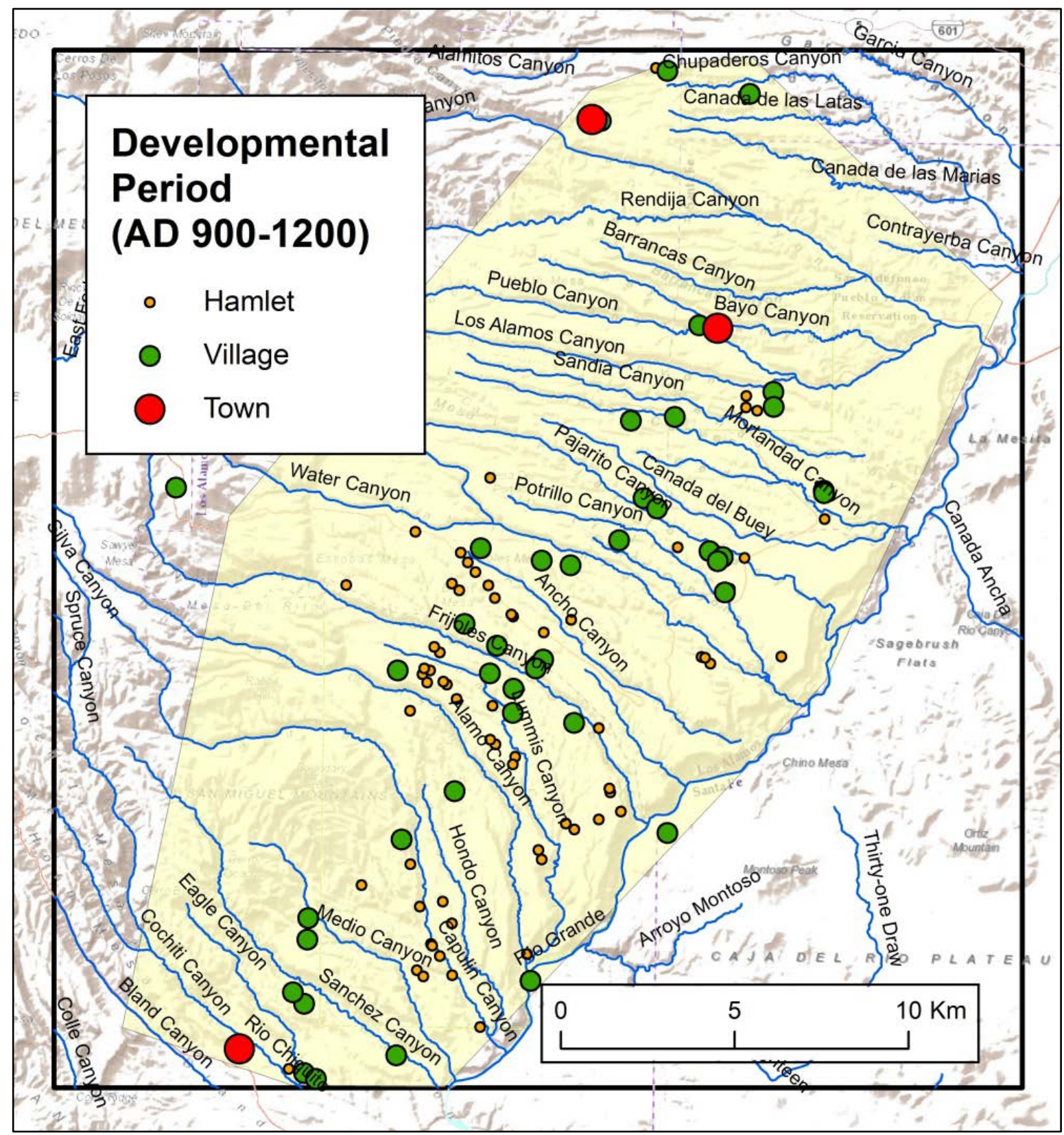

Figure 3.6. Distribution of aggregated sites on the Pajarito Plateau during the Developmental Period (AD 900-1200). Areas highlighted in yellow denote the spatial range of all archaeological sites dating to this time period.

Ford 2006). Hamlets and 1-2 room structures began to fill in the landscape of the Pajarito and a few centralized villages developed. Ortman (2014) models a momentary mean population estimate of 5,722 persons during the Early Coalition (AD 1200-1250) (Table 3.3). Population 
nearly doubles towards the end of the Early Coalition on the Pajarito, expanding rapidly between AD 1250-1280 to a momentary mean estimate of 10,797 persons (Table 3.3). At this time there would be 20 villages with a hundred or more inhabitants and seven with 200 or more people. By comparison, on the Jemez there are possibly two pueblos with comparable populations, Patokwa (LA96) and Little Boletsakwa (LA136), 11 hamlets, and 4 villages (Kulisheck 2005: Table A.1). Most of these hamlets are found in or near San Diego Canyon on terraces overlooking the Jemez River, or to the east along Vallecitos Creek, and San Juan Canyon.

Such a rapid increase in population exceeds the rates for in situ growth (Crown et al. 1996: 195-196). There is a growing consensus that immigration is the only way to achieve such rapid population growth and multiple lines of evidence indicate that the source population was the northern San Juan Basin and adjacent areas of the Four Corners region (Duwe 2011; Ortman 2012). Models of alternative routes of migration show that travel through the Jemez Mountains and into the Northern Rio Grande by way of the Pajarito Plateau was an efficient route of travel between these regions (Safi 2014). For the Jemez Plateau, some archaeologists have long linked the coincident abandonment of the Gallina Phase occupations to the northwest as a possible source population for the Jemez (e.g., Ford et al. 1972; Ellis and Dodge 1989). Recent archaeological interpretations by Elliott (1998), as well as Jemez oral traditions (see quote by Whatley in Roberts 2010) do not support this hypothesis. Instead migrants to the Jemez, which do not appear to arrive in as large numbers as those of the Pajarito during the Vallecitos Phase, are likely from the Four Corners region as well. Yet Kulisheck (2005) reports that only a limited number of ceramic finds near the modern village of Cañon along the Jemez River have stylistic affinities to the San Juan Basin, supporting hypotheses for alternative origins, such as endogenous development or possibly immigration from other regions (Kulisheck 2005). 


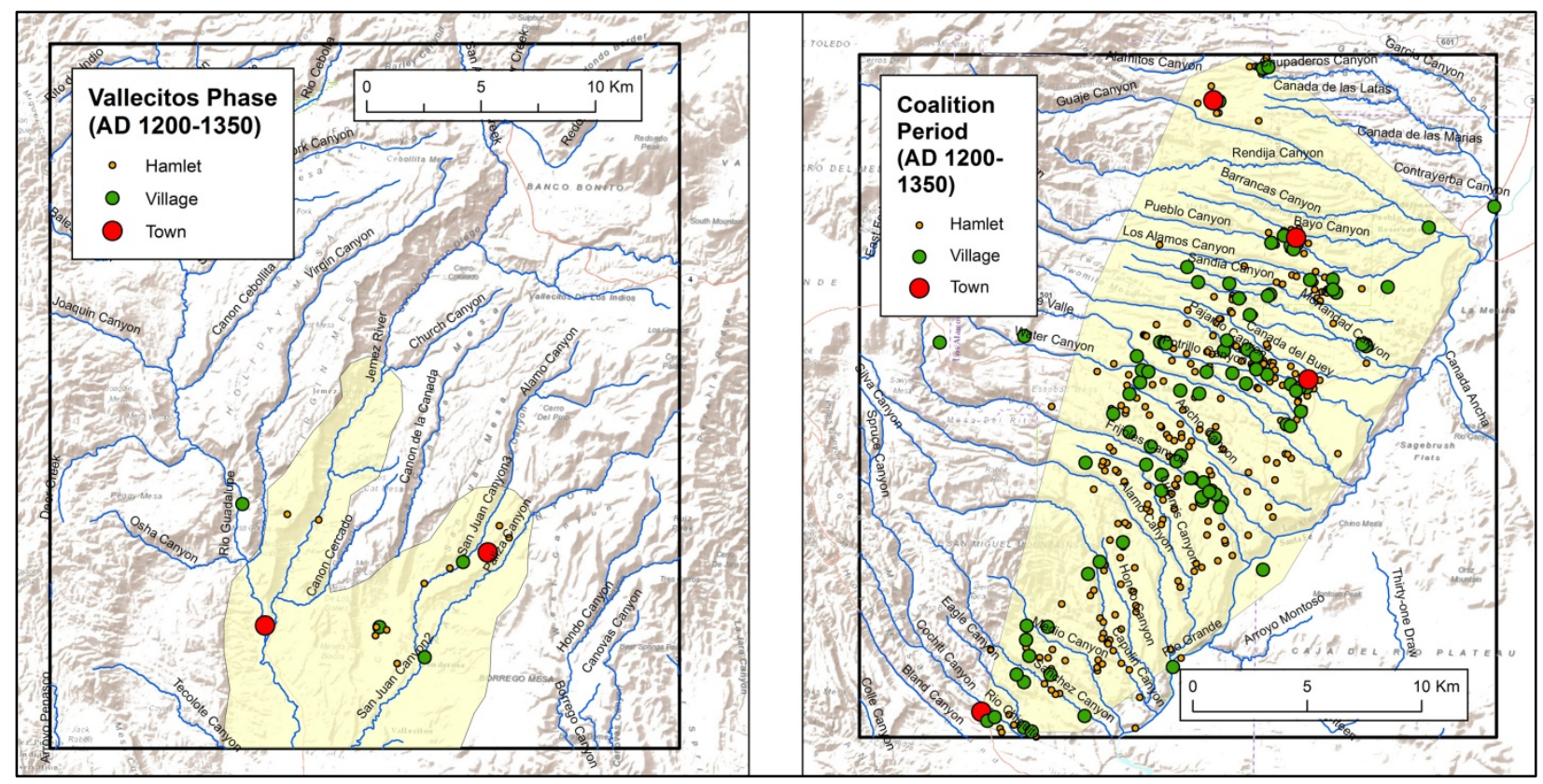

Figure 3.7. A comparison of Vallecitos Phase/Coalition Period (AD 1200-1350) aggregated site distributions between the Jemez (left) and Pajarito (right) Plateaus. Areas highlighted in yellow denote the spatial range of all archaeological sites dating to this time period.

The "filling in" of the landscape with dispersed hamlets lacking community-integrating communal architecture suggests there was minimal collective action above the household level during the Early Coalition. Studies of changes in ceramic form and paint styles found little conformity in ceramic styles at hamlet sites on the Pajarito, which was argued to reflect less cooperative social structures during the Early Coalition (Kohler and Root 2004a, b). Communal structures, like subterranean kivas, appear at some Pajarito sites, but none are reported at Vallecitos Phase sites on the Jemez Plateau (Kulisheck 2005). During the Early Coalition Period and Vallecitos Phase we see what may be the origins of a dual settlement pattern, with a landscape populated with both increasingly aggregated villages and small 1-2 room structures, referred to as field houses (Kulisheck 2005). These small structures, found in both regions, are inferred to be sites of household-level agricultural production. The few water control features 
identified during inventory surveys at Bandelier, such as V-shaped agricultural check dams, are associated with small hamlets and field houses, suggesting water management occurred, but that it was coordinated at the household level, and most likely for moisture retention for agricultural production (Rory Gauthier, 2013, personal communication).

If immigrants drove population increases, then the minimal coherence of social institutions and organizations we see when compared to what is seen in the "donor" populations of the Mesa Verde region potentially reflects a shift to less centralized forms of social organization. Rather than an immediate "transplant" of social institutions from the Mesa Verde world, it appears that extant locals and immigrants coalesced while "filling in" the landscape with households and family-scaled hamlets and small multi-family villages. However, the rapid reorganization towards the Late Coalition on the Pajarito, perhaps driven by a larger influx of immigrants due to the late $13^{\text {th }}$ century "Great Drought" in the Four Corners region, suggests that collective action strategies of social organization, whether brought by immigrants or locally developing, took shape on the Pajarito Plateau by the end of the Early Coalition and into the Late Coalition Period. This does not appear to be the case in the less densely settled Jemez Plateau during the Vallecitos Phase.

\subsection{Late Coalition Period/Vallecitos Phase (AD 1280-1350)}

Populations of the Pajarito Plateau reach their peak during the Late Coalition Period. Unfortunately the archaeological record of the Jemez Plateau isn't finely resolved enough to identify intra-period changes during the Vallecitos Phase. Kulisheck (2005) identifies multiple instances along the eastern portions of the Jemez Plateau where aggregated pueblos dating to the Vallecitos Phase cluster within the same catchment area. In other contexts, such as Chacoan 
occupations, such spatial clustering of small pueblos is seen as evidence for inter-community cooperation and exchange (Roney 1996).

During this period population and settlement distributions reach their peak on the Pajarito, with an estimated momentary mean population of 11,267 persons between AD 1280-1315 (Table 3.3). The spatial distribution of sites across a range of niches of the Pajarito Plateau is interpreted as a "filling in" of the landscape, perhaps by late-comers forced to take less desirable lands (Gabler 2009). Even though regional population may have reached its peak, village population densities were still lower than the Classic Period. Part of this is due to the continued occupation of small hamlets and field houses (Preucel 1990; Ortman 2016). Schmidt’s (2008) investigation of faunal remains from excavated roomblocks at Coalition sites at LANL found evidence for the continuation of diversified subsistence strategies with wild plant and animal sources persisting as important parts of diet. Kohler et al. (2004a), supported by detailed ceramic studies in Curewitz's dissertation (2008), show that ceramic styles begin to standardize across the region during the Late Coalition, which they interpret as the emergence of cooperative networks and regional expressions of identity. Communal features, like kivas, are present across the Pajarito although kivas continue to be constructed across the spectrum of community sizes (hamlets to towns). Van Zandt (1999: Table 6.22) found that kiva floor areas remain constant through approximately AD 1375, indicating only small numbers of people could use these features at any one time, which contrasts with the Great Kivas seen later in the Classic Period.

By the end of the Coalition Period (AD 1315-1350) on the Pajarito Plateau the momentary mean population shows a decrease to 9,579 persons (Table 3.3). The first decadal scale dry period after communities aggregate on mesa-tops begins after the end of this period in 1358 (Table 3.1). The dual residence pattern (Ortman 2016; Preucel 1990) and similar architectural 
elements (kiva size and numbers, etc.) on the Pajarito continue, but we begin to see population densities at large villages increase (Table 3.3).

Returning to the Jemez Plateau, relatively few field house sites date to the Vallecitos Phase (Kulisheck 2005), but their presence in conjunction with aggregated communities suggests either the beginning of the dual residence pattern in the Jemez, or the continuation of low population densities. Only more refined chronologies of Jemez sites can help to resolve this uncertainty.

\subsection{Early to Middle Classic Period/Paliza Phase (AD 1350-1450)}

The Classic Period and Paliza Phase are defined in the Jemez Mountains by the intensification of maize agriculture, coalescence of communities into large aggregated pueblos, and archaeological manifestations of different regional ceramic types suggesting the ethnogenesis of the modern Pueblo began during the Classic Period. Archaeologists interpret many aspects of the archaeological record associated with this ethnogenesis with the increased deployment of collective action strategies to mitigate risks associated with resource scarcity and increased population densities (Kohler et al. 2004a; Orcutt 1991). Villages in both regions became large, but there are major differences in settlement patterns (Figure 3.8). First, commensurate with the increase in village sizes on the Jemez Plateau was an increase in overall regional population. By contrast, populations of the Pajarito begin their decline, with regional populations living almost exclusively in aggregated communities. During this Early Classic Period (AD 1350-1400) the Pajarito Plateau momentary mean population was approximately 6,524 persons (Table 3.3). Fewer Ancestral Pueblo people on the Pajarito appear to have maintained the dual residences of field houses and villages and instead chose to live in aggregated villages during a time punctuated by two decadal scale droughts (Table 3.1). Field 
houses on the Pajarito Plateau are also smaller than those of the Jemez Plateau and have fewer storage features (Dolan et al. 2017). As I will examine in more detail in Chapter 8, Pajarito villages are increasingly found closer to water sources during the Classic Period.

Scholars hypothesize that the ethnogenesis of Keres and Tewa peoples began during the Classic Period. This is based on intra-regional differences in material culture, the spatial patterning of sites across the Pajarito Plateau (Walsh 2000), and oral traditions among descendant communities (Vint 1999). Glaze-painted ceramics, which historically were made by Keres peoples, were introduced across the southern Pajarito Plateau during the Classic Period (Kohler et al. 2004a:216). Concentrations of glaze painted ceramics are highest from Frijoles Canyon southward. Biscuitwares and incised types, which historically were made by Tewa peoples, were predominant to the north of Frijoles Canyon (Kohler et al. 2004a:216). For example, only $7.6 \%$ of the sherds analyzed at the town site of Tsirege (LA170), the first large town north of Frijoles Canyon divide, were identified as Rio Grande glazewares (Duwe 2011: 620). Even so, having 7.6\% glazeware sherds is considered high for an Ancestral Tewa site. There are differences in the distribution of stone tool raw material types as well. Pedernal chert dominates artifact assemblages north of Water Canyon (just to the north of Frijoles Canyon), while Obsidian Ridge-Rabbit Mountain obsidian sources dominate assemblages to the south (Kohler et al. 2004a: 217). Cultural affiliation studies for Bandelier National Monument, which incorporated historical ethnographic data and modern oral traditions of descendant communities, also identified this cultural split, with Frijoles Canyon being the shared boundary between Ancestral Tewa cultural areas to the north, and Ancestral Keres to the south (Levine and Merlan 1997). 


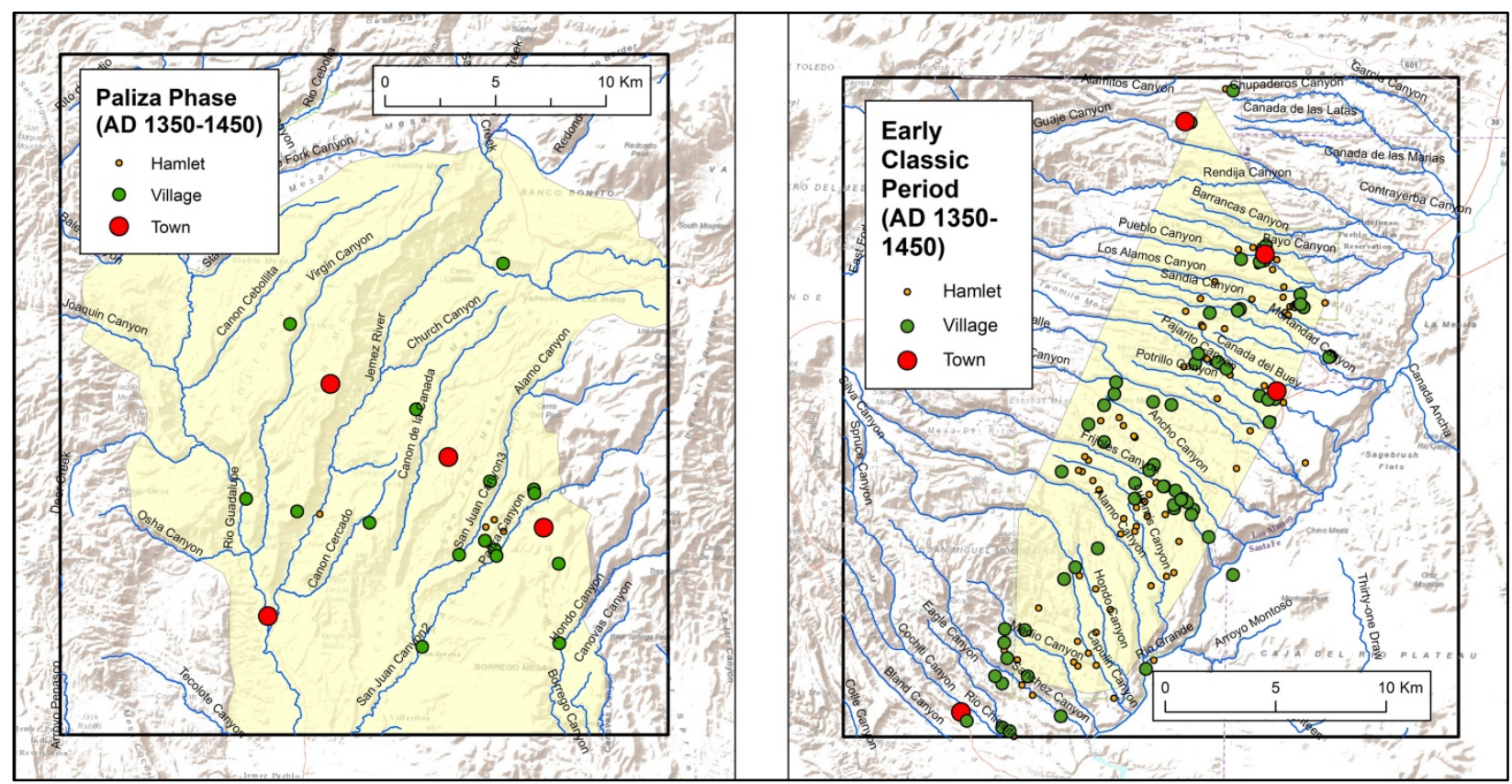

Figure 3.8. A comparison of Paliza Phase/Early Classic Period (AD 1350-1450) aggregated site distributions between the Jemez (left) and Pajarito (right) Plateaus. Areas highlighted in yellow denote the spatial range of all archaeological sites dating to this time period.

Kohler et al. (2004b) hypothesized that craft specialization and inter-regional trade were critical strategies for buffering resource scarcity during the Classic Period on the Pajarito Plateau. There is archaeological evidence for specialized production of ceramics, obsidian tools and potentially cotton textiles (as inferred from the recovery of bone awls). Kohler et al. (2004b) argue that inter-regional trade and markets for exchange may have developed in the Northern Rio Grande area. Studies of artifact relatedness and provenience studies (Duwe 2011; Curewitz 2008) find that ceramics made on the Pajarito Plateau, as well as obsidian from the Jemez Mountains, were exported from the Pajarito Plateau and into the Northern Rio Grande. These trade networks and inter-regional economic and social ties during a period of ethnogenesis, may have served as a "pull” for mesa-top villagers during the Classic Period to join related 
communities found off of the mesa-tops of the Pajarito Plateau in other lowland regions of the Rio Grande Valley.

Ascertaining the degree to which craft specialization occurred on the Jemez Plateau is challenging due to the lack of excavated sites, but surface surveys suggest limited inter-regional trade, as trade wares make up very minor components of archaeological assemblages (Matt Liebmann, 2015, personal communication). Far more work will need to be done to generate data and synthesize the existing evidence to further test these hypotheses, but the aforementioned studies, as well as regional population studies (Duwe 2011; Ortman 2016), support the argument that emerging economic networks, and integrative ideologies across the Northern Rio Grande, fundamentally reorganized the social landscape during the Classic Period.

Towns and villages became the focus of settlement in both regions. Towns, aggregated communities with greater than 500 rooms, are relatively evenly spaced across both regions (Figure 3.9). Towns typically have multiple kivas, large plazas, and multi-storied roomblocks. Great Kivas appear in both regions during this time. Mean floor areas of kivas increase from 10-15 $\mathrm{m}^{2}$ during the Coalition Period to $40-70 \mathrm{~m}^{2}$ in the Classic Period of the Pajarito Plateau (Van Zandt 2006: Table 8.5). This suggests that kivas were the setting in towns and villages for integrating larger social groups. Many of the towns and large villages also have reservoir features, which I discuss in detail in relationship to social organization and resource management in subsequent chapters. Yet, by the Middle Classic Period (AD1400-1450) the estimated regional population on the Pajarito Plateau had dropped to 4,584 persons (Table 3.3) and we see the nearly complete decline of the use of field houses (Ortman 2016). The dual residence settlement pattern fell into disuse and communities atop the Pajarito Plateau were increasingly concentrated into villages. By contrast, Kulisheck (2005) identifies an increase in the number of villages and 
towns during the Paliza Phase on the Jemez Plateau, while also the continued use and occupation of field houses.

Out-migration is the most widely accepted explanation for population decline across the Pajarito Plateau. Duwe (2011) argues, based on evidence from ceramic petrography and demographics that populations moved off the mesa-tops and into surrounding areas to the north, such as the Rio Chama, during the Classic Period. This is echoed by Ortman (2016) and supported by his population estimates for the Chama region (Figure 3.9). The greatest increase in Chama populations occurred during the late $14^{\text {th }}$ and early $15^{\text {th }}$ centuries. This is well after the depopulation of the Mesa Verde region in the late $13^{\text {th }}$ century, to which the rapid rise in the Chama area population is usually attributed. Gabler (2009) identifies another vector of movement, with an intra-regional redistribution of sites southward across the Pajarito Plateau during the Classic Period. It is notable that Cochiti oral traditions speak to a gradual movement south across the Pajarito Plateau during prehispanic times (Preucel 2005).

The possibility that Ancestral Pueblo people of the Pajarito Plateau moved west to the Jemez is neither well supported in Pueblo oral traditions (Levine and Merlan 1997), nor in the archaeological evidence. Shepard's (1938) petrographic analysis of glazewares at Jemez sites did identify Pajarito glazewares at Jemez sites, suggesting there was some Classic Period interaction between these regions. However, the numbers of glazeware sherds recovered in ceramic assemblages at Jemez Plateau sites are exceedingly low (Liebmann 2006, 2012: 130; Morley 2002), no Biscuit wares are recovered (Creamer 1996), and there is little to no evidence for Jemez Black and White ceramics on the Pajarito Plateau (Rory Gauthier, 2013, personal communication). 


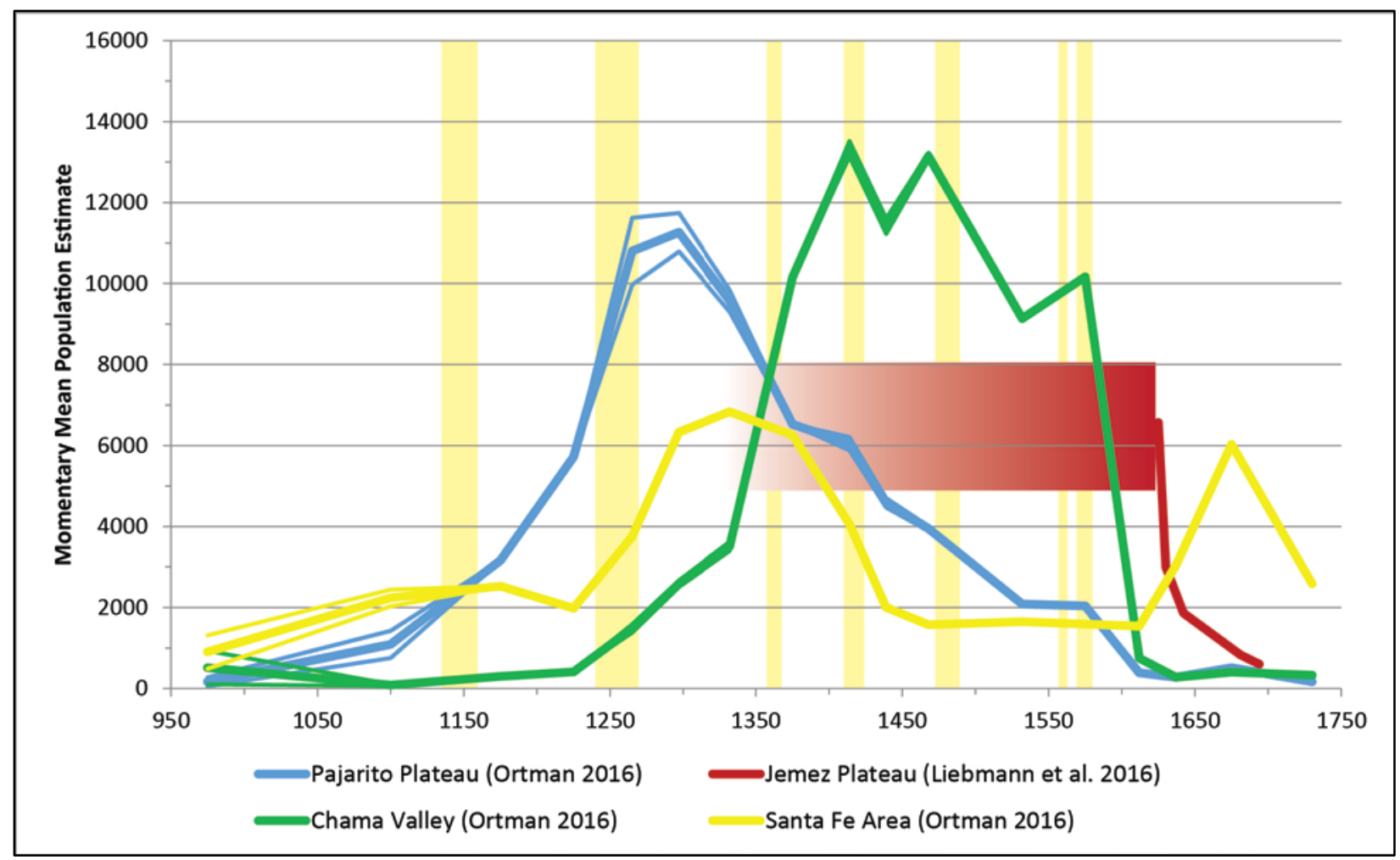

Figure 3.9. An intra-regional comparison of momentary mean population histories in the Northern Rio Grande, with drought periodicities between AD 1100-1700.

\subsection{Late Classic/Jemez Period (AD 1450-1600)}

By the Late Classic Period, populations on the Pajarito Plateau were clustered in a few areas, mostly along Frijoles Canyon and at the large villages of Tsirege and Tsankawi. All of these locations are close to perennial water sources (Figure 3.10). On the Pajarito Plateau, momentary mean population estimates drop from 3,948 persons at the beginning of period to 2,040 persons by the end (Table 3.3). The few Pajarito population centers are large villages or towns. The most prominent site is Perege (LA84), a site located just outside of my study area overlooking the Rio Grande that is ancestral to San Ildefonso Pueblo. This village is the closest lowland Rio Grande valley site of a size, location, and architectural layout more typically seen upstream on the Rio 
Grande and in the Rio Chama. If Perege is added to the population total, it alone would make up $38 \%$ of the Pajarito momentary mean population between AD 1450-1515, while the estimated populations of three town/village sites make up $47 \%$ of the entire Pajarito Plateau population between AD 1515-1550. All four sites would make up 73\% of the overall momentary mean population estimate between AD 1550-1600.

By comparison, populations peak across the Jemez Plateau during the Jemez Period. There is an increase in very large settlements west of Canyon San Diego and likely for the first time a higher overall population than that of the Pajarito Plateau (Figures 3.9). Based on room counts and population estimates (Liebmann et al. 2016) many of the Jemez Plateau towns were far larger than any Pajarito villages. Four sites (Seshukwa, Amoxiumqua, Kwastiyukwa, and Tovakwa) have estimated room counts greater than 1,000 (Kulisheck 2005: Table A.1, and Liebmann et al. 2016). The towns of the Jemez Plateau are often arranged around multiple plazas, while most of the largest Pajarito villages still in use during the Late Classic are built around a large central plaza. Field houses continued to be used on the Jemez Plateau (Kulisheck 2005), and presumably so did the continuation of the dual residence pattern. Both of these appear to be abandoned on the Pajarito in the 1400s.

It is during this time period that we see the earliest historical descriptions of these regions. Differences in the earliest interactions with the Spanish largely reflect the prehispanic depopulation of much of the Pajarito Plateau. While the earliest interactions between Coronado's expeditionary forces and Pueblo peoples were focused on the Central and Northern Rio Grande and not the Jemez Mountains, entradas were made to the Jemez area. Barrionuevo entered the Jemez area as part of Coronado's expedition in 1541 to ascertain the size of local populations and resources of the region. In the late $16^{\text {th }}$ century the region was documented by Gallegos, 


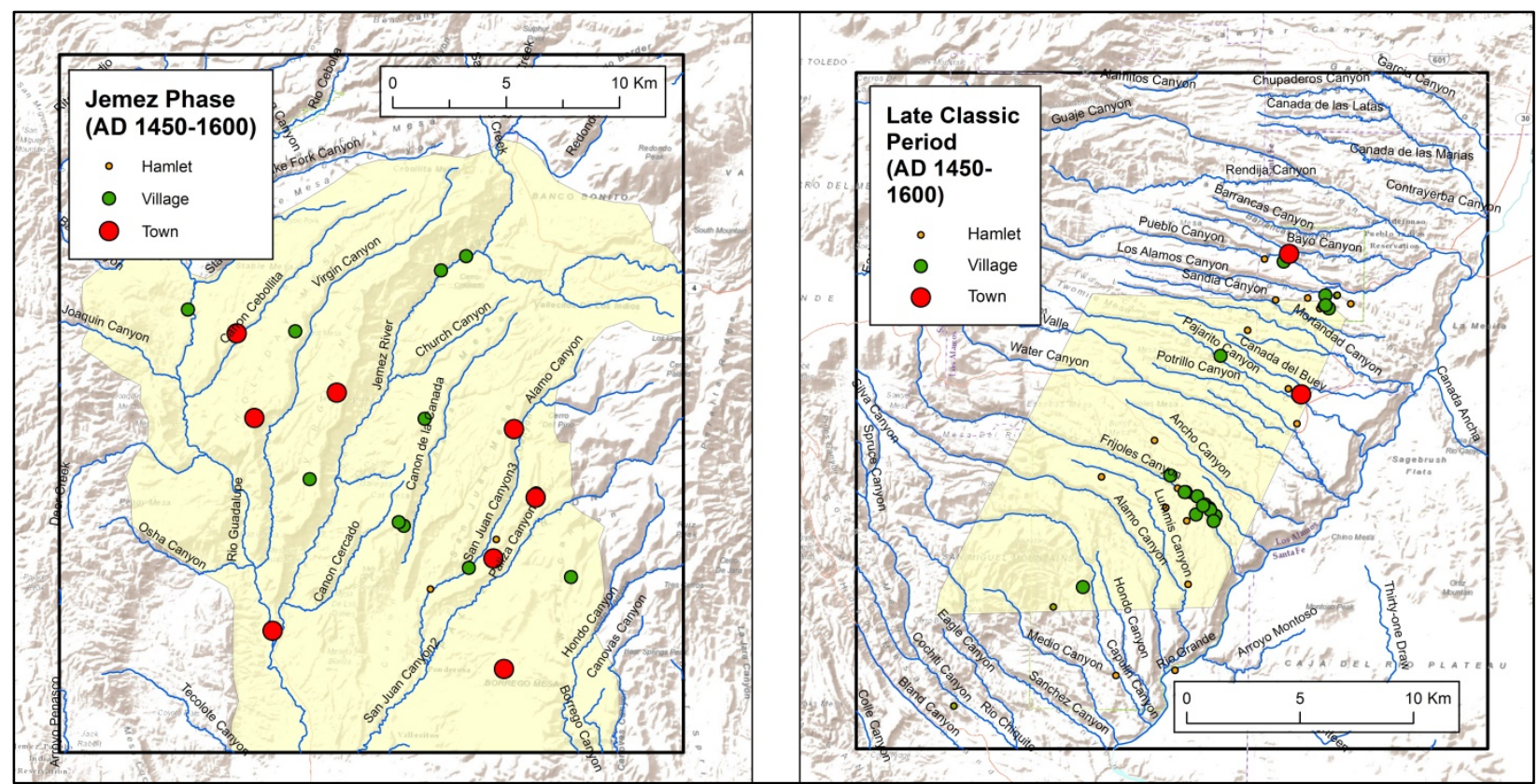

Figure 3.10. A comparison of Jemez Phase/Late Classic Period (AD 1450-1600) aggregated site distributions between the Jemez (left) and Pajarito (right) Plateaus. Areas highlighted in yellow denote the spatial range of all archaeological sites dating to this time period.

Espejo, and Oñate (Kulisheck 2005), although concerted efforts to missionize the Jemez did not begin until the $17^{\text {th }}$ century. Although the Spanish did visit Tewa communities of the Rio Grande, the only village of the Pajarito Plateau they may have visited is Tsirege, although the village is not named, and its visitation can only be inferred (Barrett 2002).

\subsection{Historic Period/Guadalupe Period (AD 1600-1760)}

By AD 1600 the Pajarito Plateau was largely depopulated, save for the village at Tsirege to the north, a few hamlets and villages in Frijoles Canyon, and the Cochiti village of Kotyiti to the south (Figure 3.11). By contrast, large occupations on Jemez Plateau, including villages on mesa-tops far above perennial water, continued through the Pueblo Revolt and into the earliest decades of the $18^{\text {th }}$ century (Liebmann 2012). Populations did decline precipitously in the Jemez 
region, but not in direct association with Spanish contact. Instead these began their rapid drop in the $17^{\text {th }}$ century, after congregación led to widespread re-settlement in valley bottoms (Liebmann et al. 2016).

Detailed comparative studies integrating historical sources, archaeological materials, and oral histories of the Pueblo Revolt, reveal something of the social dynamics of this tumultuous period (Liebmann et al. 2005; Liebmann 2012 Liebmann et al. 2017; Preucel et al. 2002). In both regions, the mesa-tops became refuges for Pueblo communities, where some traditional practices were revived and some long-standing villages, like Boletsakwa on the Jemez Plateau, were reinhabited (Liebmann 2012). Historical records of the movement of people between communities of the Jemez Mountains is corroborated by archaeological evidence by obsidian sourcing at Revolt Era sites (Liebmann et al. 2017) and more diverse ceramic assemblages from excavated contexts (Wiseman 2017). It is not until after the 1700s that non-Pueblo peoples begin to make their mark in the Jemez Mountains, whether by Spanish settlements and land grants (Simmons 1969), the arrival of Athabaskan nomadic tribes (Carrillo 1992), or the eventual incursion of Anglo explorers, missionaries, and settlers in the $19^{\text {th }}$ century (Smith 2005).

\subsection{Summary}

This chapter provides the necessary background information to frame the environmental and cultural variables in the SES model (Figure 3.1). Using a Jemez Mountains-specific paleoprecipitation record I have identified multiple dry and wet periods through the duration of my study. In so doing I have isolated dry periods in the paleoclimate record most likely to influence hydrological systems. These periods are roughly analogous to regionally identified mega-droughts, although there is some local variability in the timing and intensity of these 
events. These records are integrated into the paleohydrological model in Chapter 5, discussions of reservoir use-life histories in Chapter 7, and in the synthesis and conclusions presented in Chapter 9.

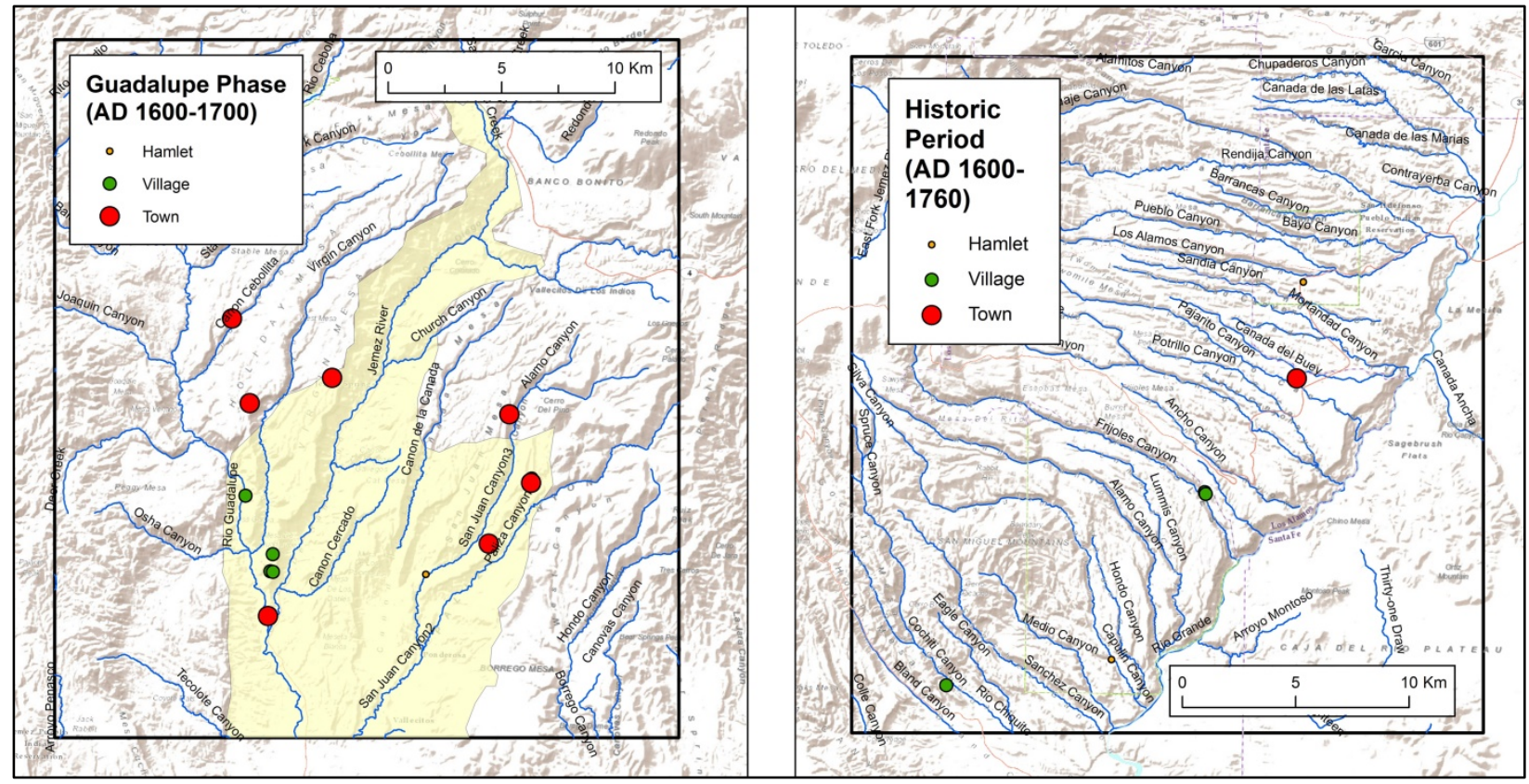

Figure 3.11. A comparison of Guadalupe Phase/Historic Period (AD 1600-1760) aggregated site distributions between the Jemez (left) and Pajarito (right) Plateaus. Areas highlighted in yellow denote the spatial range of all archaeological sites dating to this time period.

In this chapter, I presented the first comparative cultural history between the Jemez and Pajarito Plateaus that extends beyond the Revolt Era. Compiling such a comparative history presented challenges, but they are nothing new to comparative archaeology (Smith 2011). Differences in temporal resolution and population estimates limit the extent of these comparisons. It is nonetheless evident that these regions share similar settlement patterns, highland agriculturalist adaptations, and evidence for collective action strategies in social 
organization associated with coalescence and aggregation, yet their population histories are asynchronous. In nearly every instance, cultural developments on the Pajarito Plateau preceded those of the Jemez Plateau. I will consider the implications of these differences, and particularly for how natural resource management strategies influenced trajectories of cultural history, in Chapter 9. 


\section{CHAPTER 4. AN ETHNOLOGICAL STUDY OF COMMON POOL WATER RESOURCES IN PUEBLO SOCIETIES}

Archaeological evidence for the social institutions, norms, and rules surrounding resource management is typically scant. This makes applying common pool resource theory to archaeological contexts problematic. Inferring social institutions from material remains alone is generally considered inadequate, and archaeologists have long turned to ethnographic analogs to make inferences about social dynamics in the archaeological record. In this chapter I present examples from ethnographies, ethnohistorical records, and oral histories to demonstrate that there is a tradition of Pueblo collective action for water management. I first discuss some of the challenges in applying ethnographic analogies to archaeological research in the North American Southwest. I then follow with ethnographic examples of collective action strategies of water management spanning the Eastern and Western Pueblos, as well as a few key examples from Tohono O’odham water management practices in the Sonoran Desert (Figure 4.1). I use Ostrom's (1990) design principles of robust collective action institutions as a framework to identify and characterize social institutions associated with water management in Pueblo societies. These observations demonstrate that when traditional Pueblo communities undertook collective action strategies to build water infrastructures they often, but not always, managed water as a common pool resource. I conclude the chapter with ethnographic examples of behaviors associated with reservoir construction, use, and maintenance. These examples provide testable hypotheses for geoarchaeological investigations of Ancestral Pueblo reservoirs. This 
chapter gives perspectives on key relationships between water resources, resource users, resource providers, and infrastructures in the socio-ecological model to be presented in Chapter 9. It also provides examples of the systemic contexts and cultural transformations necessary for further hypothesis testing in geoarchaeological investigations.

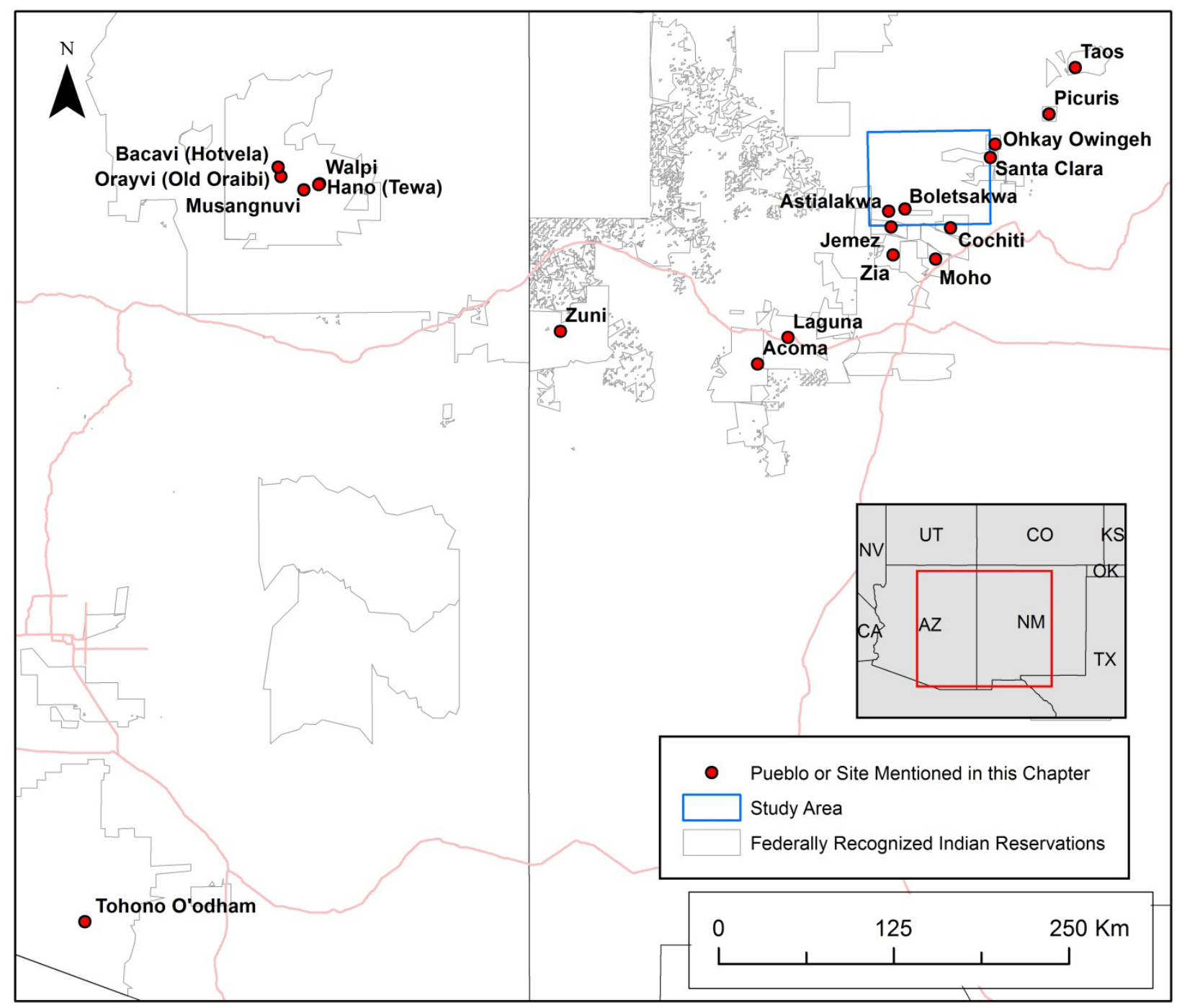

Figure 4.1. Pueblo communities and archaeological sites discussed in this chapter. 


\subsection{The Challenges of Applying Ethnographic Analogies to Archaeology}

The "laboratory of anthropology" that is the North American Southwest (Fowler 2000) has long been the scene of debate in North American archaeology over how to apply ethnographic information to the archaeological record. Many early researchers used oral traditions and modern observations to better understand the archaeological record through the direct historical approach (see Fowler 2000 for a discussion). The direct historical approach projects observations from modern societies, such as about social organization, beliefs, or practices, to archaeological contexts (Steward 1942; Lyman and O’Brien 2001). Processual archaeologists critiqued the direct historical approach for being done ad hoc and uncritically (Cordell and Plog 1979), and with little consideration for the suitability of these analogies (Dozier 1970).

While widespread applications of the direct historical approach are cautioned (Spielmann 2005), the application of ethnographic research, oral traditions, and linguistics are increasing in archaeological research of the North American Southwest (e.g., Ware 2014). This is a result of several factors: engagement with descendant communities in North American archaeology (partly as a function of NAGPRA legislation); Native Americans both working with and becoming archaeologists; and a greater appreciation for continuities of social organization through the historical period (Ferguson 1996; Preucel 2005). In some cases, researchers are reinstituting Julian Steward's call for archaeology to serve as a "historical anthropology" (Ortman 2012; Ware 2014).

To make common pool resource theory do work, I too must confront the long-standing dilemma of deciding how to best apply ethnographic information to archaeological contexts. The cultural practices surrounding water management I wish to reconstruct in the archaeological 
record are not being practiced today by the direct descendants of the past communities of the Jemez Mountains. As reviewed in the previous chapter, beginning in the $15^{\text {th }}$ century the mesatops of the Jemez Mountains were abandoned for the valley bottoms of the Rio Grande and its tributaries. These new valley bottom contexts led to a shift in water management strategies and technologies (Snead 2006). The large early historic, and possibly prehispanic water reservoir feature constructed in a palustrine wetland near Laguna Pueblo (Huckleberry et al. 2016), and artificial ponds at Ohkay Owingeh (Ortiz 1969) are some of the few historically documented water storage features in valley bottoms. Pueblo irrigation systems (the extent of which are debated, see Ackerly 1995; Adler 2015) and villages in close proximity to perennial water sources at lower elevations appear to have precluded the continued use of reservoirs (Snead 2006). This limits the number of relevant historical and modern examples of water management in the ethnographic record of the Eastern Pueblos.

Pueblo ethnographic records of mesa-top water management exist, but they come primarily from mesa-top communities in the Western Pueblos of Hopi and Acoma. Western Pueblos used water storage features and managed these and other natural water features through the historic period, including through documented periods of water scarcity (Figure 4.2). Some of these features, such as those at Acoma Pueblo, are still in use today (Figure 4.3). Yet, there are differences in cultural histories, social organization, and environmental settings between the Eastern and Western Pueblo, and these differences impact the potential of applying records from one region to another (Spielmann 2005). For example, social structures of Western Pueblo are kin and clan based, while Eastern Pueblos are typically sodalities. That being said, ethnographers have identified attributes of Eastern Pueblo social structure, particularly of the Jemez and Keres, which share more similarities to the Western Pueblo than the east (Ellis 1964), and have even 
hypothesized that the moieties of the Jemez may be a historical development associated with the Pueblo Revolt (Liebmann 2012). Regardless, this chapter demonstrates that basic rules and social institutions govern water use in both contexts, providing a warrant for careful application of these analogs. I handle inferences of prehistoric institutions from ethnographic sources with caution, and make limited use of the direct historical approach of social organization types or specific rules and norms.

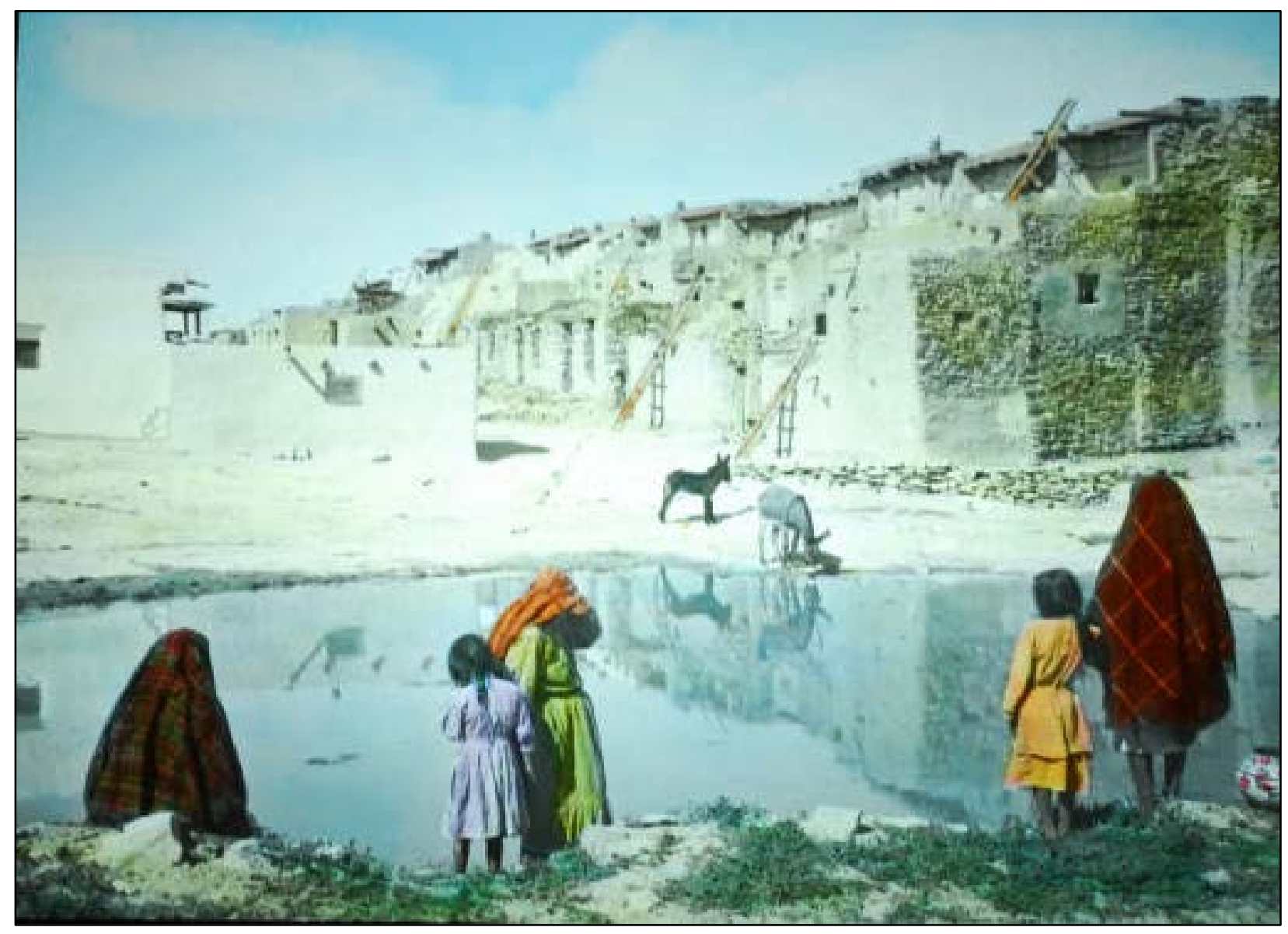

Figure 4.2. Acoma Pueblo water cistern, ca. 1920-1940 (000-099-1390, UNM Elizabeth Willis DeHuff Pictorial Collection, Special Collections and Center for Southwest Research, University of New Mexico Libraries). 


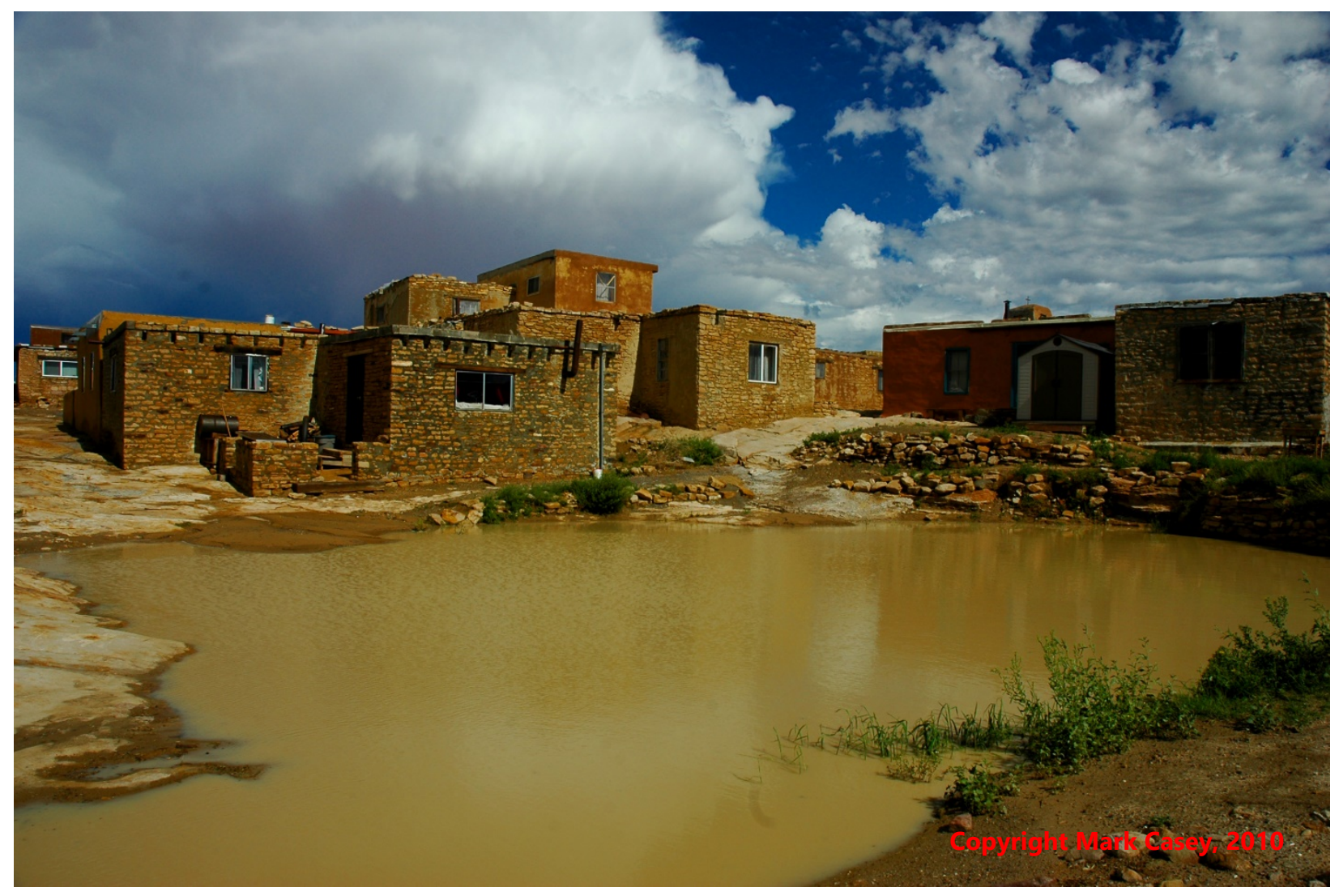

Figure 4.3. Acoma cistern after a monsoon rainstorm, 2010.

(https://azexplore.files.wordpress.com/2010/08/acomacistern-2.jpg, with permission from Mark Casey).

Though reservoir features may not be used today in the Eastern Pueblos, it would be premature to say that reservoirs and other water storage features were not part of the lives of communities of the Eastern Pueblos in the historical past, or that social institutions surrounding water management systems didn't continue, albeit in different forms. In his The Ethnogeography of Tewa Indians, John Harrington has an entry for the Tewa name for archaeological water reservoir features:

Poqwa - 'water tank' 'water reservoir' 'basin of water' (po 'water' + qwa). The artificially constructed reservoirs of ancient Tewa pueblos were called thus. (Harrington 1916:86) 
Jemez oral traditions include descriptions of reservoir use at Ancestral sites. In 1875 Oscar Loew recorded Jemez oral traditions from the Jemez governor Hosta about reservoir use at the site of Astialakwa (Loew 1875:177). Nearly one hundred and forty years later, former Jemez governor Paul Tosa shared oral traditions about reservoir use at the Ancestral Jemez site of Boletsakwa (T. J. Ferguson, 2014, personal communication). These examples speak to the landscapes of memory, to which features (both cultural and natural) are imbued with meanings, moral dimensions, and identity (Colwell-Chanthaphonh and Ferguson 2006). The appreciation for Ancestral Pueblo landscapes by Pueblo peoples, and archaeology in general, is well articulated in the Jemez Mountains (e.g., Anschuetz et al. 2001; Anschuetz and Merlan 2007; Ortiz 1969; Snead 2008), which further supports the possibility of continuity between archaeological features and modern practices.

While the use of reservoirs ceased within historical memory of the Eastern pueblos (Ortiz 1969), other forms of water management, especially irrigation agriculture, are central to Pueblo communities in the Northern Rio Grande. The operation of these systems demands robust social institutions, of which there is ample evidence from the Eastern Pueblos (see discussion in Ellis 1964; Lange 1959:44; Parsons 1936:95; Sando 1982; White 1935:41). Dozier (1970:153) suggested the potential for continuity in social institutions of resource management from the prehispanic period into the historic period, and social institutions surrounding irrigation may be a fruitful analog for prehistoric institutions of water management, even if the technologies differed. 


\subsection{Collective Action and Social Institutions of Pueblo Water Management}

Pueblo ethnographic records contain examples for many of the Ostrom’s (1990) design principles of robust institutions for collective resource management. This should be no surprise, since the construction, maintenance, and use of water storage features demands some form of collective action.

The demand for water may be a universal, but the ways in which societies meet their water needs are myriad. First, it should be recognized that Pueblos view water as costly and vulnerable to periods of scarcity. The significance of water, deeply embedded in the ethics of Pueblo society, is spoken to by Helen Sekaquaptewa of Old Oraibi (located on Hopi third mesa). Her autobiography provides a rare female perspective on traditional Pueblo lifeways as they underwent significant change in the $20^{\text {th }}$ century. It is important, because water acquisition is often associated with women in our conceptualizations of Pueblo societies (Babcock 1994), and in Ancestral Pueblo iconography (Schaffer and Gardner 1998). Sekaquaptewa speaks to the traditional importance of water, the responsibility for water acquisition falling to the household, and the inherent insecurity of water in mesa-top communities:

Every drop of water was precious, and there was never enough. From infancy we were taught to drink sparingly; even then there were times when we were always thirsty. You never asked for a drink when visiting at a neighbor's house but went home to drink from your own water. (Sekaquaptewa 1969:21-22)

Water conservation continues to be a central ethic in Pueblo societies (Whiteley and Masayeva 1998). Ethnographic observations by W. W. Hill at Santa Clara demonstrate that the cost of water acquisition was a function of distance and time, and that this factored into decisions 
over water acquisition. Water insecurity then relates to the increasing amount of work required to acquire water:

The principal source of supply was Santa Clara Creek, immediately north of the village. When this dried up or was muddied by flood, water was secured from one of four other localities. One was the Rio Grande, although this was normally dry during July and August. Other sources were three springs: one about three or four miles southeast of the village; another, P'ocibe, about a mile or mile and a half west on Santa Clara Creek, and a third, P'ocipa, about a mile north of the pueblo. The greater part of the day was often consumed carrying water from these more distant locations, and in such instances every drop was carefully handled. (Hill 1982:41)

Late $19^{\text {th }}$ century observers of Pueblo domestic water collection strategies clearly describe the needs, technologies of collection and transport, and individual strategies for water acquisition. However, estimating the significance of water acquisition costs varies by ethnographer. Adolph Bandelier frames the pursuit of domestic water as essential, but not too troubling of an effort:

The Indian needs, in order to stay for any length of time in a given locality, water, wood, a limited area of cultivable soil, and reasonable safety. Water need not be always in close proximity to his village. If that village is perched on a high mesa, a spring at the foot of the height will be sufficient, provided the declivity is not too steep. In places where the tribe had, for the sake of security, to select an inexpugnable rock as its residence, natural cavities played the part of reservoirs, and the water supply furnished by rain was artificially increased every winter by accumulating snow in the tanks. At this day we have an instance of the kind at Acoma. A distance of half a mile or a mile from the banks of a river was, and is, not looked upon as a great inconvenience by the women, whose duty it is to furnish the household with drinking water by carrying it on their heads in jars or urns. Leather bags were also used for carrying water, in quantities larger than those which the "tinaja," as the water-jar is called in Spanish, could contain. (Bandelier 1892:13-14)

John G. Owens, who as a graduate student accompanied Jesse Walter Fewkes to Hopi, worked with Hopi women in his ethnographic research. His first person observations of water 
acquisition at the village of Walpi are similar to Bandelier's, but display a greater appreciation for the efforts necessary to acquire water, particularly because mesa-top reservoirs only hold water seasonally during the monsoons:

But the greatest tax is made upon the physique of the women by the heavy burdens which they carry up the mesa. The Hopi villages are situated upon the top of mesas, which stand about six hundred feet above the plain. The springs which furnish the inhabitants water are situated in the foothills. All the water used, except what can be caught from melting snow in winter and from rains during the two rainy months of summer in a few small holes on the mesa top, must be carried up the mesa on the backs of women, in jugs holding about three gallons. This is the hardest thing in the life of a Hopi woman. A file of eight or ten women wearily tugging their way up the steep and rocky trail, each with her water-jug on her is back is a sad but picturesque sight. (Owens 1892:163-164)

The technology of water transport determines how many trips to water sources would be necessary given an individual's daily water requirements. I discuss ethnographic observations of carrying capacity in subsequent chapters, but here it should be noted that women are nearly always identified as the ones who acquire water, and that water is often transported in ceramic jars or canteens. Vessel sizes and water needs are discussed later, but estimates for daily water needs range from the bare minimum for survival (1.5 liters [L]) to $10 \mathrm{~L}$ a day to meet typical personal and household needs (Gleick 2000; Kohler 2007). This means individuals may have had to make multiple trips to not only meet their own personal needs, but the needs of entire households.

CPR theory is focused on how social institutions develop to collectively build, maintain, and utilize resources. Individual needs are met, at least partially, by collective action. Examples of Ostrom’s design principles (Chapter 2) put into action for water management can be found in many Pueblo ethnographies. 
Examples of the first principle - clearly defined boundaries of those who have rights to use CPR and the boundaries of CPR itself - can be found in records of reservoir and spring use at Hopi villages and at Acoma Pueblo (with one caveat: no description of reservoir use states whether or not individuals from outside the community are allowed to use water reservoirs; instead ethnographers differentiate between individual or clan ownership or being held as a commons). Water reservoirs at Acoma were described as early as 1541 by expedition chronicler Pedro de Castaneda, during Francisco Vázquez de Coronado’s siege of Acoma (Castaneda 2002:123). The features were described as collecting rainfall and snow, much as they are in descriptions at Hopi. Water from reservoirs is described as a commons, and the multiple reservoirs of Acoma potentially provided the entirety of the community's water needs (Sedgwick 1926:25-26). The autobiography of James Paytiamo, an Acoma chief in the early $20^{\text {th }}$ century, speaks to the continued use of water reservoirs as common resources at Acoma Pueblo. James Paytiamo describes rules of use of these features, which serve as boundaries as to how these mesa-top water features can be used:

The water supply of a village is its most important concern, and Acoma, being many hundred feet in the air, is greatly dependent upon the water-holes on top of the mesa. There are three large reservoirs and several smaller ones. No one may wash in these places but must carry the rainwater to several smaller depressions in the rocks. Baths were taken in big pottery vessels in the homes. (Paytiamo 1932:145)

By contrast, early $20^{\text {th }}$ century observations at Hopi by the New Zealand ethnologist Ernest Beaglehole, a researcher interested in ethnological study of property, sees a more complicated range of access rights to reservoir features and other small natural bedrock catchments. Rules about boundaries and access surrounding water rights are not as clear as at Acoma, particularly 
for smaller natural and artificial water catchments. Access is relative to external factors, such as inheritance, or scarcity due to droughts:

Natural cavities or hollows in the rock surface of the mesa top as well as reservoirs fanned by damming up depressions with earth and stones are used as thawing cavities for the collection of winter snows and for the collection of summer rain water. The water so stored is used for stock, for laundry purposes and for making the adobe mud used in house building. Small holes may be owned by individual women, larger ones by a group of related women, especially if the holes are adjacent to house blocks, and these are inherited in the maternal line. In many cases, however, the holes are common property and are used by all the women of the village as long as the supply of water holds out. (Beaglehole 1937:13)

These types of water catchment features and management arrangements are discussed in Sekaquaptewa’s autobiography which largely corroborates Beaglehole’s observations, and speaks to instances when there was conflict over access and control of water reservoir features at Old Oraibi [Orayvi] in the early $20^{\text {th }}$ century:

Nearly every family had a cistern, a big basin in the sand rock that cropped out all over the mesa, where they caught and stored rain water for a supplementary supply. When there was snow, they would pile it up and pack it around their cistern as high as six feet so that as the snow melted the water would run into the cistern. The biggest cisterns were made during the time of the Catholic Priests, because they had better tools. These cisterns were claimed by the village chiefs. Each family guarded its cistern jealously, and there were sometimes big fights over this water. (Sekaquaptewa 1969:21)

How the water from these cisterns was used speaks to its range of uses beyond consumption.

For example, in the late winter-early spring cistern water was used for annual maintenance plastering and adobe making during a time of year before agricultural pursuits, but when reservoirs were full due to snowmelt: 
In the late winter and early summer, both sexes cooperate in necessary housebuilding, because at these times snow and rain, collecting in cavities and dams on the mesa top, render it possible to make mud plaster without the otherwise extremely arduous preliminary task of carrying up water from springs below the mesa. (Beaglehole 1937:26)

Building and heavy repairing, as mentioned earlier, are usually, though not always, done during the March moon because of ready access during this month to thaw waters collected in mesa cavities. The work is done by parties of men and women, kin and clansfolk. (Beaglehole 1937:58)

At Hopi there appeared to be different property relationships associated with natural springs, which were the primary sources for domestic water. Springs were owned by clans, which were responsible for their maintenance. This involved the clan leading and coordinating labor of a work party made up of the entire community. While the springs were clan owned, water from the springs was available to all members of the community. Therefore, these features were in effect held as a toll good, freely available for use, provided everyone contributed to their maintenance:

Each year members of the clan assume control of the work of cleaning away the mud and debris from the source of the spring, clan members delegating to themselves the hardest and dirtiest tasks. They also perform ritual to feed and strengthen the spring and thus assure ample water for the succeeding year. People of the village use the spring freely at all times except for four days preceding the public performance of the Flute ceremonial, when there is a blanket prohibition against any use of the spring for secular purposes. At this time water is obtained from another spring, Ianl'va' associated with the Eagle (Hawk) clan. (Beaglehole 1937:13)

The second design principle is that there is proportional equivalence between benefits and costs of the CPR, whereby the appropriation and provision of common pool resources are adapted to local contexts. At Hopi there are multiple observations of the individual costs in collective action to maintain springs and water reservoir features, as well as a range of other resources. While these collective costs and corresponding efforts can be driven by coercion, 
Beaglehole sees them largely as duties of all village members, with labor given free of proscription:

A different type of obligation is involved I think, in the second main type of working party, the party organized on a village basis to work for the town or crier chief, to clean out village springs, to repair stock reservoirs or village trails or to help specific unfortunate families in the villages. The obligation in these cases is not so much one of self-interest, as one based on traditional loyalty for the village officers, traditional pride in the village and its equipment, or on charitable feelings for the sick and unfortunate. Village working parties are organized by the crier chief or other responsible individual and announced by the crier chief four days ahead. Sometimes katsina may initiate the actual work by going from house to house and gathering together the men. Most of the men make an effort to perform their share of the work and the household members are more than a little ashamed of themselves (villagers do not allow them to forget this easily) if one at least from their number is not present as a representative. (Beaglehole 1937:29)

Resource costs for maintaining water as a common pool resource are embedded in collection action. An ethnographic example of the cost of maintenance comes from Beaglehole at the aforementioned $D O \cdot j i{ }^{\prime} \cdot v a^{`}$ spring, located at the base of the Second Mesa near Mishongnovi [Musangnuvi]. Here, the maintenance of spring by the Hopi is embedded in rituals linking leadership, collective action, and resources:

...A good example of this is the work connected with the annual cleaning out of the spring DO'ji.'va, by a working party based on village cooperation.

On the day arranged the crier chief calls at about seven a 'clock in the morning urging the women and girls to begin preparing food. Another reminder is called out about two hours later and at eleven, a third call is made to tell the men that all should assemble at the spring and to tell the women to commence baking the special corn dish somi'viki. Beside the spring in the shade of the cottonwood trees the old men of the Water clan, "owner" of the spring, together with town chief, and society chiefs begin to smoke ritually over a number of prayer offerings lying on a plaque in the centre of the group. The smokers exchange relationship terms and for the most part carry out their duties in a serious fashion. At intervals, however, they exchange gossip and joke together. Occasionally one not too old or decrepit leaves the group and assists the 
workers among whom there is a division of labor according to age and strength. The able-bodied assume the heavier tasks of digging and carrying sand from the terraces of the spring to a nearby dump. The old men hoe weeds. Water clan members bailout water from the spring and then dig out with their hands the black noisome mud at the bottom. Older children form a chain gang and pass containers of mud from hand to hand until the last youth empties the contents some distance away. The work is coordinated by common sense and custom, the nominal leader occasionally directing the allotment of work. Besides the traditional expectancy that all should work according to ability in the interests of the common good of the village, the work is lightened by the pleasure of working in company and enlivened by the usual good natured banter, gossip and laughter at any little untoward incident.

As soon as the source of the spring is cleared of mud the head of the Water clan places two prayer sticks in the ground on the north wall of the spring. Meal is sprinkled over the offerings with prayers for rain and the continued fertility of the spring. He next places two prayer feathers on a bundle of wafer bread, sprinkles them with crumbled tobacco, meal and food, and places the offering at the bottom of the spring. The offering is usually placed in pottery bowls before being fed to the spring but on one occasion the bowls were left in the village by mistake. Bowls used the previous year were salvaged intact but were returned to under-water ledges without being used a second time. The ritual is concluded by sprinkling meal in the spring with prayers for its strength. This is done by each of the ritual smokers. A prayer feather is placed on the north rim and a short trail of meal laid down leading toward the east. All participants then join in the feast provided by the women and girls. Before entering a house on the return to the village each person purifies himself by holding his hands over a smoking sprig of juniper. Failure to do this will result in household members suffering from swellings and sores on the body. The spring is again tended to and fed four days before the public performance of the Flute ritual and thereafter closed for use until the Flute ceremony is finished. (Beaglehole 1937:30-31)

The third example is collective-choice arrangements, whereby resource appropriators participate in the decision-making process surrounding the resource. There is little direct ethnographic evidence for how rules about water management were made, or how many people participated in decision making. Instead, as the examples already presented show, there is evidence for centralized control over resource management, and presumably rules of governance. Governance varies, whether by clan control of springs in Western Pueblos (Beaglehole 1937), or cacique or chief control of irrigation systems in Eastern pueblos (Hill 1982; Lange 1959). It is 
possible that arrangements followed a pattern of community members petitioning for change in resource allocation, or use to the village's governing body, however in some cases, such as the small ( $<100$ person) community of Picuris the titular role of the mayordomo largely gave way to collective decision-making (Ford 1977). For example, Dozier (1966) recounts the procedure for acquiring communal labor at Hano [Tewa], a village of Tewa speakers, on the First Mesa at Hopi. At Hano, permission to call for a labor party was asked of the Village Chief with associated rituals, expectations of organization of tasks by male clan leaders, and food sharing (Dozier 1966:94).

Yet, decision making over the management of resources related to the impacts of modernization on pueblos may provide insights into how decisions over resource use ultimately affect collective choice arrangements. The one good ethnographic example of water storage features I found from the eastern pueblos comes from Ohkay Owingeh (San Juan Pueblo), as recorded by Alfonso Ortiz. While explaining seasonal economic pursuits, in relationship to political responsibilities cycling between moieties, Ortiz described maintenance associated with two artificial "ponds" near the village. These ponds were used seasonally for domestic water in the fall and winter after the closing of irrigation canals adjacent to the village. The maintenance of the ponds fell on the Women's society. Yet, in contrast to the Hopi example, only the Women's society, rather than the entire community, was responsible for up keeping the pond.

One of these ponds is about a hundred yards north of the village, and the other about the same distance west of the village. While the Women's society directs the cleaning, other women who are not Made People are drafted to help, with an offering of tobacco. There must be a pair of such women to clean each of the ponds, and both moieties are paired to carry out the task. After this basic requirement is fulfilled, other women of the village may volunteer to help carry away the trash baskets. With the drilling of wells in the village proper by the federal government several decades ago, the ponds have fallen into disuse. In still more recent years the ponds have almost dried up entirely because of the steadily falling water table in the area. (Ortiz 1969:170) 
There is no further description by Ortiz of whether the features were out of use, or the decisions behind ceasing maintenance, but it can be inferred that users may have simply decided that maintenance was more costly than the government dug wells. That the social institutions surrounding the use of the ponds were still within historical memory, even decades after the digging of wells, speaks to the endurance of this resource management strategy. Finally, while it can't be ascertained without a hydrological analysis, well pumping can lower water tables. If that occurred here, it would be an example of a new technology undermining both resource availability and the operation of social institutions surrounding resource management.

Monitoring of water management systems by those who are part of or are accountable to the appropriators in Pueblo communities appears in informal daily mechanisms such as gossip, and avoidance (Ellis 1951). There are a few examples of more formal monitoring to assure collective action strategies of providers as well as users. Water reservoirs constructed at the Hopi village of Bacavi [Hotvela] on Third Mesa are characterized as "a play area for children," and "a general gathering place in the summer for older people to sit and exchange thoughts" (Whiteley 1988:99). Informal monitoring can be inferred to have occurred in these contexts, and the conflicts over water described by Beaglehole and Sekaquaptewa reflect the inherent conspicuousness of water collection and transport from nearby sources into the villages. The need for monitoring of providers of CPR, and the potential for them to manipulate water infrastructure for their own interests can be found in the story James Paytiamo relates about his grandfather's experience as a chief:

There was one special water-hole known as the water-gage and it was a place used in their ceremonials. It is on the north cliff of Acoma, between two large reservoirs. It is about eight feet deep, six feet across the top, and nearly round in shape. 
During the year's period of office for the field chief, if the rains are heavy enough to keep this water-gage full in the dry moon-the last half of June and the first half of July - then the watching community automatically re-elects the field chief for life. This is a terrible thing for the field chief, as it practically separates him from his wife and family, but he is judged to have such a power over the rain that the village cannot afford to lose his powers as field chief.

Unfortunately for my grandfather, a very heavy rainy season came in his year of office. The rains started early in June and it rained often until the last part of September. Grandfather took his partners to the pool at night and dipped the water out, trying to keep it low, but the rains came in torrents to fill it up. So his appointment for life was sealed. The cloudburst tore a great gully down the side of the Laguna mountains, which was plainly visible from Acoma. So that is my grandfather's mark. You can see it still. (Paytiamo 1932:145-146)

Graduated sanctions for resource appropriators who violate community rules can be found in ethnographic descriptions across a range of social institutions (e.g., Ellis 1953), but there are few examples of sanctions associated with Puebloan water management. I have not been able to find instances where sanctions were imposed on community members over the extraction of water from reservoirs. In Eastern Pueblo societies there are reports that irrigators use the "first come, first served” approach, which reduces the complication of apportionment and sanctions, but makes distribution less equitable (Ford 1977; Lange 1953:675). One example of sanctioning is the use of coercion to secure labor for the annual maintenance of reservoir features documented at Bacavi [Hotvela]:

Pongyaletstewa [Coyote Clan] sponsored a ritual which resulted in the establishment of the pond. At that time two Motsin Kachinas came out and forced all the men to help with the pond. This happened too any time the ponds were cleaned out; these Kachinas came out and forced men to clean them. This is how the pond was made, by Pongyaletstewa's sponsorship (translated from Hopi). (Whiteley 1988:99) 
The degree of force used by the kachinas to induce assistance in pond maintenance was not reported to Whiteley, but Sekaquaptewa's recollection of maintenance of the water well includes a description of sanctions for not assisting:

Every spring and fall there was a community cleaning of the well. The sand and weeds that had accumulated in the basin had to be cleaned out and carried away. This was important, and several kachinas took charge, going to every house and ordering everyone to report at the well on that day to work. It was their duty. Some young men might run away just for the fun of having the kachinas chase them, but if one refused to go he was whipped hard with yucca branches. No one was excused. (Sekaquaptewa 1969:20)

As Beaglehole recorded, and others have noted, informal teasing of those who do not contribute to collective action likely went a long way in discouraging non-compliance to collective work or rule breaking. More formal examples of graduated sanctions in Pueblo society, including intense corporal punishment, can be found in the ethnographic literature (Ellis 1951), and embedded in myths and oral traditions (Parsons 1939).

\section{Mechanisms for resolving conflicts over CPR access and appropriation in Pueblo}

societies consist of inter-personal negotiation and appeals to tribal governance. The only example I have encountered of conflict resolution over CPR access is Sekaquaptewa's aforementioned description of conflicts over water rights and access of mesa-top reservoirs and cisterns ending in fights (Sekaquaptewa 1969:21). Lange (1959:43-44) identifies instances in multiple pueblos (both Eastern and Western) where conflicts are resolved through appeals to tribal governance. Governance structures varied between Eastern to Western Pueblos, but institutionally sanctioned violence as a mechanism for conflict resolution is present in Pueblo society (Ellis 1953). 
The inter-related institutions of clans and religious societies of the Western Pueblos, and moieties, curing societies, and katsina groups of the Eastern Pueblos speaks to the robust nested enterprises of water CPRs with other natural resources, and social institutions. In the Western Pueblos clans controlled different resources, as well as different tasks in the ritual calendar, all of which required collective action. Medicine societies appeared to control collective action in Eastern Pueblos, in addition to warrior societies that cross-cut relationships between moieties. Both Eastern and Western Pueblos also had katsina societies that added an additional layer of embedded social relations and obligations within a community, including water management. For example, in Whiteley’s (1988:99) description of reservoir construction at Bacavi the Coyote clan is in charge of organizing the collective action to build the new reservoirs, with katsina responsible for eliciting labor for construction. The building and maintenance of reservoir features, which served a functional purpose of providing water, were also nested within spiritual and symbolic realms, and often tied together in their control by governance structures. Leslie White recorded that initiation rituals for new chiefs at Acoma included trips to distant springs to collect water, which was returned to the village and poured into reservoirs (White 1973:45-50). This action establishes a link between governance and water. However, nested enterprises caused conflict when cross-cutting relationships made resolving ownership or priority rights problematic. Such an instance was documented at Taos Pueblo, where a conflict over irrigation water, which should have been resolved by the ditch boss, instead spiraled into a rift between rival factions in the village (Beals and Siegel 1966:143-144).

Finally, because traditional Pueblo communities were only loosely organized above the level of autonomous village (even political alliances, such as those seen during the Pueblo Revolt, were subject to factionalism and were ultimately short-lived [Liebmann et al. 2017])., there was 
little concern for higher-level authorities outside of the community commandeering a CPR arrangement. Therefore, the self-determinacy of community-based institutions for resource management is assumed to be a given in Pueblo societies.

In conclusion, this ethnological review suggests that water storage features likely exhibited many aspects of CPRs in Pueblo society, but not all of Ostrom's design principles are present across the ethnographic records of Pueblo water management. This may partly result from the fact that ethnographers are limited in their opportunities to identify how rules and institutions surrounding CPRs develop, since they often do not study communities for durations long enough to observe changes to CPR regimes. Also, many of the mechanisms of management and conflict resolution surrounding CPRs appear to be enacted beyond the gaze of the ethnographer. Nonetheless, these findings support that the hypothesis that collective action strategies existed for Historical Pueblo managing traditional water sources, and therefore it cannot be ruled out that collective action strategies for water management existed in prehispanic Ancestral Pueblo communities as well.

\subsection{Pueblo Water Management during Periods of Water Scarcity}

The ethnographic record also provides evidence illustrating how collective action in Pueblo communities reduced vulnerability to droughts through social norms, rules, and ritually mandated governance. Sekaquaptewa describes the strain of water collection during the driest part of the year at Old Oraibi [Orayvi], when there was only one reliable water source. Water collection intensified to a 24-hour cycle, yet social norms of conservation, equal access, and orderly acquisition mitigated the insecurity: 
On any day fifty years ago, or one hundred, or five hundred years ago, a two-tofive-gallon earthen water jug sat on each stone step (of terraces leading down to well spring). Sometimes the line of water jugs extended up and beyond the top level of the basin and back up the sandy path toward the village. Carrying water was the task of the older women. Each put her jar in place in the line and retired to the surface to await her turn. When there was enough water to fill a jar, the owner first in line went down and dipped the water into her jug with a gourd. As she moved out, the next woman in line moved her jar and everyone moved one step closer to the well. Sometimes one might save herself the effort by calling to a friend. "Move mine up too."(Sekaquaptewa 1969:18)

Once home, she emptied her water into a larger storage vessel and returned to the well to get in line again. When the flow was low, in June and July, this went on day and night. A women might take two jars and tell her husband to come on down by the time they were filled and carry one jar for her. (Sekaquaptewa 1969:19)

Richard Townshend visited Jemez Pueblo in the late $19^{\text {th }}$ century, and his notes on his time spent in Jemez were compiled posthumously and published in A Tenderfoot in New Mexico. He recounts a series of collective action practices undertaken by the Jemez during a drought. These actions are embedded in ritual, likely with oversight by community leaders. The Jemez, living at Walatowa, collected domestic water from the Jemez River, and irrigated fields from canals that diverted Jemez River water upstream of the Pueblo. When confronting a period of water scarcity during a drought, the Jemez first processed up the canyon to pray to the image of St. Margarita on San Diego Canyon (Townshend 1924:67). When this didn’t work, the idol of San Joaquin was taken from the sanctuary, insultingly dragged by horse down to the muddy puddles of the Jemez River, and then whipped and verbally assaulted for the lack of response to repeated prayers by the community (Townshend 1924:68). When the drought still did not break, Townshend relates a ritual seemingly devoid of appeals to the saints that integrated all members of community:

\footnotetext{
"We have other things we can do," he said, "much stronger than what we do with San Joaquin. But we don't talk about them to everybody." The secrets of their own old religion were too sacred for me; nevertheless, all the same the
} 
drought went on. Day by day the strings of patient squaws who marched in single file, each with her water jar balanced on her head, found less water in the pools of the river-beds, and the men's faces grew more and more anxious as they watched the cloudless sky. Then one day I saw with surprise that the biggest ollas were being borne on their heads down to the river, and all day long the women passed up and down the trail that led from it to the village, and instead of their using up the water in their daily washing and cooking it was stored in innumerable jars on the level eaves of the flat-roofed houses along the village streets. Rows upon rows of jars there were, and every one of them brimming full. (Townshend 1924:72)

Meanwhile the men of the community had brought their horses down from grazing in the mountains, corralled them, and that evening all mounted their horses and began racing through the village:

Up to the house where I was standing dashed a wild pony with two young men and a small boy clinging to his back, the boy on his withers, and one of the men all but slipping off his tail. "Water wanted," they cried in the Indian tongue, "much water wanted;" and much water, sure enough, they got. For in a deluge on top of them water rained from the house-eaves as the squaws, squealing in their eagerness, turned olla after olla upside down over their heads. Their wet skins shone like gleaming bronze as they cried, "Thanks, much thanks," and dashed away to another house in quest of another shower bath.

The paleface himself has been ducked. Now will the water spirits make for us much rain." So they did apparently. You may explain it any way you like, but next day the drought broke up, and we were blessed with a magnificent downpour. And those primitive rainmakers of Jemez were quite satisfied that this was the result of their performance. What could be clearer than that the spirits of the water which the squaws fetched from the river and poured from the eaves had called down the spirits of the waters that were above the firmament and that their call had been obeyed? (Townshend 1924:73-75)

The actions at Old Oraibi [Orayvi] and Jemez suggest dry periods, whether the typical intraannual dry seasons or inter-annual droughts, were met with embedded social rules, norms, and larger-scale collective action. An example reflecting continuities between prehispanic and ethnographic Pueblo approaches to responses during droughts is found in Jeançon’s (1923) report on excavations at Poshuouinge along the Chama River. Jeançon’s excavations 
documented a world quarter shrine located southeast of the site that included a complex of features, including three nearby water tanks. Unfortunately, the dimensions of the tanks are not described, but his informant, Aniceto Swaso of Santa Clara, related how these tanks were used during droughts, and that similar practices involving ritual leadership and collective action to enact ritual collection of water were still performed by Tewa peoples.

When the people of Po-shu lived in the village and there came a long dry spell, the summer and winter caciques, with some other men (Koshare?), would go to the world shrine and pray for rain. They would stay there for four days and nights and make magic to bring the rain. Only a very few men knew the rain medicine, and they had to fast all the time that they were praying and making magic. Then on the fifth day, before the sun came up, they would go down the path between the stones and all the time they kept on making magic until they reached the tanks. There they would stop, and when the sun just began to come up the rain would come down in a gentle shower and fill up the tanks. It did not rain any place else than at the tanks. Even the edge of the ground around the tanks did not get wet; the water only fell directly into the tanks. A runner was then sent to the village and told the people to bring with them the small ceremonial vessels for carrying the sacred water and to come to the tanks. When they arrived there the water was dipped out with the ceremonial cups. (PI. 43, A, A, C.) No human hand must touch the water, and then the people carried the water back to the village, where parts of it were drunk and other portions reserved for extra strong medicine. Then in a very short time it rained all over the country and the drought was broken. In going and coming from the shrines and tanks and from the village the people must keep between the rows of stones which made the sacred paths. In case none of the doughnut-shaped cups were at hand, an abalone (?) shell was used to dip out the water to the people. If the prayers for rain failed, the ceremony was repeated, and always after the fourth attempt rain fell. This never failed."

The informant further said that this same ceremony is still performed in times of extreme drought and that only a very few men now know how to do it. Jeançon (1923:72)

These examples beg the question: how would communities reliant upon rotating governance structures that often associated rain and crop success with good governance respond to long-term droughts that exceeded the capacity for social rules and norms buffer the risks of water 
insecurity? Collective action strategies that enhance infrastructures associated with vulnerable resources would logically buffer the risks of resource scarcity for communities. However, to take the Jemez example, what might happen if the community-wide drenching event did not coincide with rainfall? Another example to consider is the relationship between governance tenure and the rain gauge reservoir at Acoma. A full reservoir caused by ample rain may signify good governance, but what if the reservoir goes dry, or if in Jeançon's example, the rains never filled the reservoirs near the shrines? Would either of these scenarios reflect poor governance or ritual practice, and what would the consequences be to existing social institutions?

Zia Pueblo provides an example. Stevenson (1894:10-12) described visiting Zia in 1890 during a period of water and food scarcity. Disease and historical depredations had reduced Zia to only 106 inhabitants by 1890 . Due to limited water sources for irrigation, agricultural production was low, and the Zia turned to ceramic production to trade for food. Yet, food acquired from trade would not always be enough:

Each year a period comes, just before the harvest time, when no more pottery is required by their Indian neighbors, and the Sia must deal out their food in such limited portions that the elders go hungry in order to satisfy the children. When starvation threatens there is no thought for the children of the clan, but the head of each household looks to the wants of its own, and there is apparent indifference to the sufferings of neighbors. When questioned, they reply: "We feel sad for our brothers and our sisters, but we have not enough for our own." Thus, when driven to extremes, nature asserts itself in the nearest ties of consanguinity and the "clan" becomes secondary. At these times there are no expressions of dissatisfaction and no attempt on the part of the stronger to take advantage of the weaker. The expression of the men changes to a stoical resignation, and the women's faces grow a shade paler with the thought that in order to nourish their babes they themselves must be nourished. (Stevenson 1894:12)

This example shows how periods of scarcity lead to household needs taking precedence to collective action approaches to resource allocation. At Zia a period of scarcity occurred annually, 
but what might happen during an event of longer severity? I believe the repeated examples of Pueblos associating good governance with resource abundance suggests it is not unreasonable to think the opposite would be true during times of resource scarcity. If so, collective action strategies and infrastructure providers could be seen as ineffectual, and resource scarcity could potentially be a driver of social changes, such as movement or social reorganization.

\subsection{Pueblo Uses of Water Reservoirs and Geoarchaeological Expectations}

The ethnographic record affords opportunities to identify behaviors surrounding reservoir use that may leave behind archaeological signatures. In Chapters 6 and 7 I deploy a behavioral geoarchaeology approach (Roos and Wells 2017) to evaluate alternative hypotheses as to how prehispanic reservoir features functioned. Here, I identify and describe ethnographic elements of reservoir construction, maintenance, and abandonment that may inform geoarchaeological interpretations of archaeological water storage features (Table 4.1). These processes, and their geoarchaeological correlates, are incorporated into my research design for site formation hypothesis testing in Chapter 6, and in feature-specific discussions in Chapter 7.

Besides the sources already mentioned in this chapter and compiled in Table 4.1, a particular set of observations made outside of the Eastern and Western Pueblos are especially relevant. The Tohono O’odham in the Sonoran desert of Southern Arizona have a history (and prehistory) of reservoir use. Historical records and late 20th century observations show they constructed water storage features to collect water from both irrigation canals, as well as from surface runoff (Nabhan 1986). Today these features are used primarily as stock tanks, but they continue to be a part of traditional knowledge, and are discussed as part of revitalization movements of traditional agriculture and foodways (Paganelli-Votto and Manuel 2010). Ethno-agronomic studies of these 
features in the $20^{\text {th }}$ century provide a wide range of observations that may be archaeologically relevant (Hutchinson 1982; Nabhan 1986). In addition, archaeologists have demonstrated the prehispanic usage of these features (Bayman 1997; Bayman et al. 2004), which will be discussed further in Chapter 6, and supports arguments for the endurance of these sustainable water management practices.

\section{Reservoir construction}

Kirk Bryan (1925:147) observed that Tohono O’odham built reservoirs (represas) to impound water by excavating soils to create a basin, and then used the excavated soil to create an earthen berm downstream of the basin. Water storage was typically limited to the excavated basin within the horse-shoe shaped berms. Once water entered into a reservoir the water retention properties of the underlying soils or bedrock of the basin were a significant factor in storage efficiency (NRCS 2005). A series of infilling flooding events are seen as necessary by Hispanic ranchers to seal unlined stock ponds near Abiquiu, NM, as the fine-grained flood deposits are understood to form an impermeable layer at the base of stock tanks (Michael Bremer, 2016, personal communication). For the Tohono O'odham natural swales in alluvial washes lined with fine-grained flood deposits were reported as loci for agriculture because the water retained within these natural basins (McGee 1896).

Reservoirs can come in a range of sizes, can have different water sources, and not every attempt to construct a reservoir results in a hydrologically efficient feature. First, reservoirs can vary in size due to particularities of physical contexts, water demands, and management practices reservoirs, even if they are constructed by farmers within the same culture (Hutchinson 1982:28). The nature of the water source can have a considerable impact on feature morphology and 
landscape position (Crown 1987). Modified springs with walls to form a catchment basin like those discharging at Hopi (Beaglehole 1937) or Zuni (Whipple and Ives 1856), or basins dug into shallow water tables (Ortiz 1969) may not have drainage areas commensurate with potential

Table 4.1. Ethnographic practices of reservoir use and possible geoarchaeological correlates.

\begin{tabular}{|c|c|}
\hline Ethnographic practice & Geoarchaeological correlate \\
\hline \multicolumn{2}{|l|}{ Construction } \\
\hline $\begin{array}{l}\text { Basin created through excavation of soils } \\
\text { to increase potential storage volume, soils } \\
\text { used in earthen berm (Bryan 1925:147) }\end{array}$ & $\begin{array}{l}\text { Evidence of basin excavation, berm (particularly } \\
\text { the base and core of berm) constructed with } \\
\text { sediments with sedimentological and pedological } \\
\text { characteristics similar to soils of basin }\end{array}$ \\
\hline $\begin{array}{l}\text { Accumulating silts at bottom of basin } \\
\text { which form impervious, water-retaining } \\
\text { lining (M. Bremer, 2016, personal } \\
\text { communication, Nabhan 1986) }\end{array}$ & $\begin{array}{l}\text { Lenses of silt and clay sediments, with generally } \\
\text { hydrophobic mineralogical properties at the bottom } \\
\text { of reservoir basins }\end{array}$ \\
\hline $\begin{array}{l}\text { Differing water storage efficiency between } \\
\text { features, dependent upon management } \\
\text { approaches (Hutchinson 1982:28) }\end{array}$ & $\begin{array}{l}\text { In comparisons between features would see } \\
\text { variability in size, shape, and storage volume }\end{array}$ \\
\hline $\begin{array}{l}\text { Construction of water storage feature not } \\
\text { completed, or feature not functional } \\
\text { (Castaneda 2002:165) }\end{array}$ & $\begin{array}{l}\text { Hydrological model and/or partial construction } \\
\text { suggests limited potential for water storage }\end{array}$ \\
\hline $\begin{array}{l}\text { Reservoir or “walled spring” is excavated } \\
\text { down to water table or a modified spring } \\
\text { to obtain water (Whipple and Ives 1856; } \\
\text { Ortiz 1969; Crown 1987) }\end{array}$ & $\begin{array}{l}\text { Feature with little to no catchment area to collect } \\
\text { surface runoff, active spring discharging in basin } \\
\text { and/or evidence of hydric soils indicating shallow } \\
\text { water table }\end{array}$ \\
\hline $\begin{array}{l}\text { Reservoirs constructed to capture surface } \\
\text { runoff from rainfall events, snow melt, or } \\
\text { as holding pond for irrigation water } \\
\text { (Beaglehole 1937:27-31; Castaneda } \\
\text { 2002:123; Hutchinson 1982; Loew } \\
\text { 1875:177; Sekaquaptewa 1969) }\end{array}$ & $\begin{array}{l}\text { Hydrological calculations of run-off from } \\
\text { catchment area will correspond to accommodating } \\
\text { storage volume of basins, evidence for additional } \\
\text { water management features (e.g., canals) if part of a } \\
\text { larger irrigation network. }\end{array}$ \\
\hline \multicolumn{2}{|l|}{ Maintenance } \\
\hline $\begin{array}{l}\text { Burning and clearance of vegetation in the } \\
\text { catchment area (Nabhan 1982:28) }\end{array}$ & $\begin{array}{l}\text { Charcoal concentrations in basin sediments during } \\
\text { use-life higher and/or differences in fuel load/type } \\
\text { due to frequency of burning }\end{array}$ \\
\hline $\begin{array}{l}\text { Periodic cleanout of in-filling sediments } \\
\text { within the basins and berm repair (Ortiz } \\
\text { 1969; Beaglehole 1937:27-31; } \\
\text { Sekaquaptewa 1969; Whiteley 1988) }\end{array}$ & $\begin{array}{l}\text { Truncations in sediments of basin, possibly } \\
\text { majority of basin fill reflective of end of use-life } \\
\text { and post-abandonment, fine-grained basin } \\
\text { sediments added to berm }\end{array}$ \\
\hline Daily Use & \\
\hline
\end{tabular}




\begin{tabular}{|l|l|}
\hline $\begin{array}{l}\text { Meeting places for daily visiting } \\
\text { (Whiteley 1988; Sekaquaptewa 1969) }\end{array}$ & $\begin{array}{l}\text { Domestic, non-water related debris along berms and } \\
\text { near reservoirs }\end{array}$ \\
\hline $\begin{array}{l}\text { Trails leading to water sources from } \\
\text { villages (Gregory 1916:132) }\end{array}$ & $\begin{array}{l}\text { Physical trails and/or artifact distributions to and } \\
\text { from water sources (Phillips and Leckman 2012) }\end{array}$ \\
\hline Abandonment & $\begin{array}{l}\text { Potentially unconformable depositional contacts if } \\
\text { post-abandonment changes in catchment area lead } \\
\text { to differences in sedimentological characteristics, } \\
\text { rates, and soil development, potentially } \\
\text { sediments after abandonment (Ortiz } \\
\text { 1969:171) } \\
\text { conformable contacts if little change to catchment } \\
\text { area }\end{array}$ \\
\hline $\begin{array}{l}\text { Wetlands attracting wildlife (Whiteley } \\
1988: 99)\end{array}$ & $\begin{array}{l}\text { Paleoecological evidence for post-abandonment } \\
\text { changes in ecology }\end{array}$ \\
\hline Breaching of berms (Hutchinson 1982) & Portions of berm washed out \\
\hline
\end{tabular}

storage volumes like reservoirs capturing surface runoff. Finally, not all features built to store water are completed or achieve their designed function. A particularly tragic example is the failed water well dug in the winter of 1541 by the Pueblo of the Southern Tiwa village of Moho. The mesa-top village faced a severe water shortage during a 50+ day siege by the Spanish, and the villagers attempted to excavate a water well. During construction the well caved in, thirty people reportedly died, and it apparently never provided water (Castaneda 2002:165). The location of Moho is uncertain, with possible sites ranging from near Albuquerque to the Santa Ana Mesa overlooking San Felipe Pueblo (Poling 2015).

\section{Annual maintenance}

Observations of reservoirs show that they require annual care. This includes not only maintenance of the berm and basin, but the catchment area as well. The catchment areas of Tohono O’odham reservoirs, up to $100 \mathrm{~m}$ upslope of the basin, were cleared during the dry season (June) to facilitate surface runoff (Hutchinson 1982:28). This including burning 
vegetation off of the banks of the reservoir and the dry basin. Brush from clearance was used to construct artificial weirs to further direct water towards the catchment basin. Charcoal from routine burning may become incorporated in berm and basin fill sediments. Nabhan (1986) observed that maximizing the efficiency of floodwater farming (including reservoirs) required minor adjustments to infrastructure at critical times, including temporary features like additional ditches, patches to berms, or brush weirs, to increase water recovery.

A major annual activity would be the cleaning out the reservoir basin and repairing of the berm. These activities are reported for reservoirs (Ortiz 1969; Whiteley 1988) and springs (Beaglehole; Sekaquaptewa 1969), and especially for irrigation canals (e.g., Ford 1977; Lange 1959). These clean-out events would remove sediments, truncating depositional sequences in the basin and potentially disturbing unexcavated deposits through wet deformation. If reservoir basin sediments are incorporated into berm fill then one would expect berm deposits to be an amalgam of excavated natural soils and basin sediments.

\section{Daily use}

Reservoirs near villages were places of social gathering, where community members would informally meet (Dennis 1940:150, Whiteley 1988:99,131). Therefore, I expect domestic debris around features to reflect heavy traffic from repeated use, and potentially higher concentrations of sherd fragments from jars associated with water collection. Yet, the ethnographic record also shows a concern about cleanliness around water sources (Paytiamo 1932), as well as records of cleaning out features and springs (Ortiz 1969; Sekaquaptewa 1969; Whiteley 1988). Basin fill contemporaneous to reservoir use should be relatively free of artifacts while areas around and outside the features may have high artifact concentrations. Daily trips to water sources, 
particularly if they are far from villages, may lead to the creation of trails. The geologist Herbert E. Gregory noted that prominent Hopi trails going to springs, often with little accommodation for topography or relief (Gregory 1916:132), and an Edward S. Curtis photograph from Hopi shows female water carries traversing a well-worn path (Figure 4.4).

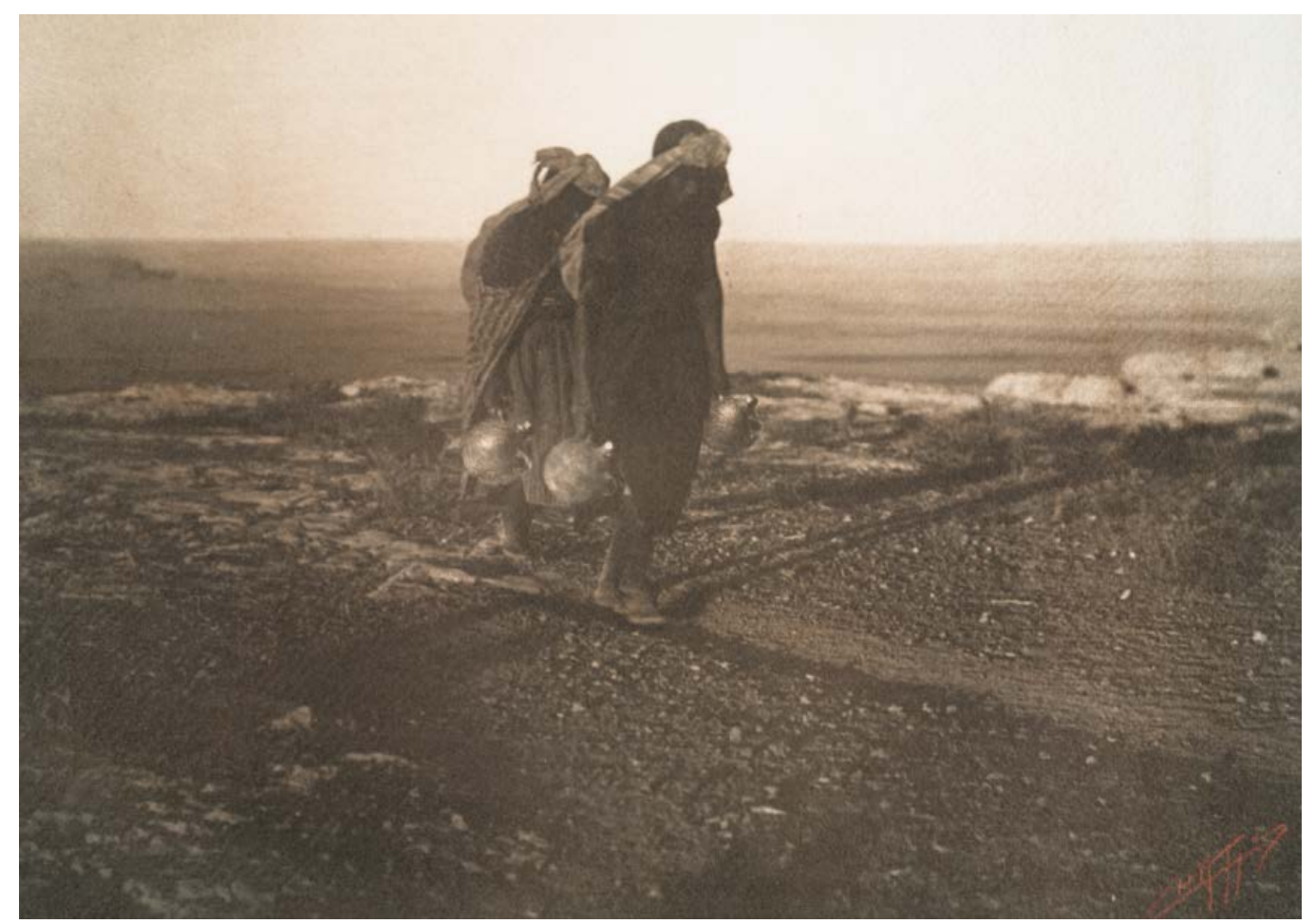

Figure 4.4. Hopi water carriers, ca.1900, by Edward S. Curtis (note well-worn path) (From the New York Public Library, The Miriam and Ira D. Wallach Division of Art, Prints and Photographs: Photography Collection, retrieved from http://digitalcollections.nypl.org/items/510d47da-821b-a3d9-e040-e00a18064a99).

\footnotetext{
Abandonment

When features fall into disuse I would expect changes in aquatic habitats reflected in paleoecological indicators persevered in sediments, sedimentation within basins, and breaches of the berms. At Bacavi, loud frogs were cited as a problem when one of the artificial ponds fell
} 
into disuse (Whiteley 1988:99), suggesting that a wetlands developed within the pond. At Ohkay Owingeh ponds dried up, in part because accumulating silts and clays were not cleaned out (Ortiz 1969:170). From the Tohono O’odham we see evidence of breached berms, and local impacts to vegetation with the cessation of burning and clearing (Hutchinson 1982). Therefore, if reservoirs and catchment areas stop being maintained, or there are climatological or hydrological changes - like the falling water table at Okah Owingeh - then I would expect to see breaches of berms, and changes in sedimentation sequences, such as in rates of sedimentation, sedimentary organics or geochemistry. Also, I may see increases in cultural detritus washing into the basin with abandonment, as efforts to keep areas around water sources clean towards the end of the feature's use-life may be loosened.

\subsection{Summary}

This foray into the ethnographic literature may be an atypical exercise for a dissertation focused on geoarchaeological data. Yet, it provides important perspectives across multiple domains. First, it demonstrates the utility of common pool resource theory to better understand social institutions, by drawing analogies from the ethnographic literature. It shows that social institutions in Pueblo society were central to the management of water as common pool resources, and that the operations of these social institutions were critical during periods of water resource scarcity. The likelihood that institutions for the management for common pool resources existed in Ancestral Pueblo communities is supported by the ubiquity of these institutions and associated CPR features across the North American Southwest. That rules and norms around reservoir storage features, which unlike irrigation canals do not have the same problem with equivalency to introduced Spanish traditions of water management, existed in 
some communities into the ethnographic present speaks to the endurance of collective action strategies towards their management. The review of the literature also shows that property relationships surrounding water were highly contingent upon the nature of the resource, such as open access resources policies surrounding springs as compared to reservoirs, which were subject to shifting access arrangements depending upon availability. The literature also shows that the cost of resource acquisition was a critical factor in decision-making and collective action. These observations will be particularly relevant in the least cost path models I present in Chapter 8.

Testable hypotheses about functional aspects of reservoir construction, use, and abandonment are integrated into a behavioral model of reservoir use-life histories, addressed in Chapter 6. Finally, while I do not believe the ethnographic records of water management are either extensive or detailed enough to evaluate whether some forms of Pueblo social organization are more likely to successfully manage water CPRs than others, this exercise does provide perspectives on the relationships between resource users, infrastructure, and infra-structure providers, which will be critical for developing the diachronic socio-ecological systems models in Chapter 9. 


\section{CHAPTER 5. PALEOHYDROLOGY}

In this chapter I address the questions of whether the hydrological system of the Jemez Mountains is sensitive to droughts, and if so, how would water availability be affected by droughts in the past? Here, I compile geological, hydrological, and modern environmental data from the Jemez Mountains to assess the sensitivity of its hydrological system to precipitation variability. Then, I develop qualitative paleohydrological models of natural water availability for both study regions. The findings from this chapter are used in two components of the SES model: hydrological systems and water resources (Figure 1.3), and are relevant to discussions of reservoir hydrology and least cost analyses of water acquisition costs.

\subsection{Hydrology, Paleohydrology, and Traditional Pueblo Hydrological Knowledge}

The hydrological cycle traces the movement of water between the atmosphere, land, and the oceans (Chahine 1992). Characteristics of underlying geological formations have a significant influence on where water is present in the landscape (Fetter 2000). Geological units that bear water are aquifers, with saturated portions of the geological sequence referred to as the phreatic zone, and unsaturated portions referred to as the vadose zone. There are two types of aquifers: perched aquifers and regional aquifers. Regional aquifers are continuous, saturated geological formations, which only have surface expressions as springs due to faulting, exposures of the 
formation, such as in deeply incised canyon bottoms, or some combination thereof (Stevens and Meretsky 2008). Water accumulates within regional aquifers over millennia. Perched aquifers are shallower than regional aquifers and are underlain by an impermeable stratum (an aquitard). They are frequently discontinuous and localized, and typically understudied by hydrogeologists because they lack economic utility in industrial, commercial, or municipal settings. That being said, depending on the size of the perched aquifer and the scale of the demand, discharges from perched aquifers can be sufficient for people to utilize, although they are more susceptible to variability in precipitation than regional aquifers. Paleohydrology provides long-term perspectives by studying water distribution and system function of hydrological systems in the past (Baker 1998). Past systems are modelled by using modern hydrological observations, paleoprecipitation records, and geomorphological reconstructions (Brown 1997). Such studies are relevant to climate science modelers, to both understand current configurations of hydrological systems and to model system change (Benito et al. 1998).

Archaeologists use paleohydrological research through geoarchaeological reconstructions of alluvial systems. A few examples in North American Archaeology include using alluvial and paleoecological data to infer evidence for Clovis Period droughts (Haynes 1991; but see Holliday 2000), alluviation rates in studies of site formation processes of archaeological sites in alluvial settings (e.g., Ferring 1986), and integrating paleo-stream flow reconstructions with alluvial records and cultural sequences to better understand early agricultural practices in the North American Southwest (Nails et al. 2011). Hydroarchaeology, as recently conceived by Kirk French (2009) and others (French et al. 2012; Jazwa 2016) links paleoprecipitation estimates and watershed hydrology to develop models of stream discharges in relationship to population 
dynamics and water management systems. My study certainly fits within the aims of hydroarchaeology.

However, an approach taken as part of the Village Ecodynamics Project (VEP) in the North American Southwest inspired my study. Kenneth Kolm and Schaun Smith developed a quantitative paleohydrological model to address questions about whether or not droughts reduced surface water availability to the point where Ancestral Pueblo communities experienced water insecurity (Kolm and Smith 2012; Smith 2008). Their model focuses on geohydrology, because they hypothesized that springs were the most utilized water sources in their study area. Using modeling software (Hydrological Systems Analysis), they integrated quantitative geohydrology and present-day attributes of the hydrological system with tree-ring based annual precipitation reconstructions (Smith 2008). Their model generated simulations of annual prehistoric drinking water supplies and spatio-temporal reductions in water availability. However, when correlated with models of prehistoric population, they found that water availability stayed within the carrying capacity of regional population estimates (Kolm and Smith 2012:79). There was nonetheless a correlation between population aggregations around perennial springs during periods of reduced discharges; and agent-based model simulations run with increasing populations through time found that individual agents expended greater energy on water acquisition (Kolm and Smith 2012:83).

Many of the fundamental concepts of hydrology, rooted in concepts developing out of Hellenic and Classical traditions (Biswas 1970), are paralleled in traditional Pueblo concepts of water embedded in daily observation and practice (Figure 5.1). Harrington compiled nearly one hundred Tewa expressions for water, including a name for springs with discharge rates sensitive to rainfall, groundwater, the differences of properties of water based on its source, and 
correlating streamflow sinks to the presence of alluvial aquifers (Harrington 1916: 58, 81, 87).

Pueblo traditional ecological knowledge sees humans (through prayers and right actions) as vital to the continued operation of the hydrological cycle. Saile’s (1990) model of Pueblo spiritual geography shows the connections linking human communication to the spirit world to facilitate rain, with loci for interaction with the spirit world at springs and lakes, and particularly wet places in mountains. Visits by multiple tribes to the tops of mountains, such as Mount Taylor, during droughts to pray and make actions to encourage precipitation demonstrate the association between moisture and high elevations (Parsons 1918:184-185). Water spirits like ayvanu or katsina reside in or below springs, and offerings are made at springs to ensure continued discharge and the functioning of the entire water cycle (Harper 1929; Ladd 1983; Parsons 1925: 7, 124-125; White 1973:45-50). These springs can cease flowing if not properly respected (Hewitt 1993:90-92). Dozier (1970) argues that the central focus on rainmaking in ritual and in governance may reflect the deep tradition of reliance on dryland farming, even after communities came to depend on irrigation agriculture in historic times. Functional similarities between traditional Puebloan hydrological knowledge and scientific approaches to hydrology are important to recognize in order to justify applying principles of rational choice decision-making to models of water acquisition.

\subsection{Geohydrology of the Jemez Mountains}

In this section I present the geological and geohydrological context, and the spatial distribution of water resources of each study area. The Jemez Mountains arise in north-central New Mexico. They are flanked by the Rio Grande Rift Valley to the east, and to the west by the 


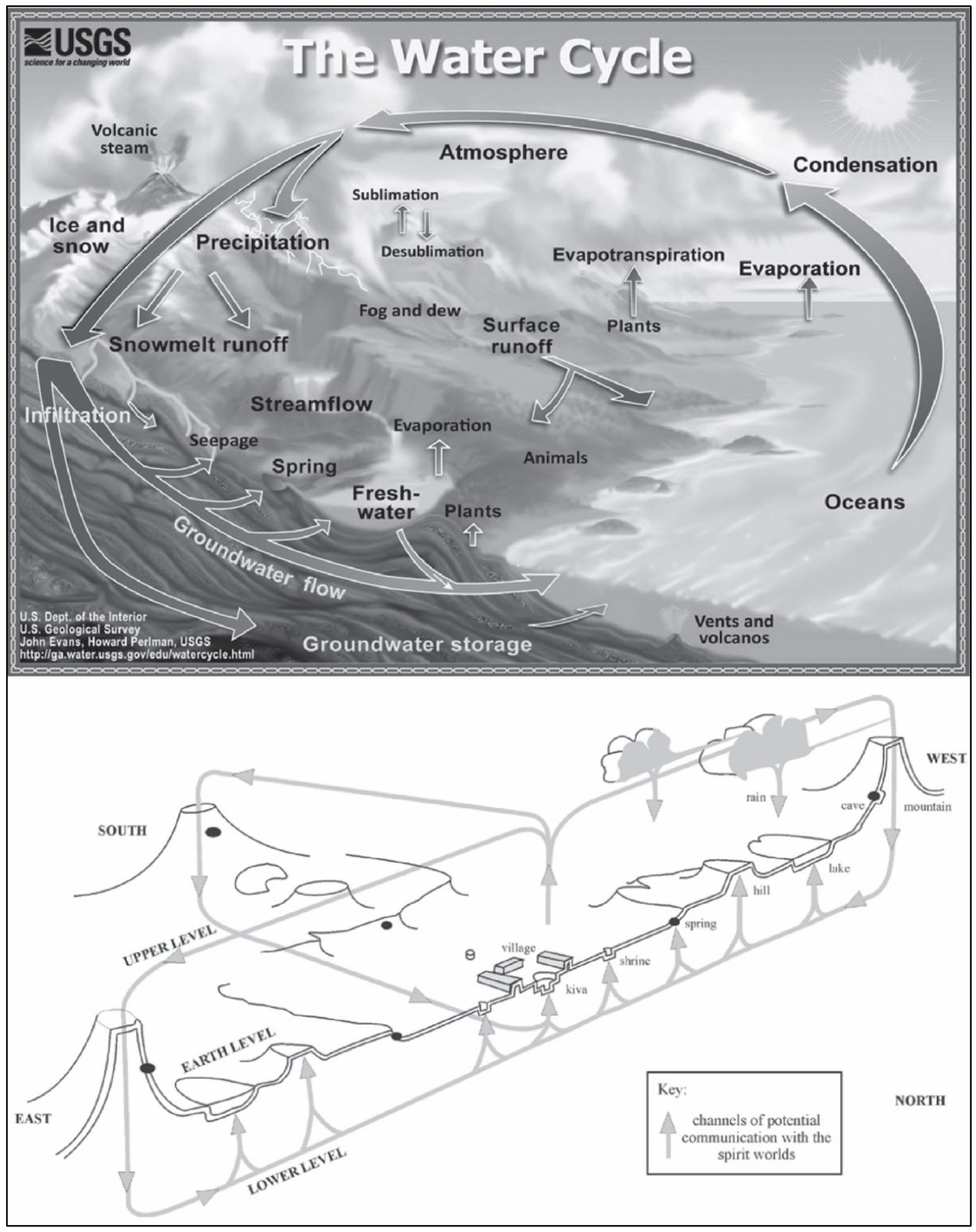

Figure 5.1. The scientific model of the hydrological cycle (above) (http:/ga.water.usgs.gov/edu/watercycle.html, accessed 8/1/2017) and Puebloan channels of communication with the spirit world (below) (based on Saile 1990: Fig 5-9, in Anschuetz and Merlan 2007). 
uplifted Sierra Nacimientos at the edge of the Colorado Plateau (Figure 5.2). The basement below the volcanic rocks of the Jemez Mountains differs between the Jemez and Pajarito Plateaus. Colorado Plateau basement deposits extend below the Jemez Plateau. These consist of Precambrian gneiss overlain by Pennsylvanian sedimentary rocks of the Madera Formation, and Permian sedimentary rocks of the Abo and Yeso Formations (Figures 5.3 and 5.4). The basement of the Pajarito is inferred to be Precambrian gneiss as well, but the deepest tested rocks are much younger sedimentary rocks of the Tesuque Formation of the Late to Middle Miocene Period (formerly Tertiary) (Broxton and Vaniman 2005) (Figures 5.5 and 5.6). These are overlain by even younger interbedded volcanic and sedimentary deposits of the Totavi Lentil, and Puye Fanglomerates, as well as Cerros del Rio Basalt flows. These deposits date from the Eocene to Earliest Pleistocene Period. The differences in the hydrological properties between the basement rocks of these regions are critical for appreciating water availability, and which I will discuss further.

The Jemez Mountains are volcanic, and are part of the Jemez Lineament, a series of volcanic fields aligned west to east along a crustal flaw across northern New Mexico (Aldrich 1986). These fields have been active since at least the late Cenozoic with older volcanic deposits that indicate activity as far back as the early Cenozoic (Gardner et al. 1986). While there is evidence for volcanic activity for at least the last 16 million years (e.g., the Tschicoma Formation outcropping at Sierra de los Valles above the Pajarito Plateau), the geological formations that make up the majority Jemez Mountains today are largely the result of eruptions 1.6 and 1.2 million years ago (Smith et al. 1970). These eruptions formed the massive Valles Caldera (24 km across), along with a series of secondary domes, and the skirt-like deposits of tuff ringing the caldera (labeled Qbt in Figure 5.2). These tuff deposits formed due to an ignimbrite eruption - a 


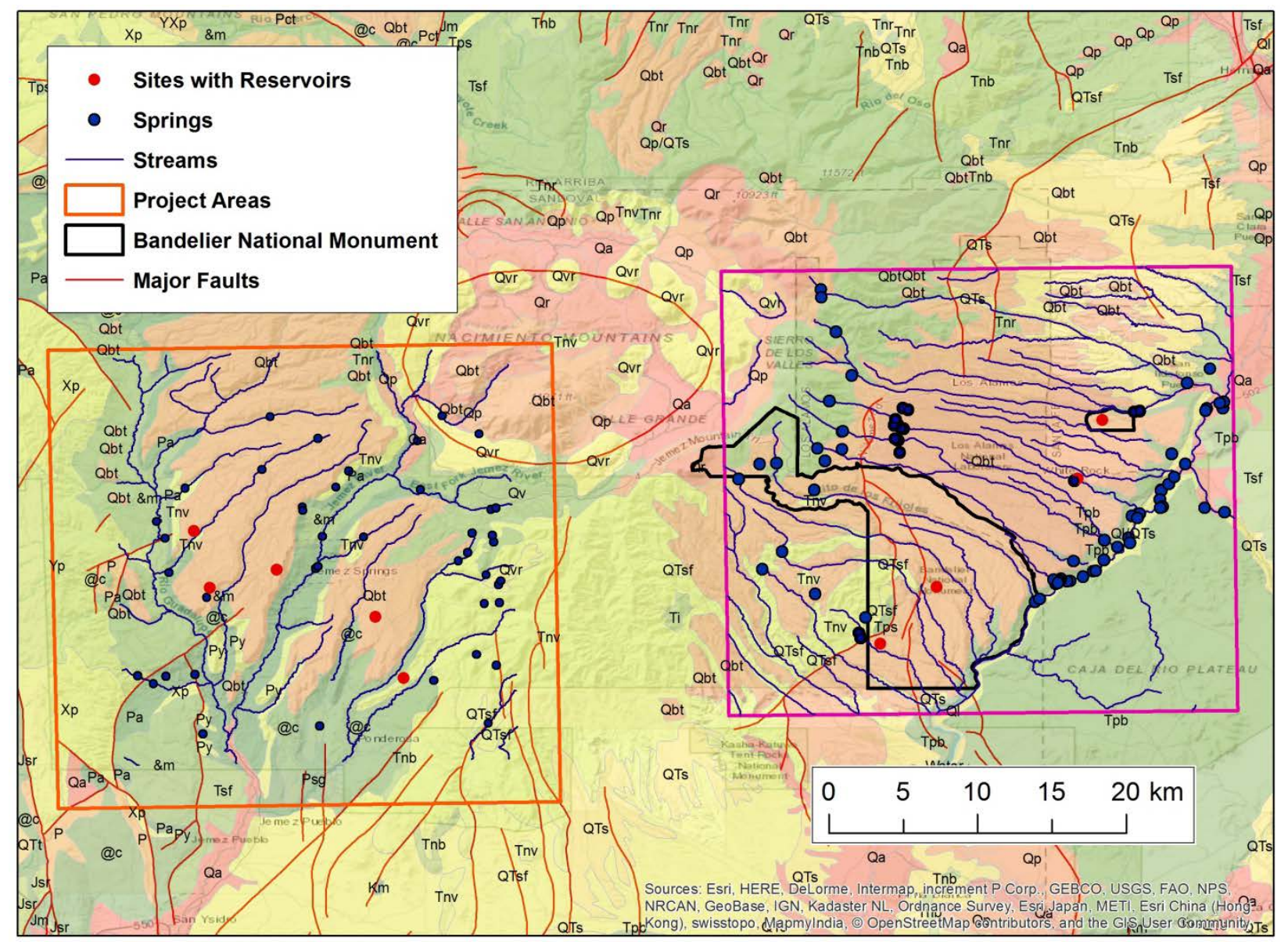

Figure 5.2. Surface geology of the Southern Jemez Mountains (based on Smith et al. 1970; Green and Jones 1997).

massive event where hot ash, pumice, gas, and crystals flowed, potentially up to the speed of sound, across the surrounding landscape around the caldera. Mapped as Bandelier Tuff (Qbt), these deposits, which can be over a thousand feet thick, register ignimbritic events at 1.6 and 1.2 million years ago (Smith et al. 1970). They are now deeply dissected by canyons and form the series of high table-top mesas of the southern Jemez and Pajarito plateaus. These plateaus served as the settings for highland Ancestral Pueblo settlements. More recent volcanic events (labeled Qvr in Figure 5.2) are the ongoing formation of resurgent domes within the Caldera, the Banco Bonito Lava Dome formed by a small set of eruptions approximately 50,000-60,000 years ago, 
the Battleship Rock ignimbrite, and the more regionally extensive El Cajete ash fall deposits found across mesa-tops of the Southern Jemez Mountains (Toyoda et al. 1995; Zimmerer et al. 2016).

The thick, blanket-like formations of volcanic tuff mantling both regions makes them appear very similar; however important differences in faulting and geological formations below the tuffs greatly influence regional geohydrological systems. The Jemez fault runs parallel to the mesatops, forming the deeply incised San Diego Canyon. The canyon captures the majority of the water draining from the Valles Caldera (Kelley et al. 2007; Tafoya 2012) (Figure 5.3). By contrast, Pajarito Plateau faults run perpendicular to the slopes of the Plateau, and the streams do not capture water from the Valles Caldera (Figure 5.5). The impact of this setting can be seen by comparing discharge rates of the two major streams of each plateau. Over an 80 year period the Jemez River daily average discharge is $71 \mathrm{ft}^{3} / \mathrm{sec}$. By comparison, over the 16 years of intermittent recording (1983-2014) the Rito de los Frijoles, the only perennial stream in the Pajarito Plateau, it averages only $2 \mathrm{ft}^{3} / \mathrm{sec}$ daily discharge (U.S. Geological Survey 2016).

Springs are documented across the region, many of which originate from regional aquifers. The regional aquifer of the Jemez Plateau is recharged by the mixing of meteoric and endogenic waters, which pass through both volcanic and sedimentary geological units (Figure 5.4). This imparts geochemical attributes to the water that reduces its qualities for human consumption. In many springs of the Jemez Plateau, and in segments of the Jemez River, groundwater is both heated and high in dissolved minerals, which raises the saturated conductivity levels past thresholds where the water is safe to consume (Tafoya 2012). The hot springs we enjoy for recreation, and potentially for geothermal energy exploration, would not have been viable domestic water sources for Ancestral Pueblo people. By contrast, the regional aquifer below the 
Pajarito Plateau is entirely potable. However, it is also deeply buried, and discharges only along White Rock Canyon at the Rio Grande (Figure 5.6). Otherwise, springs across the Pajarito are associated with faults running perpendicular to the slope of the mesas of the Pajarito discharging water from perched aquifers (Figure 5.5). Therefore, in both cases understanding the availability of natural surface water for Ancestral Pueblo communities demands an appreciation of the hydrological conditions of sub-regional perched aquifers. In Appendix A, I compile the first list of all springs in both regions. Published discharge measurements and radiometric dates of groundwater are included, as are classifications of discharge sensitivities to droughts.

Six contexts of the Jemez Plateau have natural surface water: 1) isolated springs in canyon bottoms associated with alluvial aquifers, 2) springs emanating along canyon walls from perched aquifers, 3) springs discharging from the regional aquifer, 4) small natural tinajas and step pools, 5) perennial streams, and 6) intermittent streams (Figures 5.3 and 5.4). Overall there is more water on the Jemez because of the aforementioned features of its structural geology. San Diego Canyon captures nearly the entirety of the runoff from the Valles Caldera, which flows perennially down the Jemez River. The Jemez fault presents along an axis that cross-cuts the agriculturally productive mesa-tops of the Southern Jemez Plateau, thereby making water sources available across multiple points near many of the Ancestral Pueblo villages.

The runoff from the Valles Caldera and adjacent uplands support perennial streams in multiple drainages: the Jemez River, the Rio Guadalupe, Lake Fork Canyon, Rio Cebolla, and Vallecito Creek. The Rio Cebolla, Lake Fork Canyon, Rio Guadalupe and Vallecito Creek frame the northwestern, western, and eastern boundaries of the Southern Jemez Plateau, with the Jemez River bisecting the region (Figure 5.3). Other drainages today have only intermittent flows, supported seasonally in their upper reaches by springs, and seasonal run-off by snow-melt or 
monsoon rain events. As I will discuss in the least cost analyses, the greater range of options for perennial water benefitted Ancestral Pueblo communities of the Jemez Plateau.

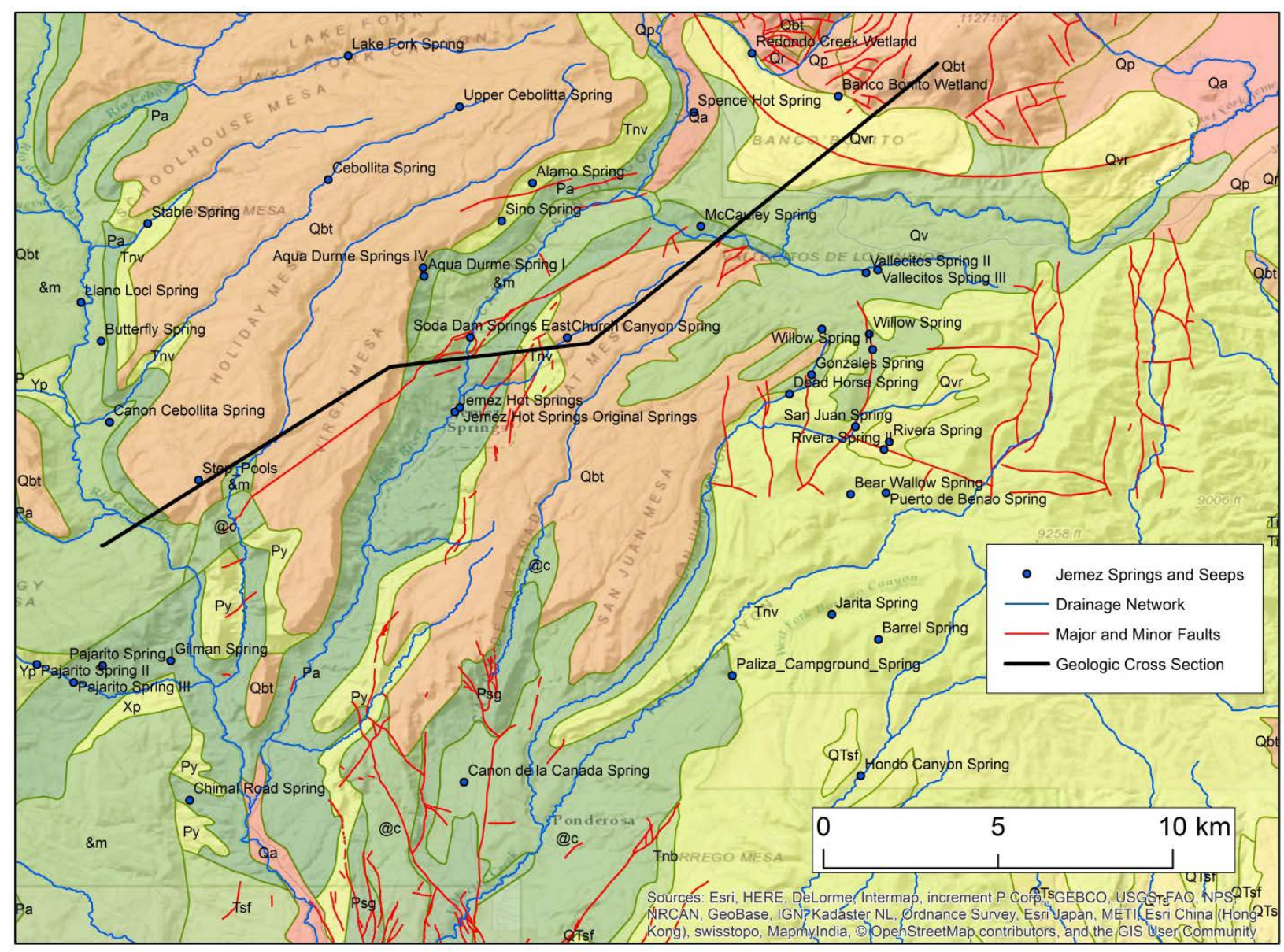

Figure 5.3. Surface geology and hydrology of the Jemez Plateau (based on Smith et al. 1970; Green and Jones 1997; Kelley et al. 2007). 


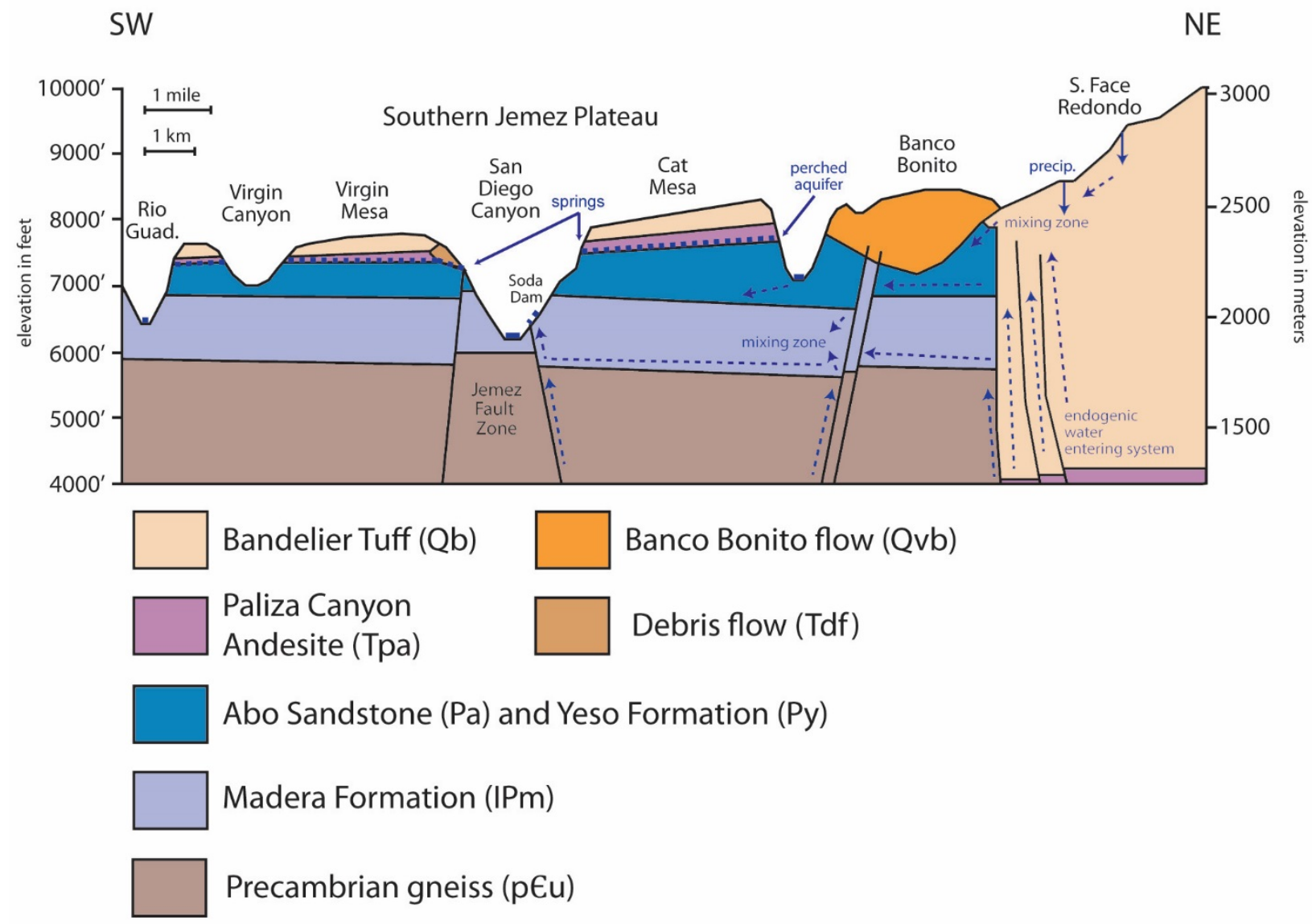

Figure 5.4. Hydrogeological cross section of the Jemez Plateau (Kelly et al. 2007; Tafoya 2012).

Springs closest to mesa-top villages are associated with a perched aquifer discharging along canyon margins at debris flows in contact with Paliza Canyon Andesites. An aquitard of mudstones at the top of the Permian Abo and Yeso Formation inhibits the downward percolation of meteoric water passing through overlying volcanic rocks along the mesa-tops, as well as water contributed from shallow alluvial aquifers on the upper portions of these mesas (Figure 5.4). A series of springs have consistent, perennial discharge along the margins of San Diego canyon, and to the west along the southern margins of Holiday, Stable, and School House Mesas (Figure 5.3). Springs in San Diego Canyon (Church, Sino, Agua Durme, Alamo) have high, persistent discharges and are used for municipal water by the Village of Jemez Springs. Radiogenic dating 
of tritium $\left({ }^{3} \mathrm{H} /{ }^{3} \mathrm{He}\right)$, which compares background levels of the radioactive isotope of hydrogen, (half-life of 12.32 years) to elevated local levels due to releases by LANL and atomic detonations, is used to date the age of water in geohydrological systems. Tritium dating of water from Sino Springs estimates the meteoric water from this spring to be 50-75 years old (Vuataz and Goff 1986: 1850). Half-century scale groundwater residence times of these springs, and their continued use even under increasing demands as municipal water sources, suggests that perched regional aquifer in the Jemez would not be sensitive to significantly reduced discharges during dry periods on human timescales, and they are located near Ancestral Jemez archaeological sites.

There are a few contexts across the Southern Jemez where small springs are mapped along the mesa-tops in low order drainages. The discharge from these springs contributes to the base flow of both perennial and intermittent drainages. Cebollita Springs, located in Cebollita Canyon between Holliday and Stable mesas, emanates in the canyon bottom from an alluvial aquifer. Wet meadows are present in the area of the spring today, but landscape modifications for ranching, such as pumping water to fill stock tanks, have likely lowered the water table. None of these mapped springs, of which there are only a few, are particularly close to villages (Cebollita Springs is $4 \mathrm{~km}$ from Tovakwa), and they likely would only provide seasonal water and be sensitive to droughts. The possibility of there being now-dry springs and seeps discharging from perched aquifers is suggested by artificial tanks and wells found in some drainages today. Forest Service maps of water resources identify artificial tanks and wells used primarily as water sources for cattle along Canon de Canada, Virgin Canyon, and Paliza Canyon. Future investigations of these artificial features and the hydrological contexts may identify the possibility of contexts for surface discharge in the past. 
Even more ephemeral sources are small natural basins in bedrock on mesa-tops (tinajas) or in step-pools in drainages along mesa-edges that trap surface water. No large tinajas were observed in the Jemez. However, a series of step-pools formed on slick-rock in Virgin Canyon near the Ancestral Pueblo village of Kwastiyukwa were observed filled with water during site visits in 2015. I documented the locations and storage volumes of some of these pools, and although small they could provide usable quantities of water shortly after rainfall events. I observed similar slick rock contexts at the base of mesas below the Ancestral Pueblo village of Wabakwa, however the extent of slick rock exposures in drainages was more limited, and no standing water was observed in the field.

Despite so many water sources, not all are potable. The geothermal springs emanating along the bottom of the San Diego Canyon are often too hot and too high in dissolved mineral concentrations for human consumption. Meteoric and endogenic waters mix deep within Pennsylvanian and Permian sedimentary rocks, and then discharge along the Jemez Fault Zone from Permian units (Tafoya 2012). The Soda Dam is formed by cold water springs charged in calcium carbonate, while springs within the village of Jemez Springs are geothermal. These springs may not have served as potable water sources, but descendant communities regard them as sacred and they likely held cultural significance to their ancestors as well (Tafoya 2012).

Natural surface water has been identified in six contexts of the Pajarito Plateau (Figure 5.6): 1) springs in the Sierras de los Valles (SdV); 2) fault controlled springs and seeps discharging in canyon bottoms of the westernmost portions of the Pajarito Plateau (W-Paj); 3) isolated seeps and springs emanating from shallow alluvial and perched aquifers; 4) springs from White Rock Canyon (WRC) at the confluence of multiple drainages with the Rio Grande; 5) intermittent flow 
in canyon bottom streams; and 6) perennial flow in the Rio Grande and Frijoles Canyon

(Broxton and Vaniman 2005; Dale 1996; Longmore et al. 2007; Purtymun 1995).

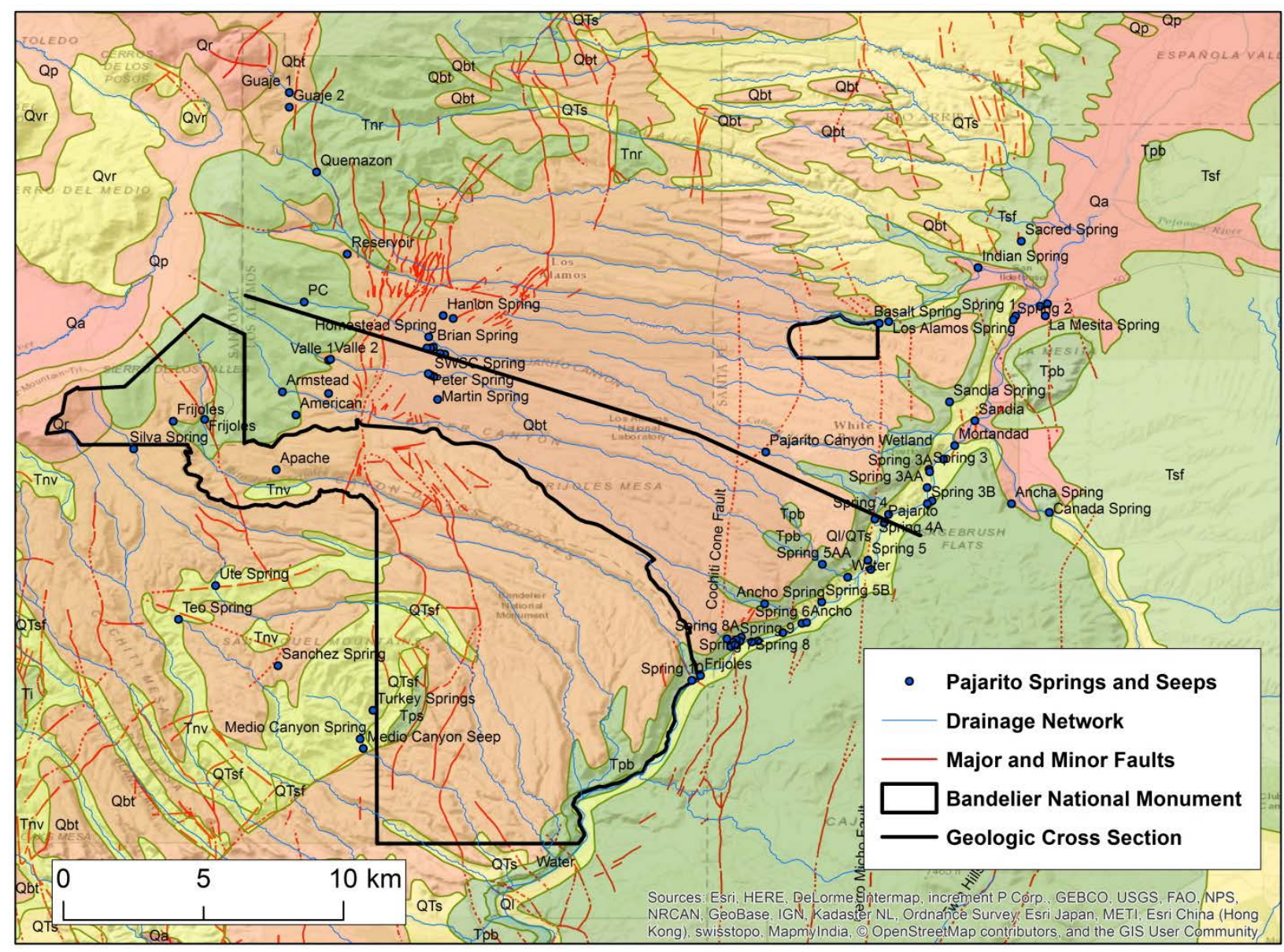

Figure 5.5. Surface geology and hydrology of the Pajarito Plateau (based on Smith et al. 1970; Green and Jones 1997).

Multiple perennial springs discharge along the flanks of the Sierras de los Valles (SdV), well to the west $(>12 \mathrm{~km})$ of the large Ancestral Pueblo settlements of the Pajarito Plateau. These springs, found at elevations 8000-8660 ft, discharge groundwater from alluvial deposits at contacts with the Tschicoma Formation volcanic rocks, at the head of many of the drainages of the Pajarito (Figure 5.5). Purtymun (1995: Table XXII-A) identifies 13 springs along the flanks 


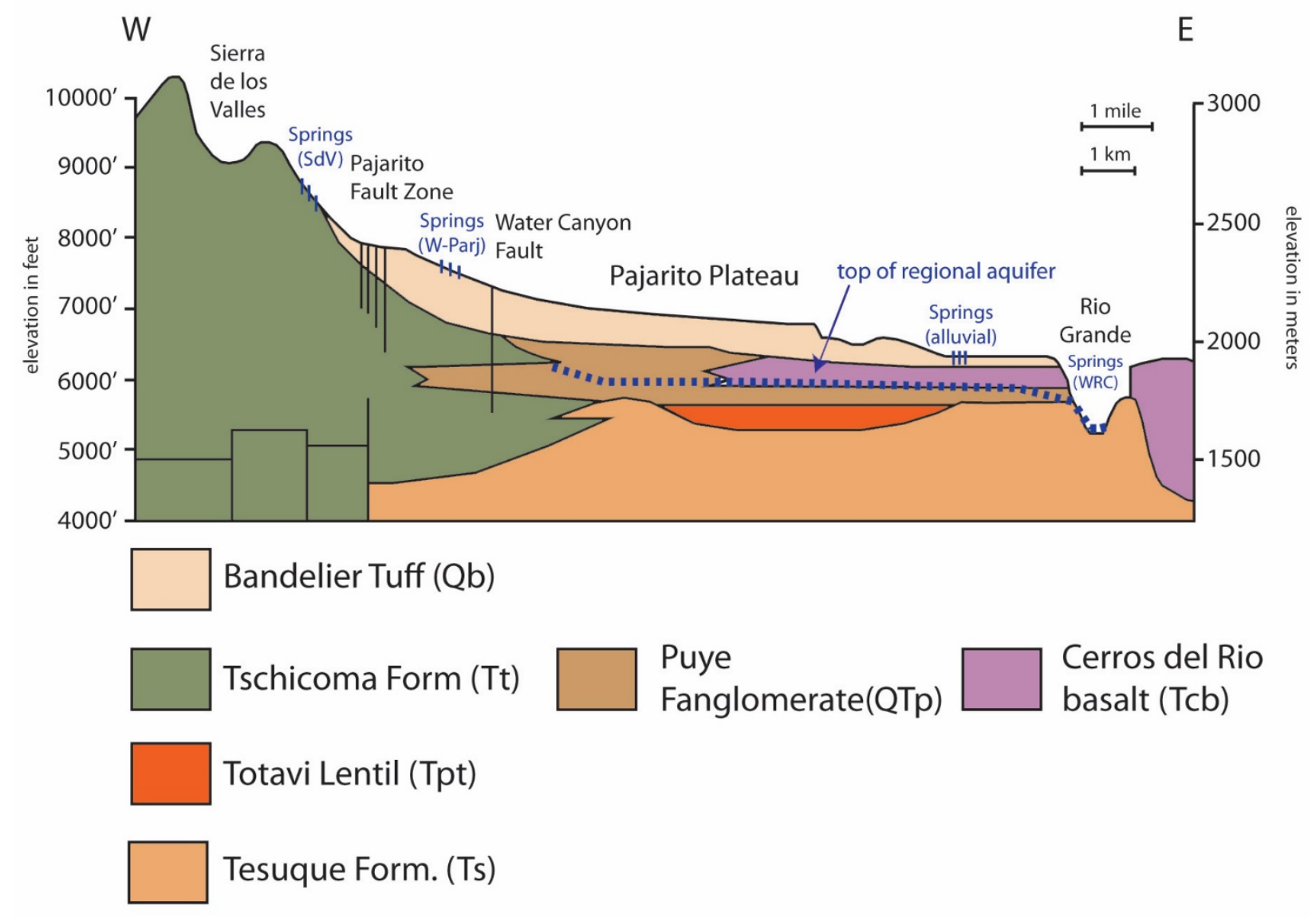

Figure 5.6. Hydrogeological cross section of the Pajarito Plateau (based on Purtymun 1995; Broxton and Vaniman 2005).

of the SdV, with discharge rates estimated from less than 1 up to 150 gallons per minute. Tritium and ${ }^{14} \mathrm{C}$ dating of spring water discharging from seven springs, found the water to be modern and therefore largely derived from recent precipitation upslope in the SdV (Longmore et al. 2007). However, discharge rates are steady with very little precipitation-induced variability (Longmore et al. 2007). These springs were not likely water sources for large Ancestral Pueblo villages because they are more than $10 \mathrm{~km}$ distant and they typically only support flow in drainages $1-2$ km from each spring. 
Unique, isolated geohydrological settings across the highly permeable tuff landscapes of the Pajarito Plateau produce springs that contribute to channel flows along portions of drainages. Save for the Frijoles Creek and the Rio Grande, all of the drainages have only intermittent flows, except for periods of high surface water runoff during spring snow-melt and monsoonal rain events. Besides the springs of the Sierras de los Valles, which support surface flows of the uppermost reaches of the drainages, additional small springs were recently identified along the western edge of the Pajarito Plateau (Dale and Yanicak 1996). These springs are in canyon bottoms along fractures in Bandelier tuff running parallel to the Pajarito fault zone near Los Alamos, at elevations between 7408-7480 ft. (Figures 5.5, 5.6). They are classified as "perched intermediate springs” by Longmore et al. (2007), and stream flow observations immediately downstream of these springs range from 3.49 to 22.67 gallons per minute (Dale and Yanicak 1996: Figure 3.17). ${ }^{3} \mathrm{H} /{ }^{3} \mathrm{He}$ and $14 \mathrm{C}$ dating of some of these springs by Longmore et al. (2007) indicates water sources are primarily modern meteoric water. The sensitivity of these springs to precipitation is supported by field observations, as they typically dry up in the summer (Dale and Yanicak 1996). Like the springs of the Cerro de los Valles, these contexts on the western edge of the Pajarito Plateau are far removed from the Ancestral Pueblo village areas and, due to their distance, it is unlikely that these springs were sources of domestic water for villagers.

Water comes to the surface closer to the villages on the Pajarito from perched aquifers, albeit sometimes only seasonally. As surface water moves downstream in canyon bottoms it infiltrates into the thick, permeable alluvial sediments in channel bottoms. A network of monitoring wells bored into canyon bottom alluvial deposits at Los Alamos National Labs found that water is tens of feet deep, although water table levels fluctuate seasonally in response to precipitation (Purtymun 1995:26-27). Water from these alluvial aquifers then infiltrates deeper into the 
regional aquifer. In cases where alluvial units are thin in deeply incised canyons and are underlain by a shallow impermeable geological unit, forming an aquitard, groundwater may reemerge to the surface as springs, seeps, and renewed streamflow. In the lower Los Alamos Canyon, less than $2 \mathrm{~km}$ from the site of Tsankawi, a series of springs emerge in the canyon bottom from a perched aquifer (Figure 5.5). Just downstream of the confluence of Los Alamos and Pueblo Canyons are two springs, Basalt and Los Alamos Springs, from an alluvial aquifer at the contact with underlying impermeable basalts of the Cerros del Rio Formation exposed in the deeply incised canyon bottom (Purtymun 1995: Figure I-AC). Flows in the otherwise dry Alamo Canyon rise to 10-30 gallons per minute; although discharges from these springs are only estimated at 0.8-6.6 gallons per minute (see Appendix A). Basalt and Los Alamos Springs may have been reliable sources for Ancestral Pueblo villagers at nearby Tsankawi, but likely only during times when the upper reaches of Los Alamos canyon alluvial aquifer were being recharged. Tritium dating of water generated wide age-ranges ( $>10,000$ to $<100$ yrs.), with evidence for historical contamination from Los Alamos National Labs. This suggesting relatively short (decadal) transit times from precipitation to spring discharge (Blake et al. 1995).

Small springs and seeps may also discharge directly from alluvial aquifers where local groundwater accumulates in older alluvial units. Alluvial wetlands, identified as the Pajarito Wetlands (locality TA-8), are recorded by LANL wetland biologists in Pajarito Canyon near the Ancestral Pueblo village of Tsirege (Nelson et al. 1997; Henne 2008), and in early site reports (Bandelier 1892: 79; Hewitt 1938: 40). Groundwater accumulating in Quaternary alluvial units on the margin of the canyon, in association with contribution of through-flow of the Bandelier tuff directed by the Cochiti Cone fault into the drainage, may be leading to the discharge of small seeps from perched alluvial groundwater along this segment of Pajarito Canyon, near Tsirege 
(Figure 5.5). ${ }^{3} \mathrm{H} /{ }^{3} \mathrm{He}$ and ${ }^{14} \mathrm{C}$ dating of groundwater from alluvial aquifers in other contexts at LANL found alluvial springs waters with mixed modern and submodern ages, which suggests that alluvial groundwater discharge, as well as the highly fluctuating alluvial water table levels (Longmore et al. 2007), are highly sensitive to inter- and intra-annual variability in precipitation.

Along southern portions of the Pajarito Plateau springs emanate from unique geological contexts along the flanks of the San Miguel Mountains. Capulin Canyon sustains surface flow from its spring-fed upper reaches to its middle reach near the site of Yapashi (Purtymun 1980). There, the deeply incised canyon exposes the Tesuque Formation, which is an aquifer further to the east along the Pajarito Plateau and overlying bedded volcanic, sedimentary, and debris flow deposits. There are also springs and seeps relatively close to the site of San Miguel. Turkey Spring discharges from volcanic deposits overlaying Tesuque formation deposits at the head of a drainage that contributes to flow in Capulin Canyon. This spring discharges 22 gallons per minute (Purtymun 1980). Springs and seeps are observed in Medio Canyon as well. Here, late Miocene basalt flows and cinders are exposed in Tesuque deposits at the base of the canyon, and I observed small seeps during visits to the site of San Miguel both before (June 2014) and after (August 2015) the monsoons. Both are potentially permanent water sources, although the very low discharge from the seep in Medio Canyon suggests that this spring may be susceptible to drought.

The only perennial stream on the Pajarito Plateau is the Rito de los Frijoles (or Frijoles Creek), in Frijoles Canyon. Otherwise, all other streams sustain only intermittent flows. Frijoles Canyon is home to Tyouyni, one of the longest-lived Ancestral Pueblo settlements, and some of the highest overall densities of Ancestral Pueblo archaeological sites on the Pajarito Plateau. Flow is sustained due to multiple springs in its headwaters and shallow base-flow in underlying 
alluvial aquifer (Purtymun 1980). That being said, there have been instances when even the Frijoles Creek goes dry. Allen summarized unpublished records of stream flow and identified periods of the Frijoles drying up in the summers of 1910, 1934, 1938, 1939, 1946, and 1951 (Allen 2004:25). Similarly, during July 2016 the creek was reported to have gone dry for 12 days, which is attributed to a delay in the start of the summer monsoons (Craig Allen, 2016, personal communication). Otherwise, there are forty-seven streams that only sustain intermittent flows. Snowmelt runoff and the occasional high magnitude monsoon event contribute runoff in these drainages (Allen 2004). Most of the drainages only sustain flows in their upper reaches from springs and greater runoff due to higher precipitation at higher elevations. For the majority of the year, runoff infiltrates into the alluvial aquifers in canyon bottoms.

The final manifestations of surface water are the perennial base flow of the Rio Grande, and springs discharging from the regional aquifer at the base of White Rock Canyon along the Rio Grande. These sources are on the eastern extreme of the Pajarito Plateau. The top of the regional aquifer is in the Puye formation, which is a fanglomerate deposit of interbedded volcanic and sedimentary rocks. The top of the aquifer ranges from 6400-5600 ft., although down-well measurements show it does fluctuate (up to $345 \mathrm{ft}$. annually) within the Puye Formation. However, these fluctuations are still below ground surface, and limit the surface discharges to White Rock Canyon. Over thirty springs have been recorded in White Rock Canyon, including some from higher perched aquifers at the canyon mouth (Blake et al. 1995; Purtymun 1995). These springs are not present at the mouths of every canyon, but are present only in canyons from Frijoles Canyon northward. They provide reliable and consistent discharges of potable water, at distances 3-5 km from the nearest Ancestral Pueblo villages. 


\subsection{The Influence of Late Holocene Landform Evolution on Hydrological Conditions}

In the prior section I characterized the current state of the hydrological system in the Jemez Mountains. But do these observations hold true through the Late Holocene? Were there differences in the past bio-physical settings that rendered the hydrological system more or less susceptible to droughts in the past? Discharges from alluvial aquifers, and therefore base-levels of stream flows, are particularly sensitive to climate variability, therefore changes in alluvial regimes within the time-scale of this study may influence the paleohydrological model. In this section, I consider the evidence for Late Holocene landform evolution and its potential influence on the hydrological system of the Jemez Mountains.

Two factors related to climate variation can have significant impacts on components of hydrological systems associated with alluvial and other perched aquifers: vegetation changes and alluvial geomorphology (Newman et al. 2006). Vegetation can intercept rainwater and absorb it through soil moisture, thereby reducing surface runoff (Marston 2010). Vegetation changes, whether by anthropogenic impacts due to forest clearance or farming, overgrazing by Historic period sheepherders and farmers, modern land management regimes, or climate induced ecological changes all may have had their impacts to hydrological systems (Stevens and Meretsky 2008). Climate changes can cause significant impacts to water availability from streams if alluvial aquifers are shallow and sensitive to precipitation variation (Larkin and Sharp 1992; Pigati et al. 2014). Lowering water tables can desiccate alluvial floodplains, making them vulnerable to channel downcutting during high magnitude flooding events. Channel downcutting then serves as a positive feedback for the overall lowering of aquifer base level. These changes can be investigated through direct testing of preserved alluvial sequences or spring deposits. 
A growing body of literature from these two study areas suggests that vegetation changed in the Jemez Mountains through the Late Holocene. While the best published records of past vegetation encompassing the entirety of the time period of this study are from bogs and wetlands reflecting high elevation mixed-conifer forests in the Jemez Mountains (e.g., Anderson et al. 2008), Allen (2004) synthesized the existing paleo-vegetation records across the Pajarito Plateau and identified more open vegetation through the Late Holocene, and in particular the increase in juniper and pine associated with forest recruitment in the last two hundred years. Developing paleoecological records from the Jemez Plateau preserved in sediments from alluvial sequences and confined basins (Christopher Roos unpublished), tree-ring records (Farella 2015; Liebmann et al. 2016; Swetnam et al. 2016), and reservoir sediments (Aiuvalasit and Kiahtipes 2017) suggest less dense forest conditions across the Jemez Plateau during the Late Holocene, with forest recruitment associated with depopulation beginning in the 1630s (Liebmann et al. 2016). Vegetation changes like these influence hydrological systems (Rodriguez-Iturbe 2000). More open, undisturbed, vegetation regimes may facilitate the recharge of shallow hydrological systems, by increasing soil moisture through slow absorption rather than rapid runoff as overland flow across unvegetated surfaces.

The published alluvial records from the Jemez Mountains suggest asynchronous fluvial responses across the region, which do not conform to widely applied models of alluvial responses to climatic drivers developed for the Colorado Plateau (e.g., Dean et al. 1985; Hall 1977; Karlstrom 1988). Instead, dated alluvial chronologies along the eastern Pajarito Plateau appear to show heterogeneity in fluvial responses, potentially reflective of differences in lithology, gradients, and vegetation changes within each respective catchment (Nick Kessler, 2017, personal communication). Hall and Periman (2007) conducted a detailed 
geoarchaeological study of an alluvial terrace sequence near the mouth of the Rio del Oso. The catchment area of this stream captures northeastern segments of the Valles Caldera and drains into the Rio Chama. The Rio del Oso experienced cycles of channel incision and aggradation through the late Holocene, with a significant, final incision around AD 1400 (Hall and Periman 2007). In studies of the Central Pajarito Plateau, as well as in canyon bottoms of the Frijoles (Reneau 2000), Rendija, and Sandia Canyons (Reneau and McDonald 1996), geomorphologists have identified highly variable records, with overall net aggradation in drainage sections through the Late Holocene. Yet, there was asynchronous channel incision, which was discontinuous across different reaches within drainage systems and reflective of basin-specific processes and structural controls (Nick Kessler, 2017, personal communication). Modern observations of fluvial responses to large fires in watersheds have identified the potential for rapid channel incision, particularly if intense summer precipitation after fires erodes cobble-boulder armors along channel beds to expose finer alluvial materials below, which can then erode rapidly (Reneau 2000). Future studies on the Pajarito will have to consider whether or not vegetation changes, and potentially fire, drove channel incision.

Periods of alluvial incision appear to correlate to Drakos and Reneau's observations (2007, 2013) of Late Holocene eolian events across the mesa-tops of the Central Pajarito Plateau. Direct geoarchaeological observations and radiocarbon dating show eolian sediments unconformably mantling older Holocene soils occurred during the Late Coalition through Early Classic Period occupations (AD 1270-1410). A second period of eolian sedimentation at the end of the Classic Period indicates additional and potentially more widespread deposition. They infer that the sediments were likely sourced from nearby desiccated floodplains and fans at the mouths of 
canyons, a process which is still observed today (Drakos and Reneau 2007:128). These findings suggest a major reorganization of fluvial regimes beginning in the late 1200s.

Yet we don't see this at all on the Jemez Plateau. The unpublished results of the Jemez FHiRE project, as well as alluvial fire histories in higher elevations (Fitch and Meyer 2015) report neither significant channel incision in the major drainages nor widespread eolian deposition during periods of Ancestral Pueblo occupation. More fieldwork and syntheses will need to be undertaken to understand the mode and tempo of fluvial responses during occupation sequences across the both regions.

If widespread channel incisions led to the lowering of stream base levels and water tables of alluvial aquifers of the Pajarito Plateau, then surface water availability could have been reduced. This could have influenced spring and seep discharges from alluvial aquifers and streams which had formerly been perennial. Major droughts, such as the 1240-1270 drought, which correlates with the beginning of eolian sedimentation, or those in the $15^{\text {th }}$ century, may have led to state changes in the alluvial systems of the Pajarito Plateau, with shifts to intermittent flows during the Classic Period. This has implications for the paleohydrological model presented later in this chapter, and in least cost analyses presented in Chapter 8.

\subsection{Modern Climate and Stream Flow Analogs}

The final attribute of the environmental record necessary for paleohydrological modeling, as well as modeling of water storage in reservoirs (see Chapters 6 and 7) is to characterize the impacts of annual climate variation on spatio-temporal patterns of precipitation and hydrology. 
Modern instrumental records of precipitation and stream flows in the Jemez Mountains provide perspectives on how wet, normal, and dry precipitation patterns affect the hydrological cycle.

\section{Inter-regional comparisons of precipitation records}

Because the Touchan et al. (2011) record does not distinguish sub-annual ring growth (i.e., early- and late-wood) or rainfall intensity, there are limits to understanding how annual climate variability impacts the hydrological system at intra-annual scales. The record only reconstructs precipitation for the October to June growing season, rather than the entire water year. This omits the monsoon season precipitation between July and September. The precipitation reconstruction also does not allow intra-regional comparisons across the Jemez Mountains. Identifying whether or not there is a precipitation gradient between the study areas is important, because such a gradient can impact hydrological systems. Finally, the paleoprecipitation record masks whether or not the intensity of individual rainfall differs between wet years and dry years. Precipitation intensity is important because it factors into thresholds for surface runoff, which is critical for stream flows, recharging alluvial aquifers, and filling the basins of Ancestral Pueblo reservoirs features with water. As such, a review and analysis of the modern precipitation record helps to characterize the attributes of the spatial variability in precipitation, patterns in rainfall seasonality and intensity during annual wet, dry, and normal conditions.

Elevational gradients, topography, and weather patterns drive spatio-temporal variability of precipitation in the Jemez Mountains. Mean annual precipitation ranges from $25 \mathrm{~cm}$ at the lowest elevations along the canyon bottoms, up to $90 \mathrm{~cm}$ at highest elevations along the rim of the Valles Caldera (PRISM Climate Group 2016) (Figure 5.7). Bowen $(1990,1996)$ synthesizes 
climatological data for LANL, and his study serves as the primary source for regional climate and meteorological information, along with precipitation records from local weather stations and stream flow records from stream gauges. Bowen's (1996) analysis of the network of public and private weather stations across the Pajarito Plateau shows that rainfall totals for both monsoon and non-monsoon precipitation increase with elevation, with the precipitation gradient more pronounced for winter rainfall than for monsoonal rain. He attributes the enhanced high elevation precipitation during winter to seasonally focused upslope winds.

A comparison of annual precipitation values between weather stations at Jemez Springs and Bandelier demonstrates that on average the Southern Jemez Plateau receives more precipitation than the Southern Pajarito Plateau. Using the total record of annual water year precipitation (October to September) of each of these stations, which are at roughly similar elevations, and situated in the heart of Ancestral Pueblo occupation areas, there is a $7.37 \mathrm{~cm}$ difference in precipitation (Table 5.1). Yet, this difference is affected by different lengths of the precipitation records. When the 36 years with records shared in common are compared, the difference in mean annual precipitation is only $2.6 \mathrm{~cm}$, with Jemez Springs still receiving more rainfall (Bandelier at $39 \mathrm{~cm}$ vs. $41.6 \mathrm{~cm}$ at Jemez Springs). More rainfall at Jemez Springs holds up even though it has more years of precipitation with negative z-scores than Bandelier (16 vs. 18). The Bandelier record has greater variability, reflected in a higher standard deviation than Jemez Springs (9.8 vs. 10.5). For 25 of the 36 years, the $z$-scores of each region share either the same positive or negative trend, suggesting regional synchrony in annual precipitation, but lower overall precipitation on the Pajarito Plateau (Figure 5.8). 


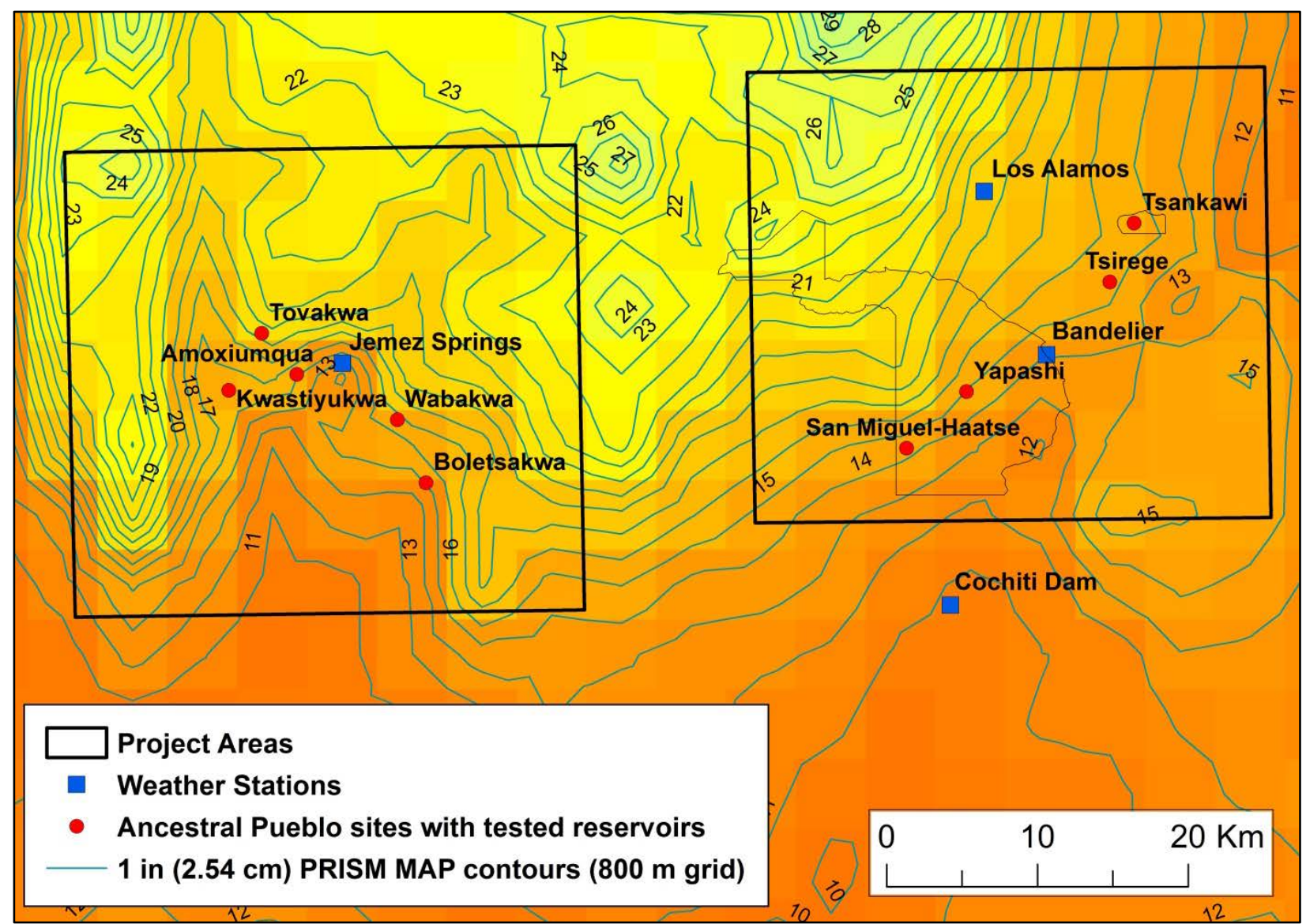

Figure 5.7. Mean annual precipitation map (PRISM Climate Group 2017) of the Southern Jemez Mountains (in inches).

Table 5.1. Summary precipitation data from weather stations in the Jemez Mountains.

\begin{tabular}{|l|l|l|l|l|l|}
\hline $\begin{array}{l}\text { Weather } \\
\text { Station }\end{array}$ & $\begin{array}{l}\text { Elevation } \\
(\mathbf{m})\end{array}$ & Years & $\begin{array}{l}\text { Mean Annual } \\
\text { (water year) } \\
\text { Precipitation } \\
\text { (cm) }\end{array}$ & $\begin{array}{l}\text { Oct-June } \\
\text { (cm) }\end{array}$ & $\begin{array}{l}\text { July-Sept } \\
\text { (cm) }\end{array}$ \\
\hline Jemez Springs & 1908 & $1934-2010$ & 43.01 & 24.03 & 18.98 \\
\hline Bandelier & 1848 & $1932-1975$ & 38.64 & 21.50 & 17.14 \\
\hline Los Alamos & 2233 & $1934-2014$ & 46.31 & 24.36 & 21.95 \\
\hline
\end{tabular}




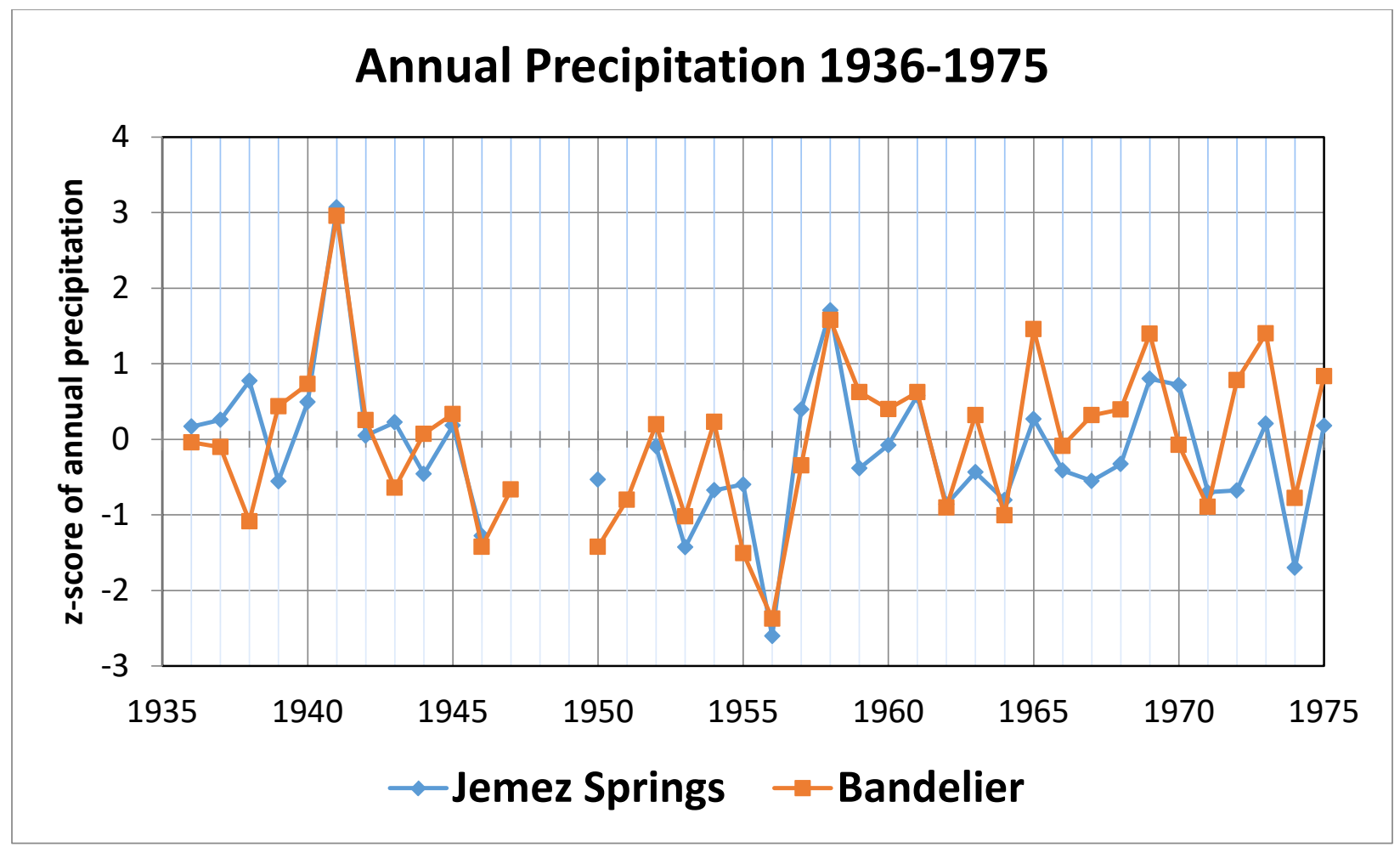

Figure 5.8. A comparison of standardized z-scores of annual precipitation between the Jemez Springs and Bandelier weather stations, 1936-1975.

Bowen $(1990,1996)$ interprets this difference to be largely a function of a rain shadow formed by the Sierra de los Valles along the eastern rim of the Valles Caldera. The biggest driver of year-to-year variability in precipitation in the Jemez Mountains is the El Niño-Southern Oscillation (ENSO) (Bowen 1990) because it influences the frequency of winter and spring storms carrying Pacific moisture tracking longitudinally across the region. Because of the rain shadow effect, more of this Pacific moisture falls as rain on the Jemez Plateau than the Pajarito Plateau. Orographic conditions are less of a factor in intra-regional variability in monsoonal precipitation because summer monsoons derive from southerly flows of tropical moisture. Bowen found that monsoon rainfall is more reliable than precipitation in other seasons, with a lower coefficient of variation in summer months (Bowen 1996:34-35). On average the three 
weather stations receive roughly $45 \%$ of their total annual precipitation during the three-month monsoon period between July and September. Fortunately, tree-ring records register the biggest drivers of inter-annual precipitation variability resulting from ENSO affects through the winter and spring. Unfortunately, they do not capture monsoonal precipitation from July to September. Therefore, modern records are necessary to characterize the nature of monsoonal precipitation between annual records of dry, wet, and normal years.

Modern records indicate precipitation intensity in normal, dry, and wet years in the Jemez, but their application to past times warrants some caution. Differences in patterns of seasonal rainfall intensity between wet, dry, and normal years are potentially the driver for climate-based impacts to both the hydrological system, as well as functional efficacy of prehistoric reservoir features. However, in contexts of the Southwest where long early-/latewood tree-ring constructions have been conducted, researchers have identified variable combinations of wet and dry seasons through prehistory (e.g., Coats et al. 2015; Stahle et al. 2009). These studies corroborate aspects of Dean’s (1996) seminal study on Late Holocene regional shifts in seasonal precipitation patterns across the Southwest, which occurred within the time-span of my research project. Therefore, modern records can suggest general aspects of precipitation regimes, but cannot be used as a proxy for prehistoric conditions.

Daily historical precipitation measurements are made publically available by the NOAA National Centers for Environmental Information. I downloaded long-term daily records for weather stations at Bandelier and Jemez Springs from the NOAA website and then I compiled annual water-year (Oct-Sept) precipitation totals for the entire spans of these weather stations. Annual precipitation totals for the years these stations have in common (1932-1975) were sorted from lowest to highest, and binned into the lowest 30\% (driest years), middle 40\% (normal 
years), and highest 30\% (wettest years). Water years were broken into the growing season (October to June) and the monsoon season (July to September), and total days of precipitation and amounts, as well as total days with precipitation equal or greater than $7.6 \mathrm{~mm}$ and $25.4 \mathrm{~mm}$ were recorded. These precipitation amounts are significant because based on average soil infiltration rates in the Jemez Mountains, a precipitation event greater than $7.6 \mathrm{~mm}$ is necessary to generate surface runoff (based on NRCS 1982, and Bonnin et al. 2006). Precipitation equal or greater than $25.4 \mathrm{~mm}$ (equivalent to $1 \mathrm{inch}$ ) is roughly equivalent to the maximum annual precipitation event.

Some subtle differences in precipitation patterns between the Jemez and Pajarito Plateaus can be identified by looking closely at trends in annual precipitation. First, it confirms Bowen's (1990) observations on the Pajarito Plateau that October to June precipitation drive annual variability. Dry years see reduced precipitation during both seasons in the instrumental record as well (Table 5.2). Yet, the impact of dry years is different between regions. The mean total annual water year precipitation in dry years is $21 \%$ lower than the mean for the Jemez weather station, but it is $45 \%$ lower for the Bandelier station. Mean annual precipitation of dry years is below the $30 \mathrm{~cm}$ precipitation threshold necessary for dryland maize agriculture at the Bandelier station $(<25.5 \mathrm{~cm})$, while the Jemez total remains above the threshold at $32 \mathrm{~cm}$. This significant decrease in mean water year precipitation from normal years in the instrumental records suggests that hydrological and potentially agricultural systems of the Pajarito would be more vulnerable to dry periods than those of the Jemez. In comparison to dry years, wet years only saw minimal differences in means, with a $25 \%$ increase in annual water year precipitation for the Jemez station, and $18 \%$ for the Bandelier station. 
Table 5.2. A comparison of mean intra-annual precipitation between the Jemez Springs and Bandelier weather stations.

\begin{tabular}{|l|l|l|l|l|l|}
\hline Year Type (\# yrs.) & $\begin{array}{l}\text { Mean Annual } \\
\text { (Oct-Sept.) } \\
\text { Precip. (mm) }\end{array}$ & $\begin{array}{l}\text { Oct-June } \\
\text { Mean } \\
\text { Precip. } \\
\text { (mm) }\end{array}$ & $\begin{array}{l}\text { Percentage } \\
\text { of days } \\
\text { with } \\
\text { precip. }\end{array}$ & $\begin{array}{l}\text { July-Sept } \\
\text { Mean } \\
\text { Precip. } \\
\text { (mm) }\end{array}$ & $\begin{array}{l}\text { Percentage } \\
\text { of days } \\
\text { with } \\
\text { precip. }\end{array}$ \\
\hline $\begin{array}{l}\text { Normal-Jemez Springs } \\
(13)\end{array}$ & 402.2 & 226 & $16 \%$ & 176.2 & $33 \%$ \\
\hline Normal-Bandelier (12) & 409.6 & 214.72 & $15 \%$ & 194.9 & $34 \%$ \\
\hline Dry-Jemez Springs (8) & 319.7 & 144.7 & $13 \%$ & 174.9 & $36 \%$ \\
\hline Dry-Bandelier (9) & 255.2 & 125.3 & $11 \%$ & 129.9 & $33 \%$ \\
\hline Wet-Jemez Springs (9) & 533.8 & 309.2 & $21 \%$ & 224.6 & $38 \%$ \\
\hline Wet-Bandelier (7) & 499.9 & 282.1 & $17 \%$ & 217.8 & $36 \%$ \\
\hline
\end{tabular}

The intensity of rainfall varies little between regions in the instrumental record, but it does vary relative to annual precipitation. Mean annual totals of days with rainfall amounts great enough to generate runoff (7.6 mm or greater) are responsive to the variability one would expect between wet, normal, and dry years. There is an increase in runoff during October to June of wet years, but little difference in the number of runoff-inducing rainfall events during monsoon season (Figure 5.8). Higher intensity rainfall ( $\geq 25.4 \mathrm{~mm}$ ) also varies between wet, normal, and dry years. The only appreciable difference in rainfall intensity between regions is that the Jemez Plateau sees less of a reduction in rainfall intensity between normal and dry years than the Pajarito does. For example, during droughts on the Pajarito Plateau the average number of higher intensity rainfall events ( $\geq 25.4 \mathrm{~mm}$ ) falls below one a year during droughts. Therefore, the intensity of rainfall and the potential for runoff correlates with annual precipitation totals. The relevance of these observations to the efficacy of water storage in reservoirs is discussed in Chapter 7. 
Table 5.3 Annual comparisons of rainfall intensities from historical weather station data.

\begin{tabular}{|l|l|l|l|l|}
\hline $\begin{array}{l}\text { Year Type } \\
\text { (\# yrs.) }\end{array}$ & $\begin{array}{l}\text { Mean (and } \\
\text { range) of } \\
\text { annual rainfall } \\
\text { events } \geq 7.6 \mathbf{~ m m}\end{array}$ & $\begin{array}{l}\text { Mean } \\
\text { Oct-June } \\
\text { rainfall events } \\
\geq 7.6 \mathbf{~ m m}\end{array}$ & $\begin{array}{l}\text { Mean July-Sept } \\
\text { rainfall events } \\
\geq 7.6 \mathbf{~ m m}\end{array}$ & $\begin{array}{l}\text { Mean (and range) } \\
\text { of annual rainfall } \\
\text { events } \geq 25.4 \text { mm }\end{array}$ \\
\hline $\begin{array}{l}\text { Normal-Jemez } \\
\text { Springs (13) }\end{array}$ & $16(12-23)$ & 9 & 7 & $2(0-4)$ \\
\hline $\begin{array}{l}\text { Normal- } \\
\text { Bandelier (12) }\end{array}$ & $18(15-21)$ & 9 & 9 & $1.64(0-4)$ \\
\hline $\begin{array}{l}\text { Dry-Jemez } \\
\text { Springs (8) }\end{array}$ & $13(5-16)$ & 5 & 8 & $1.13(0-3)$ \\
\hline $\begin{array}{l}\text { Dry-Bandelier } \\
(9)\end{array}$ & $11(5-13)$ & 5 & 5 & $0.67(0-2)$ \\
\hline $\begin{array}{l}\text { Wet-Jemez } \\
\text { Springs (9) }\end{array}$ & $22(17-32)$ & 12 & 9 & $2.57(0-5)$ \\
\hline $\begin{array}{l}\text { Wet-Bandelier } \\
(7)\end{array}$ & $21(17-23)$ & 12 & 9 & \\
\hline
\end{tabular}

Modern precipitation models (PRISM) provide a perspective on whether or not there might be regional differences in precipitation in the locations of Ancestral Pueblo villages (Figure 5.7). Most of the Ancestral Pueblo villages (7/9) with tested reservoirs fall within a relatively narrow - $4.6 \mathrm{~cm}$ (36.73-41.33 cm) - range of precipitation (Table 5.4). The outliers, Tovakwa (higher) and Boletsakwa (lower), are not in different contexts but have very different estimates of mean annual precipitation. Both are at the edges of the 800 m PRISM cells, therefore their estimates are more likely a function of an edge effect caused by the model rather than a significant difference in precipitation. The distances of these two sites from the edge of the cell, and the precipitation estimates of the closest cell, are included in Table 5.4. All of these sites, and nearby portions of surrounding mesa-tops, fall within the temperature and precipitation range of the “maize agricultural niche” modeled by Bocinsky and Kohler (2014) but, as I will discuss further, not all would be likely to fall within the niche during the driest of years. 
Table 5.4. Elevations and mean annual precipitation (based on PRISM data) of tested Ancestral Pueblo sites.

\begin{tabular}{|l|l|l|}
\hline Site & Elevation $(\mathrm{m})$ & $\begin{array}{l}\text { Mean Annual Precipitation } \\
\text { cm (in.) 1951-2006 }\end{array}$ \\
\hline Tovakwa & 2436 & $51.66(20.34)$ \\
\hline \multicolumn{1}{|c|}{ nearest grid $(<500 \mathrm{~m})$} & & $41.33(16.27)$ \\
\hline Amoxiumqua & 2377 & $41.33(16.27)$ \\
\hline Tsankawi & 2032 & $40.23(15.84)$ \\
\hline Kwastiyukwa & 2318 & $39.01(15.36)$ \\
\hline Yapashi & 1995 & $39.91(15.32)$ \\
\hline Tsirege & 2022 & $38.02(14.97)$ \\
\hline Wabakwa & 2342 & $38.02(14.97)$ \\
\hline San Miguel & 1946 & $36.73(14.46)$ \\
\hline Boletsakwa & 2208 & $30.76(12.11)$ \\
\hline \multicolumn{1}{|c|}{ nearest grid $(<200 \mathrm{~m})$} & & $38.02(14.97)$ \\
\hline
\end{tabular}

\section{Inter-regional comparisons of stream-flow records}

Construction of a paleohydrological model requires knowing the sensitivity of local stream flows to annual climatic variability, because as Purtymun (1995:26-27) identified, the recharge of alluvial aquifers and stream discharge are highly correlated with precipitation. If stream discharges do not replenish alluvial aquifers, the water table in alluvial settings will fall and available surface water will decline. Accordingly, I compiled annual stream discharge data from stream gauges on the Jemez River at Jemez Springs, and the Rito de los Frijoles (Frijoles Creek) in Bandelier National Monument (U.S. Geological Survey 2016). As with the precipitation records, I identified years with low, normal, and high discharges based on z-scores of the annual discharges, and that correspond to low, normal, and high water year precipitation values from the local weather stations. Unfortunately, because these records are shorter and not as continuous as weather station data, the years selected for each group are not all the same as the years in the prior precipitation analysis, and the regions do not share the same years of analysis. I should also note that these historical records are not likely to capture the full range of potential discharges, as 
evidenced by recent paleohydrological work in the Santa Fe River watershed that correlated modern stream discharges to tree-ring records (Margolis et al. 2011). This inhibits the interpretative potential of this analysis, but a few observations are possible.

Charts with average daily discharges plotted annually show discharges are greatest during spring runoff due to snowmelt, and that precipitation significantly influences discharge rates (Figures 5.9, 5.10). Monsoon periods have a relatively minor influence on mean discharge, save for extreme daily events seen in the Frijoles record, which are skewed by the combination of a short record, and two days in 2013 (July 27 and September 13) of record flooding associated following the Las Conchas fire (Figure 5.10). In both cases, annual variability in winter and spring precipitation has the greatest direct effect on the recharge of shallow perched and alluvial aquifers. Again, the Pajarito Plateau appears to be more sensitive to intra-annual variability because there is a greater difference in discharge between dry and normal years. And as mentioned earlier, the volumes of discharge of the Frijoles are far lower than those of the Jemez (Figure 5.9). Even in its driest years, the Jemez River has greater discharges than the Frijoles. That the one perennial stream on the Pajarito Plateau only discharges approximately 5-10 $\mathrm{ft}^{3} / \mathrm{sec}$ suggests that the other intermittent streams must support even lower seasonal flows, and if they were perennial in the past that they would not likely exceed these discharge rates. 


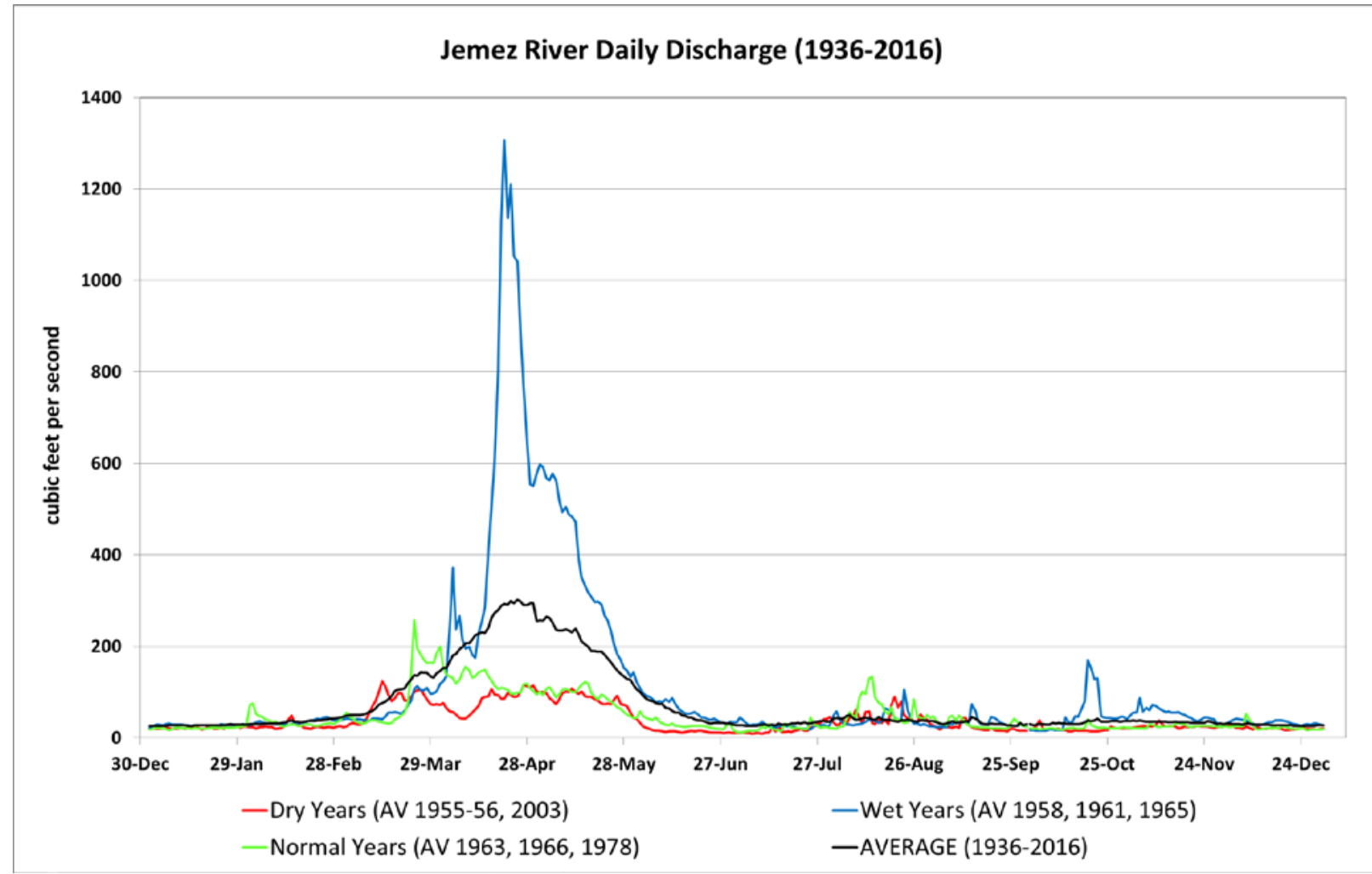

Figure 5.9. Jemez River discharge, 1936-2016 (U.S. Geological Survey 2016).

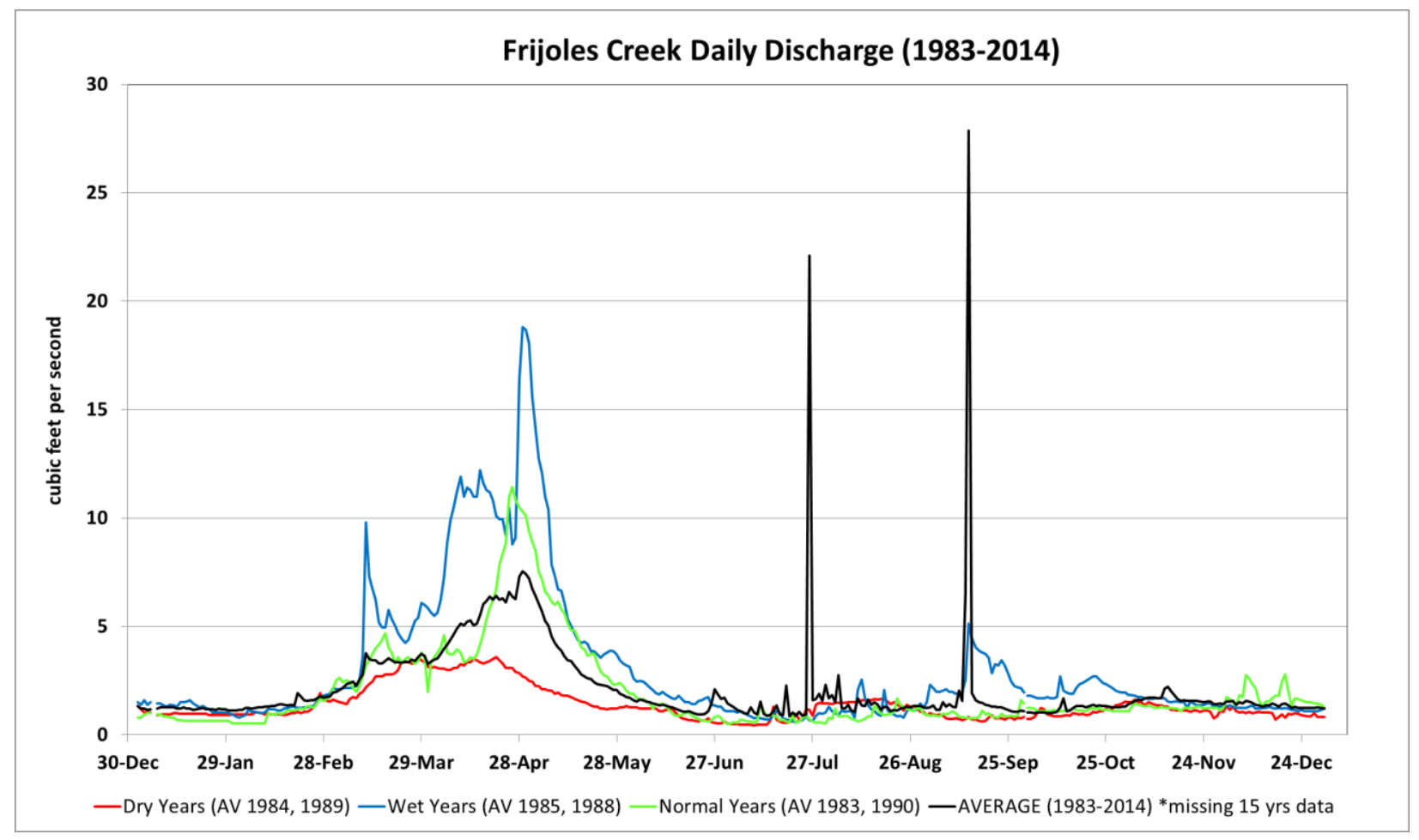

Figure 5.10. Frijoles Creek discharge, 1983-2014 (U.S. Geological Survey 2016). 


\subsection{Paleohydrological Models}

I generated qualitative paleohydrological models of water sensitivity to climate for the Jemez and Pajarito Plateaus by integrating the paleoprecipitation records from Chapter 3 with my interpretations of geohydrological and hydrological sensitivities to droughts developed in the preceding sections. Differences between regions are based primarily on the vulnerability of alluvial systems to climate variability. Because alluvial records of the Jemez Plateau indicate little change in alluvial regimes through the Late Holocene (Christopher Roos unpublished data), I simply project the structure of the current hydrological system through the entire study period. In this steady-state model, intermittent streams and springs fed by shallow, perched aquifers provide water only during wet and normal years, but are considered vulnerable to significantly reduced flows during the hydrological droughts identified in the paleoprecipitation record.

This pattern contrasts with the Pajarito Plateau, where geomorphic evidence indicates that channel incision and floodplain desiccation began possibly as early as the late 1200 s, and certainly in the 1400s. Hence, the current state of the hydrological system may not be analogous to prehistoric times. While the evidence is limited, it suggests that before the late 1200s the alluvial systems of the Pajarito may not have been as sensitive to droughts. It is possible that streams that are now intermittent and vulnerable to droughts were less vulnerable prior to the late 1200s. The drought occurring from 1240-1270 may have served as a catalyst for this state change in hydrological systems of the Pajarito Plateau. Therefore, for the paleohydrological model I project that dry periods before the late 1240-1270 drought would not make streams of the Pajarito vulnerable to reduced or no flow. These streams would certainly have experienced reduced flows at these times, but it is less likely that flows were reduced entirely during these earlier dry periods. For the paleohydrological model, this means that I do not model the 1131- 
1158 hydrological drought as a cultural drought. Future iterations of this model will benefit from sub-basin level modeling of stream and aquifer sensitivities to precipitation and alluvial conditions, which could be applied in a dynamic way to Late Holocene contexts, as well as direct testing of alluvial deposits to document drainage-by-drainage alluvial histories.

In Tables 5.5 and 5.6 I present my categorizations of the water types in both study areas. I classify water source into eight types. Categorizations of individual water sources are listed in Appendix A. I categorize the sensitivity of each to both inter- and intra-annual variability in precipitation, and place them into two groups. Group A water sources are not vulnerable to hydrological droughts (perennial sources), while Group B sources are vulnerable to reduced or no discharge during hydrological droughts (vulnerable sources). Mapped distributions of water sources are depicted in a series of figures (Figures 5.11-5.14). Figures 5.11 and 5.12 reflect the paleohydrological models for the Jemez Plateau. Figures 5.13 and 5.14 are the same distributions, but for the Pajarito Plateau. Comparing the spatial distribution of perennial and vulnerable water sources provides an opportunity to assess whether or not there are differences in the vulnerability of hydrological systems to droughts between these two regions.

Statistical analyses of resource density and distribution helps to characterize the sensitivity of natural water resources to droughts. Resource density was calculated by dividing the length of streams and the number of springs by the surface area of each project area (Table 5.7). Geomorphologists typically use this analysis within watersheds, but here I conduct these calculations for each project area. The density analysis shows that the Pajarito Plateau has more linear meters of streams and more springs than the Jemez Plateau, and overall more dense drainage network. Yet, there are critical differences between the regions when it comes to water availability. Seventy percent of the stream lengths of the Jemez Plateau are perennial, while only 
nine percent of the stream lengths of the Pajarito Plateau are perennial. A similar, but less

pronounced pattern is observed with springs. Ninety five percent of the Jemez Plateau springs are perennial, while fewer are perennial (78\%) on the Pajarito Plateau. Therefore, while the Pajarito Plateau may be better watered (i.e., have a higher density of water sources), the sources are far more vulnerable to droughts.

Table 5.5. Water types of the Jemez Plateau.

\begin{tabular}{|l|l|l|l|l|l|}
\hline Water Type & $\begin{array}{l}\text { Number } \\
\text { of } \\
\text { Water } \\
\text { Sources }\end{array}$ & $\begin{array}{l}\text { Sensitivity to } \\
\text { intra-annual } \\
\text { precipitation } \\
\text { variability }\end{array}$ & $\begin{array}{l}\text { Sensitivity to } \\
\text { inter-annual } \\
\text { precipitation } \\
\text { variability }\end{array}$ & $\begin{array}{l}\text { Water } \\
\text { Class }\end{array}$ & $\begin{array}{l}\text { Water } \\
\text { Group }\end{array}$ \\
\hline Stream (perennial) & 26 & Moderate & Low & 1 & A \\
\hline Stream (intermittent) & 17 & High & Moderate & 2 & B \\
\hline Spring (regional aquifer) & 12 & Low & Low & 3 & A \\
\hline Spring (perched regional aquifer) & 26 & Low & Low & 4 & A \\
\hline Spring (perched aquifer) & 0 & Moderate & High & 5 & B \\
\hline Spring (alluvial aquifer) & 3 & Moderate & High & 6 & B \\
\hline Artificial reservoir & 6 & High & High & 7 & B \\
\hline Surface water (tinajas) & 1 & High & High & 8 & B \\
\hline
\end{tabular}

Table 5.6. Water types of the Pajarito Plateau.

\begin{tabular}{|l|l|l|l|l|l|}
\hline Water Type & $\begin{array}{l}\text { Number } \\
\text { of } \\
\text { Water } \\
\text { Sources }\end{array}$ & $\begin{array}{l}\text { Sensitivity to } \\
\text { intra-annual } \\
\text { precipitation } \\
\text { variability }\end{array}$ & $\begin{array}{l}\text { Sensitivity to } \\
\text { inter-annual } \\
\text { precipitation } \\
\text { variability }\end{array}$ & $\begin{array}{l}\text { Water } \\
\text { Class }\end{array}$ & $\begin{array}{l}\text { Water } \\
\text { Group }\end{array}$ \\
\hline Stream (perennial) & 2 & Moderate & Low & 1 & A \\
\hline Stream (intermittent) & 47 & High & Moderate & 2 & B \\
\hline Spring (regional aquifer) & 42 & Low & Low & 3 & A \\
\hline Spring (perched regional aquifer) & 17 & Low & Low & 4 & A \\
\hline Spring (perched aquifer) & 5 & Moderate & High & 5 & B \\
\hline Spring (alluvial aquifer) & 12 & Moderate & High & 6 & B \\
\hline Artificial reservoir & 9 & High & High & 7 & B \\
\hline Surface water (other) & 0 & High & High & 8 & B \\
\hline
\end{tabular}




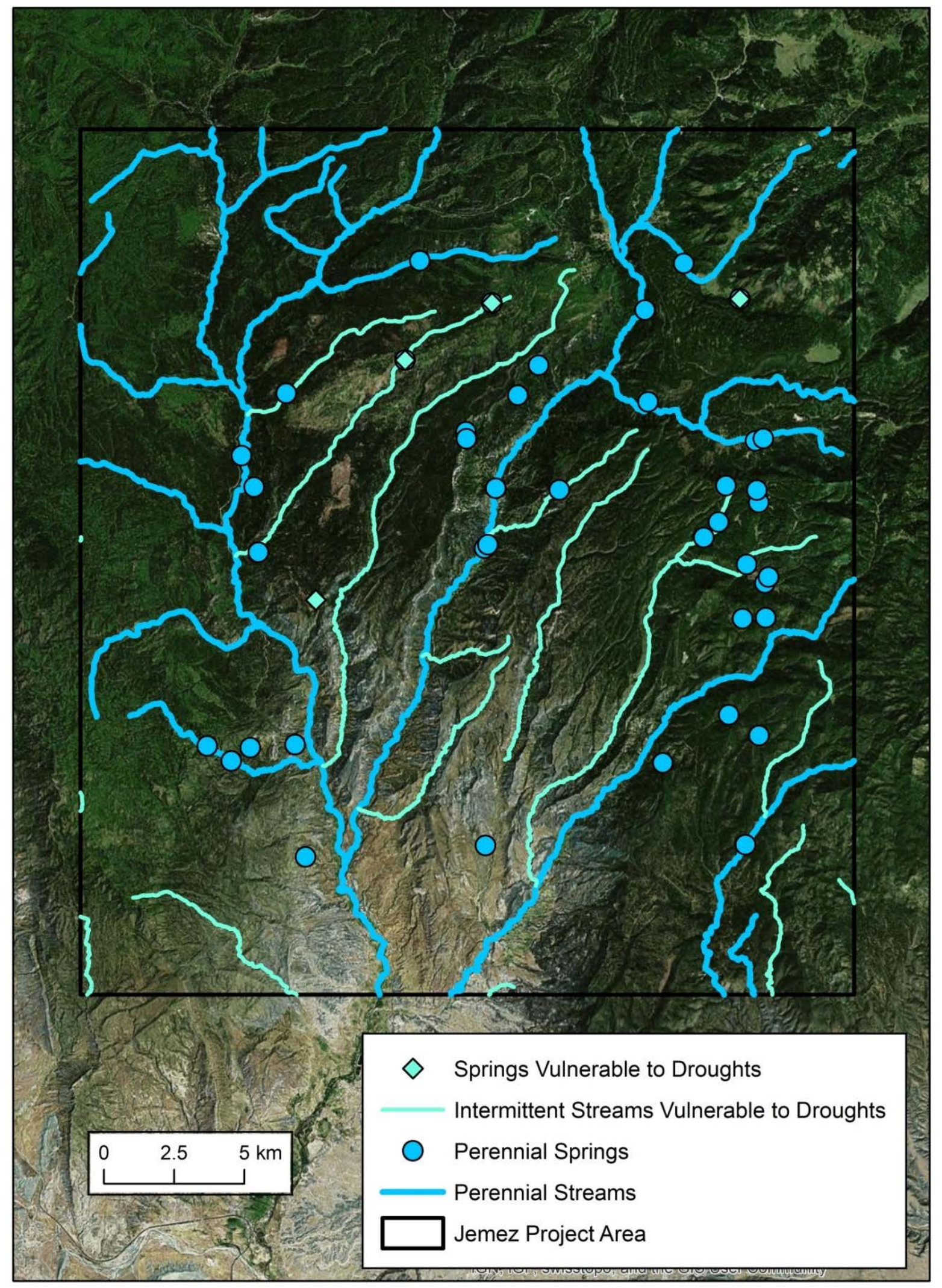

Figure 5.11. Jemez Plateau paleohydrological model, normal and wet periods. 


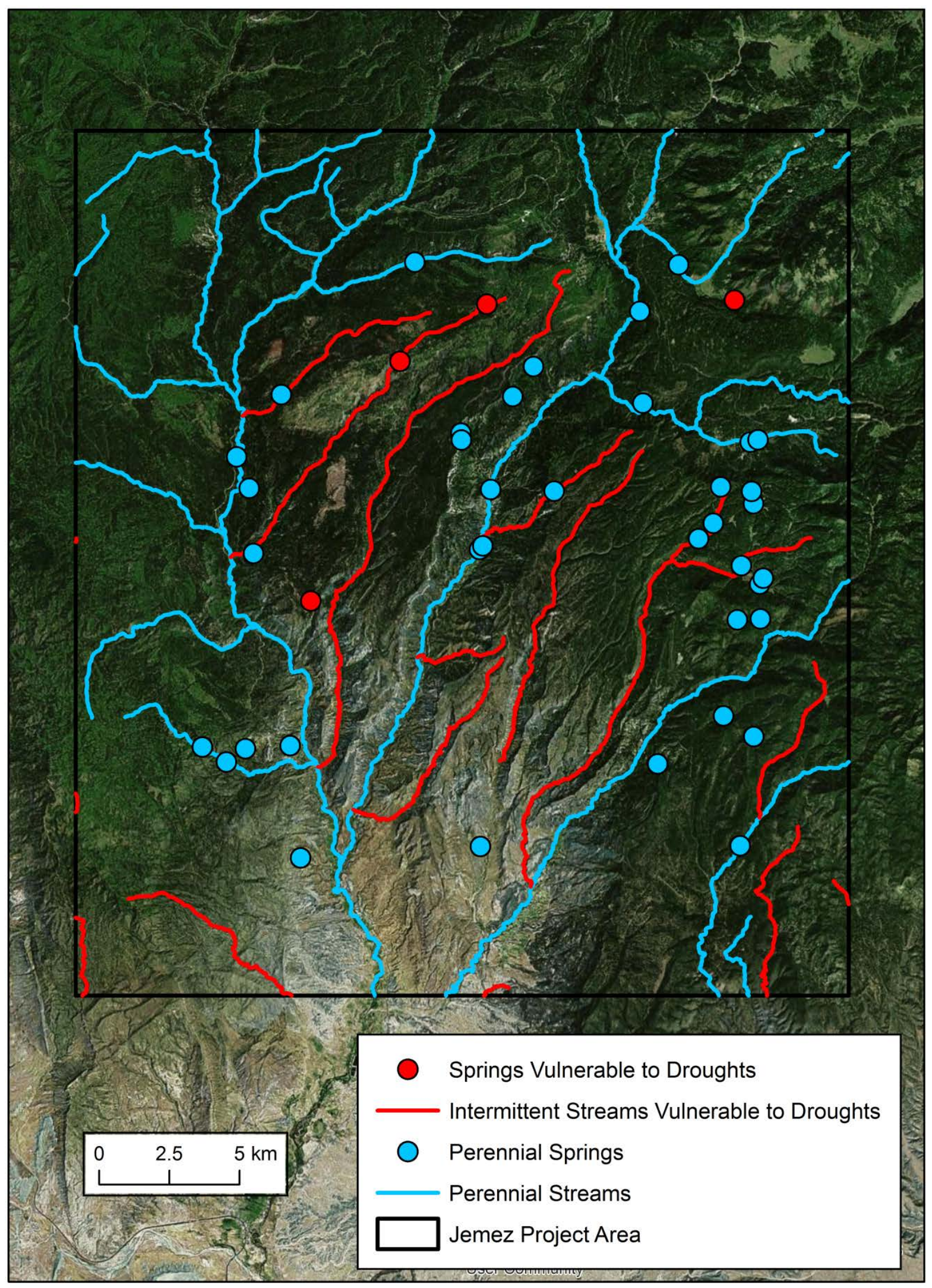

Figure 5.12. Jemez Plateau paleohydrological model, dry periods. 


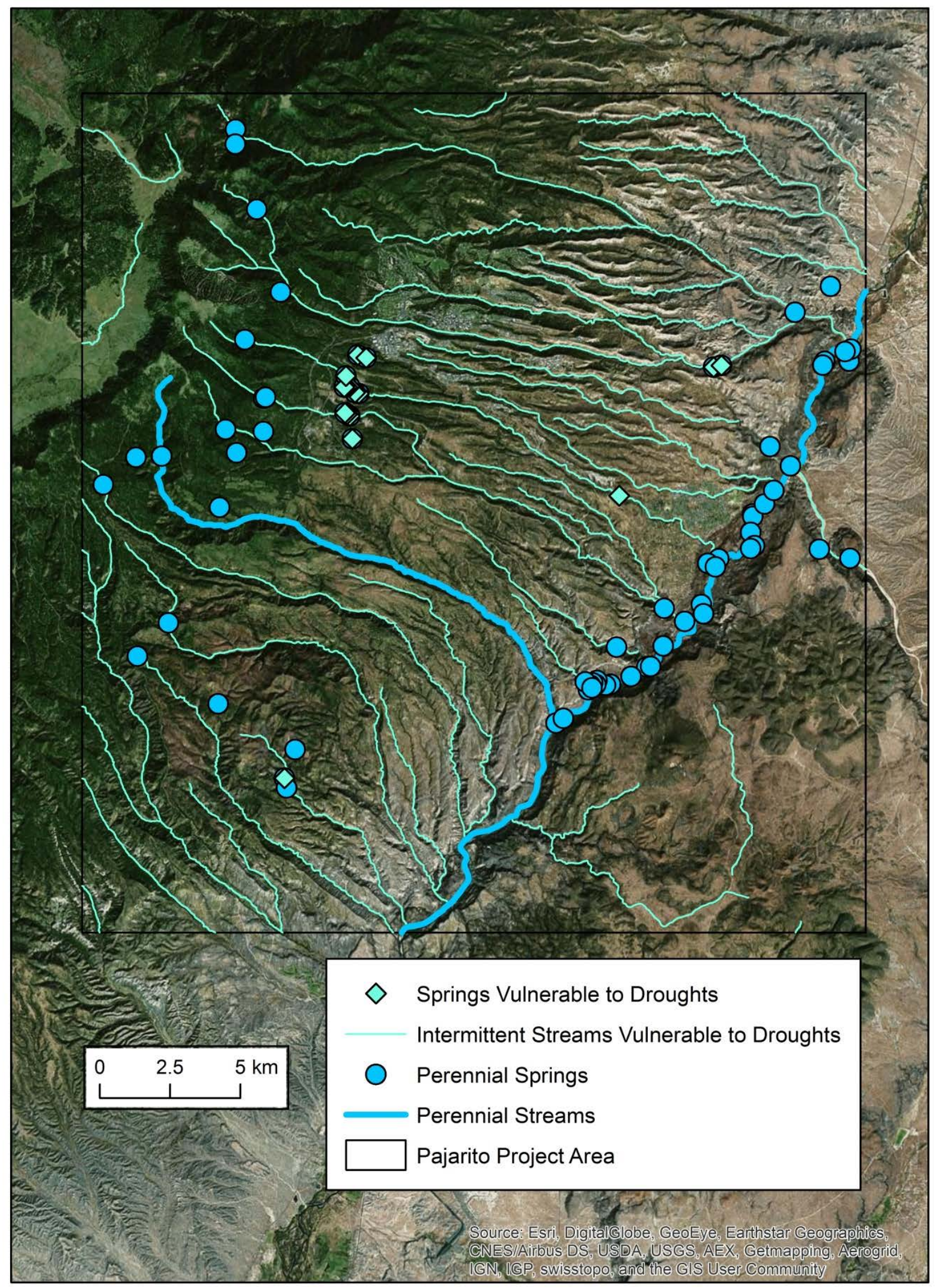

Figure 5.13. Pajarito Plateau paleohydrological model, normal and wet periods. 


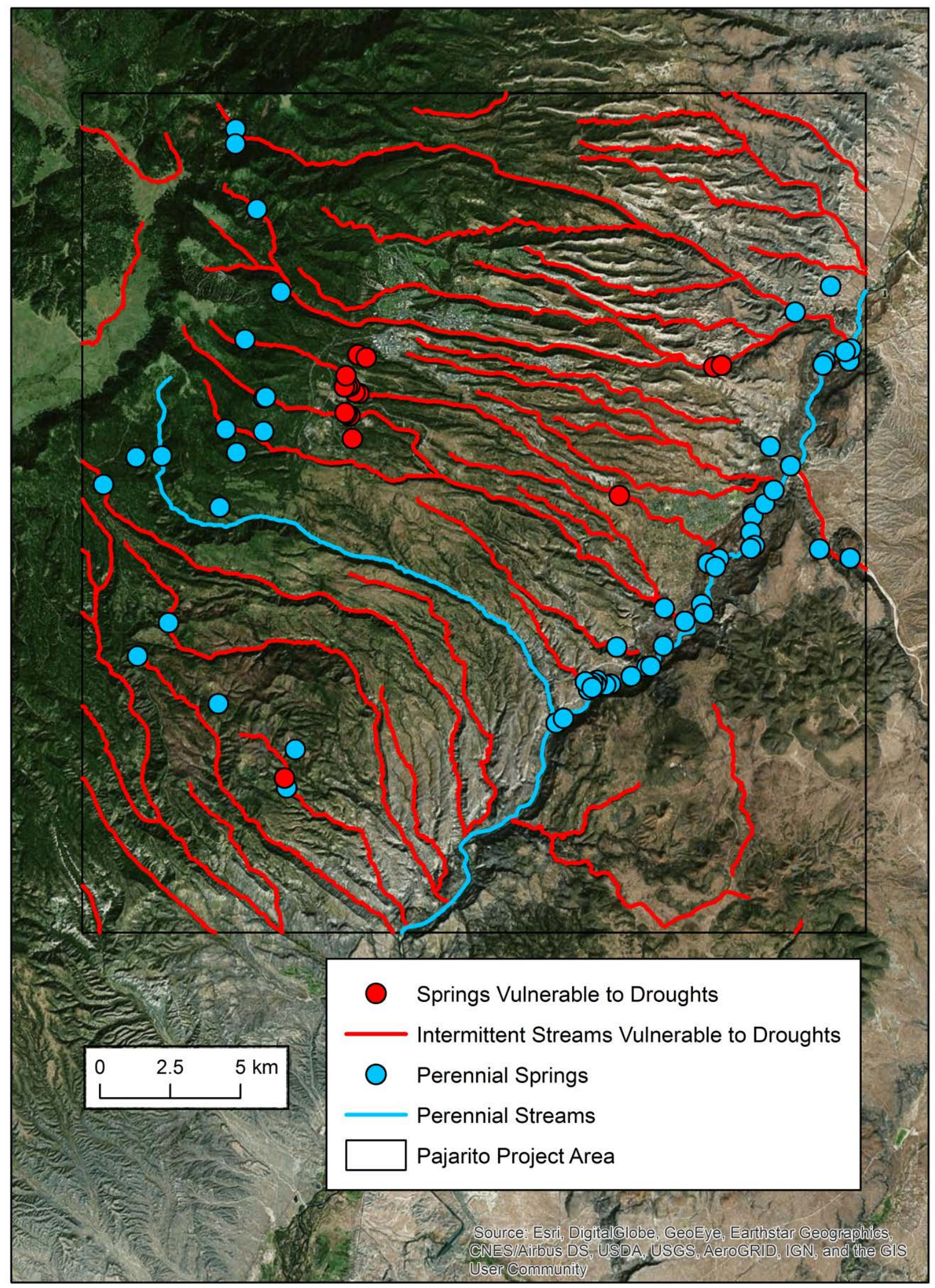

Figure 5.14. Pajarito Plateau paleohydrological model, dry periods. 
Table 5.7. Results of water resource density analysis.

\begin{tabular}{|l|l|l|l|l|}
\hline Water Type & \multicolumn{3}{|l|}{ Jemez Plateau (847,447.931 $\left.\mathbf{~ m}^{\mathbf{2}}\right)$} & \multicolumn{2}{l|}{ Pajarito Plateau (830,740.452 $\left.\mathbf{~ m}^{\mathbf{2}}\right)$} \\
\hline & $\begin{array}{l}\text { Resource } \\
\text { Quantity }\end{array}$ & Resource Density & $\begin{array}{l}\text { Resource } \\
\text { Quantity }\end{array}$ & Resource Density \\
\hline $\begin{array}{l}\text { All drainages } \\
\text { (wet) }\end{array}$ & $740,991 \mathrm{~m}$ & $8.743793841417733 \mathrm{e}-4$ & $843,725 \mathrm{~m}$ & $10.156300887396 \mathrm{e}-4$ \\
\hline $\begin{array}{l}\text { Perennial } \\
\text { streams }\end{array}$ & $518,465 \mathrm{~m}$ & $6.117956998115557 \mathrm{e}-4$ & $79,929 \mathrm{~m}$ & $0.962141662989585 \mathrm{e}-4$ \\
\hline $\begin{array}{l}\text { Vulnerable } \\
\text { streams }\end{array}$ & $222,526 \mathrm{~m}$ & $2.625836843302176 \mathrm{e}-4$ & $763,796 \mathrm{~m}$ & $9.19415923663243 \mathrm{e}-4$ \\
\hline $\begin{array}{l}\text { All springs } \\
\text { (wet) }\end{array}$ & 41 & $0.000455354223291 \mathrm{e}-4$ & 76 & $0.000914846506114 \mathrm{e}-4$ \\
\hline $\begin{array}{l}\text { Perennial } \\
\text { springs }\end{array}$ & 38 & $0.000448405130391 \mathrm{e}-4$ & 59 & $0.0007102097876413 \mathrm{e}-4$ \\
\hline $\begin{array}{l}\text { Vulnerable } \\
\text { springs }\end{array}$ & 3 & $0.000035400405030 \mathrm{e}-4$ & 17 & $0.000 .046367184729 \mathrm{e}-4$ \\
\hline
\end{tabular}

To compare the distributions of water resources between regions independent of cultural factors, I conducted an average nearest neighbor analysis (Table 5.8). The analysis was undertaken using the area of each project region and distributions of each water type using the Spatial Analyst tool in ArcGIS. This analysis identifies whether water sources are clustered, randomly distributed (null hypothesis), or evenly dispersed across the regions. The tool calculates a nearest neighbor ratio and z-scores, with z-scores less than -1.96 (at a 95\% confidence interval) indicating clustering, and z-scores greater than 1.96 (at the 95\% confidence interval) being dispersed (Table 5.8). Water types with scores falling in-between are considered randomly distributed. The analysis finds that in both regions the distributions of streams are either randomly or evenly dispersed. By contrast, springs are clustered, except for the few vulnerable springs of the Jemez Plateau, which are randomly dispersed. How Ancestral Pueblo settlement patterns relate to these distributions are examined in Chapter 8. However, unless settlement patterns indicate clustering of habitation sites around springs, the natural distribution of water sources suggests that streams are most likely to be the closest water sources. Therefore, 
the distribution of these sources, and their vulnerabilities to droughts, become critically important in assessing community vulnerabilities to droughts.

Table 5.8. Results of water resource average nearest neighbor analysis.

\begin{tabular}{|l|l|l|l|l|}
\hline Water Type & \multicolumn{2}{|l|}{ Jemez Plateau (847,447.931 $\mathbf{~ m}^{2}$ ) } & \multicolumn{2}{l|}{ Pajarito Plateau (830,740.452 $\mathbf{~}^{2}$ ) } \\
\hline & $\begin{array}{l}\text { Critical } \\
\text { Value } \\
\text { z-score }\end{array}$ & $\begin{array}{l}\text { P-value } \\
\text { (determination) }\end{array}$ & $\begin{array}{l}\text { Critical } \\
\text { Value } \\
\text { z-score }\end{array}$ & $\begin{array}{l}\text { P-value } \\
\text { (determination) }\end{array}$ \\
\hline $\begin{array}{l}\text { All drainages } \\
\text { (wet) }\end{array}$ & $\mathbf{3 . 6 5 6 4 5 2}$ & $\mathbf{0 . 0 0 0 2 5 6}$ (dispersed) & $\mathbf{2 . 1 8 5 2 4 7}$ & $\mathbf{0 . 0 2 8 8 7 1}$ (dispersed) \\
\hline $\begin{array}{l}\text { Perennial } \\
\text { streams }\end{array}$ & 1.364028 & 0.17256 (random) & 0.39094 & 0.69585 (random) \\
\hline $\begin{array}{l}\text { Vulnerable } \\
\text { streams }\end{array}$ & $\mathbf{2 . 2 0 9 4 9 1}$ & $\mathbf{0 . 0 2 7 1 4}$ (dispersed) & 1.7036 & 0.08846 (random) \\
\hline $\begin{array}{l}\text { All springs } \\
\text { (wet) }\end{array}$ & $\mathbf{- 3 . 6 5 1 0 3 6}$ & $\mathbf{0 . 0 0 0 2 6 1}$ (clustered) & $\mathbf{- 9 . 9 8 6 3 2 6}$ & $<\mathbf{0 . 0 0 0 0 1}$ (clustered) \\
\hline $\begin{array}{l}\text { Perennial } \\
\text { springs }\end{array}$ & $\mathbf{- 3 . 6 5 1}$ & $\mathbf{0 . 0 0 0 2 6}$ (clustered) & $\mathbf{- 8 . 7 7 4 9}$ & $<\mathbf{0 . 0 0 0 0 1}$ (clustered) \\
\hline $\begin{array}{l}\text { Vulnerable } \\
\text { springs }\end{array}$ & -0.4994 & 0.617487 (random) & $\mathbf{- 6 . 6 1 4 6}$ & $<\mathbf{0 . 0 0 0 0 1}$ (clustered) \\
\hline
\end{tabular}

\subsection{Summary}

In conclusion, the paleohydrological model, even one this simple, supports the argument that the hydrological systems of both regions are sensitive to long-term droughts. That being said, the underlying water resource base of the Pajarito Plateau is more vulnerable to droughts than those of the Jemez Plateau. The Pajarito has more water sources than the Jemez, yet when resource sensitivity to hydrological droughts is considered the data indicate that the Jemez water sources are less vulnerable to droughts. The Jemez water sources are more likely to be perennial, and therefore more resilient to droughts, than the vulnerable water sources of the Pajarito. 
Temporal models of Ancestral Pueblo vulnerabilities to hydrological droughts can be generated from the paleoprecipitation and archaeological record. In Figure 5.15, I present the archaeological cultural histories of each region, with periods of hydrological droughts. When droughts make up the majority of a cultural period I classify the period as a hydrological dry period. I do not classify the hydrological drought of 1131-1158 as a cultural dry period because the proxy records of vegetation and alluvial responses presented in this chapter suggest that the hydrological system was resilient enough so as to not significantly reduce water availability for Ancestral Pueblo. I discuss my paleohydrological distribution of water resources for normal and wet periods as compared to dry periods in my analysis of reservoir use histories in Chapter 7; factor them into my water acquisition cost analyses in Chapter 8; and in the socio-ecological models I present in Chapter 9.

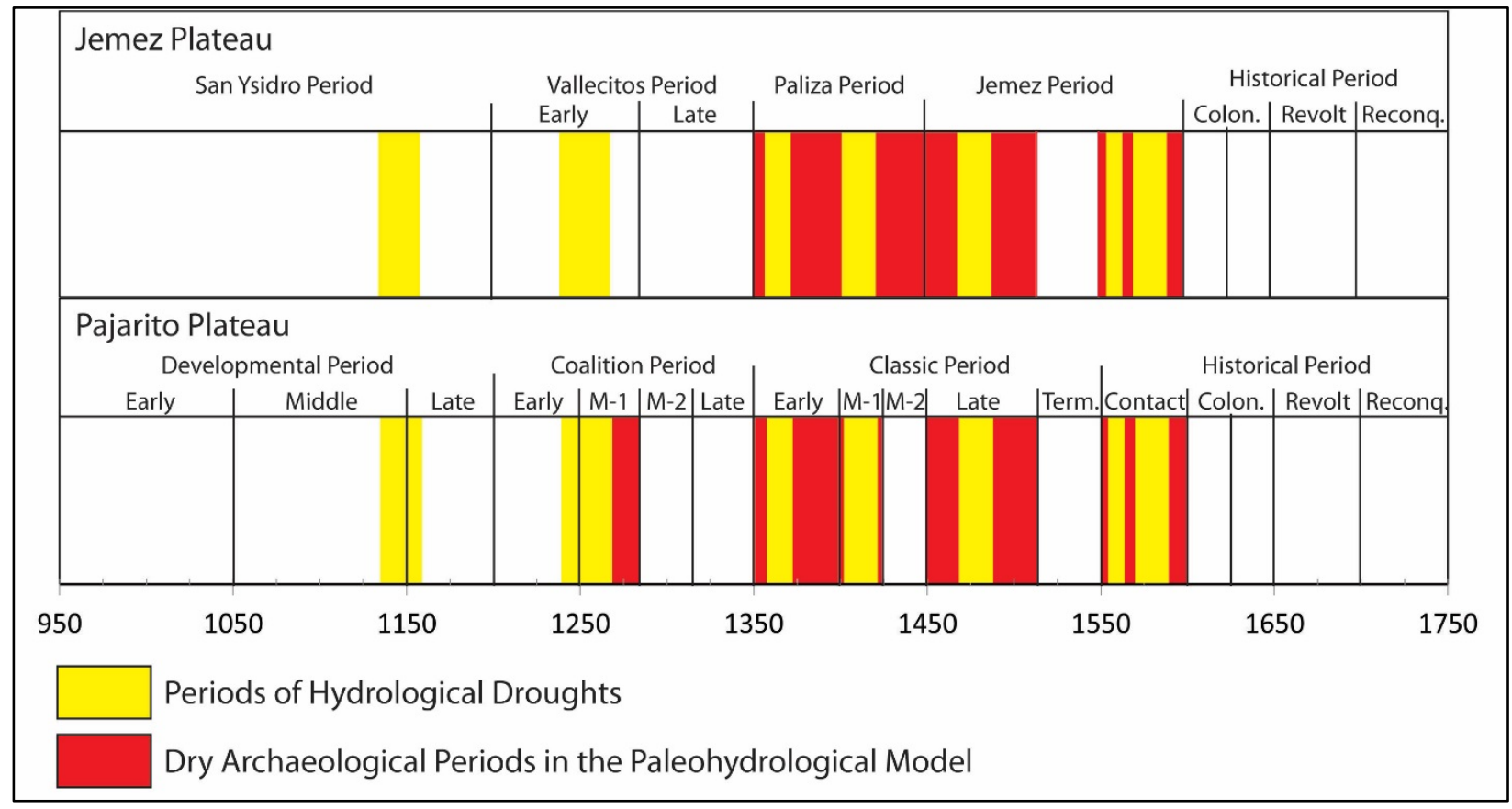

Figure 5.15. Archaeological periods when hydrological systems were vulnerable to droughts. 


\section{CHAPTER 6. RESEARCH DESIGN FOR TESTING RESERVOIR FEATURES}

In this chapter I present the research design and methods I used to test whether or not reservoirs were built to store water, and if so, if they buffered the risk of water scarcity for communities. First, I summarize the state of archaeological research into Ancestral Pueblo reservoir features. I identify useful methods and theoretical approaches from these studies, which I apply in my own investigations. I then present the research design to evaluate alternative hypotheses for how these features functioned. I frame my investigations as an application of behavioral geoarchaeology. I conclude by presenting the geoarchaeological methods and analytical techniques I use in my study, and a summary of expectations.

\subsection{Previous Archaeological Research of Ancestral Pueblo Reservoirs}

Archaeologists recognize a great diversity of prehispanic water management technologies in the North American Southwest (e.g., Anschuetz 1998; Crown 1987; Doolittle 2000). Yet, most investigations of water management focus on irrigation. The extensive Hohokam irrigation networks (e.g., Purdue et al. 2010; Ravesloot et al. 2009) or newly discovered systems associated with early agriculture (e.g., Damp et al. 2002; Huckleberry and Rittenour 2015) are important examples of prehispanic water management. In the Northern Rio Grande, water management studies are directed towards either determining whether or not irrigation systems existed in prehispanic times (Adler 2015; Greiser and Moore 1995), or how water management was incorporated into dryland farming (e.g., Anschuetz 1998). 
It has been thirty years since the last regional synthesis of archaeological water storage features (Crown 1987; Turney 1984). Turney, an engineer long involved with archaeological research, summarized the technological aspects of prehistoric reservoir construction and use (1984). Crown (1987) developed a typology for water control features, and differentiated between water reservoirs and water catchment basins. For Crown, reservoirs collect water diverted from natural sources, store it, and then distribute it to feed irrigation systems. Catchment basins collect and store surface runoff, typically from lower order drainages rather than artificially diverted water. The water is impounded behind horse-shoe shaped berms, and then manually extracted. Using Crown’s typology, the Ancestral Pueblo features I am investigating are catchment basins, not reservoirs. I call these features reservoirs, however, because it is what they are commonly referred to in this region, and there are no reservoirs, as defined by Crown. A good deal of work on these features has been conducted since Crown and Turney's summaries. In Figure 6.1, I map the sites and regions with published studies of reservoir features. Geoarchaeological approaches figure prominently in investigations over the last thirty years, and provide the examples I used to develop a research strategy for testing multiple features. Archaeological studies of water storage features in the Mesa Verde region of the Northern Southwest show how integrating hydrological engineering, dating, and paleoecological reconstructions can help us understand the role that water storage played in regional cultural histories. Rohn $(1963,1972)$ made some of the earliest archaeological reports on reservoirs in the region, and later Haase (1985) and Wilshusen et al. (1997) synthesized reservoir distributions, sizes, and limited excavations with local culture histories. These researchers identified important relationships between water storage volumes, reservoir chronologies, and the proximity of these features to nearby villages. Wilshusen et al. (1997) excavated the Wood Canyon Reservoir, and 


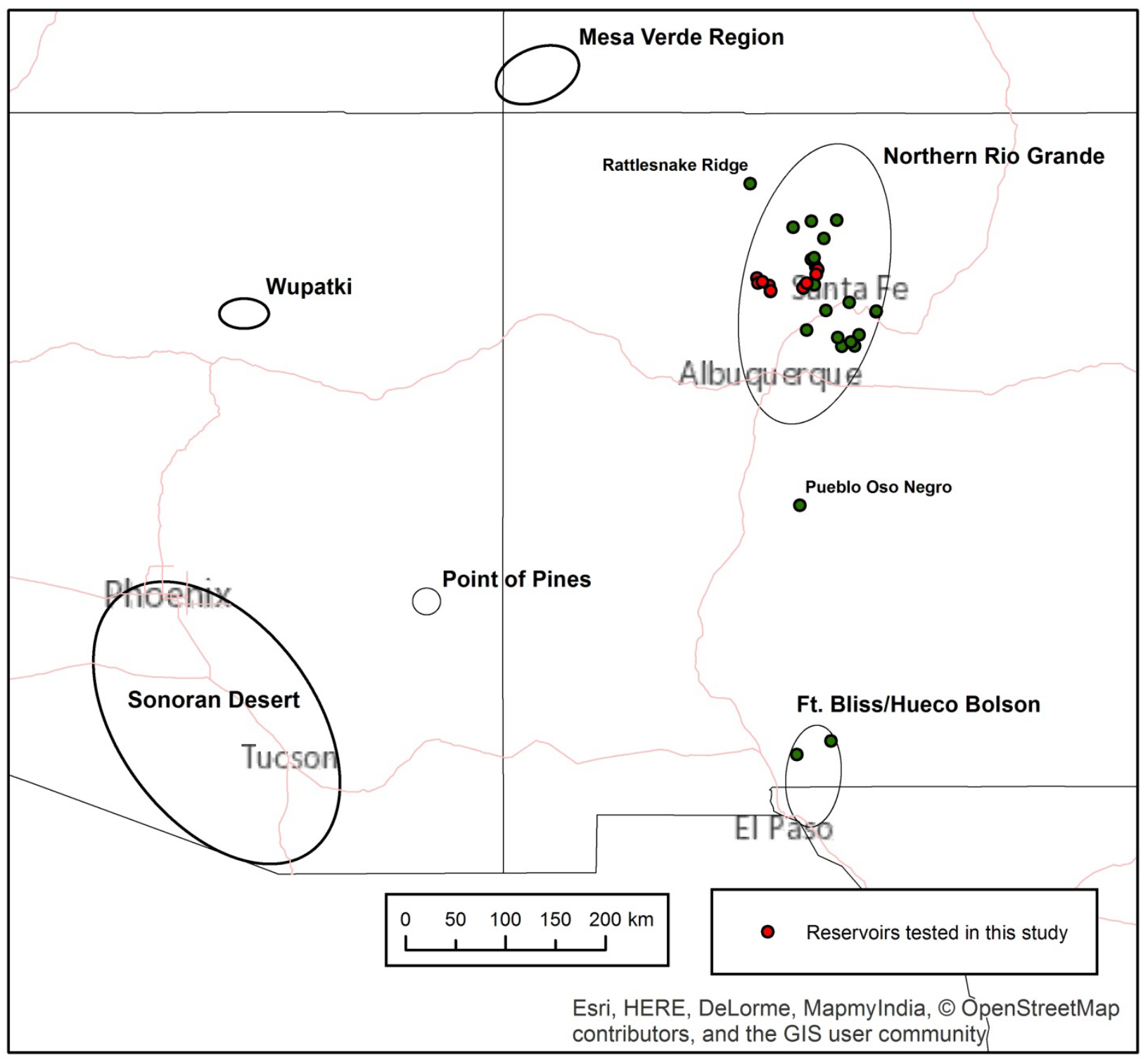

Figure 6.1. Locations of documented reservoir features across the North American Southwest.

demonstrated that testing both earthen berms and basins is necessary to reconstruct construction histories. Their work also addressed how these features inform our understandings of how water management relates to community formation, and droughts. Unfortunately, the lack of direct 
dating limited their ability to draw close correlations between reservoir use-histories and occupation sequences.

Long-term studies of multiple features by a team of engineers led by Wright (2006) integrated hydrological engineering with traditional archaeological investigations to better understand Ancestral Pueblo water management technologies. Wright and colleagues generated detailed topographic maps and hydrological estimates of reservoir storage capacities of multiple features. They excavated multiple basins to identify sedimentation sequence histories, which in some cases they were able to directly date. Pollen studies as part of these investigations, as well as prior work (Wyckoff 1977) showed that basin sediments can preserve rich pollen assemblages from the surrounding environment. Yet, Benson et al. (2014) criticize Wright’s hydrological interpretations at the Mummy Lake/Far View Reservoir at Mesa Verde. Using more sophisticated mapping and hydrological models, and greater command of the archaeological literature, they argued that the Mummy Lake/Far View feature was an open-air ceremonial structure and not a reservoir. Based on these studies, other researchers in the Mesa Verde region now acknowledge that reservoirs can inform studies of cooperation and social organization, like other more frequently studied feature class types (e.g., Kohler and Van West 1996; Kohler et al. 2012).

Bayman's studies of reservoirs in Southern Arizona integrated multiple lines of evidence (Bayman et al. 2004) and ethnographic information (Bayman 1997) to understand feature hydrology in relation to prehistoric settlement patterns. Reservoir features are identified as components of Hohokam irrigation networks (Bayman and Fish 1992), but water storage features are also found in the Sonoran desert away from irrigation networks. Researchers were uncertain if these features held water year-round or not. If they did not, then these settlements, often far 
from perennial natural water, could only be seasonal occupations. The ethnographic record suggested dual-residence settlement patterns by Tohono O’odham, which was driven in part by water scarcity (Bayman 1997). Direct testing, studying modern stock ponds as analogs, and paleoecological studies of ostracodes and pollen (Palacios-Fest et al. 2008) indicated that these features could hold water year-round (Bayman et al. 2004). Therefore this technology may have allowed year-round occupations in otherwise marginal areas. Bayman's work is important because he identifies the utility of using paleoecological indicators to identify the presence of water, shows both the opportunities (and limitations) of ethnographic records, and explores the impact that understanding these features has on the study of settlement patterns. Studies in southern New Mexico, far west Texas, and early work in the Point of Pines region of Arizona present some of the best examples of integrating geoarchaeological approaches to reconstruct how water features functioned. In excavations at Point of Pines in Arizona, Wheat (1952) recorded stratigraphic evidence in artificial depressions. He identified some features as water catchment basins, while he classified others as walk-in wells on floodplains that were excavated down through alluvium to tap the alluvial aquifer. Scarborough (1988) conducted excavations at the Hot Wells Storage Basin in the Hueco Bolson region of far west Texas. Trenching in the storage basin was undertaken to determine how the feature was constructed and used, as well as to better calculate its potential water storage volumes. Estimations of storage volume, and evaporation potential in relationship to nearby Jornada Mogollon settlements, led Scarborough to conclude that this feature didn’t hold water year-round.

Monica Murrell's thesis research (2006) at a reservoir feature at the site of Pueblo Oso Negro in the Chupadera Basin of south central New Mexico is the first recent study to explicitly frame testing reservoirs as a geoarchaeological problem using multi-proxy evidence. She integrated 
limited radiocarbon dating, stratigraphic and paleoecological studies of sediments from basin cores, and hydrological modeling to understand when and how the feature functioned. Pollen and ostracod evidence suggested that the feature held water, potentially year round. It was well positioned to capture surface runoff, and it was excavated deep enough to access groundwater of a shallow water table. Her integrated approach was further expanded upon in a study of a reservoir feature at site FB 9122 on the Dona Aña Range at Fort Bliss in New Mexico (MacWilliams et al. 2009). This study integrated a wider range of analytical approaches such as micromorphology, stable carbon isotope analyses, and the dating of short-lived charred tissues to reconstruct when and how this feature functioned, showing how multi-proxy evidence makes interpretations of these features possible.

Water management features associated with agriculture are well studied in the Eastern and Western Pueblo contexts, however reservoir features are not. This is unfortunate, because most of the ethnographic examples come from these cultural contexts. Anschuetz has extensively synthesized water management practices in the Tewa Basin, while Vivian $(1974,1990)$ and Vivian and Watson (2015) undertook long-term studies of water control features in Chaco Canyon. Reservoirs in these regions vary greatly in size and in the effort of study. Huckleberry et al. (2016) recently reported on geochronological studies of the large reservoir formed by an impoundment along the Rio San José at Laguna Pueblo, and through dating established its likely prehispanic origins. In the Sinagua region of Arizona, Berry (2014) undertook hydrological modeling of multiple small water storage features at Wupatki National Monument to examine issues surrounding sustainability of communities there, while Anderson and Potter recognize that artificial water storage features integrate with long-standing Pueblo beliefs and practices surrounding settlements near water (Anderson and Potter 2015). 
There are recorded, but unexcavated reservoirs and other water control features at many sites in the Northern Rio Grande (Turney 1990), particularly in the Galisteo Basin (Nelson 1914), Northern Rio Grande (Snead 2006), and the Jemez Mountains (Bice 1980; Elliott 1982; Turney 1984). Due to their small size compared to the large sizes of associated villages, as well as the potential for historical modifications, Snead $(2006,2008)$ questions if reservoirs in the Northern Rio Grande efficiently stored water. Citing ethnographic evidence and Pueblo oral traditions surrounding springs and shrines, he proposes that in the Northern Rio Grande these features instead served as watery shrines with little utilitarian function. Mortar mixing pits (Van Zandt 2006) and open-air shrines (Ford 2014, and Ford in Van Zandt 2006:139) have also been proposed as alternative explanations for these features. Yet, no reservoir features in the Northern Rio Grande have been archaeologically tested, and neither Snead $(2006,2008)$ nor anyone else has articulated how to test these different hypotheses.

\subsection{Behavioral Geoarchaeology as Research Design}

Investigations of reservoirs in other regions of the Southwest, and in other cultural contexts (Aiuvalasit et al. 2010) demonstrate that geoarchaeological approaches are well suited for determining when and how reservoirs functioned. Yet, until the most recent works by Murrell (2006), MacWilliams et al. (2009), and Benson et al. (2014), researchers were usually not explicit about stating their geoarchaeological expectations when investigating these features. Behavioral geoarchaeology presents an opportunity to utilize middle-range theory to better structure hypothesis testing and research designs for geoarchaeological research. Based on Michael Schiffer's approach to site formation processes (see Schiffer 1987 and LaMotta and Schiffer 2001), soils and sediments have their own life-histories, and are subject to both natural 
and cultural transformations. Geoarchaeologists, with their methodological training grounded in the geosciences, traditionally focus more on natural transformations of sediments and soils than cultural transformations. Geoarchaeologists investigating cultural features are increasingly using behavioral archaeology to structure their analyses (e.g., Mentzer et al. 2017; Stein 2001; Van Keuren and Roos 2013), and Roos and Wells (2017) recently proposed that there should be a behavioral geoarchaeology to reconstruct human behavior in sediment and soils.

By considering how human behaviors impact the geoarchaeological record, and by being clear about our expectations, the behavioral approach can make hypothesis testing more explicit in geoarchaeology. First, we can model the chain of human behaviors which may leave behind geoarchaeological traces. Like sedimentologists benefiting from observations of depositional contexts made by process geomorphologists, ethnographic records and experimental approaches can inform our geoarchaeological interpretations of cultural site formation processes (e.g., Berna 2017; Goldberg and MacPhail 2006; Mallol et al. 2009). Second, by stating our expectations about both cultural and natural transformations we can identify the ways in which site formation processes transform behaviors in systematic contexts into traces left behind in sediments and soils of archaeological contexts. Geoarchaeological studies of cultural features can particularly benefit from identifying cultural transformation processes. Mentzer et al. (2017) used the lifehistory model to treat pedogenically altered ash deposits as artifacts, while Van Keuren and Roos (2013) identified traces of ritual abandonment processes from kiva fill. For this study, I use the behavioral approach to model geoarchaeological expectations for the different hypotheses proposed for water storage features in the Jemez Mountains. This model is a simple behavioral chain (LaMotta and Schiffer 2001) of activities associated with feature construction, use, and abandonment for each hypothetical function (Table 6.1). The alternative hypotheses proposed by 
Snead (2006) are: 1) catchment basins to store water for domestic use, 2) watery-shrines with little potential for economic use, or 3) mortar mixing pits (Van Zandt 2006). Not included in this model is the hypothesis that the features were open-air shrines (Ford 2014), as what Benson et al. (2014) interpreted for Mummy Lake/Far View Reservoir. Geoarchaeological expectations for open air shrines would be features located in places with little potential for surface runoff, minimally excavated basins, and/or compacted natural or anthropogenic soils reflecting foottraffic rather than sediments deposited by water. Although examples of excavations are limited, there are some informative archaeological, historical, and ethnographic observations on Pueblo mortar mixing features. Excavations of pits adjacent to adobe architecture in Hohokam (e.g., Howell and Homburg 2013) and Mimbres (Shafer and Drollinger 1988) culture areas are interpreted as “puddle pits” potentially used by households to mix mortar or plaster. These pits are typically small ( $\sim 1 \mathrm{~m}$ in diameter), shallow, and are lined with adobe, which is very different from the 10-30 m diameter Jemez reservoir features. The mixing pits are also numerous, and potentially associated with household-level construction rather than as community-wide features. Pits for adobe making may be identified at T'aitona (Pot Creek Pueblo), although they have not been subject to geoarchaeological investigations (Michael Adler, 2013, personal communication). Brick-making at Santo Domingo Pueblo (Khe-wa) was photographed for an article in the November 29, 1943 issue of Life Magazine on how the Cochiti Dam would affect Pueblo communities (Stackpole 1943). It shows the mixing of mud with straw, and the impressive scale of the operation in open pits, which by the mid-20 $20^{\text {th }}$ century were undertaken for commercial uses. At Zia, water and mud was mixed at the site of construction rather than at a central location (Stevenson 1894). Studies of mortar-mixing pits from medieval contexts in Europe show that mortar fragments are typically incorporated into basin sediments, and in areas 
near the pits (McAvoy 1986). It should also be expected that exotic materials used to make mortar or plaster, such as crushed tuff or sherds identified in adobe excavated at sites in Bandelier (Kohler and Root 2004a:133) would be incorporated into the fine-fraction of basin sediments. Beaglehole (1937:58) describes seasonal (spring) use of catchment basins (natural and artificial) on mesa-tops near Hopi villages as water sources to mix adobe. He does not state if mixing occurred within the basin or instead if the water was brought to sites of construction. Cameron (1999:65), however, identified mortar mixing near construction sites and not at reservoirs in historical photos from Oraibi.

Shrines are documented across the Rio Grande region, but excavations of shrines are limited due to their surficial character and cultural importance to descendant communities. Shrine features can have a similar shape to the horse-shoe shaped berms of reservoirs, such as the Shrine of the Yellow Cloud Man atop Tsikumu Peak photographed by Edward S. Curtis (1926). However it is likely that they would not be in contexts conducive for collecting or storing water. Snead (2006) does not identify any water shrines in similar contexts near villages in the ethnographic or historical record, which he argues is a reflection of historical changes in ritual practice. The closest similar contexts would be walled springs at Zuni and Hopi depicted in historical drawings and photographs (e.g., Simpson 1852). Again, these types of features have not been excavated but expectations for architectural elements, the expansion of the spring port to increase discharge, and attendant wetland vegetation can be gleaned from these documents. As sources of discharge rather than loci for water run-off, these contexts would likely have different sedimentary facies, water chemistry reflective of geohydrological conditions, and potentially far older deposits reflective of prolonged hydric settings. 
Expectations for alternative hypotheses are organized by behavior (construction, use, and abandonment) and reservoir component (catchment area, basin, and berm). I identify possible cultural and natural transformations associated with feature use-life histories for each alternative hypothesis (Table 6.1). Possible cultural transformations draw upon aspects of the ethnographic record presented in Chapter 4. Identifying both the potential for surface runoff as well as sedimentological and paleoecological proxies for water are central for evaluating the hypotheses. The literature on hydrological engineering helps to characterize hydrological contexts in the catchment area, and feature basin and berm construction. Natural depositional and postabandonment processes associated with small ponds and lakes can be identified in sedimentological and paleoecological records of basins (Cohen 2003: Figure 7.1 and Table 7.1), while comparing paleoecological and geoarchaeological results of this investigation to previously studied reservoirs helps to provide testable expectations.

Models of site formation processes between reservoirs, mortar-mixing pits, or watery shrines are not mutually exclusive. Some aspects of site formation, such as excavation of natural soils down to bedrock to form a catchment basin, would likely be no different except for perhaps the scale, between alternative hypotheses. Anticipated differences in sedimentological sequences and paleoecological records between reservoirs and watery shrines will most likely be subtle. This is why integrating geoarchaeological evidence from all tested components of the features with hydrological evidence is critical. In addition, frequency of run-off events, estimates of storage volumes and the potential for these features to meet community demands (based on population history estimates) can be used to evaluate feature efficacy. Equifinality is certainly a possibility in this context, but integrating multiple proxies and comparing the findings from multiple 
features provides the opportunity to evaluate hypothesis and develop feature specific use-life histories.

\subsection{Geoarchaeological Methods and Analyses}

Evaluating between these hypotheses required a range of data, most of which I collected using interdisciplinary approaches grounded in geoarchaeology. Some of these approaches, such as catchment basin analyses and developing modern analogs of aquatic habitats, are more typically associated with hydrology and ecology. All approaches fall within the broad definition of geoarchaeological research, which is archaeological investigation facilitated by methods from the earth sciences (Butzer 1982:5).

\section{Field Methods}

Fieldwork consisted of: 1) documenting attributes of reservoir features, and the surrounding catchment area; 2) collecting water and sediment samples from stock tanks to serve as modern analogs for paleoecological studies of diatom ecology; and 3) collecting cores from reservoir basins, berms, and catchment areas. I conducted a pilot study at the site of Amoxiumqua (LA481) during the summer of 2013, to demonstrate that coring could work as a low-impact method to recover geoarchaeological samples from these features. During the summer of 2014, I sampled three stock tanks for paleoecological samples and cored all six Jemez Plateau possible reservoir features. I tested nine possible reservoirs on the Pajarito Plateau during the summer and fall of 2015. 


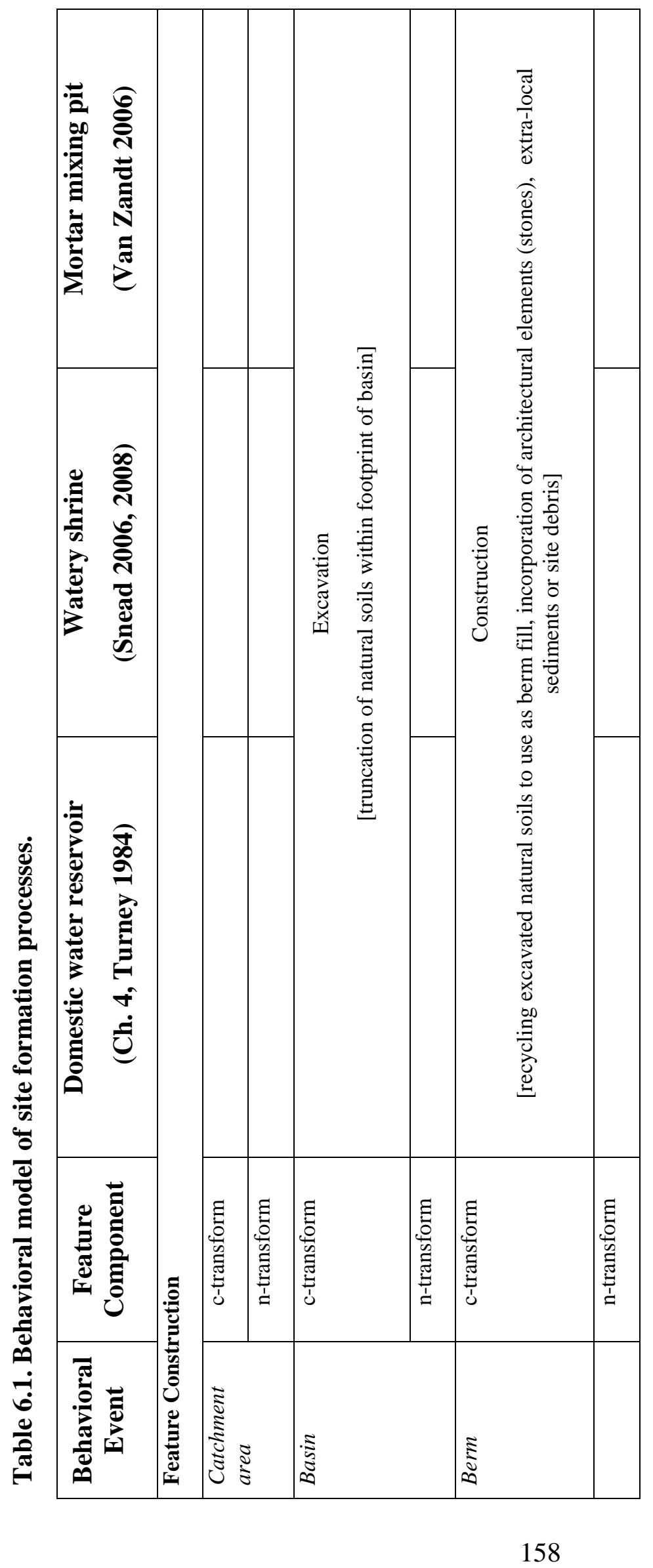




\begin{tabular}{|c|c|c|c|c|c|c|c|c|}
\hline 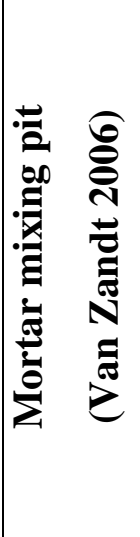 & 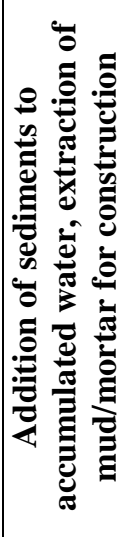 & \multirow{3}{*}{ 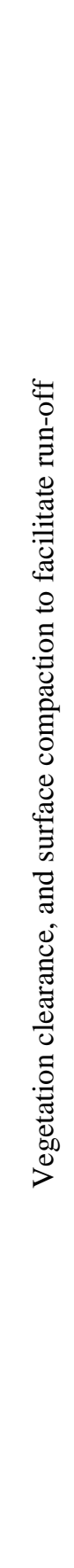 } & \multirow{3}{*}{ 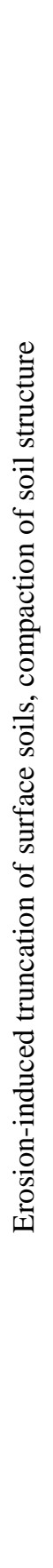 } & 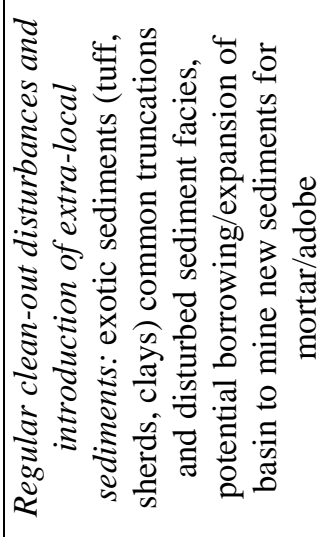 & 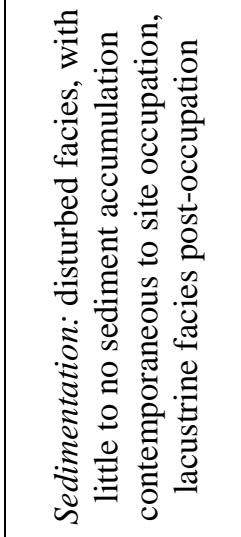 & 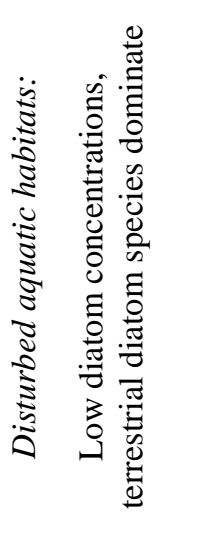 & 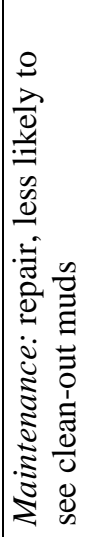 & 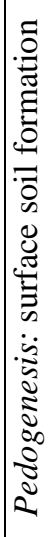 \\
\hline 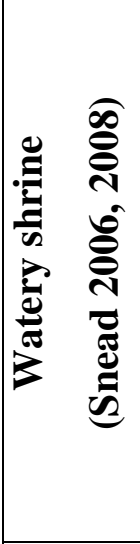 & 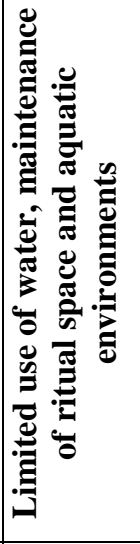 & & & 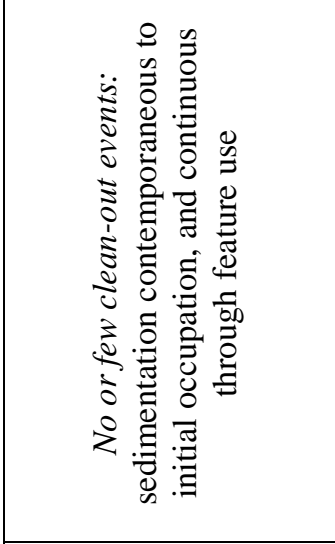 & 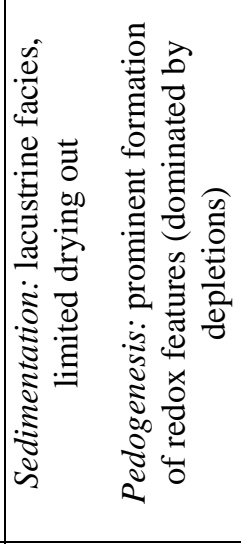 & 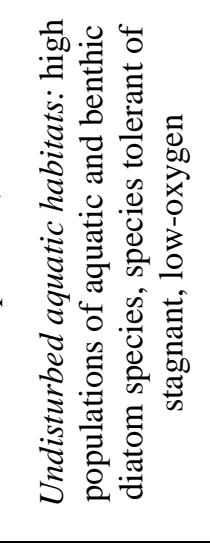 & 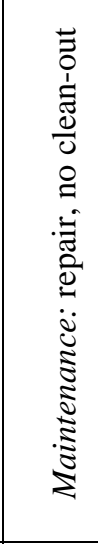 & 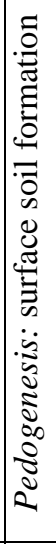 \\
\hline 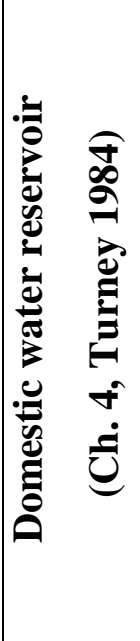 & 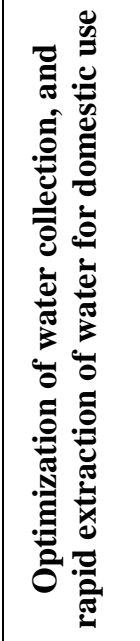 & & & 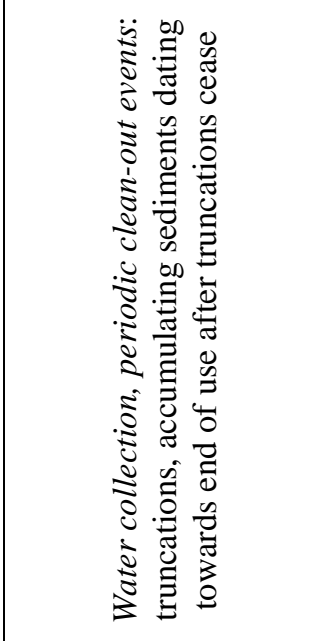 & 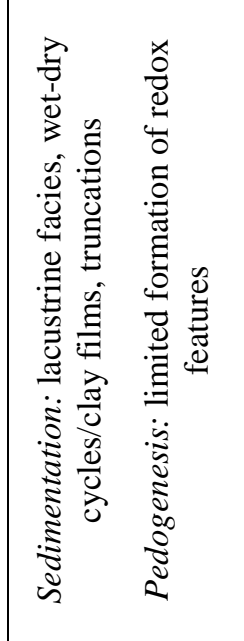 & 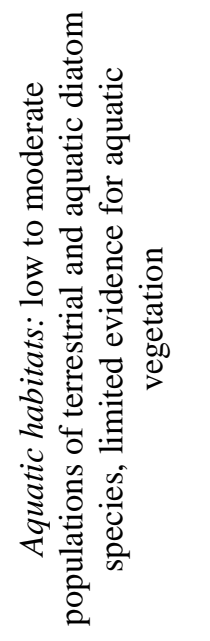 & 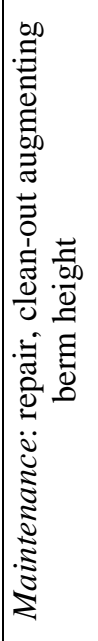 & 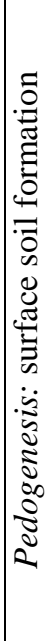 \\
\hline 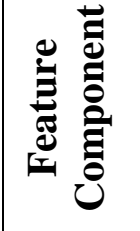 & & 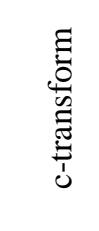 & 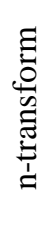 & 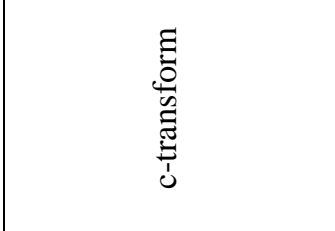 & 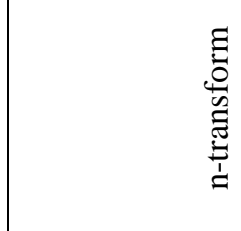 & & 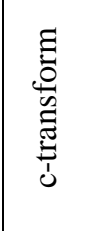 & 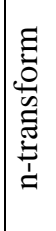 \\
\hline 줄 & 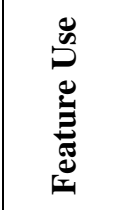 & 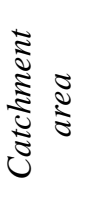 & & & $\begin{array}{l}: \overline{\tilde{v}} \\
\square\end{array}$ & & $\stackrel{\searrow}{\beth}$ & \\
\hline
\end{tabular}




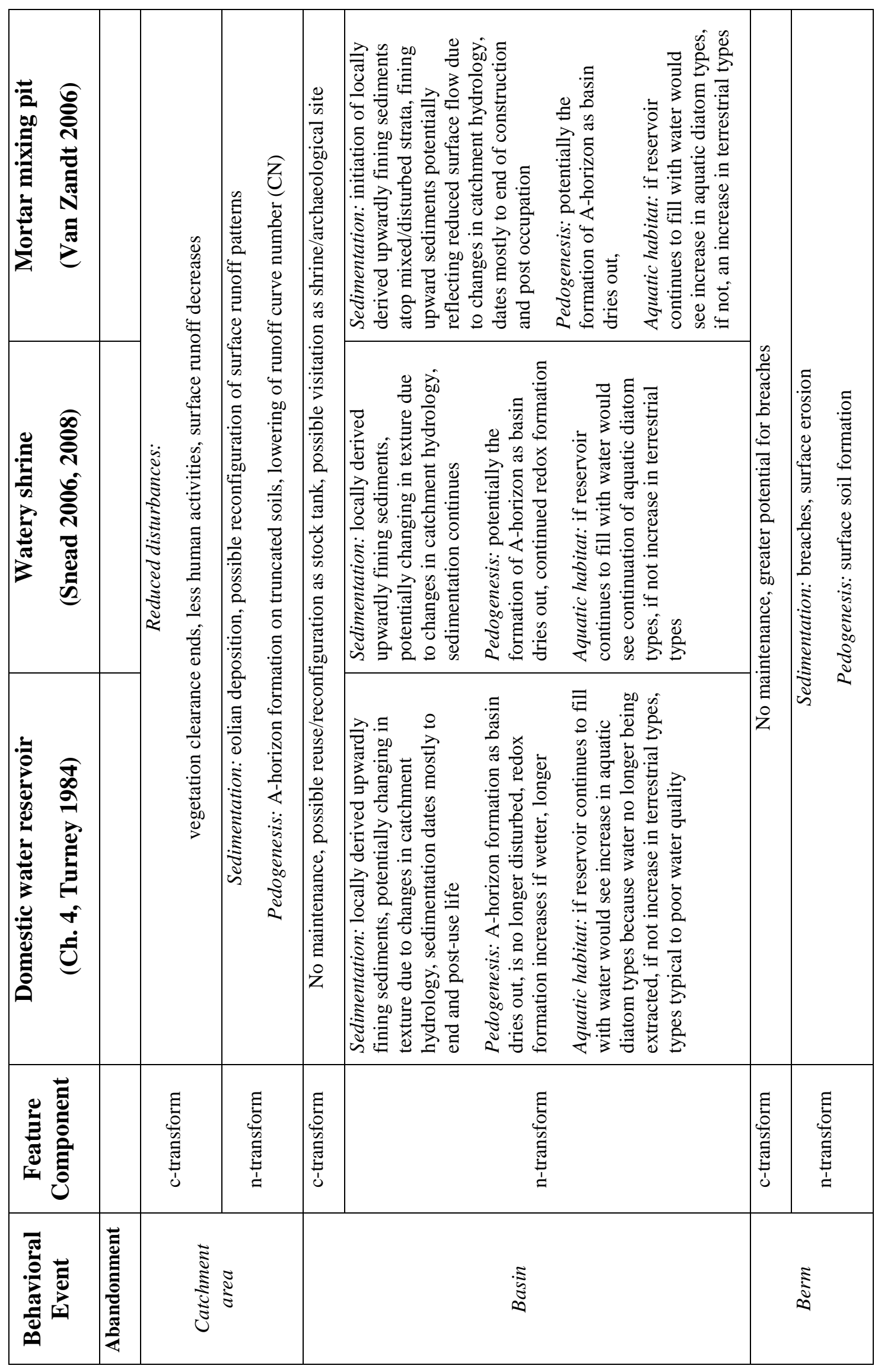


I recorded reservoir dimensions and bio-physical settings to aid in reconstructing site formation processes, water holding capacities, and runoff calculations. Compass and tape measurements were made of the standard dimensions of water storage features identified by hydrological engineers (USDA 1998; NRCS 2005) (Figure 6.2). These observations are presented in Appendix B, and discussed on a feature-by-feature basis in Chapter 7. Reservoir construction techniques, artifact concentrations, and any breaches or disturbances were documented. Vegetation and surface conditions were also described and photo-documented. I used a ring-test infiltrometer (e.g., SCS 1986; Wright 2006) to collect measurements of soil infiltration rates in the catchment areas of all of the Jemez Plateau sites, and the reservoir at Tsirege on the Pajarito Plateau. Ultimately, I could not use these measurements, because I didn’t collect the necessary penetrometer or moisture sensor readings. Instead, I applied published soils data on infiltration rates for Sandoval County (Hacker and Banet 2008) in subsequent calculations.

To better understand the results of paleoecological studies of prehispanic reservoirs, I collected sediment and water samples from modern stock ponds on the Jemez Plateau. These samples serve as modern analogs for aquatic conditions under a range of conditions. Diatoms are microscopic (2 to $200 \mu \mathrm{m}$ ) unicellular algae that live in aquatic, semi-aquatic, and moist terrestrial settings (Kennington 2002). Due to their durable and diagnostic opal silicate shells (frustules), diatoms preserve well in a variety of sedimentary contexts and can be used as proxies for paleoecological conditions. I tested three stock ponds (Figure 6.3) in May 2014, which is typically a very dry time of year. From the alluvial floodplain of Lake Fork Canyon, I tested water and sediments from a groundwater-fed stock tank. This feature provides an example of wetlands with clean water that are wet year-round. Dry surface muds collected from the Stable 
Mesa \#1 tank provide an example of diatom ecology from a runoff fed tank that dries out during the dry season. Finally, water and sediment samples from the San Juan Tank provided an example of diatom ecology from a wet runoff-fed tank. In addition, based on its water's brown color, poor smell, and the presence of cattle, the San Juan Tank likely serves as an example of water with low quality. Analyses of both these modern analogs and archaeological samples are compiled in reports presented in Appendix C.

I conducted direct geoarchaeological investigations of Ancestral Pueblo reservoirs through coring. I collected one hundred and sixteen cores from fifteen reservoir features at nine sites. I sampled berms, basins, and catchment areas. To recover enough sediment to both describe and subsample the cores for multiple analyses, I took repeated cores at each locality. Typically, I collected four cores at the lowest point within the basin, all within approximately $0.3 \mathrm{~m}$ of each other, four cores on the thickest portion of the intact berm, and two cores to serve as controls in the catchment area outside of the basin. The locations of these cores are shown on maps of each reservoir feature. Ideally, I would have collected transects of samples across basins and berms to sample from a variety of constructed and depositional contexts, but I did not due to time constraints and to minimize impacts to the features. I made a point to backfill the core holes with clean sand, until tribal monitors recommended to not do so and instead let nature takes it course. When I returned a year later to make site visits to Tsankawi and Amoxiumqua I found the 0.75 to 1.2 inch diameter holes boreholes had already infilled.

At sites close to roads I used a JMC Environmentalist's Sub-Soil Probe (ESP) with a gaspowered Yamaha EF2000 inverter to power a hand-held Bosch SDS-max Demolition Hammer to drive a 1.2 inch diameter barrel into the soil to collect intact sediment cores (Figure 6.4). Clear 
plastic liners inserted into the barrel recovered intact sediment and soil sequences from the core. The barrel is extracted with a foot jack, and plastic liners were removed from the core barrel and

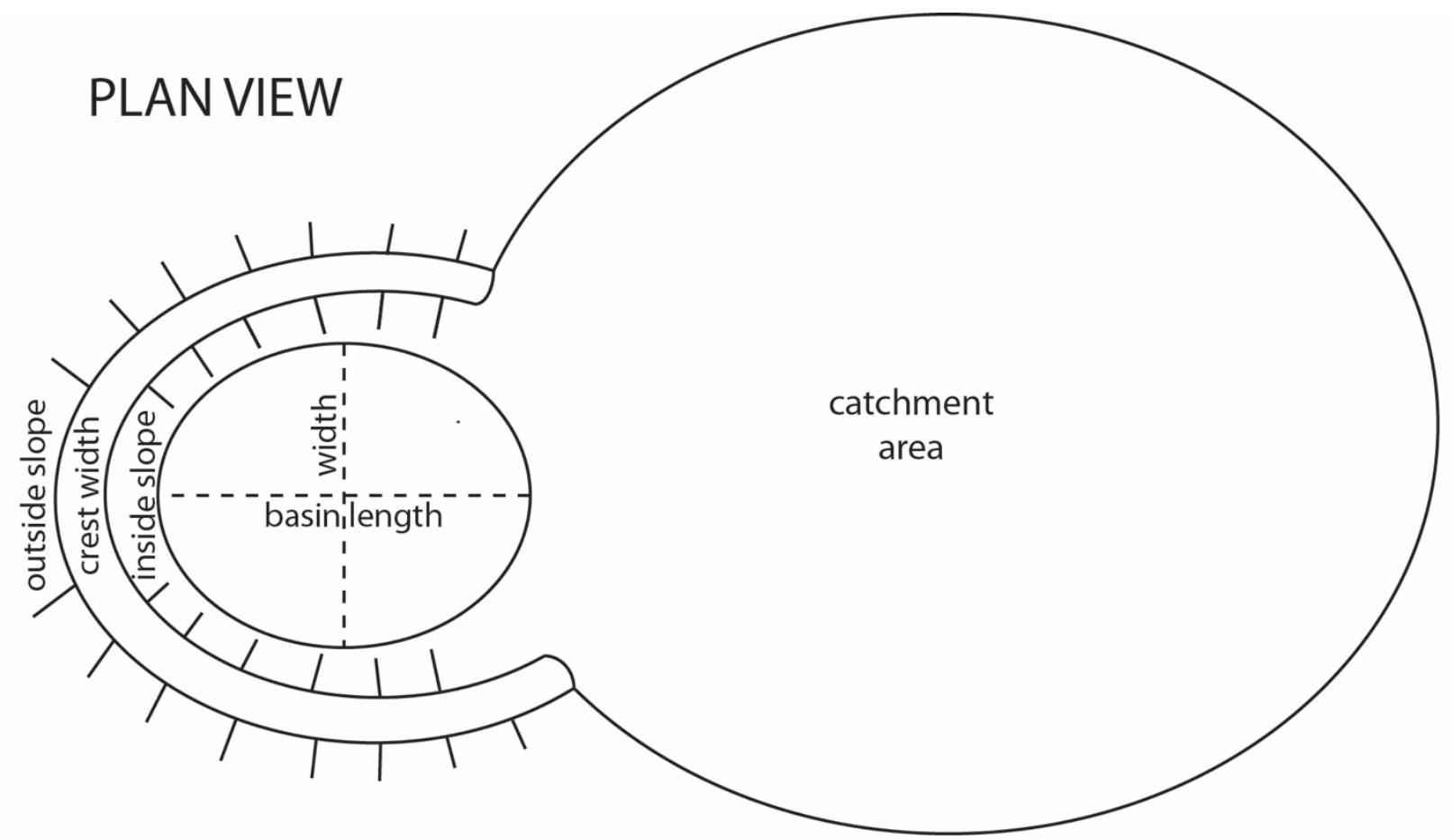

\section{PROFILE VIEW}

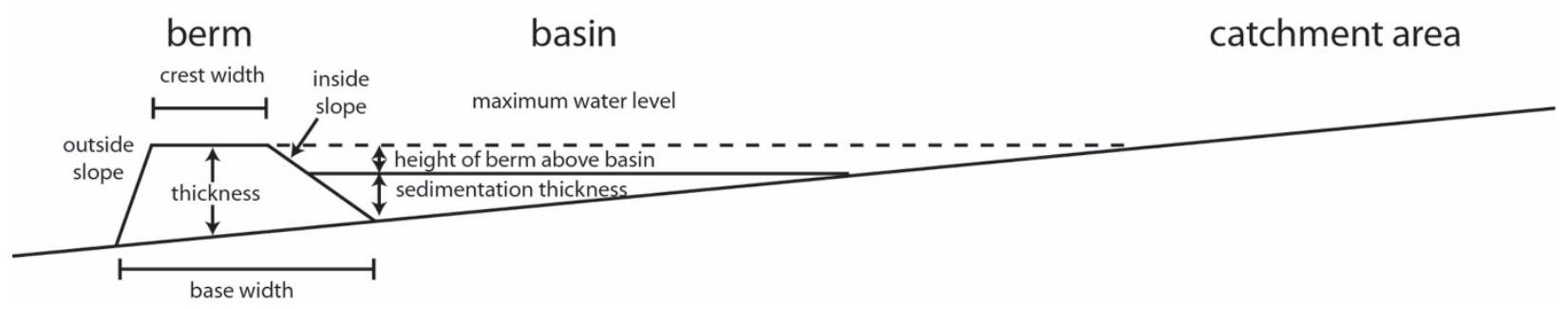

Figure 6.2. Standard dimensions of catchment basins (based on USDA 1998; NRCS 2005).

then capped to retain the core stratigraphy. I used this approach to test reservoirs at Amoxiumqua (LA481), Kwastiyukwa (LA482), Wabakwa (LA478), Tsirege (LA170), the reservoir near Tovakwa (LA61641). In cases where transporting the inverter and Demolition Hammer were 
problematic, I used a slide hammer to manually drive the core barrel. This was undertaken at the two reservoir sites at Boletsakwa (LA136, LA25092).

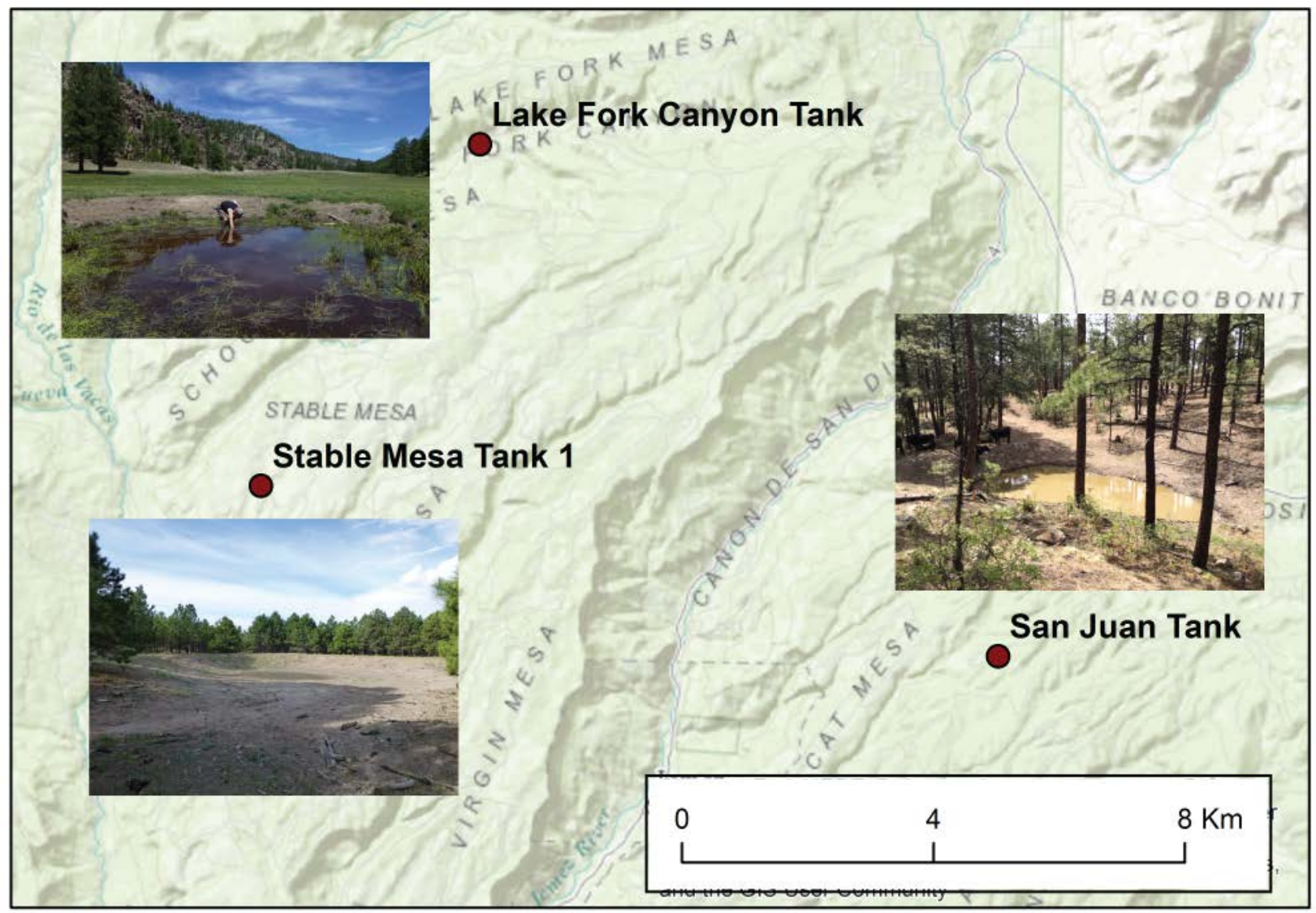

Figure 6.3. Locations of tested stock ponds.

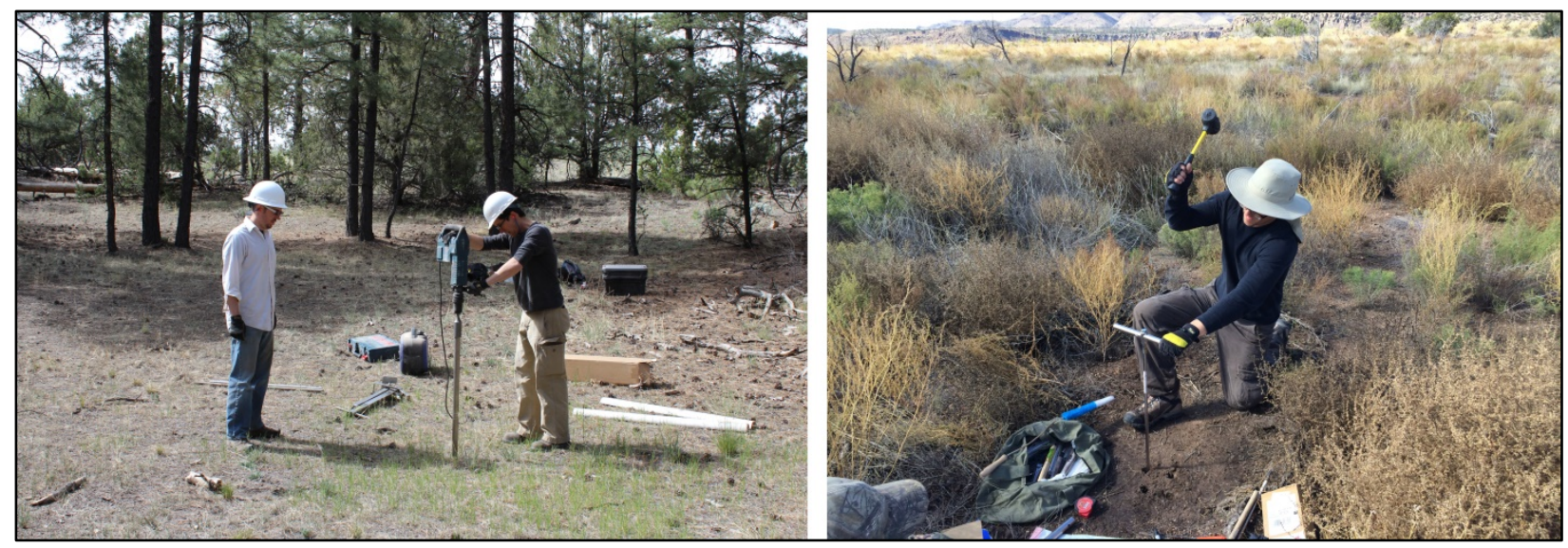

Figure 6.4. Coring using the ESP (left), and the Oakfield probe (right). 
I had to modify collection methods for the reservoirs at Bandelier National Monument. The back-country settings of these sites precluded the transport of 100 lbs. of equipment associated with the ESP. Instead, I used a 0.75 inch diameter modified Oakfield probe (Figure 6.4). The probe was driven using a rubber mallet. Extracted sediments from repeated cores were collected in clear plastic liners, and then sealed for transport out of the back country. This approach was used at reservoirs associated with the sites of Yapashi (LA250, 70790, 70798), Tsankawi (LA211), and Haatse/San Miguel (LA370, 3834).

\section{Lab Methods and Analyses}

I split, photographed, described, and sub-sampled all of the cores in the Environmental Archaeology Laboratory at SMU in Dallas, Texas. I described the cores using standard soils nomenclature (Schoeneberger 2012). Core descriptions are in Appendix D. After describing the cores, I subsampled them by stratigraphic horizon in 2-cm intervals. Typically, one core from each sampling locality was set aside to be impregnated with polyester resin for micromorphological analyses. In addition, all samples of one core from each locality were refrigerated to better ensure preservation of sediments for paleoecological analyses of diatoms and pollen.

Hydrological analyses required combining in-field measurements with 0.33 m resolution LiDAR derived digital elevation maps. I analyzed these data using the Hydrology Spatial Analyst Tools in ArcGIS 10.2. Potential storage volume was calculated as half the volume of a scalene ellipsoid. A scalene ellipsoid was considered the closest representation of the shape of the storage basin because it has a polar axis (z) shorter than the diameter of the bisecting 
equatorial circle (Figure 6.2). The radii of short and long lengths of the basin ( $a$ and $b$ ), as well as an estimation of the potential thickness of the water column (c), are used in volume calculations (Figure 6.5). Maximum thickness is measured from berm crest height to the base of the basin sediments. Because a water basin is only half of a sphere the calculated volume is halved. Calculations using the maximum thickness provide an estimate of the maximum storage volume of the feature. I present the results in Appendix E.

$$
\begin{aligned}
& \text { Reservoir Storage Volume Equation } \\
& V_{\text {reservoir basin }}=\left(\frac{4}{3} \pi a b c\right) / 2 \\
& \text { Runoff Discharge Equation } \\
& Q=\frac{(P-(0.2 * S))^{2}}{P+(0.8 * S)} \\
& P=\text { rainfall } \\
& S=\frac{1000}{C N}-10 \\
& C N=\text { runoff curve number }
\end{aligned}
$$

Figure 6.5. Equations used in hydrological calculations.

In Appendix E, I present estimations of catchment area runoff volumes based on modeled rainfall event magnitudes, as well as the maximum storage volumes of features. When runoff estimates exceed the basin storage volume, the feature is unfit and potentially "underengineered" in relationship to its catchment area. The integrity of the berm, due to erosion to the interior slope and/or overtopping, becomes compromised when it exceeds capacity. I calculated the catchment area of each reservoir using $0.33 \mathrm{~m}$ resolution digital elevation models and the 
Flow Direction and Basin Spatial Analyst Tools in ArcGIS 10.2. Surface runoff estimates were calculated using the SCS runoff curve method (SCS 1986). Runoff discharge (Q) is calculated using rainfall amounts, basin surface area, and estimates soil moisture retention, as expressed in a runoff coefficient number (CN). Estimates of yearly, 10-year, and 50-year maximum rainfall events for Jemez Springs and Bandelier were taken from the NOAA climate atlas (Bonnin et al. 2006) to provide measures for the type of high-intensity water-generating events anticipated to lead to surface flow and runoff accumulation into the drainage basin. Soils of Sandoval County are hydrologic soil group Class C soils (Hacker and Banet 2008), which are soils with slow infiltration rates when thoroughly wetted (0.05-0.15 in/hour). The cover type for the catchment basins can be considered poor ( $<30 \%$ groundcover), and is comprised of herbaceous arid to semi-arid rangeland, which generates a $\mathrm{CN}=87$. This number may be an underestimate, since many of the reservoir catchment basins would have been within active habitation areas of the villages, and likely be devoid of vegetation and/or having compacted soils (Farella 2015; KrusePeebles et al. 2010; Liebmann et al. 2016). Class D soils (soils with a high runoff potential) may better reflect catchment basins in village settings, which would have a $\mathrm{CN}=93$. Hence, I calculated runoff volumes using both $\mathrm{CN}$ numbers, which are presented in Appendix E. I discuss the significance of these estimations for each reservoir in Chapter 7.

Sediment analyses of 81 samples consisted of particle size distributions, $\mathrm{pH}$ measurements, soil organic matter measurements, and estimations of soil saturated hydraulic conductivity. I undertook these analyses to provide general sedimentological characterizations, to better understand the taphonomic properties affecting pollen preservation (Aiuvalasit and Kiahtipes in press), and to evaluate whether or not sediments infilling the basin would form an impermeable layer impeding the percolation of water into the underlying tuff substrate. The $>2 \mathrm{~mm}$ fraction 
(by weight \%) was determined by sieving, while the $<2 \mathrm{~mm}$ factions were analyzed using a Beckman-Coulter LA 13320 Laser Diffraction Particle Size Analyzer in the laboratory of Dr. Charles Frederick. Soil pH was measured using an Oakton EcoTestr pH 2 Pocket Tester. I measured soil organic matter (SOM) as a percentage of soil mass through loss-on-ignition at $360^{\circ} \mathrm{C}$ (Ben-Dor and Banin 1988). I estimated the saturated hydraulic conductivity of sediments using Saxton et al.’s (2006) Soil Water Characteristics Hydraulic Properties Calculator, Version 6.02.74 (https://hrsl.ba.ars.usda.gov/soilwater/Index.htm). Saturated hydraulic conductivity is a measurement of the capability of water to move within a saturated soil matrix. Impermeable soils have low saturated hydraulic conductivity. Saturated hydraulic conductivity of the Bandelier Tuff is reported to range from $0.00152-0.00000782 \mathrm{~mm} / \mathrm{sec}$, its variability being a function of porosity, depth, and distance from volcanic source (Peterson 2012). The results of these analyses are found in Appendix F.

Sediments from representative sections of core samples were described, dried, embedded in resin, and sectioned into blocks in the Environmental Archaeology Lab and the Department of Earth Sciences at SMU. Thin-sections were mounted on slides by Spectrum Petrographics, Inc. Sixty-nine slides were prepared, and I present the sample contexts (cores, depth, soil horizons) in Appendix G. I made observations of these samples to address specific site formation questions rather than to provide general characterizations. Therefore, I present descriptions and photomicrographs for only a limited number of samples in Chapter 7.

Paleoecological studies included stable carbon isotopes at one site (Amoxiumqua), pollen studies at six sites, and diatom analyses of nearly all of the features. Stable carbon isotope studies of 30 sediment samples from the site of Amoxiumqua were conducted to evaluate whether or not this analysis would be successful for characterizing changes in vegetation in and around the 
reservoir catchments. Samples were pre-treated to remove unburned organic tissues and carbonates in the Environmental Archaeology Lab at SMU, and were then analyzed at the University of Arizona Stable Carbon Isotope Laboratory. I present the results in the discussion of the Amoxiumqua reservoir in Chapter 7. The results of pollen analyses are not presented in this dissertation, but preliminary results show great promise for recovering high concentrations of preserved palynomorphs from basin sediments and some buried paleosols below earthen berms (Aiuvalasit and Kiahtipes 2017).

I focused the majority of my paleoecological investigations on diatom assemblages from basin sediments. Paleoecologists working in freshwater lakes, rivers, and ponds use diatoms as proxies for water depth, quality, pH, nutrient loads, and temperatures (Gaiser and Ruhland 2010; Smol and Stoermer 2010). Diatoms are a critical paleoecological proxy in paleolimnology and modern environmental monitoring (Cohen 2003). They are also used in archaeological contexts (Caran et al. 1996; Juggins and Cameron 2010; Meltzer 1991), and to study prehistoric changes in wetlands of arid environments (Winsborough 1995). Thirty six sediment and water samples were analyzed by Dr. Barbara Winsborough, a consulting ecologist who specializes in diatom analysis. Five samples (including the two water samples) were from modern stock tanks (Figure 6.4). The rest were extracted from sediments of Ancestral Pueblo reservoirs. Methods of ostrocod extraction, preparation, and analysis are presented in the reports by Dr. Winsborough, which I compiled and reformatted to present in Appendix C. The first 600 diatom valves encountered during microscopic observations for each sample were counted. The 600 valve count could not be achieved for some samples with very low diatom populations.

I summarize and incorporate the results of her studies in the discussions of each reservoir feature in Chapter 7, but some of the attributes of the modern analog samples should be 
discussed here. Each tested pond had different aquatic characteristics which are reflected in their diatom assemblages (Appendix C). Aerial species (types tolerant to frequent wetting/drying) can be present in high concentrations, and even in aquatic settings, such as the phytoplankton identified in the water sample from Lake Fork Canyon, and from mud in San Juan Tank. All of the modern analog samples have higher concentrations of aquatic species than the Ancestral Pueblo features. Because ancient features are subject to secondary depositional and taphonomic processes after abandonment, caution should be taken when making direct comparisons between modern samples to prehispanic features.

Finally, I developed chronologies of reservoir feature use-life histories. I processed 354 sediment samples to identify charred, short-lived plant tissues suitable for accelerated mass spectrometry (AMS) radiocarbon dating. I did this to reduce the possibility of "old wood" problems (Schiffer 1986) and in-built ages of wood (Gavin 2001) from skewing my targeted dating of sedimentation and construction sequences. Sediment samples were passed through 125 $\mu \mathrm{m}$ mesh screen to isolate organic tissues. Wet screened samples were first soaked overnight in a 10\% Na-hexametaphosphate solution to deflocculate the sediments. After screening aided by washes with DI water, samples were washed into gridded petri dishes and allowed to dry. I used a binocular microscope at 5-25X magnification to identify and pick charred tissues, using botanical keys (Capon 2010; Cappers and Neef 2012; Elmore 1976), and comparative collections of charred tissues from the Jemez Plateau at the SMU Environmental Archaeology Lab. Sixtyone subsamples of charcoal were selected for radiocarbon analysis. I pretreated the charcoal samples following standard Acid-Base-Acid pretreatment protocols. The W. M. Keck Carbon Cycle Accelerator Mass Spectrometry Laboratory at UC Irvine combusted, graphitized, and measured the samples. I calibrated results of AMS analyses to calendar years using Intcal13 
(Reimer et al. 2013) in OxCAL 4.2 (Ramsey 2013), and I present the results in Appendix H. I modeled probability distributions with Bayesian calibrations, using the BCAL software package with stratigraphic contexts as priors (Buck et al. 1999). Bayesian calibrations, with an explanation of priors, are presented in discussions and figures with each site-specific discussion, as are calibrations of modern dates. CALIBomb software (Reimer et al. 2004), was used to calibrate modern radiocarbon measurements to calendar years.

\subsection{Summary}

Archaeologists working in the Southwest use a range of methods to testing these types of features. In this chapter I craft an explicit research design to test alternative hypotheses through integrating multi-proxy geoarchaeological evidence to evaluate the function of many archaeological features. By targeting my geoarchaeological coring and hydrological modeling I could rapidly test multiple features while limiting impacts to sites. This approach aligned with both the preservation mandates on federal lands and the concern of descendant communities for disturbances to their Ancestral sites. The limited exposures demanded multi-proxy investigations of stratigraphy, sedimentary paleoecology, and dating to address questions, which in some cases would be easier to address through excavations generating larger exposures. Integrating hydrological modeling provides another key dataset to evaluate against the geoarchaeological

record. I present the outcomes of this approach in Chapter 7 and consider its merits in concluding statements in Chapter 9. 


\section{CHAPTER 7. RESULTS OF GEOARCHAEOLOGICAL INVESTIGATIONS}

In this chapter I present the results of geoarchaeological investigations of fifteen water reservoir features associated with nine Ancestral Pueblo villages (Figure 7.1). The goals of these investigations were to determine how these features functioned as an infrastructure designed, built, and maintained through collective action, and to place their use-life histories into broader socio-natural contexts of the Jemez Mountains. The results of direct geoarchaeological investigations and an evaluation of the site formation model of feature function are presented for each feature, by region. Underlying data are presented in Appendices B-H. Regional syntheses and inter-regional comparisons follow.

\subsection{The Jemez Plateau Reservoirs}

I tested six reservoir features across the Jemez Plateau (Figure 7.1). I identified the features to be tested from published reports of large Ancestral Pueblo villages (Elliott 1982), and by reviewing site records with Forest Service archaeologists. The only prior studies of these features consist of letter reports about reservoirs at Boletsakwa (LA136), and LA25092 (Elliott 1983 and Turney and Turney 1983). The only other site which may have a reservoir is Astialakwa (LA1825) atop Guadalupe Mesa. In 1875 the Jemez governor Hosta described the presence of a reservoir feature at this Revolt Period site (Loew 1875: 177). Yet, Liebmann (2012) did not identify any reservoir features during his intensive survey, but he did identify two U-shaped 
shrines. I did not visit this site, therefore, evaluating whether or not there were water storage features at Astialakwa will need to be the subject of a future study.

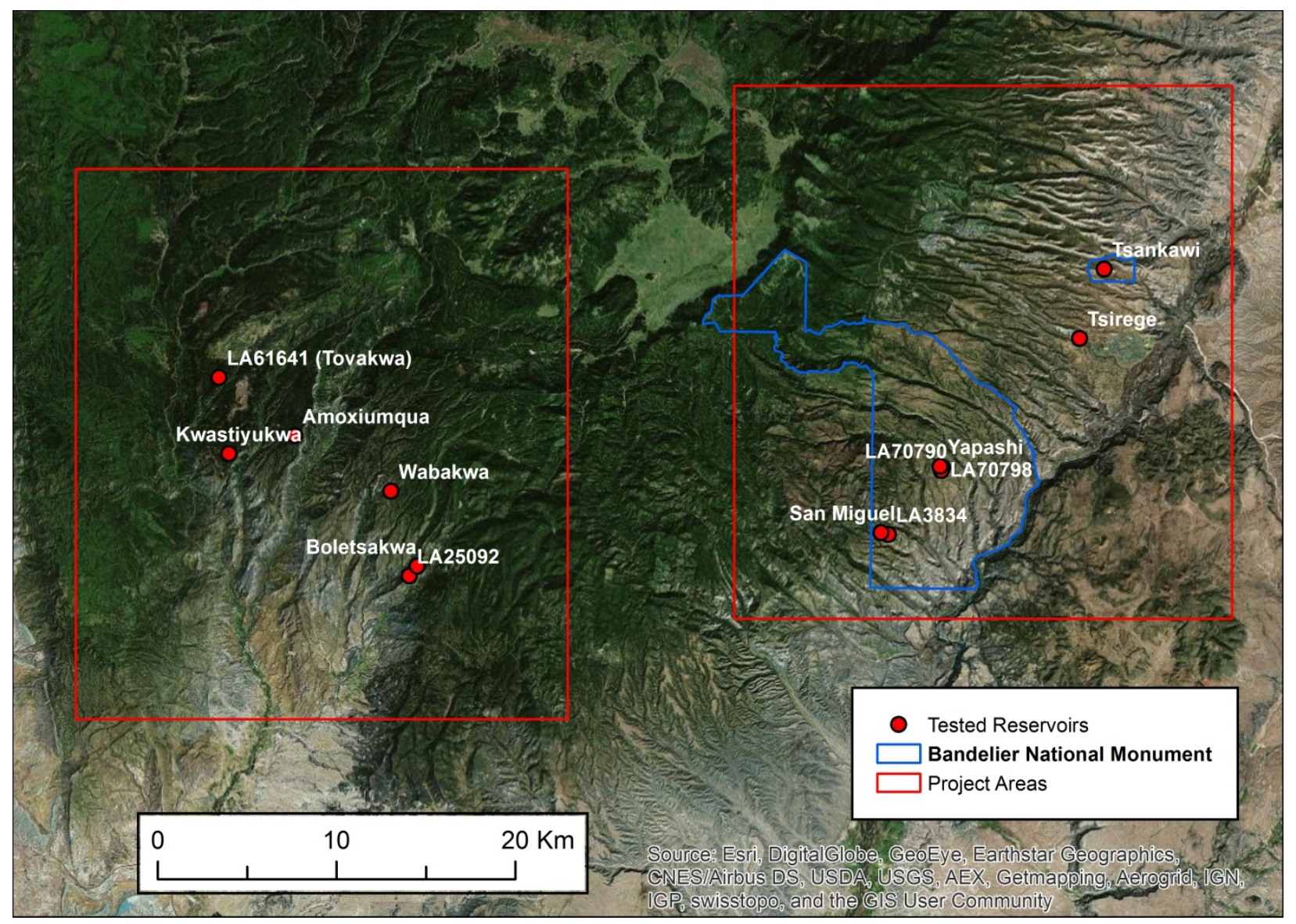

Figure 7.1. Locations of reservoir features tested in this study.

\section{Amoxiumqua (LA 481)}

The site of Amoxiumqua is located on Virgin Mesa, immediately above San Diego Canyon and west of Jemez Springs (Figure 7.1). The Towa name for the site translates as "anthill place” (Sando 1982:12), but to the Jemez this site is Tovakwa. There is confusion over its proper Towa name, as is true of many of the large Ancestral Jemez villages and towns west of San Diego 
Canyon, because early archaeologists misnamed these sites (Elliott 1986; Reiter 1938).

Excavations at Amoxiumqua between 1910-1914 are only summarized and not fully reported (Reiter 1938). These excavations and early historical accounts (Elliott 1986) show that this site was occupied into the historic period (Reiter 1938). Kulisheck (2005) estimates that there were 1250 rooms at the site, and that it was occupied between AD 1350-1700. Based on rubblevolume calculations, Liebmann et al. (2016) estimates a maximum population of 717, and terminus ante quem tree recruitment dates suggest that the occupation began to decline in the late 1500s (Josh Farella, 2015, personal communication).

The reservoir feature is located on the northwestern side of the site. It is built adjacent to a roomblock, and it impounds the upper-most slopes of a small drainage. Its entire catchment area is within the site (Figure 7.2). Early archaeologists recognized it as a water storage feature (see Figure 1.2), yet recently Arbolino and Nelson (2014: Figure 3) mapped it as a kiva. Jennie Sturm, a graduate student at the University of New Mexico, conducted a ground penetrating radar transect across a portion of the berm and basin (Figure 7.2), and found no signs of buried architectural elements of a kiva (Jennie Strum, 2015, personal communication). Vegetation in the area is regrowth of ponderosa pine, with a patch of grasses growing in the basin. Josh Farella conducted preliminary dendrochronological ring-counts of one of the large ponderosas in the foreground of the 1910 photograph (Figure 1.2) and determined that it is now approximately 200 years old (Josh Farella, 2015 personal communication). This suggests relatively recent forest recruitment around the reservoir feature. Artifacts are found across the catchment area, and are occasionally found on the surface of the basin. They are rare on the berm surface, although duff obscures most of the ground. 


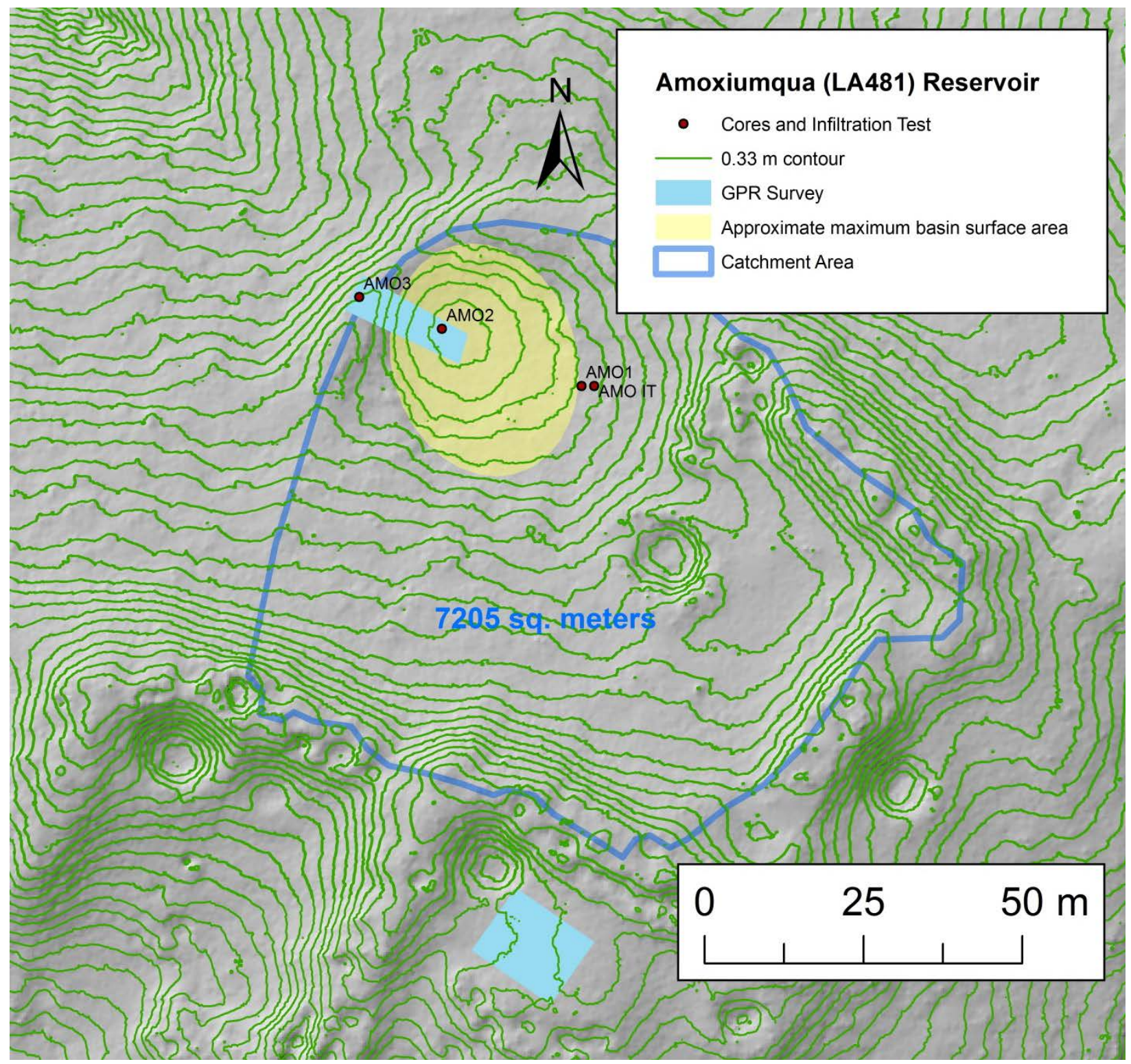

Figure 7.2. Map of coring locations, GPR survey areas, and catchment area of the Amoxiumqua (LA481) reservoir.

In my attempts to sample natural sediments and soils outside of the catchment area I repeatedly encountered only shallow $(<10 \mathrm{~cm})$ surface soils formed atop tuff bedrock. Ultimately, I collected a control sample immediately upslope of the catchment basin (AMO1 in Figure 7.2), which yielded a $59 \mathrm{~cm}$ thick A-BC1-BC2-R soil sequence (Figure 7.3 and Appendix D). From 0-6 cm is an A horizon of fine sandy loam with common decayed and undecayed plant 
tissues. The underlying BC horizons from 6-59 cm are brown clay loam to sandy clay loam with platy to moderate fine blocky subangular structure and weak clay films on ped faces (Appendix D). Charcoal and partially decayed organics are found in the BC1 horizon. When compared to the thin soils outside the site area or to the natural soil sequence preserved underneath the berm (see below for descriptions), the humic soils from the catchment area likely reflects anthropogenic accumulations as well as pedogenic alterations due to intense cultural occupation and subsequent abandonment.

\section{Amoxiumqua (LA481) Reservoir Chrono-Stratigraphic Cross Section}

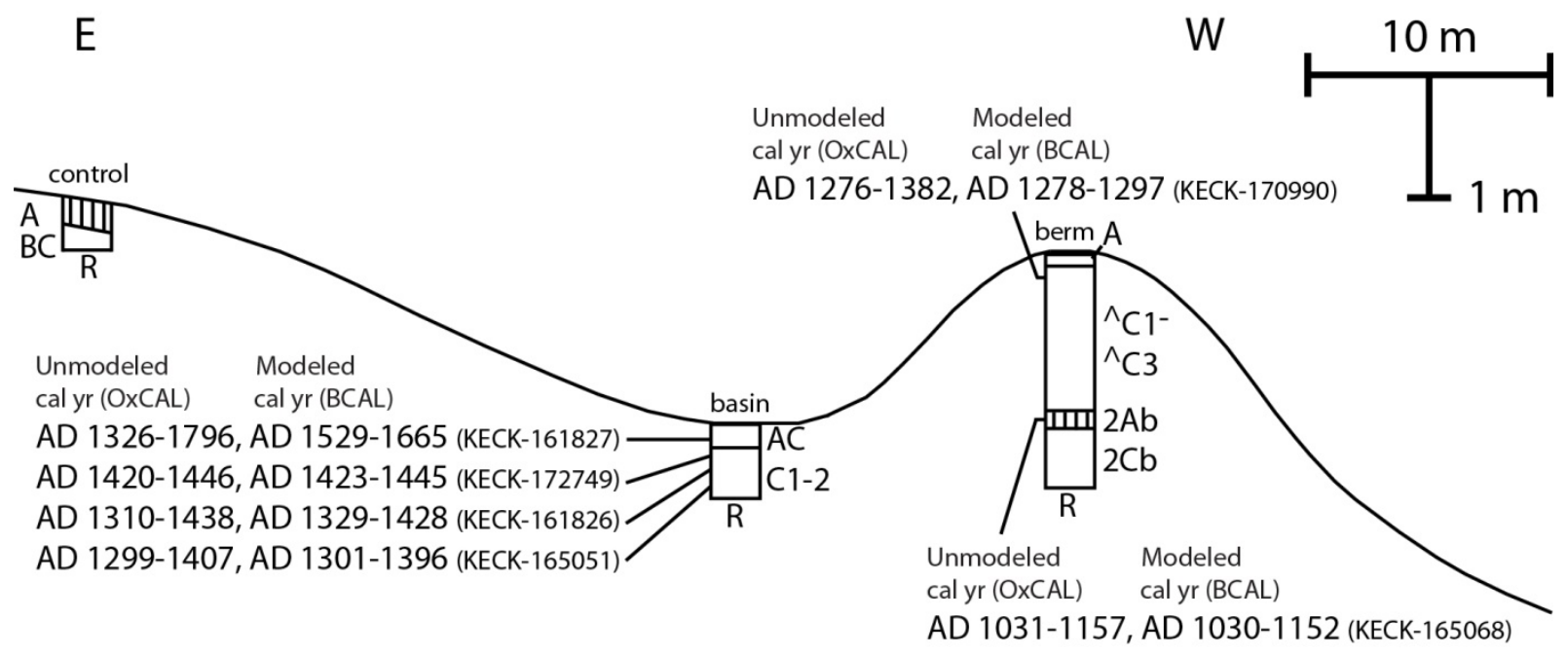

Figure 7.3. Chronostratigraphic cross section of the Amoxiumqua (LA 481) reservoir feature.

Cores into basin deposits consisted of $0.5 \mathrm{~m}$ thick bedded sediments with an AC-C1-C2-C3R soil sequence (Figure 7.2, and Appendix D). They differ from the control sediments because they have both a finer silty clay loam texture, yet also have a coarse fraction (5-20\%). From 0-20 $\mathrm{cm}$ is an AC horizon of dark reddish gray (7.5YR4/2) sandy loam. It has a platy structure and an 
abrupt lower boundary. There is some variability in the epipedon between basin cores. From 0$18 \mathrm{~cm}$ most cores have an AC horizon of dark brown (7.5YR3/2) silt to silt loam with platy structure, burned and unburned plant tissues, and an abrupt lower boundary between 0-18 cm. The core from the pilot study had a $6 \mathrm{~cm}$ thick CA horizon between the epipedon and the unweathered C horizons (18-22 cm) (Appendix D). It was relatively rich in charcoal and partially decayed organics. Four of the six AMS dates from Amoxiumqua were obtained from the basin (Figure 7.3, Appendix H). Charcoal from finely laminated sediments from $18-20 \mathrm{~cm}$ above the unconformity at the base of the AC horizon produced a modeled dated of cal AD 1529-1665 (KECK-161827), which I should note is modeled off 2-sigma calibrations, as are the rest of the reported dates through the remainder of the dissertation. Micromorphological observations from the AC horizon see no limpid coatings in the upper sample (Appendix G: A2_3-7cm), but limpid clay coatings are found along root casts on sample A2_16-20 cm at the bottom of the horizon (Figure 7.4), and in other samples deeper in the basin. This suggests soil stability within the basin, and pedogenic illuviation associated with saturation within the basin.

Between 20-50 cm the C1-C3 horizons are stratified, poorly sorted dark brown (7.5YR3/2) to very dark gray (7.5YR3/1) sandy clay loam to sandy clay with common tuff pebbles and gravels (C1-C3) horizons (Figure 7.3, Appendix D). Charcoal is found throughout all horizons. A modeled basal date of charcoal from the C3 horizon at $41 \mathrm{~cm}$ shows sedimentation in the basin began by cal AD 1301-1396 (KECK-165051). A modeled date of charcoal from $31 \mathrm{~cm}$ is slightly younger, at cal AD 1329-1428 (KECK-161826), and sedimentation continued until at least cal AD 1425-1445 (KECK-172749) at the top of the C1 horizon based on a modeled date from 25 $\mathrm{cm}$. 

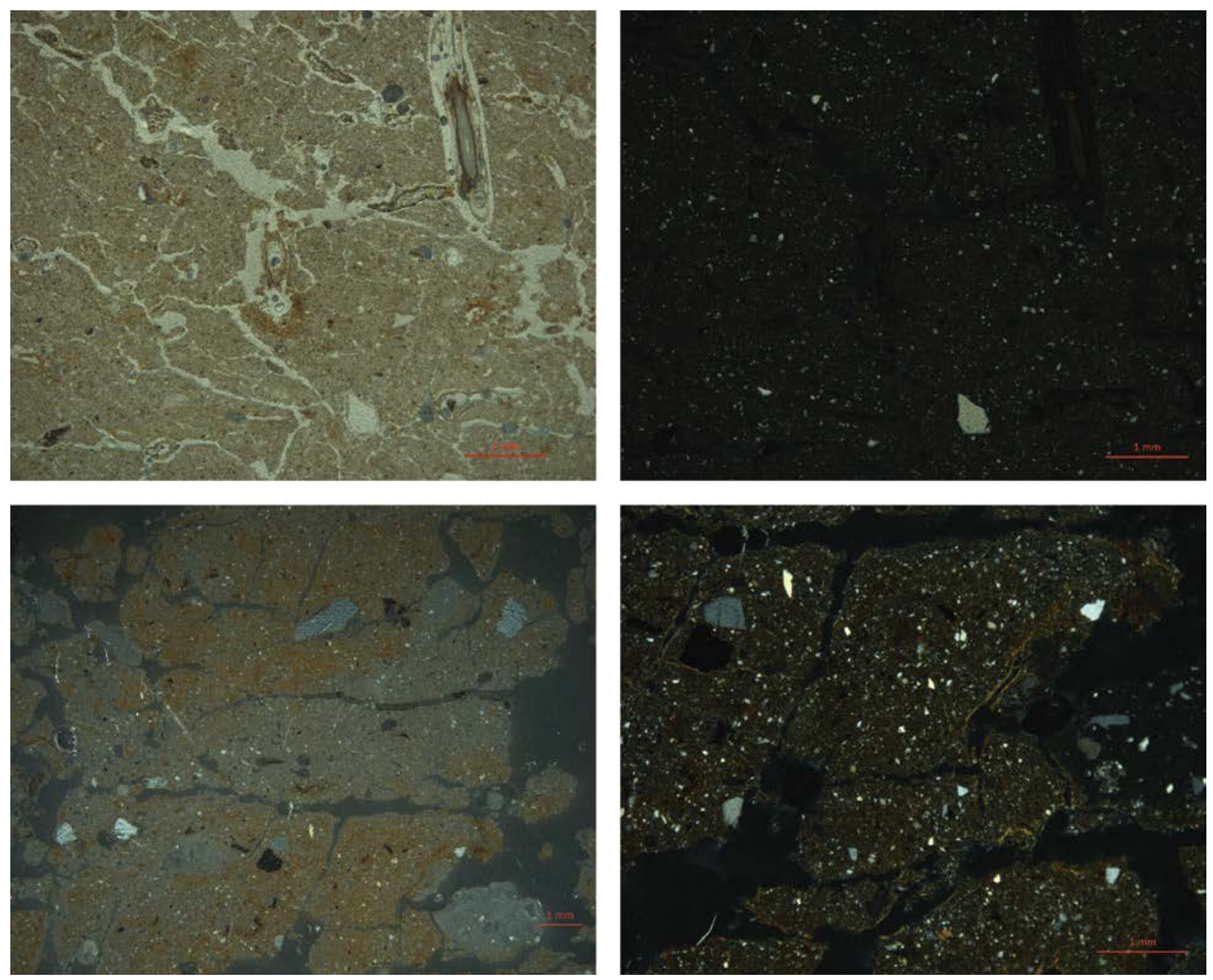

Figure 7.4. Photomicrographs of Amoxiumqua (LA481) reservoir soil samples. A2_3-7 cm in plane polarized light (PPL) and cross polarized light (XPL) (top), and A2_20.5-24.5 in oblique incident light and XPL, and XPL (bottom). Note that the upper sample lacks dusty clay coatings and high reflectance limpid clay coatings along channels that are seen in the photomicrographs from the lower sample.

Cores of the earthen berm recovered approximately $125 \mathrm{~cm}$ of fill above a buried paleosol (Figure 7.3, Appendix D). The berm fill (^C1-^C3 horizons) is light brown (7.5YR5/4) to dark brown (7.5YR3/2) sandy loam to sandy clay loam. Structure is massive to single grained with hard consistence, and charcoal and rock fragments are common. Charcoal from berm fill 
sediments collected between $20-22 \mathrm{~cm}$ below the top of the berm produced a model date to cal AD 1278-1297 (KECK-170990).

The paleosol buried below the berm fill (2Ab) is a dark brown (7.5YR3/4) loam with granular structure, common charcoal and fine tuff gravels (Figure 7.4). Charcoal from the paleosol resulted in a modeled date of cal AD 1030-1152 (KECK-165068). The paleosol is underlain by increasingly weathered $2 \mathrm{Cb}$ to $2 \mathrm{BCb}$ horizons of brown to dark reddish brown (5YR3/3) clay loam with redox concentrations to depth of $140 \mathrm{~cm}$. These subsoils are likely the closest analog to the soils that would have been excavated by Ancestral Pueblo to form the basin, and potentially serve as the berm fill. The subsoils and the berm fill share similar textures, but the berm fill lacks redox concentrations. If the subsoil redox concentrations are formed due to phreatic seepage of reservoir water seeping into the subsoil below the berm then it is not surprising that berm fill does not have relicts of these pedogenic features.

The large size of the berm and excavated catchment basin give Amoxiumqua the largest potential storage volume of all of the tested reservoirs. Runoff estimates based on its catchment area and annual maximum daily rainfall magnitudes (discussed in Chapter 5) show that no modeled rainfall intensities would exceed the storage potential of the basin (Appendix E). Estimations of saturated hydraulic conductivity for the basin sediments range between 6.91-4.05 $\mathrm{mm} / \mathrm{hr}$., and it has the second lowest mean saturated hydraulic conductivity of all the features I tested (Appendix F). This suggests that infilling sediments would increase the water-holding capacity of the feature by reducing the potential for water loss due to infiltration.

The volumes of water generated by runoff events could make significant contributions to community water budgets, albeit it is unlikely that the reservoir provided enough water for yearround use (Table 7.1). Based on a 3-10 L per person per day water demand, the catchment area 
size, and a modeled runoff curve number of 93, and not accounting for infiltration or evaporation, the typical 1-year maximum rainfall event could provide approximately 1-2 months' worth of water. Based on modern observations presented in Chapter 5, wet years would likely see runoff of significant magnitudes in both non-monsoon and monsoon seasons, while normal and dry years would see large runoff events during the monsoons. In typical monsoon years, the feature would likely generate enough water for a few months' of use, while even in dry years it would likely collect water, if rationed to near 3L a day, for at least a two month period. If there was repeated rainfall during the monsoon period, which in the instrumental records of Jemez Springs averages nearly $19 \mathrm{~cm}$ (7.48 inches) of precipitation (Table 5.1), then total accumulations in the basin may approach the volume of water expected for 50 -year rainfall events.

Table 7.1. Modeled community water budgets and reservoir storage potential for Amoxiumqua (LA481) (based on 3-10 L per person, per day estimate).

\begin{tabular}{|l|c|c|c|c|}
\hline $\begin{array}{l}\text { Daily Village } \\
\text { Water }\end{array}$ & \multicolumn{1}{l}{$\begin{array}{l}\text { Village Water Days } \\
\text { per 1-yr max } \\
\text { rainfall event (3.68 } \\
\text { Estimate }\end{array}$} & $\begin{array}{l}\text { Village Water Days } \\
\text { per 10-yr max } \\
\text { rainfall event (6.63 } \\
\text { cm, CN=93) }\end{array}$ & $\begin{array}{l}\text { VN=93) } \\
\text { Village Water Days per } \\
\text { 50-yr max rainfall } \\
\text { event (8.74 cm, CN=93) }\end{array}$ \\
\hline $50 \%(\mathrm{n}=359)$ & $1.077 / 3.59$ & $140 / 42$ & $320 / 96$ & $455 / 136$ \\
\hline $80 \%(\mathrm{n}=574)$ & $1.722 / 5.74$ & $87 / 26$ & $200 / 60$ & $284 / 85$ \\
\hline $100 \%(\mathrm{n}=717)$ & $2.15 / 7.17$ & $70 / 21$ & $160 / 48$ & $228 / 68$ \\
\hline
\end{tabular}

To provide paleoecological evidence for water conditions, four diatom samples from the basin were analyzed (Appendix D). The diatom assemblages have high species diversity (18-21 $s p$.$) , and the presence of aquatic types. Aerial types dominate the record throughout the basin fill$ 
sequence, indicating that the feature regularly dried out (Appendix C). The presence in all of the samples of Stauroneis anceps, a benthic type adapted to clean water with high dissolved oxygen levels, indicates that when there was standing water it was clean and potable. This type was found in modern analog stock ponds samples from Lake Fork Canyon and San Juan Mesa (Appendix C). There is some intra-sample variability (Figure 7.5). The upper samples (AMO2.205, 2.210) and the bottommost sample (AMO2.224) have greater taxa diversity than sample AMO2.212, which is from the top of the $\mathrm{C} 1$ horizon (Figure 7.4, Appendix C). This may reflect drier conditions towards the top of the $\mathrm{C}$ horizon, and potentially less water in the basin during the 1400s, which was a period of lower overall precipitation and likely higher community demands on water.

The AMS dates from the basin deposits, in conjunction with stratigraphic, pedogenic, and paleoecological evidence, suggests that there was a stratigraphic unconformity in the sequence at the contact between the upper epipedons and the underlying C1-C3 horizons at approximately 18-20 cm (Figure 7.3, Appendix D). The AMS dates serve as the most compelling evidence for an unconformity. An age depth model, performed in CLAM (Figure 7.5) shows a significant change in modeled depositional rates at this stratigraphic context. The pollen record from below and above the unconformity indicates a shift from vegetation reflective of disturbed conditions to pine forests (Aiuvalasit and Kiahtipes 2017). Stable carbon isotope ratios also reflect a shift in the type of vegetation sources for soil carbon, with increasingly enriched ratios ( -23\%o to 21\%o) at this contact (Figure 7.4), also suggesting a change in vegetation. There are changes in the diatom assemblage too. Aerial and cosmopolitan habitat types make up the majority of diatoms in all four samples, and many of the aquatic types are also found in samples from modern stock tanks (Appendix C). The bottom- and top-most samples have the most benthic 
aquatic types, as well as the greatest species diversity (Figure 7.5, Appendix C). In addition, there is an increase in the number of acidophilous diatoms in the uppermost diatom samples within the AC horizon (Appendix C), which may reflect increasingly acidic water conditions associated with the recruitment and establishment of pine forests across the site area after abandonment. The abrupt lower boundary and differences in texture and bedding suggest an unconformity between these horizons. The lack of soil formation in the C1 horizon, which could potentially reflect a depositional hiatus, could potentially be a cultural truncation.

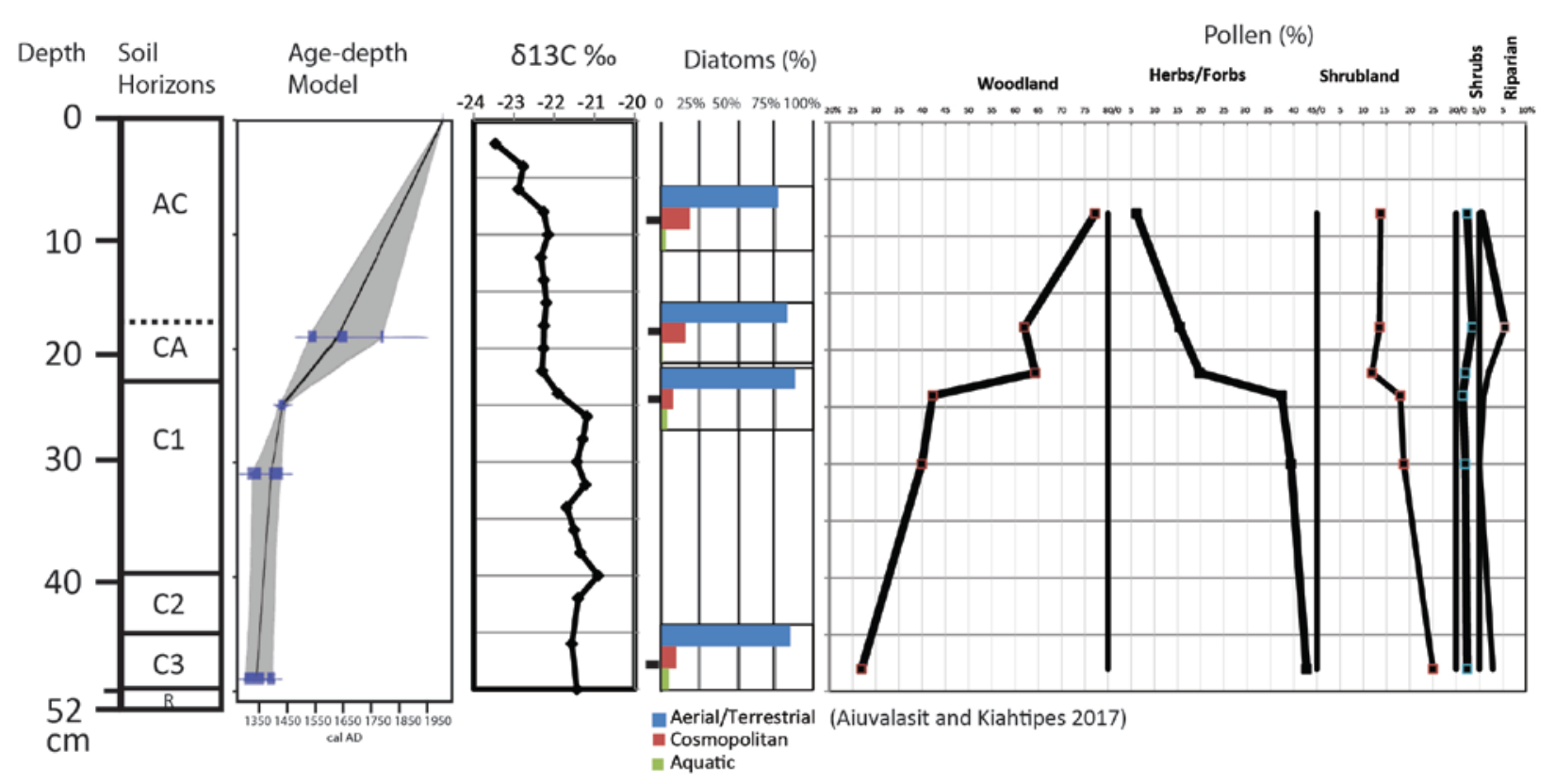

Figure 7.5. Multi-proxy evidence for a stratigraphic unconformity and post-abandonment forest regeneration at Amoxiumqua (LA481).

Multi-proxy evidence indicates that the Amoxiumqua reservoir was efficient for storing water and that its use was long, but varied. Dates from the buried paleosol and the top of the berm fill indicate that the reservoir was constructed slightly before AD 1300. Basin clean-out 
was not likely used to augment berm height, as the berm fill does not share sedimentary attributes with the basin deposits, but instead it is similar in color and structure to the soils buried underneath the berm fill. This supports a model of rapid basin excavation and berm construction, and that the sediments preserved at the bottom of the basin reflect sedimentation initiating shortly after construction. Multiple lines of evidence suggest a stratigraphic unconformity in the sediment sequence. There is no evidence for a buried soil forming at this unconformity, instead an unconformable unit, approximately 100 years younger is found atop. As this is a closed basin, with no evidence for erosion, the possibility that basin deposits were truncated, perhaps during a clean-out event cannot be ruled out. The initiation of new sedimentation atop this truncation, which potentially dates to historical times, means we cannot rule out that the truncation occurred shortly before the dated initiation of new sedimentation of the AC horizon, which may have taken place during historical reoccupation of Amoxiumqua. Multi-proxy evidence for a shift in vegetation sequences correlate with regional environmental and social histories of forest recruitment after the Pueblo Revolt and subsequent removal of Jemez populations from the mesa-tops in the middle $17^{\text {th }}$ century (Liebmann et al. 2016), which are corroborated in the sedimentary record of this feature, further support the argument for a historical truncation of the basin.

When evaluated against alternative site formation models, the geoarchaeological evidence best supports the hypothesis that the Amoxiumqua feature is a water reservoir. There is no evidence for extra-local or disturbed sediments in the basin reflecting mortar or adobe mixing. It held usable quantities of water, albeit not year-round. This is supported by the diatom record that there was enough standing water in the basin to support the establishment of aquatic habitats for benthic species, but that the feature still regularly dried out. The diatom record also suggests the 
water was potable, even though the catchment area included runoff from site areas. The feature was constructed before archaeological evidence for large-scale village aggregation, but evidence of a clean-out event late in the occupation sequence indicates it was used throughout its occupation history. Pollen records show no species types particularly diagnostic of permanently wet conditions (Aiuvalasit and Kiahtipes 2017). The pollen record for a basin without aquatic vegetation combined with the diatom record of clean water, hydrological evidence for storing usable volumes of water, and evidence for maintenance does not support the watery shrine site formation model.

\section{Boletsakwa (LA136)}

The site of Boletsakwa, which translates to "shell-eye place" (Sando 1982:13), is located on the narrow Boletsakwa Mesa overlooking Paliza Canyon (Figure 7.1). The site architecture is well documented (Liebmann 2012), but the only excavations at the site were conducted by Girl Scouts in the 1960s (Elliott 1982). Kulisheck (2005) estimates there are 650 rooms, while Liebmann et al.’s (2016) rubble mound estimates project a smaller room count and a maximum population of 413. Boletsakwa Mesa has long history of occupation. Immediately north and upslope of the site on the northern-most tip of the mesa is site LA135, known as Little Boletsakwa. Kulisheck (2005) dates this site to the Vallecitos Phase (AD 1200-1350). The main occupation of Boletsakwa dates to AD 1525-1700, with historical records, oral traditions, and archaeological evidence that this site was most intensively used during the Pueblo Revolt by the

Jemez and their Pueblo allies. It was also briefly used as a refuge site in the early $18^{\text {th }}$ century (Liebmann 2012). 
The reservoir feature is located between the northern-most roomblocks of Boletsakwa, and downslope of Little Boletsakwa (Figure 7.6). It was documented in a letter report by Elliott (1983). The engineers Turney and Turney (1983) describe its hydrological setting and excavated a test pit in basin. It is $15.5 \mathrm{~m}$ in diameter, and it has a small catchment of relatively high gradient mesa-top slopes (Appendix B). The feature is unique among the reservoir features of the Jemez Plateau because its downslope earthen berm is small, at only $0.31 \mathrm{~cm}$ high above the basin. The storage volume is largely a function of a deeply excavated basin. The vegetation around the feature and the catchment area is largely piñon-juniper, with some ponderosa pine and grasses. There are many ponderosa pine snags in the area, including on the upslope rim of the reservoir feature. This snag has a pith date of AD 1700-1709, suggesting that this feature was abandoned by the late $17^{\text {th }}$ century (Farella 2015).

The surface soils documented in the catchment area by core BOL1 are thick, very gravelly loamy sands (38 cm) underlain by a calcic horizon (Bk) between 38-53 cm (Figure 7.7, Appendix D). Pumice gravels were observed below the Bk horizon, and extended until the core excavation was stopped at a depth of $105 \mathrm{~cm}$.

I recovered an $87 \mathrm{~cm}$ thick $\mathrm{AC}-\mathrm{Ab}-\mathrm{AC} 1-\mathrm{AC} 2-2 \mathrm{CA}-2 \mathrm{C}$ soil sequence from the basin, and bound its chronology with 5 radiocarbon dates, which are modeled independent from the berm dates (Figure 7.7, Appendices D and H). By comparison, Turney and Turney (1983) excavated a 1 foot deep test pit into the northwest corner of the basin, and identified silts to depth, and encountered no bedrock in a probe which extended to a depth of 2.5 feet $(0.76 \mathrm{~m})$ below ground surface. The soil sequence in my cores consists of gravelly loamy sands between 0-60 cm (ACAb-AC1-AC2 horizons), underlain by sandy loams and gravelly sandy clay loams to $87 \mathrm{~cm}$ (2CA-2C horizons) (Figure 7.7, Appendix D). The basin sediments of Boletsakwa have the 


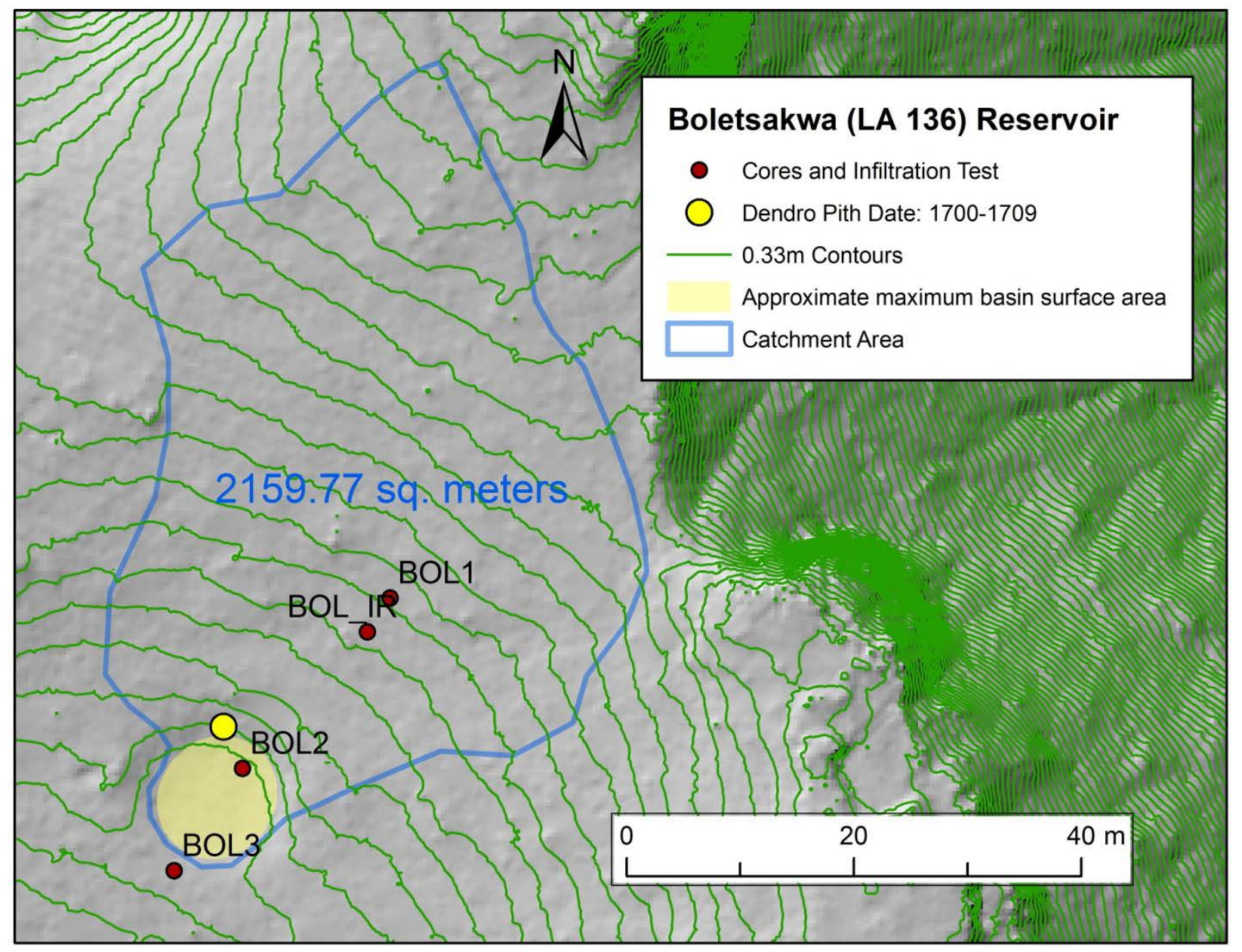

Figure 7.6. Map of coring locations, pith date of snag (Farella 2015), and catchment area of the Boletsakwa (LA136) reservoir.

highest sand fractions of any basin samples, suggesting high energy deposition (Appendix F).

This would make the basin deposits poor for storing water, which is reflected in the highest mean saturated hydraulic conductivity values (mean $=50.21 \mathrm{~mm} / \mathrm{hr}$.) of all the basins I tested (Appendix F). The AC-Ab sequence at the top of the basin between 0-16 $\mathrm{cm}$ varies between cores. It is a dark brown (7.5YR3/2) gravelly loam to sandy loam, which in some cores has a black (7.5YR2.5/1) matrix suggestive of a buried paleosol (Ab) at its base. Charcoal dated from the bottom of the AC/Ab horizon $(14-16 \mathrm{~cm})$ produced a modeled date of cal AD 1667-1808 
(KECK-172750). This age range suggests this soil formed immediately after Boletsakwa was no longer occupied by Pueblo peoples, and it coincides to the beginning of forest recruitment across the mesa-top (Farella 2015; Liebmann et al. 2016). Charcoal from the courser grained middle sedimentary packages (AC1-AC2) produced modeled dates of cal AD 1207-1261 (KECK172751) (62-68 cm) and cal AD 1417-1442 (KECK-165050) (40-42 cm) indicating continued sedimentation into the 1400s (Figure 7.7, Appendix H). These deposits correlate to the Vallecitos and Paliza Phase occupations. Modeled dates of charcoal from the finer-grained sediments at the bottom of the basin (2CA-2C horizons) date to cal AD 1162-1232 (KECK-161822) and to cal AD 1207-1277 (KECK-161823). These lower deposits are gravelly sandy loams interbedded with a few fine laminae of clay loams. These preserved interbedded deposits reflect varying depositional energies in the basin, and they are unique among the reservoir features I tested. Micromorphological observations of these interbedded deposits (Appendix G: sample B2.5_85.5-89.5) show lenses of charred material, poorly sorted heterolithic matrix, and little evidence for pedogenic development associated with hydric conditions (Figure 7.8). Even though these deposits are relatively finer grained, sediment samples from this horizon still have high saturated hydraulic conductivity (25.34 and $26.98 \mathrm{~mm} / \mathrm{hr}$.), suggesting the basal deposits had limited potential for retarding water infiltration. Below $87 \mathrm{~cm}$ are unconsolidated pumice gravels (3Cr). The low berm on the downslope side of the feature consists of $28 \mathrm{~cm}$ thick disturbed A horizons of loamy fine sand to loamy gravelly sand (A-^AC-Ab?) above unweathered gravelly pumice deposits (C1b-C2b) (Figure 7.7, Appendix D). There is possibly a buried A horizon between $24-28 \mathrm{~cm}$, which was identified due to its darker color, and fine granular structure. Two AMS dates from $18-20 \mathrm{~cm}$ below surface produced nearly overlapping dates from a charred woody stem fragment, cal AD 1433-1483 (KECK165048), and an outer ring of wood xylem, cal 
AD 1486-1636 (KECK165049). When compared to the early dates from the lowest basin fill, these berm dates suggest that the berm was remodeled later.

\section{Boletsakwa (LA136) Reservoir Chrono-Stratigraphic Cross Section}

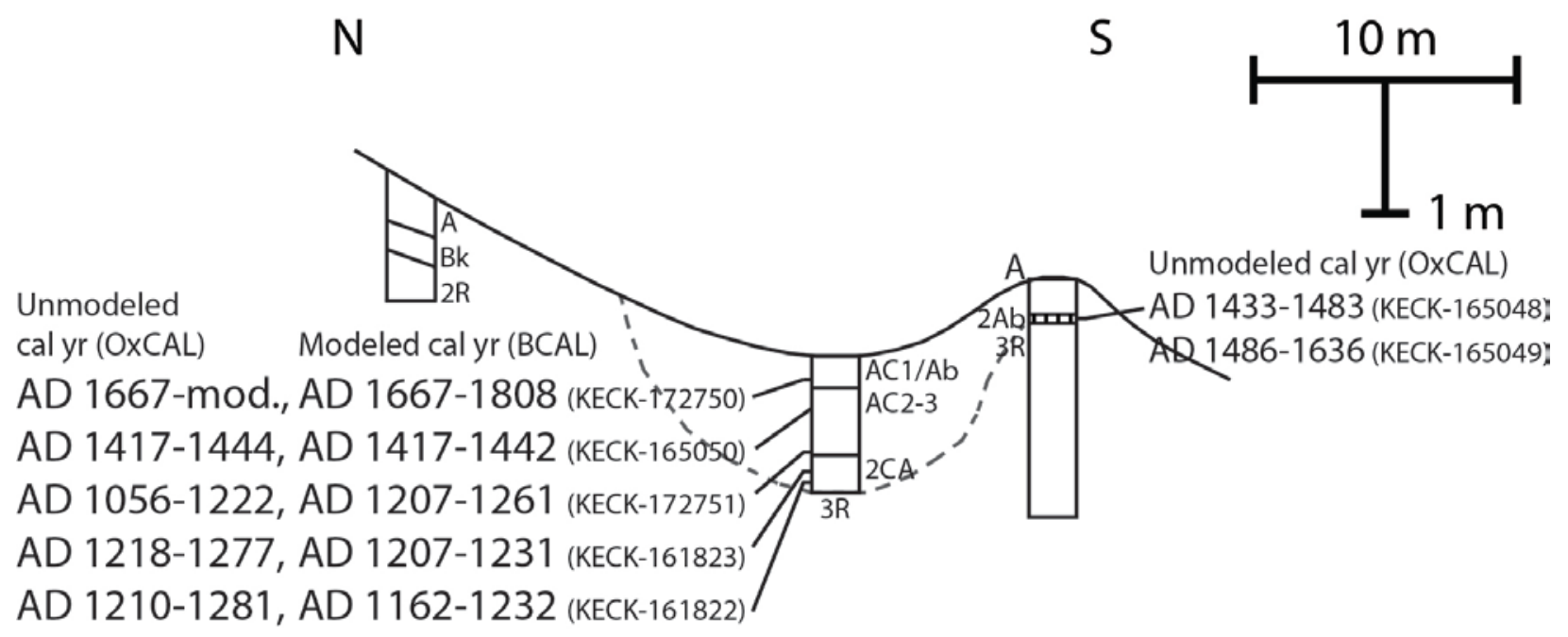

Figure 7.7. Chronostratigraphic cross section of the Boletsakwa (LA136) reservoir feature.

The basin has a maximum storage volume of $132.9 \mathrm{~m}^{3}$, which could accommodate runoff from up to approximately 50-year maximum rainfall events (Appendix E). Yet, when runoff potential is considered in relationship to the population estimates and estimates of water demands, this feature could likely only contribute a small percentage of community water needs (Table 7.2). At maximum population, the typical 1-year maximum rainfall event would provide less than a months' worth of water. Smaller populations (e.g., 210 persons), such as those that would likely be present during initial construction during the occupation of Little Boletsakwa, could have more water days, approaching the two months' worth of supply during monsoons, yet at full population at best the feature may store a months' worth of water, if the basin was 
completely devoid of sediment. Because the basin was largely filled by the time of peak population during the Pueblo Revolt, the maximum potential storage volume was much smaller, only $46.67 \mathrm{~m}^{3}$. This is roughly equivalent to the runoff generated by the typical 1-year maximum rainfall event (Appendix E), which would only be approximately 11-36 days of water for the maximum population estimate. The second reservoir feature on Boletsakwa Mesa (LA25092) would be an important supplemental source during this time period, which will be discussed further in the regional synthesis.
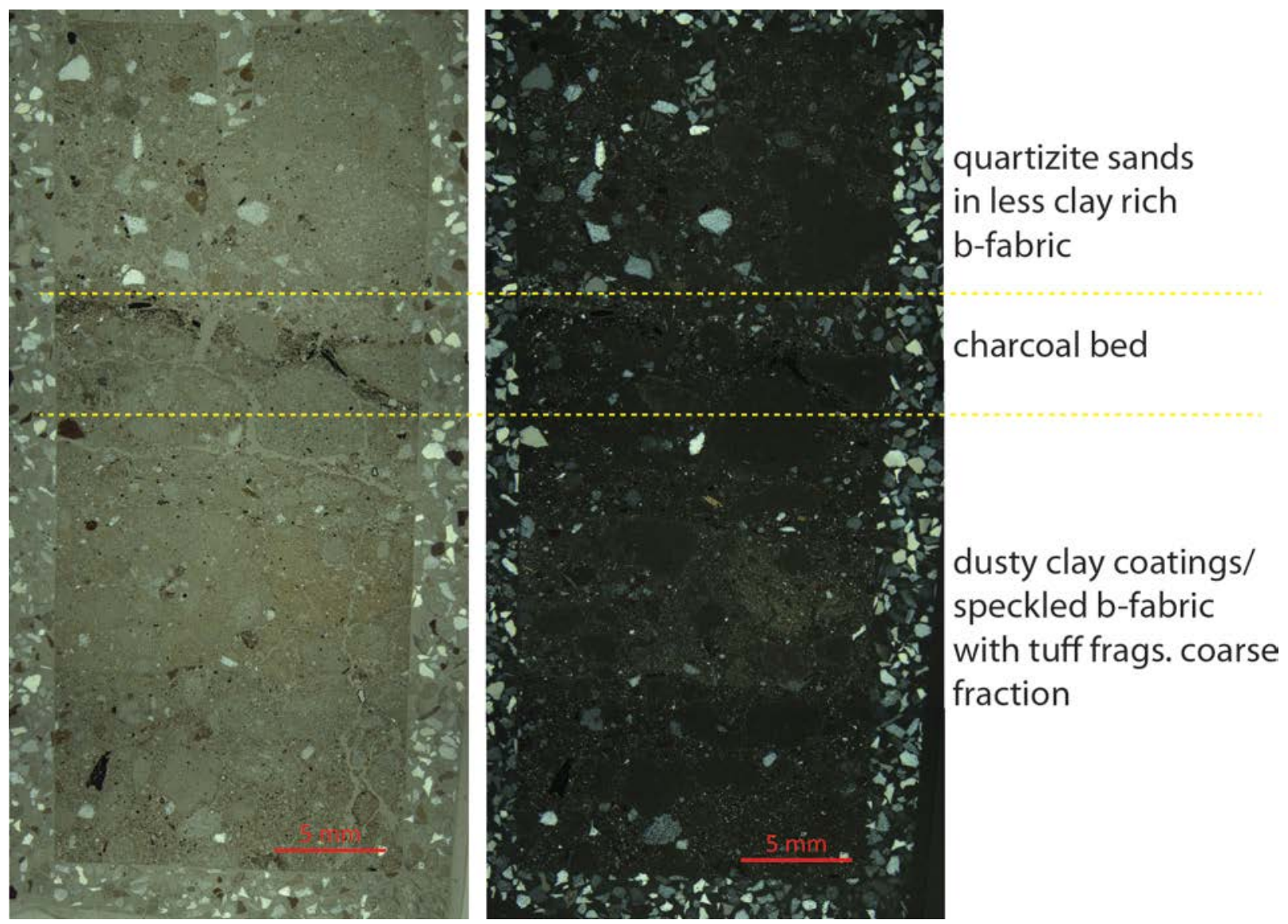

Figure 7.8. Photomicrographs of Boletsakwa (LA136) reservoir soil samples. Lamina of charred plant tissues interbedded in the 2CA horizon from the basin (sample BOL_B2.5_85.5-89.5 cm). 
Table 7.2. Modeled community water budgets and reservoir storage potential for Boletsakwa (LA136).

\begin{tabular}{|c|c|c|c|c|}
\hline $\begin{array}{l}\text { Population } \\
\text { Estimate } \\
\end{array}$ & $\begin{array}{l}\text { Daily Village } \\
\text { Water } \\
\text { Requirement (m3) }\end{array}$ & $\begin{array}{l}\text { Village Water } \\
\text { Days per 1-yr max } \\
\text { rainfall event ( } 3.68 \\
\mathrm{~cm}, \mathrm{CN}=93 \text { ) }\end{array}$ & $\begin{array}{l}\text { Village Water } \\
\text { Days per } 10 \text {-yr } \\
\text { max rainfall event } \\
(6.63 \mathrm{~cm}, \mathrm{CN}=93)\end{array}$ & $\begin{array}{l}\text { Village Water } \\
\text { Days per } 50-y r \\
\text { max rainfall event } \\
(8.74 \mathrm{~cm}, \mathrm{CN}=93)\end{array}$ \\
\hline $50 \%(n=210)$ & $0.63 / 2.1$ & $71 / 21$ & $163 / 49$ & $211 / 63$ \\
\hline $80 \%(n=330)$ & $0.99 / 3.3$ & $45 / 14$ & $104 / 31$ & $134 / 40$ \\
\hline $100 \%(n=413)$ & $1.24 / 4.13$ & $36 / 11$ & $83 / 25$ & $107 / 32$ \\
\hline
\end{tabular}

Four sediment samples from the basin were analyzed for diatoms. Two sediment samples analyzed for diatoms from these basin-bottom sediments (BOL 2.333, 2.344) at depths of 64-66 $\mathrm{cm}$ and 86-88 $\mathrm{cm}$ had the least diverse diatom assemblages of all the diatom samples from the Jemez Plateau (Appendix C). Neither have evidence for aquatic taxa. Instead, all taxa are aerial species. This indicates that during its early use there was not enough water in the feature, for long enough, for aquatic habitats to form. In conjunction with the highly permeable sediments in these lower units this feature may not have efficiently stored water during early occupations at the site of Little Boletsakwa. Sample BOL2.320, analyzed for diatoms from 38-40 cm, had much higher species diversity than the samples from deeper in the basin, and had a combination of aerial and aquatic types. Many of the aquatic and cosmopolitan species are also found in the modern analog samples (Appendix C). Interestingly, the aquatic types, such as Nitzschia amphibia are pollution tolerant, and can live in highly degraded environments. Like the other diatom samples from Boletsakwa the terrestrial types still make up the majority of the diatom assemblage. A diatom sample from this horizon (12-14 cm) was dominated by terrestrial types, with only 8 out of 600 valves counted being a non-aerial type. This includes Meridion circulare a phytoplankton that requires fresh to brackish water to become established. This indicates that at the late phase of use the feature likely held water, but for relatively short intervals. 
The use-life history of the Boletsakwa feature suggests it was built to collect water like a reservoir, but it was not particularly efficient at storing surface runoff. First, this feature has a greater storage potential than it appears it should because of how deeply it was excavated.

Second, radiocarbon dating indicates that this feature was infilling throughout the entire long and varied occupation sequence of the sites. It began infilling while Little Boletsakwa was occupied ( AD 1150-1250), continued infilled rapidly into the 1400s (Figure 7.9). Regardless of its function, the underlying unconsolidated bedrock of pumice would pose a seemingly insurmountable problem for retaining large volumes of water generated by surface runoff for long durations. Even though the bottom-most sediments are finer, the saturated hydraulic conductivity estimates are some of the highest of all of the reservoir samples I analyzed, and the paucity of aquatic diatoms indicates that these fine sediments did not accumulate in a water-rich environment.

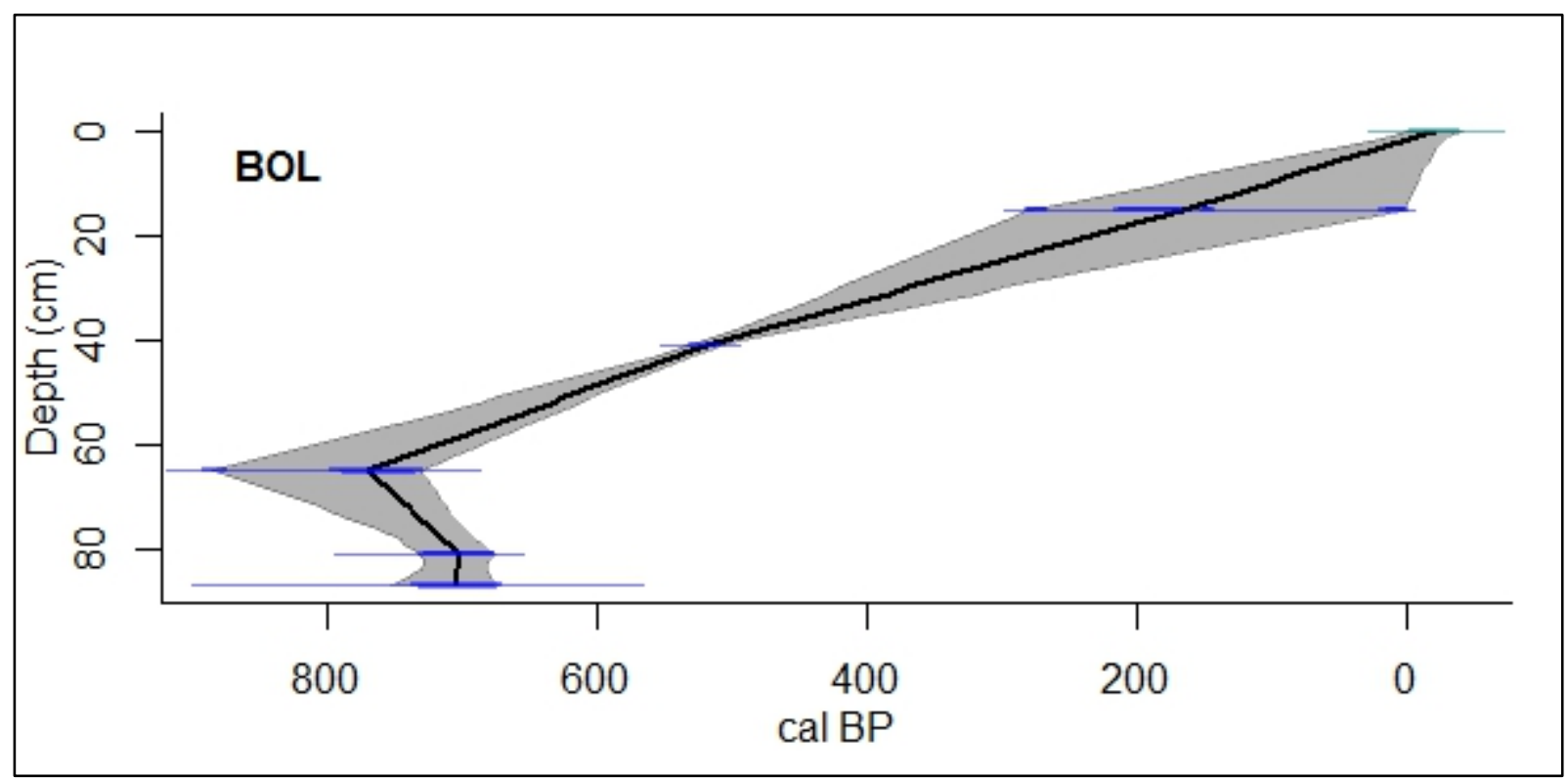

Figure 7.9. Age-depth model of Boletsakwa (LA136) basin sedimentation (CLAM 2.2, Blaauw 2010). 
By the 1400s it appears from diatom sample BOL2.320 that this feature was more regularly holding water. Dates from the berm indicate that the feature may have been remodeled at that time. Yet, the diatoms indicate that the water was of poor quality, which suggests that although water was present in the basin for longer periods of time it may not have been potable. The saturated hydraulic conductivity of these deposits may have improved because of the overall thickness of the basin deposits. The gravelly nature of the in-filling sediments reflects high energy surface run-off, and that the high gravel content would seemingly preclude mortar mixing during this time. If the site was abandoned during this time then shallow standing water could form brackish conditions reflected in the diatom assemblage, as water was lost to evaporation and slow percolation rather than consumption. Only future archaeological studies to refine the culture history of the site will be able to evaluate the intensity of use in the 1400s.

The uppermost-date at the base of a thickened A horizon capping the basin and the pith-date from the snag on the upslope rim of the feature indicates it could be used into the Revolt Period. The seemingly rapid sedimentation indicated in the age-depth model after AD 1400 may reflect an unconformity rather than an increase in sedimentation rates. The highest population, and therefore the greatest water demands, occurred during the Revolt Period. Because of basininfilling the storage potential of the feature would be limited, yet when I recalculate storage potential I estimate that it could still accommodate the runoff from the typical 1-year maximum rainfall event. This would provide some water for the refuge community, but surely not a great deal. That the A horizon was dominated by terrestrial diatom types speaks to the limited waterholding capacity of the feature, and potentially the rapid utilization or infiltration of the water it held. Turney and Turney (1983:1) identified the problems with the water-holding potential of sediments in this feature as well, stating that "Due to the porosity of the soil, it is doubtful if 
water could be stored for any great length of time.” The paleoecological record from diatoms, as well as estimates of saturated hydraulic conductivity supports their assessment. That there was no change in sedimentation between the dated base of the AC1 horizon and the surface suggests that depositional settings were uniform throughout. If so, the feature likely held water during peak occupations, and would serve as a mesa-top water source before, during, and potentially after the Pueblo Revolt. Yet, because of basin infilling and infiltration, its utility as a reservoir would be limited because it could only provide a small volume of water, which would have to be collected immediately if it was going to be used. That this feature lacks the evidence for a late occupation clean-out event like what I see at Amoxiumqua potentially reflects the acceptance of the Ancestral Pueblo at Boletsakwa that this feature had limited potential to meet domestic water needs.

\section{Boletsakwa-2 (LA 25092)}

Approximately $650 \mathrm{~m}$ southwest of Boletsakwa is the site LA 25092, a second reservoir feature recorded on Boletsakwa Mesa (Figure 7.1). The site was first documented by Elliott (1983), with additional observations by Turney and Turney (1983). There are many field houses and small agricultural features nearby, but Boletsakwa is the closest village. The feature is much larger than the reservoir at Boletsakwa, and unlike the Boletsakwa reservoir it is more typical of other reservoirs: it is $25 \mathrm{~m}$ in diameter, has a $1.3 \mathrm{~m}$ high earthen berm above the basin, and a much larger catchment area (Appendix B). The feature is positioned across a small drainage (Figure 7.10), and fans of recently deposited sheet-wash along the margin of the basin indicate that runoff still collects within the basin. Most of the runoff, however, now appears to flow around the feature and into a gully forming to the north and west of the feature. Ponderosa pines, 
as well as piñons and junipers grow along the berm, as well as in the basin. A unique attribute of this feature are four tuff boulders placed in roughly the four cardinal directions on the berm and margins of the reservoir. Turney and Turney (1983) identified one of these a small linear arrangement of boulders on the berm, and postulated it was an outlet feature. The identification of these isolated rocks across what is otherwise an earthen berm may have symbolic significance, as stone features are often associated with Pueblo shrines (Ford 2014; Ford and Swintzell 2015; Harrington 1916). This opens the possibility that these potential material correlate for behaviors not solely associated with water acquisition for consumption are present at this feature.

I tested surface soils on this portion of the mesa by core BOL2-1, and noted that although there are fewer pumice gravels on the surface than near the site of Boletsakwa, unconsolidated pumice bedrock underlies soils. The control sample from the catchment area encountered an AC/Ab-BC-2Cr1-2 soil sequence (Appendix D). A $12 \mathrm{~cm}$ thick fine sandy loam AC mantles a buried A horizon (Ab) of gravelly silt loam. The lack of pumice gravels in the mantling AC1 horizon suggests it may be derived from eolian sedimentation. A BC horizon of a massive fine sandy loam underlies the buried surface from $24-64 \mathrm{~cm}$, and is underlain by unconsolidated pumice gravels (2Cr1-2) (Figure 7.11).

Like the basin at Boletsakwa, the basin of LA25092 was excavated into a highly permeable unconsolidated pumice substrate. Turney and Turney (1983) emplaced a small test pit in the basin of this feature and identified compacted silts to a depth of 0.8 feet with no pumice. The two cores I excavated into the basin recovered $144 \mathrm{~cm}$ thick basin deposits consist of an AC-C1-C5 soil sequence above pumice deposits (Appendix D). Compared to Boletsakwa reservoir basin, these deposits are much finer textured, as gravel content does not exceed $16 \%$, sediments 


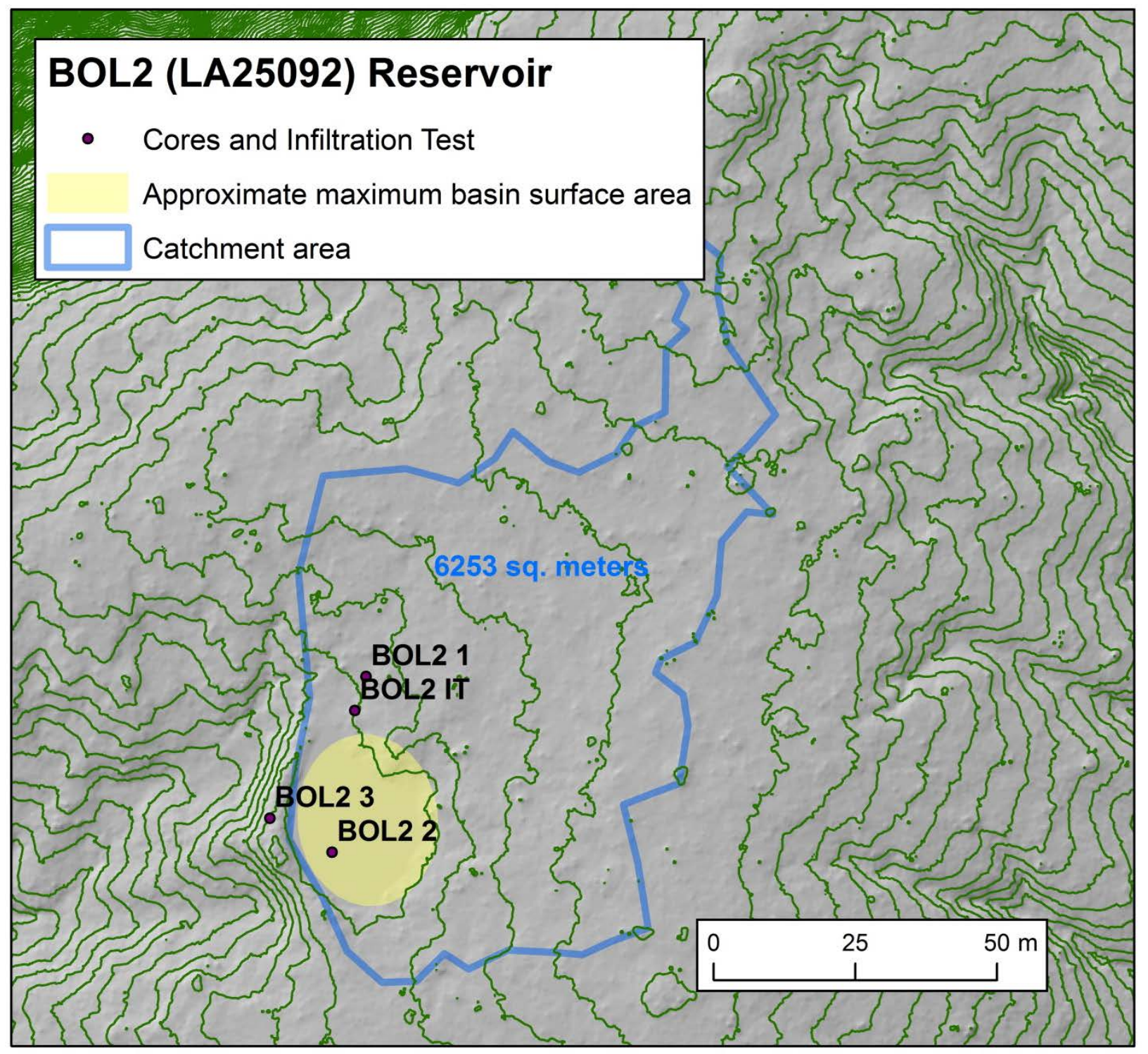

Figure 7.10. Map of coring locations and catchment area of the reservoir at LA25092.

are dominated by silts, and it has a much lower mean saturated hydraulic conductivity (mean = $8.73 \mathrm{~mm} / \mathrm{hr}$.) (Appendix F). The upper sediments (AC-C3 horizons) from 0-56 cm are silty clay loams to fine sandy loams. They generally exhibit fine platy structure and occasional fine charcoal fragments. No dates were collected from these upper deposits but age-depth models of sedimentation based on the dates from below (Figure 7.12), and surface evidence of recent deltas 
formed along the margins of the feature supports an argument for continued basin sedimentation into historic, and potentially modern, times.

\section{Boletsakwa-2 (LA25092) Reservoir Chrono-Stratigraphic Cross Section}

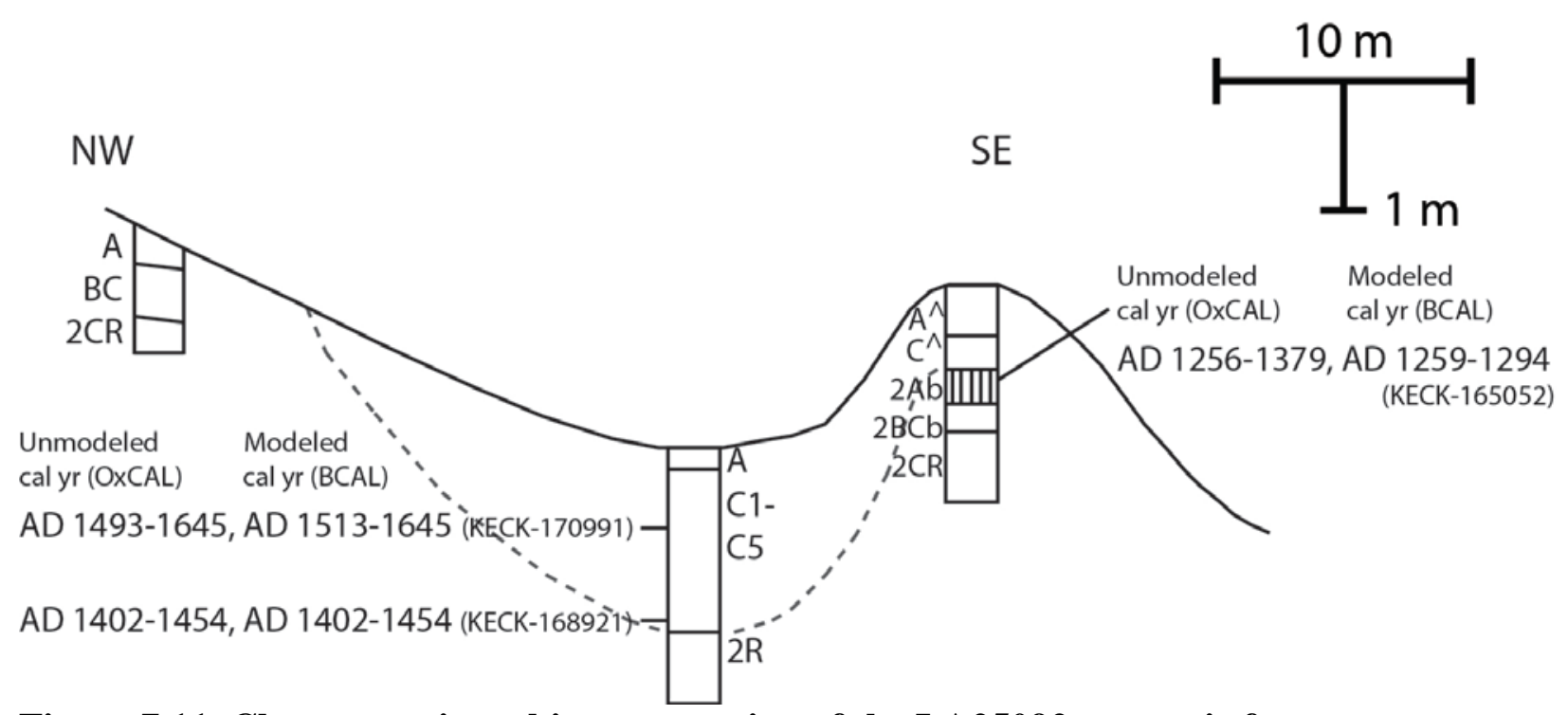

Figure 7.11. Chronostratigraphic cross section of the LA25092 reservoir feature.

Between 56-144 cm, the lowest basin horizons (C4-C5) are massive to single grained in structure, and fine upward from a gravelly very fine sandy loam to a loam. They have relatively low saturated hydraulic conductivity measurements (8.97-11.29 mm/hr.), indicating that they would reduce infiltration into the underlying pumice (Appendix F). Dated charcoal from the top of the C4 horizon (56-58 cm) produced a modeled date to cal AD 1513-1645 (KECK-170991). A modeled date from near the bottom of this sequence $(128-132 \mathrm{~cm})$ dates to cal AD 1402-1454 (KECK-168921). Using the age-depth model for the two basin dates in CLAM 2.2 software (Blaauw 2010) I extrapolated a probability distribution of cal AD 1312-1434 for the bottom of 
the basin sequence $(144 \mathrm{~cm}$ ) (Figure 7.12). I continued coring into the pumice gravels (2Cr) to a maximum depth of $205 \mathrm{~cm}$ and did not encounter consolidated bedrock.

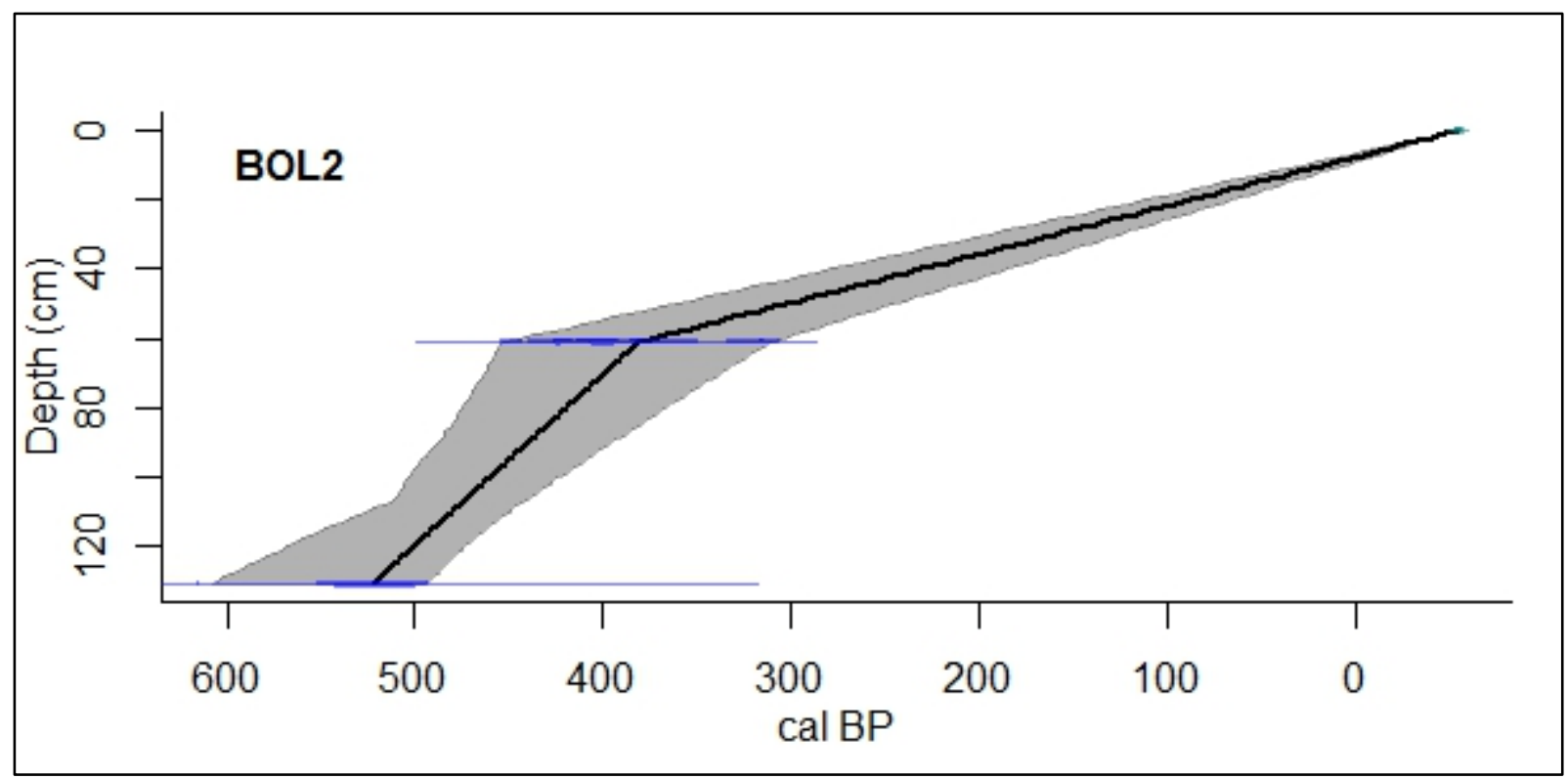

Figure 7.12. Age-depth model of LA25092 basin sedimentation (CLAM 2.2, Blaauw 2010).

The core into the berm recovered a complicated soil sequence of $A-\wedge$ CA-^C-2Ab-2Bwb2CBb-2CBkb-2Cb-2Cr (Figure 7.11, Appendix D). Fill units (A-^CA-^C) extended to a depth of $57 \mathrm{~cm}$, and were very to extremely gravelly loamy sands. The buried A horizon (2Ab horizon) was a very fine sandy clay loam with massive to single grained structure. A modeled date of charcoal from this horizon dated to cal AD 1259-1294 (KECK-165052). Below this unit were subsoils with evidence of progressively more well-developed calcic horizons (2Bwb-2CBb2CBkb) between 73-111 cm, formed over gravelly sandy loam (2Cb) between 111-135 cm, and pumice bedrock (2Cr) 135-155 cm. Calcic horizons were not identified in the control samples for 
this feature, but it should be noted that they were identified in the control samples for the Boletsakwa reservoir.

The basin had a maximum storage capacity of $717 \mathrm{~m}^{3}$, and it could easily accommodate runoff events above the 50 year maximum event (Appendix E). This feature could provide nearly twice the volume of water needed for the community of Boletsakwa than the Boletsakwa reservoir (Tables 7.2 and 7.3). Typical 1-year maximum rainfall events could produce nearly a months' worth of water for the community at maximum population. Under normal or wet monsoon periods (approximated by the 50-year rainfall event) it could provide enough runoff for two to three months' worth of domestic water.

Table 7.3. Modeled community water budgets and reservoir storage potential for LA25092.

\begin{tabular}{|l|c|c|c|c|}
\hline & $\begin{array}{l}\text { Daily Village } \\
\text { Water }\end{array}$ & \multicolumn{1}{l}{$\begin{array}{l}\text { Village Water } \\
\text { Days per 1-yr max } \\
\text { rainfall event (3.68 } \\
\text { Estimate }\end{array}$} & $\begin{array}{l}\text { Village Water } \\
\text { Days per 10-yr } \\
\text { max rainfall event } \\
\mathbf{( 6 . 6 3 ~ c m , ~ C N = 8 7 ) ~}\end{array}$ & $\begin{array}{l}\text { Village Water } \\
\text { Days per 50-yr } \\
\text { max rainfall event } \\
\text { (8.74 cm, CN=87) }\end{array}$ \\
\hline $50 \%(\mathrm{n}=210)$ & $0.63 / 2.1$ & $127 / 38$ & $355 / 106$ & $538 / 161$ \\
\hline $80 \%(\mathrm{n}=330)$ & $0.99 / 3.3$ & $81 / 24$ & $226 / 68$ & $343 / 103$ \\
\hline $100 \%(\mathrm{n}=413)$ & $1.24 / 4.13$ & $64 / 19$ & $180 / 54$ & $274 / 82$ \\
\hline
\end{tabular}

One sediment sample (BOL2_2.152) was analyzed for diatoms from near the base of the sequence (102-104 cm). The sample (Appendix C) is dominated by terrestrial species (566/600 valves), but of the 14 taxa seven are aquatic types. Three of these types were also found in the modern analog samples (Appendix C). This suggests that while the reservoir did dry out during use, it did hold water. The presence of Aulacoseira italica, a cosmopolitan aquatic species that 
requires water with $>75 \%$ dissolved oxygen that was also found in the Stable Mesa and Lake Fork Canyon stock tanks, indicates that when the basin of LA25092 did hold water that it was not brackish.

Taken together, the chronological results, potential storage volumes, and paleoecological data support the reservoir site formation model. It was more effective than the reservoir feature at Boletsakwa at doing this because it had a larger catchment area, and bigger basin. Infiltration into pumice bedrock would still be a problem, but the much finer basin sediments would be much more effective than the coarse sediment at Boletsakwa for impeding infiltration. The usehistory of the feature indicates that it likely stored water through periods of occupation of the mesa-top, including dry periods in the 1400s and likely into the historic period. The stones positioned around the feature are unique for features on the Jemez Plateau, and they may reflect ritual use or other aspects of use different from other Jemez reservoir features. Water from this feature may have been available for domestic water, but also for agricultural purposes in surrounding areas. The combined volumes of potential water storage from these two features on Boletsakwa Mesa may have seasonally provided appreciable quantities of water for the community of Boletsakwa, with LA25092 being constructed in the 1300s to supplement the declining storage potential of the Boletsakwa feature, or to serve as a source for water for the agricultural fields and small households scattered across the mesa-top.

\section{Kwastiyukwa (LA482)}

Kwastiyukwa, also known as the "Giant Footprint Ruins” (Elliott 1982:22), is located on Holiday Mesa, overlooking the Rio de Guadalupe (Figure 7.1). Kulisheck (2005) estimates the 
site has 1250 rooms, and an occupation span of AD 1450-1700. Liebmann et al. (2016) estimate a maximum population of 1444 persons. There were some early test excavations at the site (Reiter 1938), but no reports. The reservoir feature is located on the north end of the site, near small roomblocks located off of the main site area (Figure 7.13). It is one of the smaller Jemez Plateau reservoir features, with a $0.85 \mathrm{~cm}$ high berm and a $21 \mathrm{~m}$ wide basin (Appendix B). Its catchment area is small, with a very low gradient. Still, portions of the southwestern segment of the berm are washed out. Artifacts on the berm and in the areas around the berm are very common, especially downslope of the washed out segment of the berm. This suggests the area around the feature was frequently visited and that it became a midden during village occupation. Vegetation in the catchment area is dominated by grasses, while ponderosa pines are growing on portions of the berm.

The control sample collected from the catchment basin recovered a $60 \mathrm{~cm}$ thick A-BC1-BC2R soil sequence (Appendix D, Figure 7.14). A thin A-horizon of brown (10YR4/3) fine sandy loam is underlain by brown (7.5YR4/3) clay loam to sandy clay loam with moderate medium platy to fine blocky subangular structure above white tuff bedrock at $60 \mathrm{~cm}$.

Cores within the basin recovered a $60 \mathrm{~cm}$ sequence with an A-BC-CB-R soil sequence, and four charcoal samples were analyzed with AMS dating (Figure 7.14, Appendix D). Soil textures within the basin are silty clay loam to silty clay (Appendix F), and in sedimentological analyses were the most consistently fine-grained (highest silt-clay fractions) of any of the reservoirs (Appendix F). The soils have some of the lowest saturated hydraulic conductivity estimates of any samples analyzed (mean $=5.82 \mathrm{~mm} / \mathrm{hr}$.) (Appendix F). The A horizon from 0-6 cm is a very dark grayish brown sandy loam with common undecayed and decayed plant tissues. There are surface disturbances from cattle trampling. The BC horizon is dark brown, with 


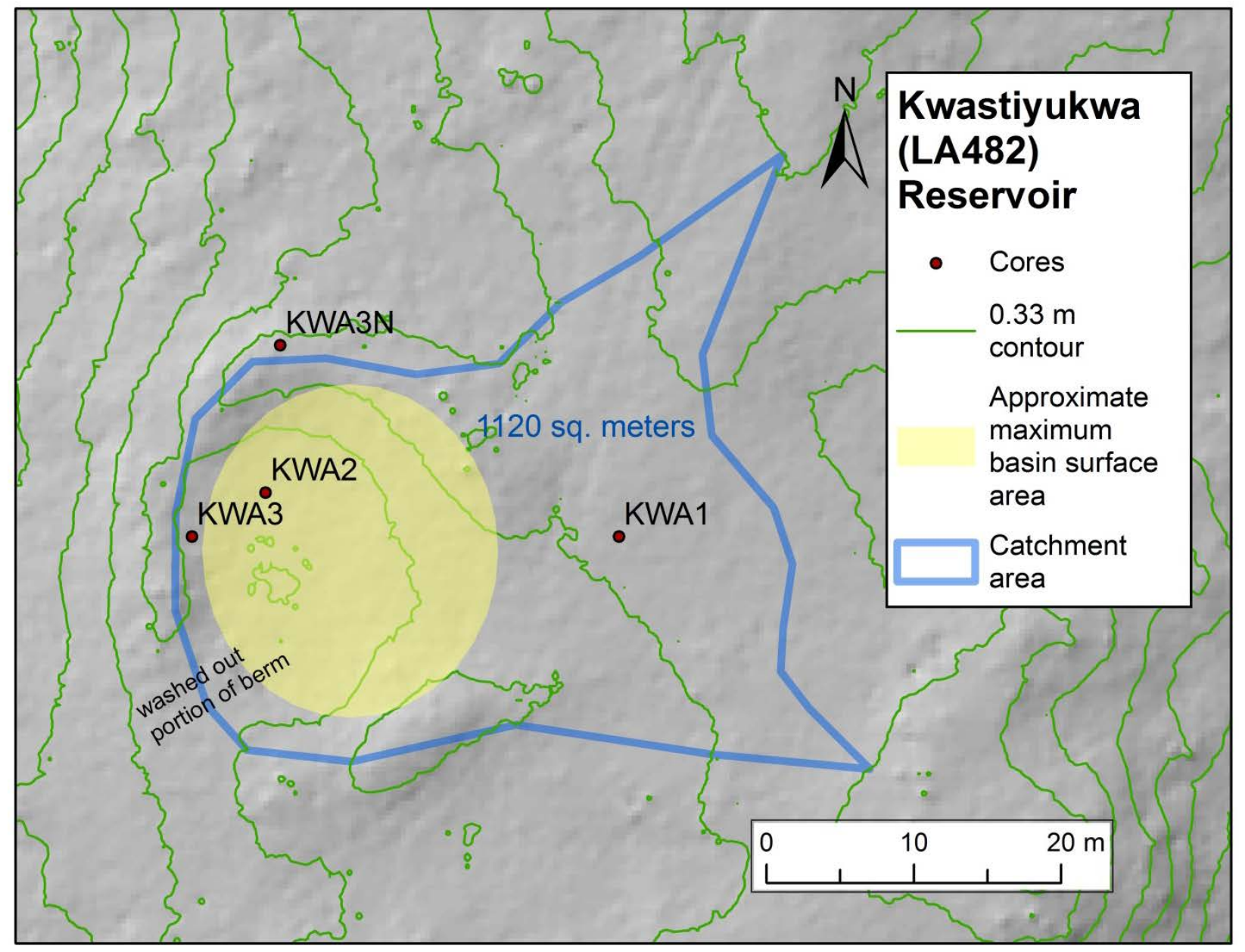

Figure 7.13. Map of coring locations and catchment area of the Kwastiyukwa (LA482) reservoir feature.

subangular blocky structure with weak slickenslides formed on ped faces. Common redoximorphic features, as well as limpid clays along ped faces are seen in soil thin sections, and reflect saturated conditions in the basin. The gravel content is high (10-20\%) in what is otherwise a fine grained matrix, with fine charcoal observed throughout. Two charcoal samples from this horizon have modeled dates of cal AD 1416-1441 (Keck-172753) and cal AD 1526-1656 (Keck165053), and are in stratigraphic sequence. The lower soil (CB) fines upward, and has platy structure with a few thin to medium laminae of sands towards the base, and 5\% very fine 
subangular tuff pebbles, which reflect initial higher energy deposition as the basin began infilling. Modeled AMS dates of charcoal from this horizon were cal AD 1314-1406 (Keck165054) and cal AD 1125-1212 (Keck-165057).

\section{Kwastiyukwa (LA482) Reservoir Chrono-Stratigraphic Cross Section}

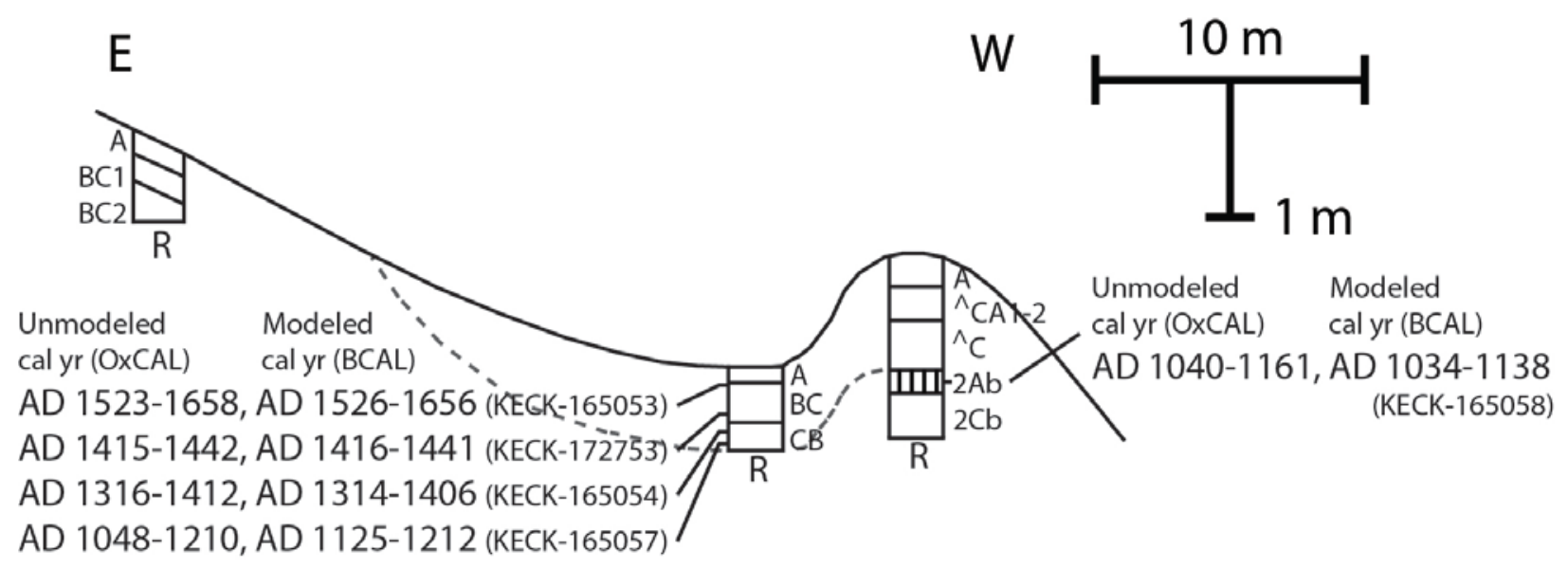

Figure 7.14. Chronostratigraphic cross section of the Kwastiyukwa (LA482) reservoir.

Cores were excavated at two portions of the earthen berm, cores 3 and 3N (Figure 7.13). An

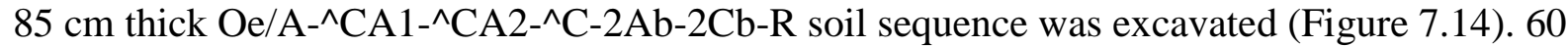
cm of dark brown (7.5YR3/4) to brown (7.5YR4/2) sandy clay loam to loamy sandy fill caps a buried surface natural surface (2Ab) (Appendix D). The fill is similar in color and texture to the buried soils in the control, but there are also pebbles and broken tuff rock fragments throughout the fill. Buried below the fill are relatively thin natural soils. From $60-70 \mathrm{~cm}$ is a buried natural surface soil (2Ab) of brown (7.5YR4/3) clay loam with weak fine blocky angular parting to granular structure, with few fine open pores and charcoal. A charcoal sample from the $2 \mathrm{Ab}$ horizon produced a modeled AMS date of AD 1034-1138 (Keck-165058). Below the buried A 
horizon are unweathered deposits (2Cb horizon) from 70-74 cm. These sediments are brown (7.5YR4/3) fine sandy loam with platy structure. The thickness of these unweathered sediments above bedrock varies from core to core, and they extend to $80 \mathrm{~cm}$ in core 3.3 and are deeper (114 $\mathrm{cm}$ ) in the northern core (3N) which sampled a thicker portion of the berm (Appendix D). This portion of the sequences is likely outside of the natural drainage impounded by the feature.

While the reservoir feature at Kwastiyukwa is not the smallest feature I tested, it is the feature that would least likely meet its community's water demands. Its maximum storage volume is only $319 \mathrm{~m}^{3}$, which can easily accommodate the low volumes of runoff generated by its small catchment area (Appendix E). But, because the population estimates for Kwastiyukwa are so high, it could only provide a very small percentage of the communities' water needs (Table 7.4).

Table 7.4. Modeled community water budgets and reservoir storage potential for Kwastiyukwa (LA482).

\begin{tabular}{|c|c|c|c|c|}
\hline $\begin{array}{l}\text { Population } \\
\text { Estimate }\end{array}$ & $\begin{array}{l}\text { Daily Village } \\
\text { Water } \\
\text { Requirement (m3) }\end{array}$ & $\begin{array}{l}\text { Village Water } \\
\text { Days per 1-yr max } \\
\text { rainfall event ( } 3.68 \\
\mathrm{~cm}, \mathrm{CN}=93)\end{array}$ & $\begin{array}{l}\text { Village Water } \\
\text { Days per } 10 \text {-yr } \\
\text { max rainfall event } \\
(6.63 \mathrm{~cm}, \mathrm{CN}=93)\end{array}$ & $\begin{array}{l}\text { Village Water } \\
\text { Days per } 50-\mathrm{yr} \\
\text { max rainfall event } \\
(8.74 \mathrm{~cm}, \mathrm{CN}=93)\end{array}$ \\
\hline $50 \%(n=722)$ & 2.17/7.22 & $11 / 3$ & $25 / 8$ & $34 / 10$ \\
\hline $80 \%(n=1155)$ & $3.47 / 11.55$ & $7 / 2$ & $16 / 5$ & $21 / 6$ \\
\hline $100 \%(n=1444)$ & 4.33/14.44 & $5 / 2$ & $13 / 4$ & $17 / 5$ \\
\hline
\end{tabular}

The analysis of three diatom samples from the basin found limited evidence for aquatic habitats in each sample, although many of the species identified were also found in modern analogs (Appendix C). A sample from 39-41 cm at the base of the BC horizon (KWA2.320) was dominated by aerial taxa, with only a few aquatic and cosmopolitan types. This indicates that 
when wet periods in the basin occurred that they were not prolonged. A diatom sample from 17$19 \mathrm{~cm}$ at the top of the BC horizon (KWA2.309) was dominated by aerial types, with the aquatic types being more cosmopolitan in habitats (e.g., Stauroneis spp.) KWA2.304, a sediment sample from the A horizon $(6-9 \mathrm{~cm})$ is dominated by terrestrial types, with some aquatic taxa that are rapid colonizers under aquatic conditions with shallow water and high nutrient loads (Appendix C). This suggests that when there was water in the basin of the feature it was of poor quality.

The way the reservoir feature at Kwastiyukwa was used by Ancestral Pueblo likely changed through time. The feature was constructed before there was a village. After initial high energy deposition in the basin, very fine grained sediments accumulated through the entire span of the village occupation. There was no evidence for clean-out events or remodeling of the feature. Based on hydrological models and saturated hydraulic conductivity estimates, the feature was efficient in storing runoff, but due to its small catchment area it did not store much water. This may not have been a problem when it was initially constructed at a time when populations of the emerging community were most certainly small, but models of storage capacity and runoff volumes show that it could in no way meet the water needs of the large Ancestral Pueblo population of Kwastiyukwa. As such, the primary function of this feature may have changed through time. It may have started as a feature to primarily store domestic water, but then later served as a watery shrine. There is no evidence for disturbed or exotic basin sediments indicative of mortar mixing. The diatom record indicates that the feature did hold water, but that the habitat was most supportive of aerial types found in muddy or wet environments. The few aquatic types are reflective of poor water quality. If it was used as a reservoir, and everyone in the community had access to the feature, there could be tremendous competition over access to the limited volume of water this resource could provide. The lack of stratigraphic evidence for basin 
truncations to increase storage capacity, the breach of the berm, and accumulations of domestic debris reflective of Ancestral Pueblo occupation near the feature suggest that that it continued to be a wet place within the site visited by community members, but that it likely no longer served as a loci for collective action to maintain a technology for storing domestic water. Therefore, although it may have been constructed as a reservoir, its use history during village occupation best fits the watery shrine site formation model. Step-pools located near the site (discussed in Chapters 5 and 8), likely provided volumes of water comparable to other large artificial water storage features near other villages, as did other sources, which will be discussed in Chapter 8 .

\section{Tovakwa (LA 61641)}

The site of LA 61641 is a reservoir feature on Stable Mesa, located approximately $600 \mathrm{~m}$ north of Tovakwa (LA 483) (Figure 7.1). The site of Tovakwa is large, with estimated room count of 1850, and an occupation span of AD 1350-1700 (Kulisheck 2005). Liebmann et al. (2016) estimate a maximum population of 1,240 at Tovakwa. Like LA25092 at Boletsakwa, LA61641 is located far from the associated village, and as my studies show, it is different from all of the other features on the Jemez Plateau in its physical context, hydrological setting, and use-history. Its berm is $1.2 \mathrm{~m}$ high and its basin diameter is $30 \mathrm{~m}$ (Appendix B). Unlike all of the other features, which are built within the upper reaches of mesa-top drainages, LA61641 is constructed at the knickpoint above an incised drainage along a mesa edge (Figure 7.15). The berm is breached in one section, and a snag growing in the breach was cored for dendrochronological study, and provided pith date of AD 1644 (Thomas Swetnam, 2015, personal communication), which provides a terminus ante quem date of $\mathrm{AD} 1644$ for both the 
berm construction and the breach (Figure 7.16). The catchment area for this feature $\left(100,566 \mathrm{~m}^{2}\right)$ is more than twice the size of the next largest catchment area (Appendix E). There are two historical impacts to this feature. A 2-track road, now blocked off from the southern approach, crosses through the basin, running perpendicular to the feature. Also, most of the catchment area is within the 2013 Stable Fire (Figure 7.15). Vegetation is “dog-hair” thickets of ponderosa pines with an understory of scattered forbs and grasses. The ground surface is covered in burned and unburned duff. Only one Jemez B/W sherd was observed on the surface during fieldwork.

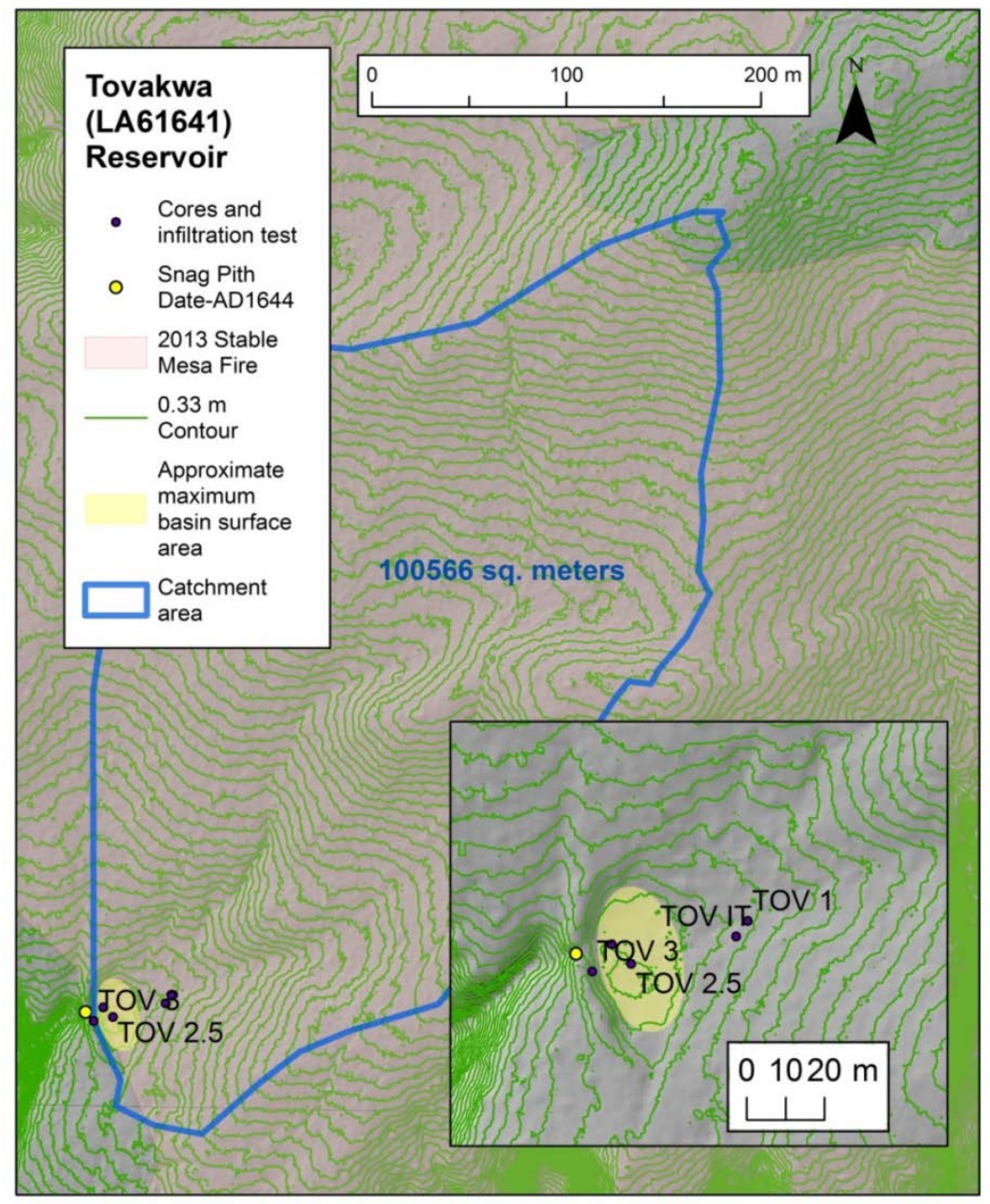

Figure 7.15. Map of coring locations and catchment area of the LA61641 reservoir feature. 


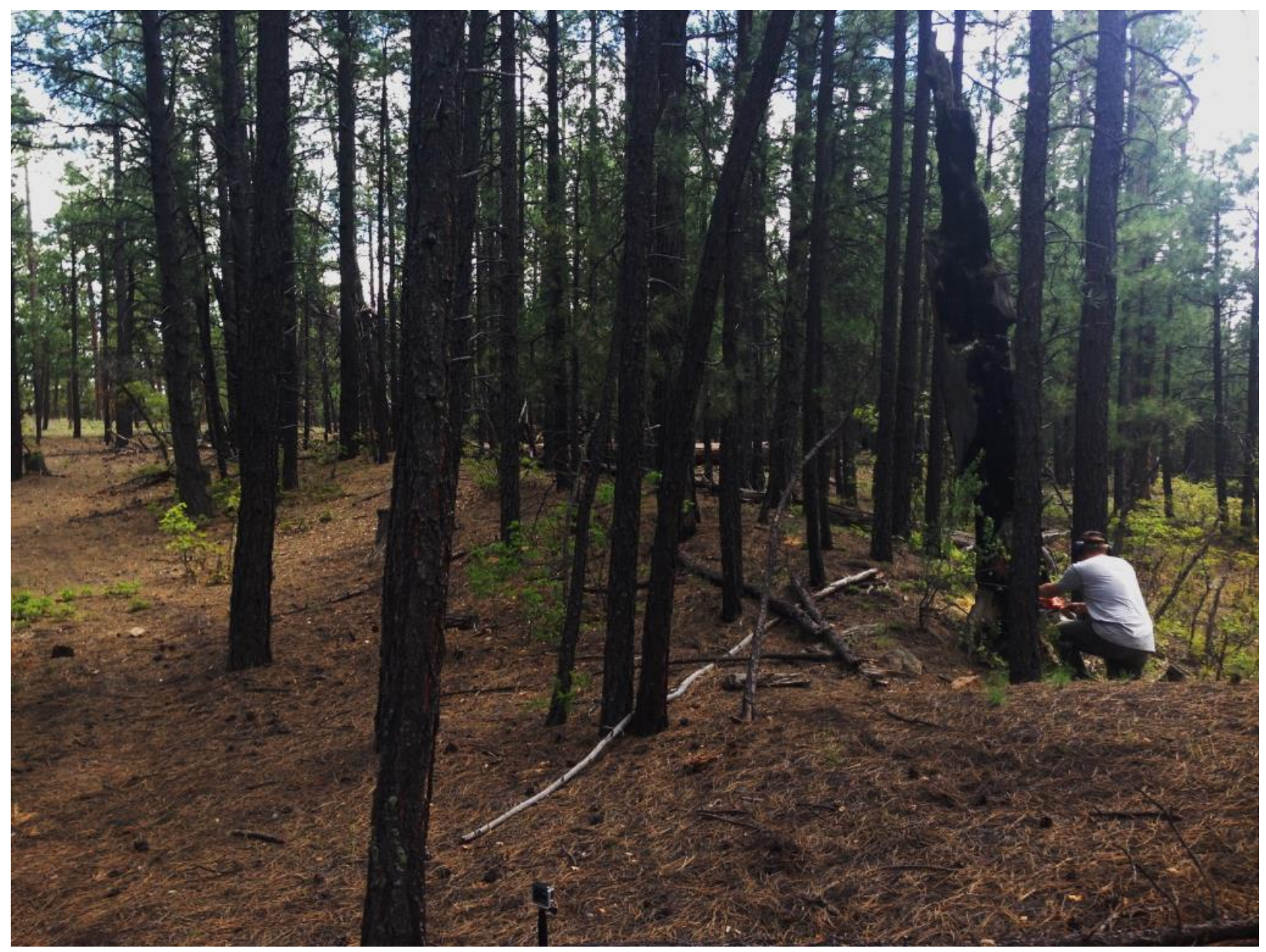

Figure 7.16. Photograph of a snag in breach of the LA61641 berm being sampled by Josh Farella in June 2015 (photograph courtesy of Tom Swetnam).

In the core from the catchment area (TOV 1) (Figure 7.15) I encountered an A1-A2-Bw-Bt-R soil sequence (Figure 7.17). Surface soils (A1-A2) of brown (7.5YR5/2) to pinkish gray (7.5YR7/2) silt to sandy loam with fine organic tissues (duff and undecayed pine needles) extended to a depth of $14 \mathrm{~cm}$ (Appendix D). Below to a depth of $52 \mathrm{~cm}$ were loamy coarse sands with rock fragments $(\mathrm{Bw})$ and hard gravelly sandy clay $(\mathrm{Bt})$ with a root mat formed at the contact with underlying tuff bedrock. This soil sequence reflects a stable upland surface. 


\section{Tovakwa (LA61641) Reservoir Chrono-Stratigraphic Cross Section}

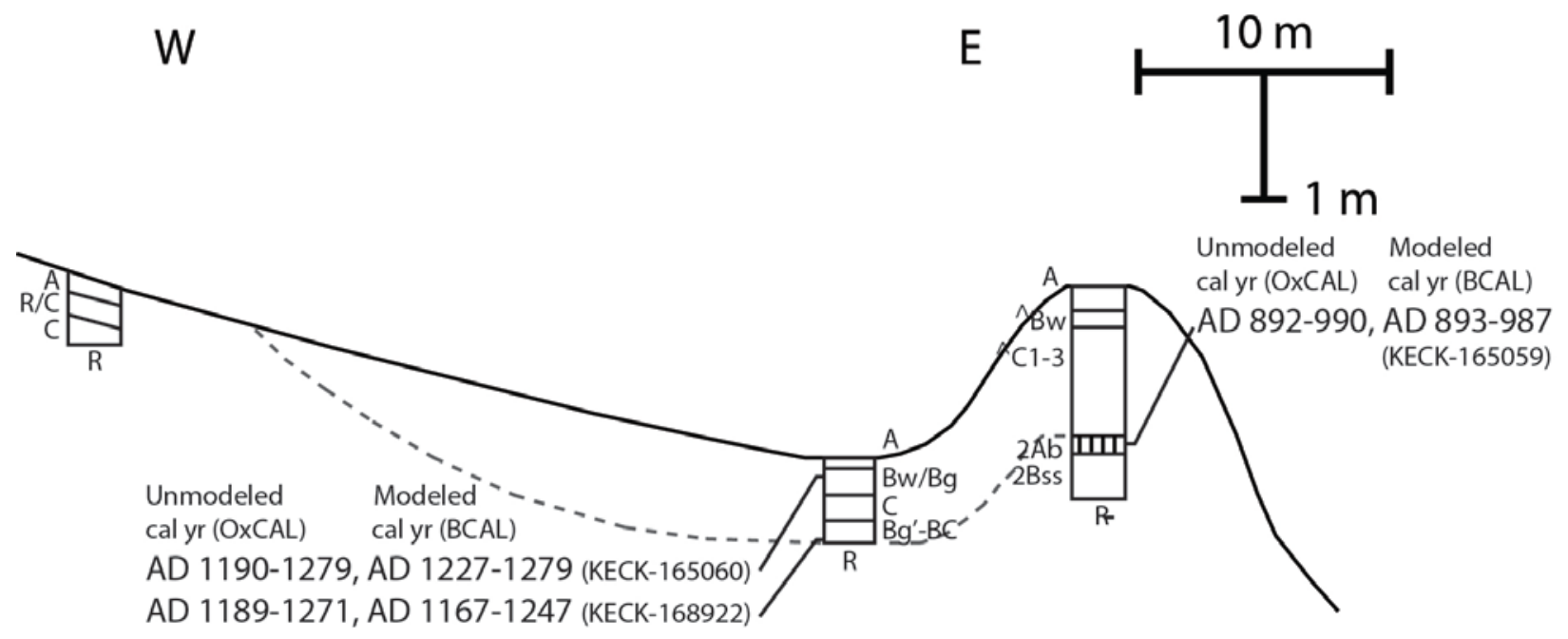

Figure 7.17. Chronostratigraphic cross section of the LA61641 reservoir feature.

I cored two portions of the catchment basin (TOV 2, 2.5), and encountered similar soil sequences (Figure 7.14). These cores registered a $70 \mathrm{~cm}$ thick A-Bw/Bg-C-Bg'-BC-B/R soil sequence (Figure 7.17, Appendix D). Estimates of saturated hydraulic conductivity from basin sediments have the lowest averages of all tested reservoir features (mean $=4.54 \mathrm{~mm} / \mathrm{hr}$.) (Appendix F). Basin sediments exhibit moderately to well-developed redoximorphic features, indicating repeated wetting and drying. The upper horizons consist of a shallow surface soil (A horizon) from 0-8 cm of dark brown (7.5YR3/2) single grained silt loam with common fine roots and charcoal. Below is a subsoil, which depending upon the core, is either a Bw or Bg horizon of pinkish gray (7.5YR6/2) silt loam with few to common brown (7.5YR4/2)(d), dark brown (7.5YR3/2)(w) sharp faint to distinct medium iron-manganese concentrations infused on ped faces. These pedogenic features become more distinct with depth, and this degree of pedogenesis reflected repeated wetting and drying of this subsoil. Charcoal from this horizon $(16-20 \mathrm{~cm})$ produced a modeled date of cal AD 1227-1279 (KECK-165060). 
An unweathered dark gray silt loam (C horizon) from 32-40 cm is underlain by a brown silty clay loam $(40-52 \mathrm{~cm})$ with well-developed redoximorphic pedogenic features $\left(\mathrm{Bg}^{\prime}\right.$ horizon) than the Bw/Bg horizon. Common dark brown (7.5YR3/2) sharp faint to distinct medium ironmanganese concentrations, soft masses, and hypocoats infused on platy ped faces and around closed and open pores, as well as possible fine manganese nodules were observed. Micromorphological observations from TOV2.2_30-34cm show that redoximorphic concentrations are well developed and common in both the groundmass and on ped faces, reflecting period saturation within the basin (Figure 7.18). My attempts to date these horizons failed, as the two samples from these horizons $(40-42 \mathrm{~cm}$ and $54-56 \mathrm{~cm}$ ) produced modern dates (Appendix H). Two-sigma calibrations of charred needles using CALIBomb returned dates of cal AD 1957-2003 (KECK 161824), and cal AD 1957-2002 (KECK-161825), while 1-sigma calibrations are AD 2000-2002, and AD 1999-2001. I picked the charred needles from some of the first cores I collected and split open, and they are likely intrusive material burned in the 2013 fire that slipped down the core barrels. While opening subsequent cores for sub-sampling I noticed that charred needles from the surface commonly fell into the tops of core tubes during collection, and I took greater caution in both core collection and sub-sampling to avoid intrusive material.

The lowest most deposits (BC-B/R horizon), between 52-70 cm, are dark brown (7.5YR3/2) silty clay loams with increasingly larger white tuff gravels with depth. There are faint to distinct medium iron-manganese concentrations decreasing in frequency and prominence with depth, but also dispersed fine charcoal through these horizons. Charcoal from 60-64 cm produced a modeled date of cal AD 1167-1247 (KECK-168922). The unmodeled distribution overlaps with the date from the top of the basin, suggesting rapid infilling of the basin. 


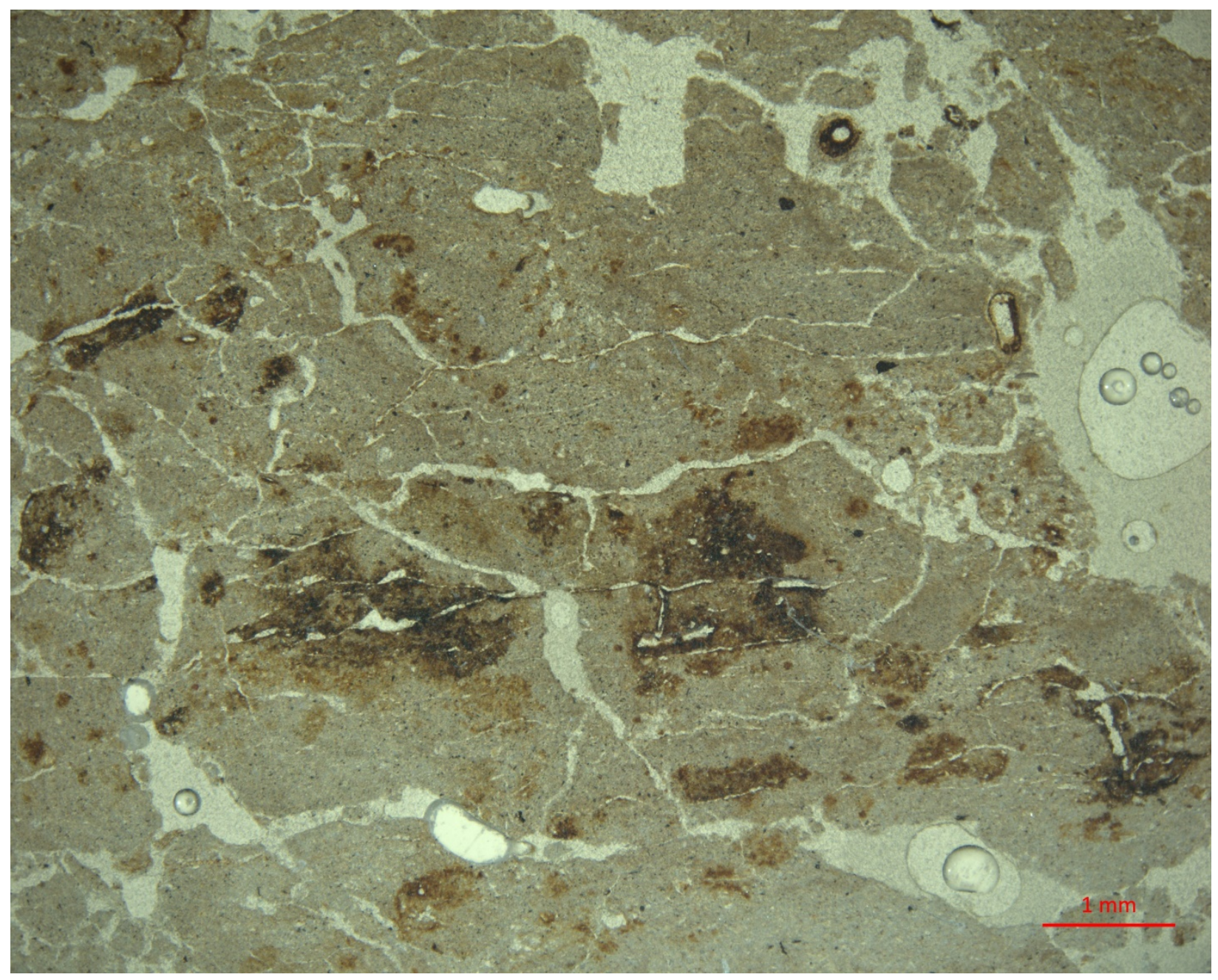

Figure 7.18. Photomicrograph of a LA61641 soil sample. Pedogenic redoximorphic concentrations in soil thin section of sample TOV2.2_30-34 cm (PPL).

I excavated three cores into the berm (Figure 7.15). Two (3.1 and 3.3) penetrated through fill and into underlying natural soils, while 3.2 terminated within fill at a depth of $95 \mathrm{~cm}$. The berm

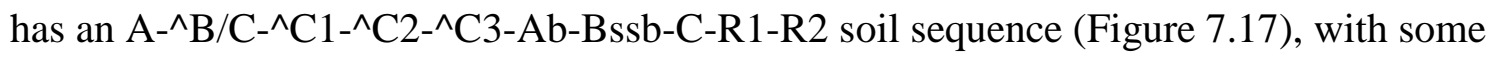
variability between cores (Appendix D). The fill sequence extends to a depth of $108 \mathrm{~cm}$, and is sandy loam to sandy clay loam with some tuff gravels. The color and texture of the lower fill horizons $(\wedge \mathrm{C} 2-\wedge \mathrm{C} 3)$ is similar to the natural $\mathrm{C}$ horizons of the control sample, but with occasional masses of sandy clay loam. This suggests that these soils were excavated out of the 
basin and redeposited to form the berm. There were differences in stratigraphy in the two cores that penetrated below fill. There is an Ab horizon of very dark gray (7.5YR3/1) sandy loam with massive to granular structure in core 3.1, which is absent in core 3.3. Instead of an Ab horizon, core 3.3 has a truncated Bssb horizon of extremely hard clay. A charcoal sample from 110-112 cm from the Ab horizon of core 3.1 produced a modeled date of AD 893-987 (KECK-165059). This date precedes basin sedimentation, and indicates the underlying natural soils at the point in the landscape reflect soil forming conditions well before human activities were believed to be a dominant factor across the landscape. Underlying sediments are weathered clays (Bssb) and fine sandy loam (Cb), above friable tuff bedrock (R1-R2), which was encountered at approximately $122 \mathrm{~cm}$ in core 3.3, and at $160 \mathrm{~cm}$ in core 3.1 .

As large as the LA61641 reservoir is, it is underfit for its drainage area. It could store the second-most volume of water of all of the features I tested $\left(730 \mathrm{~m}^{3}\right)$, but its large catchment area would generate tremendous volumes of surface runoff (Appendix E). Even the surface runoff from the typical 1-year maximum rainfall event $\left(1280 \mathrm{~m}^{3}\right)$ would exceed its maximum storage capacity (Appendix E). That this feature would quite likely annually achieve its storage capacity is good for collecting water, but bad for its structural integrity. It is no surprise then that it is breached. It definitely could have held enough water to provide the large community of Tovakwa appreciable quantities of drinking water; however, it was constructed and then infilled well before the site of Tovakwa was populated (Table 7.5). The volume of runoff from the typical 1year maximum rainfall event could generate between 37-123 days of water for Tovakwa. The likelihood of this scenario is discussed in the site-formation model. Yet, if it wasn't breached it may have continued to store water during occupation. Because of its large berm it could today 
still store $456.12 \mathrm{~m}^{3}$ of surface runoff if its berm was intact and if vegetation was removed to facilitate greater volumes of surface runoff.

Table 7.5. Modeled community water budgets and reservoir storage potential for Tovakwa and the LA61641 reservoir.

\begin{tabular}{|c|c|c|c|c|}
\hline $\begin{array}{l}\text { Population } \\
\text { Estimate }\end{array}$ & $\begin{array}{l}\text { Daily Village } \\
\text { Water } \\
\text { Requirement (m3) }\end{array}$ & $\begin{array}{l}\text { Village Water } \\
\text { Days per 1-yr max } \\
\text { rainfall event ( } 3.68 \\
\text { cm, CN=87) }\end{array}$ & $\begin{array}{l}\text { Village Water } \\
\text { Days per } 10-y r \\
\text { max rainfall event } \\
(6.63 \mathrm{~cm}, \mathrm{CN}=87)\end{array}$ & $\begin{array}{l}\text { Village Water } \\
\text { Days per } 50-y r \\
\text { max rainfall event } \\
(8.74 \mathrm{~cm}, \mathrm{CN}=87)\end{array}$ \\
\hline $50 \%(n=620)$ & 1.86/6.2 & $392 / 118^{*}$ & $*$ & $*$ \\
\hline $80 \%(n=992)$ & 2.98/9.92 & $245 / 74 *$ & $*$ & $*$ \\
\hline $100 \%(n=1240)$ & $3.72 / 12.4$ & 196/59* & $*$ & $*$ \\
\hline
\end{tabular}

Three sediments samples from within basin fill were analyzed for diatoms (Appendix C). All of the samples (at depths 28-30, 44-46, 62-64 cm) were dominated by terrestrial types, but each also had cosmopolitan and benthic types. The uppermost sample (TOV2.315) had the greatest species diversity $(\mathrm{n}=18)$, and a type Pinnularia appendiculata reflective of cool, unpolluted standing water (Appendix C). The middle sample (TOV2.323) has the fewest benthic types, and suggests only damp to moist conditions dominated in the basin. The bottom-most sample (TOV2.332) is like the sample above it, but with a few more valves of aquatic types. $\mathrm{pH}$ tolerances shift in the diatom sequence. The lowest sample (TOV2.332) has the highest percentage of acidophilous types (25\%), while the top-most sample has the highest percentage of alkaphilous types (9\%). This indicates that water quality and aquatic habitats changed through the relatively brief period of reservoir sedimentation. Shifts in water habitats within a basin that dries out are not uncommon, and such a model is proposed for the diatom assemblage observed for the Stable Mesa stock tank (Appendix C). 
The chronological and sedimentological evidence for rapid sedimentation, well before the established chronology of the village of Tovakwa, as well as its distance from the site and position on the landscape, suggests that while this feature was a reservoir, it was not constructed to provide water for Tovakwa. The basin dates indicate rapid infilling ceased before AD 1300 (Figure 7.19). No other reservoir feature I sampled has such strongly developed redoximorphic features, which have potentially formed due to continued saturation of soils over the last 700 years since sedimentation ceased. Therefore, it could have held water between the end of sedimentation at approximately AD 1300 to until the berm breached in the early 1600s. However, this scenario is unlikely because I would expect additional sedimentation over these three hundred years, unless a late-occurring breach happened during a flooding event that also truncated basin sediments. This is probably unlikely as the cessation of sedimentation within the basin likely reflects the outflow caused by a breach. It would also be unlikely that a tree would begin growing immediately in the breach, as it would be subject to continued high-energy flows if the catchment area wasn't forested during occupation. It is more likely that the growth of the tree in the berm is more reflective of landscape-wide forest recruitment after the abandonment of Tovakwa, which is seen in tree recruitment dates in the 1640s at the site (Farella 2015: 23, Liebmann et al. 2016). The large catchment area is likely to generate run-off events today, although less frequently considering the dog-hair thicket vegetation and duff covered soils would impede runoff. Still, it is likely runoff enters and saturates the basin, which would contributes to the continued formation of pedogenic redox features. 


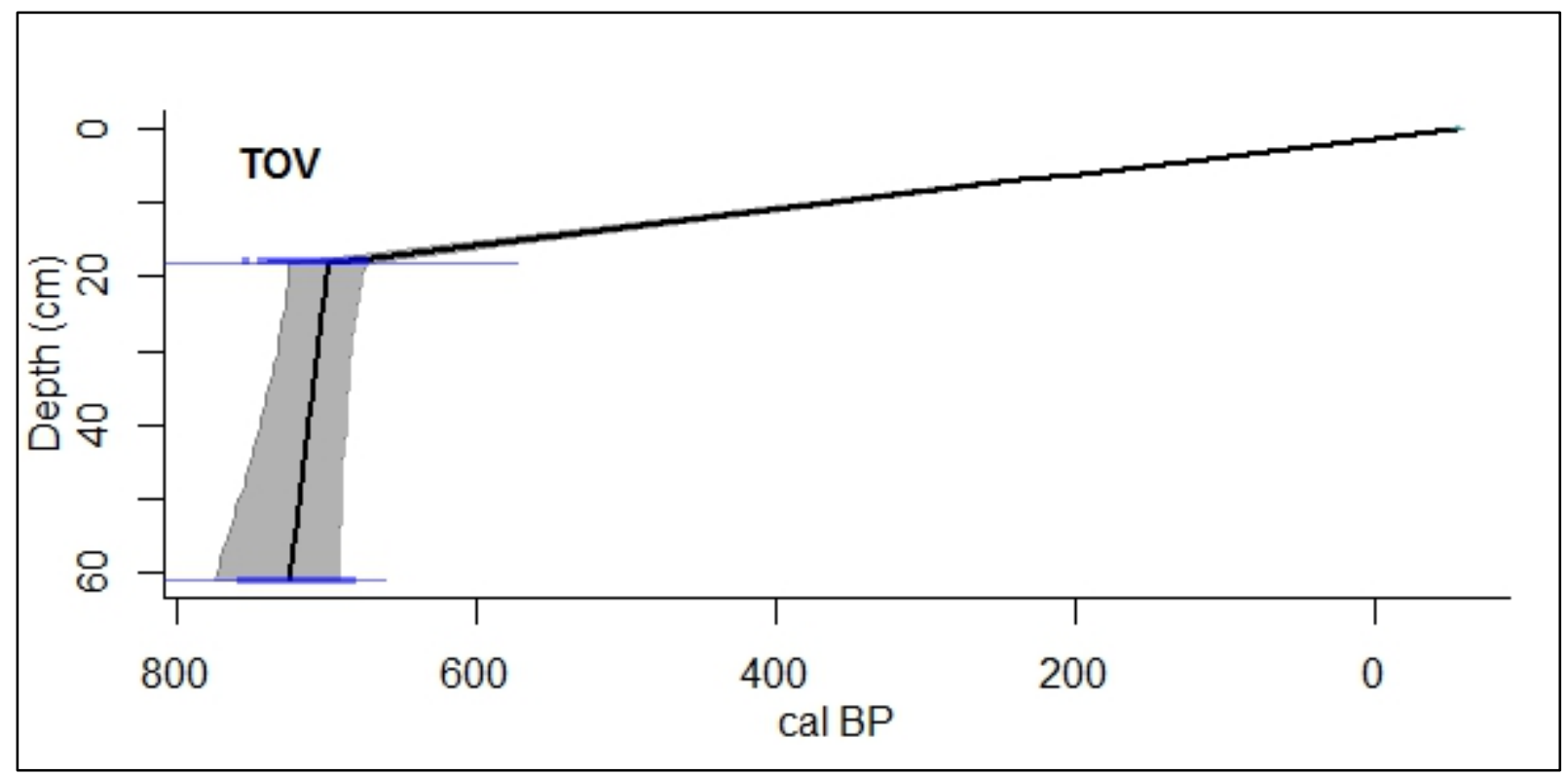

Figure 7.19. Age-depth model of LA61641 basin sedimentation (CLAM 2.2, Blaauw 2010).

Based on its chronology, LA61641 is likely an example of Ancestral Pueblo water management to provide domestic and agricultural water for the small scale communities which preceded the formation of large villages on the Jemez Plateau. The absence of occupation sites in the immediate vicinity and its location at a knickpoint suggests it that it did not become a focal point of settlement. It also can’t be ruled out that the feature was intended not only to impound water, but to reduce flow the rates downslope surfaces. In regards to meeting the water needs of the villager of Tovakwa, in Chapter 8 I identify that there are other natural water sources near the site that would be less costly for villagers to acquire than water from LA61641. Therefore, while this feature was built to store a great deal of water, based on its chronology and underfit size for its catchment, it likely did not function as a reservoir for domestic water through the long occupation of Tovakwa. 


\section{Wabakwa (LA478)}

Wabakwa, which translates from Towa to "Medicine Water Bowl Place” (Chris Toya, 2017, personal communication) is located on San Juan Mesa overlooking Cañon de la Canada (Figure 7.1). Kulisheck (2005) estimates 1400 rooms and an occupation span of AD 1350-1450. Liebmann et al. (2016) estimate maximum population of 297 persons. The site has not been excavated, but it has been subject to recent investigations as part of the Jemez FHiRE project (e.g., Farella 2015). The reservoir feature is located on the southwestern edge of the site (Figure 7.20). The feature has a $30 \mathrm{~m}$ in diameter basin along its long axis, but its berm rises only $0.45 \mathrm{~m}$ above the basin (Appendix B). Its earthen berm does not share the same horse-shoe shape as the other features. Instead, it is a reverse J, with the long axis perpendicular to the slope. The catchment area is small $\left(1,108 \mathrm{~m}^{2}\right)$ and consists of the southwestern margins of the site. The vegetation in the area is grasses with a mix of ponderosa, pinon, and juniper. There are relatively young ponderosa pines growing on the berm and margins of the basin.

The control sample was located just outside and upslope of the feature basin, and recovered an A-C1-C2-C3 soil sequence (Figure 7.21). Natural soils in the catchment consist of a $14 \mathrm{~cm}$ thick A horizon of dark brown very gravelly loam sand to sandy loam formed on pumice deposits (C1-C2) of extremely gravelly coarse sandy loam to angular tuff gravel (Appendix D). A deeply buried silt loam (C3 horizon) was encountered at the base of the core between 92-94 $\mathrm{cm}$. 


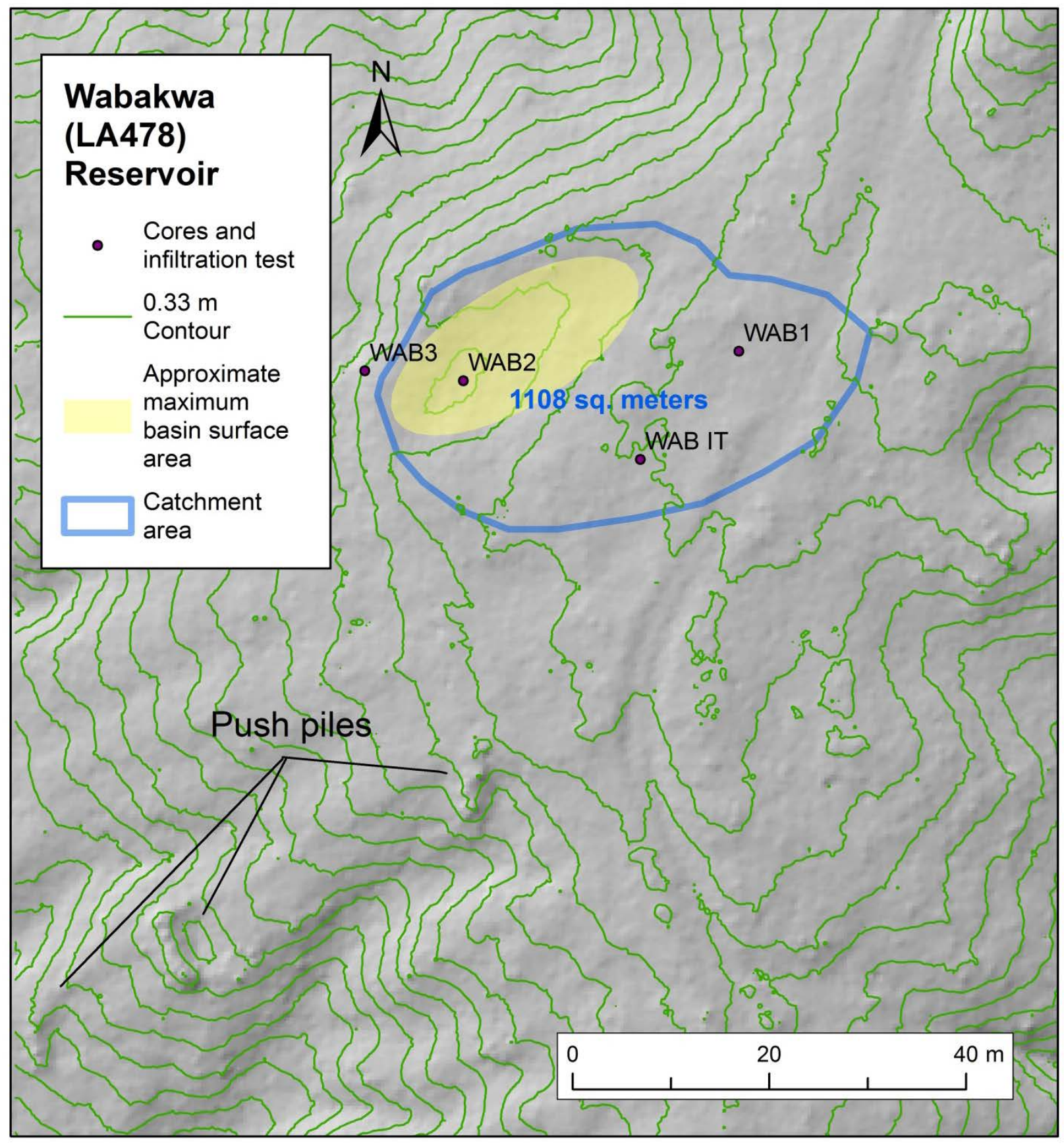

Figure 7.20. Map of coring locations and catchment area of the Wabakwa (LA478) reservoir feature. 


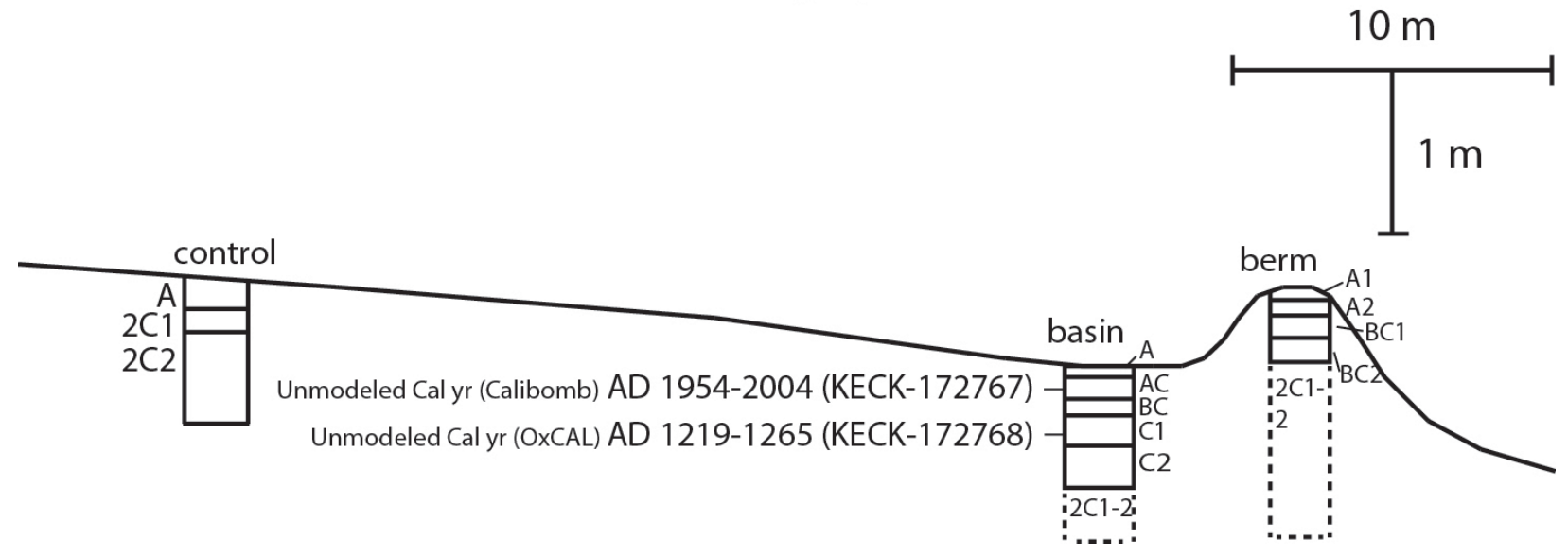

Figure 7.21. Chronostratigraphic cross section of the Wabakwa (LA478) reservoir feature.

Cores in the basin recovered a soil sequence of A-AC-BC-C1-C2-2C1-2C2 (Figure 7.21). 62 cm of sandy loam and gravelly sandy loams basin in-filling deposits were found above pumice gravels (Appendix D). Even excluding a sediment sample from the gravelly surface horizon, the Wabakwa basin has the second highest estimates of saturated hydraulic conductivity of all Jemez Plateau reservoirs (average $=15.31)($ Appendix F). An A-AC sequence of sandy loam with 5$20 \%$ gravels, and single grained to very weak fine granular structure was observed from 0-22 cm. A sample from 16-18 cm returned a modern date, but when calibrated with CALIBomb dates to cal AD 1954-2004 (KECK-172767), but with a 1-sigma age range of only AD 20012002. Forest service records show no historical fires from between 1970 and 2012. A prescribed burn during the fall of 2012 on San Juan Mesa, undertaken as part of the Southwest Jemez Mountains Collaborative Forest Landscape Restoration Project (CFLRP) Project burned part of the southeastern portion of the site of Wabakwa, immediately adjacent to the catchment area (Parmenter 2015). It is likely that this date reflects down core contamination like at Tovakwa, 
but it could also reflect recently burned plant tissues, although there was little surface evidence for rapid runoff and sediment accumulation in the basin, or down core contamination.

From 22-34 cm is a BC horizon of brown gravelly sandy clay loam, with brown (7.5YR4/4) fine soft masses throughout and moderate fine subangular blocky structure. This unit has the lowest estimated saturated hydraulic conductivity $(7.85 \mathrm{~mm} / \mathrm{hr}$.), reflecting its high silt percentages and low gravel content (Appendix F). From 34-62 cm below this soil was brown gravelly to very gravelly sandy loam to sandy clay loam (C1-C2 horizons). A charcoal sample from the top of this sequence between 34-36 cm (WAB2.318) produced a calibrated date of AD 1219-1265 (Keck-172768). High saturated hydraulic conductivity estimates (10.19-35.05 $\mathrm{mm} / \mathrm{hr}$.) reflect poor water holding characteristics of this basin (Appendix F). Below $62 \mathrm{~cm}$ is very extremely gravelly loam of the underlying pumice gravels were encountered (2C1-2C2).

The berm cores recovered a soil sequence of A1-A2-BC1-BC2-2C1-2C2-3C (Figure 7.21). The underlying pumice gravels were encountered at $34 \mathrm{~cm}$, and consisted of brown gravelly to extremely gravelly loamy coarse sand (2C1-2C2) between 34-170 cm (Appendix D). Below, there was a brown silt loam (3C) from 170-173 cm. The sediments of the berm fill consisted of dark brown to brown gravelly sandy loam to fine sandy loam (A1-A2) between 0-16 cm, underlain by a moderately hard clay loam (BC1-BC2) between 10-34 cm. I did not observe charcoal in berm sediments either during stratigraphic descriptions or during my repeated attempts to sieve sediments to find macroscopic charred tissues. A cut snag, possibly of a juniper, was identified on the berm; however, it was not sampled for dendrochronological dating. This snag would suggest that the berm is not a recent feature.

The feature has the smallest catchment area of the Jemez Plateau reservoirs (Appendix B), which leads to very small estimates of potential surface runoff (Appendix E). Even though the 
population estimates for Wabakwa are the smallest for all of the Jemez Plateau sites, the feature would not store an appreciable volume of water for the community under normal conditions (Table 7.6). Generally, it would store less than a month of water from typical annual maximum rainfall events. Even 10- and 50-year rainfall events could store less than a month of water at maximum populations using $10 \mathrm{~L}$ a day.

Table 7.6. Modeled community water budgets and reservoir storage potential for Wabakwa (LA478).

\begin{tabular}{|c|c|c|c|c|}
\hline $\begin{array}{l}\text { Population } \\
\text { Estimate }\end{array}$ & $\begin{array}{l}\text { Daily Village } \\
\text { Water } \\
\text { Requirement (m3) }\end{array}$ & $\begin{array}{l}\text { Village Water } \\
\text { Days per 1-yr max } \\
\text { rainfall event ( } 3.68 \\
\mathrm{~cm}, \mathrm{CN}=93)\end{array}$ & $\begin{array}{l}\text { Village Water } \\
\text { Days per } 10-y r \\
\text { max rainfall event } \\
(6.63 \mathrm{~cm}, \mathrm{CN}=93)\end{array}$ & $\begin{array}{l}\text { Village Water } \\
\text { Days per } 50-y r \\
\text { max rainfall event } \\
(8.74 \mathrm{~cm}, \mathrm{CN}=93)\end{array}$ \\
\hline $50 \%(n=149)$ & $0.45 / 1.49$ & $51 / 15$ & $117 / 35$ & $167 / 50$ \\
\hline $80 \%(n=238)$ & $0.71 / 2.38$ & $32 / 10$ & $73 / 22$ & $104 / 31$ \\
\hline $100 \%(n=297)$ & $0.89 / 2.97$ & $26 / 8$ & $59 / 18$ & $83 / 25$ \\
\hline
\end{tabular}

One sediment sample was analyzed for diatoms (Appendix C). WAB2.226 (50-52 cm) had an assemblage of diatoms unlike any other analyzed sample. The analyst devoted additional time to multiple slides, but only 56 valves, the fewest of any sediment sample, were counted. Of these 56, the majority were aquatic types, including Gomphonema parvulum, which was an aquatic type found in all of the modern analog samples. Navicula reichardtiana, as well as Gomphonema parvulum are taxa indicative of eutrophic conditions. Therefore, this feature has the most evidence for standing water, albeit of poor quality, yet paradoxically it has some of the worst preservation conditions for diatoms.

When compared to the site formation model, the feature at Wabakwa is the least likely to be a water storage feature. It does have a berm, and an excavated basin with infilling sediments. 
Yet, its overall shape is different than all other reservoir features, as it lacks the horse-shoe shaped basin. The sedimentation sequence within the basin is unlike the others because there is little fine-grained component, and dates from the sequence which may indicate a mixture of modern and prehistoric-aged sediments in the basin. Unlike the other Jemez reservoir features there was poor diatom recovery, with ambiguous results. The assemblage reflects standing water, but that there were poor conditions for diatom propagation and preservation. Dating of the feature was inconclusive because of both prehistoric and modern basin dates, and the lack of charcoal recovered from the berm. The one prehistoric date does fall within the occupation history of the site. Yet, there is neither evidence of a stratigraphic unconformity between the prehistoric date and the historic date, nor stratigraphic evidence for a mechanism to cause intrusive charcoal, other than as a function of sampling.

The findings also do not compare well with the other site formation models, and it may reflect other activities. It lacks sedimentological attributes of mortar mixing pits, or the evidence for continuous sedimentation of watery shrines. Additional possibilities to consider are that it is a historic erosion control feature, or that it was a pit excavated in the prehistoric period. It being a historical feature is supported by the presence of other, more recent artificial berm features on and near the same slope (Figure 7.20). While these features are recent, the Wabakwa reservoir may be a previous effort to mitigate erosion along the 2-track road, which has since collected runoff and sediments. If that is the case, it would have to be an early historic feature, because a cut juniper (undated) stump on the berm. This shows that the feature has been in place for decades, if not centuries, and therefore it may be a prehistoric feature. If so, it could be something like a borrow pit or even an incomplete reservoir, which has since infilled with both prehistoric and historic sediments. Although the evidence is limited, and at times contradictory, I 
believe that this feature was not a reservoir, which means it likely did not buffer against the risk of drought-induced water scarcity for the villagers of Wabakwa.

\section{Jemez Plateau Regional Synthesis}

Evaluating the results of geoarchaeological investigations against the site formation model demonstrates the utility of the approach and the necessity of directly testing these features. When these use-histories are compared against site-specific chronologies it shows that decision-making on the Jemez Plateau reflects village-specific solutions to water management, rather than a region-wide pattern of construction, use, and abandonment (Figure 7.22). Multi-proxy hydrological, sedimentological, and chronometric evidence suggests that features at Kwastiyukwa and Wabakwa were probably not water reservoirs for the entirety of their use histories. At Kwastiyukwa, feature size and the small catchment area were limiting factors for this feature to meet community water demands. The feature could collect and store water throughout the occupation history of the village, but not enough to make an appreciable contribution to village demands at peak population. The lack of evidence for maintenance means it likely was a wet place more like a shrine than a reservoir providing domestic water.

The feature at Wabakwa is unlike other features because of its form, and due to its small catchment area it could only collect very small quantities of water. Its sedimentation sequence shows rapid infilling, with uncertainty in the dating because of the recovery of a modern radiocarbon date, and uncertainty over the quality of water which would collect in the feature due to poor preservation contexts for diatoms. Instead, this feature may have had another function, such as a prehistoric borrow pit, a partially constructed reservoir, or possibly a very early historic berm. 


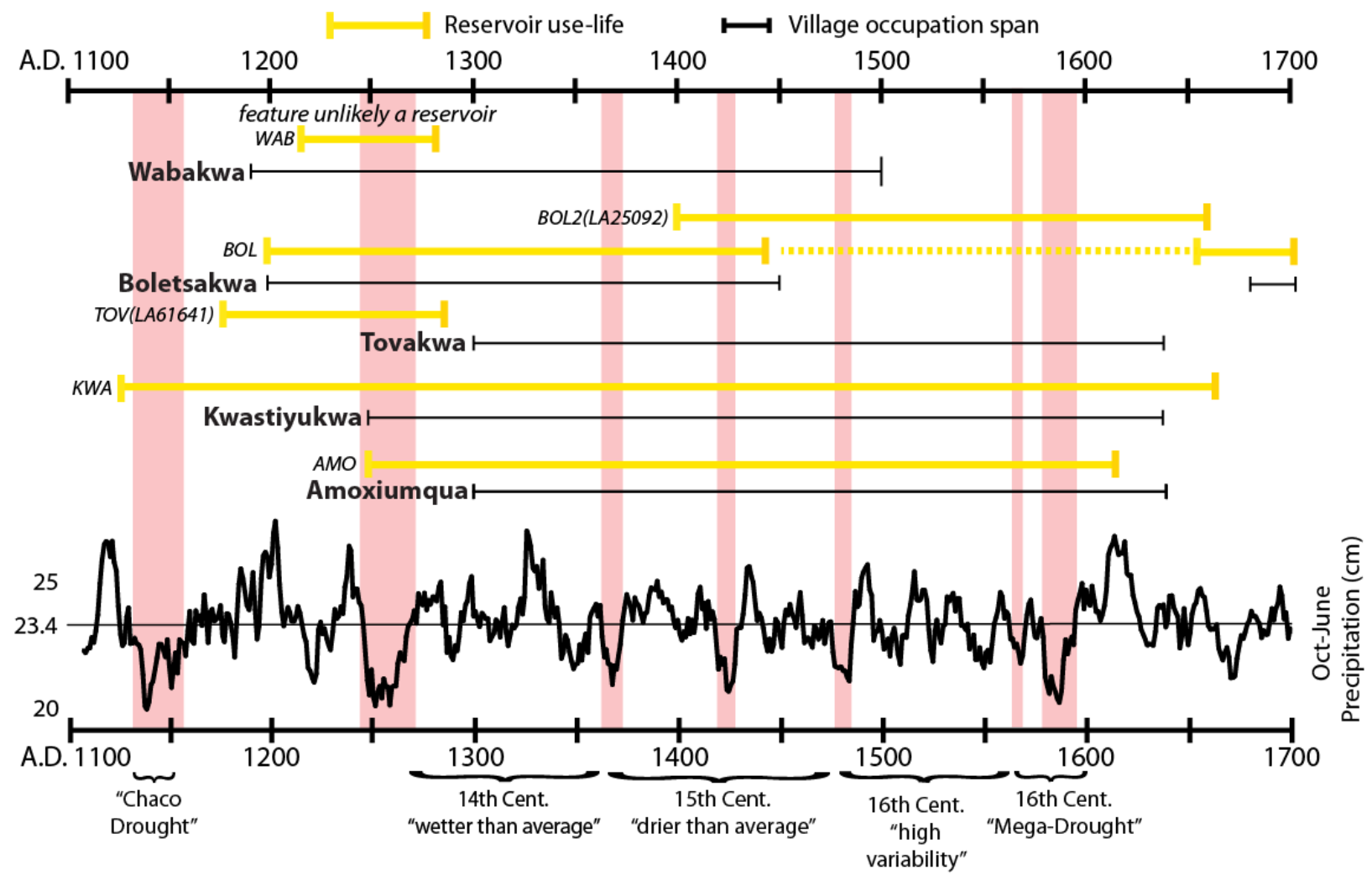

Paleoprecipitation model with 9-yr moving averages from Touchan et al. 2011. Modeled hydrological droughts are highlighted. Occupation chronologies based on Kulisheck 2005, Liebmann 2012, and Liebmann et al. 2016.

Figure 7.22. Jemez Plateau village occupation and reservoir chronologies with modeled periods of hydrological droughts and paleoprecipitation records.

The feature near Tovakwa (LA61641) is nearly as large as Amoxiumqua and it could store appreciable volumes of water to nearby residents of Tovakwa. It was also built earlier than expected. Yet, unlike the others it was undersized for its catchment area, it is breached, and it likely did not provide water during the occupation sequence at Tovakwa. This feature, like those at Kwastiyukwa, Amoxiumqua, and Boletsakwa reflects a previously unappreciated early water management system atop the Jemez Plateau, beginning during the latter portions of the San Ysidro Phase and the beginning of the Vallecitos Phase. These periods are under-represented in the archaeological record, with few mesa-top sites identified. These features reflect a more 
intensive and earlier presence on the mesa-tops of the Jemez Plateau than archaeologists have realized. They also reflect water management embedded in local cultural practice, potentially hundreds of years before the rise of large populations, which are in part associated with immigrant populations.

Of the five Jemez Plateau sites tested, the features at Amoxiumqua and Boletsakwa are the only features that likely provided domestic water during the occupations of Ancestral Pueblo villages. Yet, they are very different. Amoxiumqua stands out as the archetypical of what a reservoir should be in regards to chronology of use and storage potential. The two reservoir features at Boletsakwa have more complicated history. This is perhaps due to the technological challenges of storing water in a context with pumice substrate, and because of the site's long, varied occupation history. The small reservoir at Boletsakwa has a long history of use, and could store more water than I anticipated because of its deeply excavated basin. It likely reflects water management associated with Little Boletsakwa (LA135) more than Boletsakwa. The LA25092 reservoir, a far more substantial feature, would certainly augment the limited water available from the other feature. Its use beginning in the late 1300s is interesting, because its construction precedes the Revolt era occupation of Boletsakwa, during which demand may have been highest. This suggests it was used for other purposes, such as for agriculture or by households dispersed across the southern end of the mesa.

When these features use-lives are compared to drought periodicities, the only clear correlation is that they were all used through both wet and dry periods (Figure 7.22). The features at Amoxiumqua and Kwastiyukwa were constructed during dry periods, potentially reflecting water management to mitigate the risk of water scarcity for what at the time could only have been very small communities. The construction of features at the other sites (Boletsakwa 
and Tovakwa) do not correlate to hydrological droughts, and none of the sites appear to stop being used during droughts. The construction and use of these features by Ancestral Pueblo communities on the Jemez Plateau was driven less by drought-induced scarcity, and more to reduce water acquisition costs.

\subsection{The Pajarito Plateau Reservoirs}

Reservoir features on the Pajarito Plateau are identified in survey reports (Powers and Orcutt 1999) and in region-level summaries of ecology and water management (Allen 2004, Snead 2006). I tested nine reservoirs associated with four large village sites. There are at least four more sites across the project area with reported reservoirs that I did not test. I did not test Poretero de las Casas (LA115166) at Bandelier because both the site and the reservoir feature were smaller than the other sites. The other sites, Guaje Canyon (LA12700), Otowi (LA169), and Puyé (LA47) are located on Forest Service, Tribal, or LANL properties. Occupation histories of these sites, as well as our understanding of regional water management practices, could benefit from future investigations. Because site-specific population histories and chronologies are more refined on the Pajarito Plateau, I can say more about the relationships between feature use-life histories and population estimates. In Figure 7.23 I present the momentary mean population estimates for the four sites I tested in this study (Ortman 2016), and I refer to this figure throughout the remainder of the chapter as I discuss water demands for each site in relationship to reservoir use-life histories. 


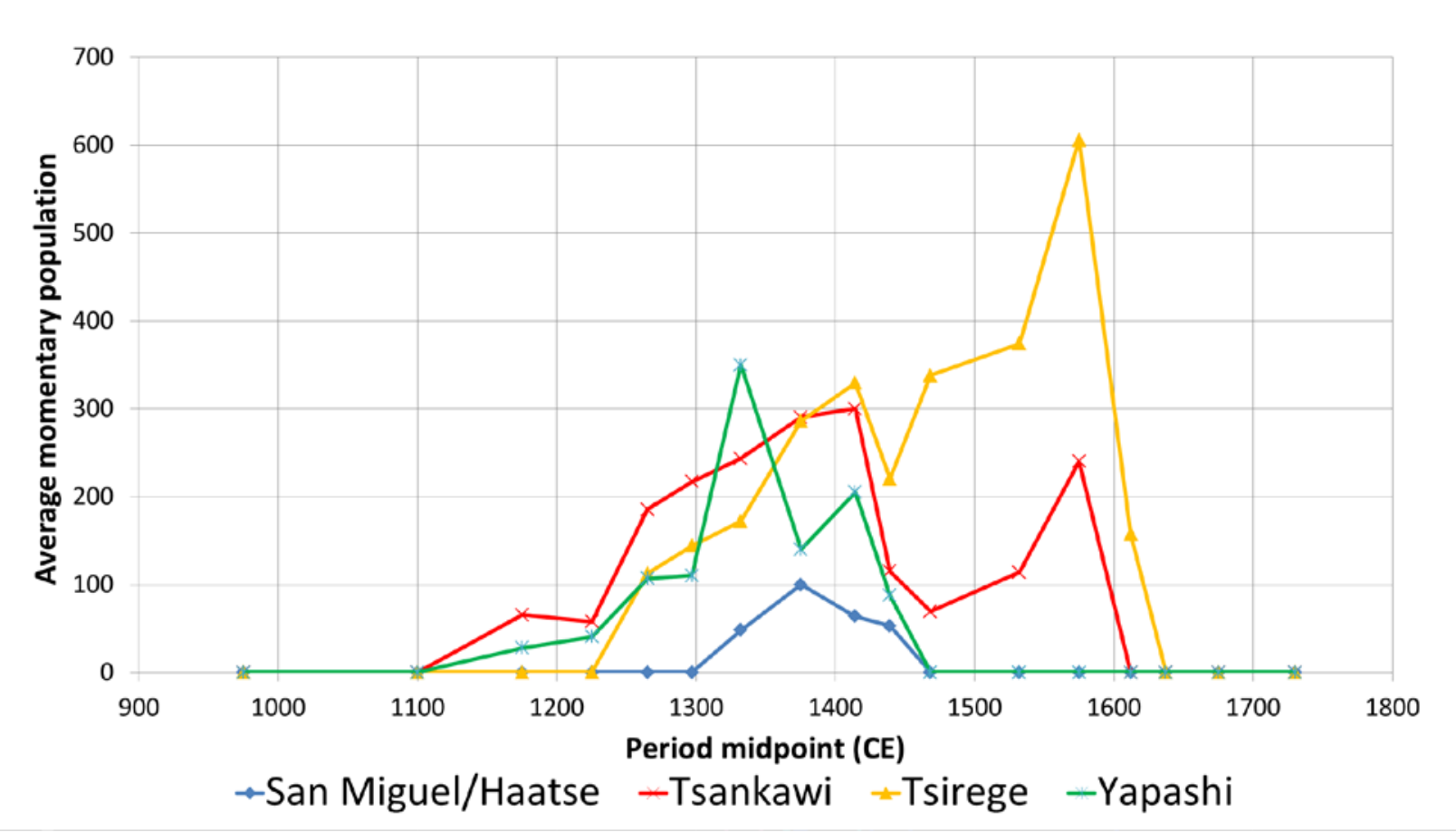

Figure 7.23. Momentary mean population estimates of the four village sites on the Pajarito with tested reservoir features (Ortman 2016).

\section{San Miguel/Haatse (LA 370)}

The site of San Miguel, which in Keres is called Haatse “earth” or Ra-tye Ka-ma Tzeshumain "the old Houses at the Rabbit" (Bandelier 1892:159), is located on the upper portion of Capulin Mesa in the southwestern corner of Bandelier National Monument (Figure 7.1).

Tributaries coming off the mesa top drain into Medio Canyon to the south. The San Miguel Mountains overlook the site to the west. The site was first reported by Bandelier (1892:158-159). Hewett conducted some testing at the site (1938: 46), but the results were never fully reported (Mathien 1991). Subsequent inventory surveys by the NPS have generated detailed maps and surface artifact counts at the village (Powers and Orcutt 1999: Figure 6.18). Ortman (2016) estimates that the site had 100 rooms and a maximum momentary mean population estimate of 
100 persons. The ceramic-based chronology reflects an occupation limited to AD 1300-1450

(Figure 7.23). It is the smallest village with a reservoir that I tested in this study.

The reservoir was reported in the earliest descriptions of the site (Bandelier 1892:159; Hewett 1938:46), and it is located approximately 50 meters southeast of the roomblock, near the edge of the mesa. Its catchment area includes most of the site (Figure 7.24), and its gradient is high. Soils are thin and eroded, with exposed bedrock across many portions of the catchment area. Artifacts on the surface of the catchment area are very common, suggesting upslope middens and erosion from the main site area. The catchment area is mostly low grasses with a few junipers, which increase in numbers along the mesa edge. The diameter of the basin is only $14 \mathrm{~m}$, and it has the smallest surface area of any feature $\left(93.25 \mathrm{~m}^{2}\right)$, which is only slightly larger than the nearby LA3834 feature (Appendix B). Much of the berm appears to be washed out. The berm is $0.4 \mathrm{~m}$ high above the basin, but only $0.14 \mathrm{~m}$ above the height of the downslope surface. Tuff blocks are incorporated into the berm across its entire construction. There are many dislocated blocks downslope of the berm, as well as sediments washed out between the rocks, indicating the berm was once higher.

The shallow basin of the San Miguel reservoir has a 64 cm thick AC(1)-Ab/AC(2)-Cb1-Cb2R soil sequence (Figure 7.25). The surface soils varied slightly between cores (Appendix D). All were capped by a $10 \mathrm{~cm}$ thick AC horizon of dark brown poorly sorted gravelly sandy loam to sandy clay loam. This horizon had platy structure reflecting intact bedding, while also having few roots. It has very high estimated saturated hydraulic conductivity measurements (24.06 $\mathrm{mm} / \mathrm{hr}$.) indicating limited water holding potential (Appendix F). Below was either an AC2 horizon (Core 2.2) or an Ab horizon (Core 2.1) from 10-16 cm. The Ab horizon was black (7.5YR2.5/2) gravelly sandy clay loam with weak fine granular structure, while the AC2 horizon 


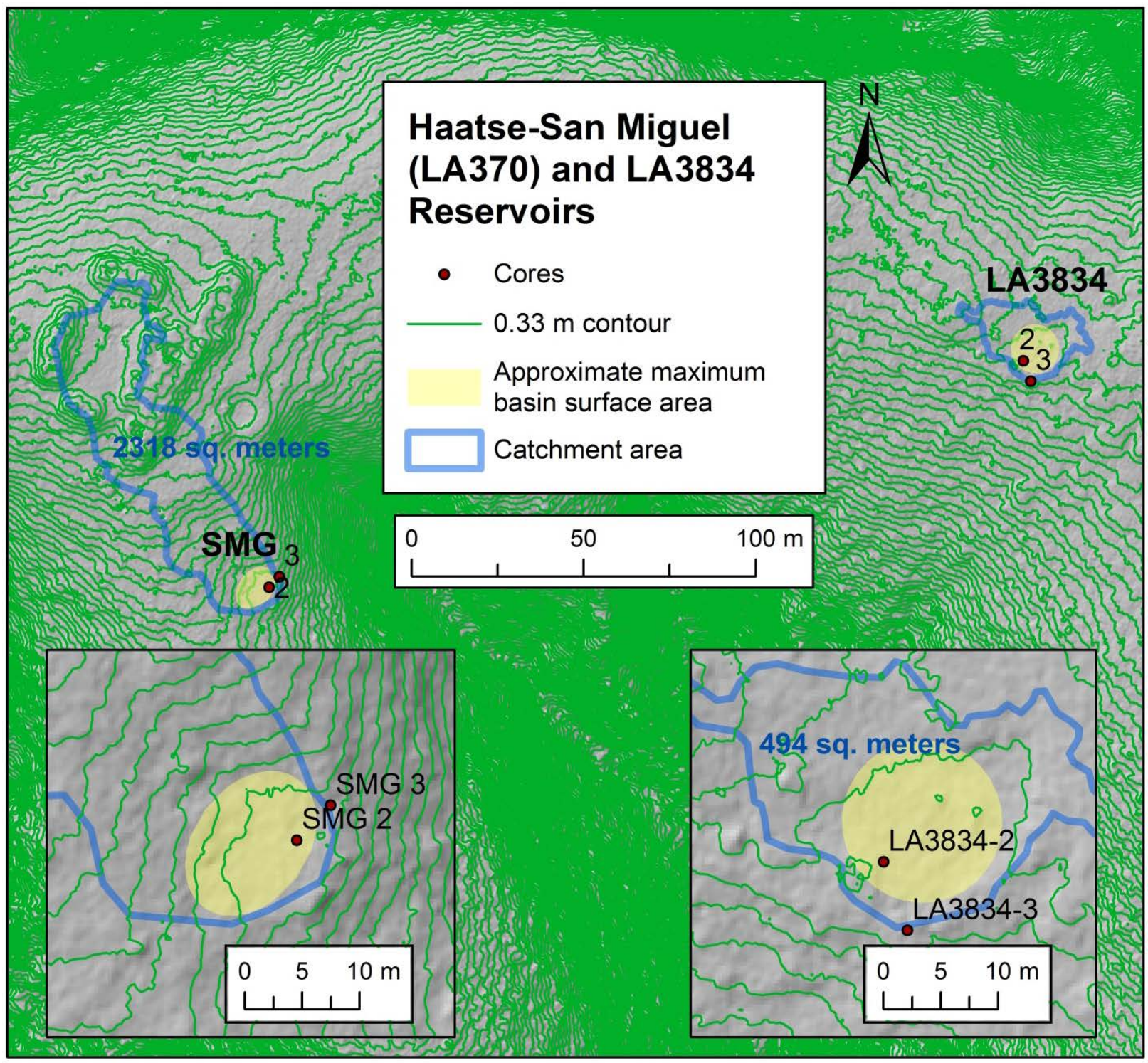

Figure 7.24. Map of coring locations and catchment areas of the Haatze/San Miguel and LA3834 reservoir features.

was similar, but lacked soil structure. This horizon has an even worse estimated saturated hydraulic conductivity levels (52.69 mm/hr.) (Appendix F). Two charcoal samples were dated from the Ab horizon of core 2.1 (Figure 7.24 and Appendix H). A modern age distribution was returned from the analysis of one sample (Keck-170999), which with a 1-sigma distribution in CALIBomb dated to cal AD 1955-1956. A second charcoal sample from different charred tissues 
produced a modeled date of cal AD 1422-1445 (Keck-172757). This suggests the presence of buried soils, but with active contributions of new charcoal through sedimentation and in situ deposition. The underlying soils (Cb1-Cb2 horizons) extending down from $16 \mathrm{~cm}$ to the contact with tuff bedrock at $64 \mathrm{~cm}$ are dark brown (7.5YR4/3) extremely gravelly sandy clay loam. The estimated saturated hydraulic conductivity levels for these deposits are lower, (13.23-15.64), but the average of these basin estimates are the second highest of all tested basins (average $=26.4$ $\mathrm{mm} / \mathrm{hr}$.). Charcoal from the base of the reservoir fill $(60-64 \mathrm{~cm})$ produced a modeled date of cal AD 1300-1395 (Keck-172758).

I documented a $62 \mathrm{~cm}$ thick $\wedge$ AC-C1-C2-R soil sequence (Figure 7.25), in one core into the berm (Appendix D). The core was collected from immediately downslope of the berm surface, because there were few clear opportunities across the berm crest to achieving a core that samples entirely through the constructed material down to bedrock. From $0-14 \mathrm{~cm}$ is a dark brown gravelly fine sandy loam $\wedge$ AC horizon. Aggregated charred short-lived tissues from between 12 $18 \mathrm{~cm}$ were analyzed, and returned a modeled date of cal AD 1243-1287 (Keck-172759). Below the $\wedge$ AC horizon are unweathered horizons (C1-C2) of dark brown extremely gravelly loamy sand. Tuff bedrock was encountered at $62 \mathrm{~cm}$.

Even though the reservoir feature is small it could provide appreciable quantities of water to the small population at San Miguel, although there is limited evidence in the diatom assemblage for the presence of water. At full population, the typical 1-year maximum rainfall event could produce enough runoff for over a month of village use. However, rainfall events of greater magnitudes would overtop the berm, limiting the potential for storing larger volumes and 


\section{Haatse/San Miguel Reservoirs Chrono-Stratigraphic Cross Sections}
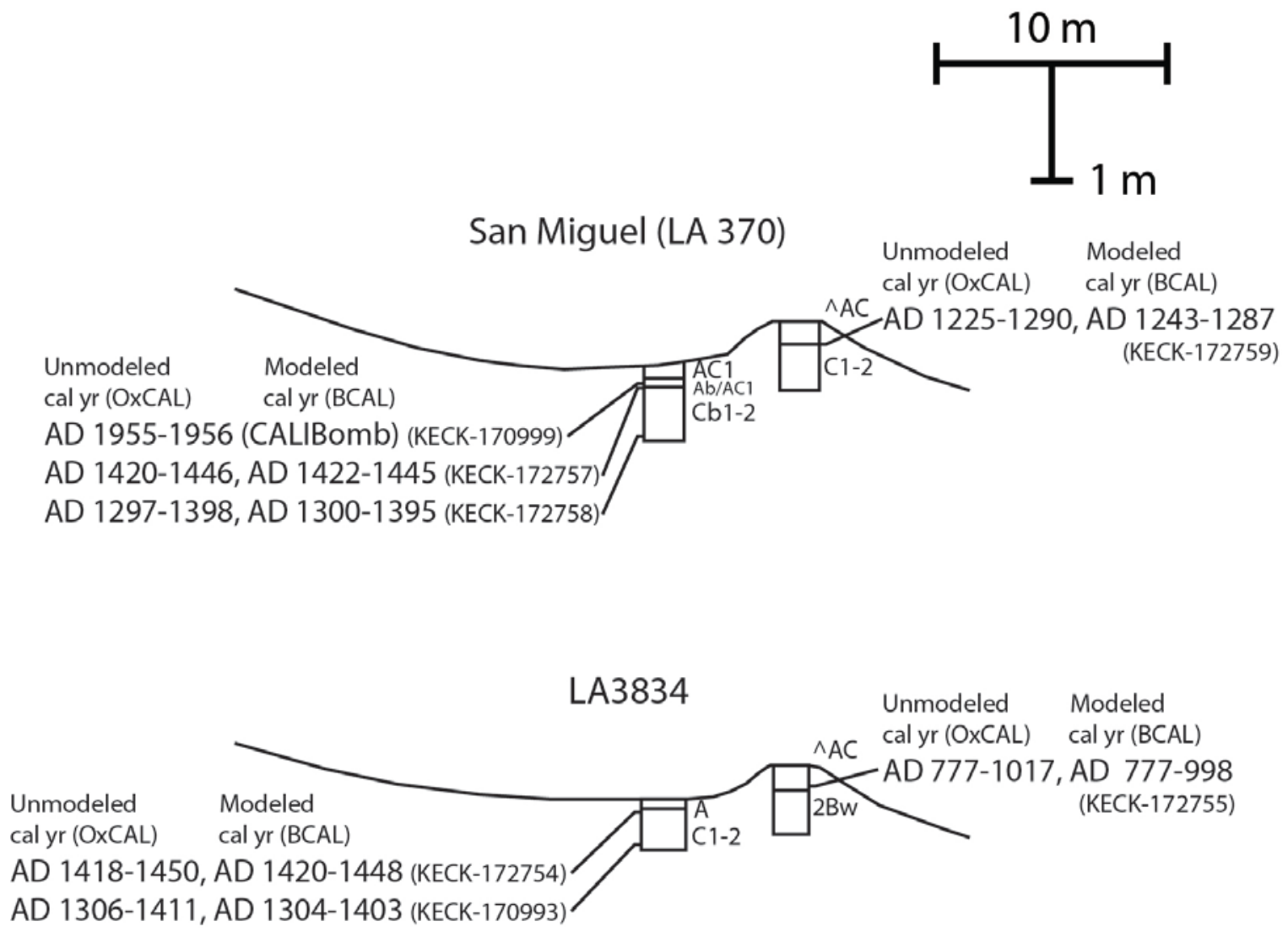

Figure 7.25. Chronostratigraphic cross sections of the Haatse/San Miguel and LA3834 reservoir features.

increasing the likelihood of berm failure. Sediments from one sample (SMG2.109), collected from 16-18 cm, were analyzed for diatoms. Only 5 taxa were identified in the 600 valve count, and all are aerial forms (Appendix D), indicating that this feature only experienced damp conditions, but that it did not hold enough water for long enough to support aquatic taxa.

Radiometric dates from the berm and basin fill indicate that this feature was likely constructed in the late 1200s to early 1300s, and then rapidly infilled with sediments into the mid- 1400s. The feature is small, but it had a relatively large catchment area with a high gradient. It could fill rapidly, with volumes of water that could provide the village with appreciable 
quantities of water (Table 7.7). Larger runoff events could overtop the feature, and there is surface evidence for breaching and berm failure. This suggests that it would require frequent maintenance. Yet, despite hydrological evidence that it held water, diatoms indicate that while it was a wet setting there was not standing water in the feature for long enough to support aquatic species. In addition, the sedimentological attributes of the basin fill do not reflect fine sediments settling into the basin associated with standing water. Instead, it is likely that water from high energy runoff events would fill the basin, and any water have to be quickly extracted for economic use because it would rapidly be lost to infiltration and evaporation out of the small, shallow basin. The hydrological evidence supports this feature being a water reservoir, although only more testing could better resolve its use-history. More paleoecological analyses could help with identifying whether or not there was standing water in the basin. If the basin had been regularly cleanout out, then the lack of aquatic types could be reflective of infilling towards the end of use-life and post-abandonment, which would not be unexpected in a small, potentially breached feature.

Table 7.7. Modeled community water budgets and reservoir storage potential for Haatse/San Miguel (LA370).

\begin{tabular}{|c|c|c|c|c|}
\hline $\begin{array}{l}\text { Population } \\
\text { Estimate } \\
\end{array}$ & $\begin{array}{l}\text { Daily Village } \\
\text { Water } \\
\text { Requirement (m3) }\end{array}$ & $\begin{array}{l}\text { Village Water } \\
\text { Days per 1-yr max } \\
\text { rainfall event ( } 1.38 \\
\text { in, } \mathrm{CN}=93)\end{array}$ & $\begin{array}{l}\text { Village Water } \\
\text { Days per } 10 \text {-yr } \\
\text { max rainfall event } \\
(2.43 \text { in, } C N=93)\end{array}$ & $\begin{array}{l}\text { Village Water } \\
\text { Days per } 50 \text {-yr } \\
\text { max rainfall event } \\
(3.23 \text { in, } \mathrm{CN}=93) \\
\end{array}$ \\
\hline $50 \%(n=50)$ & $0.15 / 0.5$ & $298 / 89$ & $432 / 130 *$ & $*$ \\
\hline $80 \%(n=80)$ & $0.24 / 0.8$ & $186 / 56$ & $270 / 81^{*}$ & * \\
\hline $100 \%(n=100)$ & $0.3 / 1$ & $149 / 45$ & $216 / 65^{*}$ & * \\
\hline
\end{tabular}




\section{LA3834}

The site of LA3834 is located approximately 225 m east of San Miguel (Figure 7.1 and Figure 7.24) on the same mesa-top setting as the site. The site was originally documented in 1959, and recorded more extensively in 1989 as part of the Bandelier surveys (Site Report on file at Bandelier National Monument). The site consists of a one room structure, artifact scatter, and a reservoir feature. Ceramics on the feature date to between AD 1315-1425, although a few Glaze F body sherds are reported across the site indicate a later ( AD 1640-1720) presence at the site. Its catchment area is only $494 \mathrm{~m}^{2}$, and its storage volume is only $41 \mathrm{~m}^{3}$, which are the smallest estimates of any feature I tested across both project areas (Appendices B and E). The berm is only $0.3 \mathrm{~m}$ above the basin, and consists of an arcuate ring of tuff boulders and earthen material. Vegetation across the catchment area and basin is low forbs and grasses with junipers. Very few artifacts were observed on the ground surface, and in the original archaeological survey.

The cores within the basin recovered a $36 \mathrm{~cm}$ thick AC-C1-C2-C3 soil sequence (Figure 7.24, Appendix D). From 0-6 cm, the AC horizon was dark brown loamy fine sand, with single grained structure and few fine roots. It has a very high (36.41 mm/hr.) estimated saturated hydraulic conductivity (Appendix F). This horizon likely reflects very recent sedimentation within the basin. The underlying C1-C3 sequence from 6-36 cm consisted of a dark brown fining upward sequence of gravelly clay loam to clay loam with a weak medium platy structure. This horizon has a much lower estimated saturated hydraulic conductivity (5.76-6.29 mm/hr.), which would help reduce the rate of infiltration (Appendix F). Aggregated charred tissues from 10-16 cm produced a modeled date of cal AD 1420-1448 (Keck-172754), while a charcoal sample from the bottom of the basin $(34-36 \mathrm{~cm})$ generated a modeled date of cal AD 1304-1403 (Keck- 
170993). These dates suggest sedimentation in the basin contemporaneous with village occupation.

The core emplaced on the small berm registered a $20 \mathrm{~cm}$ thick $\wedge$ AC-2Bw soil sequence. The $\wedge \mathrm{AC}$ horizon is a $6 \mathrm{~cm}$ thick dark brown loam to fine sandy loam with single grained structure. These surface sediments are likely winnowed basin sediments with an eolian contribution. Below, from 6-20 cm, is a brown loam to clay loam, with weak fine subangular blocky structure (2Bw). Aggregated charred tissues from across the boundary between these horizons $(4-10 \mathrm{~cm})$ produced a modeled date of AD 777-998 (Keck-172755), which likely reflects charcoal preserved in soils formed before construction of the berm, rather than a time of occupation.

In typical years, the reservoir of site LA3834, which has the smallest modeled maximum potential storage volume of all tested features, could only meet a minor fraction of the water demands at the site of San Miguel (Table 7.8). Runoff of typical 1-year rainfall event would provide less than a months' worth of water while either major rainfall events or cumulative runoff events associated with monsoon periods could provide approximately a month or more of water. Combined with water from the San Miguel reservoir this would be significant, but considering that this feature would likely only store water from low-frequency, high magnitude events it likely would not be that effective as a storage basin.

I had one sediment sample from the basin of LA 3834 analyzed for diatom s. Only 82 valves were identified in sample LA3834_2.109 (16-18 cm) (Appendix C). All but 2 valves observed were aerial taxa. The two aquatic valves were both of Navicula cryptotenella, but the analyst states it is just as likely that these few valves could be reworked or transported into the basin rather than reflect an aquatic episode in the basin (Appendix C). These paleoecological findings 
indicate that wet conditions in this feature were only temporary, and the low total count suggests the basin was a poor setting for even aerial taxa.

Table 7.8. Modeled community water budgets and reservoir storage potential for Haatse/San Miguel and LA3834.

\begin{tabular}{|c|c|c|c|c|}
\hline $\begin{array}{l}\text { Population } \\
\text { Estimate } \\
\end{array}$ & $\begin{array}{l}\text { Daily Village } \\
\text { Water } \\
\text { Requirement (m3) }\end{array}$ & $\begin{array}{l}\text { Village Water } \\
\text { Days per 1-yr max } \\
\text { rainfall event (1.38 } \\
\text { in, } \mathrm{CN}=87)\end{array}$ & $\begin{array}{l}\text { Village Water } \\
\text { Days per } 10 \text {-yr } \\
\text { max rainfall event } \\
(2.43 \text { in, } C N=87) \\
\end{array}$ & $\begin{array}{l}\text { Village Water } \\
\text { Days per } 50-y r \\
\text { max rainfall event } \\
(3.23 \text { in, } C N=87) \\
\end{array}$ \\
\hline $50 \%(n=50)$ & $0.15 / 0.5$ & $37 / 11$ & $103 / 31$ & $160 / 48$ \\
\hline $80 \%(n=80)$ & $0.24 / 0.8$ & $23 / 7$ & $64 / 19$ & $100 / 30$ \\
\hline $100 \%(n=100)$ & $0.3 / 1$ & $19 / 6$ & $51 / 15$ & $80 / 24$ \\
\hline
\end{tabular}

The low potential for runoff and small storage volume reflect a feature that would likely only rarely collect water in useful volumes for local villagers. Radiometric dates from the basin closely mirror the dates from the San Miguel feature, indicating it was used between AD 13001450. Because the berm date came from the contact with the underlying Bw horizon, it more likely reflects ages of natural soils preceding settlement than it does berm construction. This limits the certainty of identifying a construction date for the berm. I include the potential contribution of this feature to evaluate the artificial water supply at San Miguel, but the infrequency of infilling due to its small catchment area likely meant that this feature made only minor contributions to community water demands. It is likely that this feature would be more of a watery shrine that could occasionally be drawn upon for water, rather than a reliable water source, particularly during dry periods. 


\section{Tsankawi (LA211)}

The site of Tsankawi, which translates from Tewa to "gap of the sharp, round cactus" (Hewett 1938:35) is located on a small isolated mesa between Los Alamos and Sandia Canyons (Figure 7.1). Excavations were conducted by Hewett (1938), but his work was never fully reported (Mathien 1990). Ortman (2016) estimates that there are 300 rooms at the site and that the occupation spanned between AD 1225-1600. Unlike other big site population estimates, this site had bimodal population peaks at AD 1400 and AD 1575 (Figure 7.23), with a maximum population of 300 at around AD 1400. Three small reservoir features are identified at Tsankawi (Powers and Orcutt 1999: Figure 6.17). On the site map I have numbered these features TK-1 to -3 , starting clockwise from the north (Figure 7.26). TK-1 and TK-2 are undisturbed; however TK-3 is breached along an interpretative trail across the mesa, and includes signage describing the feature as a possible reservoir. Hewett (1906: Plate VII) identifies TK-2 and TK-3 on his site map. Dick Ford is reported to have hypothesized that these particular features are shrines instead of reservoirs (Ford in Van Zandt 2006). I discuss the results of my geoarchaeological investigations of each of these features below.

I did not collect control samples for each catchment area because soils were thin on the mesatop, and most of the catchment areas were near roomblocks. This limited the locations where I could sample. Two cores were collected in the TK-2 catchment area to serve as controls for mesa-top soils (labeled TK2_1 in Figure 7.26). In the first of the control samples (TK-2_1.1) I identified a $20 \mathrm{~cm}$ thick, A-A/R soil sequence (Figures 7.27). From 0-10 cm, the A horizon is a dark brown (7.5YR3/3) fine sandy loam (Appendix B). It has a single grained structure and common, undecayed plant tissues and roots. Below from $10-20 \mathrm{~cm}$ is a dark brown (7.5YR3/3) extremely gravelly fine sandy loam to clay loam with fractured white tuff rock fragments of 


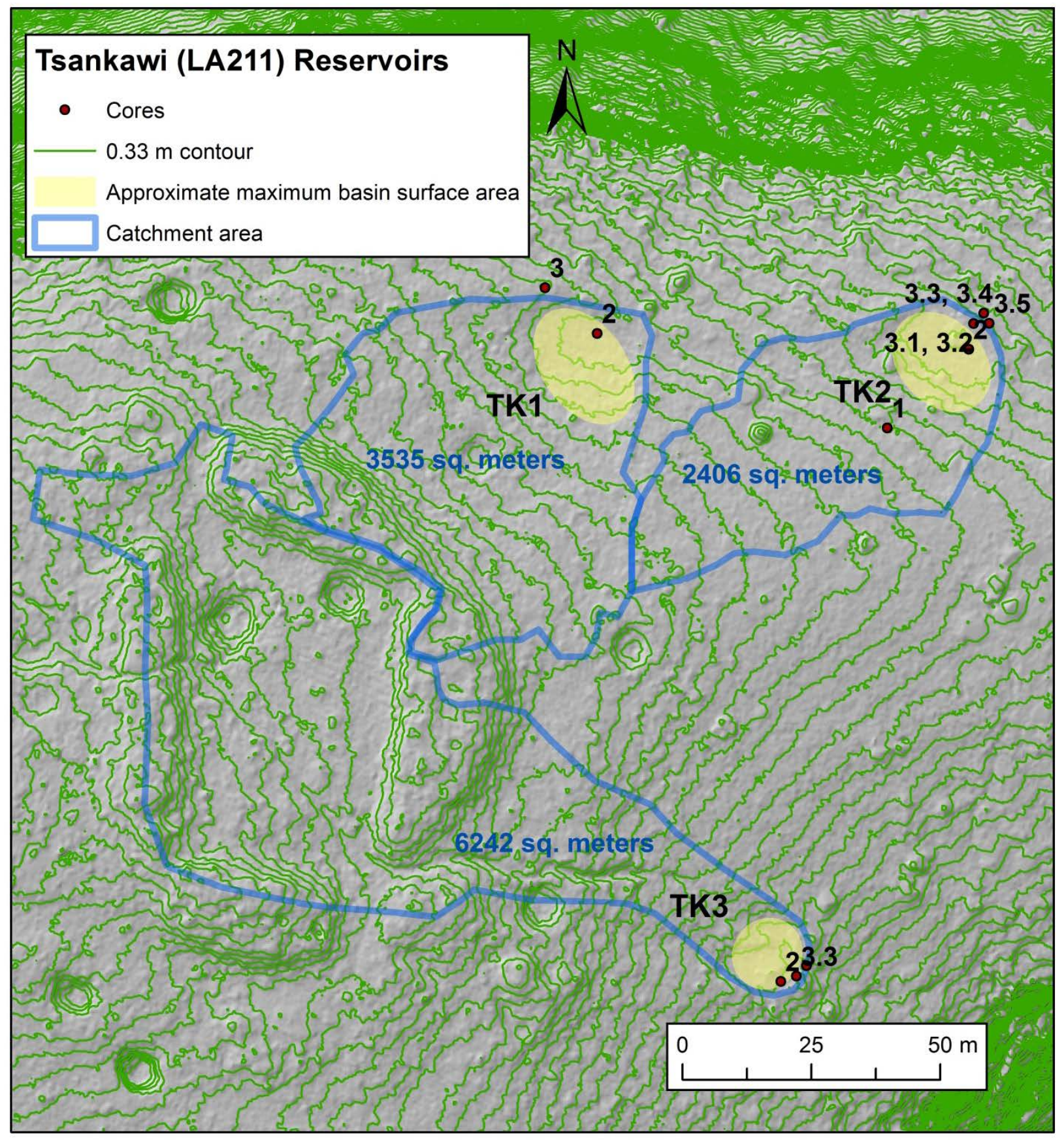

Figure 7.26. Map of coring locations and catchment areas of the Tsankawi (LA211) with reservoir features. 


\section{Tsankawi (LA211) Reservoir Chrono-Stratigraphic Cross Sections}
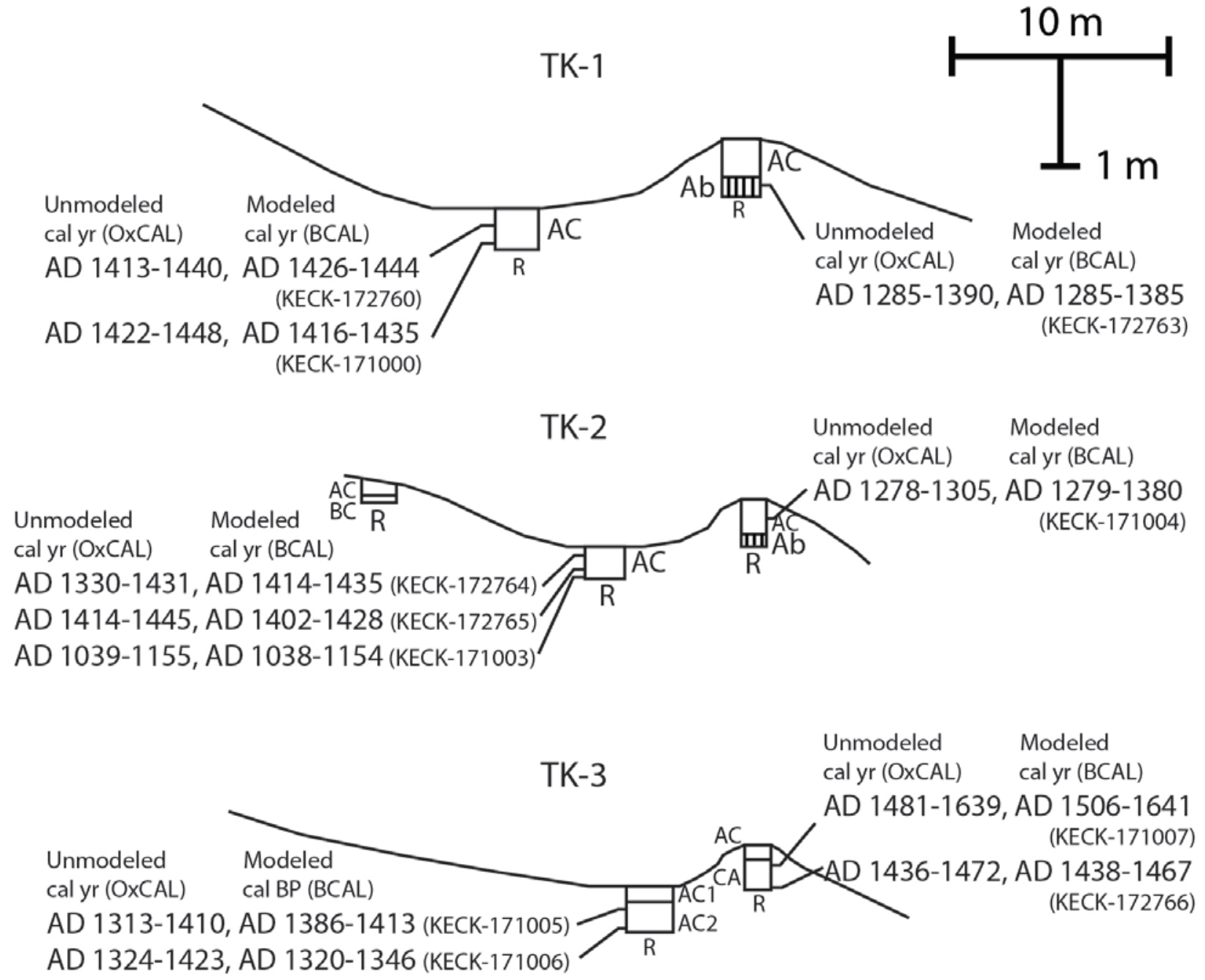

Figure 7.27. Chronostratigraphic cross sections of the Tsankawi (LA211) reservoir features.

bedrock. The second control sample, Core 1.2, recovered a $20 \mathrm{~cm}$ thick A-BC-R soil sequence.

Like the other control sample the A horizon from $0-10 \mathrm{~cm}$ is a dark brown (7.5YR3/3) fine sandy loam. Particle size analysis (Appendix F) of this horizon shows it is very low in gravels (2.9\%), nearly equal fractions in sand (41.8\%) and silt (40.2\%), and relatively high saturated hydraulic conductivity (13.75-16.68 mm/hr.). From 10-14 cm is a BC horizon of brown (7.5YR5/4) loamy 
sand with $10 \%$ fine tuff gravels. Particle size analysis of this horizon found it dominated by silt (55.9\%) with a very low content of gravel (1.9\%) (Appendix F). Below are white tuff bedrock fragments from 14-20 cm (R horizon). These thin soils indicate very limited in-situ soil formation, and suggest erosion across the Tsankawi Mesa followed by the limited eolian sedimentation, such as what is seen in other mesa-top contexts of the Central Pajarito (Drakos and Reneau 2007).

\section{TK-1 (LA211)}

TK-1 is located north of the Tsankawi roomblocks. Its 3,535 $\mathrm{m}^{2}$ catchment area includes northern portions of the site (Figure 7.26, Appendix E). The feature has an oval shaped basin that is $22 \mathrm{~m}$ in diameter (Appendix B). Bedrock outcrops along its southern and western margins suggest its oval shape may in part be a function of topographic variability in bedrock. At its highest the berm is $0.75 \mathrm{~m}$ above the basin, but this is only towards its north side. The berm is possibly breached along the eastern portion of the feature, with exposed architectural rocks in what is now a swale where an artificial berm should be. Tuff rock fragments are observed in wall construction in the eastern and northern portions of the berm, but rocks become fewer and are no longer continuous to the northwest. Very few artifacts were observed around the feature. Vegetation is dominated by forbs like rabbit brush in the basin and across the catchment area, while a few junipers grow along the berm and downslope of the feature.

The basin fill is a $42 \mathrm{~cm}$ thick AC horizon of very dark gray loam to clay loam. (Figure 7.27) Its structure is single grained, with 1-5\% very fine tuff gravels and occasional large tuff rock fragments (Appendix B). There is some variability in the particle size distributions of samples 
within this horizon. The uppermost sample $(0-2 \mathrm{~cm})$ has a high sand content (48.9\%), while the two lower samples (12-14, 32-34 cm) have nearly identical particle size distributions dominated by silt (Appendix F). This impacts the water-holding characteristics of the basin. The uppermost surface sample has a very high estimated saturated hydraulic conductivity rate (40.31 mm/hr.), while the lower two are far lower (5.56-7.2 mm/hr.). The uppermost portion of the fill likely reflects eolian mantling, with little potential for storing water, while the finer grained lower portions of the horizon would reduce infiltration rates and are likely a function of water-laid deposits. White tuff bedrock is at the base of the horizon at $42 \mathrm{~cm}$. The modeled date of a charcoal sample from 8-14 cm dates to cal AD 1426-1444 (Keck-172760), while a sample from 36-42 cm dates to cal AD 1416-1435 (Keck-171000) (Figure 7.26, Appendix H). These dates indicate rapid sedimentation within the basin in less than a century.

The berm has a $40 \mathrm{~cm}$ thick AC-^CA-2ACb-R soil sequence (Figure 7.27). The AC horizon from $0-10 \mathrm{~cm}$ is a dark brown (7.5YR3/2) loam to very fine sandy loam (Appendix F). It is single grained, has many roots, and some fine gravels. From $10-27 \mathrm{~cm}$ is a $\wedge$ CA horizon of dark brown (7.5YR3/2) medium to fine sandy loam. It is single grained, with increasing numbers of tuff rock fragments, including some with charcoal, towards its base. Charcoal collected from this fill horizon between 19-25 cm produced a modeled date of cal AD 1285-1385 (Keck-172763). This fill horizon included rocks, and it capped an intact buried surface. Below was a 2ACb horizon from 27-32 cm. This horizon was dark brown (7.5YR3/4) loam to silt loam, with few medium tuff gravels, a single grained structure, and very few fine roots. Below, from $32-39 \mathrm{~cm}$ there are white tuff rock fragments of the underlying bedrock (R horizon).

TK-1 was well designed to store high magnitude runoff events, as it could accommodate the water from at least a 50-year maximum rainfall event (Table 7.9). Alone, it could store 
approximately one months' worth of water for the maximum estimated population with the runoff from the typical 1-year maximum rainfall event, and enough water for multiple months in periods when the village had either low populations or during wet periods.

Table 7.9. Modeled community water budgets and reservoir storage potential for the Tsankawi-1 reservoir (TK-1).

\begin{tabular}{|c|c|c|c|c|}
\hline $\begin{array}{l}\text { Population } \\
\text { Estimate }\end{array}$ & $\begin{array}{l}\text { Daily Village } \\
\text { Water } \\
\text { Requirement (m3) }\end{array}$ & $\begin{array}{l}\text { Village Water } \\
\text { Days per 1-yr max } \\
\text { rainfall event (1.38 } \\
\text { in, } \mathrm{CN}=93)\end{array}$ & $\begin{array}{l}\text { Village Water } \\
\text { Days per } 10-y r \\
\text { max rainfall event } \\
(2.43 \text { in, } \mathrm{CN}=93)\end{array}$ & $\begin{array}{l}\text { Village Water } \\
\text { Days per } 50 \text {-yr } \\
\text { max rainfall event } \\
(3.23 \text { in, } C N=93)\end{array}$ \\
\hline $50 \%(n=150)$ & $0.45 / 1.5$ & $152 / 45$ & $341 / 102$ & $421 / 126$ \\
\hline $80 \%(n=240)$ & $0.72 / 2.4$ & $95 / 28$ & $213 / 64$ & $263 / 79$ \\
\hline $100 \%(n=300)$ & $0.9 / 3$ & $76 / 23$ & $170 / 51$ & $211 / 63$ \\
\hline
\end{tabular}

One diatom sample from the basin (TK1_2.214) at a depth of 26-28 cm was analyzed. A 600 valve count was conducted, and 599 of the valves were from terrestrial types (Appendix C). The one aquatic type, Denticula sp., may be a contaminant because it was corroded. The diatom evidence from sedimentary records indicates that during periods of sedimentation the basin was a damp setting, but that there was not standing water in the shallow basin for long enough to support aquatic types.

Contradictory multi-proxy evidence suggests the feature collected water, but that when sediments accumulated within the basin it was not storing water long enough to support aquatic habitats. Sediments infilling the basins were, at least in part, water-laid, and the radiometric dates indicate rapid infilling. The silt dominated fraction easily conforms to sediments which could be deposited through eolian processes, yet there is a course fraction of pumice gravels (18.5\%) in a 
sediment sample from 12-14 cm (Appendix F). These gravels could not be eolian in origin, and can derive only from either runoff or cultural emplacement. Therefore, it is most likely that the majority of the sediments in the basin accumulated through surface runoff. The date from construction fill of the berm puts construction as early as AD 1300, and the volume of water modeled to runoff into this feature shows it could hold appreciable quantities of water to be used by the community of Tsankawi. If water was stored in the feature between approximately AD 1300 and AD 1400, there is no sedimentary or paleoecological evidence for it. Instead, radiocarbon dating shows rapid sedimentation during the early 1400s. Clean-out events removing sedimentation during the 1300s cannot be ruled out. Basin infilling occurred during a time when there was widespread eolian sedimentation in the region (Drakos and Reneau 2007), which means eolian sedimentation on the mesa-top may have contributed to the rapid infilling of the basin, which was not cleaned out of the feature by residents of Tsankawi. More intensive paleoecological sampling could provide additional insights into this site formation model, but the evidence suggests that this feature served as a reservoir, but with limited potential for long-term water storage due to its small size, and potentially rapid sedimentation

\section{TK-2 (LA211)}

TK-2 is located on the mesa-top surface to the northeast of the site. Its catchment area is the smallest of the three features $\left(2,406 \mathrm{~m}^{2}\right)$, and does not include the site (Figure 7.26$)$. The catchment area has thin soils with exposed bedrock. Its basin is $20 \mathrm{~m}$ in diameter, and its berm rises $0.5 \mathrm{~m}$ above the basin (Appendix B). It is constructed of earth and tuff rubble. Vegetation is dominated by forbs like rabbit brush, and junipers, which grow on portions of the berm. Few artifacts were observed around the feature. 
The basin of TK-2 has a $40 \mathrm{~cm}$ thick CA-C1-C2 soil sequence, which I dated with three charcoal samples (Figure 7.27, Appendix D). From 0-8 cm is a CA horizon of dark brown (7.5YR3/2) loam to fine sandy loam with weak medium platy parting to single grained structure, and few gravels (5.5\%). A charcoal sample spanning the contact of the CA-C1 horizons from 6$10 \mathrm{~cm}$ dated to cal AD 1414-1435 (Keck-172764). From 8-30 cm is a C1 horizon. It is a brown (7.5YR4/2) gravelly fine sandy loam with massive structure. Both this horizon and the surface horizon have moderate saturated hydraulic conductivity estimates $(12.79-12.95 \mathrm{~mm} / \mathrm{hr}$.) (Appendix F). A charcoal sample from 24-26 cm produced a modeled date of cal AD 1402-1428 (Keck-172765). Gravel content increases to 24.1\% (Appendix F). The bottom-most soil of the basin fill is a C2 horizon from 30-40 cm. It is a brown (7.5YR5/4) gravelly sandy clay loam with single grained structure and common white tuff rock fragments with depth. The gravel fractions indicate that these deposits are largely water-lain, but the coarse texture gives it a very high saturated hydraulic conductivity estimate $(46.63 \mathrm{~mm} / \mathrm{hr}$.), which would not impede infiltration (Appendix F). A charcoal sample from 34-38 cm produced a modeled date of cal AD 1038-1154 (Keck-171003). This sample may be of charcoal inherited from natural soils formed below basin truncation. This sample likely pre-dates the construction and use of this feature because it is much older the berm, or any other basin sample on the Pajarito Plateau.

The berm of TK-2 has a $42 \mathrm{~cm}$ thick $\wedge$ AC1-^AC2-2Ab-2BC-R soil sequence (Figure 7.27). The ${ }^{\wedge} \mathrm{AC} 1$ horizon from $0-6 \mathrm{~cm}$ is a dark brown (7.5YR3/2) loam to sandy clay loam with weak medium platy to massive structure (Appendix D). The underlying $\wedge$ AC2 horizon from 6-32 cm is a dark brown (7.5YR3/2) loam to gravelly loam with gravels increasing with depth and a large tuff rock from $22-26 \mathrm{~cm}$. Charcoal from $18-24 \mathrm{~cm}$ was analyzed and produced a modeled date of cal AD 1285-1385 (Keck-171004). A buried surface (2Ab) from 32-38 $\mathrm{cm}$ is a brown 
(7.5YR4/3) clay loam. It is slightly firm, with weak medium platy parting to weak fine granular structure. Underneath this buried horizon is a brown (7.5YR3/2) gravelly sandy clay loam 2BC horizon. It has moderate medium platy structure, with $20-40 \%$ fine to medium tuff gravels. Tuff bedrock (R) was encountered at the base $(42 \mathrm{~cm})$.

As the smallest of the three reservoir features at Tsankawi, TK-2 is modeled to have stored the least amount of surface runoff. Runoff from typical maximum 1-year rainfall events would generally provide less than one month of water for the community of Tsankawi, therefore it likely augmented the collection of water from the other two features (Table 7.10). It was constructed to retain water even up to runoff from a 50-year rainfall event, which if it occurred could provide a good deal of water. In dry years, when high magnitude rainfall events were rare, the water it would collect would be minimal when compared to community demand.

Table 7.10. Modeled community water budgets and reservoir storage potential for the Tsankawi-2 reservoir (TK-2).

\begin{tabular}{|c|c|c|c|c|}
\hline $\begin{array}{l}\text { Population } \\
\text { Estimate } \\
\end{array}$ & $\begin{array}{l}\text { Daily Village } \\
\text { Water } \\
\text { Requirement (m3) }\end{array}$ & $\begin{array}{l}\text { Village Water } \\
\text { Days per 1-yr max } \\
\text { rainfall event (1.38 } \\
\text { in, } \mathrm{CN}=87)\end{array}$ & $\begin{array}{l}\text { Village Water } \\
\text { Days per } 10-y r \\
\text { max rainfall event } \\
(2.43 \text { in, } C N=87)\end{array}$ & $\begin{array}{l}\text { Village Water } \\
\text { Days per } 50 \text {-yr } \\
\text { max rainfall event } \\
(3.23 \text { in, } C N=87) \\
\end{array}$ \\
\hline $50 \%(n=150)$ & $0.45 / 1.5$ & $61 / 18$ & $169 / 51$ & $262 / 78$ \\
\hline $80 \%(n=240)$ & $0.72 / 2.4$ & $38 / 11$ & $106 / 32$ & $164 / 49$ \\
\hline $100 \%(n=300)$ & $0.9 / 3$ & $31 / 9$ & $84 / 25$ & 131/39 \\
\hline
\end{tabular}

One sediment sample (TK2_2.214) from 28-36 cm was analyzed for diatoms (Appendix C). Only 88 valves were found, and all but one of the valves was an aerial type. The one aquatic type was heavily corroded, which suggests it was a wind blow contaminant. This coupled with the 
low diatom counts indicates that this small, shallow basin was not conducive to the formation of aquatic habitats.

Like TK-1, the multi-proxy evidence largely supports the reservoir site formation model for TK-2, with the exception of the paleoecological record. The hydrological data indicates that TK2 would collect water, and sedimentological data reflects deposition by surface runoff. The sediments are more varied in TK-2, with coarse gravels present in a loamy matrix, which could only be redeposited in the excavated basin through surface runoff. However, the diatom evidence shows only wet conditions in the basin and it does not indicate the presence of standing water. The feature may reflect limited water-born sedimentation during use as a reservoir (C1-C2 horizons) which was then capped by a mostly eolian surface mantle (CA horizon). When considering the unmodeled age distributions from the feature TK-1, and excluding the basal date from what may be pre-construction soils, the dating sequence shows the similar gap in chronology between the date from berm fill and basin infilling. Therefore, a similar site formation model, with construction in the early 1300s, regular basin clean-out, followed by basin sedimentation in the 1400s towards the end of its use-history, cannot be ruled out.

\section{TK-3 (LA211)}

TK-3 is located southeast of the roomblocks. Its catchment area includes the majority of the site and its plaza, and it is the largest catchment area of all of the Tsankawi reservoirs (Figure 7.26). Artifacts are common in the catchment area, as they are eroding from upslope surface middens and roomblocks. There is exposed bedrock in the catchment area, including along the upslope margins of the feature, which include many small pecked cupules in the bedrock along 
the feature margins (Figure 7.28). This suggests that bedrock was exposed in this area during prehistory as well. Its basin is $15 \mathrm{~m}$ in diameter, and its earth and rubble berm rises $0.35 \mathrm{~m}$ above the basin surface (Appendix B). The berm includes upright tuff slabs, but it is breached along a trail through the site.

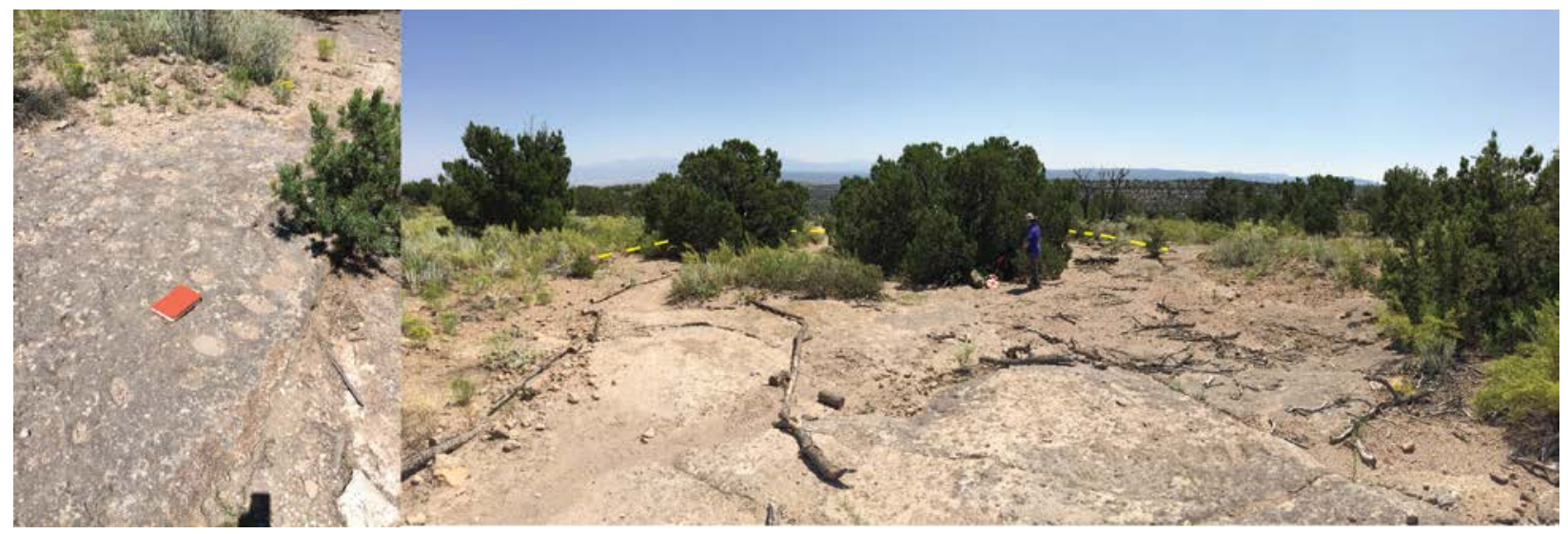

Figure 7.28. Photographs of reservoir TK-3 at Tsankawi (LA211). Photograph on left is of bedrock cupules exposed along the margins of the feature basin. Photograph on the right is of reservoir feature, with the berm length in dashed yellow line. The trail that breaches the berm is between the two junipers in the center of the photograph.

The basin fill consists of a $52 \mathrm{~cm}$ thick AC1-AC2-R soil sequence (Figure 7.27). From 0-16 $\mathrm{cm}$ is an AC1 horizon of dark brown (7.5YR3/2) silt loam with very fine to medium sand and very weak fine platy parting to single grained structure (Appendix D). The saturated hydraulic conductivity estimate for this horizon is high (19.39 mm/hr.), much like the other Tsankawi reservoir features (Appendix F). The AC2 horizon from 16-52 cm is a very dark gray (7.5YR3/1) sandy loam to silt loam. It has a weak medium platy structure and some fine charcoal throughout. The sediments have higher clay contents than any of the other basin sediment samples analyzed from either TK-1 or TK-2, low sand fractions (11.3-27.5\%), but still have high gravel 
percentages (up to 10.3\%) in some samples (Appendix F). There are occasional large tuff rock fragments through the core. Saturated hydraulic conductivity estimates from the AC2 horizon is low (6.07-6.36 mm/hr.), which would impede infiltration (Appendix F). Two charcoal samples from this horizon were dated. From $18-20 \mathrm{~cm}$ a charcoal sample produced a modeled date of cal AD 1386-1413 (Keck-171005). Charcoal from 34-36 cm produced a modeled date of cal AD 1320-1346 (Keck-171006). White tuff bedrock was encountered at the base (R).

The berm of TK-3 has a $34 \mathrm{~cm}$ AC-CA-R soil sequence. It was challenging to identify a location on the berm with intact sediment sequences reflective of berm fill because the discontinuous upright slabs of the berm face create an uneven burn surface. The AC horizon is a dark brown (7.5YR3/3) fine sandy loam. It varies in thickness from 6-14 $\mathrm{cm}$ between cores 3.1, 3.3, and 3.4. Charcoal samples were collected from the thick AC horizon of the 3.2 core. Charcoal from 16-18 cm dated to AD 1506-1641 (Keck-171007). The CA horizon from approximately $10-34 \mathrm{~cm}$ is a dark brown (7.5YR3/2) very fine sandy loam to loam, with single grained structure, large tree roots, and white tuff rock fragments. Charcoal from 28-34 cm dated to cal AD 1438-1467 (Keck-172766). The implications of these dates, which post-date the berm fill, are discussed below. Tuff bedrock was encountered at the base.

While this feature could store more water than any other feature at Tsankawi, it was underfit for its modeled catchment area (Table 7.11). Runoff estimates for even the typical 1-year maximum rainfall event would exceed its basins’ storage capacity (Appendix E). When full, it would hold at least a months' worth of water, yet it didn't have the extra capacity to handle storing runoff from larger rainfall events, or potentially accumulations from multiple events. 
Table 7.11. Modeled community water budgets and reservoir storage potential for the Tsankawi-3 (TK-3) reservoir.

\begin{tabular}{|c|c|c|c|c|}
\hline $\begin{array}{l}\text { Population } \\
\text { Estimate }\end{array}$ & $\begin{array}{l}\text { Daily Village } \\
\text { Water } \\
\text { Requirement (m3) }\end{array}$ & $\begin{array}{l}\text { Village Water } \\
\text { Days per } 1-y r \text { max } \\
\text { rainfall event } \\
(1.38 \text { in, } C N=93)\end{array}$ & $\begin{array}{l}\text { Village Water } \\
\text { Days per } 10-y r \\
\text { max rainfall event } \\
(2.43 \text { in, } C N=93)\end{array}$ & $\begin{array}{l}\text { Village Water } \\
\text { Days per } 50 \text {-yr } \\
\text { max rainfall event } \\
(3.23 \text { in, } C N=93) \\
\end{array}$ \\
\hline $50 \%(n=150)$ & $0.45 / 1.5$ & $212 / 64^{*}$ & $*$ & $*$ \\
\hline $80 \%(n=240)$ & $0.72 / 2.4$ & $133 / 40 *$ & $*$ & $*$ \\
\hline $100 \%(n=300)$ & $0.9 / 3$ & $106 / 32 *$ & $*$ & $*$ \\
\hline
\end{tabular}

Two sediment samples from TK-3 were analyzed for diatoms. TK3_2.207, from 14-16 cm, had a 600 valve count. Six taxa were identified, and all were aerial except for two valves of Gomphonema parvulum which is an aquatic species indicative of polluted waters (Appendix C). The other sample (TK3_2.212) from 24-26 cm had poor recovery, with only 114 valves identified. While aerial types still dominated the assemblage there were three aquatic and cosmopolitan species identified with whole valves preserved, which suggests in situ deposition rather than being wind-blown contaminants. The types identified survive in a range of aquatic habitats, and do not provide much additional perspective on water conditions. A sponge spicule and chrysophyte statocysts (the siliceous stage of Chrysophyceae algae) were also preserved, which further supports the evidence for aquatic conditions. Some of the species (both aerial and aquatic) are centric types which typically thrive in windy contexts which disturb the water column.

Of the three features at Tsankawi, TK-3 had the most evidence supporting the interpretation that it is a reservoir feature. Like the others, it could store a significant quantity of water that the community could use. The finer grained texture of the basin fill as compared to the others supports a model of fines settling out in standing water within the basin. The presence of a minor component of aquatic diatom taxa indicates that standing water did occur in the basin. Yet, it 
would be underfit for the estimated runoff, and be subject to overflowing. That the interior of the berm is armored with tuff rock slabs potentially reflects an attempt to impede erosion. While the basin sediments reflect a chronology similar to the other Tsankawi reservoirs, its berm fill postdates the basin fill. This is different from the other features at Tsankawi. Based on the dates, fill likely occurred through the 1300s and the early 1400s, while the berm dates to the 1400 s and possibly as late as the early 1600 s. Alternative site formation processes that could explain a later date for berm construction could involve the incorporation of basin clean-out during the wholesale remodeling of the berm, yet there was no evidence for truncations within the basin fill. Only more extensive excavation and stratigraphic investigations could help to resolve the relationships between the chronology of basin fill and berm deposits, but based on these dates the continued use of this feature into at least the $16^{\text {th }}$ century cannot be ruled out.

\section{Tsirege (LA170)}

Tsirege, which translates from Tewa to "down at the bird place” (Harrington 1916), is a large Ancestral Pueblo village located atop a narrow mesa between Pajarito Canyon and Cañada de Buey near the modern community of White Rock (Figure 7.1). It was first reported by Bandelier (1892), and it was subject to early excavations by Hewett (1938:39-40). Ortman (2016) estimates that Tsirege has 606 rooms, that its occupation spanned from approximately AD 1250-1625, and that it had a maximum population of 600 at AD 1575 (Figure 7.23). Tsirege was one of the last large Ancestral Tewa villages occupied on the Pajarito Plateau. LANL archaeologists continue to document and analyze materials from the site, which include a recent reevaluation of tree ring dates (Towner 2008) and ceramic studies (Duwe 2008). 
The reservoir feature at Tsirege is located just north of the site in the same mesa-top setting as the site (Figure 7.29). It was documented in early investigations (Hewett 1906: Plate VII, Hewett 1938: 40), and it is included in recent site maps (Duwe 2008). It has the largest basin diameter of the features I tested on the Pajarito Platea (30 m), as well as the largest catchment area $\left(37,075 \mathrm{~m}^{2}\right.$ ) (Appendices B, and E). The basin has largely filled with sediments, as the berm is only $0.2 \mathrm{~m}$ above the basin. The berm is substantial, but it has been breached (Figure 7.30). The breach exposes earth and tuff rubble fill in the berm down to bedrock. A small channel has formed at the breach, which has downcut $(<0.25 \mathrm{~m})$ into basin fill and continues up and outside of the basin into the catchment area. Artifacts are common along the berm surface. Dog-leash surveys concurrent with my investigation were undertaken by LANL archaeologists (Figure 7.30). The basin vegetation is dominated by forbs, while the catchment area is low grasses and piñon-juniper.

I cored a control sample upslope of the catchment basin, adjacent to a small upslope channel. The soils of the $64 \mathrm{~cm}$ thick sequence are CA-Ab-Bw-Cr (Figure 7.31). From 0-22 cm, the CA horizon is a dark brown (7.5YR3/2) coarsening upward loamy sand to sand (Appendix D). The deposits are single-grained, and likely represent recent accumulations of sheet wash along the margins of the channel. An Ab horizon was identified from 22-38 cm. This horizon is a light brown (7.5YR6/4) fine sandy loam, with weak medium platy structure. Below is a thin Bw subsoil from 38-42 cm of dark brown (7.5YR3/4) clay loam to gravelly clay loam with moderate fine angular blocky structure. From 42-64 cm is a dark brown (7.5YR3/4) extremely gravelly clay loam to sandy loam, with large roots, and tuff rock fragments of the Cr horizon. 


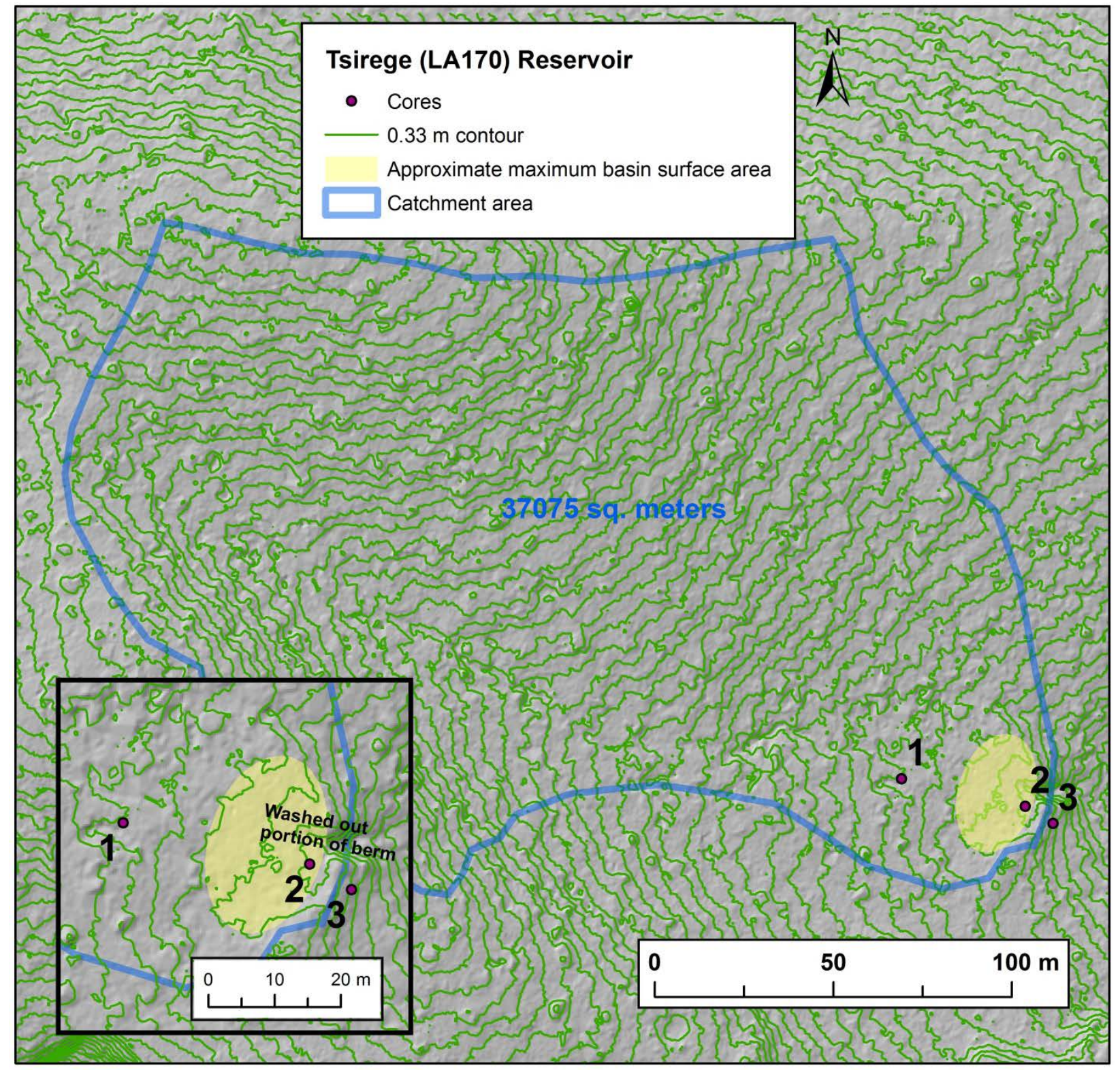

Figure 7.29. Map of coring locations and catchment area of the Tsirege (LA170) reservoir feature.

Cores in the basin recovered $107 \mathrm{~cm}$ of relatively unweathered sediments. The soils had a CA1-CA2-C-2C1-2C2-2C3 sequence (Figure 7.31). (Appendix D). The uppermost horizon (CA1) from 0-38 $\mathrm{cm}$ is brown (7.5YR4/2) silt loam with weak medium platy to single grained structure. Charcoal from the base of this horizon $(30-34 \mathrm{~cm})$ produced a modeled date of cal AD 


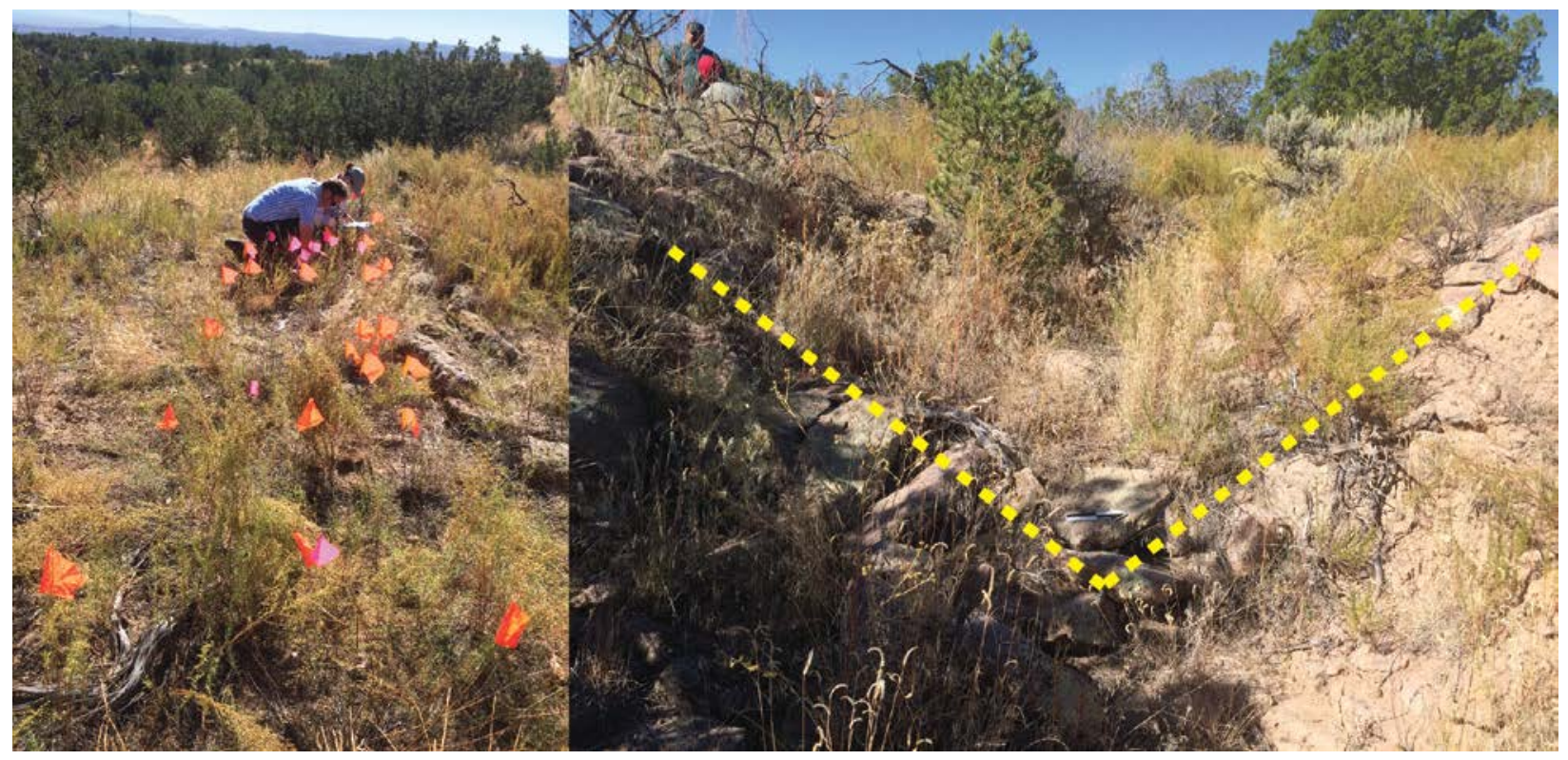

Figure 7.30. Photographs of the Tsirege (LA170) reservoir. LANL archaeologists documenting artifacts (marked with pin-flags) along berm feature of Tsirege (left), and photograph of breach in berm (right). Photographs courtesy of LANL.

1422-1439 (Keck-171008). Below from 38-48 cm is a relatively unweathered CA2 horizon, with moderate, medium platy structure. Unweathered dark brown gravelly silty clay loam is below from 48-62 cm (C horizon). Below an abrupt lower boundary at $62 \mathrm{~cm}$ the gravel content of the basin increases. From 62-84 cm is a brown (7.5YR4/2) extremely gravelly loam (2C1 horizon). Charcoal from 74-80 cm produced a modeled date of cal AD 1416-1434 (Keck-171009). A 2C2 horizon from 84-102 cm is a gravelly coarse sandy loam, with a sherd identified at 94-96 cm. Charcoal from the base of this soil $(96-102 \mathrm{~cm})$ produced a modeled date of cal AD 1393-1420 (Keck-171010). The bottom-most horizon $(102-107 \mathrm{~cm})$ is a very dark gray $(7.5 \mathrm{YR} 3 / 1)$ sandy clay loam, with a contact with white tuff bedrock at its base. The differences in texture through the basin fill suggests higher energy depositional events during the beginning of sedimentation (2C1-2C3 horizons), followed by lower-energy deposition (CA1-C horizons). Saturated hydraulic conductivity estimates are fairly uniform and low throughout C-2C horizons (4.84-6.08 
$\mathrm{mm} / \mathrm{hr}$.), while an analyzed sample from the surface is higher (9.63 mm/hr.) (Appendix F). These estimates suggest that basin fill impeded the downward infiltration of collected runoff in a rapidly accumulating basin.

\section{Tsirege (LA170) Reservoir Chrono-Stratigraphic Cross Section}

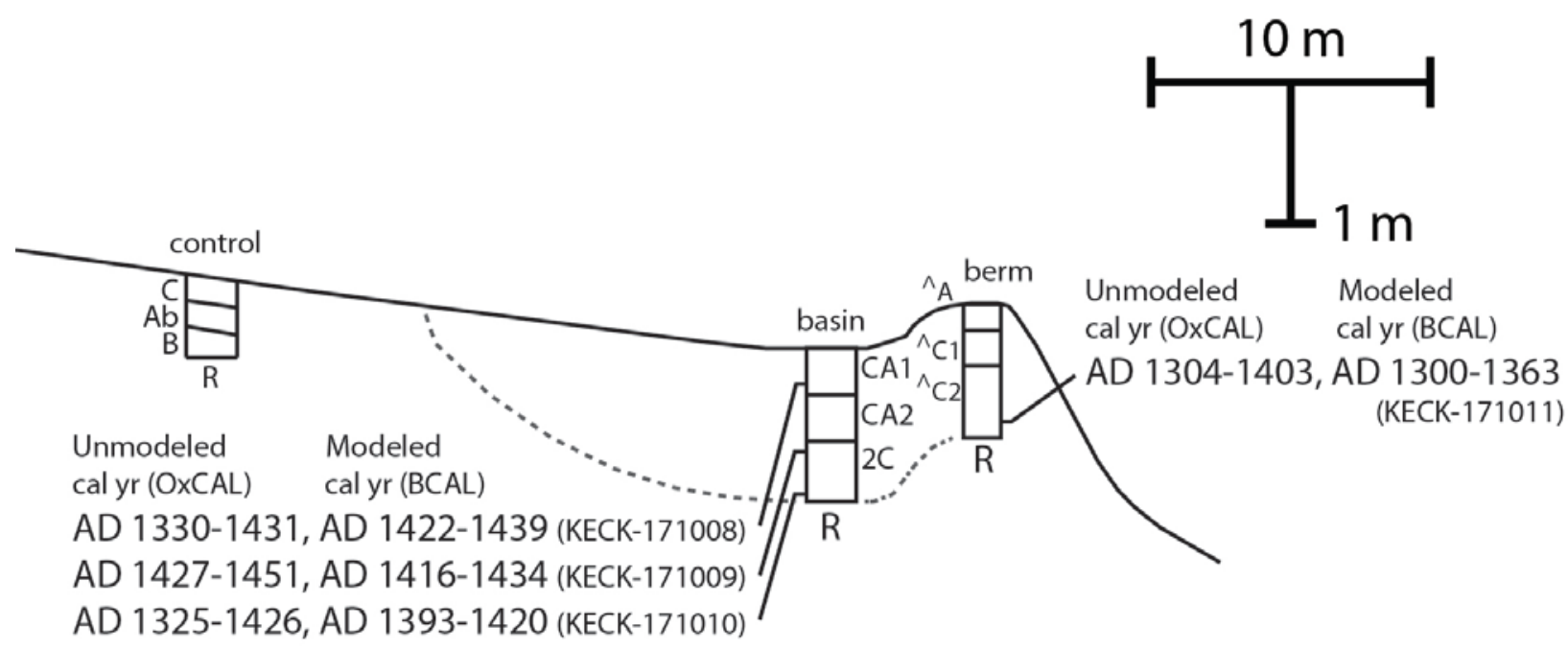

Figure 7.31. Chronostratigraphic cross section of the Tsirege (LA170) reservoir feature.

I recovered a $74 \mathrm{~cm}$ thick $\mathrm{CA}-\wedge \mathrm{C} 1-\wedge \mathrm{C} 2-\wedge \mathrm{C} 3 / \wedge \mathrm{C} 4$ soil sequence from cores located downslope of the crest on the backside of the berm (Figure, 7.29, Figure 7.31, Appendix D). I found fill directly atop bedrock. From $0-12 \mathrm{~cm}$ is a dark brown (7.5YR3/3) fine sandy loam with very weak fine granular to single grained structure (CA horizon). A $\wedge$ C1 horizon of brown (7.5YR4/3) medium to coarse sandy loam from $12-18 \mathrm{~cm}$, is underlain by a ^ $\mathrm{C} 2$ horizon from 18-30 cm of a dark brown (7.5YR3/2) gravelly loam. From $30-38 \mathrm{~cm}$ is a ${ }^{\wedge} \mathrm{CA}$ dark brown (7.5YR3/2) gravelly loam with weak, very fine subangular blocky structure parting to single 
grained. The bottom-most soil is a $\wedge \mathrm{C} 3$ horizon from $38-84 \mathrm{~cm}$. It is a dark brown $(7.5 \mathrm{YR} 3 / 3$ gravelly loamy sand, with decreasing gravels with depth, which terminates at bedrock. One charcoal sample from berm fill was analyzed. Charcoal from this bottom-most horizon (76-80 cm) produced a modeled date of cal AD 1300-1363 (Keck-171011).

Of all the features I tested on the Pajarito Plateau, this feature could provide the greatest volume of water from the runoff of the typical 1-year maximum rainfall event (Appendix E). This is largely a function of the high runoff potential of its large catchment area. Yet, the feature is underfit for its catchment as even the runoff from the typical 1-year maximum rainfall event would exceed its capacity (Table 7.11). It should be no surprise then that the feature is breached, or that the basin rapidly infilled with sediments from surface runoff. When populations were smaller the feature could potentially store enough water to supply villagers with domestic water for entire seasons. As I discuss further, it may have continued to store water during occupation if it wasn't already breached, but if so, it would have a much smaller storage potential after it infilled. At its present infilled state, I calculate that if it wasn't breached the feature could store $62.85 \mathrm{~m}^{3}$ of surface runoff, which for a population of 600 , could only provide $10-35$ days of water (10L vs. 3L daily requirement).

Table 7.12. Modeled community water budgets and reservoir storage potential for Tsirege (LA170).

\begin{tabular}{|c|c|c|c|c|}
\hline $\begin{array}{l}\text { Population } \\
\text { Estimate }\end{array}$ & $\begin{array}{l}\text { Daily Village } \\
\text { Water } \\
\text { Requirement (m3) }\end{array}$ & $\begin{array}{l}\text { Village Water } \\
\text { Days per } 1-y r \text { max } \\
\text { rainfall event (1.38 } \\
\text { in, } \mathrm{CN}=87)\end{array}$ & $\begin{array}{l}\text { Village Water } \\
\text { Days per } 10-y r \\
\text { max rainfall event } \\
(2.43 \text { in, } C N=87)\end{array}$ & $\begin{array}{l}\text { Village Water } \\
\text { Days per } 50 \text {-yr } \\
\text { max rainfall event } \\
(3.23 \text { in, } C N=87)\end{array}$ \\
\hline $50 \%(n=300)$ & $0.9 / 3$ & $443 / 133 *$ & $*$ & $*$ \\
\hline $80 \%(n=480)$ & $1.44 / 4.8$ & $277 / 83 *$ & $*$ & $*$ \\
\hline $100 \%(\mathrm{n}=600)$ & $1.8 / 6$ & $222 / 67^{*}$ & $*$ & * \\
\hline
\end{tabular}


Three sediment samples from the basin were analyzed for diatoms. Only 184 valves could be counted in the bottom-most sample, TSR2.144 (86-88 cm) (Appendix D). The species were dominated by aerial types, but there were 12 valves of Craticula ambigua an aquatic type tolerant to poor water quality in water bodies that dry out due to evaporation. This indicates that there were periods of standing water. There were also broken valves from an extra-local species, which indicates dry, windy periods occurred as well. Sample TSR2.128 $(54-56 \mathrm{~cm})$ was diatomaceous, and while dominated by aerial types it had abundant species associated with both clean water in aquatic settings (Stauroneis anceps) and evaporation (Craticula ambigua). This indicates seasonal accumulations of potable water in the basin, but like the lower sample, that the feature also dried out. The uppermost sample, TSR2.115 (28-30 cm), was diatomaceous, but there were only three species, and they were all aerial types. This suggests that towards the end of the infilling sequence of the basin it was not regularly holding water at volumes and for durations long enough to support aquatic habitats.

Radiocarbon dating of charcoal from basin sediments indicates that it filled rapidly between approximately AD 1325 and 1450 (Figure 7.32). Because the berm was constructed directly onto bedrock, I was only able to date charcoal from the bottom of the berm fill, which is contemporaneous to the probability distributions of the basin fill. The rapid sedimentation within the basin is a function of high volumes of surface runoff from its large catchment area entraining coarse sediments which then settled in the basin. It appears to have filled by AD 1450, and the lack of subsequent accumulations in the basin indicates that the breach may have occurred at this time. This would have presented water challenges to the latest occupants of Tsirege, because the site did not reach peak population until approximately AD 1600 (Figure 7.23). At this stage of the occupation, the feature may have provided some water if the berm wasn't already breached, 
and it may have served as a watery shrine. The high concentration of artifacts identified across the reservoir by LANL survey crews suggests it was visited throughout the site's history. In this regard, it is similar to the use-history of Kwastiyukwa, while the termination of its use-life before intensive occupation is similar to the feature at Tovakwa (LA61641).

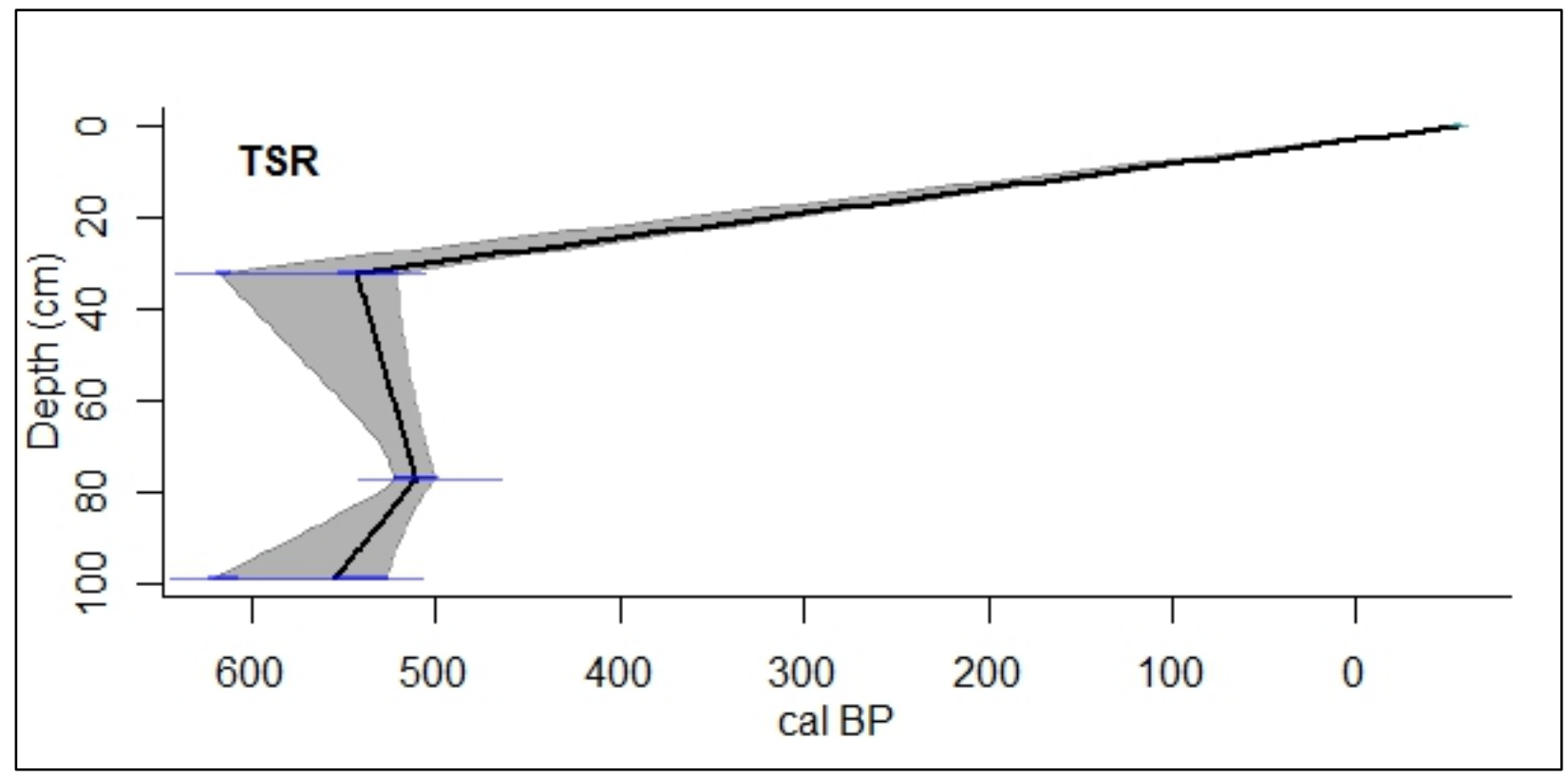

Figure 7.32. Age-depth model of Tsirege (LA170) basin sedimentation. Surface modeled as the radiocarbon present in Clam 2.2 (Blauuw 2010).

\section{Yapashi (LA250)}

The site of Yapashi was first reported on by Bandelier (1892:151-152), and Prince 1903. It is located on a broad mesa called the Potrero de las Vacas, between Alamo Canyon to the north and Capulin Canyon to the south (Figure 7.1). Bandelier (1892:152) reports that Keres speakers identify the site as Tit-yi Ha-nat Ka-ma Tze shum-a, "old houses above in the north," as well as Mo-katsh Zaitsh, "where the panthers lie extended." The name of Yapashi appears to be given 
by Prince (1903), who recounted collecting stone human fetishes from the site, which in Keres are called Yap-a-shi. The early investigations at Yapashi by Hewett were never fully reported, but are summarized by Mathien (1991). The site was intensively surveyed as part of the Bandelier archaeological inventory surveys in 1989, which generated artifact counts from 18 intensive collection units across the site, as well as a detailed site map (Powers and Orcutt 1999: Figure 6.19). Ortman (2016) estimates 350 rooms at the site, and a maximum population of approximately 350 persons in AD 1325. Chronologies based on ceramics estimate that Yapashi was occupied from AD 1225-1450 (Figure 7.23). There are three reservoir features at Yapashi (Figure 7.33). Unlike the reservoirs Tsankawi, two of the three features at Yapashi have their own site designations: LA70798 and LA70790. I discuss the results of my investigations at these features in subsequent sub-sections.

The main reservoir is southeast of the village (YAP in Figure 7.33), and it is mentioned in early reports (Bandelier 1892:151; Hewett 1938:44; Prince 1903:12). Its catchment area includes Yapashi's very large plaza. The reservoir has the largest berm by height, crest width, and base width of all of the tested reservoir features across the Pajarito Plateau (Appendix B). The berm is not breached. It was constructed with tuff boulders, many of which are exposed on the interior wall, berm crest, and backslope (Figure 7.34). It has the second largest basin diameter (25 m), and its high berm creates a great deal of storage potential, giving it the largest maximum storage volume of the tested Pajarito reservoirs. Ancestral Pueblo artifacts were common across the berm surface, and a collection unit (Sample No. 18) at the reservoir documented Biscuit Wares (A-B) and Glazewares A-D (Site Records, on file at Bandelier Nat. Monument). In addition, there is a large boulder with dozens of pecked cupules atop the northeastern side of the berm (Figure 7.34). The catchment area is vegetated by piñon and juniper with low grasses. There are a few burned 


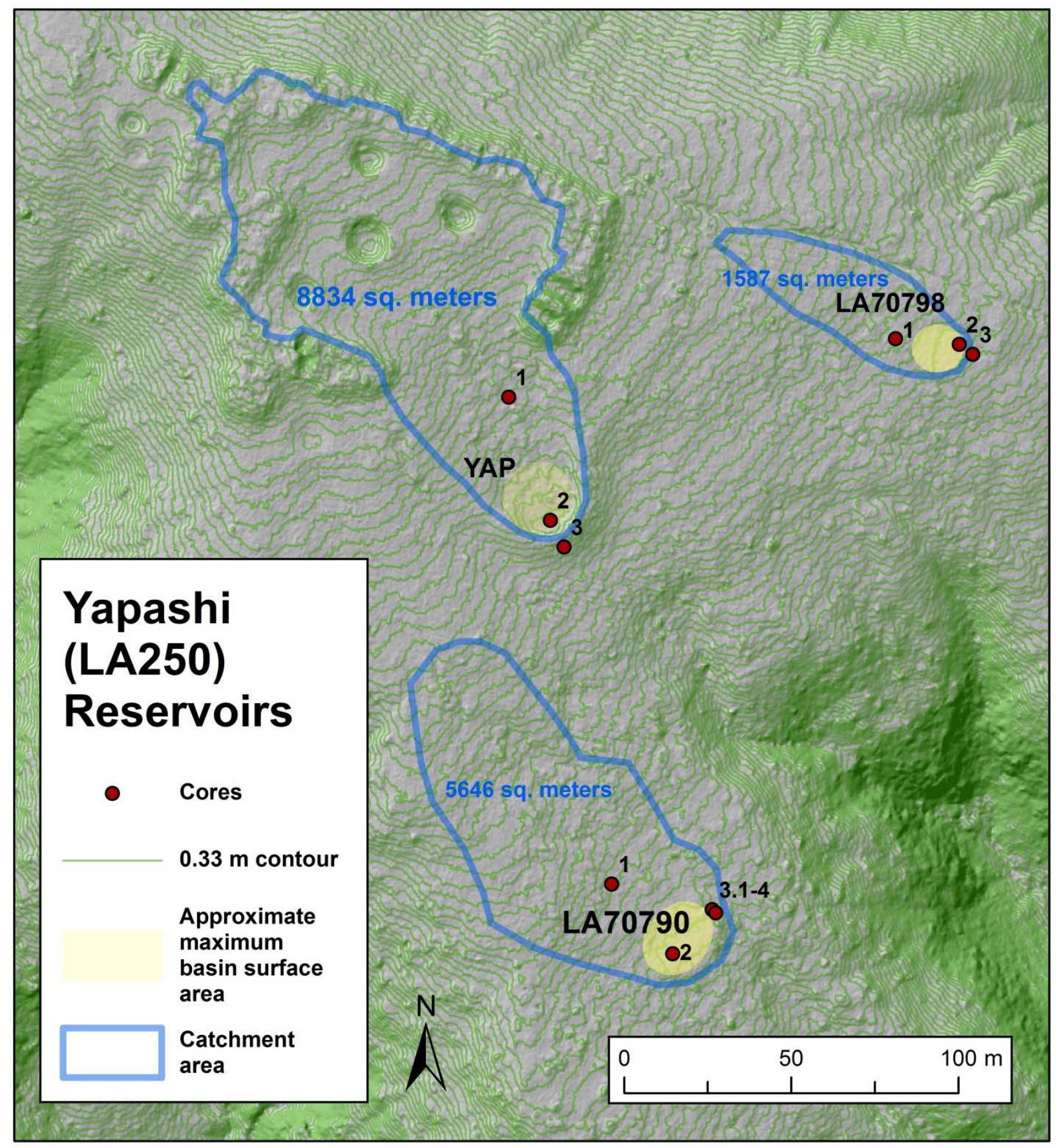

Figure 7.33. Map of coring locations and catchment areas at Yapashi (LA250) and its associated reservoir features (YAP, LA70790, and LA70798).

ponderosa pine snags in the catchment area, reflective of the 2011 Las Conchas fire. Grasses are thick in the basin, and soft, muddy clayish sediment darkened by charcoal runoff was observed 
in portions of the basin surface. A fallen, burned snag of a medium size cottonwood is in the basin. The cottonwood, which typically only grow close to water, the thick grasses, and moist basin surface sediments provide evidence that this feature continues to hold surface runoff.

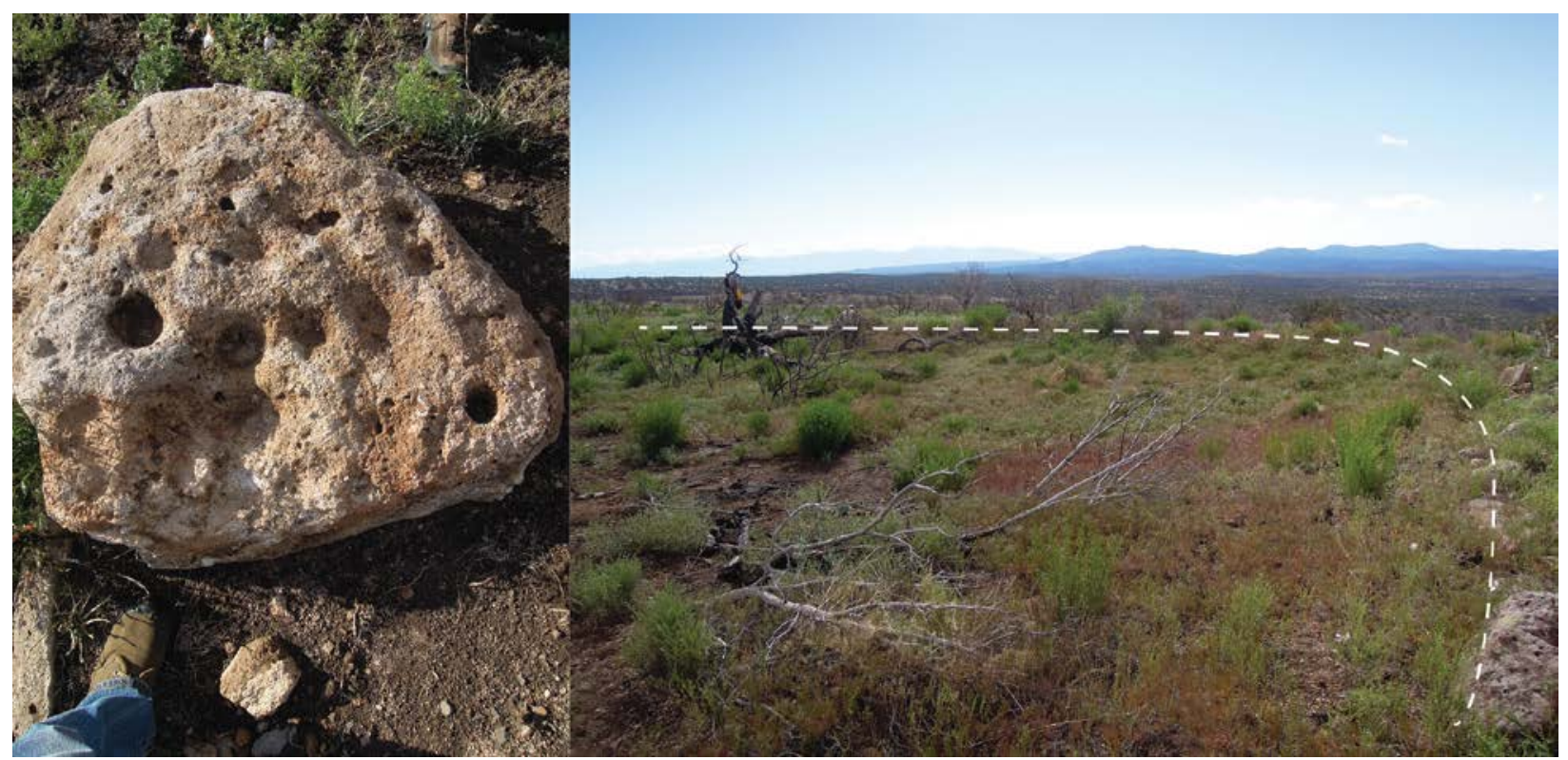

Figure 7.34. Photographs of Yapashi (LA250) reservoir feature. A pecked cupule shrine boulder (left), and feature overview (right, looking to the southeast, the dashed line is basin outline, burned snag mentioned in the text is in background).

The control sample was collected between the roomblocks and the reservoir basin (Figure 7.33) and recovered a shallow $20 \mathrm{~cm}$ thick AC1-AC2-Bw-R soil sequence (Figure 7.35). From 0$6 \mathrm{~cm}$ is a brown sandy loam AC1 horizon, with weak medium platy structure parting to single grained structure (Appendix D). The AC2 horizon is coarsening upward dark brown gravelly loamy sand from 6-14 cm. These surface soils have high estimated saturated hydraulic conductivity measurements (25.34-32.28 mm/hr.), reflecting limited potential for impeding 
infiltration (Appendix F). From 14-20 is a thin Bw horizon of dark brown loam to clay loam, with white tuff bedrock at its base.

\section{Yapashi Reservoirs Chrono-Stratigraphic Cross Sections}
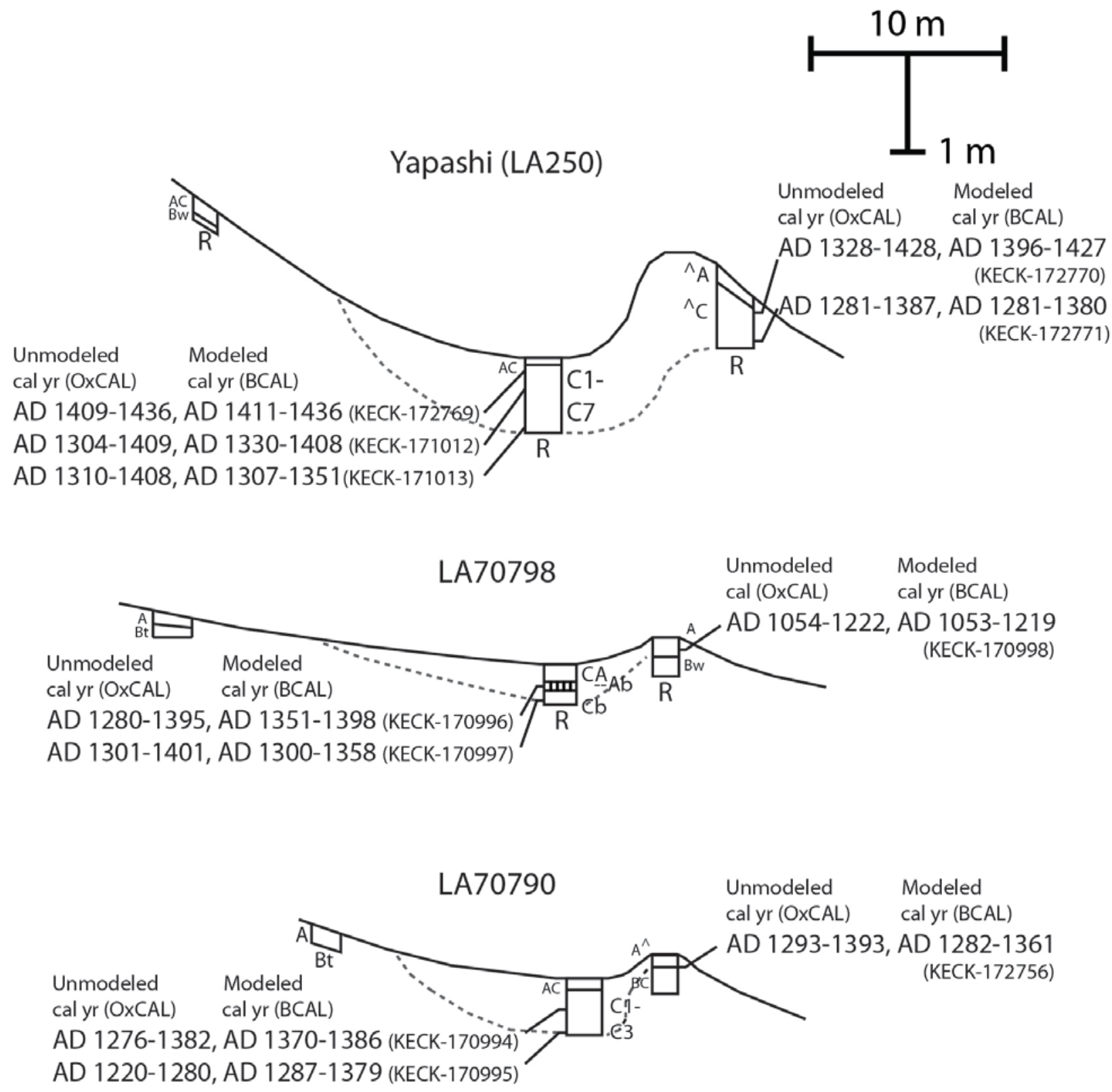

Figure 7.35. Chronostratigraphic cross sections of the Yapashi (LA250), LA70798, and LA70790 reservoir features. 
Cores in the basin recovered an approximately $78 \mathrm{~cm}$ thick AC-C1-C7-R soil sequence (Figure 7.35). From 0-6 cm there was an AC horizon of black (7.5YR2.5/1) silt loam with common very fine silt-sized black charcoal towards it base. Though the sediments are dominated by silts (66.3\%) the saturated hydraulic conductivity estimate for the CA horizon is high (26.04 $\mathrm{mm} / \mathrm{hr}$.) (Appendix F). The charcoal-rich fines in this horizon may represent basin infilling after the 2011 Las Conchas fire. The C horizons are differentiated largely by alternating percentages of gravel content. Dark gray (7.5YR4/1) silt loam was encountered between 6-16 cm (C1 horizon). A charcoal sample from 10-16 cm was analyzed, and returned a modeled date of cal AD 1411-1436 (Keck-172769). The C2 horizon (16-26 cm) is a gravelly silt loam, which alternates with a silt loam between 26-34 cm of the C3 horizon. The saturated hydraulic conductivity estimates for these horizons is high $9.62-10.78 \mathrm{~mm} / \mathrm{hr}$., indicating they have limited water holding capacity (Appendix F). A charcoal sample from 30-36 cm was analyzed and returned a modeled date of cal AD 1330-1408 (Keck-171012). The C4 and C5 horizons (34-50 and 50-62 cm respectively) are gravelly silt loams that are massive and fine upward in the C4 horizon, but have weak platy structure in the C5 horizon. The C6 horizon is a very dark gray (7.5YR3/1) very gravelly loam, which is underlain by a very dark gray (7.5YR3/1) silt loam (C7 horizon). A charcoal sample from this deepest horizon in the basin was collected from 68-74 cm, and returned a modeled date of cal AD 1307-1351 (Keck-171013). Saturated hydraulic conductivity estimates from the C4 horizons and below are lower (4.08-8.02 mm/hr.) and would more effectively impede infiltration (Appendix F). Tuff rock fragments were encountered at the base of the core at $78 \mathrm{~cm}$.

Four cores were collected from the berm. Because the crest width of the berm was too rocky at the surface to attempt coring, I instead cored downslope along the side of the berm. Core 3.1 
was located $1.5 \mathrm{~m}$ downslope of the berm crest, $65 \mathrm{~cm}$ below the crest. Cores 3.2 and 3.3 were placed $2.25 \mathrm{~m}$ downslope, and $\sim 80 \mathrm{~cm}$ below the crest. Core 3.4 was placed $2.75 \mathrm{~m}$ downslope and $\sim 85 \mathrm{~cm}$ below the crest. The descriptions below as well as both charcoal samples are from Core 3.3 (Appendix D). The berm slope soils have an $\wedge$ AC-^C1 sequence (Figure 7.35). The ^AC horizon from 0-18 cm is a very dark gray (7.5YR3/1) clay loam, with gravels increasing with depth. From 18-58 cm is a dark brown (7.5YR3/2) gravelly sandy loam of a ${ }^{\wedge}$ 1 horizon. Two charcoal samples from the ${ }^{\wedge} \mathrm{C} 1$ horizon were analyzed. From $20-22 \mathrm{~cm}$ below surface a modeled date from charcoal returned an age distribution of cal AD 1396-1437 (Keck-172770). A sample from 52-54 cm produced a modeled date of cal AD 1281-1380 (Keck-172771). Based on the berm height and core stratigraphy I do not think any of the berm cores extended below fill, and that these dates reflect material used in berm construction.

The Yapashi reservoir feature could store appreciable volumes of surface runoff, although even with its large berm and catchment basin it could be overtopped by the largest runoff events. Typical 1-year maximum rainfall events could provide 1-2 months of water at the maximum population estimates, and potentially enough water to supply community needs for entire seasons under wet conditions (Table 7.13). At low populations it could provide enough water for yearround use, although (as I will discuss further) infiltration, evaporation, and reduced water quality would certainly inhibit the likelihood that water would be used year-round.

Three basin sediment samples were analyzed for diatoms, and all were counted to 600 valves (Appendix C). The bottom-most sample (YAP2.231) at 60-62 cm was noted for being very diatomaceous. Of the 600 valves counted all but two were aerial types. The two valves of aquatic taxa were Rhopalodia gibba, which is found in aquatic settings that dry out. This type was also found all in my modern analog sediment samples (Appendix C). The diatom population of 
Table 7.13. Modeled community water budgets and reservoir storage potential for Yapashi (LA250).

\begin{tabular}{|l|c|c|c|c|}
\hline $\begin{array}{l}\text { Population } \\
\text { Estimate }\end{array}$ & $\begin{array}{l}\text { Daily Village } \\
\text { Water } \\
\text { Requirement (m3) }\end{array}$ & $\begin{array}{l}\text { lillage Water } \\
\text { Days per 1-yr max } \\
\text { rainfall event (1.38 } \\
\text { in, CN=93) }\end{array}$ & $\begin{array}{l}\text { Village Water } \\
\text { Days per 10-yr } \\
\text { max rainfall event } \\
\mathbf{2 . 4 3} \text { in, CN=93) }\end{array}$ & $\begin{array}{l}\text { Village Water } \\
\text { Days per 50-yr } \\
\text { max rainfall event } \\
\text { (3.23 in, CN=93) }\end{array}$ \\
\hline $50 \%(\mathrm{n}=175)$ & $0.525 / 1.75$ & $325 / 98$ & $731 / 219$ & $1002 / 301$ \\
\hline $80 \%(\mathrm{n}=280)$ & $0.84 / 2.8$ & $203 / 61$ & $457 / 137$ & $626 / 188$ \\
\hline $100 \%(\mathrm{n}=350)$ & $1.05 / 3.5$ & $163 / 49$ & $365 / 110$ & $501 / 150$ \\
\hline
\end{tabular}

sample YAP2.210, from 18-20 cm, was all aerial taxa. The uppermost sample, YAP2.303 from the CA horizon, was sampled to evaluate near-contemporary conditions associated with the lens of ashy sediments capping the basin. This sample, from 4-6 cm, was nearly entirely aerial taxa, but there were seven valves of two aquatic taxa, one of which Encyonema silesacum was present in the modern analogs from Stable Mesa and Lake Fork Canyon. This suggests that standing water continues to occur periodically within the reservoir basin at Yapashi, and potentially did so after the Las Conchas Fire.

The multi-proxy evidence supports the reservoir site formation model for the Yapashi feature. It shares the overall morphology of other reservoir features, and it would store appreciable volumes of water. There is limited evidence in the paleoecological record that it was a periodically wet setting, although the diatom evidence shows little evidence that the basin was perennially wet. Radiocarbon dating of the basin and berm fill show that it was constructed in the early 1300s. Overlapping age probability distributions from the basin sediments indicate that it infilled rapidly with sediments through the 1300s and into the early 1400s (Figure 7.36). This correlates to the period of highest village populations, and the decline of populations in the 1400s. The absence of a buried soil in the upper portion of the basin is surprising, considering there was likely a lag of many hundreds of years between the uppermost date from $10-16 \mathrm{~cm}$, 
and the lens of ash and charcoal rich silt likely associated with the 2013 Las Conchas Fire in the upper $6 \mathrm{~cm}$ of the basin. More fine-scaled sedimentological and micromorphological studies may help resolve whether there was limited soil formation in the C1 horizon, or if there is evidence which could support an argument for truncation of basin sediments.

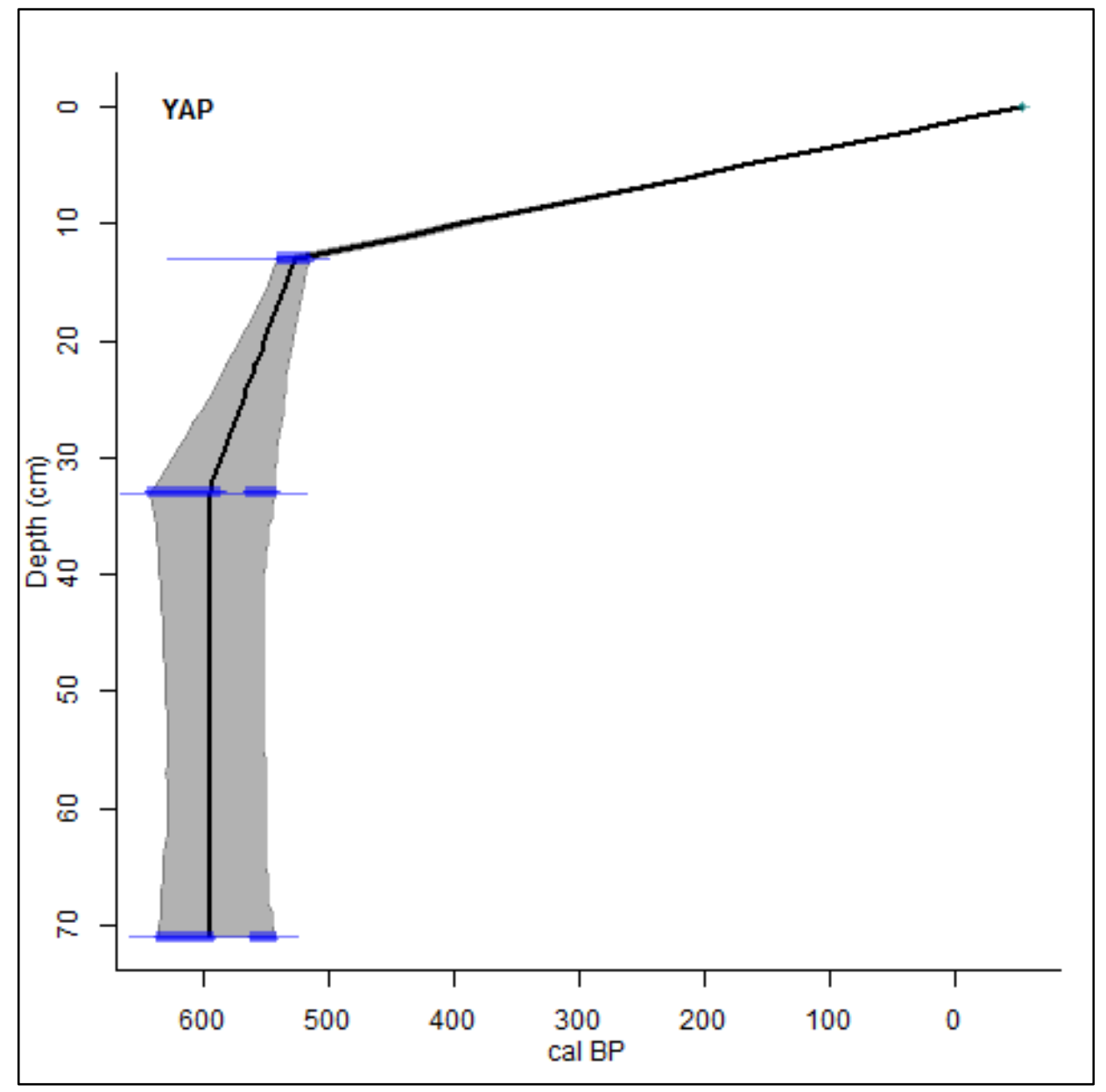

Figure 7.36. Age-depth model of Yapashi reservoir basin sediments, (CLAM 2.2, Blaauw 2010). 


\section{LA70798}

Site LA70798 is located approximately $100 \mathrm{~m}$ east of the site of Yapashi on the same mesatop surface (Figure 7.33). The site was first documented in 1989 as part of the Bandelier inventory survey. The site has multiple components, and includes the reservoir, a Coalition Period small pueblo $10 \mathrm{~m}$ to the east, and surface rubble approximately $40 \mathrm{~m}$ to the southeast. Artifact assemblages from the reservoir feature include Glaze A \& B ceramics, as well as earlier types (Santa Fe B/W) potentially associated with the small roomblock. Based on the ceramics they estimated that the reservoir was in use between AD 1300-1500, and that it was used in association with Yapashi (Site Report, On File at Bandelier National Monument).

The catchment basin is $18 \mathrm{~m}$ in diameter, and the basin is filled with sediments nearly level with the rock-lined berm (Appendix B). Sediments between rocks of the berm are winnowed out, indicating that this feature is commonly breached. It has a small catchment area of 1,587 $\mathrm{m}^{2}$ (Appendix E). Vegetation in the catchment area is largely grass and forbs, with some junipers near the roomblocks of Yapashi.

Cores excavated into the basin recovered a $42 \mathrm{~cm}$ thick CA-C-Ab-CBb-Cb-R soil sequence (Figure 7.35). From 0-12 cm is a dark brown (7.5YR3/2) gravelly sandy clay loam to silt loam CA horizon with moderate medium granular structure (Appendix D). Sediment samples from this horizon have moderately high estimates for saturated hydraulic conductivity (9.34-10.3 $\mathrm{mm} / \mathrm{hr}$.) (Appendix F). From 12-20 cm is a C horizon of dark brown (7.5YR3/2) silt loam, with an abrupt lower boundary. Below this unweathered horizon is a buried A horizon (Ab) from 20$26 \mathrm{~cm}$. It is a very dark brown (7.5YR2.5/2) silty clay loam with weak fine granular structure. Charcoal from 22-28 cm, produced a modeled date of cal AD 1351-1398 (Keck-170996). From 26-34 cm is a brown (7.5YR4/2) silty clay loam. This BCb horizon has weak fine granular 
structure, and a few fine open pores with faint very fine dark brown (7.5YR3/4) iron

concentrations on pore walls. Below this horizon is a brown (7.5YR4/2) gravelly clay loam from 34-42 cm. Charcoal from 36-42 cm produced a modeled date of AD 1300-1358 (Keck-170997). White tuff fragments of bedrock were recovered at its base.

Cores extracted from the berm were located just off and downslope of the berm, and recovered an AB-Bw soil sequence. From 0-20 cm, the AB horizon was a dark brown (7.5YR3/2) sandy lay loam to gravelly sandy clay loam. Charcoal from $18-20 \mathrm{~cm}$ produced a modeled date of cal AD 1053-1219 (Keck-170998). The contact between the AB and the underlying Bw horizon frequently was a tuff rock fragment. The Bw horizon from 20-34 cm was a brown (7.5YR4/3) sandy clay loam to clay loam, with gravels increasing with depth, as well as common faint fine brown (7.5YR4/4) mottles. Because the core was located off of the berm, this soil sequence more likely represents natural soils impacted by surface disturbances associated with the reservoir rather than construction fill.

LA70798 is the smallest of the three reservoir features at Yapashi, and would contribute the least amount of water to the overall community water budget. At maximum population the typical 1-year maximum rainfall event would provide approximately less than 10 days of water for the community, and under rare circumstances would it collect more than a months' worth of domestic water (Table 7.14). Fifty-year rainfall events would breach the feature, thereby limiting its potential for water storage during wet periods and supporting the surface evidence for basin infilling and erosion.

Two sediment samples were analyzed for diatoms. Both were diatomaceous (600 valve counts), and dominated by aerial taxa (Appendix D). Six taxa were identified in sample LA70798_2.214 (24-26 cm), while only four taxa were identified in LA70798_2.207 (12-14 cm). 
This suggests that this feature represented a damp setting, but that there was little opportunity for aquatic habitats to form in what could only ever have been a very small, shallow pool of standing water within the basin.

Table 7.14. Modeled community water budgets and reservoir storage potential for Yapashi (LA250) and LA70798.

\begin{tabular}{|c|c|c|c|c|}
\hline $\begin{array}{l}\text { Population } \\
\text { Estimate }\end{array}$ & $\begin{array}{l}\text { Daily Village } \\
\text { Water } \\
\text { Requirement } \\
\text { (m3) }\end{array}$ & $\begin{array}{l}\text { Village Water } \\
\text { Days per 1-yr } \\
\text { max rainfall } \\
\text { event ( } 1.38 \text { in, } \\
\mathrm{CN}=87)\end{array}$ & $\begin{array}{l}\text { Village Water } \\
\text { Days per 10-yr } \\
\text { max rainfall } \\
\text { event }(2.43 \text { in, } \\
\mathrm{CN}=87)\end{array}$ & $\begin{array}{l}\text { Village Water } \\
\text { Days per } 50 \text {-yr } \\
\text { max rainfall } \\
\text { event ( } 3.23 \text { in, } \\
\mathrm{CN}=87)\end{array}$ \\
\hline $50 \%(n=175)$ & $0.525 / 1.75$ & $35 / 10$ & $96 / 29$ & $135 / 40 *$ \\
\hline $80 \%(n=280)$ & $0.84 / 2.8$ & $22 / 6$ & $60 / 18$ & $84 / 25^{*}$ \\
\hline $100 \%(n=350)$ & $1.05 / 3.5$ & $17 / 5$ & $48 / 14$ & $67 / 20^{*}$ \\
\hline
\end{tabular}

Two sediment samples were analyzed for diatoms. Both were diatomaceous (600 valve counts), and dominated by aerial taxa (Appendix D). Six taxa were identified in sample LA70798_2.214 (24-26 cm), while only four taxa were identified in LA70798_2.207 (12-14 cm). Therefore, this feature was a damp setting, but there was little opportunity for aquatic habitats to form in what could only ever have been a very small, shallow pool of standing water within the basin.

Evaluated against the site formation models, this feature could either be a reservoir or a watery shrine feature. It has the overall shape and morphology of a reservoir, but it would be an exceptionally small feature, with limited potential for providing appreciable quantities of water for the large community of Yapashi. Yet, it did hold water, but not long enough to support aquatic habitats. In regards to its use history, the date from the berm suggests a possible construction as early as AD 1050-1220s. However, because the berm is so low, it cannot be ruled 
out that my sampling reflects the age of charcoal in an intact A horizon immediately off of the berm rather than berm construction fill. Basin dates indicate that it was used primarily through the 1300s, and rapidly infilled. Unlike the other Yapashi features, I identified a shallow, buried A horizon in the basin. This may reflect differential use-histories within the basin, as sedimentation in the basin ceased in the late 1300s-early 1400s, and a soil formed. As hydrological conditions and occupation histories changed through time it cannot be ruled out that there was a change in use from a reservoir to supplement water from other features to a small watery shrine.

\section{LA70790}

Site LA70790 is located approximately $200 \mathrm{~m}$ south of the site of Yapashi (Figure 7.33). It was first recorded in 1989 as part of the Bandelier Inventory Survey. The site has multiple components, and consists of a reservoir and 11 terrace segments, which are located downslope of the reservoir. Artifacts recovered in surface inventories had many Santa Fe B/W sherds, which may be washed in from a site upslope of the feature that has an earlier Santa Fe B/W component. The archaeologists assigned an early date based on these ceramics (AD1175-1350), but associated the feature use-life with Yapashi (site report on file at Bandelier National Monument).

The basin is $22.5 \mathrm{~m}$ in diameter. Its earthen and stone-lined berm is only $0.2 \mathrm{~m}$ above the basin surface. The basin is largely filled with sediment (Appendix B). It has a catchment area of 5,646 $\mathrm{m}^{2}$ (Appendix E), but a new channel has formed to the north of the feature. This channel pirated much of the feature's catchment area. This was likely a post-abandonment phenomenon, caused by gradient changes associated with basin infilling. The catchment area vegetation is largely grasses and forbs, with scattered junipers across the catchment area and the berm. 
My control sample from the catchment area recovered an $18 \mathrm{~cm}$ thick AC-Bt-C/R soil sequence (Figure 7.35). The AC horizon from $0-8 \mathrm{~cm}$ is a dark brown (7.5YR3/2) sandy loam to loamy sand with medium granular parting to single grained structure (Appendix D). From 8-12 $\mathrm{cm}$ is a Bt horizon of dark brown (7.5YR3/3) silty clay, with weak medium subangular blocky structure. Below this relatively well developed soil is dark brown (7.5YR3/3) gravelly silt clay, with large tuff rock fragments of unconsolidated bedrock (C/R horizon).

From the basin I recovered a $57 \mathrm{~cm}$ thick AC-C1-C2-C3 soil sequence (Figure 7.35). The AC horizon from $0-8 \mathrm{~cm}$ is a dark brown (7.5YR3/2) sandy loam to sandy clay loam with fine granular to single grained structure. Below is a $\mathrm{C} 1$ horizon from 8-38 cm, of dark brown (7.5YR3/2) gravelly sandy loam with massive to single grained structure. Both the AC and C1 horizons have high saturated hydraulic conductivity estimates (40.75 and $19.82 \mathrm{~mm} / \mathrm{hr}$., respectively) (Appendix F). Charcoal from 32-36 cm returned a modeled date of cal AD 13701386 (Keck-170994). The C2 horizon from 38-44 cm is an extremely gravelly sandy loam with single grained structure. From $44-56 \mathrm{~cm}$ is the bottom-most horizon, the C3 horizon, mantling tuff bedrock. It is a dark brown (7.5YR3/2) fine to medium sandy loam with single grained structure. Sediment samples from these lower horizons have very low saturated hydraulic conductivity estimates (4.29-4.61 mm/hr.), which would impede the infiltration of water (Appendix F). Charcoal from 50-56 cm returned a modeled date of cal AD 1287-1379 (Keck170995).

There was variability in subsoils between the four cores excavated into the berm at LA70790. Soils consisted of a $42 \mathrm{~cm}$ thick $\wedge$ AC-CB sequence. From $0-12 \mathrm{~cm}$ the $\wedge$ AC horizon was a very dark brown (7.5YR2.5/3) gravelly sandy clay with moderate medium granular structure. Charcoal from 8-12 cm returned a modeled date of cal AD 1282-1361 (Keck-172756). Below 
was dark brown (7.5YR3/3) sandy clay loam to sandy loam with massive structure, and large tuff rocks fragments. Gravel content varied between cores, as did the degree of soil development, such as Core 3.2, which had moderate, medium subangular blocky structure (Appendix D).

When compared to water demands at Yapashi, the LA70790 reservoir could provide approximately a months’ worth of water under wet and normal conditions (Table 7.15). This would make this feature an important component in the water management system at Yapashi. Its maximum storage volume of $177 \mathrm{~m}^{3}$ would inhibit its potential for storing larger volumes of water associated greater runoff. Considering its size, landscape position, and catchment area, it is not surprising that there is evidence of erosion across the berm, and that there has been channelization due to runoff events of a greater magnitude than the feature could accommodate after it infilled with sediments.

Table 7.15. Modeled community water budgets and reservoir storage potential for Yapashi (LA250) and LA70790.

\begin{tabular}{|c|c|c|c|c|}
\hline $\begin{array}{l}\text { Population } \\
\text { Estimate } \\
\end{array}$ & $\begin{array}{l}\text { Daily Village } \\
\text { Water } \\
\text { Requirement (m3) }\end{array}$ & $\begin{array}{l}\text { Village Water } \\
\text { Days per } 1 \text {-yr max } \\
\text { rainfall event } \\
(1.38 \text { in, } C N=87)\end{array}$ & $\begin{array}{l}\text { Village Water } \\
\text { Days per } 10 \text {-yr } \\
\text { max rainfall event } \\
(2.43 \text { in, } C N=87)\end{array}$ & $\begin{array}{l}\text { Village Water } \\
\text { Days per } 50 \text {-yr } \\
\text { max rainfall event } \\
(3.23 \text { in, } C N=87)\end{array}$ \\
\hline $50 \%(n=175)$ & $0.525 / 1.75$ & $124 / 37$ & $337 / 101 *$ & $*$ \\
\hline $80 \%(n=280)$ & $0.84 / 2.8$ & $78 / 23$ & $210 / 63 *$ & $*$ \\
\hline $100 \%(n=350)$ & $1.05 / 3.5$ & $62 / 19$ & $168 / 50 *$ & $*$ \\
\hline
\end{tabular}

One sediment sample (LA70790_2.225) from near the base of the sedimentation sequence was analyzed for diatoms (Appendix C). The sample was diatomaceous (600 valve count), but was all aerial species, save for one exotic valve that was likely blown-in. The sample also had other macrofossils. The presence of a sponge spicule and abundant statocysts are additional 
evidence for the presence of water, perhaps in greater quantities than suggested by the aerial diatoms. Yet, unlike any other sample from any other basin sample, abundant phytoliths and vascular plant fragments were found in the sample. The analyst interprets this context to be one that was wet enough to support plant growth, which was not cleaned out, but not wet enough to support aquatic habitats (Appendix C).

The size, its morphology, and infilling sediments support the reservoir site formation model; although like LA70798 it may have had alternative functions. Unlike LA70798, it could provide an appreciable volume of water to the community of Yapashi. Yet, the recovery of abundant microfossils of phytoliths and vascular plants in the one diatom sample is unlike any of the other features, indicating that the basin became a wet vegetated surface. This would support the model of watery shrine, however terraces documented downslope of the reservoir advances an alternative hypothesis. This feature could store water to be used (either directed overflow from the berm or by pot watering) to downslope agricultural terraces. It could also have been a site for plant propagation. Further evaluating this hypothesis could benefit from paleobotanical studies of basin sediments, integrating phytolith, macrofossils, and pollen records. Its chronology suggests that it was constructed by AD 1300, if not slightly earlier based on the age distribution of the bottom-most basin date. There is very limited overlap in the age distributions of the basin dates, with the beginning of use potentially in the early 1200s and lasting until as late as approximately AD 1400. This means the feature may have had a longer use-life than the other Yapashi reservoirs. Considering the upslope site with a Santa Fe B/W component, it cannot be ruled out that this feature had a use history that preceded the founding of Yapashi, which would make it more similar to the use-life histories of reservoirs on the Jemez Plateau. 


\section{Pajarito Plateau Regional Synthesis}

Evaluating the results of feature-specific investigations against the site formation models and site-specific chronologies affords the opportunity to identify region-wide trends in water management on the Pajarito Plateau. The majority of these features were likely water reservoir features, collecting surface water runoff. Yet, the small sizes of most of these features meant that they stored only a limited volume of water. A few features, such as site LA3834 at San Miguel, or LA70798 at Yapashi, are so small and infilled so rapidly that they likely were inefficient at storing water for village use and may have instead served communities as watery shrines. The limited paleoecological evidence in the diatom records for aquatic habitats in basins potentially reflects both little long-term water storage and infrequent infilling. This suggests that water was either collected immediately from these features, and/or that in most cases these features are below a size threshold for forming aquatic habitats, even when full.

Some clear trends in decision-making about water management are shown through intraregional comparisons of feature use-life histories. Typically, Ancestral Pueblo people of the Pajarito Plateau constructed multiple small features, potentially as a strategy to increase the total potential volume of water which could be collected without investing in one large feature. This approach would lead to increased labor costs per unit of water for village residents, which I will discuss more in subsequent sections in this chapter, and in Chapter 9. Except for perhaps the LA70790 reservoir feature, none were built before aggregation of the large villages of the Pajarito (Figure 7.37). Instead, nearly all of the features were constructed around AD 1300, when all village populations were rising, if not peaking (Figure 7.23), potentially during the time of immigration from the Four Corners region (Ortman 2012, 2016). The majority of the usehistories are also within the longest climatically wet period of the occupations (Figure 7.37). 
Based on instrumental records of modern annual precipitation patterns presented in Chapter 5, wet years are the only times when runoff from high magnitude rainfall events occurs reliably enough to fill reservoirs. This suggests that during the overall wet interval throughout the $1300 \mathrm{~s}$ these features would have been an efficient technology for storing water, even though they rapidly infilled with sediment.

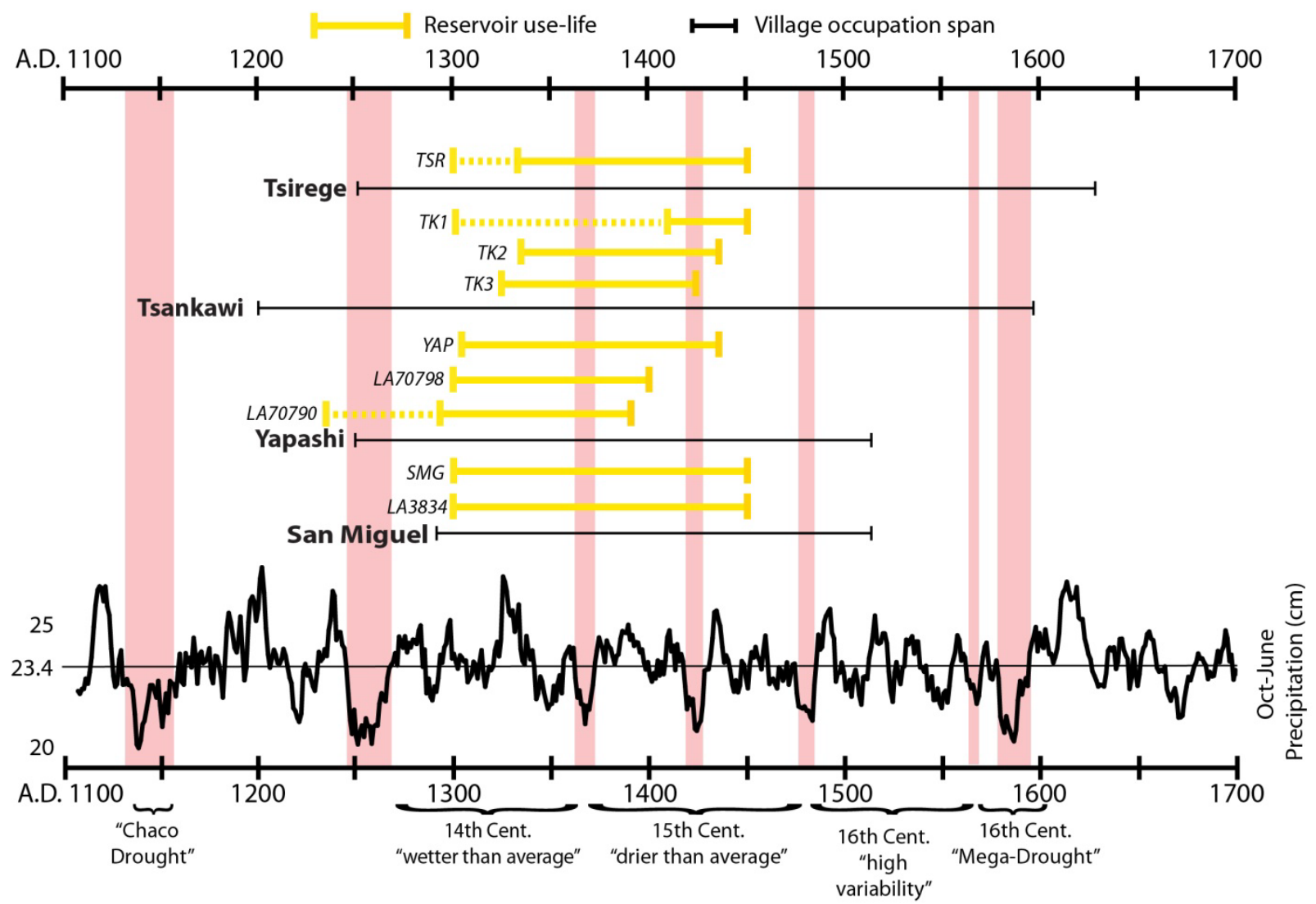

Paleoprecipitation model with 9-yr moving averages from Touchan et al. 2011. Modeled hydrological droughts are highlighted. Occupation chronologies based on Orcutt 1999, Ortman 2012, and Ortman 2016.

Figure 7.37. Pajarito Plateau village occupation and reservoir chronologies with modeled periods of hydrological droughts and paleoprecipitation records. Dashed reservoir use-life histories reflect earlier radiocarbon dates from berm samples. 
As similar as the chronologies of water management are across the Pajarito Plateau, the uselife history of Tsirege stands out as an outlier. It is the only site with just one reservoir feature. It is also the only site at which a reservoir was not used during the peak of population, which at Tsirege was approximately AD 1525, well after this feature stopped infilling with sediments (Figure 7.23). The dating of the rapid infilling sequence, as well as the breach, suggests that it failed during occupation. If its failure correlates to the failures of other features, it may reflect a common mechanism: wide-spread flooding events infilling and breaching reservoirs either during or after droughts in the early to mid-1400s, as I discuss below. Fortunately, a nearby natural water source was available at Tsirege, which may have compensated for the breach and allowed continued occupation of this site.

Remarkably, the end of use-life histories for nearly all of these features, as reflected by the cessation of basin infilling, all occurred by the early to middle 1400s (Figure 7.37). I commonly found eroded berms and infilled basins, which speaks to potential modes of infrastructure failure. Rock-lined interior walls of these small basins were potentially a strategy to mitigate the impact of high magnitude runoff events on the integrity of the berms, but the most effective strategy to maintain efficiency would have been routine maintenance. However, in my cores I identified little evidence for maintenance of these features. Instead, within the limits of chronological resolution afforded by radiocarbon dating, I see rapid infilling. Gaps between dated berm construction fill and basin sedimentation, potentially reflective of complete basin-cleanout, was only observed at TK-1, although chronological resolution of dating would have to be tighter across all of the features to better resolve these relationships.

Such a widespread phenomenon of basin infilling and feature abandonment, across multiple communities, each with their own population histories, suggests influences by region-wide 
socio-natural drivers. The end of reservoir use is coincident with both the hydrological drought in the early to middle 1400s, and the population decline across the Pajarito Plateau (Figure 7.23). Droughts in the early 1400s, and the attendant increase in eolian mantling across mesa-tops documented in the Central Pajarito Plateau (Drakos and Reneau 2007), may have reduced feature efficiency by impacting the catchment hydrology. Based on sedimentological evidence of coarse grained fractions (gravels and sands) the primary mode of deposition within the basins was through slope wash rather than infilling through eolian deposition. The introduction of eolian fines into the suspended load of surface runoff may have exacerbated basin infilling. Channel downcutting in valley bottoms (seen as a possible source of eolian sediment) during this time period (Drakos and Reneau 2007) could reflect the impacts of high magnitude rainfall events following, or during dry periods. Unlike Tsirege, none of the other large sites with reservoirs had a close alternative water source that was not vulnerable to droughts, which made them particularly vulnerable to the failure of a reservoir, whether due to infilling and breaching or their low storage potential during droughts.

\subsection{Inter-regional Comparisons of Ancestral Pueblo Water Management Strategies}

To better identify the ways in which collective action decision making surrounding water impacted community sustainability, I compare three different aspects of these systems: the technology of water storage, strategies of water management, and use-life histories of water management features.

\section{Technology}

The site formation model allowed me to evaluate the multi-proxy evidence against a series of expectations in order to identify feature function. In most cases, the data supports my hypothesis 
that these features were built to collect and store water, although not all stored water well. In Figure 7.38 I plot the catchment area of each feature against the potential maximum storage volume as a measure of feature efficiency. In a few cases, these features lacked the hydrological attributes necessary to efficiently collect and store water. In particular, the basins of the features at Tovakwa and Tsirege are clearly underfit for the volumes of runoff generated by their catchment areas. They have the lowest ratios of maximum storage volumes to catchment areas $(0.0073,0.0108)$, and in both cases the modeled runoff from the 1-yr maximum rainfall even exceeds their storage capacity (Tables 7.5, 7.11). The conspicuous breaches of their berms speak to their inefficiency. Interestingly, in both cases sedimentation in the basins ceased well before peak occupation, indicating that alternative water management strategies without the use of these features were successful in meeting community water needs. Therefore, their short use-histories in relationship to village population histories reflect the decision to abandon these features, likely due to their failures and the availability of less costly natural alternatives. Interestingly, all of the features with a maximum storage volume to catchment area ratio less than 0.54 have evidence for a breached or eroded berm, while all of those above do not.

Reservoir construction differs between regions. In both regions, basins are excavated down to bedrock in order to accommodate greater storage volumes. Jemez features have higher storage volumes, owing to their diameter and higher berms (Appendix B). Yet, the biggest difference is in how berms were constructed. Jemez Plateau berms are all primarily earthen material, while those of the Pajarito are largely tuff cobbles and boulders. It is unlikely that these cobbles and boulders were excavated out of the basins to generate storage volume because the basins are so shallow. Instead the rocks were likely collected from elsewhere and then drylaid with fill sediments. In some features such as Tsankawi-3 the interior of the berms are armored with tuff 
slabs. This may have served to protect the berm during high magnitude erosion events, to which the Pajarito Plateau features were at a greater risk than the Jemez Plateau features.

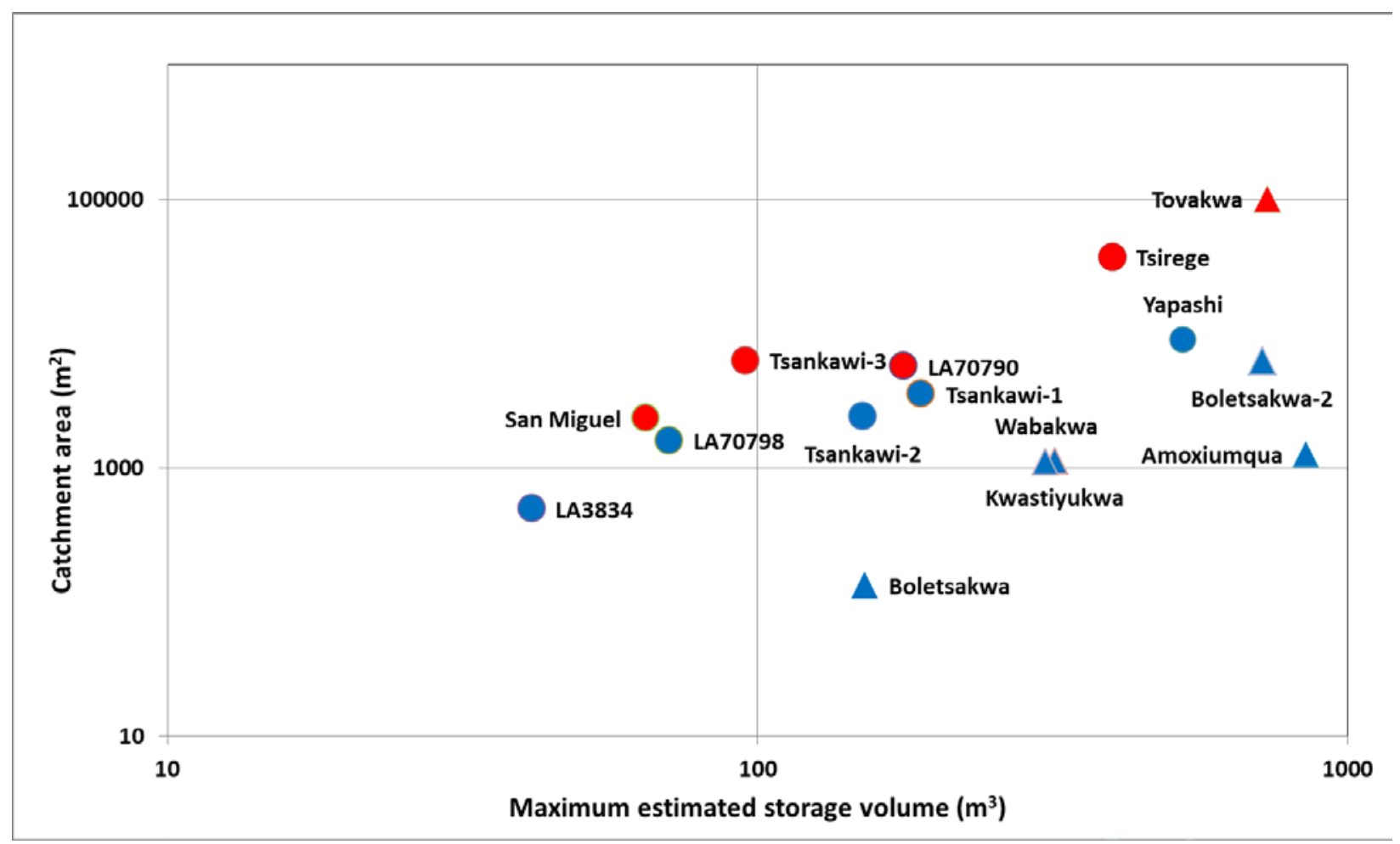

Figure 7.38. Relationships between reservoir catchment areas and basin storage volumes (circles are Pajarito Plateau, triangles are Jemez Plateau, red are features with significant evidence for breaching, and blue are not breached).

\section{Water Management}

These features by and large served their purpose to collect and store water near villages, thereby reducing water acquisition costs. They did not, however, collect and store enough water to provide a year-round artificial water source close to their village. In Table 7.16 I present maximum population estimates, ranges of daily village water requirements, and the number of days of water the typical 1-year maximum runoff event could provide a community. These 
estimates include the sum of water stored from multiple reservoir features when appropriate.

These estimates demonstrate multiple important aspects of water management practices. First, although the reservoirs on the Pajarito are smaller, when they collected water they better meet their community's water needs than those of the Jemez Plateau. That is because the combined storage volume of multiple features adds up to significant volumes of water, especially since the communities were smaller on the Pajarito Plateau. The estimated maximum population of Tsirege, the largest Ancestral Pueblo village on the Pajarito Plateau, is only half of the estimates for the largest villages of the Jemez Plateau. Finally, I should caution that my estimates of village water days likely overestimate because water loss to infiltration and evaporation is not factored in, and there were likely limits of household-level secondary storage technology (jars) and space in households.

Table 7.16. Estimates of daily village water requirements and the number of days water stored in reservoirs from a 1-year maximum rainfall event could provide.

\begin{tabular}{|l|l|c|c|}
\multicolumn{1}{l}{} & \multicolumn{1}{l}{$\begin{array}{l}\text { Population } \\
\text { Estimate }\end{array}$} & \multicolumn{1}{l}{$\begin{array}{l}\text { Daily Village Water } \\
\text { Requirement } \\
\text { 3L/10L }\end{array}$} & $\begin{array}{l}\text { Village Water Days } \\
\text { per 1-yr max } \\
\text { rainfall event }\end{array}$ \\
\hline Amoxiumqua & $100 \%(\mathrm{n}=717)$ & $2.15 / 7.17$ & $70 / 21$ \\
\hline Boletsakwa (LA136, LA25092) & $100 \%(\mathrm{n}=413)$ & $1.24 / 4.13$ & $100 / 30$ \\
\hline Kwastiyukwa & $100 \%(\mathrm{n}=1444)$ & $4.33 / 14.44$ & $5 / 2$ \\
\hline Tovakwa (LA61641) & $100 \%(\mathrm{n}=1240)$ & $3.72 / 12.4$ & $196 / 59$ \\
\hline Wabakwa & $100 \%(\mathrm{n}=297)$ & $0.89 / 2.97$ & $26 / 8$ \\
\hline Haatse/San Miguel (LA370, LA3834) & $100 \%(\mathrm{n}=100)$ & $0.3 / 1$ & $168 / 51$ \\
\hline Tsankawi (LA211, TK1-3) & $100 \%(\mathrm{n}=300)$ & $0.9 / 3$ & $213 / 64$ \\
\hline Tsirege (LA170) & $100 \%(\mathrm{n}=600)$ & $1.8 / 6$ & $222 / 67$ \\
\hline Yapashi (LA250, LA70790, LA70798) & $100 \%(\mathrm{n}=350)$ & $1.05 / 3.5$ & $242 / 49$ \\
\hline
\end{tabular}

The number of reservoir features at a site may serve as a proxy for social organization in a community because they would likely require different forms of coordination to manage. Sites 
with single water storage features more likely reflect a community-wide water management regimes that cross-cuts ties of family, clan, or sodalities. The ethnographic record of Pueblo water reservoir use presented in Chapter 4 and ethnographic records of social organization surrounding kivas, another feature reflective of collective action, suggests that sites with multiple water reservoir features reflect feature-specific water management coordinated by clans or sodalities. That single features at villages dominates the water management strategies of the Jemez Plateau, while multiple features are the norm on the Pajarito Plateau, supports the hypothesis that different strategies of social organization operated between these regions. I discuss the importance of this distinction in Chapter 9, when I consider how resource management contributes to the long-term sustainability of Ancestral Pueblo communities.

\section{Chronologies and use-life histories}

The most significant regional differences in how these water storage technologies were used relates to their lifespan relative to village occupation histories and drought episodes, as seen in Figure 7.39. Differences in water management histories are clear. Features on the Jemez Plateau were generally constructed before the development of large aggregated villages, while those on the Pajarito Plateau were built after villages were already established. The Jemez reservoirs were likely constructed by small communities, and may have served as loci for resource procurement for emerging mesa-top communities and as a signifier for social organization. That these features were built before the commonly accepted timing of immigration from the Colorado Plateau and the Northern Southwest suggests in-situ development of water resource management on the Jemez Plateau. There is no region-wide correlation between the construction of these features and droughts. Reservoirs at Kwastiyukwa and Amoxiumqua appear to be constructed during 
hydrological droughts; however they were not the same droughts. Instead feature construction appears to relate more to an individual villages’ population history rather than any regional trend.

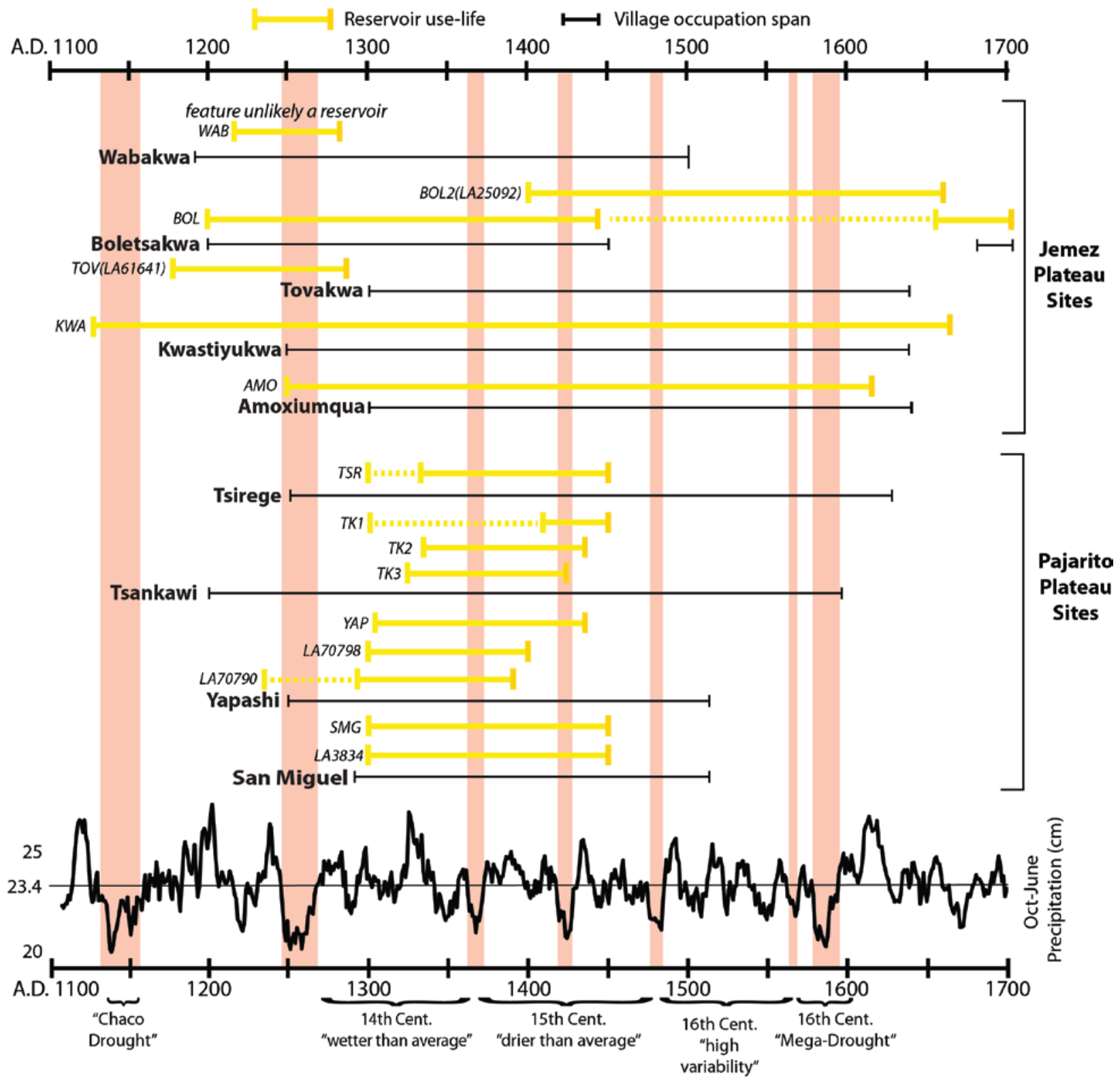

Paleoprecipitation model with 9-yr moving averages from Touchan et al. 2011. Modeled hydrological droughts are highlighted. Occupation chronologies based on Orcutt 1999, Ortman 2012, and Ortman 2016.

Figure 7.39. Reservoir use-life histories, village occupation spans, and paleoprecipitation model for all tested features (AD 1100-1700). 
On the Pajarito Plateau, features were constructed during a time of rising village populations, but well after these villages were established. They all appear to have been constructed and used during the $14^{\text {th }}$ century. This shows a coordinated effort to address water management as a response to the demands of a growing population, rather than repurposing of existing agricultural features. The possibility this technology and style of feature construction was brought with immigrants from the Colorado Plateau and the Northern Southwest cannot be precluded, and would account for the different styles of feature construction. In relationship to paleoclimate, construction of these features occurred during the prolonged wet period in the $14^{\text {th }}$ century, immediately after the drought in the late 1200s, during a period when water collection based on surface runoff would have been most successful.

In terms of use histories, both regions see the premature failure of large bermed features (Tovakwa and Tsirege) but otherwise their use-life histories differ. Some of the Jemez reservoirs have stratigraphic evidence of unconformities within the period of village occupations which can be interpreted as evidence for clean-out events. This suggests coordinated maintenance of these features on the Jemez Plateau. None of the Pajarito reservoirs show evidence of this. In relationship to paleoclimate, there appears to be no correlation between the ends of feature uselife on the Jemez Plateau, perhaps because they benefitted from clean-out events increasing storage potential. The overall wetter conditions of the Jemez Plateau (Chapter 5) may have ensured that some water was stored in the basins during droughts. This would encourage the continued use of these features, some of which were potentially used into the early historic period. By contrast, the nearly synchronous (within the limits of radiocarbon dating) abandonment of the Pajarito reservoirs correlates to the droughts and population declines during the early $15^{\text {th }}$ century. While the Pajarito reservoirs may have provided more water, their 
approach to water management appears to be more vulnerable to drought. First, my review of the climatological records in Chapter 5 showed that droughts lead to less high magnitude rainfall events. That means that these features would less frequently collect water during droughts. Second, multiple features would require more labor for upkeep, which could be problematic to coordinate if management of individual features was undertaken by clans or sodalities and not at the community-wide level, and especially if these features were largely ineffective during megadroughts. These factors, registered in the geoarchaeological record of these reservoirs and in ethnographic records of descendent communities, could be potential causes for the breakdown of collective action strategies of water management on the Pajarito Plateau.

\subsection{Summary}

First, in terms of methods and analyses, applying a site formation model made adjudicating between alternative feature functions possible. Equifinality is unavoidable in many instances, but the continued application and refinement of such approaches helps us to appreciate the behavioral complexity of the material record. The multi-proxy approach was essential for

reconstructing feature use-lives, although studying so many features meant that I could not investigate individual features as intensively as may be warranted. In the future, more intensive sampling is warranted to better understand these geoarchaeological contexts and refine hypothesis testing in geoarchaeological contexts.

The technological aspects of water storage are fundamentally the same in both regions, but how water storage technologies were employed, when they were used, and their utility differed considerably between them. On the Jemez Plateau, Ancestral Pueblo built these features well before the establishment of large villages, and they continued to use and maintain them 
throughout their occupation. They typically only built one feature at a site, and only a few of the largest villages have these features. By contrast, on the Pajarito Plateau multiple features are found at most of the largest villages, and these features were typically constructed at the peak of village populations, and then abandoned coincident with population declines associated with a regional drought in the early 1400s. These findings suggest different cultural strategies towards collective action and resource procurement, as evidenced in water management. It should be noted that I identified no significant difference in technologies across the Pajarito Plateau between Ancestral Tewa or Keres approaches to water management.

A major finding is that while these features stored water none of them could store enough water to be the sole, year-round supply for any village. The water infrastructure built on the Pajarito Plateau was more costly to construct and could provide a greater percentage of a community's water needs than the systems of the Jemez Plateau. Yet, higher costs as well as greater hydroclimate vulnerability made these systems less robust than those of the Jemez Plateau. All communities, regardless of the setting, would have had to use alternative, natural water sources such as springs and streams to augment their water needs throughout the year. How members of a community chose to meet their needs, through alternative strategies to residence patterns, and the costs of these decisions during wet periods and dry periods, is addressed in the next chapter. 


\section{CHAPTER 8 MODELING ANCESTRAL PUEBLO WATER ACQUISITION COSTS}

My reconstruction of reservoir use-life histories found that it was unlikely that any of these features provided year-round water for their communities. Ancestral Pueblo people would have to make daily trips from villages or field houses to natural water sources, especially during droughts and the times of the year when reservoirs were dry. Therefore, investigating reservoirs alone is not sufficient to understand water management strategies in the Jemez Mountains. In this chapter, I argue that modeling water costs in terms of travel time may serve as another proxy for understanding the impact of climate variation on water management strategies. I used geographic information system (GIS) software to undertake a least cost analysis (LCA) of travel time between water sources, including those vulnerable to hydrological droughts, and Ancestral Pueblo sites across both project areas. First, I introduce the methods and theory for modeling water acquisition costs. I then present the results of my analyses by region. I conclude with regional comparisons to identify feedbacks between Ancestral Pueblo decision-making strategies for water management and climate-induced changes to hydrological systems.

\subsection{Developing Least Cost Analyses of Ancestral Pueblo Water Acquisition}

Least cost analysis (LCA) integrates cultural and environmental data within a GIS framework to calculate the most efficient route between two points. Typically, archaeologists use LCA to identify potential routes of travel between sites (Herzog 2013). Recent summaries of LCA methods identify the potential for these modeled routes to serve as proxies for resource 
acquisition costs (White and Surface-Evans 2012). Distance, time, and energy are all forms of costs amenable to measurement. Integrating these proxies of resource cost with other datasets is used to better understand how resource management relates to political economy (e.g., McCoy et al. 2011). However, this approach has yet to be employed as a measure for approximating how changes in climate impact resource costs.

Modeling water acquisition costs is amenable to a pairwise comparison through LCA. Water is a resource that must be consumed every day by every member of a community. It is found in fixed locations, but it is not uniformly distributed across landscapes. Its availability is sensitive to climate change. As identified in the preceding chapters, humans need a daily minimum of 3L of water a day, and 10L of water per person is considered a global standard of water use in preindustrial societies (Gleick 1996; Kohler et al. 2007). Ethnological records presented in Chapter 4 show that the distance to water was a factor in Pueblo decision-making regarding where to live and how to allocate time and energy towards acquiring water (Figure 4.4). Unlike biological resources, the distribution of water is spatially discrete. Springs and streams exist in relatively fixed locations across in landscapes, which is an important attribute for conducting point-to-point cost analyses. Therefore, the spatio-temporal sensitivity of water to climate change can be modeled as a simply being "on or off" depending upon the sensitivity of the hydrological system to external drivers like drought.

Because hydrological droughts impact water distributions at regional scales, and Ancestral Pueblo settlement systems operate at regional scales as well, the impact of droughts on resource acquisition costs needs to be undertaken across entire landscapes. Regional-scale studies in these densely settled landscapes demands analyzing costs between thousands of sites and hundreds of water sources, which exceed the capabilities of built-in Spatial Analyst tools and Modelbuilder 
applications in ArcGIS software. An application written in Python 3.6 by Ian Jorgenson (2017) uses the spatial analyst tools and workflow for LCA analyses in ArcGIS Pro software to efficiently conduct the necessary tens of thousands of LCA analyses. Unlike Modelbuilder, the custom script allows multiple steps of the analyses to be iterated, identifies and reports errors without halting runs, and saves outputs in formats ready for subsequent analyses. In Figure 8.1, I present Jorgeson's (2017) workflow of this script. The application made it possible for me to analyze water acquisition costs for the entirety of both project areas.

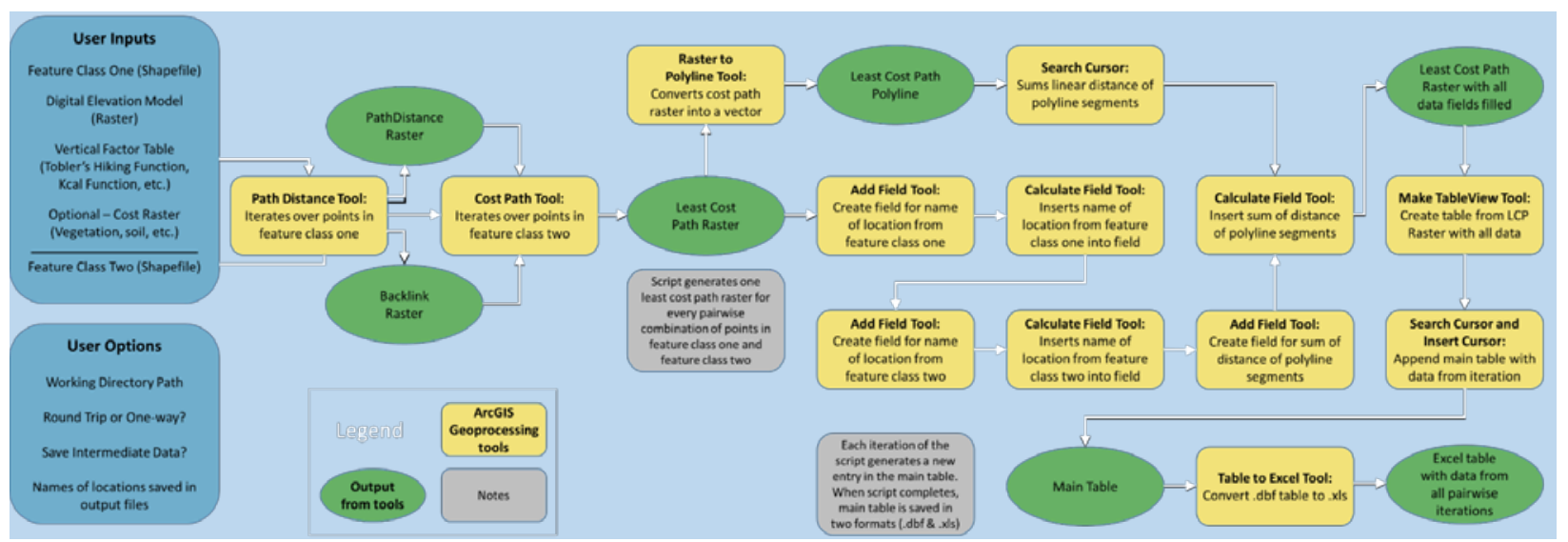

Figure 8.1. Workflow of a least cost analysis (Jorgeson 2017).

Environmental and cultural inputs are necessary to conduct a least cost analysis. I compiled stream and spring location data from geospatial datasets created by the National Forest Service, National Park Service, and Los Alamos Laboratory. The cost surface is a 10-m digital elevation model raster of each region's study area derived from nation-wide LiDAR mapping done by the USGS. To calculate a cost for traversing each 10-m cell of the raster I used the Tobler hiking function as a vertical factor in the path distance tool (Tobler 1993). The Tobler hiking function is an observation-based model of the time it takes to for humans to traverse different degrees of 
slope based on a $4 \mathrm{~km} / \mathrm{hr}$ walking rate on nearly level surfaces, which adjusts (faster or slower) depending on slope. It is commonly used as a vertical factor in archaeological applications to attribute costs in travel time to a raster surface, although other vertical factors can be used, or it can be modified dependent upon conditions (see discussion by White 2015). For example, to more realistically reflect travel time, the impact on travel time of carrying burdens (like water) could be considered. Approaches to estimate an individual's carrying capacity vary. Agents in the VEP model transport $20 \mathrm{~kg}$ (44 lbs.) (Kohler 2012: Table 4.1). This likely overestimates the amount of water that could be carried. Carrying 44 pounds of water $(20 \mathrm{~L})$, regardless of distance, presents physical challenges in terms the carrying technology used to distribute the load, and certainly would slow down transport. I did not factor water or vessel weight into the vertical factor I used in my analysis, but the potential for incorporating the effect of water weight will be considered in the concluding chapter.

Archaeological site data for the Jemez Plateau was compiled by National Forest Service archaeologists. The sites are found on Forest Service lands, the Banco Bonito area of the Valles Caldera National Preserve, and a few sites on adjacent non-forest service lands. The Pajarito Plateau archaeological site information is from a database compiled by the Village Ecodynamics Project II (Ortman 2016) based on survey data generated by multiple federal agencies. I analyzed a total of 3,190 archaeological sites and 50 water sources (48 spring points, perennial streams aggregated into a single polyline feature, and vulnerable streams similarly aggregated) on the Jemez Plateau, and on the Pajarito Plateau 2,290 archaeological sites and 86 water sources (84 spring points, perennial streams aggregated into a single polyline feature, and vulnerable streams similarly aggregated). There are more sites in the original databases, but I excluded some 
sites because they were outside of the project areas I defined, or because multi-component sites often had duplicate entries in the databases.

To compare archaeological water costs to a measure of water costs across these landscapes free of cultural decision-making, I generated a random sample of 500 points each across both project areas and ran least cost analyses from these control points to water (Figure 8.2). I then compared these costs against the archaeological costs of water acquisition. I constrained the area in which points were generated to match the areas where sites are located. This excluded high elevation areas, and the areas where little or no survey data is available, like tribal lands. This choice led to a 31\% reduction in area for the Jemez Plateau, and a 55\% reduction in area for the Pajarito Plateau.

137,482 analyses between archaeological sites and water sources were undertaken, and an additional 22,205 analyses were undertaken for the control points. Analyses were divided into each project area. Rather than make path distance raster files for each stream, raster analyses were done only for each stream type: perennial streams and intermittent streams. Because of the processing time involved (approximately 65 hours total), I only conducted one-way analyses from water sources to sites and controls. Round-trip runs were done for some sites, and differences in travel times (but not necessarily routes) were minimal. To reduce processing time, each project area was divided into sub-regions, and analyses were run in batches by sub-region (Figure 8.3). Each sub-region overlapped, so that sites and sources on the boundaries of the subregions would have calculations to all of the closest sources. The outputs of all analyses consisted of rasters generated during intermediary steps of the analyses (path distance and backlink rasters), polyline shapefiles of each calculated path, and an excel table with time (hours) and distance (kilometers) calculated for each least cost path. The results of these analyses were 


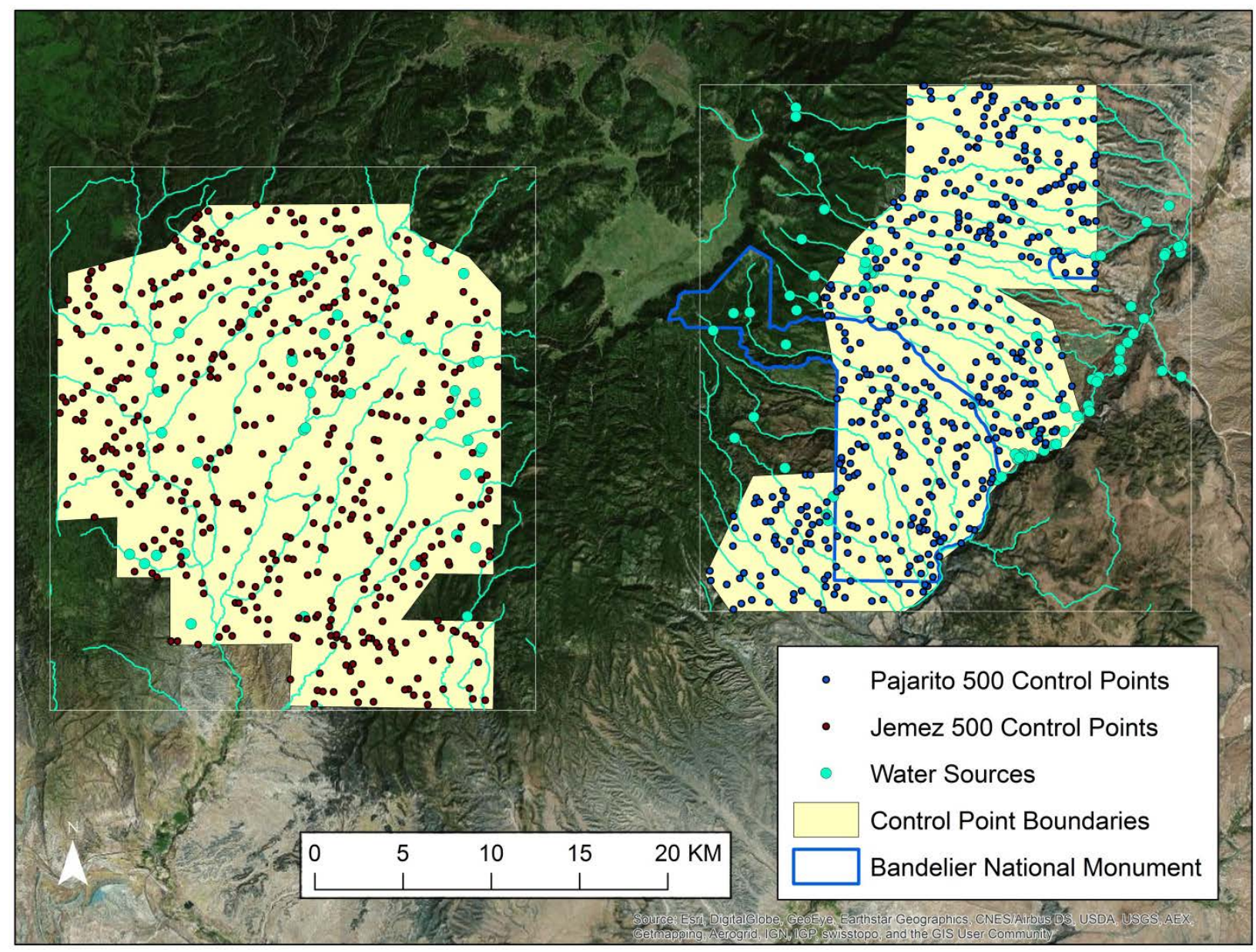

Figure 8.2. Spatial distributions of random points used for control LCA study.

then compiled by site, and then collated by travel time and water source type (as identified in Chapter 5). Figure 8.4 provides an example of cost paths and travel times between the site of Amoxiumqua (LA481) and three water sources: its reservoir, the closest intermittent stream vulnerable to droughts, and the closest perennial water source. The results are available upon request from the author, and will be distributed to federal and tribal archaeologists. 


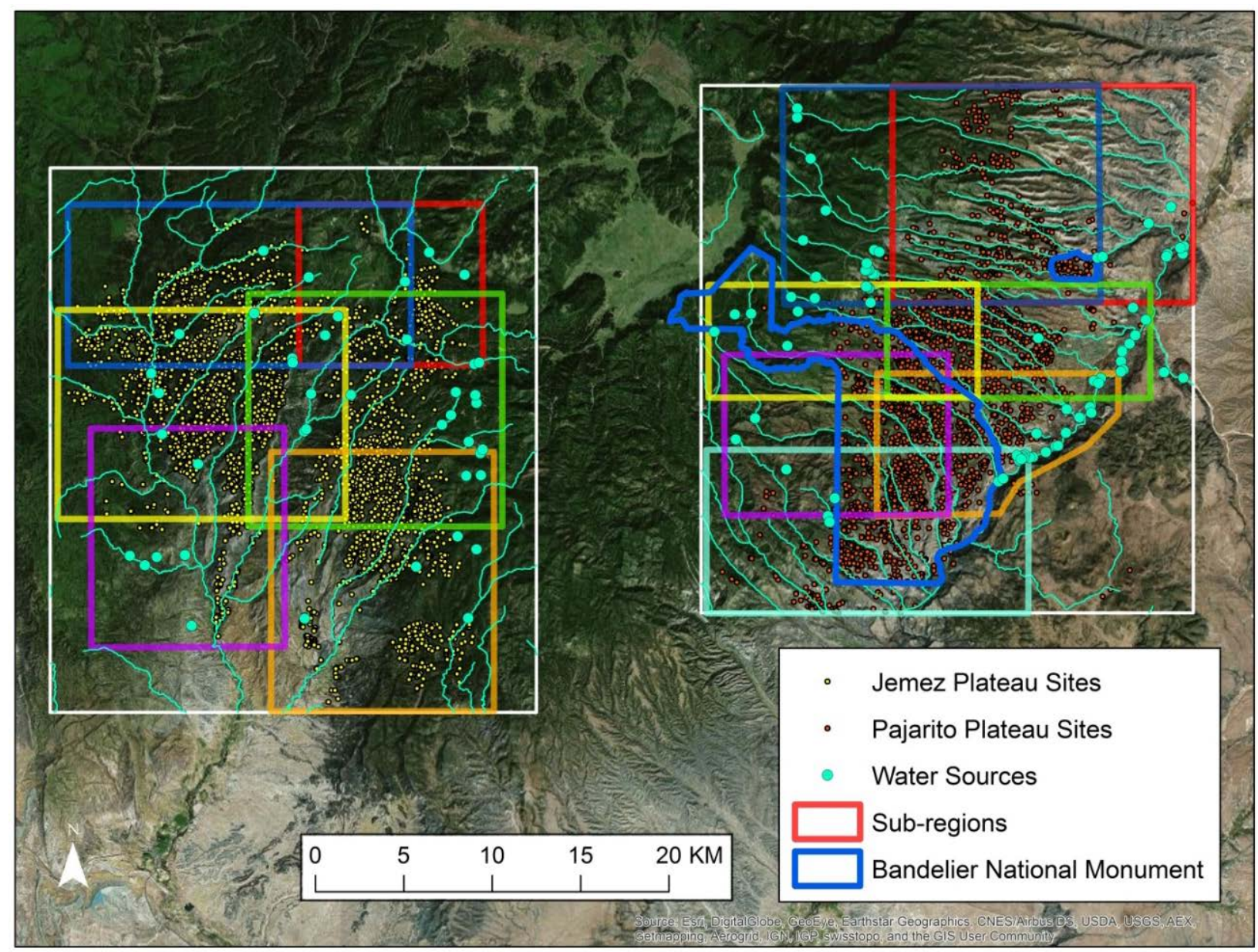

Figure 8.3. Map of sub-regions used to break-out least cost analyses.

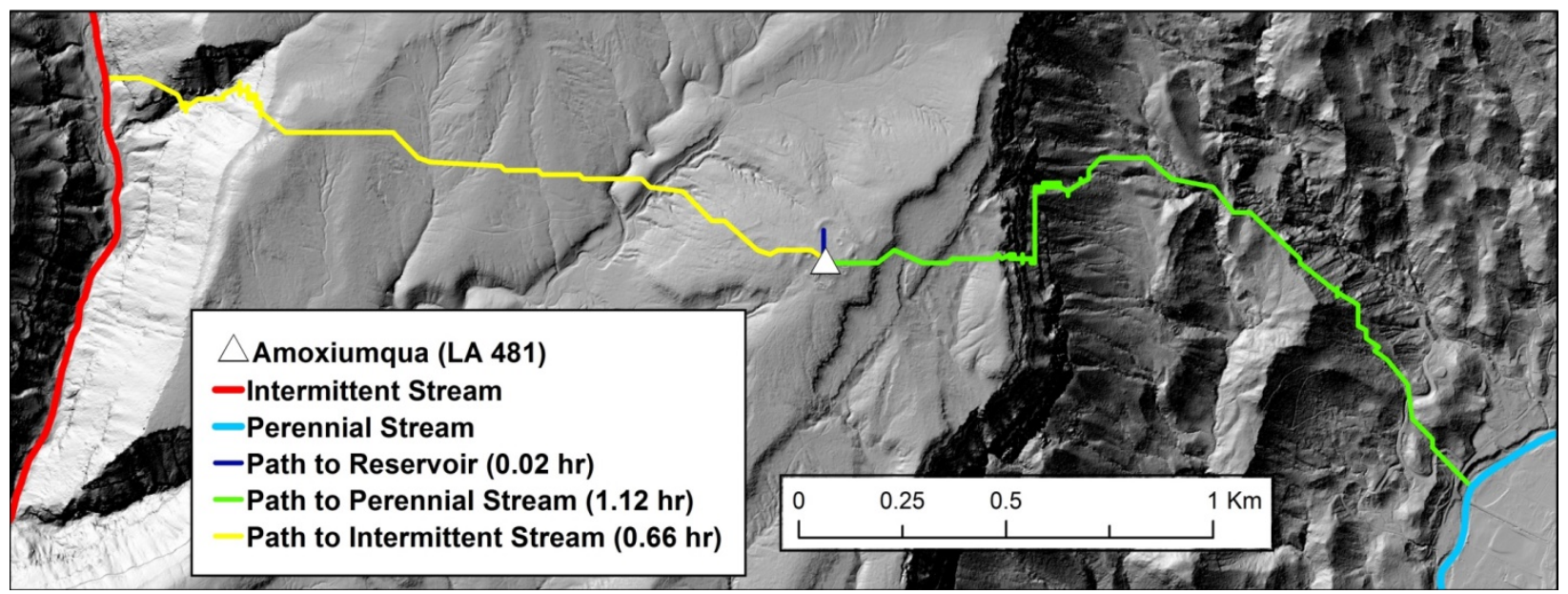

Figure 8.4. Cost paths and travel times from nearby water sources to Amoxiumqua (LA481). 
Sites within each region were categorized by a number of attributes: size, chronology, and intra-regional location. I consider site size an important variable in water management as increasingly aggregated communities require collective action decisions towards resource management. Big sites are either villages (greater than 50 rooms, but less than 500), or towns (greater than 500 rooms). The 500 room threshold for towns is greater than what was used in Kohler’s (2004:2) studies at Bandelier (200 rooms), but matches Ortman’s criteria (2016). Small sites consisted of fieldhouses, agricultural fields, and hamlets. Hamlets are defined locally as sites with more than 12 rooms, but less than 50 (Kohler 2004:2). It is presumed that the small sites reflect decision making about resource management at the household level of organization rather than at the community level. 3,117 sites small sites on the Jemez Plateau were included in this analysis, and 41 big sites. The Pajarito Plateau study area has 2,187 small sites, and 103 big sites. The chronology of their occupation is a critical attribute. Poor chronologies of sites on the Jemez Plateau mean that I can only make general interpretations of diachronic changes in water acquisition costs, and only at large sites. The more refined chronologies of sites on the Pajarito afford a greater range of interpretations in this region. Finally, I considered intra-regional variability in settlement location, because settlement patterns vary across both regions. On the Jemez Plateau, settlements seem to first appear on the eastern mesa-tops and then spread to the west (Kulisheck 2005), while on the Pajarito, sites along Frijoles Canyon (i.e., near permanent water) appear to have the greatest longevity (Kohler et al. 2004b). LCA provides an opportunity to test if these observations about regional settlement patterns were in part a function of water availability. 


\subsection{Least Cost Analysis of the Jemez Plateau}

The least cost analysis of travel times from natural water sources to 500 randomly generated points provides a baseline for water costs on the Jemez Plateau independent of Ancestral Pueblo decision-making regarding site location. The mean minimum distance to a natural water source, regardless of type, is 0.26 hours. 58\% of the random points are closest to a perennial water source, while $42 \%$ are closest to an intermittent source vulnerable to droughts (Figure 8.5 ). There is little difference in the mean costs between travelling to perennial verses vulnerable sources ( 0.27 vs. 0.25 hours), but if vulnerable sources are not available due to a drought the average cost to the nearest alternative perennial water source jumps to 0.71 hours. This analysis shows that independent of any other factors, perennial sources are more ubiquitous across the landscape. It also shows that there is little difference in travel time to perennial or vulnerable water sources and as expected, sites closest to vulnerable sources incur increased water acquisition costs if they have to instead travel to the nearest alternative perennial source.

On the Jemez Plateau, $41.2 \%$ of the small sites are closest to perennial water sources, while 59.8\% are closest to vulnerable water sources (Figure 8.6). These ratios are nearly the reverse of the random samples. Like the random samples, under normal and wet precipitation regimes there are only minor differences in mean one-way travel times to closest water sources $(0.24$ hours to sites closest to perennial and 0.28 hours to sites closest to vulnerable). When vulnerable water sources were not available during hydrological droughts, travel times would increase significantly to the small sites. Mean one-way travel time from the nearest perennial source to these vulnerable small sites is 0.83 hours during drought. The locations of these sites suggests that other factors, such as proximity to agricultural areas, could play a larger factor in fieldhouse location than does proximity to water. 


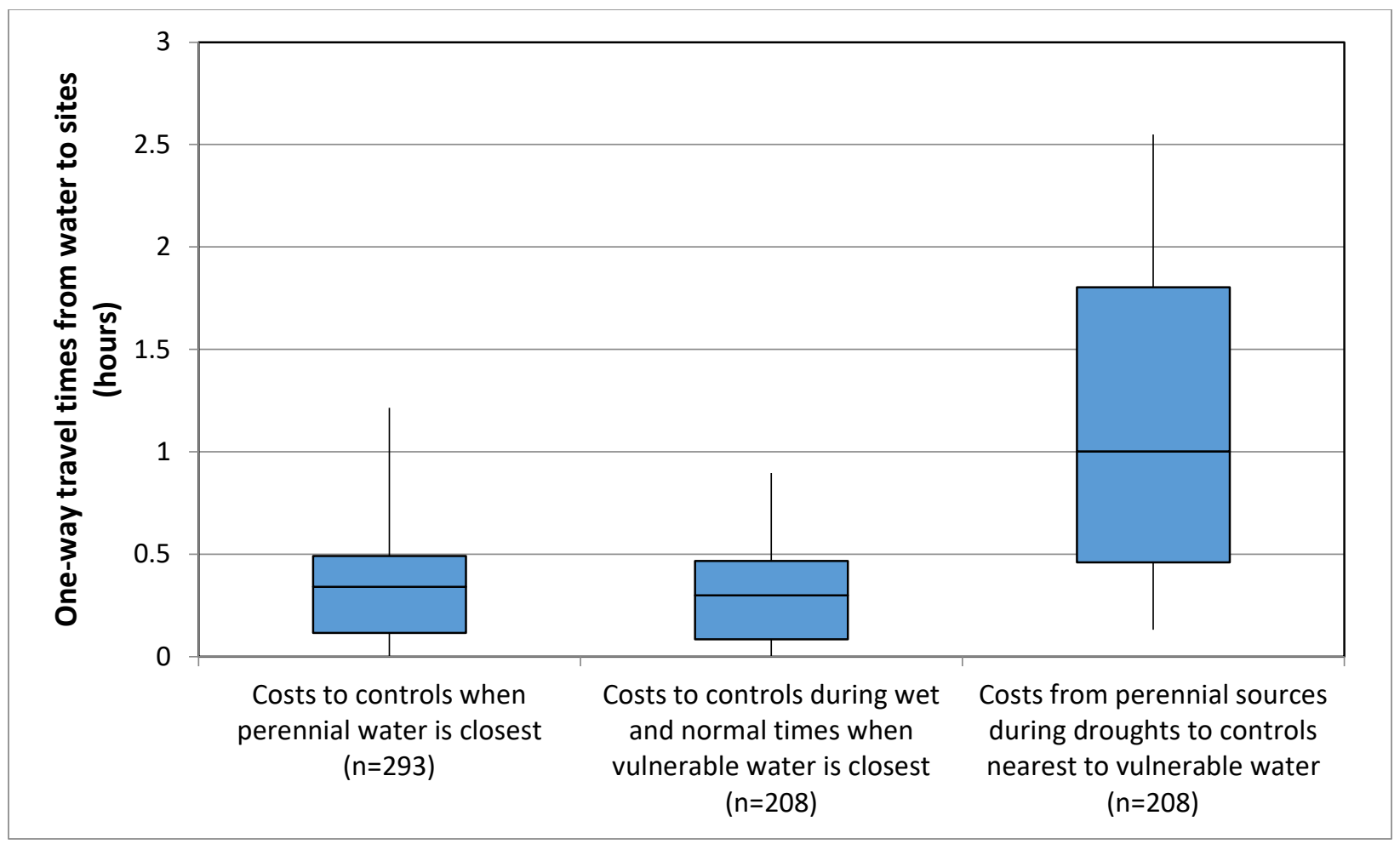

Figure 8.5. Box plots of travel time between water sources and 500 control samples on the Jemez Plateau.

Intra-regional comparisons in small site distances to water display little variability across the Jemez Plateau. I broke the Jemez Mountains into three regions: the highland contexts of Banco Bonito, east of San Diego Canyon, and west of San Diego Canyon. Based on chronologies of large villages, Kulisheck (2005) argued that the eastern Jemez Plateau was settled before the western mesa-tops, although the chronometric results from reservoir features indicate that the western mesa-tops may have been occupied earlier than we previously recognized. 212 of the 214 Banco Bonito sites are closest to perennial water sources, yet travel times to water are slightly longer than those in lower elevations across the mesa-tops (Figure 8.7). The differences between east and west sides of the Jemez Plateau are minimal. Both have the same ratios of small sites closest to perennial water as compared to vulnerable sources ( $37 \%$ perennial vs $63 \%$ 


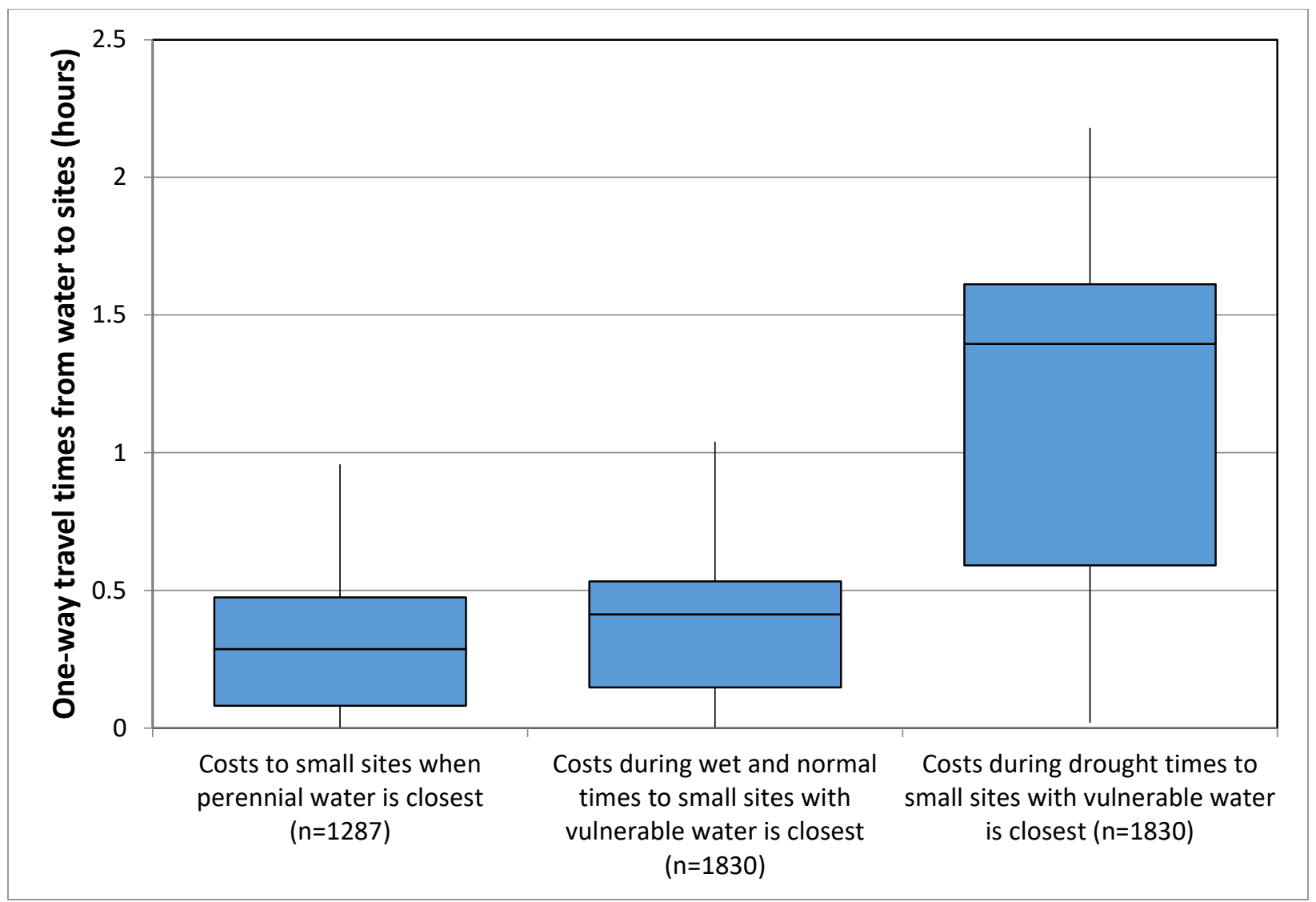

Figure 8.6. Box plots of one-way travel times between water sources and small Ancestral Pueblo sites of the Jemez Plateau region.

vulnerable), and there are little differences in the distributions of water costs (Figure 8.7). The only major difference is that western perennial water sources are closer to sites than those of the eastern mesa-tops. The lack of significant difference between these two regions suggests there were not intra-regional differences in settlement patterns in relationship to water acquisition strategies.

The 41 villages and towns of the Jemez Plateau have similar, but less pronounced differentials in water acquisition costs than the small sites. The proximity of big sites to water types closely matches the control samples. 59\% of the big sites are closest to perennial water 


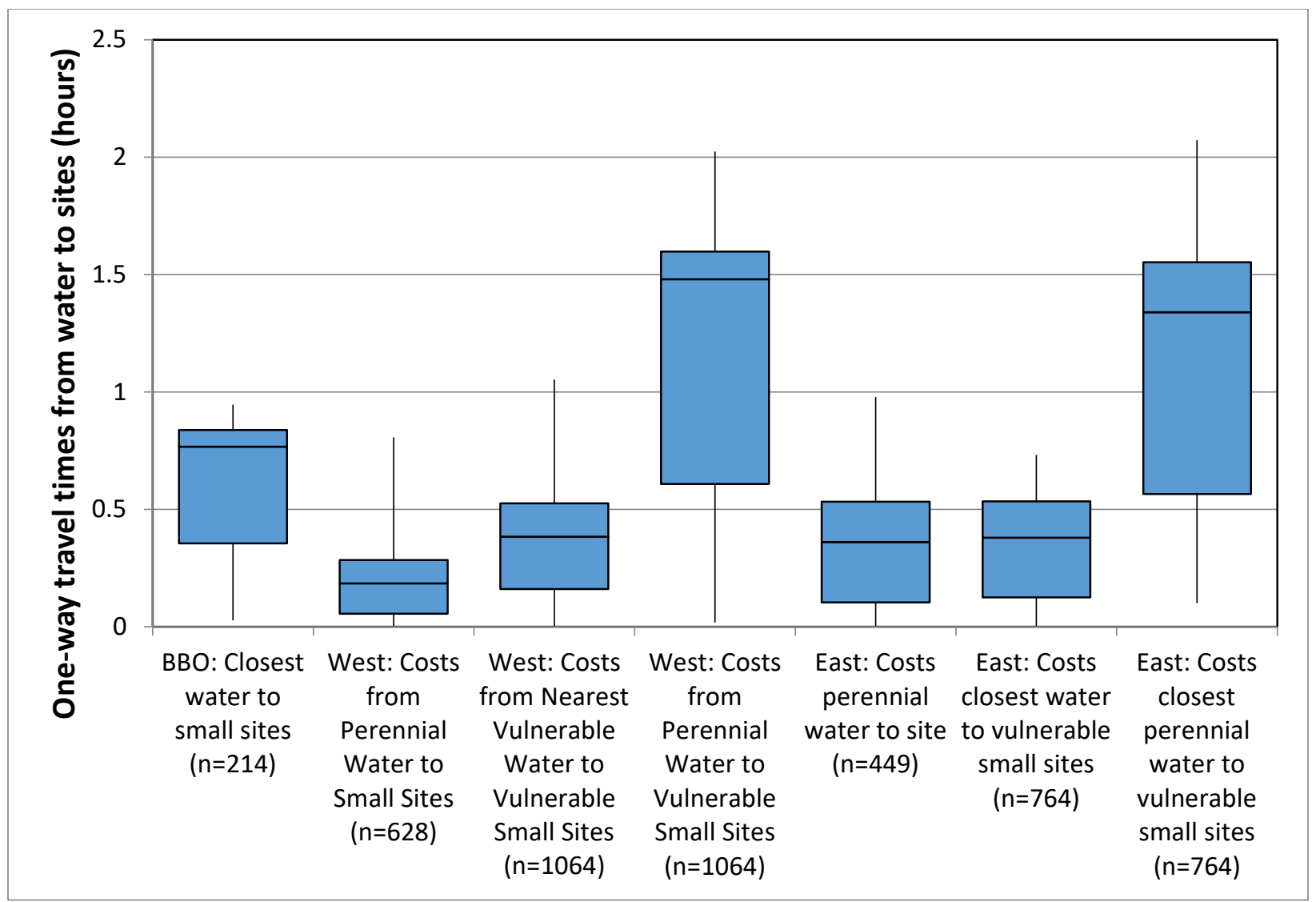

Figure 8.7. Intra-regional comparison of small site water acquisition costs across the Jemez Plateau region.

sources (Figure 8.8). Vulnerable water sources (which include all reservoirs) are the closest water sources to only $41 \%$ of big sites. This suggests that proximity to perennial water was a greater concern for the development of aggregated villages than for the locations of small sites. Mean travel times to closest water sources during normal and wet times are the same between big sites closest to perennial sources or vulnerable sources ( 0.23 hours); a two-sampled t-Test assuming equal variances identifies no differences in the means $(\mathrm{p}=0.913863)$. There is, as would be expected, a significant difference in travel time during droughts. The 17 sites closest to vulnerable water sources see their mean one-way travel time to perennial water increase to 0.87 
hours. This is a $287 \%$ increase in travel time to water and a greater increase than what I observed in the control samples closest to intermittent streams.

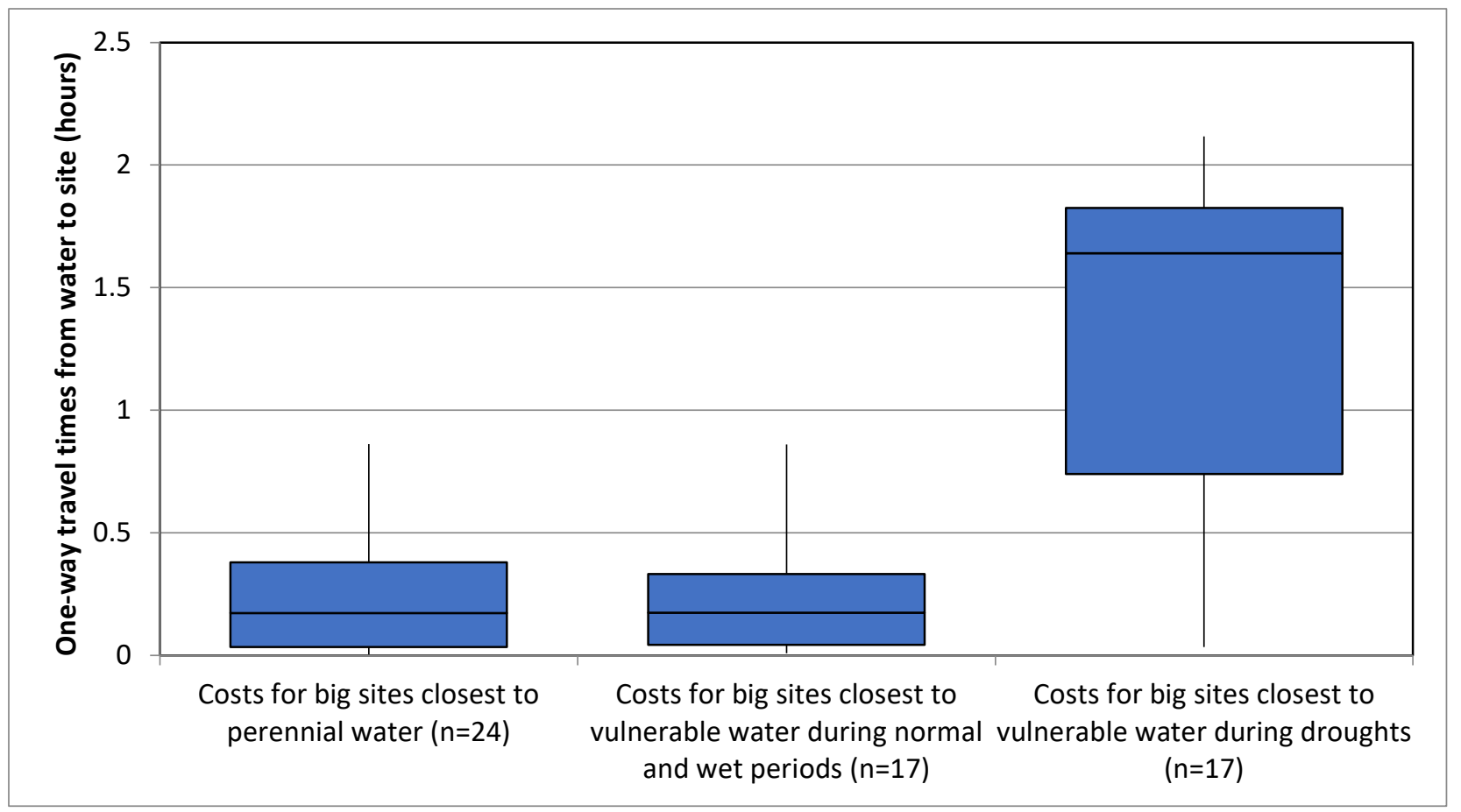

Figure 8.8. Box plots of one-way travel times between water sources and big Ancestral Pueblo sites of the Jemez Plateau region.

Boxplots of water acquisition costs of reservoir features shows the importance of reservoirs for reducing water acquisition costs at large communities (Figure 8.9). In every case the next closest water to a big site is a source vulnerable to droughts. When they hold water, reservoirs make water acquisition costs almost negligible. As compared to average time to the closest vulnerable water source, reservoirs had a lower travel time by an average 0.48 hours. This supports the hypothesis that reservoirs were important features for reducing water acquisition 
costs when Ancestral Jemez communities developed in locations where water resources were vulnerable to droughts.

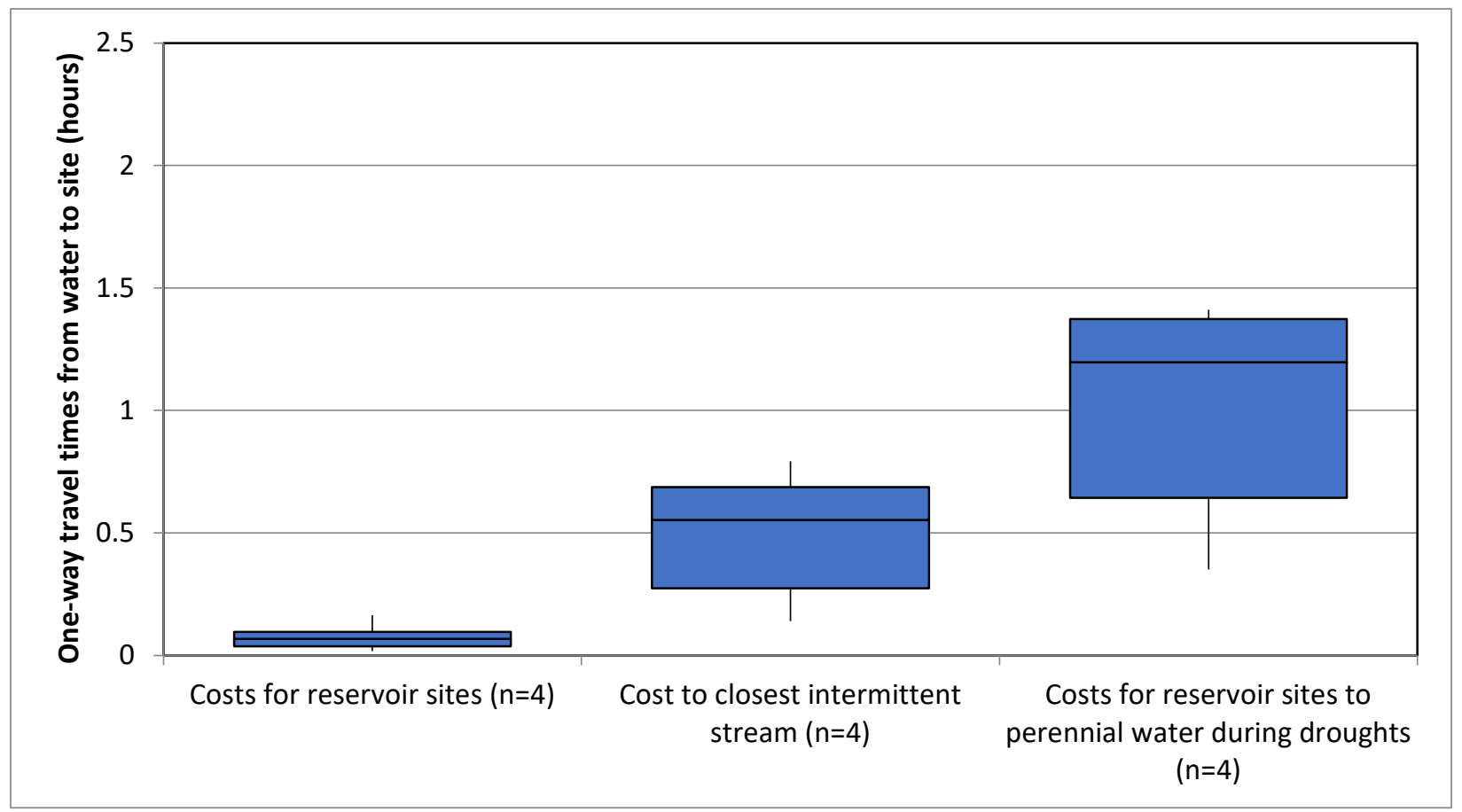

Figure 8.9. Box plots of one-way travel times between water sources and big Ancestral Pueblo sites with reservoirs in the Jemez Plateau region.

Of the ten town sites across the Jemez Plateau, four have reservoirs. Of the remaining six town sites, only two have their closest water sources vulnerable to droughts: Wabakwa and Seshukwa. The cost differential in travel time to perennial water at Seshukwa is 0.55 hrs, which is not as high as most of the other town sites that are closest to water sources vulnerable to drought. By contrast, Wabakwa was particularly vulnerable to droughts if its reservoir was nonfunctional. Unless there were nearby water sources that are not present today, the one-way travel time to the closest perennial source, Dead Horse Springs, is 1.4 hours. Unpublished results of dating charred corn from Wabakwa and ceramics recovered during surveys indicate that the site 
was depopulated between AD 1425-1450 (Chris Roos, 2016, personal communication). Therefore, increased water acquisition costs during the early $14^{\text {th }}$ century hydrological drought cannot be ruled out as a contributing factor to the depopulation of the site. Considering that water sources vulnerable to droughts are the closest sources for six of the ten town sites of the Jemez Plateau, other cultural and environmental factors must have influenced Ancestral Pueblo villagers' decisions to commit to locations with high water costs. In the case of the four villages with reservoirs, the construction of these features before the development of highly aggregated communities likely served as a positive feedback for growing settlements.

Using the chronologies of big sites (Kulisheck 2005; Liebmann et al. 2016), and the paleohydrological model of wet and dry archaeological periods (Figure 5.15), I can make general assessments of how water acquisition costs may have changed through time. During archaeological phases without hydrological droughts, I calculated water acquisition costs based on the closest available water, regardless of whether it was perennial or vulnerable to drought. I calculated travel time from the closest perennial water to big sites during archaeological periods dominated by hydrological droughts. The chronologies of reservoir use-life histories were factored in as well. Based on my interpretation of hydrological observations of Jemez Plateau reservoirs, I argue that Jemez reservoirs would hold water for at least short durations during droughts. Therefore, I used the travel time to reservoirs as the closest source during droughts instead of perennial sources. In this analysis, I categorized Wabakwa as a site without a reservoir.

The chronology of water costs shows the sensitivity, through time, of big villages to droughts. Travel times increase, but the upper interquartile range during dry periods stays below one hour, and no average one-way travel time during a drought exceeds 0.5 hours (Figure 8.10). 
The lower quartile is no different between wet or dry periods. This reflects the high percentage of sites not affected by droughts in the Jemez (73\% if the four sites with reservoirs are included). The very low costs in travel time from water to sites during the earliest cultural phases appears to reflect initial settlements developing close to water, and lower risks for periods of water scarcity. During the Vallecitos Phase (AD 1200-1350) Boletsakwa is the only site with an early estimated large population with a reservoir. My geoarchaeological investigations found that the other Jemez Plateau reservoirs were functioning during these early phases, but before the ceramicbased chronologies indicate these communities had large populations. Reservoirs proved beneficial by maintaining low water acquisition costs during the subsequent dry periods when populations were increasing. In all, while costs increase during droughts on the Jemez Plateau, they do not increase tremendously, or above thresholds for travel time to water seen in ethnographic contexts or in agent based models (Kolm and Smith 2012). 


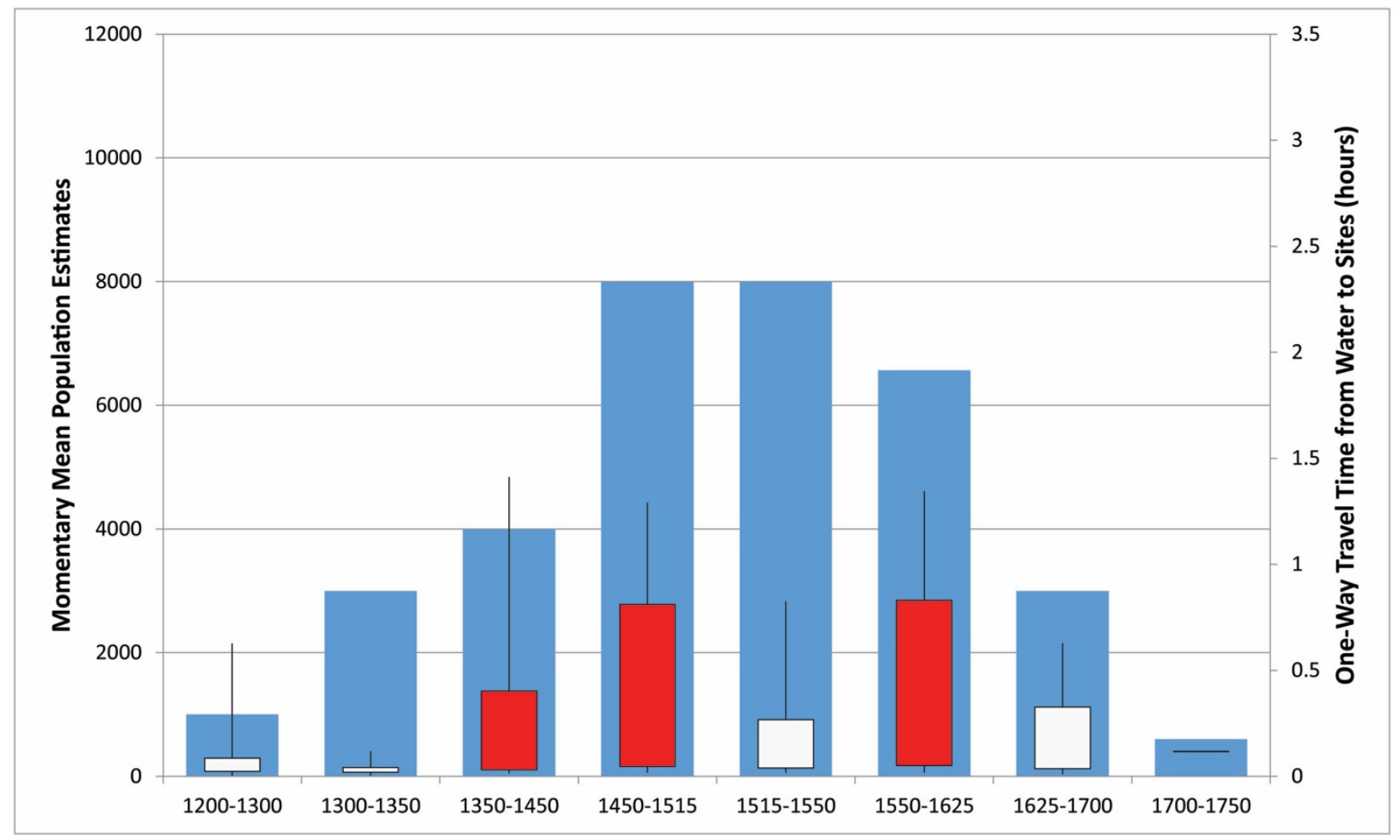

Figure 8.10. Chronological model of Jemez Plateau water acquisition costs (box plots) and maximum estimated regional population histories (blue bars). Box plots in white are archaeological periods without droughts, while box plots in red are periods with droughts.

\subsection{Least Cost Analysis of the Pajarito Plateau}

The least cost analysis of travel times from natural water sources to 500 randomly generated points provides a baseline for water costs on the Pajarito Plateau independent of Ancestral Pueblo settlement patterns. The mean minimum distance to a natural water source, regardless of type is 0.19 hours. Only $7 \%$ of the random points are closest to perennial water sources, while 93\% are closest to intermittent sources vulnerable to droughts. There is little difference in the mean costs between travelling to perennial versus the closest vulnerable water sources (0.18 vs. 0.25 hours). Yet, when vulnerable water sources were not available during a drought, travel time to the closest perennial source would have averaged 1.27 hours (Figure 8.11). This analysis shows, independent of any other factors, that vulnerable water sources are more ubiquitous 
across the landscape of the Pajarito Plateau. Therefore, successful long-term adaptations to permanent settlement in this region would have to factor in the overall vulnerability of the hydrological system of the Pajarito Plateau to mitigate the risk of water scarcity and drastically increased water acquisition costs due to droughts.

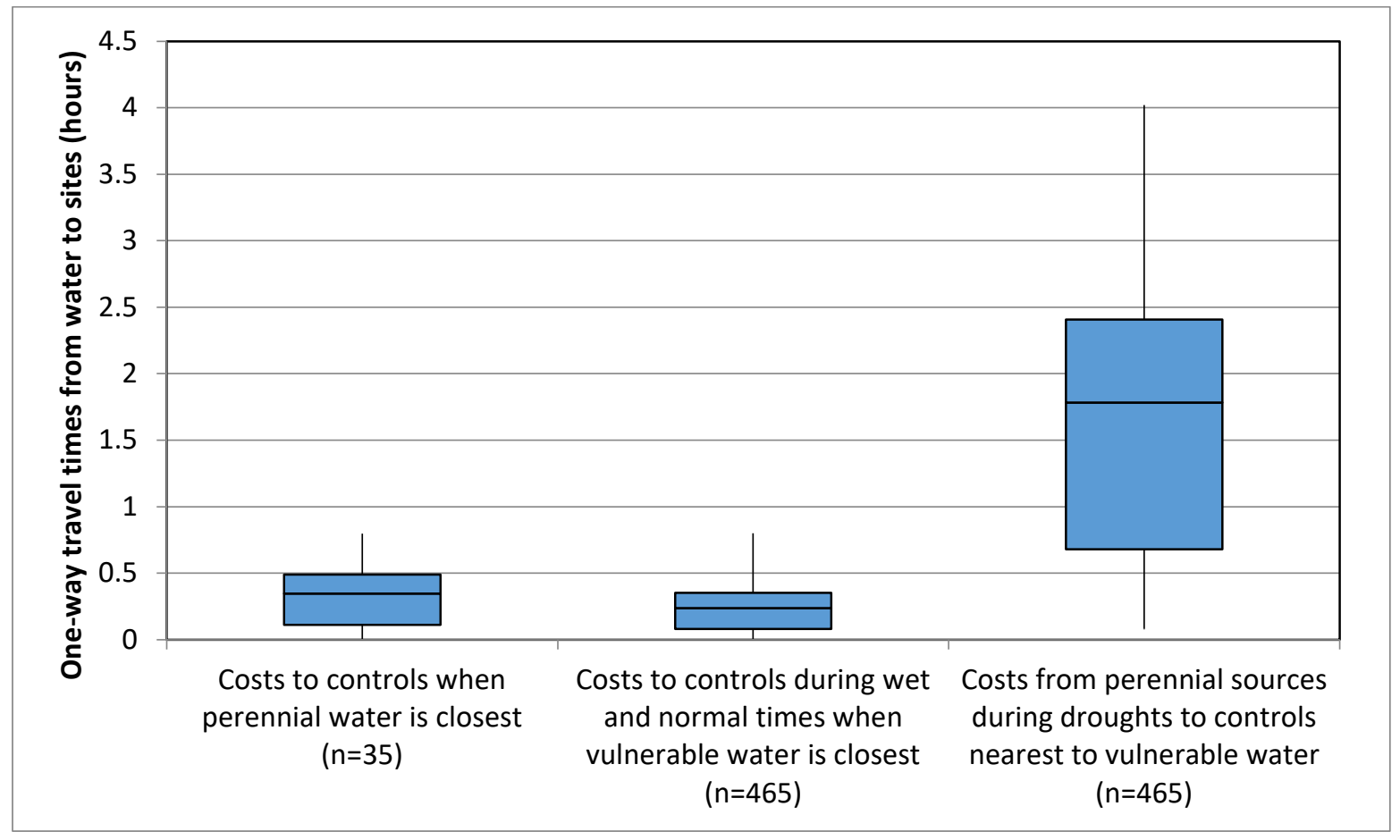

Figure 8.11 Box plots of travel time between water sources and 500 control samples on the Pajarito Plateau.

The closest water sources of the small Ancestral Pueblo sites on the Pajarito Plateau mimic the distribution of the control samples. 94\% of the small Ancestral Pueblo sites are closest to vulnerable water sources. Mean travel times to closest vulnerable water sources are only 0.17 hours, but are 1.17 hours to the closest perennial water sources (Figure 8.12). Of the small sites vulnerable to droughts with archaeological estimates of occupation spans $(n=1,586)$, the mean 
duration of occupation is 217 years. Only 6\% of sites $(n=134)$ are closest to perennial sources. Ninety two of these sites are near Frijoles Canyon. The rest are found along White Rock Canyon of the Rio Grande and towards the southern end of the project area near Turkey Spring. The mean duration for small sites near perennial water with occupation spans $(n=83)$ is 195 years. Being situated near perennial water does not seem to have conferred an advantage for longer occupation durations at small sites.

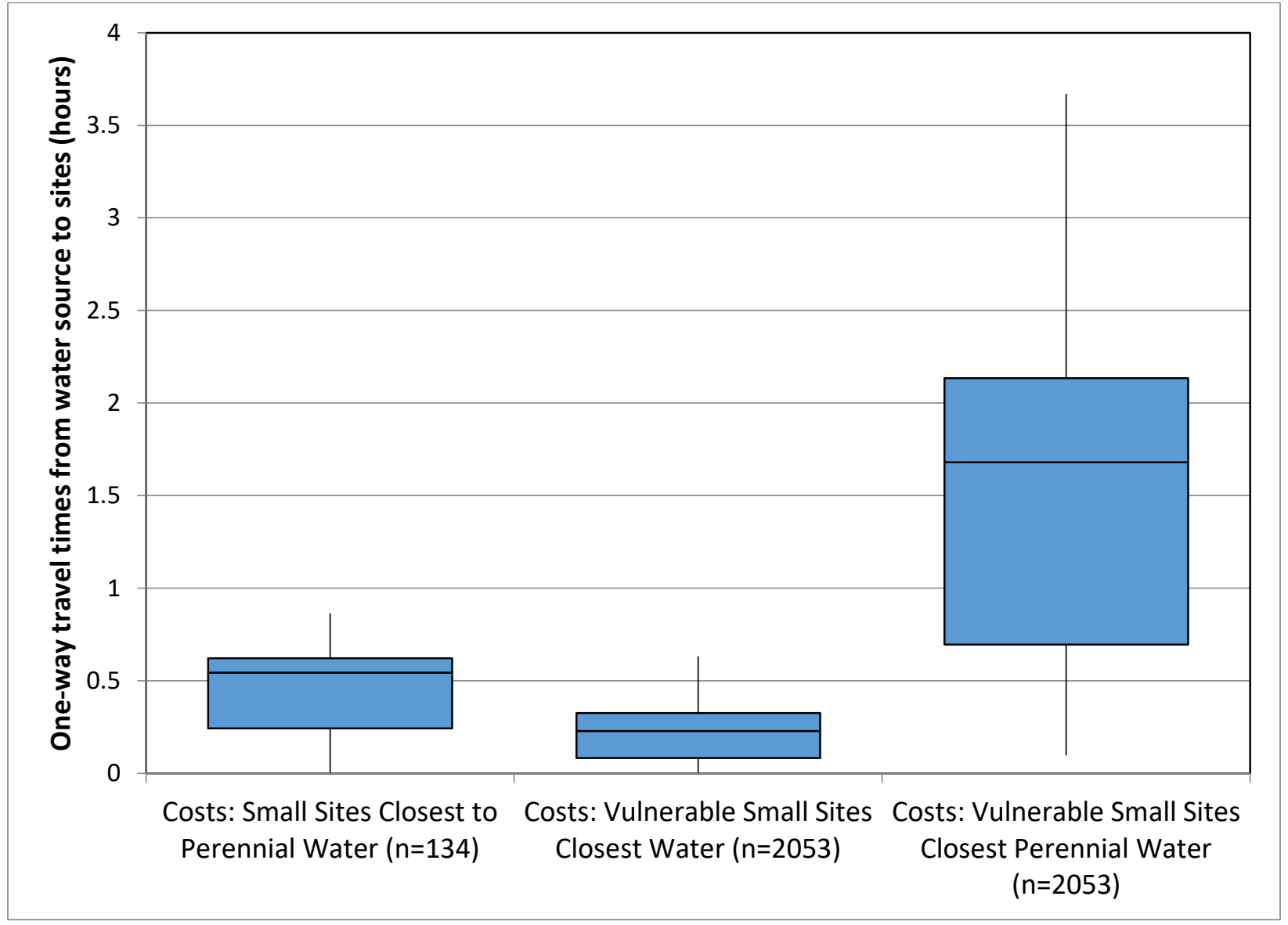

Figure 8.12. Box plots of one-way travel times between water sources and small Ancestral Pueblo sites of the Pajarito Plateau region. 
$15 \%$ of big sites of the Pajarito Plateau are closest to perennial water sources, while $85 \%$ are closest to vulnerable sources (Figure 8.13). The average travel time from water, regardless of water type, to big sites in normal and wet conditions is the same ( 0.15 hours). All of the big sites closest to perennial water sources, except for LA12579, which is located along the Rio Grande in White Rock Canyon, are found along Frijoles Canyon. However, there is a significant increase in travel time to alternative perennial water sources from sites closest to water sources vulnerable to droughts. During droughts, one-way travel time from perennial water goes from 0.15 hours to 1.32 hours at vulnerable sites, a $773 \%$ increase in travel time.

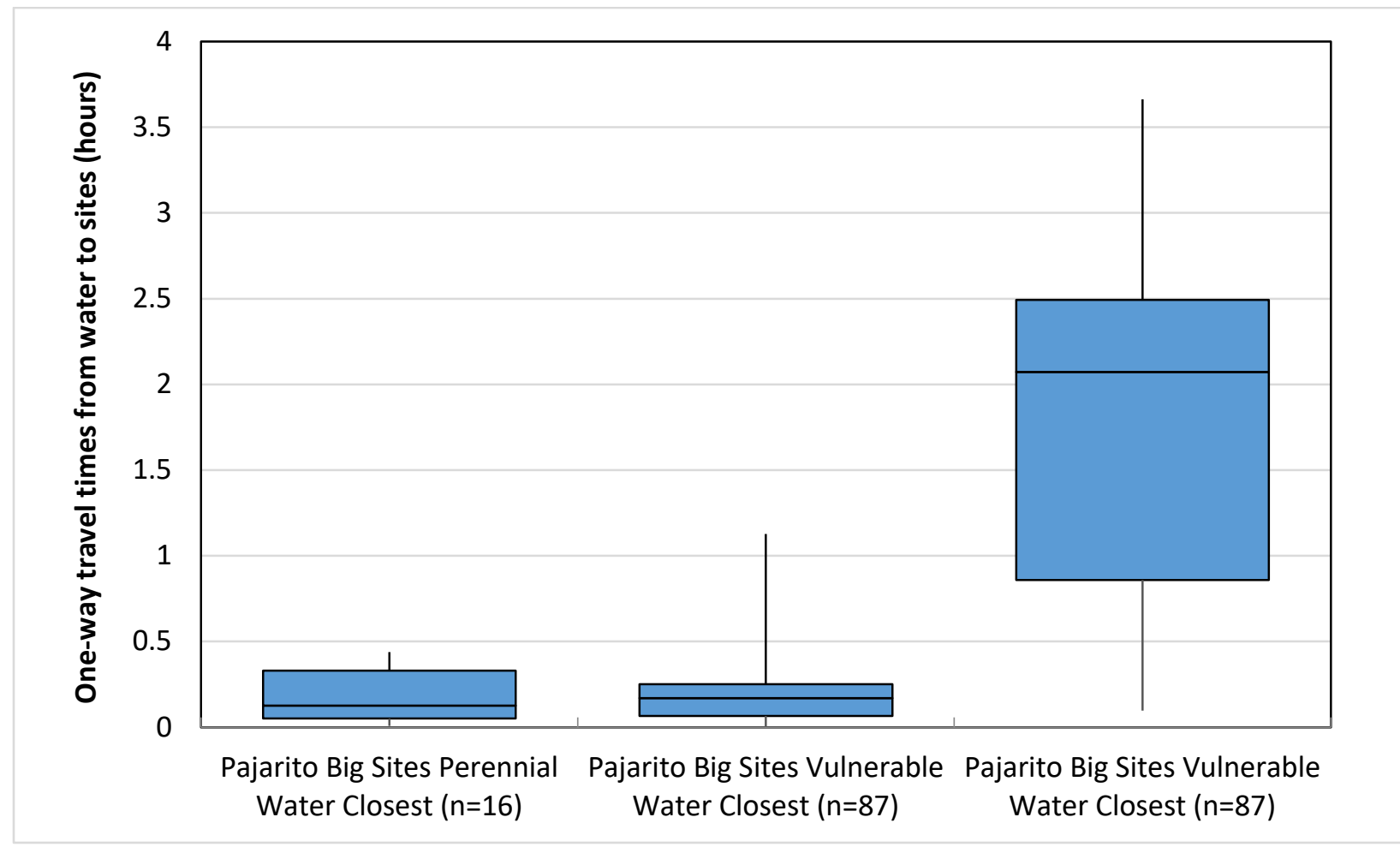

Figure 8.13. Box plots of one-way travel times between water sources and big Ancestral Pueblo sites of the Pajarito Plateau region. 
Reservoirs reduce water acquisition costs substantially. However, I found in my hydrological and geoarchaeological studies that Ancestral Pueblo reservoirs on the Pajarito Plateau did not store appreciable volumes of water during hydrological droughts. Many of the sites with reservoirs have water sources closer than perennial streams that may be less vulnerable to droughts. Basalt Springs near Tsankawi, wetlands in Pajarito Canyon near Tsirege, the upper reaches of Capulin Canyon near Yapashi, and seeps observed in Medio Canyon near San Miguel are all between 0.13-0.69 hours from these sites. Figure 8.14 depicts the relationships between how alternative intermittent water sources impact water costs at large villages with reservoir features. The dramatic increase in travel time to perennial sources would be avoided if these alternative water sources were available during droughts.

Proximity to water appears to correlate to the longevity of site occupations on the Pajarito Plateau. Big sites that are closest to perennial water, which on the Pajarito are found mostly along Frijoles Canyon, have average occupation durations of 221 years. By comparison, big sites near vulnerable water sources average only 136 years in duration. Sites with tested reservoir features average 215 years, and if occupation durations for sites with reported (but untested) reservoir features are included (Portero de las Casas, Otowi, and Guaje), the average duration of occupations for all reservoir sites increases to 226 years. This suggests that water storage features, in conjunction with a host of other factors associated with collective action seen in these villages (see Van Zandt 2006), may have contributed to the sustainability of communities which otherwise would have been more vulnerable to droughts.

Modeling water acquisition costs through time relative to paleohydrological models of water availability, reservoir use-life histories, and site occupation histories shows that water acquisition costs increase during droughts (Figure 8.15). In every instance, hydrological droughts increased 


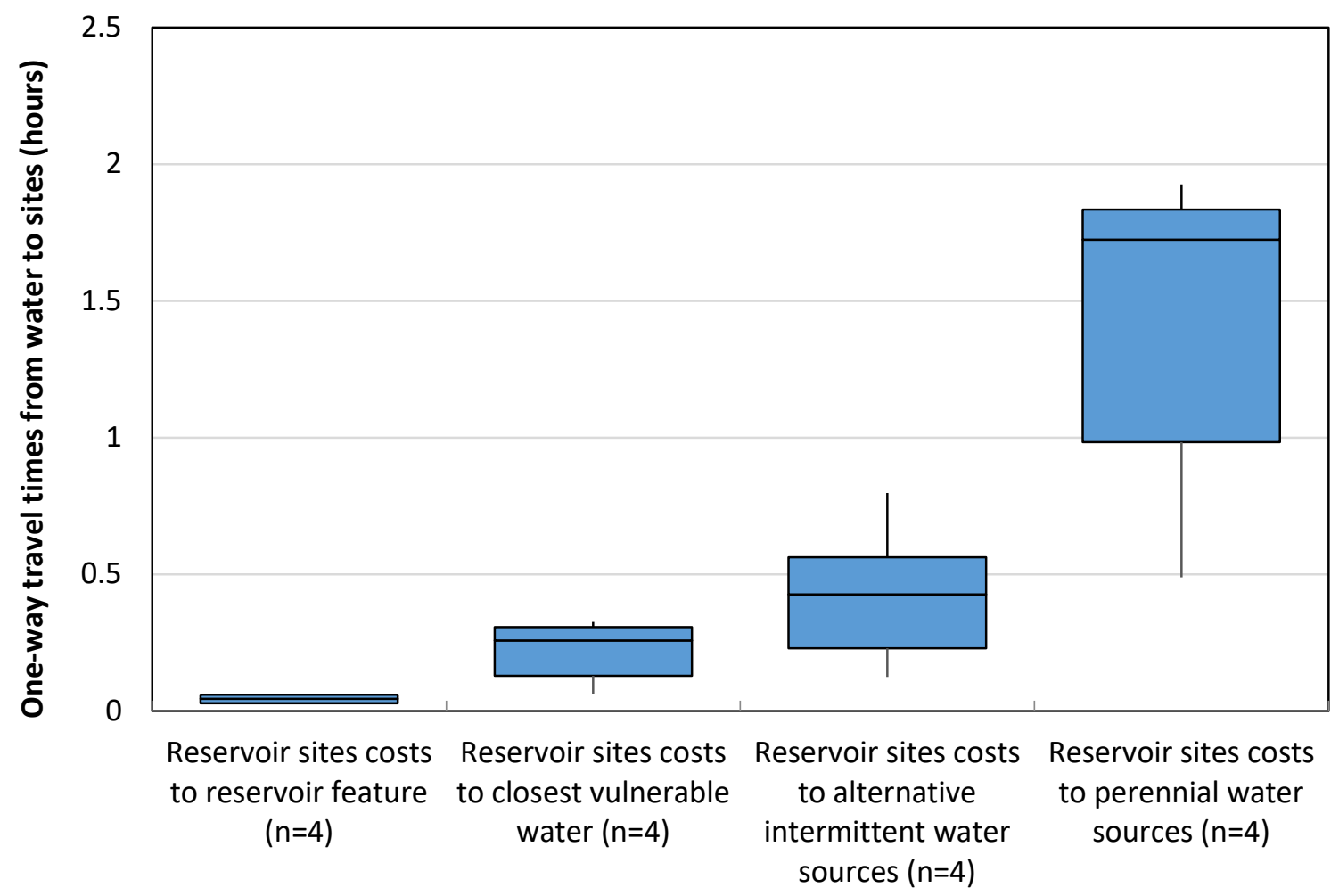

Figure 8.14. Box plots of one-way travel times between water sources and big Ancestral Pueblo sites with reservoirs of the Pajarito Plateau region.

water acquisition costs and in most cases the regional population declines as well. In this analysis I do not model the droughts during the transition between the Middle and Late Developmental Period (AD 1131-1158) as dry archaeological periods, because the geomorphic evidence suggests that channel downcutting had not yet impacted alluvial hydrology (see Chapter 5). This period would certainly have been drier, but geomorphic evidence does not suggest a state-change in the alluvial system. Peak populations then, occurred through periods with low overall water acquisition costs. The beginning of the population decline began during a time of low acquisition costs as well, but also during a time when hydrological systems were potentially undergoing a state change, likely resulting in highly variable but significantly increased water acquisition costs. Subsequent droughts through the Classic Period correlate to either periods of the greatest 
decrease in regional population, or precede major drops in population during subsequent periods. The AD 1350-1400 archaeological period of drought saw a 32\% decline in momentary mean population. The other two significant periods of modeled population decline occurred after drought periods. A 47\% decrease in population occurred from AD 1515-1550, while an 81\% decrease occurred from AD 1600-1625. While there were periods with potentially reduced water acquisition costs, populations did not rise during these periods. Instead, the travel times and settlement patterns indicate that during the 1500s the remaining populations were centered nearer to less vulnerable water sources, similar to what Kolm and Smith (2012) saw in the Mesa Verde region.

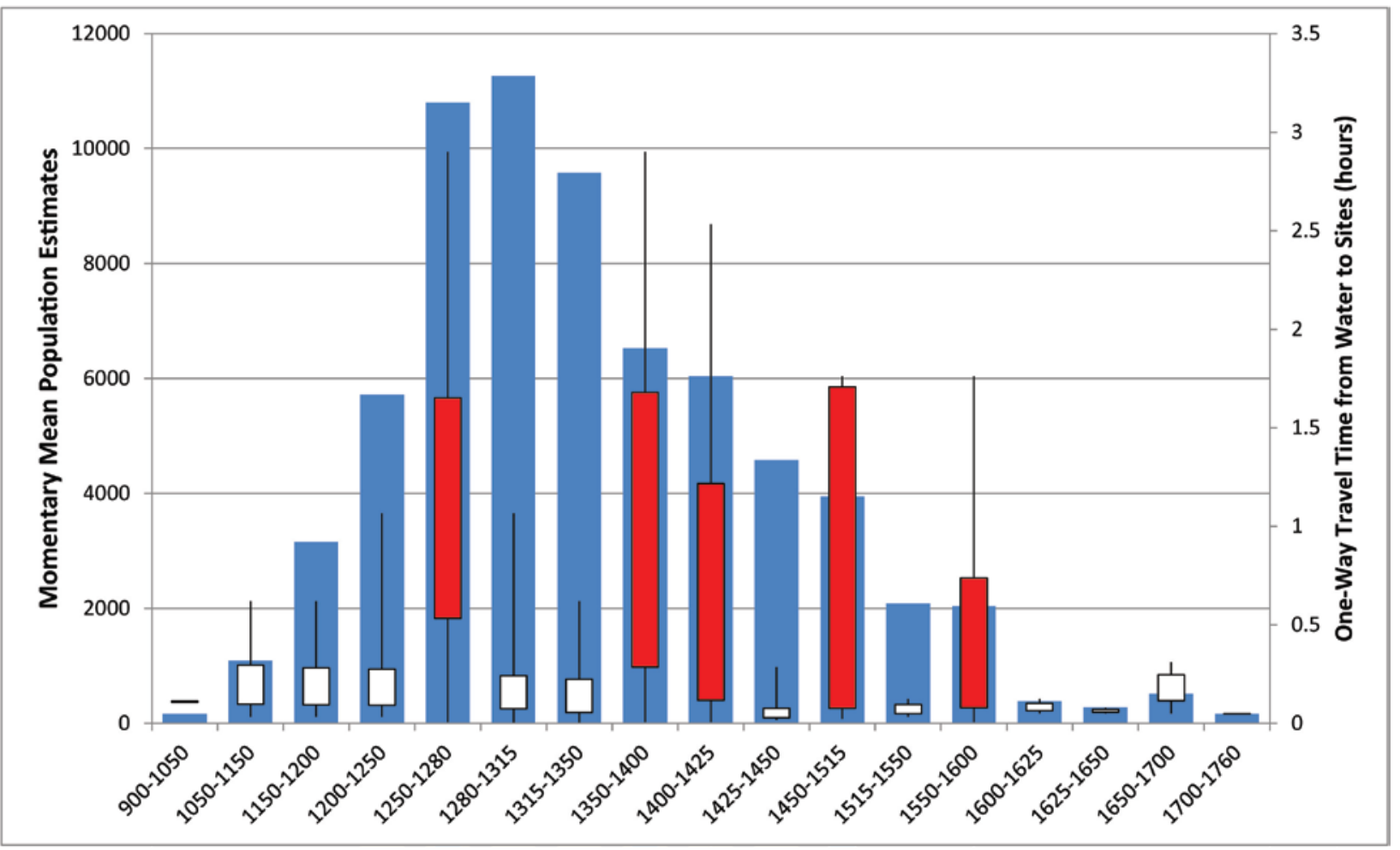

Figure 8.15. Chronological model of Pajarito Plateau water acquisition costs (box plots) and maximum estimated regional population histories (blue bars). Box plots in white are archaeological periods without droughts, while box plots in red are periods with hydrological droughts. 


\subsection{Comparing Ancestral Pueblo Water Acquisition Costs between the Jemez and Pajarito Plateaus}

In nearly every case, droughts made water more costly to acquire for Ancestral Pueblo communities of the Pajarito Plateau than it did for the communities of the Jemez Plateau. This is largely as a function of the limited perennial water sources available to Ancestral Pueblo communities of the Pajarito. In Table 8.1, I present counts and average travel times of water acquisition costs, as well as the results of paired t-tests and Mann-Whitney U tests to identify if there are statistical differences in travel times between regions for the same class of site types and water sources. F-tests of variance were first conducted and all paired analyses had unequal variances. 2-tailed t-tests assuming unequal variances were conducted to determine, within a specified degree of certainty, whether the two means of populations are different, or whether the difference might have occurred by chance. The Mann Whitney U test was used for smaller samples, where t-tests are unreliable. In both cases, the null hypothesis is that there is no difference in travel times between populations being compared.

Side by side counts show that far more Jemez Plateau sites, and especially random control sites, are closer to perennial water than those on the Pajarito. This likely reflects the underlying hydrological differences between these regions. This is especially true in the archaeological record of small sites, which suggests that the dual residence pattern of the Jemez Plateau was more likely to reduce vulnerabilities of water insecurities during periods of droughts than such a pattern on the Pajarito Plateau. It cannot be ruled out that proximity to water contributed to the longevity of the dual residence pattern on the Jemez Plateau, while conferring no benefit during droughts on the Pajarito Plateau. 
Table 8.1 Regional comparisons of descriptive statistics and means testing of LCA results.

\begin{tabular}{|c|c|c|c|}
\hline Category & \# Sites & $\begin{array}{l}\text { Mean } \\
\text { Travel } \\
\text { Time (hrs) }\end{array}$ & $\begin{array}{l}\text { Results 2-tailed t-test, } \\
\text { assuming unequal } \\
\text { variance (alpha } 0.05 \text { ), } \\
\text { or Mann Whitney } U \\
\text { Test }\end{array}$ \\
\hline Jemez Controls: perennial water closest & 293 & 0.27 & \multirow{2}{*}{$\begin{array}{l}\mathrm{p}=0.526605 \text {, cannot } \\
\text { reject }\end{array}$} \\
\hline Pajarito Controls: perennial water closest & 35 & 0.25 & \\
\hline Jemez Controls: vulnerable water closest & 208 & 0.25 & \multirow{2}{*}{$\mathrm{p}<0.001$, reject } \\
\hline Pajarito Controls: vulnerable water closest & 465 & 0.18 & \\
\hline Jemez Controls: vulnerable water dry period & 208 & 0.71 & \multirow{2}{*}{$\mathrm{p}<0.001$, reject } \\
\hline Pajarito Controls: vulnerable water dry period & 465 & 1.27 & \\
\hline Jemez Small Sites: perennial water closest & 1287 & 0.25 & \multirow{2}{*}{$\mathrm{p}<0.001$, reject } \\
\hline Pajarito Small Sites: perennial water closest & 134 & 0.30 & \\
\hline Jemez Small Sites: vulnerable water closest & 1830 & 0.28 & \multirow{2}{*}{$\mathrm{p}<0.001$, reject } \\
\hline Pajarito Small Sites: vulnerable water closest & 2053 & 0.17 & \\
\hline Jemez Small Sites: vulnerable water dry period & 1830 & 0.83 & \multirow{2}{*}{$\mathrm{p}<0.001$, reject } \\
\hline Pajarito Small Sites: vulnerable water dry period & 2053 & 1.17 & \\
\hline Jemez Big Sites: closest to perennial water & 24 & 0.23 & \multirow{2}{*}{$p=0.772$, cannot reject } \\
\hline Pajarito Big Sites: closest to perennial water & 16 & 0.15 & \\
\hline Jemez Big Sites: closest vulnerable water & 17 & 0.23 & \multirow{2}{*}{$p=0.503$, cannot reject } \\
\hline Pajarito Big Sites: closest vulnerable water & 87 & 0.15 & \\
\hline Jemez Big Sites: perennial water for dry period & 17 & 0.87 & \multirow{2}{*}{$p=0.004$, cannot reject } \\
\hline Pajarito Big Sites: perennial water dry period & 87 & 1.32 & \\
\hline Jemez Reservoir Sites: time to reservoir & 4 & 0.06 & \multirow{4}{*}{$\begin{array}{l}\text { Counts too small for } \\
\text { either t-tests or Mann } \\
\text { Whitney U tests }\end{array}$} \\
\hline Pajarito Reservoir Sites: time to reservoir & 5 & 0.04 & \\
\hline Jemez Reservoir Sites: time to perennial water & 4 & 0.82 & \\
\hline Pajarito Reservoir Sites: time to perennial water & 5 & 1.09 & \\
\hline
\end{tabular}

Overall, the similarity in travel times from closest water sources to sites, regardless of water types, suggests that communities were located in part to minimize travel times to water. No mean travel time to closest water (regardless of being a perennial or vulnerable source) is greater than 0.3 hours. Factoring in the cost of the return trip, it appears that the ideal total travel time to acquire water in this model was less than one hour. In both regions, sites with reservoirs dramatically reduced water acquisition times, although as I identified in Chapter 7, communities 
with reservoirs still needed to acquire water from natural sources at least part of the time. The difference, however, is that reservoirs at sites on the Jemez Plateau were likely to provide some water during droughts while those on the Pajarito Plateau were not. Therefore, during droughts communities on the Pajarito Plateau would necessarily have to use alternative natural sources. This would not be too costly before channel downcutting impacted alluvial aquifers beginning around AD 1400. After streams of the Pajarito became vulnerable to drought, my analysis shows the penalty of increased water acquisition costs would have been substantial, regardless of site type. The longest lived sites on the Pajarito Plateau often had nearby sources that were less vulnerable to droughts than others, and it cannot be ruled out that these water sources may have contributed to their longevity.

Trends in water acquisition times between the regions generally follow the same pattern: similarly low costs to perennial and nearest vulnerable water sources, but during droughts communities closest to vulnerable water sources incurred significantly higher costs in travel time to alternative perennial sources. Communities close to perennial water sources were less vulnerable to increased water costs than more distant communities. The same is true for the few big sites with reservoir features. This suggests that Ancestral Pueblo people in both regions were potentially vulnerable to increased water acquisition costs due to droughts. The distributions of water costs as reflected in box plots show there was a far greater range in water acquisition costs during droughts than during wet and normal times, meaning unequal cost increases across the region. Such unequal intra-regional distributions of resources could compound social tensions within and between communities. This phenomenon is observed in archaeological data integrated with resource availability models in the Northern San Juan basin (Glowacki 2015; Schwindt et al. 2016). Their findings of intra-regional variability in resource vulnerabilities to drought, and in 
alternative cultural responses, are particularly relevant to this context because some of the Ancestral Pueblo people of the Northern San Juan basin were likely immigrants to the Jemez Mountains (Ortman 2012).

The results (Table 8.1) show that for big sites there is no statistical difference between Jemez and Pajarito travel times to closest water sources. This suggests that between regions Ancestral Pueblo people took similar approaches to coalesce into communities near water. This served communities well in normal and wet climatic periods, but during hydrological droughts it did not. The dramatic increase in travel times for Pajarito communities during times of drought as compared to Jemez communities is statistically significant, and reflects the inherent vulnerability of the Pajarito landscape to droughts and the limited options for Pajarito mesa-top communities to relocate to perennial water in order to buffer against the risks of drought induced water insecurity.

In every case, there was no statistical similarity in travel times for small sites between the Jemez and Pajarito Plateaus (Table 8.1). This suggests there were fundament differences between these regions in the spatial relationships between fieldhouses and water sources. Whether or not these differences were a function of underlying hydrological differences or the ways in which dual residence patterns operated between these regions will be discussed in relationship to other factors in the next chapter.

\subsection{Summary}

The results of the LCA study address the third research question in my dissertation by providing a quantifiable way to model water acquisition costs and to identify how droughts may 
have impacted Ancestral Pueblo communities in the Jemez Mountains. It is clear that droughts increased water acquisition costs. These results reveal whether or not collective action decisions for water management introduced vulnerabilities into communities that would impact community sustainability. Feedbacks between collective action decisions regarding site settlement systems and using reservoirs in relationship to droughts impacted these regions in different ways. The dual residence pattern would continue to be an effective drought mitigation strategy for households on the Jemez Plateau because a sizable percentage of fieldhouses were near perennial water sources and the hydrological system did not undergo significant changes in ways that would introduce new resource arrangement to the Ancestral Jemez.

The same cannot be said for the Pajarito Plateau, as the region-wide reduction in water availability, likely beginning in the late 1200s due to channel downcutting, meant that seasonal occupation of fieldhouses dispersed across the landscape would no longer confer lower water acquisition costs. Aggregated sites close to water sources, and those with reservoirs further from perennial water, would be less vulnerable to increased water acquisition costs. However, because of differences in infrastructure and climate the reservoirs on the Pajarito Plateau were only a robust collective action strategy during wet or normal climate periods. This would introduce intra-annual fragilities in Pajarito communities with reservoir features because these features would be relied upon during seasons of the year when they were less likely to hold water, as well as inter-annual fragilities with little to no water storage in dry years, when the features would be needed most. This was not the case on the Jemez Plateau. The implications of these findings to the long-term sustainability of communities across both regions are addressed in the next chapter in period-by-period socio-hydrological models. 
One of the key findings of this analysis is that while droughts can increase acquisition costs substantially across both regions, the increased costs would never exceed ethnographic examples of the distances Pueblo people would travel for water (Kolm and Smith 2012). Therefore, an important distinction must be made: while water was never scarce for Ancestral Pueblo people, energetically cheap water could be scarce. Communities would likely never truly run out of water. This is an important finding, because it supports moving from ecologically driven models about the relationships between socio-ecological systems and decision making related to scarcity, to focusing more on the nested socio-economic contexts for risk-anticipating decision making. These results show that droughts could create a significant differential in water costs, whereby a previously “inexpensive” resource incurs a far greater cost than it had before. Droughts would put greater time demands on a community, as well as taking time away from other necessary economic or social pursuits, and potentially straining existing institutions for resource management. I consider the implications of these cost increases in relationship to the lost opportunity costs for broader economic developments in the Northern Rio Grande (e.g., Kohler et al. 2004b) in the final chapter.

From a methodological standpoint, this analysis presents a new approach for approximating resource costs in archaeological landscape studies. The ability to conduct large numbers of analyses allowed me to investigate entire culture areas in a relatively reasonable length of time using personal computers. It could also be used to conduct exploratory analyses involving multiple runs to better approximate resource costs and travel routes. For example, my analysis did not include any accommodation for how the weight of water would impact travel times, or the social context for water acquisition. A maximum load of $10 \mathrm{~L}$ of water (weighing $22 \mathrm{lbs}$ ) seems possible using a combination of technologies documented in archaeological and 
ethnographic records, which would mean that each individual would need to make one trip to water per day. However, between water and vessel weight, these trips would be slowed.

Otherwise, multiple, daily trips would be required, which during droughts could lead to rationing and increasingly greater portions of a day spent in water acquisition. Alternative factors reflecting travel times burdened by water, or routes that incorporate archaeological trails or either include (or exclude) certain landscape features or archaeological sites could be incorporated to better approximate costs, which could potentially lead to even higher water costs than those modeled in this study. 


\section{CHAPTER 9. SYNTHESES AND CONCLUSIONS}

In this final chapter I synthesize the results of my interdisciplinary analyses within a comparative socio-ecological systems (SES) framework. This framework allows me to address the fourth research question in my dissertation, in which I ask whether or not collective action strategies undertaken to manage water resources through droughts impacted the long-term sustainability of mesa-top communities. I use the SES framework to identify feedback mechanisms operating between interrelated components of climate, hydrology, built infrastructure, and the socio-economic context of Ancestral Pueblo communities. I then identify how the sustainability of these communities was affected by examining the feedbacks generated by tradeoffs between differences in collective action approaches to water management, which while seemingly robust in some contexts, generated fragilities in others. I conclude by considering the broader impacts of this study for conceptualizing the impacts of resource management and climate change on the long-term sustainability of socio-ecological systems.

\subsection{Diachronic Socio-hydrological Systems Models}

I synthesized socio-hydrological models (Figure 1.3) for five archaeological time periods across both regions using the data I compiled and generated in the preceding six chapters. These models summarize the results of my study while also identifying the key ways Ancestral Pueblo communities managed water in relationship to climate driven variability in hydrology. 


\section{San Ysidro Phase/Late Developmental Period (AD 1100-1200)}

During the Late Developmental Period on the Pajarito Plateau, and in limited evidence from the San Ysidro Phase of the Jemez Plateau, we see the first archaeological evidence for Ancestral Pueblo sedentary agriculturalists living on mesa-tops. I hypothesized that dryland farmers drawn to the “maize agricultural niche” and living atop mesas (Bocinsky and Kohler 2014), would experience water insecurities because of the paucity of mesa-top water sources. The degree to which collective action was employed to manage water during these initial occupations appears to have set up different cultural trajectories between the Jemez and Pajarito Plateaus, well before the coalescence of aggregated communities.

Archaeologists have identified little evidence for mesa-top occupation during the San Ysidro Phase on the Jemez Plateau, yet my geoarchaeological investigations show it is likely that during this time some water storage features were constructed (Figure 9.1). Reservoirs at Kwastiyukwa, Tovakwa, and possibly Boletsakwa were constructed. Construction dates for the Jemez reservoirs are asynchronous and significantly, do not appear to correlate to the AD 1131-1158 drought. Before and after this dry interval there were wet periods (AD 1110-1119, AD 11831202), during a century with more wet than dry years. Kwastiyukwa may have been constructed before the AD 1131-1158 drought, while the other features were constructed as early as the latter half of the $12^{\text {th }}$ century.

This suggests a greater Ancestral Pueblo presence on mesa-tops during the San Ysidro Phase than previously realized, and that during this period communities of the Jemez Plateau were already engaged in collective action strategies for water management. The lack of well dated archaeological sites from this period makes estimating population size of the resource users 


\section{Jemez Plateau}

San Ysidro Phase (AD 1100-1200)

Resource Users

Small dispersed households

of farmers and foragers

\section{Domestic water}

open access natural sources, also possible access to a few family controlled reservoirs
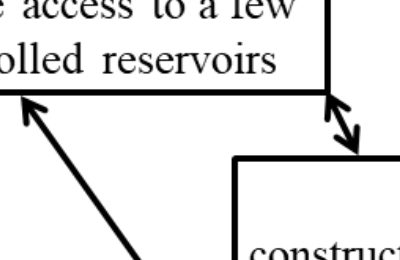

construc

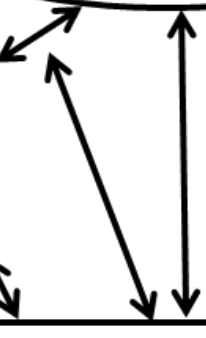

Reservoirs

Infrastructure Providers

Household level coordination

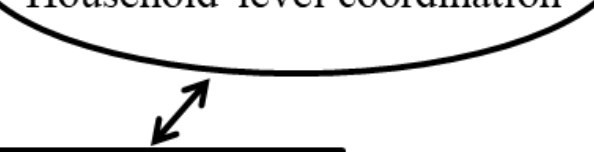
household-level agriculturalists to mesa-tops
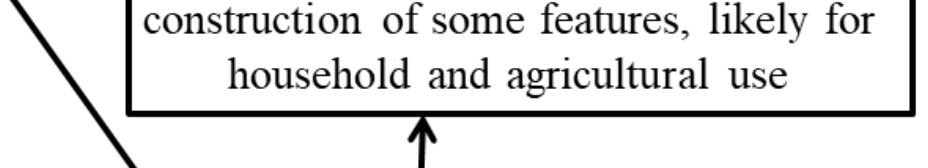

\section{Hydrological Systems}

Discharges at or above modern conditions

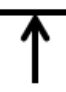

More wet than dry precipitation intervals (one drought AD 1131-1158)

Figure 9.1. The socio-hydrological system model of the Jemez Plateau during the San Ysidro Phase (AD 1100-1200).

problematic. Nonetheless, I suspect the construction of these features was undertaken by small populations, demanding costly labor on a per person basis, unless multiple households from across the region came together to build these features. Small populations can build substantial water management infrastructures, as is seen in large infrastructures in Central Mexico (Aiuvalasit et al. 2010; Neely et al. 2015). On a per person basis for these small populations, it 
can be presumed that these features were costly to build, though costs were ultimately outweighed by this robust solution to meet seasonal water needs. These features were all constructed at locations where the closest water sources were ones vulnerable to reduced discharges during droughts. Therefore, these artificial features could provide mesa-top water sources at places Ancestral Pueblo people were drawn to during the San Ysidro Phase, presumably for agricultural purposes.

The likely success of these features for storing water, especially having been constructed during a predominantly wet period, suggests they served as a strong positive feedback for emerging social institutions for collective action. Postulating the dynamics of resource providers is problematic due to limitations of the archaeological data, but it can be presumed that coordination to build these features was undertaken at the household level by emerging communities. It also cannot be ruled out that the coordination for the construction and management of these features was a locus for resource providers coming from households and extended families to emerge into leadership roles in communities (Kohler et al. 2012). These early features potentially reflect how decision-making surrounding water management using water storage features could be a catalyst for community aggregation in locations that otherwise were less amenable to settlement. The seasonal availability of water from these features could reflect a strategy to ensure water availability during collective agricultural events, such as planting crops in the late spring and harvesting crops in the late fall. These activities could take place even if permanent settlement had yet to occur on the mesa-tops of the Jemez Plateau. If so, these features may have facilitated the continued pattern of seasonal rounds inferred by Ford (2013) from archaeological deposits in Jemez Cave. Ford (2013) sees evidence for the endurance of Developmental Period patterns, with settled communities in valley bottoms, which then 
seasonally exploited upland resources. This hypothesized scenario could help explain the limited archaeological evidence for mesa-top occupations during this time period, as exploitation transitioned from primarily non-domesticated sources to agriculture.

Although there was a larger population on the Pajarito Plateau, including increasingly aggregated communities of hamlets and small villages, none of the reservoir features on the Pajarito Plateau dated to the Late Developmental Period (Figure 9.2). This is surprising, because momentary mean populations estimates for the 12 villages average 33 persons, with a maximum village estimate of 160 persons at Caja del Rio North (LA174) (Ortman 2016). These increasingly aggregated, albeit small, hamlets and villages would have demanded the emergence of inter-family coordination and cooperation. Yet, there may have been little incentive to commit to collective water resource management. Based on the alluvial records from the Pajarito Plateau, I hypothesize that many of the intermittent streams now vulnerable to droughts were perennial water sources during this early time period. Only three of the 12 villages occupied during this period were closest to what are now perennial water sources. If the closest water sources for the other nine sites were available at this time, then the average one-way distance from water for all of the sites would have been only 0.22 hours. This is below the modeled average travel time to closest water sources for both regions (see Chapter 8). Therefore, the socio-environmental conditions for driving collective action approaches to water management may not have been necessary on the Pajarito Plateau during the Late Developmental Period. Interestingly, of the 12 hamlet to village sized sites occupied at this time, 10 were abandoned by AD 1400, the time in the paleohydrological model when intermittent water sources may have started becoming vulnerable to droughts on the Pajarito Plateau. Only the site of Otowi (LA169), which has a 
reported but untested reservoir feature, has occupations extending into the historic period (AD 1600).

Pajarito Plateau Late Dev. (AD 11001200)
Resource Users

Widely dispersed households of farmers and foragers in hamlets and

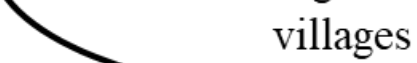
intensity mesa-top settlements, initial coalescence across region

$\pi$

mestic water

Open access natural water

\section{Hydrological Systems}

Discharges at or above modern conditions

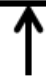

More wet than dry precipitation intervals (one drought AD 1131-1158)

Figure 9.2. The socio-hydrological system model of the Pajarito Plateau during the Late Developmental Period (AD 1100-1200). 


\section{Vallecitos Phase/Coalition Period (AD 1200-1350)}

For the majority of the Vallecitos Phase on the Jemez Plateau most of the sites continue to be found in riverine settings (Elliott 1998); however by the end of the phase we see the initial archaeological evidence for aggregated communities on mesa-tops (Elliott 1982; Kulisheck 2005) (Figure 9.3). Little confidence can be given to developing momentary mean population estimates through this period, but the increase in the number and size of sites indicates growing populations (Kulisheck 2005; Liebmann et al. 2016). Amoxiumqua and Tovakwa developed during this time period, and reservoir features were in operation at both sites before archaeological evidence for occupations. Dates of sedimentation sequences reflect the continued infilling of these features through this time period, including the cessation of sedimentation at the feature near Tovakwa (LA61641). While field house chronologies are poor (Kulisheck 2005), the distribution of both field houses and aggregated sites suggest that the dual residence pattern of mesa-top occupations began during the Vallecitos Phase. This likely allowed households the flexibility to mitigate drought-induced resource scarcity by continuing a pattern of being less reliant on collective action strategies for water acquisition. This strategy reduced the likelihood communities would need to rely on reservoirs for year-round water. They could spread the risk at the household-level for at least part of the year (e.g., spring and early summer), which correlates to the times when household members needed to be at their fields for planting and crop management.

The drought between AD 1240-1270 would have increased water acquisition costs across the Jemez Plateau, but given the distribution of perennial water sources and archaeological sites during this Phase, this period of drought evidently had less of an impact here than for peoples of the Pajarito Plateau. Nevertheless, because of the poor chronological control it is hard to evaluate 
Jemez Plateau

Vallecitos Phase

(AD 1200-1350)

Resource Users

Dual residence farmers-

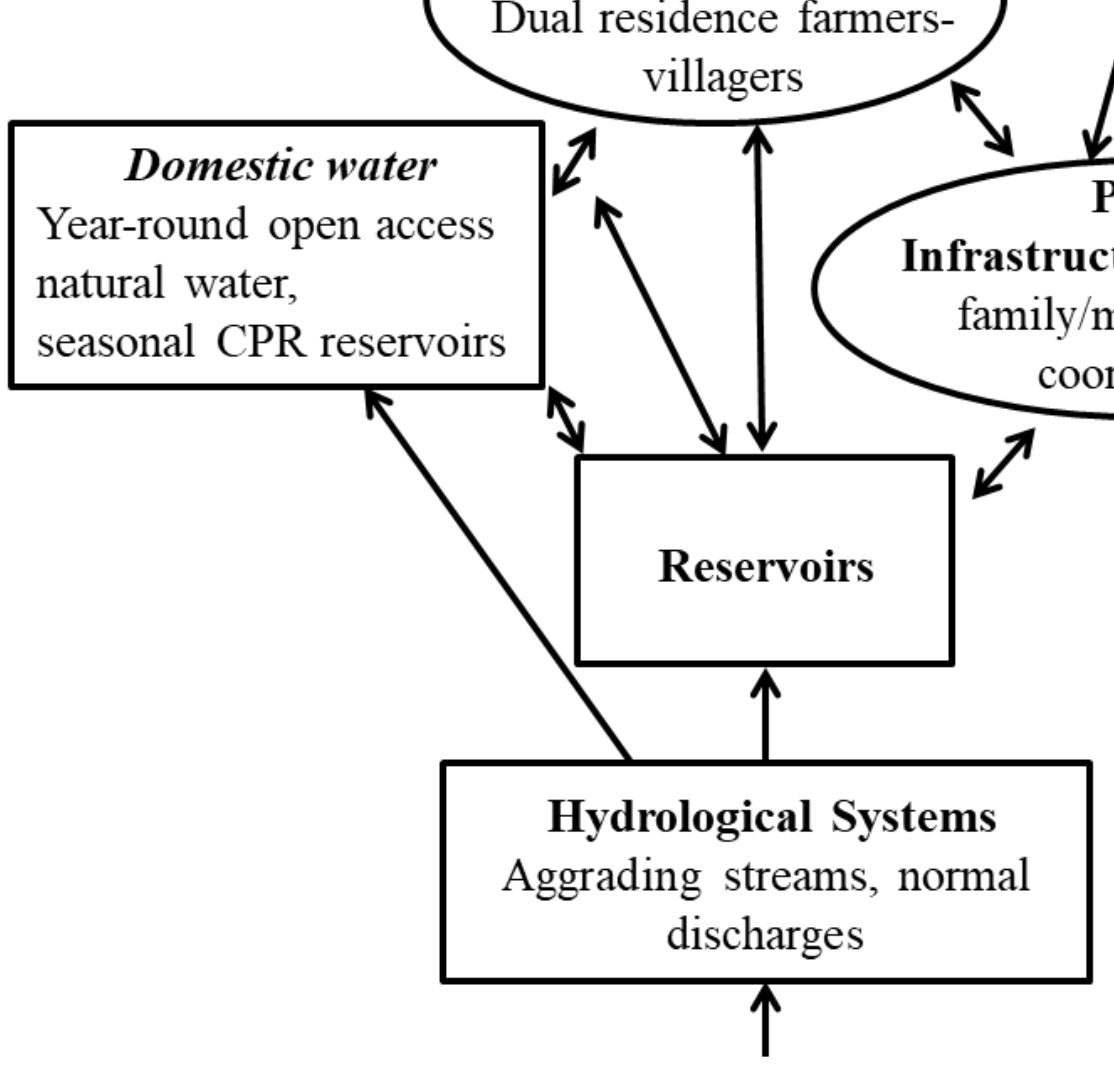

Long period of normal to wet times, one dry interval (AD 1240-1270)

Figure 9.3. The socio-hydrological system model of the Jemez Plateau during the Vallecitos Phase (AD 1200-1350).

whether this drought was a catalyst for the emergence of aggregation as a settlement strategy. It is also hard to assess the timing and magnitude of movement into the region, and whether or not 
immigrants drove aggregation on mesa-tops during this time, as it seems to have on the Pajarito Plateau.

That this existing water management infrastructure continued to be used through the Vallecitos Phase, even during a major drought, reflects the success of collective action for water management. The transformation of these strategies by new immigrants and coalescing communities cannot be ruled out, but certainly the endurance of these features signals positive feedbacks towards water management. If new forms of social organization were developing in these communities, such as sodalities, then the success of existing infrastructure to buffer increases in water acquisition costs during the AD 1240-1270 droughts would reinforc the societal roles, practices, and institutions for water management. Costs for feature maintenance would have been minimal, and there is no geoarchaeological evidence for basin clean-out during this time period. The exception is LA61641 near Tovakwa. Sediment aggradation in the basin ceased during this time period, but pedogenic evidence for standing water in basin sediments suggests it continued to periodically hold water. There are closer water sources to Tovakwa than LA61641, so perhaps the growing community forming a half kilometer south of this feature did not see the necessity of continued maintenance, or maybe it was constructed under a different water management regime.

The socio-hydrological system of the Coalition Period on the Pajarito Plateau contrasts in many ways to the Vallecitos Phase on the Jemez Plateau. The modeled Ancestral Pueblo population of the Pajarito Plateau peaks by the end of this time period (Figures 9.4 and 9.5). This is coincident with the construction of water reservoir features at villages far from water sources across the region. The rapid population rise is attributed to the immigrants of Pueblo peoples from the Northern San Juan region (Ortman 2012). Settlement patterns during the middle 
Coalition (AD 1280-1315) consisted of small hamlets and villages (Gabler 2009), presumably driven by both immigrants and local settlements drawn to agricultural surfaces on mesa-tops (Gabler 2009; Kohler 2004; Ortman 2012). The type of settlements suggests that the main push of immigrants from the early to middle Coalition consisted of households and related families, rather than entire communities, which aligns with observations of abandonment and sociopolitical context in the Northern San Juan region (Glowacki 2015). If so, then the settlement pattern during this period suggests that the resource management decisions of these initial settlers were likely coordinated at the household to family level, as new communities "filled in" exploitable agricultural niches across the landscape (Gabler 2009). Under these circumstances, field houses would serve as effective markers of household level property ownership and access, a strategy with clear antecedents in the Northern San Juan region (Kohler 1992). Aggregation doesn't become the dominant form of settlement until the Late Coalition (AD 1315-1350). That this occurred in the decades after the peak of emigration, suggests that a dynamic period of endogenous social re-organization and coalescence on the Pajarito drove the emergence of new strategies for collective action, property relations, and social organization.

The Late Coalition sees the transition from a settlement pattern with the majority of the population living in small hamlets and only $40 \%$ of people living in villages or towns, to the emergence of the Classic Period settlement model where upwards of $80 \%$ of people live in villages or towns (Figure 9.4). This may have set up the conditions for a rigidity trap (e.g., Hegmon et al. 2008), whereby strong feedbacks for collective action strategies of resource management and related social institutions inhibited the resilience of communities to low frequency, high magnitude disturbances, such as hydrological droughts. 


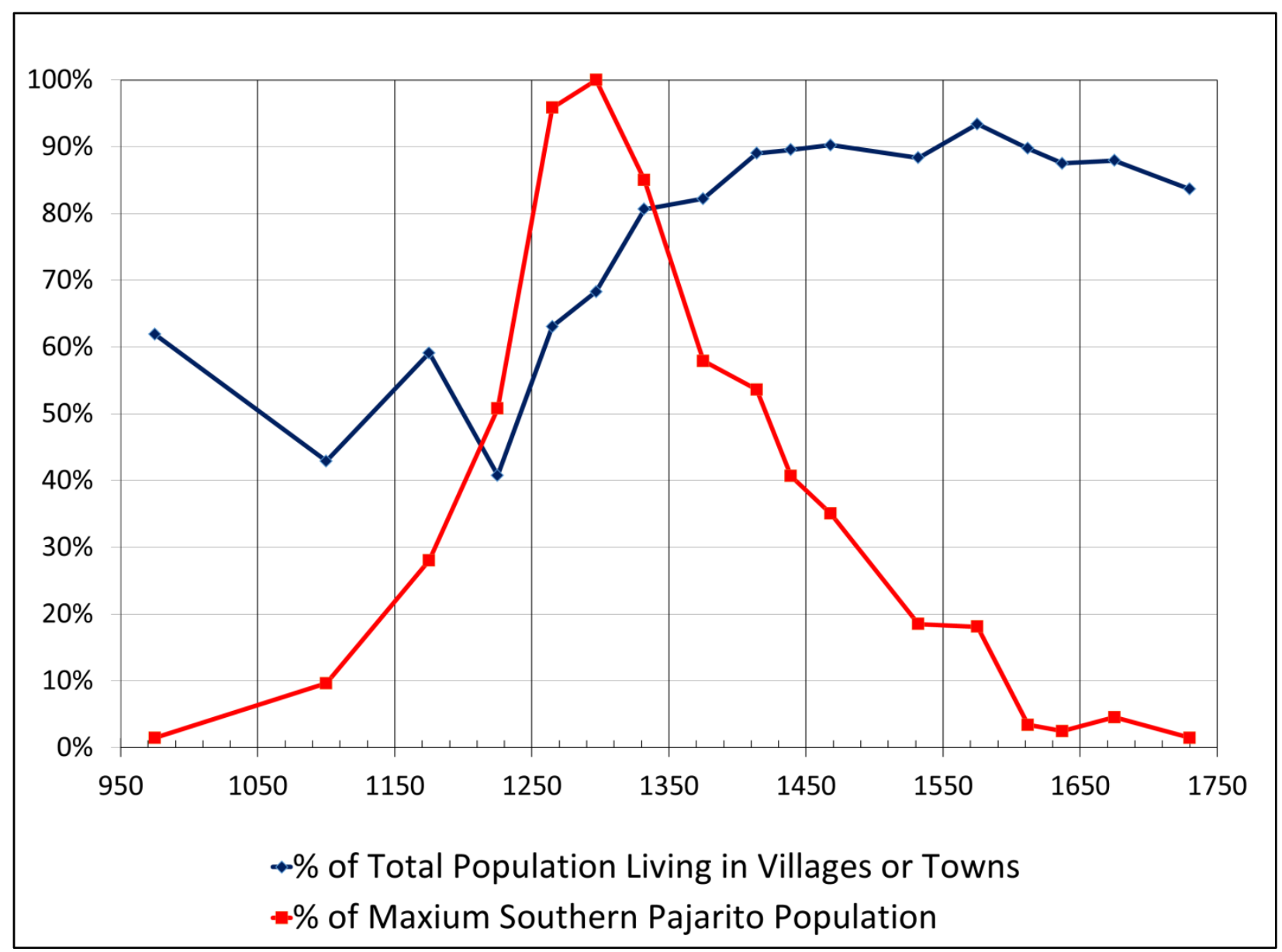

Figure 9.4. Momentary mean population estimates of the Pajarito Plateau as a percentage of maximum population with the percentage of population living in aggregated communities.

Reservoir features began to be used across the Pajarito Plateau at approximately AD 1300. Except for San Miguel, these features were constructed after the initial settlement of the villages, when they have at least 100 modeled inhabitants (Figure 7.23). San Miguel was likely founded around $\mathrm{AD}$ 1300, coincident with the construction of its reservoir features. The timing of construction in relationship to population, climate, and settlement reorganization suggests significantly different resource arrangements for collective action spurred the construction of reservoirs on the Pajarito Plateau than what was acting on the Jemez Plateau. Construction on the Pajarito occurred when populations were highest, during a wet period, and at the inflection point 
in the reorganization of settlement patterns from dispersed dual residences to aggregated communities.

\section{Pajarito Plateau Coalition Phase (AD 1200-1350)}

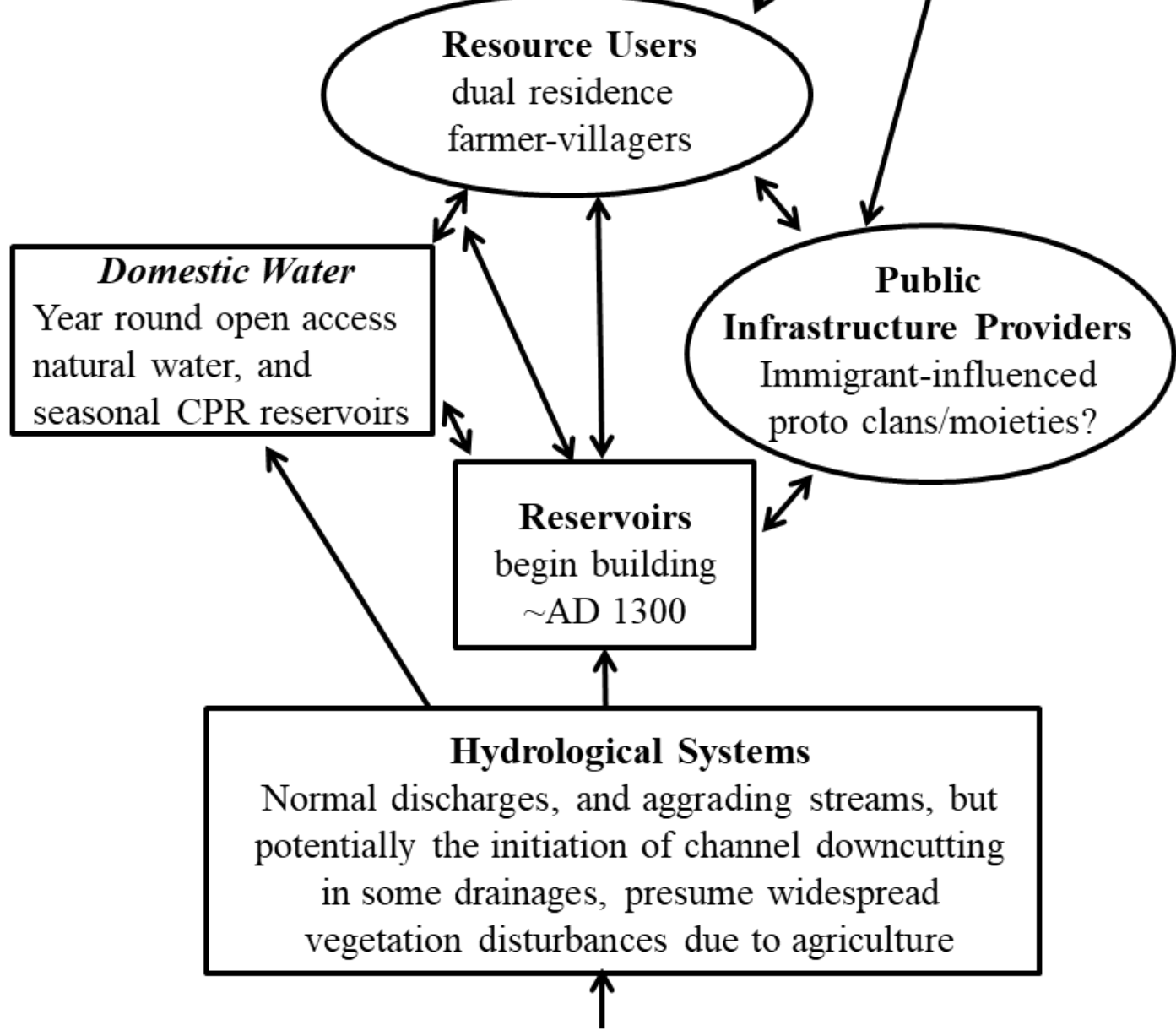

Long period of normal to wet times, one dry interval (AD 1240-1270)

Figure 9.5. The socio-hydrological system model of the Pajarito Plateau during the Coalition Period (AD 1200-1350). 
I should note that there was a tradition of collective water resource management in the Northern San Juan, the likely point of origin for Ancestral Pueblo people who led to the population spike in the Northern Rio Grande and Jemez Mountains during this period. In the Northern San Juan water storage features are typically not found in direct association with villages, but instead in hydrologically efficient locations across the landscape (Wilshusen et al. 1997; Wright 2006). However, many of the late period villages during the $13^{\text {th }}$ century in the Mesa Verde region are located in direct association with natural springs or seeps on mesa and canyon edges (Kolm and Smith 2012). Directly transferring these water management strategies from the Northern San Juan to the Jemez Mountains would be problematic for two reasons. First, the permeable tuffs of mesa-tops have very few water sources, which preclude founding a village directly atop a perennially discharging spring. Second, as the Pajarito landscape was already settled in the Coalition, the opportunities to make carte blanche decisions over where to place reservoirs or villages would be limited.

Therefore, the establishment of common pool resources for water storage occurred among communities with a tradition of collective resource management, but one potentially transplanted from another region and adapted to the cultural and hydrological landscapes of the Pajarito Plateau. Instead of building features in hydrologically efficient locations relatively independent of village locations, these features were constructed close to existing villages, approximating the relationships between springs and villages of late $13^{\text {th }}$ century sites in the Northern San Juan. The decline of the dual residence system at the end of the Late Coalition meant that decision-making regarding water management shifted from the household-level decision to the community-level. It is interesting that multiple features were constructed at most of these sites. This opens the possibility that each feature represents the coordinated action of a particular social unit, as 
Beaglehole describes for Hopi (1937), rather than the community-wide integrative water management strategy seen at sites with single water storage features on the Jemez Plateau. Considering how most of these smaller features are underfit for their catchment areas, they would likely require coordinated maintenance to repair damage to their berms from overtopping flooding events.

Unlike the low populations seen on the Jemez Plateau, the larger populations of the Pajarito Plateau meant that reservoirs had a low initial per person cost to construct on the Pajarito Plateau. Such arrangements for water management, coordinated by newly emerging relationships between resource providers and users focused on villages, were likely successful under wet conditions. Water was not the only resource with evidence for increased collective action through the Coalition Period. Ceramic analyses of large white ware bowls suggests that communal feasting began during this period (Curewitz 2008). In addition, the construction of plaza-centered villages (Van Zandt 2006) suggests the formation of collective space for food sharing and public gatherings. And, of course, the very act of emigration, all reflect positive feedbacks towards collective action solutions to resource management issues in these growing populations.

The initiation of aggregation, the highest regional populations, and the construction of reservoirs are all coincident with the longest wet period (AD 1270-1359) of Ancestral Pueblo occupation on mesa-tops. Under these wet conditions there would have been few instances when these features did not collect and store at least some water every year. This suggests that these features were built less out of concern for water scarcity, but instead to reduce acquisition costs. During the Late Coalition, constructing reservoirs would have served as a low-cost strategy in emerging aggregated communities where collective action was an effective approach to resource 
management. Water acquisition costs were already low, so such features likely served to further buffer against risk and potentially serve as signifiers for emerging institutions. Such feedbacks differed considerably in the Classic Period.

\section{Paliza Phase/Early Classic Period (AD 1350-1425)}

The Paliza Phase and Early Classic Period are the first archaeological periods when infrastructures and social institutions for water management, developed under different hydrological and social conditions, were faced with repeated hydrological droughts - in AD 1359-1369 and 1413-1424. On the Jemez Plateau, the Paliza Phase sees the continuation and expansion of the aggregation patterns that first developed at the end of the Vallecitos Phase. Reservoirs continued to be used (Figure 9.6). Large villages become ubiquitous across mesa-tops of both the eastern and western sides of San Diego canyon, and both the dual residence settlement pattern and the use of water storage features at large villages endure. Aggregated Jemez communities appear to be agglomerative, with multiple plazas and kivas instead of roomblocks built around large central plazas like what is seen on the Pajarito. The dual residence pattern continued, and Dolan et al. (2017) report that Jemez field houses are larger than those of the Pajarito, and contain more storage features. The continuation of this pattern of household to extended-family level strategies would buffer the risks of food insecurities and maintain property rights. It would also help reduce higher water acquisition costs during drought. Yet, the overall greater efficiency of the Jemez reservoir features, slightly higher rainfall amounts, and limited long-term impact of these droughts on hydrological system function, likely meant that infrastructure and institutions for water management were robust through this period of resource scarcity. 
Jemez Plateau Paliza Phase

\section{(AD 1350-1425)}

Aggregation into larger villages with multiple plazas, continued dual residence pattern, population expansion to western mesas, little trade

Resource Users

Dual residence farmer-

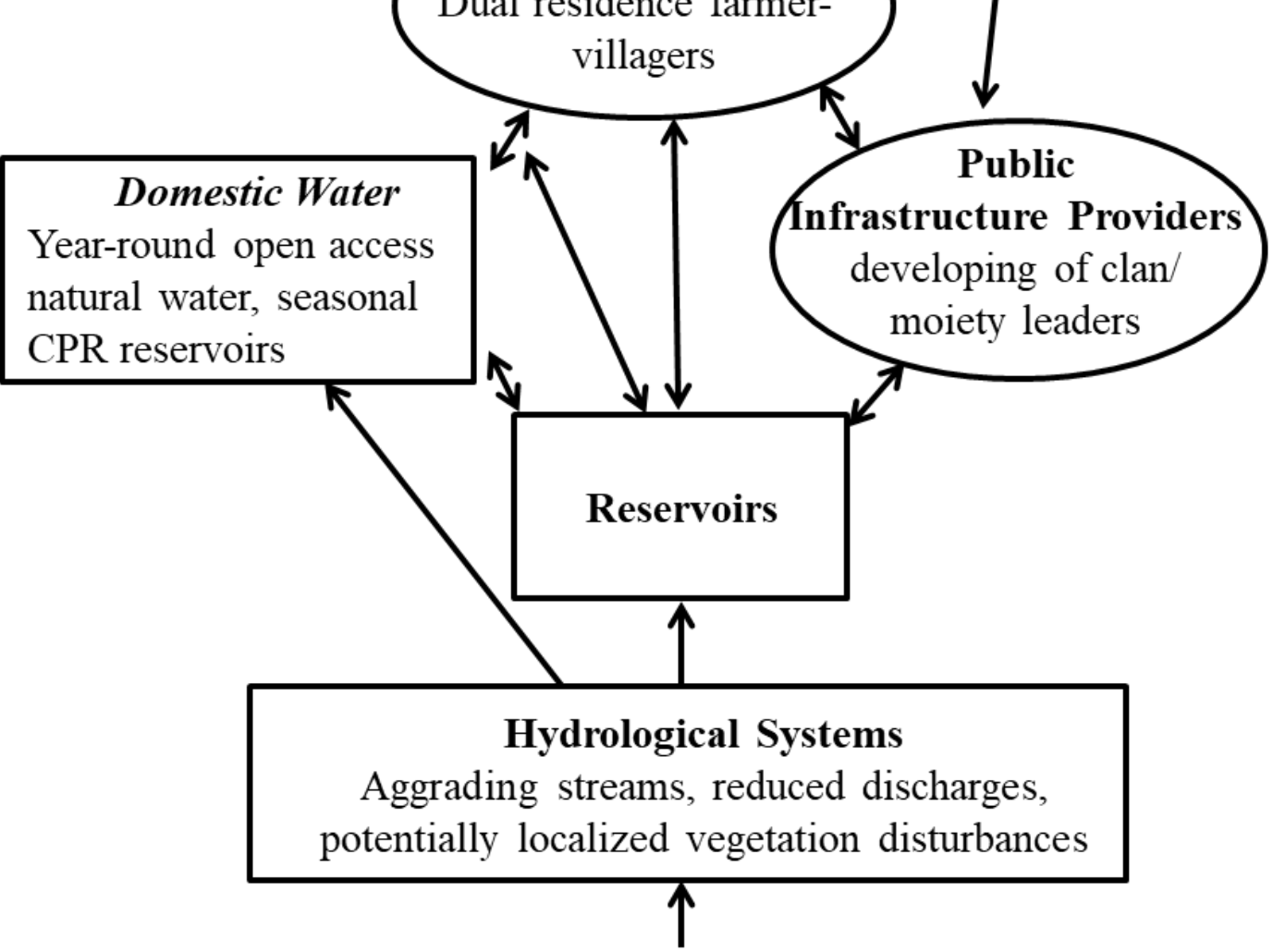

Beginning of higher precipitation variability, two droughts, no wet periods

Figure 9.6. The socio-hydrological system model of the Jemez Plateau during the Paliza Phase (AD 1350-1425).

By comparison, the Early Classic Period of the Pajarito Plateau saw significant changes which can be tied to the impacts of droughts, and the unintended consequences of previous resource management decisions. The initiation of a state-change in the hydrological system due to droughts likely had the biggest effect. My paleohydrological model suggests that these 
droughts, potentially coupled with increased erosion associated with mesa-top agricultural disturbances to soils (Kohler et al. 2004a), may have led to channel downcutting, causing the desiccation of floodplains and alluvial aquifers to lower. This could potentially have led to drainage-by-drainage transitions from perennial streams to fluvial systems sustaining only intermittent flows. The frequency and volumes of water stored in reservoir features would also be affected by droughts. Droughts would reduce the number of run-off generating rainfall events, while my geoarchaeological analysis indicates that Pajarito reservoirs did not hold water as efficiently or for as long as those of the Jemez Plateau. Therefore, these technologies in this context were less robust during droughts at a time when communities were becoming increasingly vulnerable to higher water acquisition costs due to lower stream discharges. This reconfiguration of resource distributions would increase water acquisition costs substantially for communities established under different resource arrangements on the Pajarito Plateau, which further enhanced the vulnerability of communities to periods of water scarcity.

At the same time, collective action responses to resource insecurity appear to become more entrenched in Pajarito communities, even though regional populations began to decline. The Early Classic Period sees the full transition away from dual residences to residence solely in aggregated communities. Such a transition, begun in the late $13^{\text {th }}$ century during a wet climate period, would have created vulnerabilities in water management strategies during the hydrological droughts of the Early Classic Period (Figure 9.7). As water sources became more vulnerable to droughts, the high percentage of fieldhouses closest to vulnerable sources meant that these sites would no longer confer any cost advantages for water acquisition. Yet, aggregation into villages and towns could lead to a contraction in the possible options for nearby water sources, which would further increase travel times to water. Reservoirs, which would only 
reliably hold water in the early spring and monsoon season, would be increasingly relied upon year-round. This would in turn have caused demands on feature use that would become increasingly out of phase with seasonal supplies.

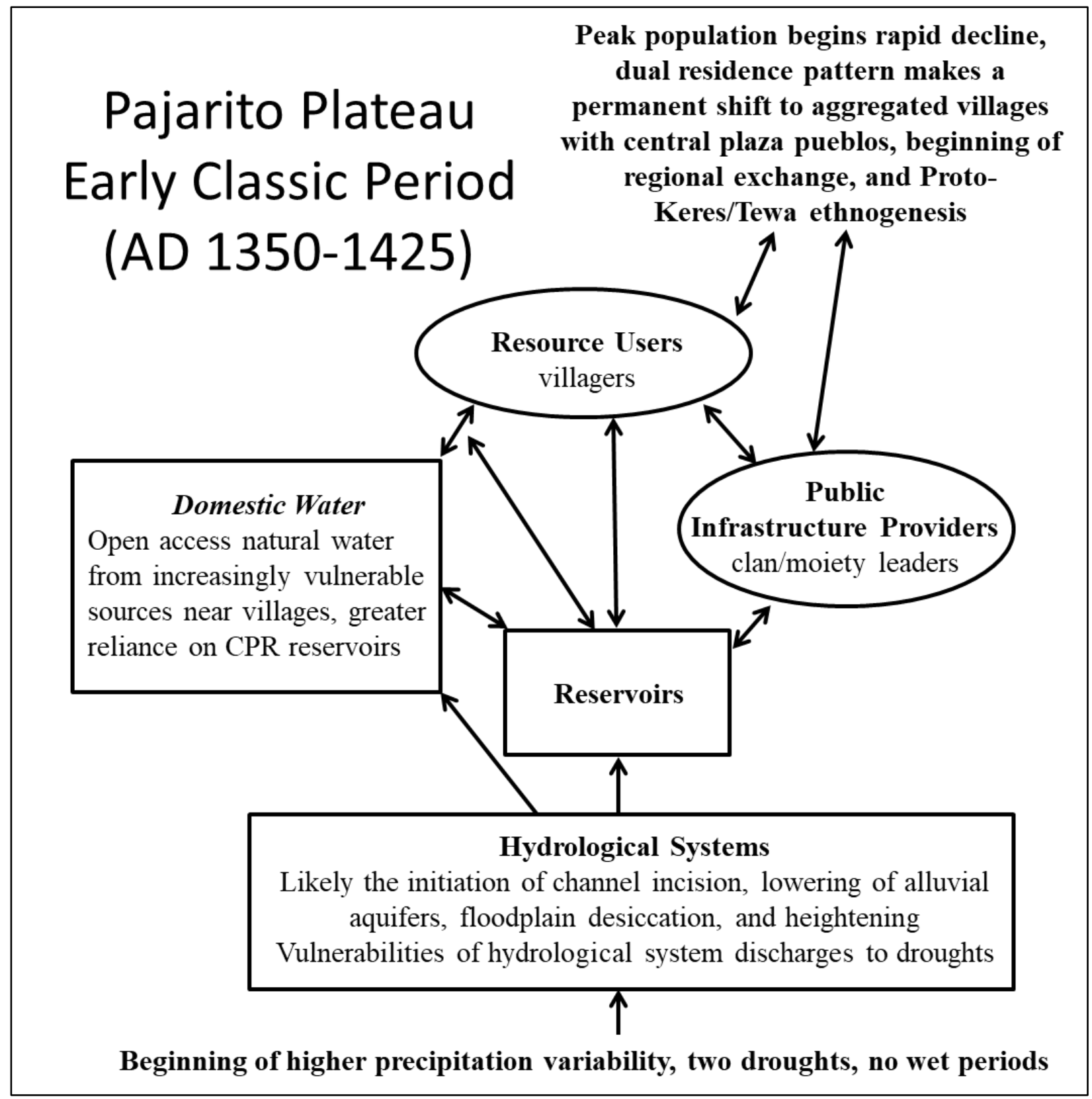

Figure 9.7. The socio-hydrological system model of the Pajarito Plateau during the Early Classic Period (AD 1350-1425). 
Decisions surrounding water management made in the Early Classic had long-lasting consequences for Ancestral Tewa and Keres communities. Populations became increasingly aggregated into a few communities, yet overall the regional populations fell. Kohler et al. (2004a, b) recognized that Classic Period settlement dynamics do not fit models of localized intensification, in which they predicted that settlements would disband into more dispersed settlement patterns when faced with resource stress. Instead aggregation continued at a few select communities. This suggests that some communities were successfully engaging in aggregation, yet individuals, households, and potentially larger social units were leaving the mesa-tops. Kohler et al. (2004b) argue that emerging regional market economies may have buffered the risks of resource insecurity for communities willing to engage in specialized economic production. Archaeological evidence for increases in turkey husbandry and hunted game (Kohler et al. 2004a), ceramic production (Curewitz 2008; Duwe 2011), and lithic manufacturing (Walsh 1998) are all seen as possible ways specialized production for market exchange may have intensified in the remaining communities of the Pajarito Plateau. Yet, the population declines show that not everyone adopted this strategy. In their study of Ancestral Tewa settlement patterns, Duwe and Anschuetz (2013) see movement as a fundamental Ancestral Tewa response to resource insecurity. Movement of Ancestral Pajaritans off the Plateau certainly occurred and likely contributed to population increases in other portions of the Northern Rio Grande (Figure 3.10). The feedbacks driving abandonment of the Pajarito Plateau became even more pressing during the Middle and Late Classic. 


\section{Jemez Phase/Middle-Late Classic Periods (AD 1425-1600)}

This period sees a highly variable climate record punctuated at the beginning and the end by hydrological droughts (Touchan et al. 2011), as well as the complete divergence of Ancestral Pueblo lifeways between these regions. On the one hand, there is the full expression of prehispanic Ancestral Pueblo culture across the Jemez Plateau (Figure 9.8). Large aggregated villages with populations estimated at two to three times the size of the largest mesa-top communities of the Pajarito Plateau fluoresced across the Jemez Plateau. Associated field houses continue to be found across the region. Communities continued to have multiple plazas, multiple kivas, but also larger "great kivas” at many of the largest villages. Water management practices, founded 500-600 years earlier with the initial mesa-top settlements, endured. Reservoir features at Amoxiumqua and Boletsakwa show evidence of maintenance during this period, and a second feature (LA25092) is constructed on Boletsakwa Mesa during this phase. Yet, the role of these features in these communities changed. Significant population increases meant that these features contributed smaller and smaller shares of the overall community water budgets. As such, communities would have had to rely less and less on the water stored in these features for domestic water. The reservoirs at Kwastiyukwa and the small feature close to Boletsakwa likely no longer served as effective water storage features due to their small sizes, limited catchment areas, and the reduced storage potential due to basin infilling. Instead, these features may have served other purposes. Pueblo ethnologies show that such features retain not just spiritual significance (e.g., Jeancon 1923), but can be signifiers of fecundity and good governance by resource providers (Paytiamo 1934). The coordination required for their management would likely have served as potent symbols for the enduring social relationships and emergent leadership within these communities (Kohler et al. 2012). 
Jemez Plateau Jemez Phase (AD 1425-1600)
Maximum village sizes with multiple plazas, dual residence pattern endures, limited evidence for inter-regional trade, beginning of Spanish interaction

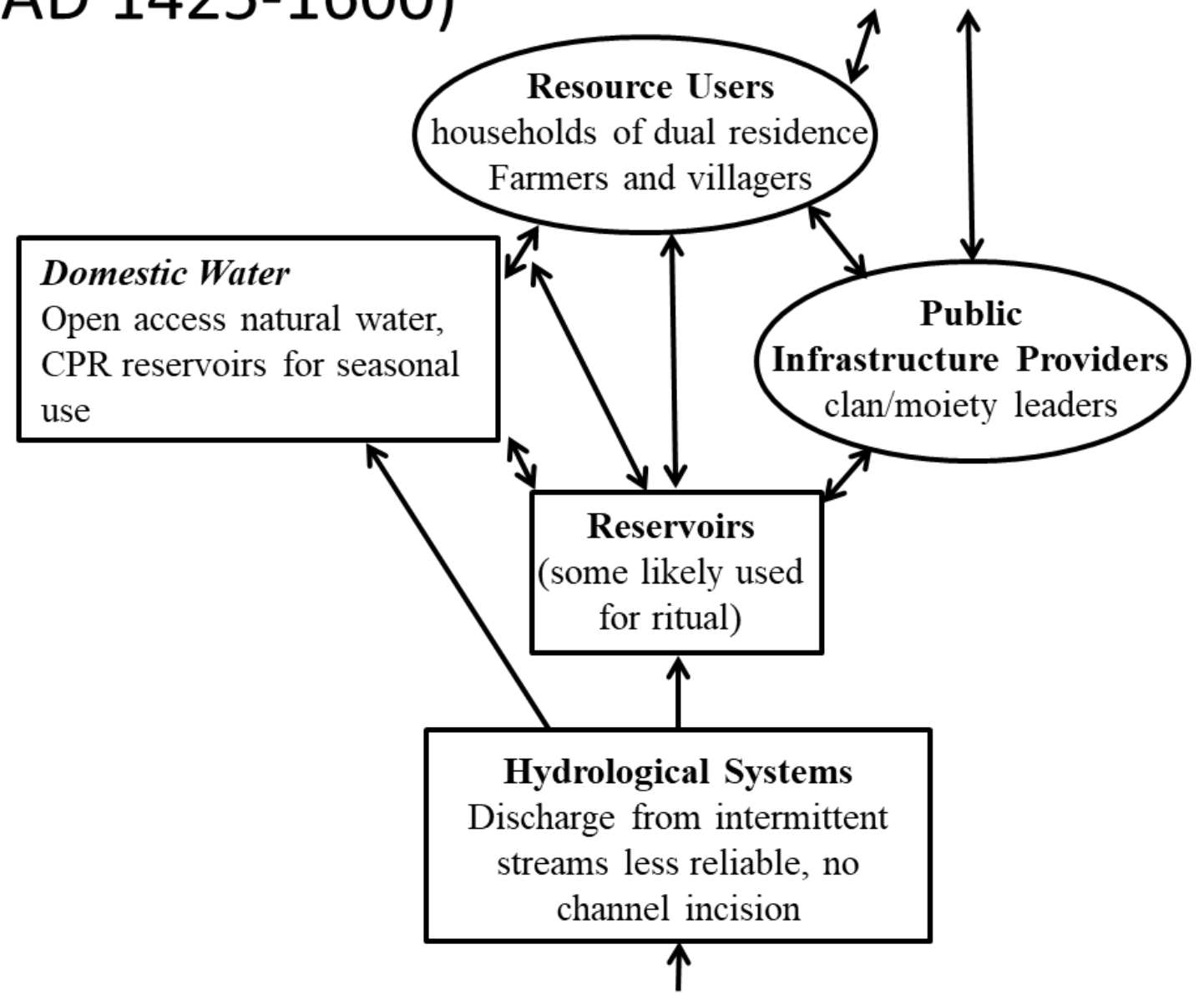

High variability, three dry intervals (AD 1473-1483, 1558-1568, 1573-1583), no wet periods

Figure 9.8. The socio-hydrological system model of the Jemez Plateau during the Jemez Phase (AD 1425-1600).

On the other hand, populations continued to decline across the Middle to Late Classic Periods on the Pajarito Plateau (Figure 9.4). Evidence for collective action strategies to buffer food scarcity in the form of communal feasting and standardization of ceramic styles (Curewitz 
2008), and increased reliance on domesticated foodstuffs (Kohler and Root 2004b), reflect a continued investment in collective action solutions to resource scarcity. It appears that on the Pajarito Plateau, once communities aggregated, households did not return to the dual residence pattern abandoned in the Late Coalition (Kohler et al. 2004a). Yet, for all the other evidence for collective action, analogous practices for water management were abandoned (Figure 9.9). Reservoirs show no signs of maintenance such as clean-out events, and most of the berms show evidence of breaching. Water reservoirs infilled with sediments and they all stopped being used at approximately AD 1450. This includes the features at Tsirege and Tsankawi, sites that continued to be occupied.

Instead, the few remaining villages that persist through this time period are all close to water. The physical settings of these villages can be considered refugia, locations which retained the ability to support isolated communities in otherwise inhospitable settings (Chester and Robson 2011). By the end of the Classic Period the Pajarito Plateau, a region that three hundred years prior was densely populated, the few aggregated communities left were all located near water sources less vulnerable to hydrological drought. These include Ancestral Keres sites in the upper reaches of Capulin Canyon and Frijoles Canyon to the south, and the Ancestral Tewa sites of Tsankawi, and Tsirege to the north. All of these sites are within the distances Ancestral Pueblo travel to water under ideal conditions, and none relied on reservoir infrastructures for domestic water. 


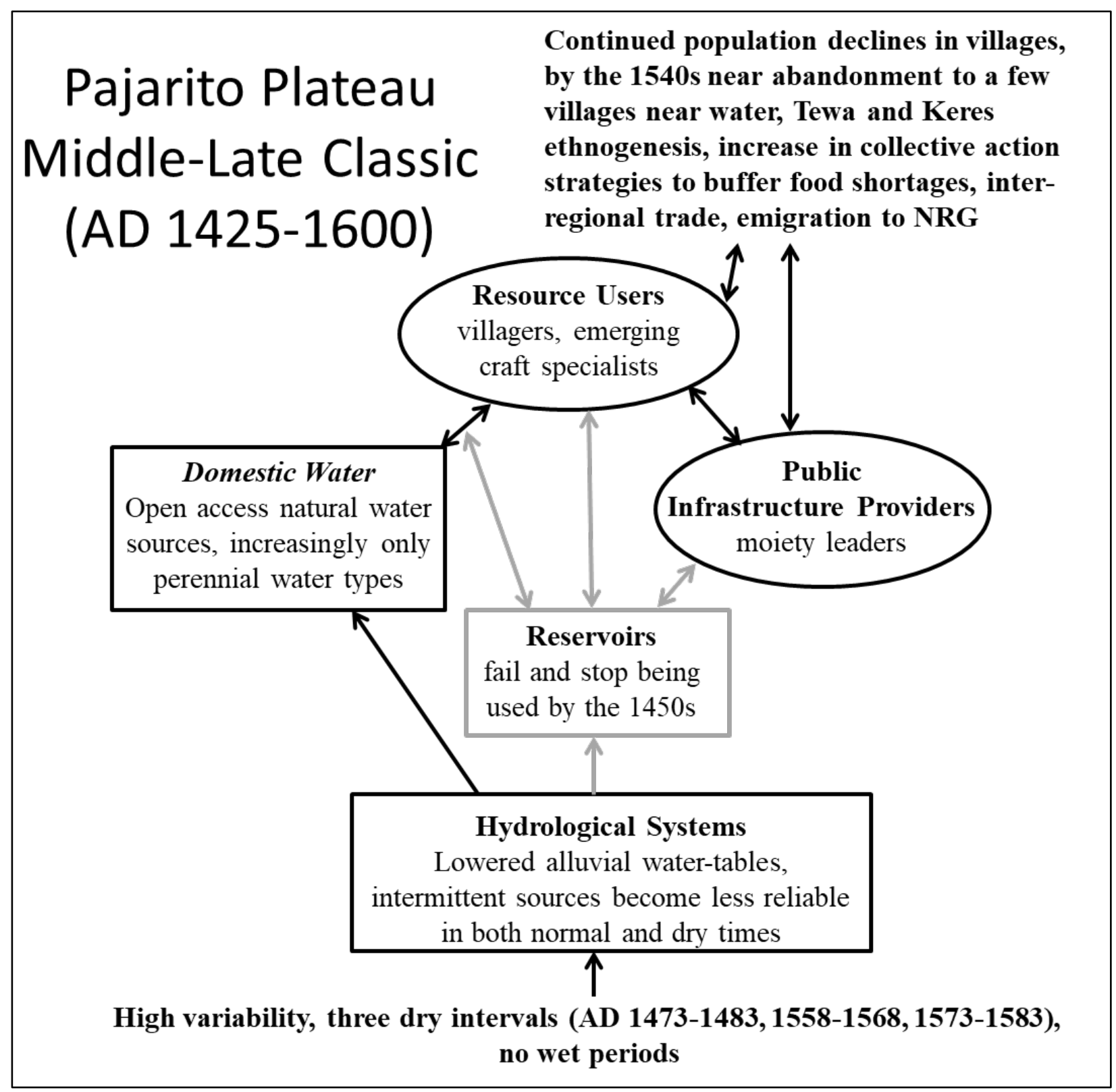

Figure 9.9. The socio-hydrological system model of the Pajarito Plateau during the MiddleLate Classic Period (AD 1425-1600).

The time spent acquiring ever costlier water for mesa-top communities during the Middle to Late Classic Period meant less time devoted to specialized economic pursuits. The likelihood for drought induced food scarcity during these time periods was probably high, yet collective action approaches like food sharing and intensification are evident (Kohler et al. 2004a). The failure of 
collective strategies to manage water on the mesa-tops would especially have impacted the sustainability of communities far from natural water. Communities situated near permanent water sources, like Tyounyi in Frijoles Canyon, which has architectural wood cutting dates extending into the 1500s (Kohler et al. 2004a), may not have experienced these pressures. However communities enduring in the Jemez Mountains would likely experience conflict over control of the remaining productive territory, and changing social networks associated with both market exchange and ethnogenesis of Tewa to the north and Keres to the south.

So where did the people of the Pajarito go, and why did institutions for water management seemingly fail when collective action associated with other resource arrangements appeared to continue? First, the lack of shared material culture (Liebmann 2012) and oral traditions (Levine and Merlan 1997) indicates that residents of the Pajarito did not move to the Jemez Plateau. Instead, oral traditions and material correlates indicate that Ancestral Tewa and Keres moved off of the mesa-tops and into aggregated pueblo communities along the Northern Rio Grande. Developing nodes of new economic networks in valley bottoms may have served as attractive "pulls" to pueblo communities of the Pajarito who were facing, at the very least, increased water acquisition costs. Regional population models show dramatic increases in the population of the Chama coincident with population declines on the Pajarito (Figure 3.10). The cost/benefit ratio of collective action for water management in the valley-bottom contexts of the Rio Grande were likely more favorable than on the mesa-tops. Water storage features are reported at some large aggregated sites in the Northern Rio Grande (Snead 2006), including a feature at Ohkay Owingeh, that tapped shallow alluvial aquifers, and continued to be used into the $20^{\text {th }}$ century (Ortiz 1969). The transfer of social institutions for water management from mesa-top contexts to valley-bottoms, potentially reoriented around irrigation (Dozier 1970:153) is a reasonable 
hypothesis worth exploring in future research. While the chronology, technology, and distribution of proto-historic irrigation is debated (e.g., Adler 2015), social institutions for coordinating water management were likely far more successful in the better watered contexts of the Rio Grande and its major tributaries than in mesa-top settings. Therefore, as gravity pulls water downhill, Ancestral Pueblo peoples may have been pulled into socio-ecological contexts where their efforts would be more likely to receive a return, and the institutions (and attendant power dynamics between resource providers and users) could propagate among increasingly aggregated communities in valley bottoms.

\section{Early Historic Period (AD 1600-1700)}

The upheaval wrought by Spanish colonialism had major impacts on the Jemez through this time period, yet based on oral histories and geoarchaeological evidence, Jemez people continued to use reservoirs into the historic period. The forced movement of the Jemez into valley bottom contexts, and their taking refuge in mesa-top villages, encouraged a revitalization of traditional practices, and fostered hybridization of cultural traditions and new forms of social organization (Liebmann 2012; Liebmann et al. 2017). Refuge sites, often situated in contexts where defense was a primary concern, required mesa-top water sources during sieges (Figure 9.10). Those sites, which include Boletsakwa and Astialakwa, have oral traditions of reservoir use, and my geoarchaeological cores at Boletsakwa suggest that its reservoirs could have held water during its refuge occupation. Archaeological evidence indicates that Amoxiumqua was also occupied during this period. An unconformity and subsequent infilling of sediments in the site's reservoir basin indicate that it was likely cleaned out sometime during this period. This is remarkable, because it speaks to the endurance of an Ancestral Pueblo water management tradition begun in 


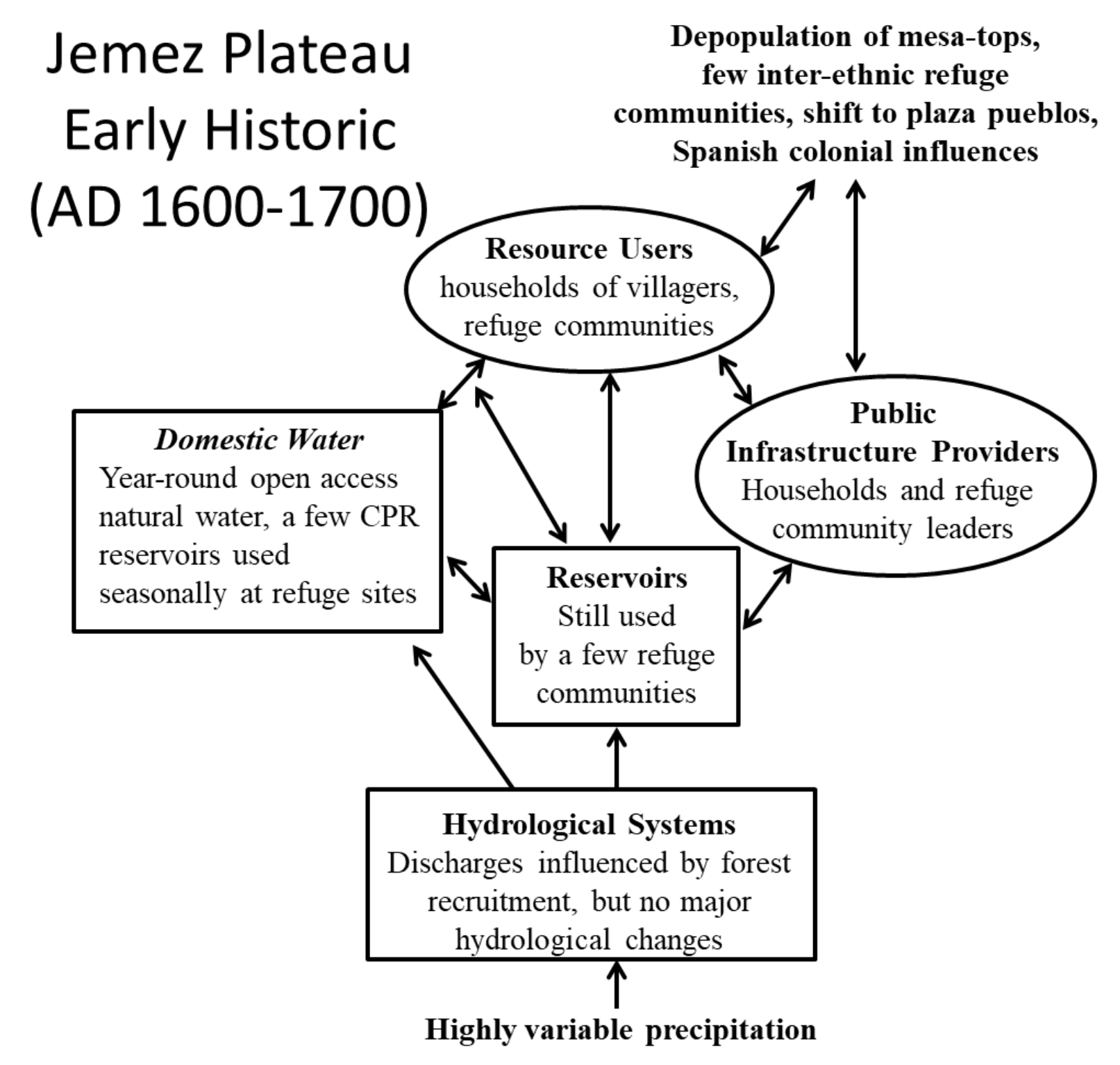

Figure 9.10. The socio-hydrological system model of the Jemez Plateau during the Early Historic Period (AD 1600-1700).

the region in the 1100s, and that developed under very different social and environmental conditions than what the Jemez peoples faced in the $16^{\text {th }}$ and $17^{\text {th }}$ centuries. By contrast, at this time the population of the Pajarito Plateau was very small (Figure 9.11). Multiple ethnic groups were utilizing upland resources, practicing animal husbandry, and permanent settlement was 
limited to a few agricultural sites (Smith 2005). There were refuge settlements along the northern and southern margins of the Pajarito Plateau (Liebmann et al. 2005), such as the important Ancestral Keres site of Hanat Kotyiti (Preucel 2000) to the south, but these sites do not have reported water storage features.

\section{Pajarito Plateau Early Historic (AD 1600-1700)}

Depopulation of mesa-tops, few refuge communities, Spanish colonial influences

Resource Users households of smallscale refuge communities

Domestic Water Open access closest natural water sources (year-round)

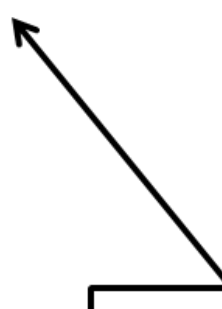

Hydrological Systems Discharges primarily from intermittent streams, incised channels likely begin to infill

Highly variable precipitation

Figure 9.11. The socio-hydrological system model of the Pajarito Plateau during the Early Historic Period (AD 1600-1700). 


\subsection{Recognizing Sustainability in the Archaeological Record}

Did collective action strategies for water resource management impact the long-term sustainability of mesa-top communities? I believe the answer is yes, but these strategies did so in decidedly different ways between regions. Residents of the Jemez Plateau developed enduring collective action water management strategies. These strategies enhanced the long-term sustainability of communities settled in locations that would otherwise incur high water acquisition costs. They did this by initiating water management as a form of collective action very early in their culture history to reduce water acquisition costs, well before large populations and widespread settlement. Construction was costly for these small populations during the San Ysidro Phase, but the payoffs of close, seasonally abundant water were high during times of low overall demands. Benefiting from slightly higher overall precipitation across the Jemez Plateau, these features likely stored some water during droughts, contributing at least in part to reducing water acquisition costs. This would signal the success of collective action in these villages, which may serve as a positive feedback for more collective action across other domains, and the formation of social institutions among growing populations. These features align with examples of robust drought mitigating strategies identified by hazards researchers (Wilhite and BuchananSmith 2005).

The residents of the Jemez Plateau also benefitted from living in a hydrological setting that did not experience any major state-changes through the time period of this study. This is critical for two reasons. First, traditional ecological knowledge developed around the relationships between climate and water management likely retained its value. As such, the range of the potential impacts of climate variation on hydrological systems was likely very similar in the 1100 s as it was in the 1600s. This may have allowed cultural changes that could readily 
compensate for rising populations, and for new social forms and institutions for resource management to emerge with a degree of certainty regarding water resource arrangements.

Cultural decisions surrounding water management did just as much to limit vulnerabilities to droughts as the stability of the hydrological system of the Jemez region. First, the chronologies of feature construction relative to population histories reflect community-specific decisions about water, rather than as a synchronous region-wide phenomenon. These community-based approaches to adaptively manage resources are seen as being particularly resilient to the impacts of climate change (Tompkins and Adger 2004). Second, Jemez water management practices were robust. The size of reservoirs and the endurance of the dual residence pattern buffered the risks associated with over-reliance on an infrastructure that works well to capture runoff from monsoons and spring runoff, but is vulnerable to periods of limited water collection during both seasonal dry periods and inter-annual droughts. The dual residence pattern allowed households to commit to a centralized place as communities emerged, but not absorb all of the risk associated with aggregated communities, like having water demands exceeding the holding capacity of the reservoir, especially during seasons when it likely did not hold water. As populations rose and the potential contributions of reservoirs to water budgets declined, households could still turn to sources at or near field houses during times of water scarcity. Movement, a concept central to understanding the adaptive capacity of prehispanic settlement systems (e.g., Duwe and Anschuetz 2013; Nelson et al. 2010; Preucel 2005; Snead 2008), was key to reducing risk, which for the Jemez appears to manifest as intra-regional movement linked to seasonally shifting risk between household and community.

Jemez water management practices likely contributed to the overall sustainability of communities because it minimized susceptibility to the risks of resource scarcity associated with 
aggregation. An axiom of sustainability is that "policies robust to uncertainty in one group of parameters are necessarily vulnerable to uncertainty in another group” (Anderies et al. 2007: 15194). Based on my findings, I hypothesize that the dual residence pattern, which likely functioned primarily as a robust household-level risk reduction strategy for agricultural production was also robust for water management. The endurance of the field house complexes, which are larger and have more storage features than those found in other regions of the Northern Rio Grande (Dolan et al. 2017) meant that households could retain greater control over their agricultural production (Kohler 1992), while buffering against the risks of water insecurity as well. Therefore, Ancestral Pueblo people of the Jemez may have developed a solution to avoid some of the vulnerabilities of resource scarcity associated with droughts: collective water management buffered some of the risk of resource scarcity associated with seasonal aggregation. Otherwise, there was the assumption of risk at the household level, which was a robust strategy to droughts in the hydrological context of the Jemez Plateau.

On the Pajarito Plateau, an over-reliance on collective action approaches to water management practices enhanced fragilities to water scarcity, and reduced the sustainability of mesa-top villages. The construction of reservoirs, not early on but often a generation or two later, during the rapid rise in populations, suggests that these features were constructed as a consequence of coalescence rather than as a way to facilitate aggregation. That multiple features were constructed at the same time at all of the largest mesa-top villages potentially reflects the regional adoption of a resource management strategy, potentially as part of a suite of sociopolitical strategies, rather than village-specific decision-making contingent upon local contexts. Constructing many small features meant increased costs for construction and maintenance, potentially signifying management divided among internal social groups, which also may have 
generated more complicated rules of use and coordination problems. These small features were less reliable at storing water, particularly during droughts, thereby limiting the potential effectiveness for these features to buffer the risks of water scarcity. This would be problematic as aggregating communities increasingly made year-round demands upon their infrastructure.

The fragilities of both the infrastructure and institutional arrangements for their management were exposed during droughts, but particularly so beginning in the late 1200s when channel downcutting made stream discharges more vulnerable to drought. Channel downcutting and the decline of alluvial aquifers would have significantly reconfigured the hydrological system, by making formerly perennial streams intermittent. This would make water acquisition costs much higher, and water sources that were close to communities at their founding were likely no longer reliable during dry periods. Village populations became increasingly aggregated during this time. Recent population reconstructions (Ortman 2016) and settlement studies (Gabler 2009) indicate that field house complexes did not endure into the Classic Period, as originally modeled by Preucel (1990). Instead, communities became increasingly aggregated, even as regional populations declined. Aggregation, potentially triggered by some combination of needs for mutual defense or specialization of economic production, unleashed a range of collective action strategies for resource management (Kohler 2004). These strategies were likely successful across other domains, but it appears they were not for water due to limitations of climate-induced hydrological changes, settlement systems, and infrastructure.

The high populations during the Late Coalition and Early Classic were ultimately unsustainable on the mesa-tops of the Pajarito Plateau. Only aggregated communities situated in a few locations with low water acquisition costs persisted. Yet, collective action approaches to resource management developed by Ancestral Pueblo communities were sustainable, just not on 
the Pajarito Plateau. Instead, collective action strategies appeared to be far more effective in meeting community needs in lowland tributaries and along the main-stem of the Northern Rio Grande, as evidenced by larger communities and higher overall populations (Figure 3.9). Movement facilitated the endurance of social institutions (e.g., Duwe and Anschuetz 2013). While communities on mesa-tops may have disbanded, it is clear that social institutions for collective action endured in the ever increasing aggregated settlements in other portions of the Northern Rio Grande, which would have likely included Ancestral Pueblo people formerly of the Pajarito Plateau. By studying the Protohistoric, my archaeological research helps to identify some of the environmental and social factors that may have contributed to the emergence of Pueblo social institutions in the Northern Rio Grande, which endure in attributes of present day communities in the region.

\subsection{Conclusions}

This study demonstrates both the potential and limitations of conducting socio-ecological archaeological research narrowly focused on one resource. Water is a resource everyone needs everyday (Fishman 2011), and in arid-land contexts a strong argument can be made that its availability is a driving factor in cultural histories (e.g., Adler et al. 1996; Ingram 2015). Archaeologists often take water as a subject, and global syntheses of the role of water in culture history continue to be written (e.g., Fagan 2011; Mithen 2012). This study explores the potential of studying water through a comparative approach, using the same data collection methods, through an intra-regional comparison between adjoining culture areas. Intra-regional studies of resource management that factor in environmental records certainly exist in the Southwest (e.g., Nelson et al. 2006; Roos 2008; Schwindt et al. 2016), but this is the first intra-regional 
comparative study focused on the impacts of water management on community sustainability. This study shows that interdisciplinary research into the natural sciences (hydrology and climatology) is essential for understanding the social role of water.

The SES framework applied to hydrological systems and water management facilitated this approach, however there are many limitations. First, as central as water is to human survival, any argument that the long-term sustainability of a community is a function of feedbacks associated with a single natural resource will not capture the range of factors influencing cultural trajectories. In the context of my study area, such an approach has some utility because water access is central to the long-standing hypothesis that drought influenced the settlement history of the Pajarito Plateau (Henderson and Robbins 1912), but certainly broader socio-economic factors must be considered. I believe this analysis shows that water availability and management strategies did impact settlement histories, but not in the way I anticipated. Water was likely never truly scarce in the region, but costs for its acquisition could and did increase significantly, particularly on the Pajarito Plateau. This is an important finding, because it demonstrates the socio-economic impact of climate change in an archaeological context. Increased water acquisition costs during droughts could unsettle the institutions for governance, but it would be just one factor out of many influencing the overall dynamic of community histories. In future work I will have to look beyond water, which will demand new data collection across other domains potentially vulnerable to climate variation such as agricultural productivity, in order to understand the broader impacts of climate change.

As archaeology strives to "matter" in contemporary society (sensu Sabloff 2016) we are increasingly called to leverage our deep-time perspectives to address modern challenges. Archaeological case studies can serve to help evaluate how resource management strategies 
assumed to be "sustainable” perform over the long-term (Guedes et al. 2016; Nelson et al. 2016). This study can provide some long-term perspectives to modern societies with similar adaptive strategies facing similar water management problems. Contemporary dryland subsistence agriculturalists, especially those in developing countries (Morton 2007; Thomas 2008), or communities culturally and legally bound to traditional lands like many Native American communities (Hanna 2007; Nillson 2008), are seen as particularly vulnerable to climate change. Arid to semi-arid regions make up over $40 \%$ of the globe, with $90 \%$ of drylands found in the developing world (FAO 2016). The IPCC forecasts a 10-30\% reduction in dryland crop production by 2080 in North Africa and Asia (Houghton et al. 2001), which would greatly challenge societies of these regions. Water management is often a central problem for dryland agriculturalists, as it is for the 1.1 billion people globally who are without reliable access to clean drinking water, often subsisting on only $5 \mathrm{~L}$ of water a day (Watkins 2006). Commonly held resources, and local institutions for their management are strained in the face of globalization, climate change, and population pressures, but there is no single "panacea" to address these problems across all contexts (Ostrom et al. 2007). Instead, archaeological studies like this one serve as an opportunity for recognizing the value of local institutions for collective action in maintaining sustainable socio-hydrological systems, the challenges associated with shifting risk from the household to community, and the potentially overwhelming impacts to infrastructure and associated social institutions by climate change. 


\section{BIBLIOGRAPHY}

Acheson, James M. 2011. Ostrom for Anthropologists. International journal of the commons 5, no. 2: 319-39.

Ackerly, N. W. 1995. “Important Variables for Prehistoric Irrigation Studies.” In Soil, water, biology, and belief in prehistoric and traditional Southwestern agriculture, ed. Henry W. Toll. Vol. 2, 279-88. Albuquerque, NM: New Mexico Archaeological Council.

Adams, E. C., and Andrew I. Duff, eds. 2004. The protohistoric Pueblo world, AD 1275-1600: University of Arizona Press.

Adger, W. N. 2003. Social capital, collective action, and adaptation to climate change. Economic Geography 79, no. 4: 387-404.

Adler, Michael A., ed. 1996. The prehistoric Pueblo world, AD 1150-1350: University of Arizona Press.

Adler, Michael A. 2015. "Water fight: archaeology, litigation, and the assessment of precontact canal irrigation technologies in the Northern Rio Grande region.” In Traditional Arid Lands Agriculture: Understanding the Past for the Future, ed. Scott E. Ingram and Robert C. Hunt, 217-36. Tucson, Arizona: University of Arizona Press.

Adler, Michael A., Todd Van Pool, and Robert D. Leonard. 1996. Ancestral Pueblo population aggregation and abandonment in the North American Southwest. Journal of World Prehistory 10, no. 3: 375-438.

Ahlstrom, Richard V. N., Van West, Carla R, and Jeffrey S. Dean. 1995. Environmental and chronological factors in the Mesa Verde-Northern Rio Grande migration. Journal of Anthropological Archaeology 14, no. 2: 125-42.

Aiuvalasit, Michael J., and Christopher Kiahtipes. In press. Assessing the Potential for Pollen Preservation from Ancestral Pueblo Water Reservoir Features, Jemez Mountains, New Mexico. Newsletter of the New Mexico Archaeological Council.

Aiuvalasit, Michael J., James A. Neely, and Mark D. Bateman. 2010. New radiometric dating of water management features at the prehistoric Purrón Dam Complex, Tehuacán Valley, Puebla, México. Journal of Archaeological Science 37, no. 6: 1207-13.

Aldrich, M. J. 1986. Tectonics of the Jemez lineament in the Jemez Mountains and Rio Grande rift. Journal of Geophysical Research: Solid Earth 91, B2: 1753-62. 
Allen, Craig D. 2004. "Ecological patterns and environmental change in the in the Bandelier landscape.” In Archaeology of Bandelier National Monument: Village Formation on the Pajarito Plateau, New Mexico, ed. Timothy A. Kohler. Vol. 12, 19-68. Albuquerque, New Mexico: University of New Mexico.

Altschul, Jeffrey H., and Adrianne G. Rankin, eds. 2008. Fragile patterns: the archaeology of the Western Papaguería: SRI Press Tucson, AZ.

Anderies, John, Carl Folke, Brian Walker, and Elinor Ostrom. 2013. Aligning key concepts for global change policy: robustness, resilience, and sustainability. Ecology and Society 18, no. 2.

Anderies, John M. 2006. Robustness, institutions, and large-scale change in social-ecological systems: the Hohokam of the Phoenix Basin. Journal of institutional economics 2, no. 2: 133-55.

Anderies, John M., and Marco A. Janssen. 2011. The fragility of robust social-ecological systems. Global Environmental Change 21: 1153-56.

Anderies, John M., Marco A. Janssen, and Elinor Ostrom. 2004. A framework to analyze the robustness of social-ecological systems from an institutional perspective. Ecology and Society 9, no. 1: 18.

Anderies, John M., Armando A. Rodriguez, Marco A. Janssen, and Oguzhan Cifdaloz. 2007. Panaceas, uncertainty, and the robust control framework in sustainability science. Proceedings of the National Academy of Sciences 104, no. 39: 15194-99.

Anderson, Kirk C., and James M. Potter. 2015. Chronostratigraphic and paleoenvironmental evidence for marsh habitats during the Early Pueblo I (AD 700-900) occupation of Ridges Basin, southwest Colorado, USA. Geoarchaeology 30, no. 2: 100-19.

Anderson, R. S., Renata B. Jass, Jaime L. Toney, Craig D. Allen, Luz M. Cisneros-Dozal, Marcey Hess, Jeff Heikoop, and Julianna Fessenden. 2008. Development of the mixed conifer forest in northern New Mexico and its relationship to Holocene environmental change. Quaternary Research 69, no. 2: 263-75.

Anschuetz, Kurt F., and Thomas Merlan. 2007. More than a scenic mountain landscape: Valles Caldera National Preserve land use history. Rocky Mountain Research Station, RMRSGTR-196. Fort Collins, CO, 2007.

Anschuetz, Kurt F., Richard H. Wilshusen, and Cherie L. Scheick. 2001. An archaeology of landscapes: perspectives and directions. Journal of Archaeological Research 9, no. 2: 157211.

Anschuetz, Kurt F. 1998. Not waiting for the rain: Integrated systems of water management by pre-Columbian Pueblo farmers in north-central New Mexico. University of Michigan. 
Arbolino, Risa D., and Kit Nelson. 2014. Patterns of ceramic exchange during the Classic and Historic Periods in the Jemez Area: Evidence from early excavations at Amoxiumqua and Giusewa. Kiva 79, no. 4: 428-58.

Babcock, Barbara A. 1994. Pueblo Cultural Bodies. Journal of American Folklore 107, no. 423: 40-54.

Baker, Craig, and Joseph C. Winter. 1981. High Altitude Adaptations Along Redondo Creek: the Baca Geothermal Anthropological Project. Office of Contract Archaeology, Albuquerque, NM.

Baker, Victor R. 1998. “Paleohydrology and the Hydrological Sciences.” In Palaeohydrology and environmental change, ed. Gerardo Benito, Victor R. Baker, and Kenneth J. Gregory, 110: John Wiley \& Sons Inc.

Bandelier, Adolph Francis Alphonse. 1892. Final Report of Investigations Among the Indians of the Southwestern United States, Carried on Mainly in the Years from 1880 to 1885. Part II. American Series IV of Papers of the Archaeological Institute of America: University Press.

Barrett, Elinore M. 2002. The Geography of the Rio Grande Pueblos in the Seventeenth Century. Ethnohistory 49, no. 1: 123-69.

Bayman, James M. 1997. "Water storage in Prehistoric Papagueria and the limitations of ethnographic analogy.” In Prehistory of the borderlands: recent research in the archaeology of northern Mexico and the southern Southwest, ed. John P. Carpenter and Guadalupe Sanchez, 85-93. Tucson, Arizona: University of Arizona Press.

Bayman, James M., Paul R. Fish, Suzanne K. Fish, Frank E. Bayham, Margaret E. Beck, Michael J. Boley, Sergio F. Castro-Reino, Christopher Descantes, Michael D. Glascock, and Deanna Grimstead, eds. 2013. Power and Economy in Early Classic Period Hohokam Society: An Archaeological Perspective from the Marana Mound Site. Vol. 207 of Arizona State Museum Archaeological Series: University of Arizona Press.

Bayman, James M., and Suzanne K. Fish. 1992. Reservoirs and locational shifts in Sonoran Desert subsistence. Research in Economic Anthropology, Supplement 6: 267-306.

Bayman, James M., Manuel R. Palacios-Fest, Suzanne K. Fish, and Lisa W. Huckell. 2004. The paleoecology and archaeology of long-term water storage in a Hohokam reservoir, southwestern Arizona, USA. Geoarchaeology 19, no. 2: 119-40.

Bayman, James M., and Alan P. Sullivan. 2008. Property, Identity, and Macroeconomy in the Prehispanic Southwest. American Anthropologist 110, no. 1: 6-20.

Beaglehole, Ernest. 1937. Notes on Hopi economic life. Vol. 15. New Haven, Connecticut: Yale University Publications in Anthropology.

Beals, Alan R., and Bernard J. Siegel. 1966. Divisiveness and social conflict: An anthropological approach. Stanford, California: Stanford University Press. 
Ben-Dor, E., and A. Banin. 1989. Determination of organic matter content in arid-zone soils using a simple "loss-on-ignition" method. Communications in Soil Science \& Plant Analysis 20, 15-16: 1675-95.

Benito, Gerardo, Victor R. Baker, and Kenneth J. Gregory, eds. 1998. Palaeohydrology and environmental change: John Wiley \& Sons Inc.

Benson, Larry V., Eleanor R. Griffin, J. R. Stein, R. A. Friedman, and S. W. Andrae. 2014. Mummy Lake: an unroofed ceremonial structure within a large-scale ritual landscape. Journal of Archaeological Science 44: 164-79.

Benson, Larry V., Kenneth Petersen, and John Stein. 2007. Anasazi (pre-Columbian NativeAmerican) migrations during the middle-12th and late-13th centuries-were they drought induced? Climatic Change 83, 1-2: 187-213.

Bergin, Michelle S., J. J. West, Terry J. Keating, and Armistead G. Russell. 2005. Regional atmospheric pollution and transboundary air quality management. Annu. Rev. Environ. Resour. 30: 1-37.

Berkes, Fikret, David Feeny, Bonnie J. McCay, and James M. Acheson. 1989. The benefits of the commons. Nature 340, no. 6229: 91-93.

Berna, Francesco. 2017. Geo-ethnoarchaeology study of the traditional Tswana dung floor from the Moffat Mission Church, Kuruman, North Cape Province, South Africa. Archaeological and Anthropological Sciences 35, no. 1: 57.

Berry, Sean P. 2014. Water use and sustainability of prehistoric dry-land farmers. Masters of Arts. Northern Arizona University.

Bice, Richard A. 1980. “An Instrument Survey of Gallina Sites on Rattlesnake Ridge.” In Collected papers in honor of Helen Greene Blumenschein. Papers of the Archaeological Society of New Mexico, 154-55. Albuquerque, NM.

Binford, Lewis R., ed. 1977. For theory building in archaeology: essays on faunal remains, aquatic resources, spatial analysis, and systemic modeling. New York, NY: Academic Press.

Biswas, Asit K. 1970. History of hydrology: Elsevier Science Limited.

Blaauw, Maarten. 2010. Methods and code for 'classical'age-modelling of radiocarbon sequences. Quaternary geochronology 5, no. 5: 512-18.

Blake, W. D., Fraser Goff, A. I. Adams, and D. Counce. 1995. Environmental geochemistry for surface and subsurface waters in the Pajarito Plateau and outlying areas, New Mexico. Los Alamos National Lab, LA-12912-MS, Los Alamos, NM.

Blanton, Richard E., and Lane F. Fargher. 2016. How Humans Cooperate: Confronting the challenges of collective action: University Press of Colorado. 
Bocinsky, R. K., and Timothy A. Kohler. 2014. A 2,000-year reconstruction of the rain-fed maize agricultural niche in the US Southwest. Nature communications 5: 1-12.

Bonnin, Geoffrey M., Deborah Martin, Bingzhang Lin, Tye Parzybok, Michael Yekta, and David Riley. 2006. Precipitation-frequency atlas of the United States. NOAA, Atlas 14 Addendum, Silver Spring, MD.

Bowen, Brent M. 1990. Los Alamos Climatology. Los Alamos National Lab, LA-11735-MS, Los Alamos, NM.

Bowen, Brent M. 1996. Rainfall and climate variation over a sloping New Mexico plateau during the North American monsoon. Journal of Climate 9, no. 12: 3432-42.

Broxton, David E., and David T. Vaniman. 2005. Geologic framework of a groundwater system on the margin of a rift basin, Pajarito Plateau, north-central New Mexico. Vadose Zone Journal 4, no. 3: 522-50.

Bryan, Kirk. 1925. The Papago Country, Arizona. United States Geological Survey, Washington, D.C.

Buck, Caitlin E., J. A. Christen, and Gary N. James. 1999. Towards BCal: An on-line bayesian radiocarbon calibration facility. Mémoires de la Société préhistorique française 26: 113-17.

Butzer, Karl W. 1982. Archaeology as human ecology: method and theory for a contextual approach: Cambridge University Press.

Cameron, Catherine M. 1999. Hopi dwellings: Architectural change at Orayvi: University of Arizona Press.

Campbell, Sarah K., and Virginia L. Butler. 2010. Archaeological Evidence for Resilience of Pacific Northwest Salmon Populations and the Socioecological System over the last 7,500 years. Ecology and Society 15, no. 1: 1-20.

Capon, Brian. 2010. Botany for gardeners: Timber Press.

Cappers, René T. J., and Reinder Neef. 2012. Handbook of plant palaeoecology. Groningen, Netherlands: Barkhuis.

Caran, S. C., James A. Neely, Barbara M. Winsborough, Francisca R. Sorensen, and Salvatore Valastro. 1996. A late paleo-Indian/Early archaic water well in Mexico-Possible oldest water-Management feature in the new world. Geoarchaeology 11, no. 1: 1-35.

Carballo, David M. 2013. "Labor collectives and group cooperation in pre-Hispanic central Mexico.” In Cooperation and collective action: archaeological perspectives, ed. David M. Carballo, 243-74: University Press of Colorado. 
Carballo, David M., Paul Roscoe, and Gary M. Feinman. 2014. Cooperation and Collective Action in the Cultural Evolution of Complex Societies. Journal of Archaeological Method and Theory 21, no.1: 98-133.

Carrillo, Charles M. 1992. “Oral History/History of the Abiquiu Reservoir Area.” In History and ethnohistory along the Rio Chama, ed. Frank E. Wozniak, Meade F. Kemrer, and Charles M. Carrillo, 109-76. Albuquerque, NM: U.S. Army Corps of Engineers.

Castañeda, N. P., \& Morris, J. M. 2002. Narrative of the Coronado expedition. Chicago, IL: Lakeside Press.

Chahine, Moustafa T. 1992. The hydrological cycle and its influence on climate. Nature 359, no. 6394: 373-80.

Chester, E. T., and B. J. Robson. 2011. Drought refuges, spatial scale and recolonisation by invertebrates in non-perennial streams. Freshwater Biology 56, no. 10: 2094-104.

Chorover, Jon, Peter A. Troch, Craig Rasmussen, Paul D. Brooks, Jon D. Pelletier, David D. Breshears, Travis E. Huxman, Shirley A. Kurc, Kathleen A. Lohse, Jennifer C. McIntosh, Thomas Meixner, Marcel G. Schaap, Marcy E. Litvak, Julia Perdrial, Adrian Harpold, and Matej Durcik. 2011. How Water, Carbon, and Energy Drive Critical Zone Evolution: The Jemez-Santa Catalina Critical Zone Observatory. Vadose Zone Journal 10, no. 3: 884.

Chwe, Michael S.-Y. 2009. Rational Choice and the Humanities. Occasion: Interdisciplinary Studies in the Humanities 1, no. 1: 1-15.

Coats, Sloan, Jason E. Smerdon, Richard Seager, Daniel Griffin, and Benjamin I. Cook. 2015. Winter-to-summer precipitation phasing in southwestern North America: A multicentury perspective from paleoclimatic model-data comparisons. Journal of Geophysical Research: Atmospheres 120, no. 16: 8052-64.

Cohen, Andrew S. 2003. Paleolimnology: The history and evolution of lake systems. New York, NY: Oxford University Press.

Colwell-Chanthaphonh, Chip, and Thomas J. Ferguson. 2006. Memory pieces and footprints: multivocality and the meanings of ancient times and ancestral places among the Zuni and Hopi. American Anthropologist 108, no. 1: 148-62.

Cordell, Linda S. 1996. "Models and Frameworks for Archaeological Analysis of Resource Stress in the American Southwest." In Evolving complexity and environmental risk in the prehistoric Southwest: proceedings of the Workshop" Resource Stress, Economic Uncertainty, and Human Response in the Prehistoric Southwest," held February 25-29, 1992, in Santa Fe, NM, ed. Joseph A. Tainter and Bonnie B. Tainter. XXIV of Proceedings, 25166. Reading, MA: Addison-Wesley.

Cordell, Linda S., and Don D. Fowler, eds. 2005. Southwest archaeology in the twentieth century: University of Utah Press. 
Cordell, Linda S., and Fred Plog. 1979. Escaping the confines of normative thought: A reevaluation of Puebloan prehistory. American Antiquity 44, no. 3: 405-29.

Creamer, Winifred. 1996. "Developing complexity in the American southwest: Constructing a model for the Rio Grande Valley.” In Emergent complexity: The evolution of intermediate societies, ed. Jeanne E. Arnold, 91-106: International monographs in prehistory.

Crown, Patricia L. 1987. Water Storage in the Prehistoric Southwest. Kiva 52, no. 3: 209-28.

Crown, Patricia L., Janet D. Orcutt, and Timothy A. Kohler. 1996. "Pueblo cultures in transition: The northern Rio Grande.” In The prehistoric Pueblo world, AD 1150-1350, ed. Michael A. Adler, 188-204: University of Arizona Press.

Curewitz, Diane C. 2008. Changes in Northern Rio Grande Ceramic Production and Exchange, Late Coalition Through Classic (AD 1250-1600). Washington State University.

Curtis, Edward S. 1926. The North American Indian : being a series of volumes picturing and describing the Indians of the United States, and Alaska; The Tewa. The Zuñi. Vol. 17. Cambridge, MA: The University Press.

Dale, Michael R., and Steve Yanicak. 1996. Characteristics of springs in the western Pajarito Plateau. In The Jemez Mountains Region, ed. Fraser Goff, Barry S. Kues, Margaret A. Rogers, Leslie McFadden, and Jamie N. Gardner. Albuquerque, NM.

Damp, Jonathan E., Stephen A. Hall, and Susan J. Smith. 2002. Early irrigation on the Colorado Plateau near Zuni Pueblo, New Mexico. American Antiquity 67, no. 4: 665-76.

Davies, Matthew I. J., and Freda N. M'Mbogori, eds. 2013. Humans and the environment: new archaeological perspectives for the twenty-first century. Oxford, UK: Oxford University Press.

Dean, Jeffrey S. 1988. "Dendrochronology and paleoenvironmental reconstruction on the Colorado Plateaus.” In The Anasazi in a changing environment, ed. George J. Gumerman, 119-67. Cambridge, MA: Cambridge University Press.

Dean, Jeffrey S. 1996. “Demography, Environment, and Subsistence Stress.” In Evolving complexity and environmental risk in the prehistoric Southwest: proceedings of the Workshop" Resource Stress, Economic Uncertainty, and Human Response in the Prehistoric Southwest," held February 25-29, 1992, in Santa Fe, NM, ed. Joseph A. Tainter and Bonnie B. Tainter. XXIV of Proceedings, 25-56. Reading, MA: Addison-Wesley.

Dean, Jeffrey S., William H. Doelle, and Janet D. Orcutt. 1994. Adaptive stress, environment, and demography. In Themes in Southwest Prehistory, ed. George J. Gumerman, 53-86. Santa Fe, NM.

Dean, Jeffrey S., Robert C. Euler, George J. Gumerman, Fred Plog, Richard H. Hevly, and Thor N. V. Karlstrom. 1985. Human behavior, demography, and paleoenvironment on the Colorado Plateaus. American Antiquity 50, no. 3: 537-54. 
Dean, Rebecca M., ed. 2010. The archaeology of anthropogenic environments. Vol. 37: Center for Archaeological Investigations, Carbondale, Illinois.

Dennis, Wayne. 1940. The Hopi child. New York, NY: D. Appleton-Century Company.

Dietz, Thomas, Elinor Ostrom, and Paul C. Stern. 2003. The struggle to govern the commons. Science 302, no. 5652: 1907-12.

Dolan, Sean G., Kari M. Cates, Cyler N. Conrad, and Sandi R. Copeland. 2017. Variation and Uniformity in Ancestral Puebloan Fieldhouses: A View from the Northern Rio Grande, Presentation at the Pecos Conference, Rowe, New Mexico, August 12.

Donahue, John, ed. 1997. Water, culture, and power: local struggles in a global context. Washington, D.C.: Island Press.

Doolittle, William E. 2000. Cultivated landscapes of native North America. Oxford, UK: Oxford University Press.

Douglass, John, and William M. Graves, eds. 2017. New Mexico and the Pimería Alta: The Colonial Period in the American Southwest: University Press of Colorado.

Dove, Michael R. 2013. The Anthropology of Climate Change: An Historical Reader. West Sussex, UK: John Wiley \& Sons.

Downing, Theodore E., and McGuire Gibson, eds. 1974. Irrigation's impact on society. Tucson, AZ: University of Arizona Press.

Doyel, David E., and Jeffrey S. Dean, eds. 2006. Environmental change and human adaptation in the ancient American Southwest. Salt Lake City, Utah: University of Utah Press.

Dozier, Edward P. 1966. Hano: A Tewa Indian Community in Arizona: Harcourt School.

Dozier, Edward P. 1970. The Pueblo Indians of North America. Prospect Heights, Ill: Waveland Press.

Drakos, Paul G., and Steven L. Reneau. 2007. Episodic eolian events and preservation of mesa top archaeological sites on the Pajarito Plateau, New Mexico. In New Mexico Geological Society Guidebook, 58th Field Conference, Geology of the Jemez Region II, ed. Barry S. Kues, Shari A. Kelley, and Virgil W. Lueth, 121-30. Albuquerque, NM.

Drakos, Paul G., and Steven L. Reneau. 2013. "Surficial Processes and Preservation of Ancestral Puebloan Archaeological Sites on the Pajarito Plateau, New Mexico.” In From Mountaintop to Valley Bottom Understanding Past Land Use in the Northern Rio Grande Valley, New Mexico, ed. Bradley J. Vierra, 33-53. Salt Lake City, Utah: University of Utah Press. 
Duwe, Samuel G. 2008. "Ceramic Analysis and Interpretations of Classic Period Pueblos on Los Alamos National Laboratory Collected by the Pajarito Archaeological Research Project.” In The Land Conveyance and Transfer Data Recovery Project: 7000 Years of Land Use on the Pajarito Plateau. eds., Bradley J. Vierra and Kari M. Schmidt, LA-UR-07-6205, 87-138. Los Alamos, NM.

Duwe, Samuel G. 2011. The Prehispanic Tewa World: Space, Time, and Becoming in the Pueblo Southwest. The University of Arizona.

Duwe, Samuel G., and Kurt F. Anschuetz. 2013. "Ecological Uncertainly and Organizational Flexibility on the Prehistoric Tewa Landscape: Notes from the Northern Frontier.” In From Mountaintop to Valley Bottom Understanding Past Land Use in the Northern Rio Grande Valley, New Mexico, ed. Bradley J. Vierra, 95-112. Salt Lake City, Utah: University of Utah Press.

Eerkens, Jelmer W. 1999. Common pool resources, buffer zones, and jointly owned territories: Hunter-gatherer land and resource tenure in Fort Irwin, Southeastern California. Human Ecology 27, no. 2: 297-318.

Elliott, Michael L. 1982. Large Pueblo Sites near Jemez Springs, New Mexico. United States Forest Service, Cultural Resources Report 1, Santa Fe, NM.

Elliott, Michael L. 1983. Report on Possible Reservoirs on Boletsakwa Mesa, Santa Fe National Forest, Santa Fe, NM.

Elliott, Michael L. 1986. Overview and Synthesis of the Archeology of the Jémez Province, New Mexico. Vol. 51 of Archaeology Notes. Santa Fe, NM: Museum of New Mexico, Office of Archaeological Studies.

Elliott, Michael L. 1998. Coalition Period Adaptations in the Jemez Region: Origins of the Jemez Phenomenon, Presentation at the Society for American Archaeology, Seattle, Washington.

Ellis, Florence H. 1951. Patterns of aggression and the war cult in Southwestern Pueblos. Southwestern Journal of Anthropology 7, no. 2: 177-201.

Ellis, Florence H. 1953. Authoritative control and the society system in Jemez Pueblo. Southwestern Journal of Anthropology 9, no. 4: 385-94.

Ellis, Florence H. 1964. A Reconstruction of the Basic Jemez Pattern of Social Organization: With Comparisons to Other Tanoan Social Structures. Vol. 11. Albuquerque, NM: University of New Mexico Press.

Ellis, Florence H., and Andrea E. Dodge. 1989. The spread of Chaco/Mesa Verde/McElmo black-on-white pottery and the possible simultaneous introduction of irrigation into the Rio Grande drainage. Journal of Anthropological Research 45, no. 1: 47-52. 
Elmore, Francis H. 1976. Shrubs and trees of the southwest uplands. Vol. 19. Tucson, AZ: Southwest Parks and Monuments Association.

Enquist, Carolyn, Anne Bradley, Molly Cross, Gregg Garfin, Dave Gori, Patrick McCarthy, and Rebecca Oertel. 2009. Jemez Mountain Climate Change Adaptation Workshop: Process, Outcomes and Next Steps, The Nature Conservancy, Southwest Climate Change Initiative.

Fagan, Brian. 2011. Elixir: a history of water and humankind. New York, NY: Bloomsbury Publishing.

Farella, Joshua. 2015. Terminus Ante Quem Constraint of Pueblo Occupation Periods in the Jemez Province, New Mexico. Masters thesis. University of Arizona.

Fennell, Lee A. 2011. Ostrom's law: property rights in the commons. International journal of the commons 5, no. 1: 9-27.

Ferguson, Thomas J. 1996. Native Americans and the practice of archaeology. Annual review of anthropology 25, no. 1: 63-79.

Ferring, C. R. 1986. Rates of fluvial sedimentation: implications for archaeological variability. Geoarchaeology 1, no. 3: 259-74.

Fetter, Charles W. 2014. Applied hydrogeology. Essex, UK: Pearson Education Limited.

Fewkes, Jesse W., and John G. Owens, eds. 1892. A few summer ceremonials at the Tusayan pueblos: AMS Press.

Fisher, Christopher T., James B. Hill, and Gary M. Feinman, eds. 2009. The archaeology of environmental change: socionatural legacies of degradation and resilience: University of Arizona Press.

Fishman, Charles. 2012. The big thirst: The secret life and turbulent future of water. New York, NY: Simon and Schuster.

Fitch, Erin P., and Grant A. Meyer. 2016. Temporal and spatial climatic controls on Holocene fire-related erosion and sedimentation, Jemez Mountains, New Mexico. Quaternary Research 85, no. 1: 75-86.

Folke, Carl, Stephen Carpenter, Brian Walker, Marten Scheffer, Terry Chapin, and Johan Rockström. 2010. Resilience thinking: integrating resilience, adaptability and transformability. Ecology and Society 15, no. 4.

Food and Agriculture Organization of the United Nations (FAO). 2016. Trees, forests and land use in drylands The first global assessment. Rome, Italy, 2016.

Ford, Richard I. 1977. The technology of irrigation in a New Mexico Pueblo. In Material culture: styles, organization, and dynamics of technology, ed. Heather Lechtman and Robert S. Merrill, 139-54. Saint Paul, NM: West Publishing Company. 
Ford, Richard I. 2013. “The Cultural Ecology of Jemez Cave.” In From Mountaintop to Valley Bottom Understanding Past Land Use in the Northern Rio Grande Valley, New Mexico, ed. Bradley J. Vierra, 69-80. Salt Lake City, Utah: University of Utah Press.

Ford, Richard I. 2014. The Ancestors' Legacy at Spiritual Places: Water and Shrines in the Pueblos. Newsletter of the New Mexico Archaeological Council, no. 1: 3-8.

Ford, Richard I., Albert H. Schroeder, and Stewart L. Peckham. 1972. "Three perspectives on Puebloan prehistory.” In New perspectives on the Pueblos, ed. Alfonso Ortiz, 19-39. Albuquerque, NM: University of New Mexico Press.

Ford, Richard I., and Roxanne Swentzell. 2015. "Precontact agriculture in northern New Mexico.” In Traditional Arid Lands Agriculture: Understanding the Past for the Future, ed. Scott E. Ingram and Robert C. Hunt, 330-57. Tucson, Arizona: University of Arizona Press.

Fowler, Don D. 2000. A laboratory for anthropology: science and romanticism in the American Southwest, 1846-1930. Albuquerque, NM: Univ of New Mexico Press.

French, Kirk D. 2009. The hydroarchaeological approach: Understanding the ancient Maya impact on the Palenque watershed. The Pennsylvania State University.

French, Kirk D., Christopher J. Duffy, and Gopal Bhatt. 2012. The Hydroarchaeological Method: A Case Study at the Maya Site of Palenque. Latin American Antiquity 23, no. 1: 29-50.

Gabler, Brandon M. 2009. Panarchy on the Plateau: Modeling Prehistoric Settlement Pattern, Land Use, and Demographic Change on the Pajarito Plateau, New Mexico. The University of Arizona.

Gaiser, E., and K. Rühland. 2010. Diatoms as indicators of environmental change in wetlands and peatlands. In The diatoms: applications for the environmental and earth sciences, eds., John P. Smol and Eugene F. Stoermer, 473-96. Cambridge, UK: Cambridge University Press.

Gardner, Jamie N., Fraser Goff, Sammy Garcia, and Roland C. Hagan. 1986. Stratigraphic relations and lithologic variations in the Jemez volcanic field, New Mexico. Journal of Geophysical Research: Solid Earth 91, B2: 1763-78.

Gavin, Daniel G. 2001. Estimation of inbuilt age in radiocarbon ages of soil charcoal for fire history studies. Radiocarbon 43, no. 1: 27-44.

Gladfelter, Bruce G. 2001. “Archaeological sediments in humid alluvial environments.” In Sediments in archaeological context, ed. Julie K. Stein, 93-125. Salt Lake City, Utah: Univ of Utah Press.

Gleick, Peter H. 1996. Basic water requirements for human activities: meeting basic needs. Water International 21, no. 2: 83-92. 
Glowacki, Donna M. 2015. Living and leaving: A social history of regional depopulation in thirteenth-century Mesa Verde. Tucson, Arizona: University of Arizona Press.

Goff, Fraser, Barry S. Kues, Margaret A. Rogers, Leslie McFadden, and Jamie N. Gardner, eds. 1996. The Jemez Mountains Region. Albuquerque, NM.

Goldberg, Paul, and Richard I. Macphail. 2006. Practical and theoretical geoarchaeology. Malden, MA: Blackwell Publishers.

Green, Gregory N., and Glen E. Jones. 1997. The digital geologic map of New Mexico in ARC/INFO format, 1997.

Gregory, Herbert E. 1916. The Navajo country: a geographic and hydrographic reconnaissance of parts of Arizona, New Mexico, and Utah. Vol. 380. Washington, D.C.: US Government Printing Office.

Greiser, Sally T., and James L. Moore. 1995. "The case for prehistoric irrigation in the northern Southwest.” In Soil, water, biology, and belief in prehistoric and traditional Southwestern agriculture, ed. Henry W. Toll. Vol. 2, 189-95. Albuquerque, NM: New Mexico Archaeological Council.

Grissino-Mayer, Henri D. 1996. A 2129-year reconstruction of precipitation for northwestern New Mexico, USA. Radiocarbon: 191-204.

Guedes, Jade A d'Alpoim, Stefani A. Crabtree, R. K. Bocinsky, and Timothy A. Kohler. 2016. Twenty-first century approaches to ancient problems: Climate and society. Proceedings of the National Academy of Sciences 113, no. 51: 14483-91.

Gumerman, George J., ed. 1988. The Anasazi in a changing environment. Cambridge, MA: Cambridge University Press.

Gunderson, Lance H., and Crawford S. Holling. 2002. Panarchy: understanding transformations in human and natural systems. Washington, D.C.: Island Press.

Haase, William R. 1985. Domestic water conservation among the northern San Juan Anasazi. Southwestern Lore 51, no. 2: 15-27.

Hacker, Leroy, and Christopher Banet. 2008. Soil Survey of Sandoval County Area, New Mexico. National Resources Conservation Service, Washington, D.C.

Hackett, Charles W., Bandelier, Adolph Francis Alphonse, and Fanny R. Bandelier. 1937. Historical Documents relating to New Mexico, Nueva Vizcaya and approaches thereto, to 1773. Vol. 3. Washington, D.C.: Carnegie Institution Washington, DC.

Hall, Stephen A. 1977. Late quaternary sedimentation and paleoecologic history of Chaco Canyon, New Mexico. Geological Society of America Bulletin 88, no. 11: 1593-618. 
Hall, Stephen A., and Richard D. Periman. 2007. Unusual holocene alluvial record from Rio Del Osos, Jemez Mountains, New Mexico: Paleoclimatic and archaeologic significance. In New Mexico Geological Society Guidebook, 58th Field Conference, Geology of the Jemez Region II, ed. Barry S. Kues, Shari A. Kelley, and Virgil W. Lueth, 459-68. Albuquerque, NM.

Hanna, Jonathan M. 2007. Native Communities and Climate Change: Protecting Tribal Resources as Part of National Climate Policy: Report. Natural Resources Law Center, University of Colorado School of Law, Boulder, CO.

Hardin, Garrett. 1968. The Tragedy of the Commons. Science 162: 1243-48.

Harper, Blanche W. 1929. Notes on the documentary history, the language, and the rituals and customs of Jemez pueblo. University of New Mexico.

Harrington, John P. 1916. The ethnogeography of the Tewa Indians. Vol. 29. Washington, D.C.: Government Printing Office.

Haslett, Simon K., ed. 2002. Quaternary environmental micropalaeontology. Oxford, UK: Oxford University Press.

Haynes, C. V. 1991. Geoarchaeological and paleohydrological evidence for a Clovis-age drought in North America and its bearing on extinction. Quaternary Research 35, no. 3: 438-50.

Hegmon, Michelle, Mathew A. Peeples, Ann P. Kinzig, Stephanie Kulow, Cathryn M. Meegan, and Margaret C. Nelson. 2008. Social transformation and its human costs in the prehispanic US Southwest. American Anthropologist 110, no. 3: 313-24.

Henderson, Junius, and Wilfred W. Robbins. 1912. "Climate and Evidence of Climatic Changes.” In The Physiography of the Rio Grande Valley, New Mexico: In Relation to Pueblo Culture, ed. Edgar L. Hewett, Junius Henderson, and Wilfred W. Robbins, 41-70. Washington, D.C.: US Government Printing Office.

Henne, Lisa. 2008. Evaluation of Aquatic Macroinvertebrate Communities and Habitats in the Pajarito Watershed. Los Alamos National Laboratory, LA-UR-08-06090, Los Alamos, NM.

Herzog, Irmela. 2013. “The potential and limits of optimal path analysis.” In Computational approaches to archaeological spaces, ed. Andrew Bevan and Mark Lake, 179-212. Walnut Creek, California: Left Coast Press.

Hewett, Edgar L. 1906. Antiquities of the Jemez Plateau, New Mexico. 31-32. Washington, D.C.: US Government Printing Office.

Hewett, Edgar L. 1938. Pajarito Plateau and its ancient people. Albuquerque, NM: University of New Mexico.

Hewett, Edgar L. 1993. Ancient communities in the American Desert. Albuquerque, NM: Archaeological Society of New Mexico. 
Hewett, Edgar L., Junius Henderson, and Wilfred W. Robbins, eds. 1912. The Physiography of the Rio Grande Valley, New Mexico: In Relation to Pueblo Culture. Washington, D.C.: US Government Printing Office.

Hill, James N. 1970. Broken K Pueblo: prehistoric social organization in the American Southwest. Tucson, Arizona: University of Arizona Press.

Hill, James N., and W. N. Trierweiler. 1986. Prehistoric Responses to Food Stress on the Pajarito Plateau: Technical Report and Results of the Pajarito Archaeological Research Project, 1977-1985. Final report to the National Science Foundation. Los Angeles, 1986.

Hill, James N., W. N. Trierweiler, and Robert W. Preucel. 1996. "The evolution of cultural complexity: a case from the Pajarito Plateau, New Mexico.” In Emergent complexity: The evolution of intermediate societies, ed. Jeanne E. Arnold, 107-27: International monographs in prehistory.

Hill, Willard W. 1982. Ethnography of Santa Clara Pueblo, New Mexico. Albuquerque, NM: University of New Mexico Press.

Hoagland, Steven R., Bradley J. Vierra, W. B. Masse, Alan L. Madsen, and Gerald S. Martinez. 2000. Cultural Resource Assessment for the Department of Energy Conveyance and Transfer Project. Los Alamos National Laboratory, LA-UR-01-5533, Los Alamos, NM.

Holliday, Vance T., ed. 1995. Stratigraphy and paleoenvironments of late Quaternary valley fills on the Southern High Plains. Vol. 186 of Memoirs. Boulder, CO: Geological Society of America.

Holliday, Vance T. 2000. Folsom drought and episodic drying on the Southern High Plains from 10,900-10,200 14 C yr BP. Quaternary Research 53, no. 1: 1-12.

Holmes, William H. 1905. Notes on the Antiquities of Jemez Valley, New Mexico. American Anthropologist 7, no. 2: 198-212.

Hooper, Paul L., Hillard S. Kaplan, and James L. Boone. 2010. A theory of leadership in human cooperative groups. Journal of theoretical biology 265, no. 4: 633-46.

Houghton, John T., YDJG Ding, David J. Griggs, Maria Noguer, van der Linden, Paul J, Xiaosu Dai, Kathy Maskell, and Cathy A. Johnson. 2001. Climate change 2001: the scientific basis. Cambridge, UK: The Press Syndicate of the University of Cambridge.

Howell, R. E., and Jeffrey A. Homburg. 2013. “Analysis of Adobe Architecture at the Marana Platform Mound Sit.” In Power and Economy in Early Classic Period Hohokam Society: An Archaeological Perspective from the Marana Mound Site, ed. James M. Bayman, Paul R. Fish, Suzanne K. Fish, Frank E. Bayham, Margaret E. Beck, Michael J. Boley, Sergio F. Castro-Reino, Christopher Descantes, Michael D. Glascock, and Deanna Grimstead. Vol. 207 of Arizona State Museum Archaeological Series, 33-46: University of Arizona Press. 
Huckleberry, Gary. 2001. “Archaeological sediments in dryland alluvial environments.” In Sediments in archaeological context, ed. Julie K. Stein, 67-92. Salt Lake City, Utah: Univ of Utah Press.

Huckleberry, Gary, T. J. Ferguson, Tammy Rittenour, Christopher Banet, and Shannon Mahan. 2016. Identification and dating of indigenous water storage reservoirs along the Rio San José at Laguna Pueblo, western New Mexico, USA. Journal of Arid Environments 127: 171-86.

Hudson, Mark J., Mami Aoyama, Kara C. Hoover, and Junzō Uchiyama. 2012. Prospects and challenges for an archaeology of global climate change. Wiley Interdisciplinary Reviews: Climate Change 3, no. 4: 313-28.

Hutchinson, Charles F. 1982. Application of Remote Sensing in Evaluating Floodwater Farming on the Papago Indian Reservation: Completion Report. Tucson, Arizona, 1982.

Ingram, Scott E. 2010. Human Vulnerability to Climatic Dry Periods in the Prehistoric U.S. Southwest. Arizona State University.

Ingram, Scott E. 2015. “Human Vulnerability to Dry Periods.” In Traditional Arid Lands Agriculture: Understanding the Past for the Future, ed. Scott E. Ingram and Robert C. Hunt, 131-60. Tucson, Arizona: University of Arizona Press.

Ingram, Scott E., and Robert C. Hunt, eds. 2015. Traditional Arid Lands Agriculture: Understanding the Past for the Future. Tucson, Arizona: University of Arizona Press.

Jazwa, Christopher S., Christopher J. Duffy, Lorne Leonard, and Douglas J. Kennett. 2016. Hydrological Modeling and Prehistoric Settlement on Santa Rosa Island, California, USA. Geoarchaeology 31, no. 2: 101-20.

Jeançon, Jean A. 1923. Excavations in the Chama Valley, New Mexico. Smithsonian Institution. Bureau of American Ethnology 81, Washington, D.C.

Jorgeson, Ian. 2017. Quantifying the Relationship between Geography and Social Networks, Vancouver, Canada, Presentation at the Annual Meeting of the Society for American Archaeology, April 1, Vancouver, Canada.

Juggins, Steven, and Nigel Cameron. 2010. “Diatoms and archaeology.” In The diatoms: applications for the environmental and earth sciences, ed. John P. Smol and Eugene F. Stoermer, 389-401. Cambridge, UK: Cambridge University Press.

Kamran, M. A., and G. P. Shivakoti. 2010. "Robustness, vulnerability and adaptive capacity in social ecological systems: the case of spate irrigation systems in Pakistan.” In Sustainable irrigation management, Technologies and policies III, ed. Carlos A. Brebbia, Am Marinov, and Henning Bjornlund, 63-73: WIT Press.

Karlstrom, Thor N. 1988. "Alluvial chronology and hydrologic change of Black Mesa and nearby regions.” In The Anasazi in a changing environment, ed. George J. Gumerman, 4591. Cambridge, MA: Cambridge University Press. 
Kelley, Shari A., G. R. Osburn, and Kirt A. Kempter. 2007. Geology of Cañon de San Diego, southwestern Jemez Mountains, northcentral New Mexico. Geology of the Jemez Region II, Kues, BS, Kelley, SA, Lueth, VW (Ed), New Mexico Geological Society, Guidebook 58: 16981.

Kelly, Clyde, and E. V. Anspach. 1913. A Preliminary Study of the Waters of the Jemez Plateau, New Mexico 1, no. 1: 1-78.

Kennington, Kevin. 2002. “The environmental applications of diatoms.” In Quaternary environmental micropalaeontology, ed. Simon K. Haslett, 166-84. Oxford, UK: Oxford University Press.

Kohler, Timothy A. 1992. Field houses, villages, and the tragedy of the commons in the early northern Anasazi Southwest. American Antiquity 57, no. 4: 617-35.

Kohler, Timothy A., ed. 2004. Archaeology of Bandelier National Monument: Village Formation on the Pajarito Plateau, New Mexico. Vol. 12. Albuquerque, New Mexico: University of New Mexico.

Kohler, Timothy A. 2012. “Simulation Model Overview.” In Emergence and collapse of early villages: models of central Mesa Verde archaeology, ed. Timothy A. Kohler and Mark D. Varien, 59-72. Berkley, CA: University of California Pr.

Kohler, Timothy A., Denton Cockburn, Paul L. Hooper, R. K. Bocinsky, and Ziad Kobti. 2012. The coevolution of group size and leadership: An agent-based public goods model for prehispanic Pueblo societies. Advances in Complex Systems 15, nos. 1 \& 2: 1150007.

Kohler, Timothy A., C. D. Johnson, Mark Varien, Scott Ortman, Robert Reynolds, Ziad Kobti, Jason Cowan, Kenneth Kolm, Schaun Smith, and Lorene Yap. 2007. “Settlement ecodynamics in the prehispanic central Mesa Verde region.” In The model-based archaeology of socionatural systems, ed. Timothy A. Kohler and van der Leeuw, Sander Ernst, 61-104: School for Advanced Research.

Kohler, Timothy A., Sarah Herr, and Mathew J. Root. 2004a. "The Rise and Fall of Towns on the Pajarito (A.D. 1375-1600).” In Archaeology of Bandelier National Monument: Village Formation on the Pajarito Plateau, New Mexico, ed. Timothy A. Kohler. Vol. 12, 215-64. Albuquerque, New Mexico: University of New Mexico.

Kohler, Timothy A., Robert P. Powers, and Janet D. Orcutt. 2004b. "Bandelier from Hamlets to Towns.” In Archaeology of Bandelier National Monument: Village Formation on the Pajarito Plateau, New Mexico, ed. Timothy A. Kohler. Vol. 12, 293-304. Albuquerque, New Mexico: University of New Mexico.

Kohler, Timothy A., and Mathew J. Root. 2004a. "The First Hunter/Farmers on the Pajarito Plateau (A.D. 1150-1250).” In Archaeology of Bandelier National Monument: Village Formation on the Pajarito Plateau, New Mexico, ed. Timothy A. Kohler. Vol. 12, 117-72. Albuquerque, New Mexico: University of New Mexico. 
Kohler, Timothy A., and Mathew J. Root. 2004b. "The Late Coalition and Earliest Classic on the Pajarito Plateau (A.D. 1250-1375).” In Archaeology of Bandelier National Monument: Village Formation on the Pajarito Plateau, New Mexico, ed. Timothy A. Kohler. Vol. 12, 173-214. Albuquerque, New Mexico: University of New Mexico.

Kohler, Timothy A., and van der Leeuw, Sander Ernst, eds. 2007. The model-based archaeology of socionatural systems: School for Advanced Research on the.

Kohler, Timothy A., and Van West, Carla R. 1996. “The Calculus of Self-Interest in the Development of Cooperation: Sociopolitical Development and Risk Among the Northern Anasazi.” In Evolving complexity and environmental risk in the prehistoric Southwest: proceedings of the Workshop" Resource Stress, Economic Uncertainty, and Human Response in the Prehistoric Southwest," held February 25-29, 1992, in Santa Fe, NM, ed. Joseph A. Tainter and Bonnie B. Tainter. XXIV of Proceedings, 169-96. Reading, MA: AddisonWesley.

Kohler, Timothy A., and Mark D. Varien, eds. 2012. Emergence and collapse of early villages: models of central Mesa Verde archaeology. Berkley, CA: University of California Pr.

Kohler, Timothy A., Mark D. Varien, and Aaron M. Wright. 2010. Leaving Mesa Verde: peril and change in the thirteenth-century Southwest. Tucson, Arizona: University of Arizona Press.

Kolm, Kenneth E., and Schaun M. Smith. 2012. "Modeling Paleohydrological System Structure and Function.” In Emergence and collapse of early villages: models of central Mesa Verde archaeology, ed. Timothy A. Kohler and Mark D. Varien, 73-84. Berkley, CA: University of California Pr.

Kruse-Peeples, Melissa, Hoski Schaafsma, K. A. Spielmann, and J. Briggs. 2010. “Landscape legacies of prehistoric agricultural land use in the Perry Mesa region, central Arizona.” In The archaeology of anthropogenic environments, ed. Rebecca M. Dean. Vol. 37, 122-41: Center for Archaeological Investigations.

Kues, Barry S., Shari A. Kelley, and Virgil W. Lueth, eds. 2007. New Mexico Geological Society Guidebook, 58th Field Conference, Geology of the Jemez Region II. Albuquerque, NM.

Kulisheck, Jeremy. 2005. The Archaeology of Pueblo Population Change on the Jemez Plateau A.D. 1200 to 1700: The Effects of Spanish Contact and Conquest. Southern Methodist University.

Laborda-Pemán, Miguel, and Tine de Moor. 2016. History and the Commons: A necessary conversation. International Journal of the Commons 10, no. 2: 517.

Ladd, Ed. 1983. "Pueblo Use of High-Altitude Areas: Emphasis on the A'shiwi." In Highaltitude Adaptations in the Southwest, ed. Joseph C. Winter. Vol. 2, 168-76. Albuquerque, NM: USDA Forest Service, Southwestern Region. 
LaMotta, Vincent M., and Michael B. Schiffer. 2001. "Behavioral Arhaeology: Toward a New Synthesis.” In Archaeological Theory Today, ed. Ian Hodder, 14-64. Malden, MA: Blackwell Publishers.

Lange, Charles H. 1953. The role of economics in Cochiti Pueblo culture change. American Anthropologist 55, no. 5: 674-94.

Lange, Charles H. 1959. Cochiti: A New Mexico pueblo, past and present. Austin. Austin, TX: University of Texas.

Lansing, J. S. 2009. Priests and programmers: technologies of power in the engineered landscape of Bali. Princeton, NJ: Princeton University Press.

Larkin, Randall G., and John M. Sharp. 1992. On the relationship between river-basin geomorphology, aquifer hydraulics, and ground-water flow direction in alluvial aquifers. Geological Society of America Bulletin 104, no. 12: 1608-20.

Lechtman, Heather, and Robert S. Merrill, eds. 1977. Material culture: styles, organization, and dynamics of technology. Saint Paul, NM: West Publishing Company.

Levine, Frances, and Thomas Merlan. 1997. Bandelier National Monument Ethnographic Literature Search and Consultation, 1997.

Liebmann, Matthew J. 2006. "Burn the Churches, Break Up the Bells": The Archaeology fo the Pueblo Revolt Revitalization Movement in New Mexico, A.D. 1680-1696. University of Pennsylvania.

Liebmann, Matthew J., Joshua Farella, Christopher I. Roos, Adam Stack, Sarah Martini, and Thomas W. Swetnam. 2016. Native American depopulation, reforestation, and fire regimes in the Southwest United States, 1492-1900 CE. Proceedings of the National Academy of Sciences of the United States of America 113, no. 6: E696-704.

Liebmann, Matthew J., Thomas J. Ferguson, and Robert W. Preucel. 2005. Pueblo settlement, architecture, and social change in the Pueblo Revolt era, AD 1680 to 1696. Journal of Field Archaeology 30, no. 1: 45-60.

Liebmann, Matthew J., Robert W. Preucel, and Joseph Aguilar. 2017. “The Pueblo World Transformed.” In New Mexico and the Pimería Alta: The Colonial Period in the American Southwest, ed. John Douglass and William M. Graves, 143-56: University Press of Colorado.

Lindholm, Karl-Johan, Emil Sandström, and Ann-Kristin Ekman. 2013. The Archaeology of the Commons. Journal of Archaeology and Ancient History (JAAH), no. 10.

Loew, Oscar. 1875. Report on the Ruins of New Mexico. Vol. 1875. Washington, D.C. 
Longmore, Patrick, Michael Dale, Dale Counce, Andrew Manning, Toti Larson, Kim Granzow, Robert Gray, and Brent Newman. 2007. Radiogenic and Stable Isotope and Hydrogeochemical Investigation of Groundwater, Pajarito Plateau and Surrounding Areas, New Mexico. Los Alamos National Labs, LA-14333, Los Alamos, NM.

Lucero, Lisa J., and Barbara W. Fash, eds. 2006. Precolumbian water management: ideology, ritual, and power. Tucson, AZ: University of Arizona Press.

Lyman, R. L., and Michael J. O'brien. 2001. The direct historical approach, analogical reasoning, and theory in Americanist archaeology. Journal of Archaeological Method and Theory 8, no. 4: 303-42.

Maass, Arthur, and Raymond L. Anderson. 1978.... and the desert shall rejoice: conflict, growth, and justice in arid environments. Cambridge, MA: MIT press.

MacWilliams, A. C., and David D. Kuehn, Monica L. Murrell, Phillip O. Leckman. 2009. "FB 9122 Reservoir.” In Archaeological Mitigation at FB 17 (LA 91017) and FB 9122 (LA 30116) on the Dona Ana Range, Fort Bliss, Dona Ana County, New Mexico. eds MacWilliams, A. C., Bradley J. Vierra, and Kari Schmidt, 155-212. SRI Technical Report 09-13, El Paso, Texas.

Mallol, Carolina, Susan M. Mentzer, and Patrick J. Wrinn. 2009. A micromorphological and mineralogical study of site formation processes at the late Pleistocene site of Obi-Rakhmat, Uzbekistan. Geoarchaeology 24, no. 5: 548-75.

Margolis, Ellis Q., David M. Meko, and Ramzi Touchan. 2011. A tree-ring reconstruction of streamflow in the Santa Fe River, New Mexico. Journal of Hydrology 397, 1-2: 118-27.

Marston, Richard A. 2010. Geomorphology and vegetation on hillslopes: interactions, dependencies, and feedback loops. Geomorphology 116, no. 3: 206-17.

Mathers, Clay, Jeffrey M. Mitchem, and Charles M. Haecker, eds. 2013. Native and Spanish New Worlds: Sixteenth-Century Entradas in the American Southwest and Southeast. Tucson, AZ: University of Arizona Press.

Mathien, Frances J. 1990. Three Months on the Jemez Plateau: An Account of Edgar Lee Hewett's 1905 Field Season. In "Clues to the past: papers in honor of William M. Sundt," ed. Kirkpatrick Duran, 16: 185-202, Archaeological Society of New Mexico, Albuquerque, NM.

Mathien, Frances J. 1991. Glimpses into the History of the 1908 Fieldwork at Yapashi, Bandelier National Monument. In Puebloan Past and Present: Papers in Honor of Stewart Peckham, eds. Meliha Duran and David T. Kirkpatrick, 17: 121-32. Archaeological Society of New Mexico, Albuquerque, NM.

Mathien, Frances J., Charlie R. Steen, and Craig D. Allen. 1993. The Pajarito Plateau: a bibliography. Southwest Cultural Resources Center, Division of Anthropology, National Park Service, Professional Paper no. 49. 
Mathien, Joan. 2004. "History of Archaeological Investigations on the Pajarito Plateau.” In Archaeology of Bandelier National Monument: Village Formation on the Pajarito Plateau, New Mexico, ed. Timothy A. Kohler. Vol. 12, 69-116. Albuquerque, New Mexico:

University of New Mexico.

McAvoy, F. 1986. Excavations at Daw's Castle, Watchet, 1982. Proceedings of the Somerset Archaeoloy and Natural History Society 130: 47-60.

McCoy, Mark D., Peter R. Mills, Steven Lundblad, Tim Rieth, Jennifer G. Kahn, and Rowan Gard. 2011. A cost surface model of volcanic glass quarrying and exchange in Hawai ' $\mathrm{i}$. Journal of Archaeological Science 38, no. 10: 2547-60.

McGee, William J. 1896. Sheetflood erosion. Geological Society of America Bulletin 8, no. 1: $87-112$.

McGinnis, Michael, and Elinor Ostrom. 2014. Social-ecological system framework: initial changes and continuing challenges. Ecology and Society 19, no. 2.

McKean, Margaret A. 1992. Success on the commons: a comparative examination of institutions for common property resource management. Journal of theoretical politics 4, no. 3: 247-81.

Meltzer, David J. 1979. Paradigms and the nature of change in American archaeology. American Antiquity 44, no. 4: 644-57.

Meltzer, David J. 1991. Altithermal archaeology and paleoecology at Mustang Springs, on the Southern High Plains of Texas. American Antiquity 56, no. 2: 236-67.

Mentzer, Susan M., David G. Romano, and Mary E. Voyatzis. 2017. Micromorphological contributions to the study of ritual behavior at the ash altar to Zeus on Mt. Lykaion, Greece. Archaeological and Anthropological Sciences 9, no. 6: 1017-43.

Mitchell, Peter. 2008. Practising archaeology at a time of climatic catastrophe. Antiquity 82, no. 318: 1093-103.

Mithen, Steven. 2012. Thirst: For Water and Power in the Ancient World. Cambridge, MA: Harvard University Press.

Morley, Selma E. 2002. Stylistic variation and group self-identity: Evidence from the Rio Grande Pueblos. University of California.

Morrison, Kathleen D. 1994. The intensification of production: archaeological approaches. Journal of Archaeological Method and Theory 1, no. 2: 111-59.

Morton, John F. 2007. The impact of climate change on smallholder and subsistence agriculture. Proceedings of the National Academy of Sciences 104, no. 50: 19680-85.

Murrell, Monica L. 2006. An Investigation of Prehistoric Water Management in the Chupadera Arroyo Basin, Central New Mexico. New Mexico State University. 
Nabhan, Gary P. 1982. "Papago Indian Desert Agriculture and Water Control.” In Application of Remote Sensing in Evaluating Floodwater Farming on the Papago Indian Reservation: Completion Report, 41-80. Tucson, Arizona: The Program.

Nabhan, Gary P. 1986. Papago Indian desert agriculture and water control in the Sonoran Desert, 1697-1934. Applied Geography 6, no. 1: 43-59.

Nash, Stephen E. 1999. Time, Trees, and Prehistory: Tree-Ring Dating and the Development of North American Archaeology, 1914-1950. Salt Lake City, Utah: University of Utah Press.

Natural Resources Conservation Service (NRCS). 2005. Earth Dams and Reservoirs. United States Department of Agriculture, Washington, D.C.

Neely, James A., Michael J. Aiuvalasit, and Vincent A. Clause. 2015. New light on the prehistoric Purrón Dam Complex: Small corporate group collaboration in the Tehuacán Valley, Puebla, México. Journal of Field Archaeology 40, no. 3: 347-64.

Nelson, Esther I., Tim Haarmann, David C. Keller, and Teralene Foxx. 1998. Studies of annual and seasonal variations in four species of reptiles and amphibians at Los Alamos National Laboratory. Los Alamos National Lab, LA-13476-MS, Los Alamos, NM.

Nelson, Margaret, Michelle Hegmon, Stephanie Kulow, Matthew Peeples, Keith Kintigh, and Ann Kinzig. 2011. Resisting diversity: a long-term archaeological study. Ecology and Society 16, no. 1.

Nelson, Margaret C., Michelle Hegmon, Stephanie Kulow, and Karen G. Schollmeyer. 2006. Archaeological and ecological perspectives on reorganization: A case study from the Mimbres region of the US Southwest. American Antiquity: 403-32.

Nelson, Margaret C., Scott E. Ingram, Andrew J. Dugmore, Richard Streeter, Mathew A. Peeples, Thomas H. McGovern, Michelle Hegmon, Jette Arneborg, Keith W. Kintigh, Seth Brewington, Katherine A. Spielmann, Ian A. Simpson, Colleen Strawhacker, Comeau, Laura E L, Andrea Torvinen, Christian K. Madsen, George Hambrecht, and Konrad Smiarowski. 2016. Climate challenges, vulnerabilities, and food security. Proceedings of the National Academy of Sciences of the United States of America 113, no. 2: 298-303.

Nelson, Nels C. 1914. Pueblo Ruins of the Galisteo Basin, New Mexico. Vol. 15 of Anthropological Papers. Washington, D.C.: American Museum of Natural History.

Netting, Robert M. 1981. Balancing on an Alp: ecological change and continuity in a Swiss mountain community. Cambridge, UK: Cambridge University Press.

Newman, Brent D., Enrique R. Vivoni, and Armand R. Groffman. 2006. Surface watergroundwater interactions in semiarid drainages of the American southwest. Hydrological Processes 20, no. 15: 3371-94.

Nilsson, Christina. 2008. Climate change from an indigenous perspective. Indigenous Affairs: 12. 
O'Brien, Michael J., R. L. Lyman, and Michael B. Schiffer. 2005. Archaeology as a process: Processualism and its progeny. Salt Lake City, Utah: University of Utah Press.

Olson, Mancur. 2009. The logic of collective action. Cambridge, MA: Harvard University Press.

Oosthuizen, Susan. 2013. Beyond hierarchy: the archaeology of collective governance. World Archaeology 45, no. 5: 714-29.

Oosthuizen, Susan. 2013. Tradition and Transformation in Anglo-Saxon England: Archaeology, Common Rights and Landscape. London, UK: Bloomsbury Publishing.

Ophuls, William. 1973. “Leviathan or oblivion.” In Toward a Steady State Economy, ed. Herman E. Daly, 215-30. San Francisco, CA: W. H.Freeman \& Co Ltd.

Orcutt, Janet D. 1991. Environmental Variability and Settlement Changes on the Pajarito Plateau, New Mexico. American Antiquity 56, no. 2: 315-32.

Orcutt, Janet D. 1999. “Chronology.” In The Bandelier archeological survey, ed. Robert P. Powers and Janet D. Orcutt. Vol. 57 of Intermontain Cultural Resources Manament Program, Professional Paper, 85-116: National Park Service, Department of the Interior.

Ortiz, Alfonso. 1969. The Tewa world: Space, time, being, and becoming in a Pueblo society. Chicago, IL: University of Chicago Press.

Ortiz, Alfonso, ed. 1972. New perspectives on the Pueblos. Albuquerque, NM: University of New Mexico Press.

Ortman, Scott G. 2012. Winds from the North: Tewa origins and historical anthropology. Salt Lake City, Utah: University of Utah Press.

Ortman, Scott G. 2016. Uniform probability density analysis and population history in the northern Rio Grande. Journal of Archaeological Method and Theory 23, no. 1: 95-126.

Ostrom, Elinor. 1990. Governing the commons: The evolution of institutions for collective action. Cambridge, UK: Cambridge University Press.

Ostrom, Elinor. 1993. Design principles in long-enduring irrigation institutions. Water Resources Research 29, no. 7: 1907-12.

Ostrom, Elinor. 2005. Understanding Institutional Diversity. Princeton, NJ: Princeton University Press.

Ostrom, Elinor. 2007. A diagnostic approach for going beyond panaceas. Proceedings of the National Academy of Sciences 104, no. 39: 15181-87.

Ostrom, Elinor. 2009. A general framework for analyzing sustainability of social-ecological systems. Science 325, no. 5939: 419-22. 
Ostrom, Elinor. 2014. Collective action and the evolution of social norms. Journal of Natural Resources Policy Research 6, no. 4: 235-52.

Owens, John G. 1892. "Natal ceremonies of the Hopi Indians.” In A few summer ceremonials at the Tusayan pueblos, ed. Jesse W. Fewkes and John G. Owens: AMS Press.

Paganelli Votto, Mary, and Frances Manuel. 2010. From I'itoi's Garden: Tohono O'odham Food Traditions. Sells, AZ.

Palacios-Fest, Manuel R., James M. Bayman, Lisa W. Huckell, and Suzanne K. Fish. 2008. "Paleoecology of an earthen reservoir in Organ Cactus National Monument." In Fragile patterns: the archaeology of the Western Papaguería, ed. Jeffrey H. Altschul and Adrianne G. Rankin, 165-78: SRI Press Tucson, AZ.

Pande, Saket, Maurits Ertsen, and Murugesu Sivapalan. 2014. Endogenous technological and population change under increasing water scarcity. Hydrology and Earth System Sciences 18, no. 8: 3239-58.

Pande, Saket, and Murugesu Sivapalan. 2017. Progress in socio-hydrology: a meta-analysis of challenges and opportunities. Wiley Interdisciplinary Reviews: Water 4, no. 4: 1-18.

Parsons, Elsie C. 1918. Notes on Acoma and Laguna. American Anthropologist 20, no. 2: 16286.

Parsons, Elsie C. 1925. The pueblo of Jemez. Andover, MA: AMS Press.

Parsons, Elsie C. 1936. Taos Pueblo. Vol. 2 of General Series in Anthropology. Menasha, Wisconsin: George Banta Publishing Company.

Parsons, Elsie C. 1939. Pueblo indian religion. Lincoln, Nebraska: U of Nebraska Press.

Paytiamo, James. 1932. Flaming Arrow's people. New York, NY: Duffield and Green.

Peters, Guy. 1999. The new institutionalism. London, UK: Cassell and Co.

Petersen, Kenneth L. 1994. A warm and wet Little Climatic Optimum and a cold and dry Little Ice Age in the southern Rocky Mountains, USA. Climatic Change 26: 243-69.

Phillips, Shaun, and Phillip O. Leckman. 2012. "Wandering the Desert: Least Cost Path Modeling for Water Transport Trails in the Jornada Mogollon Region, Fort Bliss, SouthCentral New Mexico.” In Least cost analysis of social landscapes: archaeological case studies, ed. Devin A. White and Sarah L. Surface-Evans, 46-66. Salt Lake City, Utah: University of Utah Press.

Pigati, Jeffrey S., Jason A. Rech, Jay Quade, and Jordon Bright. 2014. Desert wetlands in the geologic record. Earth-Science Reviews 132: 67-81.

Poling, Charles. 2015. The Search for Moho. American Archaeology 19, no. 1: 39-45. 
Powers, Robert P., ed. 2005. The peopling of Bandelier: new insights from the archaeology of the Pajarito Plateau. Santa Fe, New Mexico: School for Advanced Research.

Powers, Robert P., and Janet D. Orcutt, eds. 1999. The Bandelier archeological survey. Vol. 57 of Intermontain Cultural Resources Manament Program, Professional Paper: National Park Service, Department of the Interior.

Preucel, Robert W. 1990. Seasonal Circulation and Dual Residence in the Pueblo Southwest: A Prehistoric Example from the Pajarito Plateau, New Mexico. New York, NY: Garland Publishing.

Preucel, Robert W. 2005. “The Journey from Shipap.” In The peopling of Bandelier: new insights from the archaeology of the Pajarito Plateau, ed. Robert P. Powers, 95-102. Santa Fe, New Mexico: School for Advanced Research.

Preucel, Robert W., Loa P. Traxler, and Michael Wilcox. 2002. Now the God of the Spaniards is Dead": Ethnogenesis and Community Formation in the Aftermath of the Pueblo Revolt of 1680. In Traditions, Transitions, and Technologies An Introduction, ed. Sarah H. Schlanger, 71-93. Boulder, CO: University Press of Colorado.

Prince, L. B. 1903. The stone lions of Cochiti. Vol. 4. Santa Fe, New Mexico: Historical Society of New Mexico.

PRISM Climate Group. 2016. 800 m Grid mean annual precipitation map, Oregon State University. http://prism.oregonstate.edu (accessed May 1, 2016).

Purdue, Louise, Wesley Miles, Kyle Woodson, Andrew Darling, and Jean-François Berger. 2010. Micromorphological study of irrigation canal sediments: Landscape evolution and hydraulic management in the middle Gila River valley (Phoenix Basin, Arizona) during the Hohokam occupation. Quaternary International 216, 1-2: 129-44.

Purtymun, William D. 1995. Geologic and hydrologic records of observation wells, test holes, test wells, supply wells, springs, and surface water stations in the Los Alamos area. Los Alamos National Laboratory, LA-12883-MS, Los Alamos, NM.

Purtymun, William D., and Howard Adams. 1980. Geohydrology of Bandelier National Monument, New Mexico. Los Alamos National Laboratory, LA-8461-MS, Los Alamos, NM.

Ramsey, C. B., and Sharen Lee. 2013. Recent and planned developments of the program OxCal. Radiocarbon 55, 2-3: 720-30.

Ravesloot, John C., J. A. Darling, and Waters. 2009. "Hohokam and Pima-Maricopa irrigation agriculturalists." In The archaeology of environmental change: socionatural legacies of degradation and resilience, ed. Christopher T. Fisher, James B. Hill, and Gary M. Feinman, 232-45: University of Arizona Press.

Redman, Charles L. 1999. Human impact on ancient environments. Tucson, AZ: University of Arizona Press. 
Reed, Paul F., ed. 2002. Foundations of Anasazi culture: The basketmaker pueblo transition. Salt Lake City, Utah: University of Utah Press.

Reimer, Paula J., Edouard Bard, Alex Bayliss, J. W. Beck, Paul G. Blackwell, Christopher B. Ramsey, Caitlin E. Buck, Hai Cheng, R. L. Edwards, and Michael Friedrich. 2013. IntCal13 and Marine13 radiocarbon age calibration curves $0-50,000$ years cal BP. Radiocarbon 55, no. 4: 1869-87.

Reimer, Paula J., Thomas A. Brown, and Ron W. Reimer. 2004. Discussion: reporting and calibration of post-bomb 14C data. Radiocarbon 46, no. 3: 1299-304.

Reiter, Paul, ed. 1938. The Jemez Pueblo of Unshagi, New Mexico. Anthropological Series. Albuquerque, NM.

Reneau, Steven L. 2000. Stream incision and terrace development in Frijoles Canyon, Bandelier National Monument, New Mexico, and the influence of lithology and climate. Geomorphology 32, no. 1: 171-93.

Rodriguez-Iturbe, Ignacio. 2000. Ecohydrology: A hydrologic perspective of climate-soilvegetation dynamics. Water Resources Research 36, no. 1: 3-9.

Rohn, Arthur H. 1963. Prehistoric soil and water conservation on Chapin Mesa, southwestern Colorado. American Antiquity 28, no. 4: 441-55.

Rohn, Arthur H. 1972. Social Implications of Pueblo Water Management in the Northern San Juan. Zeitschrift für Ethnologie, H. 2: 212-19.

Roney, John R. 1996. "The Pueblo III period in the eastern San Juan basin and Acoma-Laguna areas.” In The prehistoric Pueblo world, AD 1150-1350, ed. Michael A. Adler, 145-69: University of Arizona Press.

Roos, Christopher I. 2008. Fire, climate, and social-ecological systems in the ancient Southwest: alluvial geoarchaeology and applied historical ecology. The University of Arizona.

Roos, Christopher I. 2011. Archaeology, Climate Change, and Sustainability of Human Ecosystems. Anthropology News 52, no. 4: 27.

Roos, Christopher I., and E. C. Wells. 2017. Geoarchaeology of ritual behavior and sacred places: an introduction. Archaeological and Anthropological Sciences 9, no. 6: 1001-04.

Rowland, Michael. 2010. Will the sky fall in? Global warming-an alternative view. Antiquity 84, no. 326: 1163-71.

Sabloff, Jeremy A. 2016. Archaeology matters: action archaeology in the modern world. New York, NY: Routledge.

Safi, Kristin N. 2014. Using Least Cost Pathways to Understand the Processes of Migration from the Mesa Verde Region during the Pueblo III Period. Kiva 80, no. 1: 28-44. 
Saile, David G. 1990. “Understanding the Development of Pueblo Architecture.” In Pueblo style and regional architecture, ed. Nicholas C. Markovich, Wolfgang F. E. Preiser, and Fred G. Sturm, 49-63. New York, NY: Van Nostrand Reinhold.

Sando, Joe S. 1982. Nee Hemish, a history of Jemez Pueblo. 1st ed. Albuquerque, NM: University of New Mexico Press.

Saxton, K. E., and W. Rawls. 2005. Soil water characteristics hydraulic properties calculator. https://hrsl.ba.ars.usda.gov/soilwater/Index.htm (accessed July 19, 2017).

Scarborough, Vernon L. 2003. The flow of power: ancient water systems and landscapes. Santa Fe, NM: School for Advanced Research.

Scarborough, Veron L. 1988. A Water Storage Adaptation in the American Southwest. Journal of Anthropological Research 44, no. 1: 21-40.

Schiffer, Michael B. 1986. Radiocarbon dating and the “old wood” problem: the case of the Hohokam chronology. Journal of Archaeological Science 13, no. 1: 13-30.

Schiffer, Michael B. 1987. Formation processes of the archaeological record. Albuquerque, NM: University of New Mexico Press.

Schlager, Edella, and Elinor Ostrom. 1992. Property-rights regimes and natural resources: a conceptual analysis. Land economics 68, no. 3: 249-62.

Schmidt, Kari M. 2008. “Analysis of Faunal Remains from the Land Conveyance Project, Los Alamos, New Mexico.” In The Land Conveyance and Transfer Data Recovery Project: 7000 Years of Land Use on the Pajarito Plateau. NMCRIS, 597-652. Los Alamos, NM.

Schoeneberger, Philip J. 2012. Field book for describing and sampling soils. 3rd ed. Lincoln, Nebraska: National Soil Survey Center.

Schroeder, Albert H., James Bain, and Helen G. Blumenschein. 1980. Collected papers in honor of Helen Greene Blumenschein. Albuquerque, NM, 1980.

Schwindt, Dylan M., R. K. Bocinsky, Scott G. Ortman, Donna M. Glowacki, Mark D. Varien, and Timothy A. Kohler. 2016. The Social Consequences of Climate Change in the Central Mesa Verde Region. American Antiquity 81, no. 1: 74-96.

Sedgwick, Mary Katrine Rice. 1926. Acoma, the Sky City: A Study in Pueblo-Indian History and Civilization. Cambridge, MA: Harvard University Press.

Sekaquaptewa, Helen. 1969. Me and mine: the life story of Helen Sekaquaptewa. Tucson, AZ: University of Arizona Press.

Shafer, Harry J., and Harold Drollinger. 1998. Classic Mimbres adobe-lined pits, plazas, and courtyards at the NAN Ruin, Grant County, New Mexico. Kiva 63, no. 4: 379-99. 
Shaffer, Brian S., and Karen M. Gardner. 1998. Female jar carriers of the mimbres: Probable prehistoric depictions of water transportation. North American Archaeologist 19, no. 3: 22331.

Shepard, Anna O. 1938. “Technological Notes on the Pottery From Unshagi.” In The Jemez Pueblo of Unshagi, New Mexico, ed. Paul Reiter. Anthropological Series, 205-11. Albuquerque, NM.

Simmons, Marc. 1969. Settlement patterns and village plans in colonial New Mexico. Journal of the West 8, no. 1: 7-21.

Simpson, James H. 1852. Journal of a military reconnaissance from Santa Fe, New Mexico, to the Navajo country: made with the troops under command of Brevet Lieutenant Colonel John M. Washington, chief of Ninth military department, and governor of New Mexico, in 1849. Philadelphia, PA: Lippincott, Grambo and Co.

Smith, Michael E. 2011. The comparative archaeology of complex societies. Cambridge, UK: Cambridge University Press.

Smith, Monica L. 2005. "Writing History at Bandelier National Monument.” In The peopling of Bandelier: new insights from the archaeology of the Pajarito Plateau, ed. Robert P. Powers, 103-10. Santa Fe, New Mexico: School for Advanced Research.

Smith, Robert J. 1981. Resolving the tragedy of the commons by creating private property rights in wildlife. Cato Journal 1, no. 2: 439-68.

Smith, Robert L., Roy A. Bailey, Clarence S. Ross, and Geological Survey. 1970. Geologic map of the Jemez Mountains, New Mexico. Vol. 571: U.S. Geological Survey.

Smith, Schaun M. 2008. Paleohydrogeologic modeling of groundwater resources from A. D. 600 to 1300 and the relationship to Ancestral Pueblo settlement population dynamics, central Mesa Verde region, southwest Colorado. Colorado School of Mines.

Smol, J. P., and E. F. Stoermer. 2010. “Applications and uses of diatoms: prologue.” In The diatoms: applications for the environmental and earth sciences, ed. John P. Smol and Eugene F. Stoermer, 3-7. Cambridge, UK: Cambridge University Press.

Smol, John P., and Eugene F. Stoermer, eds. 2010. The diatoms: applications for the environmental and earth sciences. Cambridge, UK: Cambridge University Press.

Snead, James E. 2006. "Mirror of the Earth: Water, Landscape, and Meaning in the Precolumbian Southwest.” In Precolumbian water management: ideology, ritual, and power, ed. Lisa J. Lucero and Barbara W. Fash, 205-22. Tucson, AZ: University of Arizona Press.

Snead, James E. 2008. Ancestral Landscapes of the Pueblo World. Tucson, Arizona: University of Arizona Press. 
Snead, James E., Winifred Creamer, and T. V. Zandt. 2004. "Ruins of our forefathers.” In The protohistoric Pueblo world, AD 1275-1600, ed. E. C. Adams and Andrew I. Duff, 26-34: University of Arizona Press.

Soil Conservation Service (SCS). 1986. Urban Hydrology for Small Watersheds. Washington, D.C., 1986.

Spielmann, Katherine A. 2005. "Ethnographic analogy and ancestral Pueblo archaeology.” In Southwest archaeology in the twentieth century, ed. Linda S. Cordell and Don D. Fowler, 194-203: University of Utah Press.

Stahle, D. W., M. K. Cleaveland, H. D. Grissino-Mayer, R. D. Griffin, F. K. Fye, M. D. Therrell, D. J. Burnette, D. M. Meko, and J. Villanueva Diaz. 2009. Cool-and warm-season precipitation reconstructions over western New Mexico. Journal of Climate 22, no. 13: 372950 .

Stahle, David W., Falko K. Fye, Edward R. Cook, and R. D. Griffin. 2007. Tree-ring reconstructed megadroughts over North America since AD 1300. Climatic Change 83, 1-2: $133-49$.

Staller, John, Robert Tykot, and Bruce Benz, eds. 2006. Histories of maize: multidisciplinary approaches to the prehistory, linguistics, biogeography, domestication, and evolution of maize. Walnut Creek, California: Left Coast Press.

Stein, Julie K., ed. 2001. Sediments in archaeological context. Salt Lake City, Utah: Univ of Utah Press.

Stevenson, Matilda C. 1894. The Sia. Vol. 11 of Annual Report. Washington, D.C.: Bureau of Ethnology.

Steward, Julian H. 1942. The direct historical approach to archaeology. American Antiquity 7, no. 4: 337-43.

Surface-Evans, Sarah L., and Devin A. White. 2012. "An introduction to the least cost analysis of social landscapes.” In Least cost analysis of social landscapes: archaeological case studies, ed. Devin A. White and Sarah L. Surface-Evans, 1-7. Salt Lake City, Utah: University of Utah Press.

Swetnam, Thomas W., Joshua Farella, Christopher I. Roos, Matthew J. Liebmann, Donald A. Falk, and Craig D. Allen. 2016. Multiscale perspectives of fire, climate and humans in western North America and the Jemez Mountains, USA. Phil. Trans. R. Soc. B 371, no. 1696: 20150168.

Tafoya, April J. 2012. Uranium-series geochronology and stable isotope analysis of travertine from Soda Dam, New Mexico: a Quaternary record of episodic spring discharge and rivern incision in the Jemez Mountains hydrothermal system. University of New Mexico. 
Tainter, Joseph A., and Bonnie B. Tainter, eds. 1996. Evolving complexity and environmental risk in the prehistoric Southwest: proceedings of the Workshop" Resource Stress, Economic Uncertainty, and Human Response in the Prehistoric Southwest," held February 25-29, 1992, in Santa Fe, NM. XXIV of Proceedings. Reading, MA: Addison-Wesley.

Thomas, R. J. 2008. Opportunities to reduce the vulnerability of dryland farmers in Central and West Asia and North Africa to climate change. Agriculture, Ecosystems \& Environment 126, no. 1: 36-45.

Tobler, Waldo. 1993. Three presentations on geographical analysis and modeling. I-93 of Technical Report: National Center for Geographic Information and Analysis. http://escholarship.org/uc/item/05r820mz (accessed September 12, 2016).

Toll, Henry W., ed. 1995. Soil, water, biology, and belief in prehistoric and traditional Southwestern agriculture. Vol. 2. Albuquerque, NM: New Mexico Archaeological Council.

Tompkins, Emma, and W. N. Adger. 2004. Does adaptive management of natural resources enhance resilience to climate change? Ecology and Society 9, no. 2: 1-14.

Touchan, Ramzi, Connie A. Woodhouse, David M. Meko, and Craig D. Allen. 2011. Millennial precipitation reconstruction for the Jemez Mountains, New Mexico, reveals changingb drought signal. International Journal of Climatology 31, no. 6: 896-906.

Towner, Ronald H. 2008. "The Current Status of Archaeological Dendrochronology and Dendroclimatology of the Pajarito Plateau." In The Land Conveyance and Transfer Data Recovery Project: 7000 Years of Land Use on the Pajarito Plateau. eds. Bradley J. Vierra and Kari M. Schmidt, Los Alamos National Laboratory, LA-UR-07-6205, 123-84. Los Alamos, NM.

Towner, Ronald H., and Mathew W. Salzer. 2013. "Dendroclimatic Reconstructions of Precipitation for the Northern Rio Grande.” In From Mountaintop to Valley Bottom Understanding Past Land Use in the Northern Rio Grande Valley, New Mexico, ed. Bradley J. Vierra, 54-68. Salt Lake City, Utah: University of Utah Press.

Townshend, Richard B. 1924. Tenderfoot in New Mexico. New York, NY: Dodd, Mead and Company.

Toyoda, Shin, Fraser Goff, Sumiko Ikeda, and Motoji Ikeya. 1995. ESR dating of quartz phenocrysts in the El Cajete and Battleship Rock Members of Valles Rhyolite, Valles Caldera, New Mexico. Journal of Volcanology and Geothermal Research 67, 1-3: 29-40.

Trigger, Bruce G. 2006. A History of Archaeological Thought. Cambridge, UK: Cambridge University Press.

Turney, William F. 1984. Prehistoric Water Reservoirs - the Southwest. In "Collected Papers in Honor of Albert H. Schroeder. Papers of The Archaeological Society of New Mexico," ed. Charles Lange, 10: 43-57, Archaeological Society of New Mexico, Albuquerque, New Mexico. 
Turney, William F. 1990. Prehistoric Reservoirs at San Lazaro. In "Clues to the past: papers in honor of William M. Sundt,” ed., Kirkpatrick Duran, 16: 307-14. Archaeological Society of New Mexico, Albuquerque, New Mexico.

Turney, William F., and Mary M. Turney. 1983. Supplemental Report to Possible Reservoirs on Boletsakwa Mesa, report on file at the Santa Fe National Forest, Santa Fe, NM.

United States Department of Agriculture (USDA). 1998. Ponds - Planning, Design, Construction. Agricultural Handbook, Washington, D.C.

Van de Noort, Robert. 2011. Conceptualising climate change archaeology. Antiquity 85, no. 329: 1039-48.

Van Keuren, Scott, and Christopher I. Roos. 2013. Geoarchaeological evidence for ritual closure of a kiva at Fourmile Ruin, Arizona. Journal of Archaeological Science 40, no. 1: 615-25.

Van West, Carla R, Thomas C. Windes, Frances Levine, Henri D. Grissino-Mayer, and Matthew W. Salzer. 2013. "The Role of Climate in Early Spanish-Native American Interactions in the US Southwest." In Native and Spanish New Worlds: Sixteenth-Century Entradas in the American Southwest and Southeast, ed. Clay Mathers, Jeffrey M. Mitchem, and Charles M. Haecker, 81-98. Tucson, AZ: University of Arizona Press.

Van Zandt, Tineke Renee. 2006. Shaping stones, shaping pueblos: Architecture and site layout in Bandelier National Monument, New Mexico, AD 1150 to 1600. University of Michigan.

Vierra, Bradley J. 2005. “Ancient Foragers of the High Desert Country.” In The peopling of Bandelier: new insights from the archaeology of the Pajarito Plateau, ed. Robert P. Powers, 19-26. Santa Fe, New Mexico: School for Advanced Research.

Vierra, Bradley J., ed. 2013. From Mountaintop to Valley Bottom Understanding Past Land Use in the Northern Rio Grande Valley, New Mexico. Salt Lake City, Utah: University of Utah Press.

Vierra, Bradley J., and Richard I. Ford. 2006. "Early maize agriculture in the northern Rio Grande valley, New Mexico.” In Histories of maize: multidisciplinary approaches to the prehistory, linguistics, biogeography, domestication, and evolution of maize, ed. John Staller, Robert Tykot, and Bruce Benz, 497-510. Walnut Creek, California: Left Coast Press.

Vierra, Bradley J., and Kari M. Schmidt. 2008. The Land Conveyance and Transfer Data Recovery Project: 7000 Years of Land Use on the Pajarito Plateau. Los Alamos National Laboratory, LA-UR-07-6205, Los Alamos, NM.

Vint, James M. 2005. "From Broken Pots to Shifting Boundaries.” In The peopling of Bandelier: new insights from the archaeology of the Pajarito Plateau, ed. Robert P. Powers, 71-78. Santa Fe, New Mexico: School for Advanced Research. 
Vivian, R. G. 1974. "Conservation and Diversion: Water-Control Systems in the Anasazi, Southwest.” In Irrigation's impact on society, ed. Theodore E. Downing and McGuire Gibson. Tucson, AZ: University of Arizona Press.

Vivian, R. G. 1990. The Chacoan prehistory of the San Juan basin. San Diego, California: Academic Press.

Vivian, R. G., and Adam S. Watson. 2015. "Reevaluating and Modeling Agricultural Potential in the Chaco Core.” In Chaco Revisited: New Research on the Prehistory of Chaco Canyon, New Mexico, ed. Carrie C. Heitman and Stephen Plog, 30-65. Tucson, AZ: University of Arizona Press.

Vuataz, François D., and Fraser Goff. 1986. Isotope geochemistry of thermal and nonthermal waters in the Valles Caldera, Jemez Mountains, northern New Mexico. J. Geophys. Res 91, B2: 1835-53.

Walsh, Michael R. 2000. Material evidence for social boundaries on the Pajarito Plateau, New Mexico. Kiva 65, no. 3: 197-213.

Ware, John A. 2014. A Pueblo social history: Kinship, sodality, and community in the northern Southwest. Santa Fe, New Mexico: School for Advanced Research.

Watkins, Kevin. 2006. Beyond scarcity: power, poverty and the glob2 al water crisis. New York, NY, 2006.

Wendorf, Fred, and Erik Reed. 1955. Alternative Reconstruction of Northern Rio Grande Prehistory. El Palacio 62: 131-73.

Weslowski, Lois V. 1981. "Native American Land Use Along Redondo Creek.” In High Altitude Adaptations Along Redondo Creek: the Baca Geothermal Anthropological Project, ed. Craig Baker and Joseph C. Winter, 105-27. Albuquerque, NM.

Wheat, Joe B. 1952. Prehistoric Water Sources of the Point of Pines Area. American Antiquity 17, no. 3: 185-96.

Wheeler, George M., Andrew A. Humphreys, and Horatio G. Wright. 1875. Report upon United States geographical surveys west of the one hundredth meridian. Washington, D.C.: US Government Printing Office.

Whipple, Amiel W., and Joseph C. Ives. 1856. Reports of Explorations and Surveys, to Ascertain the Most Practicable and Economical Route for a Railroad from the Mississippi River to the Pacific Ocean: Made Under the Direction of the Secretary of War, in 1853-6; According to Acts of Congress of March 3, 1853, May 31, 1854, and August 5, 1854. Vol. III Report of Explorations for a Railway Route, Near the Thirty-fifth Parallel of North Latitude, from the Mississippi River to the Pacific Ocean. Washington, D.C.: Tucker, B.

White, Devin A., and Sarah L. Surface-Evans, eds. 2012. Least cost analysis of social landscapes: archaeological case studies. Salt Lake City, Utah: University of Utah Press. 
White, Devin A. 2015. The basics of least cost analysis for archaeological applications. Advances in Archaeological Practice 3, no. 4: 407-14.

White, Leslie A. 1935. The Pueblo of Santo Domingo, New Mexico. Vol. 43 of Memoirs. Menasha, Wisconsin.

White, Leslie A. 1973. The Acoma Indians. Glorieta, NM: Rio Grande Press.

Whiteley, Peter M., and Vernon Masayesva. 1997. “The use and abuse of aquifers: Can the Hopi Indians survive multinational mining.” In Water, culture, and power: local struggles in a global context, ed. John Donahue, 9-34. Washington, D.C.: Island Press.

Whiteley, Peter M. 1988. Bacavi: Journey to Reed Springs. Flagstaff, Arizona: Northland Press Flagstaff.

Wilhite, Donald A., and Michael Glantz. 1985. Understanding the Drought Phenomenon: The Role of Definitions. Water International 10: 111-20.

Wilhite, Donald A., ed. 2005. Drought and water crises: science, technology, and management issues. Boca Raton, FL: CRC Press.

Wilhite, Donald A., and Margie Buchanan-Smith. 2005. "Drought as hazard: understanding the natural and social context.” In Drought and water crises: science, technology, and management issues, ed. Donald A. Wilhite, 1. Boca Raton, FL: CRC Press.

Wilshusen, Richard H., Melissa J. Churchill, and James M. Potter. 1997. Prehistoric reservoirs and water basins in the Mesa Verde Region: intensification of water collection strategies during the great Pueblo period. American Antiquity 62, no. 4: 664-81.

Wilson, James A., James M. Acheson, Mark Metcalfe, and Peter Kleban. 1994. Chaos, complexity and community management of fisheries. Marine Policy 18, no. 4: 291-305.

Winsborough, B. M. 1995. “Diatoms.” In Stratigraphy and paleoenvironments of late Quaternary valley fills on the Southern High Plains, ed. Vance T. Holliday. Vol. 186 of Memoirs, 67-82. Boulder, CO: Geological Society of America.

Winter, Joseph C., ed. 1983. High-altitude Adaptations in the Southwest. Vol. 2. Albuquerque, NM: USDA Forest Service, Southwestern Region.

Wiseman, Regge N. 2017. Giusewa: Laurens C. Hammack’s 1965 Excavations for the Visitor Center Water Line at Jemez Historic Site, Sandoval County, New Mexico. Albuquerque, New Mexico, 2017.

Wozniak, Frank E., Meade F. Kemrer, and Charles M. Carrillo, eds. 1992. History and ethnohistory along the Rio Chama. Albuquerque, NM: U.S. Army Corps of Engineers.

Wright, Kenneth R. 2006. The Water Mysteries of Mesa Verde. Boulder, CO: Big Earth Publishing. 
Wutich, Amber, Alexandra Brewis, Amanda L. Logan, Kenneth Maes, George Armelagos, Barbara A. Piperata, Paola Rattu, Edward G. J. Stevenson, Craig Hadley, and Andrea S. Wiley. 2014. Food, water, and scarcity: toward a broader anthropology of resource insecurity. Current Anthropology 55, no. 4: 444-68.

Wyckoff, Don G. 1977. Secondary Forest Succession Following Abandonment of Mesa Verde. Kiva 42, 3/4: 215-31.

Zhou, Kemin. 1997. Essentials of robust control. Upper Saddle River, NJ: Prentice Hall.

Zimmerer, Matthew J., John Lafferty, and Matthew A. Coble. 2016. The eruptive and magmatic history of the youngest pulse of volcanism at the Valles caldera: Implications for successfully dating late Quaternary eruptions. Journal of Volcanology and Geothermal Research 310: 5057. 
APPENDIX A: SPRING DATA

Documented Springs in the Jemez Plateau Study Area

\begin{tabular}{|c|c|c|c|c|c|c|c|c|}
\hline \multirow[b]{2}{*}{ Spring Name } & \multicolumn{4}{|c|}{$\begin{array}{c}\text { Location (NAD83, UTM 13N) } \\
\text { \& Hydro Context }\end{array}$} & \multicolumn{4}{|c|}{ Water Measurements } \\
\hline & $\mathbf{E}$ & $\mathbf{N}$ & Geo Unit & $\begin{array}{l}\text { Water } \\
\text { Type }\end{array}$ & $\begin{array}{l}\text { Discharge } \\
\text { Rate } \\
\text { (gpm) }\end{array}$ & $\begin{array}{l}\text { Spec. } \\
\text { Cond. } \\
(\mu \mho / \mathrm{cm})\end{array}$ & $\begin{array}{l}\text { Sampling } \\
\text { Date }\end{array}$ & Source \\
\hline $\begin{array}{l}\text { Agua Durme } \\
\text { Springs }\end{array}$ & 346446 & 3964009 & $\mathrm{Tsd} / \mathrm{Pa}$ & 4 & 100 & 160 & 5/8/1973 & $\begin{array}{l}\text { Trainer } \\
\text { 1978: } \\
\text { Table 1 }\end{array}$ \\
\hline Alamo Spring & 349089 & 3966507 & $\begin{array}{l}\text { Tnv/ } \\
\text { Qcbt/ Pa }\end{array}$ & 4 & . & . & . & . \\
\hline $\begin{array}{l}\text { Banco Bonito } \\
\text { Wetland }\end{array}$ & 356246 & 3968870 & Qal/Qvb & 6 & . & • & . & $\cdot$ \\
\hline Barrel Spring & 356927 & 3953335 & Qvec/Tpa & 4 & . & . & . & . \\
\hline $\begin{array}{l}\text { Bear Wallow } \\
\text { Spring }\end{array}$ & 356345 & 3957490 & $\begin{array}{l}\text { Qvec/ } \\
\text { Tpbhd }\end{array}$ & 4 & . & & . & . \\
\hline Butterfly Spring & 338972 & 3962169 & $\mathrm{Cu}$ (Ipm) & 4 & 50 & 365 & 11/30/1973 & $\begin{array}{l}\text { Trainer } \\
\text { 1978: } \\
\text { Table 1 }\end{array}$ \\
\hline $\begin{array}{l}\text { Canon Cebollita } \\
\text { Spring }\end{array}$ & 339128 & 3959850 & $\mathrm{Cu}$ (Ipm) & 4 & 20 & 210 & 11/30/1973 & $\begin{array}{l}\text { Trainer } \\
\text { 1978: } \\
\text { Table 1 }\end{array}$ \\
\hline $\begin{array}{l}\text { Canon de la } \\
\text { Canada Spring }\end{array}$ & 347202 & 3949415 & Pc & 3 & . & . & . & $\cdot$ \\
\hline Cebollita Springs & 344341 & 3966688 & $\begin{array}{l}\text { Qal/ Qt/ } \\
\text { Qbo }\end{array}$ & 6 & . & . & . & . \\
\hline $\begin{array}{l}\text { Chimal Road } \\
\text { Spring }\end{array}$ & 344341 & 3966688 & $\mathrm{~Pa}$ & 6 & . & & . & . \\
\hline $\begin{array}{l}\text { Church Canyon } \\
\text { Spring }\end{array}$ & 349825 & 3962072 & Tpb/Qco & 4 & $\mathrm{n} / \mathrm{a}$ & 320 & $12 / 4 / 1972$ & $\begin{array}{l}\text { Trainer } \\
\text { 1978: } \\
\text { Table 1 }\end{array}$ \\
\hline $\begin{array}{l}\text { Dead Horse } \\
\text { Spring }\end{array}$ & 354986 & 3960374 & Tpa/ Qvec & 4 & . & . & . & $\cdot$ \\
\hline Gilman Spring & 340428 & 3953005 & $\mathrm{~Pa}$ & 3 & . & $\cdot$ & . & . \\
\hline Gonzales Spring & 355488 & 3960924 & Qal/ Tpa & 4 & . & . & . & . \\
\hline $\begin{array}{l}\text { Hondo Canyon } \\
\text { Spring }\end{array}$ & 356451 & 3949441 & Tpv & 4 & . & . & . & . \\
\hline Jarita Spring & 355855 & 3954064 & Qvec/ Qal & 4 & . & . & . & . \\
\hline $\begin{array}{l}\text { Jemez Hot } \\
\text { Springs }\end{array}$ & 347169 & 3959996 & $\mathrm{~Pa}$ & 3 & 4.5 & 5500 & $12 / 4 / 1972$ & $\begin{array}{l}\text { Trainer } \\
\text { 1978: } \\
\text { Table 1 }\end{array}$ \\
\hline
\end{tabular}




\begin{tabular}{|c|c|c|c|c|c|c|c|c|}
\hline $\begin{array}{l}\text { Jemez Hot } \\
\text { Springs-Original }\end{array}$ & 347288 & 3960119 & $\mathrm{~Pa}$ & 3 & . & . & . & . \\
\hline $\begin{array}{l}\text { Kwastiyukwa } \\
\text { Step Pools }\end{array}$ & 341168 & 3958160 & Qal/Qbo & 8 & . & . & . & . \\
\hline Lake Fork Spring & 344865 & 3970219 & Qal/Qvr & 4 & . & . & . & . \\
\hline Llano Loci Spring & 338522 & 3963286 & Cu (Ipm) & 3 & . & . & . & . \\
\hline \multirow[t]{2}{*}{$\begin{array}{l}\text { McCauley/ } \\
\text { Abousleman } \\
\text { Spring }\end{array}$} & \multirow[t]{2}{*}{352986} & \multirow[t]{2}{*}{3965205} & \multirow[t]{2}{*}{ Qls } & \multirow[t]{2}{*}{3} & 359 & 170 & 12/3/1972 & $\begin{array}{l}\text { Trainer } \\
\text { 1978: } \\
\text { Table } 1\end{array}$ \\
\hline & & & & & 368 & 180 & $1 / 16 / 1973$ & $\begin{array}{l}\text { Trainer } \\
\text { 1978: } \\
\text { Table } 1\end{array}$ \\
\hline Ojo de los Judios & 355753 & 3962223 & Qvec & 4 & . & . & . & . \\
\hline Pajarito Spring I & 338837 & 3952896 & $\mathrm{~Pa}$ & 4 & . & . & . & . \\
\hline Pajarito Spring II & 337307 & 3952957 & $\mathrm{~Pa}$ & 4 & . & . & . & . \\
\hline Pajarito Spring III & 338157 & 3952426 & $\mathrm{~Pa}$ & 3 & . & . & . & . \\
\hline $\begin{array}{l}\text { Paliza } \\
\text { Campground } \\
\text { Spring }\end{array}$ & 353506 & 3952352 & Tpb & 4 & . & 240 & $10 / 2 / 1973$ & $\begin{array}{l}\text { Trainer } \\
\text { 1978: } \\
\text { Table 1 }\end{array}$ \\
\hline $\begin{array}{l}\text { Puerto de Benao } \\
\text { Spring }\end{array}$ & 357169 & 3957520 & $\begin{array}{l}\text { Qvec/ } \\
\text { Tpbhd }\end{array}$ & 4 & . & . & . & $\cdot$ \\
\hline $\begin{array}{l}\text { Redondo Creek } \\
\text { Wetland }\end{array}$ & 354255 & 3970128 & & 4 & . & . & . & - \\
\hline Rivera Spring I & 357268 & 3958971 & $\begin{array}{l}\text { Qal/ } \\
\text { Qvec/ Tpv }\end{array}$ & 4 & . & . & . & . \\
\hline Rivera Spring II & 357144 & 3958760 & $\begin{array}{l}\text { Qal/ } \\
\text { Qvec/Tpv }\end{array}$ & 4 & . & . & . & . \\
\hline San Juan Spring & 356486 & 3959420 & $\begin{array}{l}\text { Qal/ Tpa/ } \\
\text { Qvec }\end{array}$ & 4 & . & . & . & - \\
\hline \multirow[t]{6}{*}{ Sino Spring } & \multirow[t]{6}{*}{348356} & \multirow[t]{6}{*}{3965438} & \multirow[t]{6}{*}{$\begin{array}{l}\text { Tsd/ Qcbt/ } \\
\mathrm{Pa}\end{array}$} & \multirow[t]{6}{*}{4} & $<1$ & . & $5 / 8 / 1973$ & $\begin{array}{l}\text { Trainer } \\
\text { 1978: } \\
\text { Table } 1\end{array}$ \\
\hline & & & & & 4 & . & $8 / 1979$ & $\begin{array}{l}\text { Vautaz } \\
\text { and Goff } \\
\text { 1986: } \\
\text { Table 1; } \\
\text { Shevenell } \\
\text { et al. } \\
\text { 1987: } \\
\text { Table B-I }\end{array}$ \\
\hline & & & & & 21 & . & $6 / 1981$ & $\begin{array}{l}\text { Shevenell } \\
\text { et al. } \\
\text { 1987: } \\
\text { Table B-I }\end{array}$ \\
\hline & & & & & 21 & . & $3 / 1982$ & $\begin{array}{l}\text { Vautaz } \\
\text { and Goff } \\
\text { 1986: } \\
\text { Table } 1 \\
\end{array}$ \\
\hline & & & & & . & . & 9/1982 & $\begin{array}{l}\text { Vautaz } \\
\text { and Goff } \\
\text { 1986: } \\
\text { Table 1 } \\
\end{array}$ \\
\hline & & & & & 4 & & 5/13/1991 & Blake et \\
\hline
\end{tabular}




\begin{tabular}{|c|c|c|c|c|c|c|c|c|}
\hline & & & & & & & & al. 1995 \\
\hline & & & & & 21 & & 6/8/1992 & $\begin{array}{l}\text { Blake et } \\
\text { al. } 1995\end{array}$ \\
\hline & & & & & 11 & & 6/16/1993 & $\begin{array}{l}\text { Blake et } \\
\text { al. } 1995\end{array}$ \\
\hline $\begin{array}{l}\text { Soda Dam } \\
\text { Springs East }\end{array}$ & 347564 & 3962125 & Ipm & 3 & 15 & 1450 & 7/13/1973 & $\begin{array}{l}\text { Trainer } \\
\text { 1978: } \\
\text { Table 1 }\end{array}$ \\
\hline $\begin{array}{l}\text { Spence Hot } \\
\text { Spring }\end{array}$ & 352878 & 3968469 & $\mathrm{~Pa}$ & 3 & 39 & 276 & 11/7/1972 & $\begin{array}{l}\text { Trainer } \\
\text { 1978: } \\
\text { Table } 1\end{array}$ \\
\hline & & & & & 44 & 282 & $12 / 1 / 1974$ & $\begin{array}{l}\text { Trainer } \\
\text { 1978: } \\
\text { Table 1 }\end{array}$ \\
\hline Stable Spring & 340117 & 3965505 & Tnv (Tpa) & 4 & . & . & . & . \\
\hline $\begin{array}{l}\text { Upper Cebollita } \\
\text { Spring }\end{array}$ & 345278 & 3944215 & Qal/ Qbo & 6 & . & . & . & . \\
\hline $\begin{array}{l}\text { Vallecitos Spring } \\
\text { II }\end{array}$ & 356805 & 3963816 & Qal/Qvec & 3 & . & . & . & . \\
\hline $\begin{array}{l}\text { Vallecitos Spring } \\
\text { III }\end{array}$ & 357080 & 3963895 & Qal/Qvec & 3 & . & . & - & . \\
\hline Willow Spring & 356854 & 3962063 & $\begin{array}{l}\text { Qvec/ } \\
\text { Qcvm }\end{array}$ & 4 & - & . & - & . \\
\hline Willow Spring II & 356924 & 3961616 & $\begin{array}{l}\text { Qvec/ } \\
\text { Qcvm }\end{array}$ & 4 & . & . & - & . \\
\hline
\end{tabular}

Documented Springs in the Pajarito Plateau Study Area

\begin{tabular}{|c|c|c|c|c|c|c|c|c|}
\hline & \multicolumn{4}{|c|}{$\begin{array}{c}\text { Location (NAD83, UTM 13N) } \\
\text { \& Hydro Context }\end{array}$} & \multicolumn{4}{|c|}{ Water Measurements } \\
\hline Spring Name & $\mathbf{E}$ & $\mathbf{N}$ & Geo Unit & $\begin{array}{l}\text { Water } \\
\text { Type }\end{array}$ & $\begin{array}{l}\text { Discharge } \\
\text { Rate } \\
\text { (gpm) }\end{array}$ & $\begin{array}{l}\text { Sp. } \\
\text { Cond. } \\
(\mu \mho / \mathrm{cm})\end{array}$ & $\begin{array}{l}\text { Sampling } \\
\text { dates }\end{array}$ & Source \\
\hline American & 375108 & 3966783 & $\begin{array}{l}\text { Ttcg, } \\
\text { Qtoal }\end{array}$ & 4 & 5 & . & 1948 & 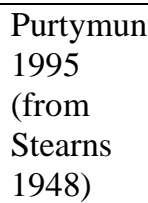 \\
\hline Ancha Spring & 395820 & 3963349 & $\begin{array}{l}\text { QTcrv, } \\
\text { Qc }\end{array}$ & 3 & 0 & . & 1948 & $\begin{array}{l}\text { Purtymun } \\
1995 \\
\text { (from } \\
\text { Stearns } \\
1948 \text { ) }\end{array}$ \\
\hline Ancho & 389824 & 3959189 & QTcrv & 3 & 30 & . & 1948 & $\begin{array}{l}\text { Purtymun } \\
1995 \\
\text { (from } \\
\text { Stearns } \\
1948 \text { ) }\end{array}$ \\
\hline Ancho Spring & 388614 & 3959875 & Qls,Qal & 3 & 65 & . & 1948 & $\begin{array}{l}\text { Purtymun } \\
1995 \\
\text { (from } \\
\text { Stearns } \\
1948 \text { ) }\end{array}$ \\
\hline
\end{tabular}




\begin{tabular}{|c|c|c|c|c|c|c|c|c|}
\hline Anderson Spring & 379713 & 3970157 & $\begin{array}{l}\text { Qaf, Qbt, } \\
\text { Qal }\end{array}$ & 6 & 4 & . & $12 / 14 / 1995$ & $\begin{array}{l}\text { Dale and } \\
\text { Yanicak } \\
\text { 1996, Fig } \\
3.17\end{array}$ \\
\hline Apache & 374505 & 3964840 & Qbt & 4 & 1 & . & 1948 & $\begin{array}{l}\text { Purtymun } \\
1995 \\
\text { (from } \\
\text { Stearns } \\
1948 \text { ) }\end{array}$ \\
\hline Armstead & 374723 & 3967611 & $\begin{array}{l}\text { Ttcg, } \\
\text { Qalo }\end{array}$ & 4 & 2 & . & 1948 & $\begin{array}{l}\text { Purtymun } \\
1995 \\
\text { (from } \\
\text { Stearns } \\
1948 \text { ) }\end{array}$ \\
\hline \multirow[t]{3}{*}{ Basalt Spring } & \multirow[t]{3}{*}{392063} & \multirow[t]{3}{*}{3969828} & \multirow[t]{3}{*}{$\begin{array}{l}\text { Qls, } \\
\text { QTcrv }\end{array}$} & \multirow[t]{3}{*}{5} & 3 & . & 1948 & $\begin{array}{l}\text { Purtymun } \\
1995 \\
\text { (from } \\
\text { Stearns } \\
1948 \text { ) }\end{array}$ \\
\hline & & & & & 6.6 & . & 6/11/1995 & $\begin{array}{l}\text { Blake et } \\
\text { al. } 1995\end{array}$ \\
\hline & & & & & 0.8 & . & 6/11/1995 & $\begin{array}{l}\text { Blake et } \\
\text { al. } 1995\end{array}$ \\
\hline Brian Spring & 379127 & 3969146 & $\begin{array}{l}\text { Qaf, Qbt, } \\
\text { Qal }\end{array}$ & 6 & 23 & . & 11/9/1995 & $\begin{array}{l}\text { Dale and } \\
\text { Yanicak } \\
\text { 1996, Fig } \\
3.17\end{array}$ \\
\hline Bulldog Spring & 379450 & 3968890 & $\begin{array}{l}\text { Qaf, Qbt, } \\
\text { Qal }\end{array}$ & 6 & 15 & . & 11/9/1995 & $\begin{array}{l}\text { Dale and } \\
\text { Yanicak } \\
\text { 1996, Fig } \\
3.17\end{array}$ \\
\hline $\begin{array}{l}\text { Burning Ground } \\
\text { Spring }\end{array}$ & 379131 & 3968091 & $\begin{array}{l}\text { Qaf, Qbt, } \\
\text { Qal }\end{array}$ & 6 & 18 & . & 12/15/1995 & $\begin{array}{l}\text { Dale and } \\
\text { Yanicak } \\
\text { 1996, Fig } \\
\text { 3.17 }\end{array}$ \\
\hline Canada Spring & 396913 & 3963030 & $\begin{array}{l}\text { QTbt, } \\
\text { QTcrv }\end{array}$ & 3 & 0 & . & 1948 & $\begin{array}{l}\text { Purtymun } \\
1995 \\
\text { (from } \\
\text { Stearns } \\
1948 \text { ) }\end{array}$ \\
\hline Chaquehui & 387742 & 3958423 & QTbt, Qfa & 3 & 0 & . & 1948 & $\begin{array}{l}\text { Purtymun } \\
1995 \\
\text { (from } \\
\text { Stearns } \\
1948 \text { ) } \\
\end{array}$ \\
\hline Charlies Spring & 378936 & 3969117 & $\begin{array}{l}\text { Qaf, Qbt, } \\
\text { Qal }\end{array}$ & 6 & 23 & . & 11/9/1995 & $\begin{array}{l}\text { Dale and } \\
\text { Yanicak } \\
\text { 1996, Fig } \\
3.17 \\
\end{array}$ \\
\hline Doe Spring & 387501 & 3958640 & $\begin{array}{l}\text { QTcrv, } \\
\text { Qls }\end{array}$ & 3 & 1 & . & 1948 & $\begin{array}{l}\text { Purtymun } \\
1995 \\
\text { (from } \\
\text { Stearns } \\
1948 \text { ) }\end{array}$ \\
\hline Frijoles & 386722 & 3957339 & Ttcg & 3 & 100 & . & 1948 & Purtymun \\
\hline
\end{tabular}




\begin{tabular}{|c|c|c|c|c|c|c|c|c|}
\hline & & & & & & & & $\begin{array}{l}1995 \\
\text { (from } \\
\text { Stearns } \\
1948 \text { ) }\end{array}$ \\
\hline Frijoles & 372455 & 3966665 & Qbo & 4 & 110 & . & 1948 & $\begin{array}{l}\text { Purtymun } \\
1995 \\
\text { (from } \\
\text { Stearns } \\
1948 \text { ) } \\
\end{array}$ \\
\hline Frijoles & 371540 & 3966616 & Tsf, Qls & 4 & 20 & . & 1948 & $\begin{array}{l}\text { Purtymun } \\
1995 \\
\text { (from } \\
\text { Stearns } \\
1948 \text { ) }\end{array}$ \\
\hline Guaje 1 & 375073 & 3978274 & Qbt, Qal & 4 & 25 & . & 1948 & $\begin{array}{l}\text { Purtymun } \\
1995 \\
\text { (from } \\
\text { Stearns } \\
1948 \text { ) } \\
\end{array}$ \\
\hline Guaje 2 & 375066 & 3977756 & Qbt, Ttrc & 4 & 40 & . & 1948 & $\begin{array}{l}\text { Purtymun } \\
1995 \\
\text { (from } \\
\text { Stearns } \\
1948 \text { ) }\end{array}$ \\
\hline Hanlon Spring & 379422 & 3970264 & $\begin{array}{l}\text { Qaf, Qbt, } \\
\text { Qal }\end{array}$ & 6 & 4 & . & $12 / 14 / 1995$ & $\begin{array}{l}\text { Dale and } \\
\text { Yanicak } \\
\text { 1996, Fig } \\
3.17\end{array}$ \\
\hline $\begin{array}{l}\text { Homestead } \\
\text { Spring }\end{array}$ & 378997 & 3969514 & $\begin{array}{l}\text { Qaf, Qbt, } \\
\text { Qal }\end{array}$ & 6 & 4.9 & • & 11/9/1995 & $\begin{array}{l}\text { Dale and } \\
\text { Yanicak } \\
\text { 1996, Fig } \\
3.17\end{array}$ \\
\hline Indian Spring & 394953 & 3971772 & Qtp,Tsf & 3 & 1 & . & 1948 & $\begin{array}{l}\text { Purtymun } \\
1995 \\
\text { (from } \\
\text { Stearns } \\
1948 \text { ) } \\
\end{array}$ \\
\hline Kieling Spring & 379315 & 3968924 & $\begin{array}{l}\text { Qaf, Qbt, } \\
\text { Qal }\end{array}$ & 6 & 15 & . & 11/9/1995 & $\begin{array}{l}\text { Dale and } \\
\text { Yanicak } \\
\text { 1996, Fig } \\
3.17\end{array}$ \\
\hline La Mesita & 396733 & 3970378 & Qls & 3 & 2 & . & 1948 & $\begin{array}{l}\text { Purtymun } \\
1995 \\
\text { (from } \\
\text { Stearns } \\
1948 \text { ) } \\
\end{array}$ \\
\hline La Mesita Spring & 396881 & 3970041 & $\begin{array}{l}\text { QTcrv, } \\
\text { Qls }\end{array}$ & 3 & 1 & . & 1948 & $\begin{array}{l}\text { Purtymun } \\
1995 \\
\text { (from } \\
\text { Stearns } \\
1948 \text { ) } \\
\end{array}$ \\
\hline Los Alamos & 396947 & 3970466 & Qls & 3 & 0 & . & 1948 & $\begin{array}{l}\text { Purtymun } \\
1995 \\
\text { (from } \\
\text { Stearns }\end{array}$ \\
\hline
\end{tabular}




\begin{tabular}{|c|c|c|c|c|c|c|c|c|}
\hline & & & & & & & & 1948) \\
\hline $\begin{array}{l}\text { Los Alamos } \\
\text { Spring }\end{array}$ & 392338 & 3969885 & $\begin{array}{l}\text { Qls, } \\
\text { QTcrv }\end{array}$ & 5 & 1 & . & 1948 & 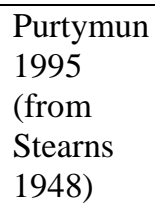 \\
\hline Martin Spring & 379222 & 3967281 & $\begin{array}{l}\text { Qaf, Qbt, } \\
\text { Qal }\end{array}$ & 6 & . & . & . & $\begin{array}{l}\text { Dale and } \\
\text { Yanicak } \\
\text { 1996, Fig } \\
3.17\end{array}$ \\
\hline $\begin{array}{l}\text { Medio Canyon } \\
\text { Seep } 1\end{array}$ & 376809 & 3955212 & Tphd/Tsf & 5 & . & . & . & 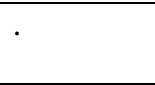 \\
\hline $\begin{array}{l}\text { Medio Canyon } \\
\text { Seep } 2\end{array}$ & 376892 & 3954870 & Tphd/Tsf & 5 & . & . & . & • \\
\hline Mortandad & 394201 & 3965442 & $\begin{array}{l}\text { Qls, } \\
\text { QTcrv }\end{array}$ & 3 & $10-100$ & & 1948 & 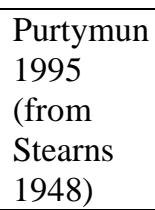 \\
\hline Pajarito & 392125 & 3962726 & $\begin{array}{l}\text { QTcrv, } \\
\text { Qls }\end{array}$ & 3 & 450 & . & 1948 & 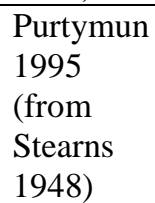 \\
\hline $\begin{array}{l}\text { Pajarito Canyon } \\
\text { Wetland }\end{array}$ & 388713 & 3965280 & Qc/Qal & 5 & . & . & & $\begin{array}{l}\text { Henne } \\
2008\end{array}$ \\
\hline PC & 375404 & 3970803 & Ttpm & 4 & 25 & . & 1948 & $\begin{array}{l}\text { Purtymun } \\
1995 \\
\text { (from } \\
\text { Stearns } \\
1948 \text { ) } \\
\end{array}$ \\
\hline Peter Spring & 378965 & 3968203 & $\begin{array}{l}\text { Qaf, Qbt, } \\
\text { Qal }\end{array}$ & 6 & 18 & . & 12/15/1995 & $\begin{array}{l}\text { Dale and } \\
\text { Yanicak } \\
\text { 1996, Fig } \\
3.17\end{array}$ \\
\hline Quemazon & 375829 & 3975430 & Ttrc & 4 & 15 & & 1948 & $\begin{array}{l}\text { Purtymun } \\
1995 \\
\text { (from } \\
\text { Stearns } \\
1948 \text { ) }\end{array}$ \\
\hline Reservoir & 376675 & 3972493 & Qc & 4 & 20 & & 1948 & 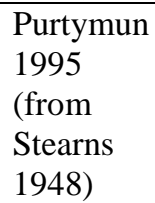 \\
\hline Sacred Spring & 396214 & 3972701 & Qtp, Tsf & 3 & 1 & & 1948 & $\begin{array}{l}\text { Purtymun } \\
1995 \\
\text { (from } \\
\text { Stearns } \\
1948 \text { ) } \\
\end{array}$ \\
\hline Sandia & 394792 & 3966319 & $\begin{array}{l}\text { Qls, } \\
\text { QTcrv }\end{array}$ & 3 & 0 & . & 1948 & 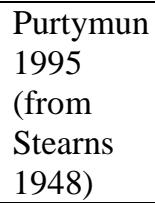 \\
\hline
\end{tabular}




\begin{tabular}{|c|c|c|c|c|c|c|c|c|}
\hline Sandia_Spring & 394069 & 3966998 & Tcar, Qfa & 3 & 0 & . & 1948 & $\begin{array}{l}\text { Purtymun } \\
1995 \\
\text { (from } \\
\text { Stearns } \\
1948 \text { ) }\end{array}$ \\
\hline Spring_1 & 396018 & 3970035 & $\begin{array}{l}\text { QTcrv, } \\
\text { Qls }\end{array}$ & 3 & 1 & . & 1948 & $\begin{array}{l}\text { Purtymun } \\
1995 \\
\text { (from } \\
\text { Stearns } \\
1948 \text { ) }\end{array}$ \\
\hline Spring_10 & 386466 & 3957169 & $\begin{array}{l}\text { QTcrv, } \\
\text { Qls }\end{array}$ & 3 & 1 & . & 1948 & $\begin{array}{l}\text { Purtymun } \\
1995 \\
\text { (from } \\
\text { Stearns } \\
1948 \text { ) } \\
\end{array}$ \\
\hline Spring_2 & 395950 & 3969895 & $\begin{array}{l}\text { QTcrv, } \\
\text { Qls }\end{array}$ & 3 & 1 & . & 1948 & 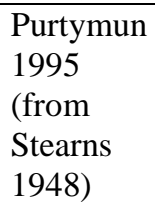 \\
\hline Spring_2A & 393868 & 3964964 & QTbt, Qc & 3 & 1 & . & 1948 & $\begin{array}{l}\text { Purtymun } \\
1995 \\
\text { (from } \\
\text { Stearns } \\
1948 \text { ) }\end{array}$ \\
\hline Spring_3 & 393450 & 3964602 & $\begin{array}{l}\text { Qls, } \\
\text { QTcrv }\end{array}$ & 3 & 20 & . & 1948 & 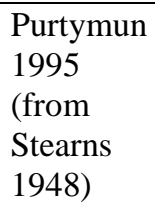 \\
\hline Spring_3A & 393458 & 3964521 & $\begin{array}{l}\text { Qls, } \\
\text { QTcrv }\end{array}$ & 3 & 50 & . & 1948 & $\begin{array}{l}\text { Purtymun } \\
1995 \\
\text { (from } \\
\text { Stearns } \\
1948 \text { ) }\end{array}$ \\
\hline Spring_3AA & 393385 & 3963957 & $\begin{array}{l}\text { Qls, } \\
\text { QTcrv }\end{array}$ & 3 & 1 & . & 1948 & $\begin{array}{l}\text { Purtymun } \\
1995 \\
\text { (from } \\
\text { Stearns } \\
1948 \text { ) }\end{array}$ \\
\hline Spring_3B & 393519 & 3963480 & $\begin{array}{l}\text { Qls, } \\
\text { QTcrv }\end{array}$ & 3 & 30 & . & 1948 & $\begin{array}{l}\text { Purtymun } \\
1995 \\
\text { (from } \\
\text { Stearns } \\
1948 \text { ) }\end{array}$ \\
\hline Spring_3B & 393382 & 3963380 & Qls & 3 & 10 & . & 1948 & $\begin{array}{l}\text { Purtymun } \\
1995 \\
\text { (from } \\
\text { Stearns } \\
1948 \text { ) }\end{array}$ \\
\hline Spring_4 & 392247 & 3963013 & $\begin{array}{l}\text { Qls, } \\
\text { QTcrv }\end{array}$ & 3 & 80 & . & 1948 & 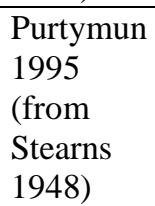 \\
\hline
\end{tabular}




\begin{tabular}{|c|c|c|c|c|c|c|c|c|}
\hline Spring_4A & 391853 & 3962856 & Qls & 3 & 120 & . & 1948 & $\begin{array}{l}\text { Purtymun } \\
1995 \\
\text { (from } \\
\text { Stearns } \\
1948 \text { ) }\end{array}$ \\
\hline Spring_5 & 391632 & 3961387 & Qfa & 3 & 10 & . & 1948 & 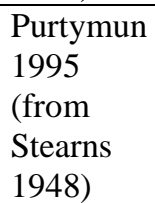 \\
\hline Spring_5A & 391707 & 3961061 & Qls, Qfa & 3 & 25 & . & 1948 & $\begin{array}{l}\text { Purtymun } \\
1995 \\
\text { (from } \\
\text { Stearns } \\
1948 \text { ) } \\
\end{array}$ \\
\hline Spring_5AA & 390308 & 3961255 & QTpt & 3 & 0 & . & 1948 & 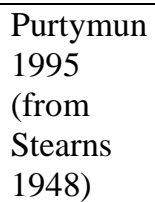 \\
\hline Spring_5B & 390271 & 3959918 & $\begin{array}{l}\text { QTcrv, } \\
\text { Qls }\end{array}$ & 3 & 10 & . & 1948 & $\begin{array}{l}\text { Purtymun } \\
1995 \\
\text { (from } \\
\text { Stearns } \\
1948 \text { ) }\end{array}$ \\
\hline Spring_6 & 389686 & 3959166 & Qfa & 3 & 60 & . & 1948 & 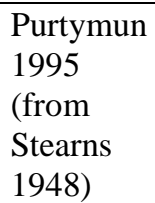 \\
\hline Spring_6A & 389133 & 3958833 & Qal & 3 & 150 & . & 1948 & 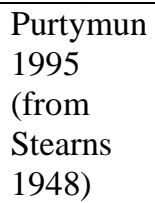 \\
\hline Spring_7 & 388403 & 3958549 & $\begin{array}{l}\text { QTcrv, } \\
\text { Qls }\end{array}$ & 3 & 175 & & 1948 & $\begin{array}{l}\text { Purtymun } \\
1995 \\
\text { (from } \\
\text { Stearns } \\
1948 \text { ) }\end{array}$ \\
\hline Spring_8 & 388221 & 3958514 & $\begin{array}{l}\text { QTcrv, } \\
\text { Qls }\end{array}$ & 3 & 70 & . & 1948 & $\begin{array}{l}\text { Purtymun } \\
1995 \\
\text { (from } \\
\text { Stearns } \\
1948 \text { ) }\end{array}$ \\
\hline Spring_8A & 387920 & 3958682 & $\begin{array}{l}\text { QTcrv, } \\
\text { Qls }\end{array}$ & 3 & 25 & . & 1948 & $\begin{array}{l}\text { Purtymun } \\
1995 \\
\text { (from } \\
\text { Stearns } \\
1948 \text { ) }\end{array}$ \\
\hline Spring_8B & 387877 & 3958541 & $\begin{array}{l}\text { QTcrv, } \\
\text { Qls }\end{array}$ & 3 & 10 & . & 1948 & 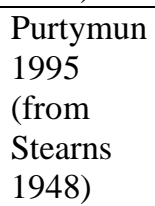 \\
\hline
\end{tabular}




\begin{tabular}{|c|c|c|c|c|c|c|c|c|}
\hline Spring_9 & 387771 & 3958598 & $\begin{array}{l}\text { QTcrv, } \\
\text { Qls }\end{array}$ & 3 & 10 & . & 1948 & 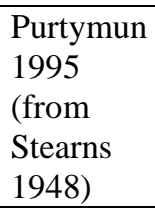 \\
\hline Spring_9A & 387684 & 3958518 & $\begin{array}{l}\text { QTcrv, } \\
\text { Qls }\end{array}$ & 3 & 0 & . & 1948 & 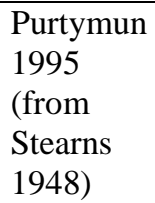 \\
\hline Spring_9B & 387617 & 3958357 & $\begin{array}{l}\text { QTcrv, } \\
\text { Qls }\end{array}$ & 3 & 0 & . & 1948 & $\begin{array}{l}\text { Purtymun } \\
1995 \\
\text { (from } \\
\text { Stearns } \\
1948 \text { ) } \\
\end{array}$ \\
\hline Starmers Spring & 379039 & 3969118 & $\begin{array}{l}\text { Qaf, Qbt, } \\
\text { Qal }\end{array}$ & 6 & 23 & . & 11/9/1995 & $\begin{array}{l}\text { Dale and } \\
\text { Yanicak } \\
\text { 1996, Fig } \\
3.17\end{array}$ \\
\hline SWSC Spring & 379030 & 3968153 & $\begin{array}{l}\text { Qaf, Qbt, } \\
\text { Qal }\end{array}$ & 6 & 18 & . & $12 / 15 / 1995$ & $\begin{array}{l}\text { Dale and } \\
\text { Yanicak } \\
\text { 1996, Fig } \\
3.17\end{array}$ \\
\hline \multirow[t]{7}{*}{ Turkey Springs } & \multirow[t]{7}{*}{377193} & \multirow[t]{7}{*}{3956229} & \multirow[t]{7}{*}{ Tphd/Tsf } & \multirow[t]{7}{*}{3} & 22.19 & . & $\begin{array}{l}\text { before } \\
1980\end{array}$ & $\begin{array}{l}\text { Purtymun } \\
\text { and } \\
\text { Adams } \\
1980\end{array}$ \\
\hline & & & & & 15.85 & 193 & $7 / 1980$ & $\begin{array}{l}\text { Shevenell } \\
\text { et al. } \\
1987\end{array}$ \\
\hline & & & & & & . & $5 / 1983$ & $\begin{array}{l}\text { Vautaz } \\
\text { and Goff } \\
\text { 1986: } \\
\text { Table } 1 \\
\end{array}$ \\
\hline & & & & & 15.85 & . & $5 / 17 / 1991$ & $\begin{array}{l}\text { Blake et } \\
\text { al. } 1995\end{array}$ \\
\hline & & & & & 4.49 & 264 & $4 / 28 / 2005$ & USGS \\
\hline & & & & & 22.44 & 263 & $8 / 25 / 2005$ & USGS \\
\hline & & & & & 40.39 & 288 & $11 / 17 / 2005$ & USGS \\
\hline Valle 1 & 376078 & 3968722 & Ttcg, Qbt & 4 & 4 & . & 1948 & $\begin{array}{l}\text { Purtymun } \\
1995 \\
\text { (from } \\
\text { Stearns } \\
1948 \text { ) }\end{array}$ \\
\hline Valle 2 & 376139 & 3968751 & Ttcg, Qbt & 4 & 4 & . & 1948 & $\begin{array}{l}\text { Purtymun } \\
1995 \\
\text { (from } \\
\text { Stearns } \\
1948 \text { ) }\end{array}$ \\
\hline Water & 391033 & 3960789 & QTcrv & 3 & 0 & . & 1948 & 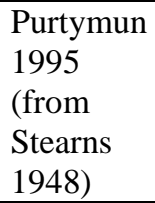 \\
\hline Water Canyon & 376063 & 3967533 & Ttcg, Qbt & 4 & 150 & . & 1948 & Purtymun \\
\hline
\end{tabular}




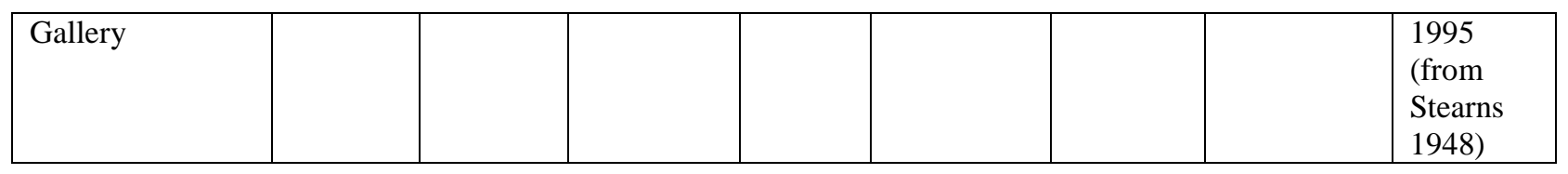




\section{APPENDIX B: RESERVOIR DIMENSIONS}

\begin{tabular}{|c|c|c|c|c|c|c|c|c|c|}
\hline \multirow[b]{2}{*}{ Site } & \multicolumn{6}{|c|}{ Basin } & \multicolumn{3}{|c|}{ Berm } \\
\hline & $\begin{array}{c}\text { Sed. } \\
\text { Thickness } \\
\text { (m) }\end{array}$ & $\begin{array}{c}\text { Berm } \\
\text { Height } \\
\text { Above } \\
\text { Basin } \\
(\mathrm{m})\end{array}$ & $\begin{array}{c}\text { Max } \\
\text { Basin } \\
\text { Diameter } \\
\text { (m) }\end{array}$ & $\begin{array}{c}\text { Min } \\
\text { Basin } \\
\text { Diameter } \\
\text { (m) }\end{array}$ & $\begin{array}{c}\text { Basin } \\
\text { Surface } \\
\text { Area } \\
\left(\mathbf{m}^{2}\right)\end{array}$ & $\begin{array}{c}\text { Max } \\
\text { Storage } \\
\text { Volume } \\
\left(\mathbf{m}^{3}\right)\end{array}$ & $\begin{array}{l}\text { thickness } \\
\text { (m) }\end{array}$ & $\begin{array}{l}\text { crest } \\
\text { width } \\
\text { (m) }\end{array}$ & $\begin{array}{c}\text { base } \\
\text { width } \\
\text { (m) }\end{array}$ \\
\hline $\begin{array}{l}\text { Amoxiumqua } \\
\text { (LA481) }\end{array}$ & 0.50 & 1.73 & 36.0 & 30.0 & 848.23 & 1261.03 & 1.20 & 3.5 & 15 \\
\hline $\begin{array}{c}\text { Boletsakwa } \\
\text { (LA136) }\end{array}$ & 1.00 & 0.31 & 15.5 & 12.5 & 152.17 & 132.90 & 0.30 & 2 & 3.5 \\
\hline $\begin{array}{c}\text { Boletsakwa-2 } \\
\text { (LA25092) }\end{array}$ & 1.44 & 1.30 & 25.0 & 20.0 & 392.70 & 717.35 & 0.60 & 4 & 10 \\
\hline $\begin{array}{l}\text { Kwastiyukwa } \\
\text { (LA482) }\end{array}$ & 0.60 & 0.85 & 21.0 & 20.0 & 329.87 & 318.87 & 0.60 & 3.5 & 6 \\
\hline $\begin{array}{c}\text { Tovakwa } \\
\text { (LA61641) }\end{array}$ & 0.72 & 1.20 & 33.0 & 22.0 & 570.20 & 729.85 & 1.08 & 2.5 & 6 \\
\hline $\begin{array}{c}\text { Wabakwa } \\
\text { (LA478) }\end{array}$ & 0.68 & 0.45 & 30.0 & 10.0 & 235.62 & 307.88 & 0.34 & 3.5 & 5 \\
\hline $\begin{array}{c}\text { Haatse/ } \\
\text { San Miguel } \\
\text { (LA370) }\end{array}$ & 0.64 & 0.40 & 14.0 & 8.5 & 93.46 & 64.80 & 0.14 & 2.9 & 2.9 \\
\hline $\begin{array}{c}\text { Haatse/ } \\
\text { San Miguel } \\
\text { LA3834 }\end{array}$ & 0.36 & 0.30 & 12.0 & 10.0 & 94.25 & 41.47 & 0.06 & 2.05 & 2.05 \\
\hline $\begin{array}{c}\text { Tsankawi-1 } \\
\text { (LA211) }\end{array}$ & 0.40 & 0.75 & 22.5 & 14.0 & 247.70 & 189.67 & 0.20 & 2 & 6 \\
\hline $\begin{array}{l}\text { Tsankawi-2 } \\
\text { (LA211) }\end{array}$ & 0.40 & 0.50 & 20.0 & 16.0 & 251.33 & 150.80 & 0.20 & 1.5 & 2.5 \\
\hline $\begin{array}{c}\text { Tsankawi-3 } \\
\text { (LA211) }\end{array}$ & 0.46 & 0.35 & 15.0 & 15.0 & 176.71 & 95.43 & 0.40 & 2.5 & 4.5 \\
\hline $\begin{array}{c}\text { Tsirege } \\
\text { (LA170) }\end{array}$ & 1.07 & 0.20 & 30.0 & 20.0 & 471.24 & 399.00 & 1.25 & 2.5 & 6 \\
\hline $\begin{array}{l}\text { Yapashi } \\
\text { (LA250) }\end{array}$ & 0.78 & 1.23 & 25.0 & 20.0 & 392.70 & 526.22 & 0.78 & 4 & 10 \\
\hline $\begin{array}{c}\text { Yapashi } \\
\text { (LA70790) }\end{array}$ & 0.55 & 0.20 & 22.5 & 20.0 & 353.43 & 176.71 & 0.30 & 2 & 2.5 \\
\hline $\begin{array}{c}\text { Yapashi } \\
\text { (LA70798) }\end{array}$ & 0.40 & 0.07 & 18.0 & 16.0 & 226.19 & 70.87 & 0.30 & 1.5 & 1.25 \\
\hline
\end{tabular}




\section{APPENDIX C: DIATOM ANALYSES REPORTS}

This appendix is a compilation of three reports by Dr. Barabara Winsborough, consulting ecologist. A table compiling all of the results is presented before the reports. I made minor edits to the report by correcting misidentified sample or site numbers and report titles. There is a glossary of diatom terminology at the end of the first report. 


\begin{tabular}{|c|c|c|c|c|c|c|c|c|c|c|}
\hline \multirow{2}{*}{ Sample ID } & \multirow{2}{*}{$\begin{array}{l}\text { Depth } \\
\text { (cm) }\end{array}$} & \multirow{2}{*}{$\#$} & \multirow{2}{*}{ \# Sp. } & \multicolumn{3}{|c|}{ Diatom Habitats (\#)* } & \multicolumn{4}{|c|}{ pH Tolerances $(\#)^{* *}$} \\
\hline & & & & Aerial & Cosmo & Aquatic & $\begin{array}{c}\text { acid } \\
(p H<7)\end{array}$ & $\begin{array}{c}\text { neutral (pH } \\
\sim 7)\end{array}$ & $\begin{array}{c}\text { alkaline } \\
(\mathrm{pH}>7)\end{array}$ & indif. \\
\hline Stable Tank 1 & mud & 490 & 30 & 39 & 125 & 326 & 218 & 155 & 113 & 91 \\
\hline Lake Fork Canyon & water & 500 & 11 & 299 & 38 & 163 & 0 & 472 & 24 & 0 \\
\hline Lake Fork Canyon & mud & 500 & 33 & 56 & 99 & 345 & 235 & 129 & 130 & 10 \\
\hline San Juan Tank & water & 125 & 14 & 65 & 23 & 37 & 2 & 76 & 33 & 0 \\
\hline San Juan Tank & mud & 500 & 25 & 166 & 77 & 257 & 4 & 271 & 195 & 0 \\
\hline AMO2.205 & $8-10$ & 600 & 20 & 466 & 115 & 19 & 62 & 460 & 72 & 6 \\
\hline AMO2.21 & $18-20$ & 600 & 19 & 498 & 94 & 8 & 38 & 524 & 30 & 8 \\
\hline AMO2.212 & $22-24$ & 600 & 18 & 527 & 49 & 24 & 6 & 563 & 21 & 10 \\
\hline AMO2.224 & $46-48$ & 600 & 21 & 508 & 63 & 29 & 6 & 532 & 44 & 18 \\
\hline BOL2.307 & $12-14$ & 600 & 10 & 592 & 3 & 5 & 0 & 577 & 21 & 2 \\
\hline BOL2.320 & $38-40$ & 600 & 16 & 515 & 15 & 70 & 1 & 556 & 41 & 2 \\
\hline BOL2.333 & $64-66$ & 600 & 6 & 591 & 9 & 0 & 0 & 579 & 21 & 0 \\
\hline BOL2.344 & $86-88$ & 600 & 7 & 595 & 5 & 0 & 0 & 575 & 4 & 21 \\
\hline BOL2_2.152 & $102-104$ & 600 & 14 & 566 & 22 & 12 & 182 & 560 & 17 & 7 \\
\hline KWA2.304 & $6-9$ & 600 & 12 & 577 & 12 & 11 & 4 & 584 & 4 & 8 \\
\hline KWA2.309 & $17-19$ & 600 & 11 & 574 & 17 & 9 & 1 & 588 & 11 & 0 \\
\hline KWA2.320 & $39-41$ & 600 & 11 & 584 & 12 & 4 & 1 & 593 & 5 & 1 \\
\hline TOV2.315 & $28-30$ & 600 & 18 & 536 & 48 & 16 & 10 & 530 & 56 & 4 \\
\hline TOV2.323 & $44-46$ & 600 & 14 & 552 & 42 & 6 & 3 & 562 & 20 & 15 \\
\hline TOV2.332 & $62-64$ & 600 & 11 & 554 & 33 & 13 & 148 & 560 & 17 & 23 \\
\hline WAB2.226 & $50-52$ & 56 & 11 & 10 & 0 & 45 & 0 & 18 & 5 & 0 \\
\hline SMG2.109 & $16-18$ & 600 & 5 & 594 & 0 & 6 & 6 & 586 & 0 & 0 \\
\hline LA3834_2.109 & $16-18$ & 82 & 5 & 80 & 0 & 2 & 0 & 78 & 0 & 0 \\
\hline TK1_2.214 & $26-28$ & 600 & 5 & 599 & 1 & 0 & 0 & 591 & 0 & 0 \\
\hline TK2_2.214 & $26-28$ & 88 & 4 & 87 & 0 & 0 & 0 & 87 & 0 & 0 \\
\hline TK3_2.207 & $14-16$ & 600 & 6 & 597 & 0 & 2 & 0 & 595 & 0 & 0 \\
\hline TK3_2.212 & $24-26$ & 115 & 9 & 100 & 4 & 2 & 0 & 101 & 5 & 0 \\
\hline TSR2.115 & $28-30$ & 600 & 3 & 600 & 0 & 0 & 0 & 600 & 0 & 0 \\
\hline TSR2.128 & $54-56$ & 600 & 6 & 476 & 71 & 53 & 0 & 545 & 53 & 2 \\
\hline TSR2.144 & $86-88$ & 184 & 5 & 139 & 0 & 12 & 0 & 139 & 12 & 0 \\
\hline YAP2.203 & $4-6$ & 600 & 7 & 585 & 0 & 14 & 7 & 590 & 0 & 0 \\
\hline YAP2.210 & $18-20$ & 600 & 4 & 595 & 0 & 5 & 5 & 595 & 0 & 0 \\
\hline YAP2.231 & $60-62$ & 600 & 4 & 598 & 0 & 2 & 0 & 598 & 2 & 0 \\
\hline LA70790_2.225 & $48-50$ & 600 & 7 & 599 & 1 & 0 & 0 & 590 & 2 & 2 \\
\hline LA70798_2.207 & $12-14$ & 600 & 4 & 598 & 0 & 2 & 2 & 598 & 0 & 0 \\
\hline LA70798_2.214 & $26-28$ & 600 & 6 & 594 & 0 & 6 & 6 & 576 & 0 & 2 \\
\hline
\end{tabular}




\title{
DIATOM ECOLOGICAL ANALYSIS OF MODERN ANALOG SAMPLES FROM THE JEMEZ RESERVOIR PROJECT, JEMEZ SPRINGS, NEW MEXICO
}

\author{
Barbara Winsborough \\ Winsborough Consulting \\ 23606 Round Mountain Circle \\ Leander, Texas 78641
}

Submitted to:

Michael Aiuvalasit

December, 2014 


\section{INTRODUCTION}

Diatoms are single-celled algae with siliceous cell walls. They are found in almost every body of marine, brackish and fresh water, and in wetlands, damp settings and soil. Many are cosmopolitan, found in similar environments in many parts of the world. In archaeological sites diatoms are found in hearth sediments, cooking features, on burned rocks and in refuse accumulations among other places. These diatoms can provide information about the nature of the aquatic environment associated with the site since archaeological occupation sites are almost always associated with a reliable water source. Paleoenvironmental reconstructions are based on diatom preferences and requirements for such things as substrate, habitat, life form, $\mathrm{pH}$, chemistry, salinity, nutrient concentrations, trophic status (pollution), and water depth.

As part of the Jemez Reservoir Project, Jemez Springs, New Mexico, this diatom study was undertaken to establish a modern analog in terms of the kinds of diatoms found in the area, for comparison with older sediment samples.

The following samples were collected from active and dry ponds.

1. 29 May 2014, mud in bottom of dry stock tank: Stable Mesa Tank

2. 2 June 2014, spring-fed Lake Fork Canyon (LFC) Stock Tank, phytoplankton

3. 2 June 2014, LFC Stock Tank, mud collected from $40 \mathrm{~cm}$ below water surface.

4. 3 June 2014, San Juan Mesa Tank, water

5. 3 June 2014, San Juan Mesa Tank, mud, tank edge

\section{METHODS}

Samples were cleaned by boiling in hydrogen peroxide to remove organic compounds, and then in hydrochloric acid to dissolve soluble minerals and disaggregate clays. Samples were repeatedly rinsed until a neutral $\mathrm{pH}$ was reached and then mounted on glass slides with Naphrax 
resin. All of the samples contained diatoms and a count of 500 valves was made on each sample, except sample 4, where the entire slide was scanned and 125 diatoms were found and recorded.

\section{RESULTS AND DISCUSSION}

The results of these diatom counts are given on Table 1. Table 2 is a list of names with complete authorship. A total of 52 species and varieties were recorded. The composition of the diatom assemblages samples as a whole provides insight into the range of ecological variables that characterize the modern habitats in the immediate area. These autecological (individual) qualities are summarized on Table 3. A set of definitions for the ecological terms used on Table 3 are included as Table 4.

The ecological characteristics of the sample set as a whole, as suggested by the autecological preferences of the most common diatoms in the sample set, are derived primarily from the ten taxa that were recorded more than 50 times in the entire study. The most common diatoms in order of abundance are Pinnularia subcapitata Gregory, Hantzschia amphioxys (Ehr.) Grunow, Surirella angusta, Luticola mutica (Kütz.) D.G. Mann, Stauroneis gracilior (Rab.) E. Reichardt, Nitzschia palea (Kütz.) Smith, Craticula cuspidata (Kütz.) D.G. Mann, Fragilaria tenera (Smith) Lange-Bertalot, Gomphonema parvulum (Kütz.) Kütz., and Gomphonema gracile Ehr.

It can be seen from Table 3 that the most abundant diatoms in the combined data set have different ecological spectra. These diatoms differ in their preferred pH: Craticula cuspidata and Surirella angusta are alkaliphilous and Pinnularia subcapitata and Fragilaria tenera are acidophilous, the remaining species are found at a circumneutral $\mathrm{pH}$ of around 7. They also vary in their preference for nutrients: 2 are oligo-mesotrophic, one is mesotrophic, six are eutrophic 
and 1 has a broad trophic range. Saprobity refers to the diatom's dependence on decomposing organic nutrients. Two of the ten most abundant diatoms are oligosaprobous, 7 are mesosaprobous and one is polysaprobous. All but one are found in fresh to brackish water. Fragilaria tenera is restricted to freshwater habitats. All are benthic forms, 6 are primarily aquatic, 3 are soil forms and one is found on moss. There are 2 planktonic diatom species in the entire assemblage but neither was abundant in any sample. Six of the diatoms are motile and 4 are not motile.

Each species was found in more than one sample but their abundances were not consistent, meaning that the environmental conditions varied slightly from one sample to the next, perhaps because of differences in habitat (phytoplankton vs sediment), water depth, vegetation, nutrient concentrations, or turbidity. Another variable is the length of time represented by each sample. The mud samples contain the accumulation of diatoms over several to many seasons whereas the phytoplankton samples represent the diatoms living at the time the water was sampled. This explains, in part, the relatively low number of species in the phytoplankton samples. In the 5 samples, species diversity ranged from a low of 11 taxa to a high of 33 and the two water samples were the least diverse, with 11 taxa in sample 2 and 14 taxa in sample 4.

Some diatom species were recorded once or twice and only in one sample and these may be accidental species transported to the site by agencies such as wind and rain or may be only an occasional member of the community. Two taxa occurred only once in large numbers (blooms), although they were found in smaller numbers in other samples. These are Fragilaria tenera in sample 1 and Stauroneis gracilior in sample 2. Blooms represent an individual's ability to 
capitalize on new conditions and increase their growth rate. High rainfall is one common mechanism that introduces nutrients needed for rapid bloom development.

\section{Sample 1 (Stable Mesa Tank)}

Sample 1 is mud in the bottom of dry stock tank \#1 on Stable Mesa. This sample is the second most diverse with 31 taxa. Craticula cuspidata and Surirella angusta are alkaliphilous and Pinnularia subcapitata and Fragilaria tenera are acidophilous but all are recorded from sample 1. There were 108 valves of Pinnularia subcapitata and 91 of Fragilaria tenera suggesting that the water was acidic part of the time and became more alkaline. Pinnularia subcapitata is found in bogs, on moss and in shallow water. There were 62 valves of alkaliphilous Craticula cuspidata. This diatom can withstand drying and elevated salinity so perhaps it replaced others under drying conditions when salts accumulated. Gomphonema gracile was abundant only in this sample and is characteristic of a circumneutral $\mathrm{pH}$, low nutrients and relatively low organics. It would appear that this stock tank was slowly filled with slightly acidic rainwater and over time became more alkaline, nutrient and organic rich, eventually drying out.

\section{Sample 2 (Lake Fork Canyon Tank-water)}

Sample 2 is a phytoplankton sample from a spring-fed Lake Fork Canyon (LFC) stock tank. This sample is the least diverse with only 11 taxa. Three taxa accounted for 364 out of 500. One of these is an aquatic mud form and the other two are aerial forms found in mud and soil. Most of the remaining diatoms are also aerial species, some of which tolerate submersion. There does not appear to have been adequate time for a diverse population to become established. Neither of the planktonic diatoms were found in this sample. 


\section{Sample 3 (Lake Fork Canyon Tank)}

Sample 3 is from the LFC stock tank, and is mud collected from $40 \mathrm{~cm}$ below water surface. This is the most diverse sample, with 33 taxa in spite of the fact that there are 222 valves of Pinnularia subcapitata. This sample also had the two phytoplankton diatoms, Aulacoseira italica (Ehr.) Simonsen (25 valves) and Meridion circulare var. constricta (Ralfs) Van Heurck (4 valves). For a phytoplankton diatom to become part of an assemblage, sufficient depth, nutrients and residence time are necessary for it to become established. The remainder of the assemblage are a combination of soil forms and benthic, epiphytic and epipelic species. There are both oligoand mesotrophic species and those that can be found in very degraded water suggesting that the water quality changed considerably over time.

\section{Sample 4 (San Juan Tank)}

Sample 4 is a water sample from San Juan Tank. There were very few diatoms in this sample and a scan of the entire slide produced 125 valves. Diversity was low with only 14 species. The most abundant diatoms are the soil diatoms Hantzschia amphioxys and Luticola mutica, accounting for 55 valves. Other soil diatoms in the sample include Luticola cohnii, Luticola paramutica (Bock) D.G. Mann, Adlafia parabryophila (Lange-Bert.) Gerd et al., Pinnularia appendiculata (Agardh) Cleve, and Pinnularia borealis. Gomphonema parvulum with 15 valves is the only aquatic diatom present in any but very low numbers. 


\section{$\underline{\text { Sample } 5 \text { (San Juan Tank) }}$}

Sample 5 is mud from the edge of San Juan Tank. It was moderately diverse with 25 taxa but there were 168 Surirella angusta, and 83 Hantzschia amphioxys. Other common species include 62 Nitzschia palea, 43 Luticola mutica and 31 Gomphonema parvulum. Surirella is benthic and probably epipelic, Hantzschia and Luticola are found on mud and soil and Gomphonema is very common in nutrient-rich, polluted, very shallow, temporarily wet habitats. Overall this assemblage is characteristic of an environment that is only temporarily submerged.

\section{CONCLUSIONS}

The result of this analysis suggests that the ecological preferences of the diatoms define the general character of the ponds, and the overall selection for the kinds of diatoms growing there. The diatom composition of each pond is different, particularly in the most abundant diatoms and reflects differences in the duration, filling rate, and depth of the water, influenced by the amount of nutrients and organic molecules that are washed into or flow into the ponds. Many of the diatoms are found in the edaphic habitat (mud, muck) and are capable of surviving episodic sediment loading and resuspension events that often produce turbid water.

\section{REFERENCES}

Bock, Walter

1963 Diatomeen extrem trockener Standorte. Nova Hedwigia 5 (1/2): 199-254.

Burkholder, JoAnn M.

1996 Interactions of benthic algae with their substrata. In Algal Ecology: Freshwater Benthic Ecosystems edited by R. Jan Stevenson, Max Bothwell and Rex L. Lowe. Academic Press, San Diego: 253-297.

Cox, Eileen J. 
2003 Placoneis Mereschkowsky (Bacillariophyceae) revisited: resolution of several typification and nomenclatural problems, including generitype. Botanical Journal of the Linnean Society 141, 53-83.

Czarnecki, David B. and Dean W. Blinn

1977 Diatoms of Lower Lake Powell and Vicinity. Bibliotheca Phycologica 28, J. Cramer, Vaduz, 119 pp.

Czarnecki, David B. and Dean W. Blinn

1978 Diatoms of the Colorado River in Grand Canyon National Park and Vicinity. Bibliotheca Phycologica 38, J. Cramer, Vaduz, 181 pp.

Evans, John H.

1959 The survival of freshwater algae during dry periods, Part II, drying experiments, Part III, stratification of algae in pond margin litter and mud. J. Ecol. 47: 55-81.

Jahn, Regine

1995 Iconographia Diatomologica 1. Die Diatomeen (Bacillariophyceae) in Ehrenberg's Material von Cayenne, Guyana Gallica (1843) von Erwin Reichardt. Koeltz Scientific Books, Champaign, Ill, 107 pp..

Krammer, Kurt

2001 Diatoms of Europe 1, ed by H. Lange-Bertalot The Genus Pinnularia. A.R.G. Gantner Verlag K.G.

Krammer, Kurt and Horst Lange-Bertalot

1988 Süsswasserflora von Mitteleuropa 2/2 Bacillariophyceae 2 Teil: Bacillariaceae, Epithemiaceae, Surirellaceae. VEB Gustav Fischer Verlag, Jena.

Lange-Bertalot, Horst

2001 Navicula sensu stricto, 10 Genera Separated from Navicula sensu lato, Frustulia. Diatoms of Europe 2, Horst Lange-Bertalot ed., A.R.G. Gantner Verlag K.G.

Porter, Stephen D.

2008 Algal Attributes: An Autecological Classification of Algal Taxa Collected by the National Water-Quality Assessment Program. U.S. Geological Survey Data Series 329. http://pubs.usgs.gov/ds/ds329/

Richman, David

2014. Diatoms of the arid southwest, Arizona, New Mexico and Trans-Pecos Texas, Checklist. New Mexico State University. Aces.nmsu.edu/diatoms/checklist.html

Van de Vijver, Bart, Louis Beyens and Horst Lange-Bertalot 2004 The Genus Stauroneis in the Arctic and (Sub-) Antarctic Regions. Bibliotheca Diatomologica 51, J. Cramer, Berlin. 
Van de Vijver, Bart \& Gabriella Mataloni

2008 New and interesting species in the genus Luticola D.G. Mann (Bacillariophyta) from

Deception Island (South Shetland Islands). Phycologia 47 (5), 451-467.

\section{Table 1: Jemez Modern Analog Diatom taxa with counts}

\begin{tabular}{|c|c|c|c|c|c|c|c|}
\hline \multirow[b]{2}{*}{ Species } & \multirow[b]{2}{*}{ pH Type } & \multicolumn{5}{|c|}{ Sample } & \multirow[b]{2}{*}{ Sum } \\
\hline & & \#1 & \#2 & $\# \mathbf{3}$ & \#4 & \#5 & \\
\hline \multicolumn{8}{|l|}{ blue $=$ benthic/aquatic species, light blue $=$ cosmopolitan species, yellow=aerial/terrestrial } \\
\hline Achnantheiopsis lanceolata (Brebisson ex kutzing) Lange-Bertalot 1997 & 1 & 7 & & & & & \\
\hline Achnanthidium minutissimum (Kützing) Czarnecki 1994 & 2 & & & & & 2 & 2 \\
\hline Adlafia parabryophila (Lange-Bertalot) Gerd Moser, Lange-Bertalot \& D.Metzeltin 1998: 89 & 2 & & 4 & 2 & 4 & 10 & 10 \\
\hline Aulacoseira italica (Ehrenberg) Simonsen 1979 & 3 & & & 25 & & & 28 \\
\hline Bacillaria paradoxa Gmelin 1788 & 4 & & & & 1 & & 1 \\
\hline Caloneis tenuis (W.Gregory) Krammer in Krammer \& Lange-Bertalot 1985: & 3 & 18 & & & 2 & 14 & 34 \\
\hline Craticula cuspidata (Kützing) Mann 1990 & 3 & 62 & 6 & 28 & & 1 & 97 \\
\hline Encyonema silesiacum (Bleisch) Mann 1990 & 2 & 2 & & 2 & & & \\
\hline Epithemia adnata (Kützing) Brébisson 1838 & 3 & & & 6 & & & 6 \\
\hline Epithemia turgida (Ehrenberg) Kützing 1844 & 3 & & & 2 & & & 2 \\
\hline Eunotia bilunaris (Ehrenberg) Souza in Souza \& Moreira-Filho 1999 & 4 & & & 3 & & & - \\
\hline Eunotia monodon Ehrenberg 1843 & 1 & & & 4 & & & 4 \\
\hline Eunotia praerupta Ehrenberg 1843 & 1 & & & 2 & & & 2 \\
\hline Fragilaria neoproducta Lange-Bertalot 1991 & 7 & 2 & & & & & 2 \\
\hline Fragilaria tenera (Smith) Lange-Bertalot 1980 & 1 & 91 & & 4 & & & 95 \\
\hline Gomphonema acuminatum Ehrenberg 1832 & 3 & & & 6 & & & 6 \\
\hline Gomphonema affine Kützing 1844 & 3 & 6 & & & & & 6 \\
\hline Gomphonema gracile Ehrenberg 1838 & 2 & 55 & & 6 & & & 61 \\
\hline Gomphonema parvulum (Kützing) Kützing 1949 & 2 & 8 & 26 & 7 & 15 & 31 & 87 \\
\hline Gomphonema sarcophagus Gregory 1856 & 1 & 8 & & 3 & & & 11 \\
\hline Hantzschia amphioxys (Ehrenberg) Grunow 1880 & 2 & 27 & 103 & 44 & 32 & 83 & 289 \\
\hline Hantzschia Grunow, 1877: 174 & 2 & & 12 & & & 11 & 23 \\
\hline Luticola cohnii (Hilse) Mann 1990 & $\underline{3}$ & & & & 14 & & 14 \\
\hline Luticola mutica (Kützing) Mann 1990 & 2 & 8 & 144 & 10 & 23 & 43 & 228 \\
\hline Luticola muticoides (Hustedt) Mann 1990 & 3 & & & 3 & & 6 & 9 \\
\hline Luticola nivalis (Ehrenberg) Mann 1990 & 2 & & & & & 2 & 2 \\
\hline Luticola paramutica (Bock) Mann 1990 & & & & & 9 & 18 & 27 \\
\hline Meridion circulare var. constrictum (Ralfs) Van Heurck 1880 & 3 & 3 & & 4 & & 2 & \\
\hline Navicula cryptocephala Kützing 1844 & 3 & & 2 & & & & 2 \\
\hline Navicula kotschyi Grunow 1860 & 3 & & & & 2 & & 2 \\
\hline Neidium bisulcatum (Lagerstedt) Cleve 1894 & 2 & 5 & & 28 & 1 & 8 & 42 \\
\hline Nitzschia amphibia Grunow 1862 & 2 & 3 & & 1 & & & 4 \\
\hline Nitzschia palea (Kützing) Smith 1856 & 2 & 31 & 30 & 10 & 4 & 62 & 137 \\
\hline Nitzschia paleacea Grunow 1881 & 3 & 14 & & 4 & & & 18 \\
\hline \begin{tabular}{|l|l|} 
Pinnularia appendiculata (Agardh) Cleve 1895 \\
\end{tabular} & 1 & 4 & & & 2 & 2 & 8 \\
\hline Pinnularia borealis Ehrenberg 1843 & 2 & & & & & 8 & 8 \\
\hline Pinnularia borealis var. rectangularis Carlson 1913 & 2 & 1 & 40 & 2 & 1 & & 44 \\
\hline Pinnularia microstauron (Ehrenberg) Cleve 1891 & 2 & 3 & & & & & 3 \\
\hline Pinnularia obscura Krasske 1932 & 2 & & & & & 1 & 1 \\
\hline Pinnularia subcapitata Gregory 1856 & 1 & 108 & & 222 & & 2 & 332 \\
\hline Pinnularia tirolensis (Metzeltin \& Krammer) K.Krammer 2000: 88; pl.65, fig.2-8, 11-13 & & & & 1 & & & \\
\hline Pinnularia viridis (Nitzsch) Ehrenberg 1843 & 2 & 5 & & 11 & & & 16 \\
\hline Placoneis elginensis (Gregory) Cox 1987 & 3 & 3 & & 12 & & & 15 \\
\hline Rhopalodia gibba (Ehrenberg) Müller 1895 & 3 & 2 & & 4 & & 1 & 7 \\
\hline Sellaphora bacillum (Ehrenberg) Mann 1989 & 3 & & & & & 2 & \\
\hline Sellaphora pupula (Kützing) Meresckowsky 1902 & 2 & 1 & & & & & 1 \\
\hline Stauroneis anceps Ehrenberg 1843 & 2 & & & 4 & & 1 & 5 \\
\hline Stauroneis borrichii (Petersen) Lund 1946 & 2 & & & & & 2 & 2 \\
\hline Stauroneis gracilior E.Reichardt, 1995 & 2 & 6 & 117 & 4 & & 19 & 146 \\
\hline Surirella angusta Kützing 1844 & 3 & 2 & 16 & 31 & 15 & 168 & 232 \\
\hline Nitzschia levidensis salinarum (Grun) Krammer \& Lange-Bertalot 1988 & & 2 & & & & & \\
\hline Ulnaria acus (Kützing) Aboal 2003 & 3 & 2 & & 2 & & & 4 \\
\hline Ulnaria ulna (Nitzsch) Compére 2001 & 3 & 1 & & 3 & & 1 & 5 \\
\hline$p H$ tolerances $1=$ acidophilous, $2=$ circumneutral, $3=$ alkaliphilous, $4=$ indifferent,.$=n o$ info & & & & & & & \\
\hline count & & 490 & 500 & 500 & 125 & 500 & \\
\hline species count & & 30 & 11 & 33 & 14 & 25 & \\
\hline
\end{tabular}


Table 2: Diatom names with complete authorship

Achnantheiopsis lanceolata (Brébisson ex Kützing) Lange-Bertalot 1997

Achnanthidium minutissimum (Kützing) Czarnecki 1994

Adlafia parabryophila (Lange-Bertalot) Gerd Moser, Lange-Bertalot \& D. Metzeltin 1998

Aulacoseira italica (Ehrenberg) Simonsen 1979

Bacillaria paradoxa Gmelin 1788

Caloneis tenuis (W. Gregory) Krammer in Krammer \& Lange-Bertalot 1985

Craticula cuspidata (Kützing) Mann 1990

Encyonema silesiacum (Bleisch) Mann 1990

Epithemia adnata (Kützing) Brébisson 1838

Epithemia turgida (Ehrenberg) Kützing 1844

Eunotia bilunaris (Ehrenberg) Mills 1934

Eunotia monodon Ehrenberg 1843

Eunotia praerupta Ehrenberg 1843

Fragilaria neoproducta Lange-Bertalot 1991

Fragilaria tenera (Smith) Lange-Bertalot 1980

Gomphonema acuminatum Ehrenberg 1832

Gomphonema affine Kützing 1844

Gomphonema gracile Ehrenberg 1838

Gomphonema parvulum (Kützing) Kützing 1949

Gomphonema sarcophagus Gregory 1856

Hantzschia amphioxys (Ehrenberg) Grunow 1880

Hantzschia Grunow, 1877

Luticola cohnii (Hilse) Mann 1990

Luticola mutica (Kützing) Mann 1990

Luticola muticoides (Hustedt) Mann 1990

Luticola nivalis (Ehrenberg) Mann 1990

Luticola paramutica (Bock) Mann 1990

Meridion circulare var. constrictum (Ralfs) Van Heurck 1880

Navicula cryptocephala Kützing 1844

Navicula kotschyi Grunow 1860

Neidium bisulcatum (Lagerstedt) Cleve 1894

Nitzschia amphibia Grunow 1862

Nitzschia palea (Kützing) Smith 1856

Nitzschia paleacea Grunow 1881

Pinnularia appendiculata (Agardh) Cleve 1895

Pinnularia borealis var. sublinearis Krammer 2001

Pinnularia microstauron (Ehrenberg) Cleve 1891

Pinnularia obscura Krasske 1932

Pinnularia subcapitata Gregory 1856 
Pinnularia tirolensis (Metzeltin \& Krammer) K. Krammer 2000

Pinnularia viridis (Nitzsch) Ehrenberg 1843

Placoneis elginensis (Gregory) Cox 1987

Rhopalodia gibba (Ehrenberg) Müller 1895

Sellaphora bacillum (Ehrenberg) Mann 1989

Sellaphora pupula (Kützing) Mereschkowsky 1902

Stauroneis anceps Ehrenberg 1843

Stauroneis borrichii (Petersen) Lund 1946

Stauroneis gracilior (Rabenhorst) E. Reichardt, 1995

Surirella angusta Kützing 1844

Tryblionella salinarum (Grunow in Cleve and Grunow) Pelletan 1889

Ulnaria acus (Kützing) Aboal 2003

Ulnaria ulna (Nitzsch) Compère 2001

TABLE 3: ECOLOGICAL CHARACTERISTICS OF THE DIATOMS FROM THE FIVE MODERN ANALOG SAMPLES

\begin{tabular}{|l|l|}
\hline $\begin{array}{l}\text { Name (see master species } \\
\text { list for complete } \\
\text { authorship) }\end{array}$ & Summary of ecological spectra for each diatom \\
\hline $\begin{array}{l}\text { Achnantheiopsis } \\
\text { lanceolata }\end{array}$ & $\begin{array}{l}\text { high alkalinity, low to moderate conductivity (3), eutrophic, } \alpha \text { - } \\
\text { mesosaprobous, tolerant to organically bound nitrogen (OBN), } \\
\text { tolerates highly degraded conditions, tolerates }>50 \% \text { DO saturation, } \\
\text { alkaliphilous, fresh-brackish water, chloride optimum low ( }<15 \\
\text { mg/L), benthic, non-motile (6) }\end{array}$ \\
\hline $\begin{array}{l}\text { Achnanthidium } \\
\text { minutissimum }\end{array}$ & $\begin{array}{l}\text { slightly acidic to slightly alkaline water over a wide range of } \\
\text { nutrient conditions (2), wide range of tolerance to nutrients, } \\
\text { indicator of low total nitrogen and total phosphorous, } \beta \text { - } \\
\text { mesosaprobous, tolerant to OBN, tolerates somewhat degraded } \\
\text { conditions, tolerates nearly 100\% DO saturation, wide range of } \\
\text { tolerance to pH, fresh-brackish water, chloride optimum low ( }<15 \\
\text { mg/L), benthic, non-motile (6), cosmopolitan }\end{array}$ \\
\hline Adlafia parabryophila & $\begin{array}{l}\text { cold, oligodystrophic water (2), mesotrophic, oligosaprobous, } \\
\text { generally intolerant to OBN, tolerates nearly 100\% DO saturation, } \\
\text { circumneutral pH, freshwater, chloride optimum low (<15 mg/L), } \\
\text { benthic, motile (6) }\end{array}$ \\
\hline Aulacoseira italica & $\begin{array}{l}\text { meso- eutrophic, } \beta \text {-mesosaprobous, tolerant to OBN, tolerates } \\
>75 \% \text { DO saturation, alkaliphilous, fresh-brackish water, } \\
\text { planktonic, non-motile (6), dry soil (8), cosmopolitan }\end{array}$ \\
\hline Bacillaria paradoxa & $\begin{array}{l}\text { eutrophic, } \alpha \text {-mesosaprobous, tolerant to OBN, tolerates }>30 \% \text { DO } \\
\text { saturation, wide range of tolerance to pH, brackish water, benthic, } \\
\text { non-motile (6), cosmopolitan }\end{array}$ \\
\hline mesotrophic, oligosaprobous, generally intolerant to OBN, tolerates \\
\hline
\end{tabular}




\begin{tabular}{|c|c|}
\hline & $\begin{array}{l}\text { nearly } 100 \% \text { DO saturation, circumneutral } \mathrm{pH} \text {, fresh-brackish } \\
\text { water, benthic, motile (6) }\end{array}$ \\
\hline Craticula cuspidata & $\begin{array}{l}\text { cosmopolitan, waters with an average to higher electrolyte content, } \\
\text { even in brackish water, usually epipelic, eutrophic and pollution } \\
\text { tolerant (2), eutrophic, } \alpha \text {-mesosaprobous, tolerant to OBN, tolerates } \\
\text { degraded conditions, tolerates }>50 \% \text { DO saturation, alkaliphilous, } \\
\text { fresh-brackish water, benthic, motile (6) }\end{array}$ \\
\hline Encyonema silesiaca & $\begin{array}{l}\text { wide range of tolerance to nutrients, indicator of low total nitrogen, } \\
\alpha \text {-mesosaprobous, tolerant to OBN, tolerates }>50 \% \text { DO saturation, } \\
\text { circumneutral } \mathrm{pH} \text {, fresh-brackish water, conductivity optimum low } \\
(<200 \mu \mathrm{S} / \mathrm{cm}) \text {, chloride optimum low }(<15 \mathrm{mg} / \mathrm{L}) \text {, benthic, non- } \\
\text { motile (6) cosmopolitan }\end{array}$ \\
\hline Epithemia adnata & $\begin{array}{l}\text { epiphytic, moderate to high alkalinity water (3) alkaliphilous to } \\
\text { alkalibiontic, warm water (5), capable of fixing atmospheric } \\
\text { nitrogen, mesotrophic, indicator of low total nitrogen and total } \\
\text { phosphorous, } \beta \text {-mesosaprobous, generally intolerant to OBN, } \\
\text { tolerates }>75 \% \text { DO saturation, alkalibiontic, fresh-brackish water, } \\
\text { conductivity optimum low ( }<200 \mu \mathrm{S} / \mathrm{cm}) \text {, benthic, non-motile (6) } \\
\text { cosmopolitan }\end{array}$ \\
\hline Epithemia turgida & $\begin{array}{l}\text { prefers high alkalinity and can tolerate high conductivity (3), } \\
\text { alkaliphilous to alkalibiontic, limnophilous, calciphilous, epiphytic, } \\
\text { in rivers (5), capable of fixing atmospheric nitrogen, capable of } \\
\text { fixing atmospheric nitrogen, mesotrophic, indicator of low total } \\
\text { nitrogen, } \beta \text {-mesosaprobous, generally intolerant to OBN, tolerates } \\
>75 \% \text { DO saturation, alkalibiontic, fresh-brackish water, chloride } \\
\text { optimum low ( }<15 \mathrm{mg} / \mathrm{L}) \text {, benthic, non-motile (6) cosmopolitan }\end{array}$ \\
\hline Eunotia cf bilunaris & $\begin{array}{l}\text { wide range of tolerance to nutrients, } \beta \text {-mesosaprobous, tolerant to } \\
\text { OBN, tolerates }>75 \% \text { DO saturation, wide range of tolerance to } \mathrm{pH} \text {, } \\
\text { fresh-brackish water, conductivity optimum low }(<200 \mu \mathrm{S} / \mathrm{cm}) \text {, } \\
\text { chloride optimum low }(<15 \mathrm{mg} / \mathrm{L}) \text {, benthic, non-motile }(6)\end{array}$ \\
\hline Eunotia monodon & $\begin{array}{l}\text { oligotrophic, indicator of low total nitrogen and total phosphorous, } \\
\text { oligosaprobous, generally intolerant to OBN, tolerates nearly } 100 \% \\
\text { DO saturation, acidophilous, freshwater, conductivity optimum low } \\
\text { ( }<200 \mu \mathrm{S} / \mathrm{cm}) \text {, chloride optimum low }(<15 \mathrm{mg} / \mathrm{L}) \text {, benthic, non- } \\
\text { motile }(6)\end{array}$ \\
\hline Eunotia praerupta & $\begin{array}{l}\text { oligo-mesotrophic, indicator of low total nitrogen, oligosaprobous, } \\
\text { generally intolerant to OBN, freshwater, tolerates nearly 100\% DO } \\
\text { saturation, acidophilous, freshwater, benthic, non-motile (6) }\end{array}$ \\
\hline $\begin{array}{l}\text { Fragilariforma } \\
\text { neoproducta }\end{array}$ & $\begin{array}{l}\text { oligosaprobous, generally intolerant to OBN, tolerates nearly } 100 \% \\
\text { DO saturation, freshwater, benthic, non-motile (6) }\end{array}$ \\
\hline Fragilaria tenera & $\begin{array}{l}\text { oligo-mesotrophic, oligosaprobous, generally intolerant to OBN, } \\
\text { tolerates nearly 100\% DO saturation, acidophilous, freshwater, } \\
\text { chloride optimum low ( }<15 \mathrm{mg} / \mathrm{L}) \text {, benthic, non-motile (6) }\end{array}$ \\
\hline $\begin{array}{l}\text { Gomphonema } \\
\text { acuminatum }\end{array}$ & $\begin{array}{l}\text { eutrophic, } \beta \text {-mesosaprobous, generally intolerant to OBN, tolerates } \\
>75 \% \text { DO saturation, alkaliphilous, fresh-brackish water, } \\
\text { conductivity optimum low }(<200 \mu \mathrm{S} / \mathrm{cm}) \text {, chloride optimum low }\end{array}$ \\
\hline
\end{tabular}




\begin{tabular}{|c|c|}
\hline & (<15 mg/L), benthic, non-motile (6) \\
\hline Gomphonema affine & $\begin{array}{l}\text { mesotrophic, } \beta \text {-mesosaprobous, generally intolerant to OBN, } \\
\text { tolerates nearly } 100 \% \text { DO saturation, alkaliphilous, fresh-brackish } \\
\text { water, benthic, non-motile (6) }\end{array}$ \\
\hline Gomphonema gracile & $\begin{array}{l}\text { mesotrophic, oligosaprobous, generally intolerant to OBN, tolerates } \\
\text { nearly } 100 \% \text { DO saturation, circumneutral } \mathrm{pH} \text {, fresh-brackish } \\
\text { water, conductivity optimum low }(<200 \mu \mathrm{S} / \mathrm{cm}) \text {, chloride optimum } \\
\text { low }(<15 \mathrm{mg} / \mathrm{L}) \text {, benthic, non-motile }(6)\end{array}$ \\
\hline Gomphonema parvulum & $\begin{array}{l}\text { prefers nutrient-rich water (3), eutrophic, indicator of high total } \\
\text { nitrogen and total phosphorous, } \alpha \text {-meso/polysaprobous, requires } \\
\text { periodic elevated concentrations of OBN, tolerates extremely } \\
\text { degraded conditions, tolerates }>30 \% \text { DO saturation, circumneutral } \\
\text { pH, fresh-brackish water, chloride optimum low (<15 mg/L), } \\
\text { benthic, non-motile (6), silt and sand attached with stalk (10), } \\
\text { cosmopolitan }\end{array}$ \\
\hline $\begin{array}{l}\text { Gomphonema } \\
\text { sarcophagus }\end{array}$ & $\begin{array}{l}\text { mesotrophic, indicator of low total phosphorous, } \beta \text {-mesosaprobous, } \\
\text { alkaliphilous, fresh-brackish water, chloride optimum low }(<15 \\
\mathrm{mg} / \mathrm{L}) \text {, benthic, non-motile (6) }\end{array}$ \\
\hline Hantzschia amphioxys & $\begin{array}{l}\text { wide range of tolerance to nutrients, indicator of high total } \\
\text { phosphorous, } \alpha \text {-mesosaprobous, tolerant to OBN, tolerates }>75 \% \\
\text { DO saturation, circumneutral pH, fresh-brackish water, chloride } \\
\text { optimum low ( }<15 \mathrm{mg} / \mathrm{L}) \text {, benthic, motile (6), dry soil (8), survives } \\
\text { prolonged dry periods (9) cosmopolitan, one of the most common } \\
\text { soil diatoms worldwide }\end{array}$ \\
\hline $\begin{array}{l}\text { Hantzschia vivax var. } \\
\text { hyperborea }\end{array}$ & $\begin{array}{l}\text { very high conductivity water, saline lakes, seacoasts (4), benthic, } \\
\text { motile (6) }\end{array}$ \\
\hline Luticola cohnii & $\begin{array}{l}\text { eutrophic, } \beta \text {-mesosaprobous, tolerant to OBN, tolerates nearly } \\
100 \% \text { DO saturation, alkaliphilous, brackish-freshwater, chloride } \\
\text { optimum low }(<15 \mathrm{mg} / \mathrm{L}) \text {, benthic, motile (6), common in soil } \\
\text { samples and seems to have a rather broad ecological spectrum but } \\
\text { absent at high nutrient concentrations ( } 7)\end{array}$ \\
\hline Luticola mutica & $\begin{array}{l}\text { eutrophic, } \alpha \text {-mesosaprobous, tolerant to OBN, tolerates low } \\
\text { amounts of organic enrichment, tolerates nearly } 100 \% \text { DO } \\
\text { saturation, circumneutral pH, brackish-freshwater, chloride } \\
\text { optimum low }(<15 \mathrm{mg} / \mathrm{L}) \text {, benthic, motile (6), dry soil (8), } \\
\text { cosmopolitan }\end{array}$ \\
\hline Luticola muticopsis & $\begin{array}{l}\text { benthic, motile (6), very widespread in the Antarctic and } \\
\text { Subantarctic Regions, high nutrient concentrations, chinstrap } \\
\text { penguin rookeries with pH 8.2, (7) }\end{array}$ \\
\hline Luticola nivalis & $\begin{array}{l}\text { oligo-mesotrophic, tolerates somewhat degraded conditions, } \\
\text { circumneutral pH, brackish-freshwater, benthic, motile (6), in soil, } \\
\text { near gull nesting areas and fur seal wallows, on lichens, mosses and } \\
\text { liverworts (7), dry soil (8) }\end{array}$ \\
\hline Luticola paramutica & $\begin{array}{l}\text { aerial and soils, Arctic and Subarctic Regions (7), “pluviatilen” } \\
\text { sites (8) }\end{array}$ \\
\hline Meridion circulare var. & wide range of tolerance to nutrients, $\beta$-mesosaprobous, tolerant to \\
\hline
\end{tabular}




\begin{tabular}{|c|c|}
\hline constrictum & $\begin{array}{l}\text { OBN, tolerates }>75 \% \text { DO saturation, alkaliphilous, fresh-brackish } \\
\text { water, conductivity optimum low }(<200 \mu \mathrm{S} / \mathrm{cm}) \text {, chloride optimum } \\
\text { low }(<15 \mathrm{mg} / \mathrm{L}) \text {, planktonic, non-motile }(6)\end{array}$ \\
\hline Navicula cryptocephala & $\begin{array}{l}\text { wide range of tolerance to nutrients, } \alpha \text {-mesosaprobous, tolerant to } \\
\text { OBN, tolerates }>50 \% \text { DO saturation, alkaliphilous, fresh-brackish } \\
\text { water, chloride optimum low ( }<15 \mathrm{mg} / \mathrm{L}) \text {, benthic, non-motile }(6) \\
\text { cosmopolitan }\end{array}$ \\
\hline Navicula kotschyi & $\begin{array}{l}\text { oligosaprobous, tolerates nearly 100\% DO saturation, alkaliphilous, } \\
\text { fresh-brackish water, planktonic, non-motile (6) }\end{array}$ \\
\hline Neidium bisulcatum & $\begin{array}{l}\text { oligotrophic, oligosaprobous, generally intolerant to OBN, tolerates } \\
\text { nearly } 100 \% \text { DO saturation, circumneutral } \mathrm{pH} \text {, freshwater, benthic, } \\
\text { non-motile (6) }\end{array}$ \\
\hline Nitzschia amphibia & $\begin{array}{l}\text { cosmopolitan, springs, creeks, epipelic, prefers high conductivity } \\
\text { (3), eutrophic, indicator of high total nitrogen and total } \\
\text { phosphorous, } \alpha \text {-mesosaprobous, requires periodic elevated } \\
\text { concentrations of OBN, tolerates highly degraded conditions, } \\
\text { tolerates }>50 \% \text { DO saturation, alkaliphilous, fresh-brackish water, } \\
\text { benthic, non-motile (6) }\end{array}$ \\
\hline Nitzschia palea & $\begin{array}{l}\text { tolerates a wide range of ecological conditions, a good indicator of } \\
\text { organic pollution, (3)cosmopolitan, } \alpha \text {-mesosaprobous to } \\
\text { polysaprobous (4), polytrophic, indicator of high total nitrogen and } \\
\text { total phosphorous, polysaprobous, indicative of elevated } \\
\text { concentrations of OBN, tolerates extremely degraded conditions, } \\
\text { tolerates }>30 \% \text { DO saturation, circumneutral pH, fresh-brackish } \\
\text { water, benthic, non-motile (6), soils (8), pond margin mud, survives } \\
\text { dry periods (9) cosmopolitan }\end{array}$ \\
\hline Nitzschia paleacea & $\begin{array}{l}\text { cosmopolitan, benthic, more or less eutrophic water with moderate } \\
\text { to high conductivity (4), eutrophic, } \alpha \text {-mesosaprobous, indicative of } \\
\text { elevated concentrations of OBN, tolerates highly degraded } \\
\text { conditions, tolerates }>50 \% \text { DO saturation, alkaliphilous, fresh- } \\
\text { brackish water, chloride optimum low ( }<15 \mathrm{mg} / \mathrm{L}) \text {, benthic, motile } \\
\text { (6) }\end{array}$ \\
\hline Pinnularia appendiculata & $\begin{array}{l}\text { cosmopolitan, prefers mineralized waters, salt-rich inland waters, } \\
\text { salines, soda lakes, generally in waters with an average to high } \\
\text { electrolyte content (1), oligo-mesotrophic, oligosaprobous, } \\
\text { generally intolerant to OBN, tolerates nearly } 100 \% \text { DO saturation, } \\
\text { acidophilous, freshwater, conductivity optimum low }(<200 \mu \mathrm{S} / \mathrm{cm}) \text {, } \\
\text { chloride optimum low ( }<15 \mathrm{mg} / \mathrm{L}) \text {, benthic, motile }(6) \text {, soil }(8)\end{array}$ \\
\hline $\begin{array}{l}\text { Pinnularia borealis var. } \\
\text { sublinearis }\end{array}$ & $\begin{array}{l}\text { moss, frequent on wet and nearly dry walls (1), oligo-mesotrophic, } \\
\beta \text {-mesosaprobous, tolerant to OBN, tolerates nearly } 100 \% \text { DO } \\
\text { saturation, circumneutral pH, fresh-brackish water, benthic, motile } \\
\text { (6), cosmopolitan }\end{array}$ \\
\hline Pinnularia microstauron & $\begin{array}{l}\text { epipelic (3), cosmopolitan, oligotrophic, oligosaprobic waters with } \\
\text { a low electrolyte content and } \mathrm{pH} \text { values, cool, oxygen-rich } \\
\text { moorland water with a very low electrolyte content (1), wide range } \\
\text { of tolerance to nutrients, } \beta \text {-mesosaprobous, tolerant to OBN, }\end{array}$ \\
\hline
\end{tabular}




\begin{tabular}{|c|c|}
\hline & $\begin{array}{l}\text { tolerates }>50 \% \text { DO saturation, circumneutral } \mathrm{pH} \text {, fresh-brackish } \\
\text { water, chloride optimum low }(<15 \mathrm{mg} / \mathrm{L}) \text {, benthic, motile }(6)\end{array}$ \\
\hline Pinnularia obscura & $\begin{array}{l}\text { Cosmopolitan in nordic-alpine regions, aerophilic, particularly in } \\
\text { moist and occasionally moist mosses and on wet rocks, one of the } \\
\text { commonest soil diatoms (1), oligosaprobous, generally intolerant to } \\
\text { OBN, tolerates nearly } 100 \% \text { DO saturation, circumneutral } \mathrm{pH} \text {, } \\
\text { fresh-brackish water, conductivity optimum low }(<200 \mu \mathrm{S} / \mathrm{cm}) \text {, } \\
\text { chloride optimum low ( }<15 \mathrm{mg} / \mathrm{L}) \text {, benthic, motile }(6)\end{array}$ \\
\hline Pinnularia subcapitata & $\begin{array}{l}\text { bogs, wet moss, oligotrophic, electrolyte-poor water (1), oligo- } \\
\text { mesotrophic, } \beta \text {-mesosaprobous, tolerant to OBN, tolerates }>50 \% \\
\text { DO saturation, acidophilous, fresh-brackish water, benthic, motile } \\
\text { (6) }\end{array}$ \\
\hline $\begin{array}{l}\text { Pinnularia tirolensis } \\
\text { (P. subgibba var. } \\
\text { tirolensis Metzeltin and } \\
\text { Krammer 1996) }\end{array}$ & $\begin{array}{l}\text { lakes, oligotrophic water with very low electrolyte content, } P . \\
\text { subgibba was described from a small moor lake, holarctic (1) }\end{array}$ \\
\hline Pinnularia viridis & $\begin{array}{l}\text { cosmopolitan, circumneutral } \mathrm{pH} \text {, oligo-mesotrophic water with } \\
\text { lower to average electrolyte content (1), wide range of tolerance to } \\
\text { nutrients, } \beta \text {-mesosaprobous, tolerant to OBN, tolerates }>50 \% \text { DO } \\
\text { saturation, fresh-brackish water, fresh-brackish water, conductivity } \\
\text { optimum low }(<200 \mu \mathrm{S} / \mathrm{cm}) \text {, chloride optimum low ( }<15 \mathrm{mg} / \mathrm{L}) \text {, } \\
\text { benthic, motile }(6) \text {, frequent at the margin of ponds and survives } \\
\text { short periods of drying, up to about a month (9) }\end{array}$ \\
\hline Placoneis elginensis & $\begin{array}{l}\text { eutrophic, } \beta \text {-mesosaprobous, tolerant to OBN, tolerates }>75 \% \text { DO } \\
\text { saturation, alkaliphilous, fresh-brackish water, chloride optimum } \\
\text { low ( }<15 \mathrm{mg} / \mathrm{L}) \text {, benthic, motile (6) }\end{array}$ \\
\hline Rhopalodia gibba & $\begin{array}{l}\text { capable of fixing atmospheric nitrogen, eutrophic, indicator of low } \\
\text { total nitrogen and high total phosphorous, } \beta \text {-mesosaprobous, } \\
\text { generally intolerant to OBN, tolerates }>50 \% \text { DO saturation, } \\
\text { alkalibiontic, fresh-brackish water, chloride optimum low ( }<15 \\
\text { mg/L), benthic, motile (6), cosmopolitan }\end{array}$ \\
\hline Sellaphora bacillum & $\begin{array}{l}\text { meso-eutrophic, } \beta \text {-mesosaprobous, generally intolerant to OBN, } \\
\text { tolerates }>75 \% \text { DO saturation, alkaliphilous, fresh-brackish water, } \\
\text { conductivity optimum low }(<200 \mu \mathrm{S} / \mathrm{cm}) \text {, chloride optimum low } \\
(<15 \mathrm{mg} / \mathrm{L}) \text {, benthic, motile }(6)\end{array}$ \\
\hline Sellaphora pupula & $\begin{array}{l}\text { tolerates high conductivity and alkalinity (3), meso-eutrophic, } \\
\text { meso-eutrophic, indicator of high total nitrogen, } \alpha \text {-mesosaprobous, } \\
\text { tolerant to OBN, tolerates degraded conditions, tolerates }>50 \% \text { DO } \\
\text { saturation, circumneutral } \mathrm{pH} \text {, fresh-brackish water, benthic, motile } \\
\text { (6), cosmopolitan }\end{array}$ \\
\hline Stauroneis anceps & $\begin{array}{l}\text { epipelic, high organic content (3), } \beta \text {-mesosaprobous, tolerant to } \\
\text { OBN, tolerates }>75 \% \text { DO saturation, circumneutral pH, fresh- } \\
\text { brackish water, benthic, motile (6) }\end{array}$ \\
\hline Stauroneis borrichii & $\begin{array}{l}\text { oligosaprobous, tolerates nearly 100\% DO saturation, circumneutral } \\
\text { pH, freshwater, benthic, motile (6), soil (8) }\end{array}$ \\
\hline Stauroneis gracilior & (as S. anceps fo. gracilis Rabenhorst 1864) epipelic, high organic \\
\hline
\end{tabular}




\begin{tabular}{|l|l|}
\hline & $\begin{array}{l}\text { content (3), } \beta \text {-mesosaprobous, tolerant to OBN, tolerates }>75 \% \text { DO } \\
\text { saturation, circumneutral } \mathrm{pH}, \text { fresh-brackish water, benthic, motile } \\
(6)\end{array}$ \\
\hline Surirella angusta & $\begin{array}{l}\text { very eutrophic water with moderate conductivity (4), eutrophic, } \beta \text { - } \\
\text { mesosaprobous, tolerant to OBN, tolerates }>75 \% \text { DO saturation, } \\
\text { alkaliphilous, fresh-brackish water, chloride optimum low (<15 } \\
\text { mg/L), benthic, motile (6) }\end{array}$ \\
\hline Tryblionella salinarum & $\begin{array}{l}\text { brackish water near seacoasts, freshwater with moderate to high } \\
\text { electrolytes, epipelic, } \alpha \text {-mesosaprobous (4), eutrophic, benthic, } \\
\text { motile (6) }\end{array}$ \\
\hline Ulnaria acus & $\begin{array}{l}\text { tolerates a wide range of ecological conditions (3), eutrophic, } \alpha \text { - } \\
\text { mesosaprobous, tolerant to OBN, tolerates degraded conditions, } \\
\text { tolerates }>75 \% \text { DO saturation, alkaliphilous, fresh-brackish water, } \\
\text { chloride optimum low (<15 mg/L), benthic, non-motile (6), } \\
\text { cosmopolitan }\end{array}$ \\
\hline Ulnaria ulna & $\begin{array}{l}\text { tolerates a wide range of ecological conditions (3), wide range of } \\
\text { tolerance to nutrients, indicator of low total nitrogen and total } \\
\text { phosphorous, } \alpha \text {-meso/polysaprobous, tolerant to OBN, tolerates } \\
\text { extremely degraded conditions, tolerates }>50 \% \text { DO saturation, } \\
\text { alkaliphilous, fresh-brackish water, chloride optimum low (<15 } \\
\text { mg/L), benthic, non-motile (6), cosmopolitan }\end{array}$ \\
\hline
\end{tabular}

Ecology references:

(1) Krammer, 2001

(2) Lange-Bertalot, 2001

(3) Czarnecki and Blinn, 1977

(4) Krammer and Lange-Bertalot, 1988

(5) Czarnecki and Blinn, 1978

(6) Porter, 2008

(7) Van de Vijver and Mataloni, 2008

(8) Bock, 1963

(9) Evans, 1959

(10) Burkholder 1996

\author{
TABLE 4: GLOSSARY OF DIATOM ATTRIBUTES AND WATER QUALITY TERMS \\ pH \\ acidobiontic - optimal occurrence at $\mathrm{pH}<5.5$, occurs below $\mathrm{pH} 7$ \\ acidophilous - mainly occurring at $\mathrm{pH}<7$ \\ circumneutral- mainly occurring at $\mathrm{pH}$-values about 7
}


alkaliphilous - mainly occurring at $\mathrm{pH}>7$

alkalibiontic - exclusively occurring at $\mathrm{pH}>7$

indifferent - no apparent optimum, tolerates a wide $\mathrm{pH}$ range

Salinity (halobion or salt spectra) concentration of sodium chloride (related to conductivity in brackish and fresh water)

\begin{tabular}{|l|l|l|}
\hline & $\mathrm{Cl}^{-}(\mathrm{mg} / \mathrm{L})$ & Salinity $(\mathrm{ppt})$ \\
\hline fresh & $<100$ & $<0.2$ \\
\hline fresh-brackish & $<500$ & $<0.9$ \\
\hline brackish-fresh & $500-1000$ & $0.9-1.8$ \\
\hline brackish & $1000-5000$ & $1.8-9.0$ \\
\hline brackish-marine & $5000-30,000$ & $9.0-30$ \\
\hline marine & $30,000-40,000$ & $30-40$ \\
\hline hypersaline & over 40,000 & over 40 \\
\hline
\end{tabular}

halophobous - occurs only in fresh water

halophilous - freshwater form stimulated by small amounts of salt

oligohalobous - freshwater, indifferent to small amounts of salt

mesohalobous - brackish water form 500-30,00 mg/l Cl, (mesosaline or mesohaline)

beta-mesohalobous - 500-10,000 mg/l

alpha-mesohalobous - 10,000-30,000 mg/l

polyhalobous - can withstand salt concentrations greater than those of the sea and tolerate concentrations of 5-35 ppt

euryhalobous - occurring over a broad range of salt concentrations

stenohalobous - occurring within a narrow range of salinities

euhalobous - marine

pleio-euryhaline - tolerates a salinity range of 5-35 ppt

\section{Oxygen requirements}

continuously high (about 100\% saturation)

fairly high (above 75\% saturation)

moderate (above 50\% saturation)

low (above 30\% saturation) 
very low (about 10\% saturation)

Saprobity (organic pollution, harmful substances, dependence on decomposing organic nutrients, along a gradient of nutrient and organic enrichment)

\begin{tabular}{|l|l|l|l|}
\hline & $\begin{array}{l}\text { Oxygen } \\
\text { saturation } \\
(\%)\end{array}$ & $\begin{array}{l}\mathrm{BOD}_{5}{ }^{20}( \\
\mathrm{mg} / \mathrm{L})\end{array}$ & \\
\hline saprophobous & & & clean, unpolluted water \\
\hline oligosaprobous & $>85$ & $<2$ & $\begin{array}{l}\text { low amounts of organic enrichment, clean } \\
\text { water }\end{array}$ \\
\hline mesosaprobous & & $2-4$ & $\begin{array}{l}\text { occurring in moderate to highly polluted water } \\
\text { and green algae }\end{array}$ \\
\hline$\beta$-mesosaprobous & $70-85$ & $4-13$ & $\begin{array}{l}\text { degraded conditions, preponderance of } \\
\text { cyanobacteria, tolerant diatoms and some } \\
\text { green algae }\end{array}$ \\
\hline$\alpha$-mesosaprobous & $25-70$ & $13-25$ & $\begin{array}{l}\text { highly degraded conditions, cyanobacteria and } \\
\text { a few diatoms }\end{array}$ \\
\hline $\begin{array}{l}\alpha \text {-meso- } \\
\text { /polysaprobous }\end{array}$ & $<1$ & $>22$ & $\begin{array}{l}\text { extremely degraded conditions, very polluted, } \\
\text { few algae }\end{array}$ \\
\hline polysaprobous & $<1$ & &
\end{tabular}

Trophic state (growth promoting substances such as nitrogen and phosphorous, often from inorganic plant nutrients

oligotrophic - nutrient poor

oligo-mesotrophic - low nutrient concentrations

mesotrophic - moderate nutrient concentrations

meso - eutrophic- rather high nutrient concentrations

eutrophic - high nutrient concentrations, nutrient rich

eurytrophic - indifferent to nutrients

hypereutrophic or polytrophic - oligo-eutrophic

nitrogen fixing algae can use dissolved atmospheric nitrogen as a nutrient source

\section{Substrate or life form}

planktonic - free floating, suspended in the water column

euplanktonic - usually suspended in the water column 
tychoplanktonic - facultatively or opportunistically planktonic during turbid periods but usually associated with benthic habitats

metaphyton - not directly attached to substrata, nor freely suspended in the water column

benthic - attached to hard surfaces or live in and on fine sediments associated with sediment, microbial mats and vegetation at or near the bottom

sessile - directly attached to substrate

epiphytic - attached to aquatic plants or other algae

epilithic - attached to rocks and pebbles

epipelic - motile forms that glide through mud

epipsammic - attached to sand grains

aerial (aerophilic, subaerial) - not submerged, commonly living in air, adapted to damp or dry habitats such as soil, moss, wet walls and muds, spray or surf zones, seeps

aquatic - submerged

edaphic - associated with sediments

epontic - sessile, firmly attached to any kind substratum, including macrophytes, rocks and sand

\section{Water flow characteristics}

limnobiontic - characteristic of non-flowing (standing) waters (lakes, ponds, lagoons)

limnophilous - optimum development in non-flowing waters

rheophilous - characteristic of flowing waters

Conductivity: The concentration of dissolved salts (electrolytes), made up of cations calcium, magnesium, sodium and potassium, and anions bicarbonate, sulphate and chloride 


\title{
DIATOM PALEOENVIRONMENTAL ANALYSIS OF SEDIMENTS FROM
}

\section{ANCESTRAL PUEBLOAN WATER RESERVOIR FEATURES AT LARGE VILLAGE \\ SITES ON THE JEMEZ PLATEAU, NEW MEXICO}

\author{
Prepared By: \\ Barbara Winsborough \\ Winsborough Consulting \\ 23606 Round Mountain Circle \\ Leander, Texas 78641 \\ Revision of April Draft, August, 2016 \\ Prepared For: \\ Michael Aiuvalasit M.A., R.P.A. \\ PhD Candidate and Research Assistant \\ Department of Anthropology \\ Southern Methodist University \\ Campus PO Box 750336 \\ 3225 Daniel Ave., Heroy Hall \# 435 \\ Dallas, Texas 75275-0336
}




\section{INTRODUCTION}

This investigation is part of a larger research project reconstructing the use-life of Ancestral Puebloan water reservoir features at large village sites in the Jemez Mountains near Jemez Springs, New Mexico. The goal of this part of the project is to investigate the diatom content of core samples taken from the deep parts of the reservoirs and determine how much water was present and how long it lasted. A set of 20 core samples was submitted for diatom analysis. A preliminary examination of each sample was done to determine if there was evidence of potential diatom presence that warranted further, more detailed analysis. There were 15 samples that showed potential to contain a useful diatom assemblage (Table 1) and these samples were analyzed in detail. The goal is to identify wet and dry periods that reflect changes in the availability of water.

Diatoms are unicellular, eukaryotic algae that are distinguished by the presence of a silica cell wall. They live in a wide variety of habitats, including soil, rocks, moss, caves, rivers, streams, ponds, lakes, bogs, lagoons, marshes, swamps, mud flats, sandy and rocky beaches, estuaries, bays and oceans. Many species are cosmopolitan, found in different parts of the world under similar environmental conditions, making it possible to predict their environmental requirements and tolerances. While diatoms are often regarded as aquatic organisms, many species are capable of surviving and reproducing in a variety of non-aquatic, aerial (not submerged) habitats, including moist and dry substrates, These algae often derive their water from moisture in the air and rain.

Diatoms can be identified to species level and a large and growing body of information exists on the range and ecological tolerances of many of the common forms. Diatoms are good indicators of water chemistry, depth, $\mathrm{pH}$, salinity, habitat, substrate, nutrient concentrations and 
pollution levels. Because of their silica cell walls they are often preserved in sedimentary deposits, making them well-suited for use in paleoenvironmental reconstruction.

\section{METHODS}

Approximately one $\mathrm{cm}^{3}$ of sediment was oxidized with $35 \% \mathrm{H}_{2} \mathrm{O}_{2}$ to remove organic material and decalcified with $31.45 \% \mathrm{HCl}$. After rinsing to a neutral $\mathrm{pH}$, the material was dried onto cover slips and mounted on glass slides with Naphrax ${ }^{\circledR}$. The slides were scanned at x1500 magnification, and the first 600 diatoms encountered in random fields were identified and recorded.

\section{RESULTS}

Overall, 9000 diatom valves were recorded during this investigation. Four of these valves were fragments identifiable only to genus (Aulacoseira sp., Rhopalodia sp., and Stephanodiscus sp.). The remaining valves represent 54 diatom species. Three diatom taxa were about ten times as abundant as the remaining species. These are Hantzschia amphioxys (Ehrenberg) Grunow (4772 valves), Pinnularia borealis Ehrenberg (1171 valves) and Luticola mutica (Kützing) D.G. Mann (1770 valves). They are present in varying amounts in all the samples.

A second set of taxa includes those species that were common but less abundant and were not recorded from every sample. These diatoms are Luticola muticopsis (Van Heurck) D.G. Mann (145 valves), Pinnularia similiformis Krammer (117 valves), Stauroneis anceps Ehrenberg (114 valves), Diadesmis contenta (Grunow) D.G. Mann (92 valves), Craticula cuspidata (Kützing) D.G. Mann (73 valves), Luticola nivalis (Ehrenberg) D.G. Mann (62 valves), Pinnularia subcapitata Gregory (61 valves), Stauroneis phoenicentron (Nitzsch) Ehrenberg (60 valves), 
Pinnularia brebissonii (Kützing) Rabenhorst (54 valves), Pinnularia obscura Krasske (52 valves), Stauroneis gracillor Reichardt (51 valves), and Stauroneis kriegeri Patrick (50 valves).

It is the association of these common diatom species and their ecological preferences, which determines the interpretation of the paleoenvironment. The ecological preferences and tolerances of the rarer species that were recorded only a few times, or only in one or a few samples, are also taken into consideration to provide information about the entire range of conditions represented by the assemblage. The abundance data is tabulated on Table 1 . The ecological preferences and tolerances of these species are listed on Table 2. Table 3 is a glossary defining the ecological terms used in this report. Unless specified, ecological information comes from a collection of sources including: Round 1981, Krammer and Lange-Bertalot 1988, Denys 1991, Vos and de Wolf 1993, Van Dam et al. 1994, Stoermer and Smol 1999, Johansen 1999, Lange-Bertalot and Genkal 1999, Winter and Duthie 2000, Krammer 2001, Lange-Bertalot 2001, Van de Vijver et al. 2004, Potapova and Charles 2007, Van de Vijver and Mataloni 2008, Porter, 2008, and others.

\section{DISCUSSION}

\section{Ecological Discussion of Common Diatoms}

The three most abundant taxa, Hantzschia amphioxys, Pinnularia borealis, and Luticola mutica, are aerial forms that live on dry soil, moss, and a variety of damp settings (Table 2). They bloom after a rain but can survive for long periods of time under dry conditions. These diatoms reflect the baseline conditions that predominated during the deposition of the samples. Because they were a significant part of the assemblages, it is assumed that they were growing under favorable conditions that reflect their ecological preferences and tolerances. These taxa are among the most 
common soil diatoms worldwide because they are tolerant to a wide range of ecological conditions, for example they are abundant in bar ditches after a rain, when water is only present briefly.

The next set of 12 species are Luticola muticopsis, Pinnularia similiformis, Stauroneis anceps, Diadesmis contenta, Craticula cuspidata, Luticola nivalis, Pinnularia subcapitata, Stauroneis phoenicentron, Pinnularia brebissonii, Pinnularia obscura, Stauroneis gracillor, and Stauroneis kriegeri, These taxa are often common, but not abundant, and they collectively help characterize the paleoenvironment. These taxa are a combination of aquatic species adapted to frequent drying and those typically associated with moss, springs, wet walls and soil, suggesting that the amount of water was variable and not very long lasting.

The genus Stauroneis is well represented in these samples. Stauroneis species tend to live in small, standing or slowly moving oligotrophic, circumneutral or slightly acidic, clean bodies of water, and are often associated with macrophytes, or on wet soils and moss, often in remote locations (Bahls, 2012).

Diatoms with internal valves called craticula are represented in this study by Craticula ambigua (Ehrenberg) D.G. Mann, and Craticula cuspidata. The formation of these structures is regarded as a response to some unfavorable environmental conditions such as desiccation, fluctuating salt content, nutritional deficiency, and a rather sudden increase in osmotic pressure. They are found in settings where strong evaporation over part of the year is a characteristic.

The remaining species were rare or common in only one sample. They tend to be aquatic species, suggesting that there was standing water but not long enough for a typically aquatic population to become well established, perhaps a few weeks. Occasionally an aquatic diatom, in this case 
Aulacoseira italica, has been recorded from dry soil. This is because it is a thick, robust form that forms long chains, is resistant to dissolution, and remains after the water is gone, but it is definitely aquatic, and common in shallow water.

\section{$\underline{\text { Paleoenvironmental Discussion of Individual Samples }}$}

These ecological preferences of the diatoms can be used to interpret the particular paleoenvironmental characteristics of the individual samples. A count of 600 valves was made on each sample. The number of taxa in a sample ranged from a low of 6 to a high of 21 .

Sample 1 (AMO2.205). This is the second most diverse sample, with 20 taxa. In addition to the soil, mud and moss species that dominate the assemblage there are also 14 aquatic diatoms, found in settings that are submerged, but dry out at least to dampness, including, in particular, Craticula ambigua (9 valves), Craticula cuspidata (18 valves) and Stauroneis phoenicentron (23 valves). The Pinnularia species and other Stauroneis species in this sample are also found in both submerged and emergent but damp, mossy settings. Nitzschia paleaceae Grunow (8 valves), and Nitzschia perminuta (Grunow) M. Peragallo (3 valves) are aquatic taxa also found in wet aerial habitats. As a whole, although about half of the valves counted are aerial forms, meaning that the damp, aerial setting characterized the site part of the time, there were brief periods when standing water was present.

Sample 2 (AMO2.210). This sample is very similar to sample 1 and has one fewer taxon (19). The sample contains a combination of the aerial forms that characterize this entire set of samples. In addition there are several aquatic species found in settings that are alternately wet and dry, 
including Craticula ambigua (2 valves), Craticula cuspidata (20 valves), Stauroneis phoenicentron (23 valves) and Stauroneis anceps (15 valves). Several other taxa are aquatic, including Neidium septentrionale Cleve-Euler (2 valves) and Nitzschia perminuta (4 valves). There was also one fragment of Ulnaria ulna (Nitzsch) Compère, a needle-shaped benthic, aquatic diatom that is found in temporary settings such as ditches and shallow pools. There are 6 species of Pinnularia (besides 92 valves of the clearly aerial $P$. borealis,). These represent a total 48 valves in the count. There is a limited amount of ecological data, as some of these Pinnularia taxa are recently described. They represent a setting consisting of oligotrophic, low conductivity, oxygen rich water associated with wet moss and wet rocks. The diatoms in this sample indicate that there were wet but very shallow conditions that may have lasted several weeks, and was followed or preceded by a moist but not submerged interval. In addition to diatoms this sample contained a particularly abundant and diverse assortment of chrysophycean statospores. These spores were produced in water, presumably as a survival strategy to survive dry conditions. The diatoms are not corroded but some were broken. Mechanical breakage can be caused by transport or by the effects of grazing. Grazing pressures include insect herbivory, particularly fly larvae, oligochaete worms, microcrustacea (cladocerans, copepods, and ostracods,), amphipods, snails, tadpoles and fish. Diatoms produce high-energy lipids and provide essential fatty acids making them a desirable food source (Julius and Theriot, 2010).

Sample 3 (AMO2.212). This sample is similar to the previous one but has fewer Pinnularia taxa and a few more Stauroneis species and aerial taxa. This may represent a slightly drier setting, or one that did not retain the moisture from a brief wet interval indicated by the presence of 
Craticula cuspidata, Gomphonema sarcophagus Gregory (2 valves), and Nitzschia perminuta (Grunow) M. Peragallo (2 valves).

Sample 4 (AMO2.224). This is the most diverse sample with 21 taxa. It is very similar to sample 2 in the composition of the assemblage. It represents a setting that was briefly submerged, and then remained wet to damp, but includes a robust aerial component as well. There were more Craticula spp. valves than in any other sample (36 valves) and these diatoms grew when the site was submerged, along with Nitzschia perminuta (11 valves), Pinnularia viridis (Nitzsch) Ehrenberg (3 valves), and Neidium septentrionale (2 valves). The ecological characteristics of Pinnularia viridis, an aquatic species, indicate that the water was circumneutral, and oligo- to mesotrophic, with low to average conductivity, whereas Nitzschia perminuta is an oligosaprobous species also tolerant of high levels of organics, perhaps reflecting a range in the degree of pollution during the presence of the water. There are 9 different Pinnularia taxa in this sample, and the abundance and diversity of Pinnularia (except Pinnularia borealis, that prefers a dry setting) and Stauroneis taxa means the site was probably damp for quite a while.

Sample 6 (KWA2.304). There were 12 taxa recorded from this sample, but 380 of these valves were Hantzschia amphioxys and 115 were Pinnularia borealis. Both of these diatoms form ribbons of cells and conditions appear to favor these two taxa and Luticola mutica (74 valves) over the other mud and moss species. Since these 3 species are sediment diatoms, the water may have been turbid, keeping the Pinnularia and Stauroneis taxa, as well as their moss substrates, from growing. There were 6 valves of Stauroneis cf. kriegeri Patrick, however, that is found in small pools of water, moss, and soil. There were small numbers of truly aquatic diatoms. Of these, Encyonema silesiacum (Bleisch) D.G. Mann (4 valves), Achnantheiopsis frequentissima Lange-Bertalot and Ulnaria ulna (1 valve) represent submerged conditions, but these are all 
early colonizers of recently submerged substrates. Encyonema silesiacum and Ulnaria ulna are common epiphytic and epilithic, shallow water species tolerant of high nutrient concentrations.

Sample 7 (KWA2.309). There were 11 species found in this sample, but of the 600 valves counted 574 belonged to the three aerial species: Hantzschia amphioxys (460 valves), Pinnularia borealis (73 valves), and Luticola mutica (41 valves). The remainder are Stauroneis spp. except for one valve of the planktonic, centric diatom Cyclostephanos cf. tholiformis Stoermer, Håkansson and Theriot, that is an ecological discord and was probably transported from the dry surface diatomite associated with a large, deep paleolake. This diatom prefers eutrophic to hypereutrophic, hardwater habitats with relatively high total dissolved solids, but it is virtually impossible to distinguish among three closely related species (Stoermer et al., 1987).

Sample 8 (KWA2.320). This was not a very diverse sample, but had a few aquatic species such as 2 valves of Craticula ambigua, and 1 valve each of Cocconeis placentula Ehrenberg and Rhopalodia gibba (Ehrenberg) Müller, both indicative of submerged conditions, along with 3 species of Stauroneis (12 valves total) that may have been living on dry or wet moss, but there was only 1 valve of Pinnularia. This habitat was not as favorable for benthic growth as other samples and was probably not wet for very long.

Sample 10 (BOL2.307). This sample had 10 taxa but 592 out of 600 valves are dry habitat aerial species. Aquatic taxa are represented by Meridion circulare (Greville) Agardh (2 valves), Nitzschia fonticola (Grunow) Grunow (2 valves) and Rhopalodia gibba (2 valves). Rhopalodia gibba has internal siliceous supports that may aid in withstanding osmotic stress and elevated conductivity or salinity, from either carbonate or chloride. There was one valve of the centric, planktonic diatom Stephanodiscus cf. minutulus (Kützing) Cleve and Möller that was probably transported to the site from a larger lake. This sample does not appear to have been submerged 
for long, nor are there any diatoms to suggest that the habitat remained humid after the water was gone. This may be a signal of a relatively drier, windier climate than the samples that have a longer moist interval.

Sample 11 (BOL2.320). There were 16 species in this sample and they are a combination of clearly aquatic diatoms, those found in wet to damp settings and aerial forms. There were two valves of the centric diatom Aulacoseira italica (Ehrenberg) Simonsen. Aulacoseira italica is a common, aquatic, alkaliphilous, meso- eutrophic, pollution tolerant form that lives both in planktonic and benthic habitats in lakes, small ponds and wetlands with submerged areas. There were 3 Cyclostephanos $c f$. tholiformis but they may have been blown in. Benthic, aquatic diatoms include Encyonema silesiacum (2 valves), Gomphonema parvulum (Kützing) Kützing (43 valves), Navicula reichardtiana Lange-Bertalot (2 valves), Nitzschia amphibia Grunow (2 valves), Nitzschia amphibia tolerates a wide range from oligotrophic to eutrophic water of lakes, ponds, wet rocks, moss, mud and floating algal mats. It prefers alkaliphilous to alkalibiontic, fresh-brackish, high conductivity water and is an indicator of high total and organic nitrogen and total phosphorous. It tolerates highly degraded conditions, $>50 \%$ DO saturation, and slight fluctuations in osmotic pressure. Gomphonema parvulum and Navicula reichardtiana have similar ecological preferences and are considered good indicators of eutrophic conditions. Other aquatic taxa include Nitzschia perminuta, Achnantheiopsis lanceolata (Brébisson) LangeBertalot (1 valve), Staurosira construens Ehrenberg (4 valves), and Ulnaria acus (Kützing) Aboal (22 valves). Staurosira construens and Ulnaria acus are tychoplanktonic and benthic, alkaliphilous forms that are found in meso- eutrophic conditions with moderate oxygen saturation. Taken together, the diatoms indicate a range of ecological conditions from wet to dry and from moderately to definitely eutrophic and polluted. 
Sample 12 (BOL2.333). This was the least diverse sample with an assemblage consisting of only 6 taxa. None of them are aquatic forms. There is no evidence that this sample represents a submerged interval. There were 9 valves of Stauroneis borrichii (Petersen) Lund, which is found in dry soil and wet moss.

Sample 13 (BOL2.344). This was the second least diverse sample, with 7 taxa. There were 595 aerial, dry setting taxa and 5 moss and soil taxa. There is no evidence of standing water.

Sample 14 (TOV2.315). This sample was relatively diverse with 14 taxa. None of them are primarily aquatic, but in addition to the taxa that are aerial species, several of the Pinnularia and Stauroneis species are found in damp to wet habitats suggesting that there may have been standing water, briefly. Pinnularia brebissonii (17 valves) was also common in sample 1. It is aerial in soils, prairie swales, peat moors, and acidic to alkaline montane water, Pinnularia microstauron (14 valves) is both aquatic and aerial in the mud of oligotrophic, oligosaprobic, low conductivity and $\mathrm{pH}, \mathrm{cool}$, oxygen-rich moorland water. It is $\beta$-mesosaprobous and has a wide range of tolerance to nutrients. There were 6 Pinnularia appendiculata valves. This diatom is also aerial and aquatic, prefers acidophilic, oligo-mesotrophic, oligosaprobous, mineralized waters, with an average to high conductivity. It is an inhabitant of soil crust communities in Arizona, that include rocks, lichens, mosses and algae in crusted hummocks (Johansen et al. 1981). The diatom ecological preferences suggest that the water that was present was cool, low nutrient, low to moderate conductivity and unpolluted.

Sample 15 (TOV2.323). There are 14 taxa in this sample. The composition of this sample is different from the others in that there are 111 valves of Pinnularia similiformis Krammer and 30 valves of Nitzschia palea (Kützing) Smith. Pinnularia similiformis is aerial and aquatic, on mosses in oligotrophic, oxygen rich, electrolyte poor moorland waters, It is mostly reported in 
mountain climates of northern Europe suggesting that it prefers cool to cold water. Nitzschia palea is both aquatic and aerial and typically found in eutrophic water but has a broad tolerance for water quality conditions. There are no real aquatic species to suggest submerged conditions rather than damp or moist.

Sample 16 (TOV2.332). This sample contained 11 taxa, of which all except perhaps one are found in aerial settings. There were 8 valves of Nitzschia paleaceae, a diatom that is found in both aquatic and wet aerial habitats. It was also present in sample 1. Because of the diversity of aerial taxa, perhaps indicating a damp mossy substrate, and the presence of a diatom that lived when it was at least wet, there is some evidence that standing water or at least small water-filled depressions were briefly present, but not long enough for aquatic diatoms to grow..

Sample 19 (BOL2 2.152). Of the 600 valves that were counted, 556 of these were Luticola mutica and Hantzschia amphioxys and Pinnularia borealis. Even so there were 14 taxa, of which 7 are aquatic. There were 15 valves of Aulacoseira italica, 8 valves of Achnantheiopsis lanceolata, 3 valves of Diploneis ovalis (Hilse) Cleve, 2 valves of Eunotia pectinalis (Kützing) Rabenhorst, 2 valves of Gomphonema angustum Agardh, and one valve of Ulnaria ulna, all aquatic diatoms common in shallow water. The ecological preferences of Aulacoseira italica serve to characterize the water quality conditions. Aulacoseira italica is a common, cosmopolitan, aquatic, alkaliphilous, mesotrophic to eutrophic, $\beta$-mesosaprobous, and tolerant to organically bound nitrogen (OBN). It tolerates $>75 \%$ DO saturation. Aulacoseira italica lives both in planktonic and benthic habitats in lakes and ponds. Many species of Aulacoseira are found in large lakes but $A$. italica also grows in small ponds, prairie potholes, and in wetlands with submerged areas. This sample definitely has a component of the assemblage that grew under submerged conditions but their numbers are small compared to the aerial forms. There 
were many chrysophycean statospores in this sample, providing further evidence of submerged conditions.

\section{CONCLUSIONS}

These data illustrate the range of environmental variability of each of the samples that is possible, within similar geology, topography, and hydrology, with climate the primary variable. These is no diatom evidence of permanent water in many of the samples that lasted long enough for an aquatic assemblage to develop at the expense of the aerial species. There were some samples that appear to have had standing water for a limited amount of time. The diatoms in the genus Craticula are common in samples 1 through 4 but were found in very low numbers elsewhere. This diatom is found in alkaline, high conductivity water that dries out, in contrast to some of the samples that appear to represent low or moderate conductivity peaty water. There is evidence of submerged conditions in five of the samples and several more of them had smaller numbers of aquatic taxa possibly indicating temporary submergence at least in places in the reservoirs. The most common habitat suggested by the diatoms is one that was not submerged but often damp enough to support mosses.

\section{REFERENCES, INCLUDING THOSE USED IN ECOLOGICAL DESCRIPTIONS}

Bahls, Loren, 2012. Five new species of Stauroneis (Bacillariophyta, Stauroneidaceae) from the northern Rocky Mountains, USA. Phytotaxa 67: 1-8.

Denys, Luc, 1991. A Check-list of the Diatoms in the Holocene Deposits of the Western Belgian Coastal Plain with a Survey of their Apparent Ecological Requirements, 1. Introduction, Ecological code and complete list. Service Geologique de Belgique, Professional Paper 1991/2, No. 246. 
Johansen, Jeffrey R., 1999. Diatoms in aerial habitats. In: The Diatoms: Applications for the Environmental and Earth Sciences, Eugene F. Stoermer and John P. Smol eds. Cambridge University Press, Cambridge, 264-273.

Johansen, Jeffrey, Samuel R. Rushforth and Jack D. Brotherson, 1981. Subaerial algae of Navajo National Monument, Arizona. Great Basin Naturalist 41 (4), 433-439.

Julius, Matthew L. and Edward C. Theriot, 2010. The diatoms: a primer. In: The Diatoms: Applications for the Environmental and Earth Sciences, $2^{\text {nd }}$ edition, John P. Smol and Eugene F. Stoermer eds. Cambridge University Press, Cambridge, 8-22.

Krammer, Kurt, 2001. Diatoms of Europe 1, ed by H. Lange-Bertalot. The Genus Pinnularia. A.R.G. Gantner Verlag K.G.

Krammer, Kurt and Horst Lange-Bertalot, 1988. Süsswasserflora von Mitteleuropa 2/2 Bacillariophyceae 2 Teil: Bacillariaceae, Epithemiaceae, Surirellaceae. VEB Gustav Fischer Verlag, Jena.

Lange-Bertalot, Horst, 2001. Navicula sensu stricto, 10 Genera Separated from Navicula sensu lato, Frustulia. Diatoms of Europe 2, Horst Lange-Bertalot ed., A.R.G. Gantner Verlag K.G.

Lange-Bertalot, H and S.I. Genkal, 1999. Diatoms from Siberia. Iconographia Diatomologica 6, Koeltz Scientific Books, Koenigstein.

Porter, Stephen D., 2008. Algal Attributes: An Autecological Classification of Algal Taxa Collected by the National Water-Quality Assessment Program. U.S. Geological Survey Data Series 329, http://pubs.usgs.gov/ds/ds329/

Potapova, M. \& D.F. Charles, 2007. Diatom metrics for monitoring eutrophication in rivers of the United States. Ecological Indicators 7, 48-70.

Round, Frank E.,1981. The Ecology of Algae. Cambridge University Press, Cambridge.

Stoermer, E.F., Hannelore Håkansson \& E.C. Theriot, 1987. Cyclostephanos species newly reported from North America: C. tholiformis sp. nov. and C. costatilimbus comb. nov. British Phycological Journal, 22 (4), 349-358, DOI: 10.1080/00071618700650421.

Stoermer, Eugene F. and John P. Smol (eds.), 1999. The Diatoms: Applications for the Environmental and Earth Sciences. Cambridge University Press, Cambridge, 264-273.

Van Dam, Herman, Adrienne Mertens, and Jos Sinkeldam 1994. A coded checklist and ecological indicator values of freshwater diatoms from the Netherlands. Netherlands Journal of Aquatic ecology 28 (1), 117-133.

Van de Vijver, Bart, Louis Beyens and Horst Lange-Bertalot, 2004. The Genus Stauroneis in the Arctic and (Sub-) Antarctic Regions. Bibliotheca Diatomologica 51, J. Cramer, Berlin. 
Van de Vijver, Bart \& Gabriella Mataloni, 2008. New and interesting species in the genus Luticola D.G. Mann (Bacillariophyta) from Deception Island (South Shetland Islands). Phycologia 47 (5), 451-467.

Vos, Peter and Hein de Wolf, 1993. Diatoms as a tool for reconstructing sedimentary environments in coastal wetlands: methodological aspects. Hydrobiologia 269/270, 285-296.

Winter, J.G. and H.C. Duthie, 2000. Epilithic diatoms as indicators of stream total N and total P concentration. J. N. Am. Benthol. Soc. 19 (1), 32-49. 
TABLE 1. Sample Inventory

\begin{tabular}{|c|c|c|c|c|c|c|c|c|}
\hline Sample \# & $\mathrm{pH}$ & & 2 & 3 & 4 & 6 & 7 & 8 \\
\hline Sample ID & & AMO2.205 & AMO2.21 & AMO2.212 & AMO2.224 & KWA2.304 & KWA2.309 & KWA2.320 \\
\hline \multicolumn{9}{|c|}{\begin{tabular}{|l|l|l|l|l|l|} 
blue $=$ benthic/aquatic species, light blue=cosmopolitan species, yellow=aerial/terrestrial & & & & \\
\end{tabular}} \\
\hline Aulacosira italica (Ehrenberg) Simonsen & 3 & & & & & & & \\
\hline Aulacosira sp. & 3 & & & & & & & \\
\hline Brevisira cf. arentii (Kolbe) Krammer & 4 & & & & & & & \\
\hline Cocconeis placentula Ehrenberg & 4 & & & & & & & \\
\hline Craticula ambigua (Ehrenberg) D.G. Mann & 3 & 9 & 2 & & 19 & & 7 & \\
\hline Craticula cuspidata (Kützing) D.G. Mann & 3 & 18 & 20 & 16 & 17 & & & \\
\hline Cyclostephanos thioliformis Stoermer, Hakansson \& Theriot & 2 & & & & & & 1 & \\
\hline Denticula kuetzingii Grunow & 3 & & & & & & 4 & \\
\hline Diadesmis contenta (Grunow ex Van Heurck) D.G. Mann & 4 & 2 & 4 & 8 & 7 & 4 & & \\
\hline \multicolumn{9}{|l|}{ Diploneis ovalis (Hilse) Cleve } \\
\hline \multicolumn{9}{|l|}{ Encyonema silesiacum (Bleisch) D.G. Mann } \\
\hline \multicolumn{9}{|l|}{ Eunotia cf. pectanalis (Kützing) Rabenhorst } \\
\hline Gomphonema angustum Agardh & 2 & & & & & & & \\
\hline \multicolumn{9}{|l|}{\begin{tabular}{|l|} 
Gomphonema parvulum (Kützing) Kützing \\
Gomphonema sarcophaqus Gregory
\end{tabular}} \\
\hline \multicolumn{9}{|l|}{ Gomphonema sarcophagus Gregory } \\
\hline Hantzschia amphioxys (Ehrenberg) Grunow & 2 & 257 & 331 & 381 & 332 & 380 & 460 & 353 \\
\hline \begin{tabular}{|l|} 
Luticola mutica (Kützing) D.G. Mann \\
\end{tabular} & 2 & 72 & 48 & 49 & 52 & 74 & 41 & 55 \\
\hline Luticola muticopsis (Van Heurck) D.G. Mann & 3 & 2 & 8 & 5 & 6 & 4 & & \\
\hline Luticola nivalis (Ehrenberg) D.G. Mann & 2 & 9 & 2 & 8 & 5 & & & \\
\hline \multicolumn{9}{|l|}{ Meridion circulare (Greville) Agardh } \\
\hline \multicolumn{9}{|l|}{ Muelleria gibbula (Cleve) Spalding \& Stoermer } \\
\hline Navicula reichardtiana Lange-Bertalot & 3 & & & & & & & \\
\hline Neidium septentrionale Cleve-Euler & 1 & & 2 & & 2 & & & \\
\hline \multicolumn{9}{|l|}{ Nitzschia amphibia fo. rostrata Hustedt } \\
\hline \multicolumn{9}{|l|}{ Nitzschia fonticola (Grunow) Grunow } \\
\hline \multicolumn{9}{|l|}{ Nitzschia palea (Kützing) Smith } \\
\hline \multicolumn{9}{|l|}{ Nitzschia paleaceae Grunow } \\
\hline Nitzschia perminuta (Grun.) M. Pergallo & 4 & 3 & 4 & 2 & 11 & 4 & & \\
\hline Pinnularia appendiculata (Agardh) Cleve & 1 & & 2 & & & & & \\
\hline Pinnularia borealis Ehrenberg & 2 & 55 & 92 & 75 & 98 & 115 & 73 & 173 \\
\hline Pinnularia brebissonii (Kützing) Rabenhorst & 3 & 35 & & & 2 & & & \\
\hline Pinnularia grunowii Krammer & 2 & & & & 3 & & & \\
\hline Pinnularia infirma Krammer & 2 & 3 & 5 & 1 & 3 & & & \\
\hline Pinnularia intermedia (Lagerstedt) Cleve & 2 & & & & 4 & 1 & & \\
\hline Pinnularia microstauron (Ehrenberg) Cleve & 2 & 1 & 4 & 1 & 4 & & & \\
\hline Pinnularia obscura Krasske & 1 & 34 & 9 & 1 & 4 & & & \\
\hline Pinnularia simliformis Krammer & 2 & & 4 & & 2 & & & \\
\hline Pinnularia subcapitata Gregory & 1 & 28 & 24 & 5 & & & & \\
\hline Pinnularia viridis (Nitzsch) Ehrenberg & 2 & & & & 3 & & & \\
\hline Planothidium frequentissimum (Lange-Bertalot) Lange-Bertalot & 1 & & & & & 4 & & \\
\hline Planothidium lanceolatum (Brébisson ex Kützing) Lange-Bertalot & 1 & & & & & & & \\
\hline Rhopalodia gibba (Ehrenberg) Müller & 3 & & & & & & & \\
\hline Rhopalodia sp. & 3 & & & & & & & \\
\hline Stauroneis anceps Ehrenberg & 2 & 27 & 15 & 17 & 14 & 1 & 9 & \\
\hline Stauroneis cf. bertrandii Van de Vijver \& Lange-Bertalot & 2 & & & 2 & & & & \\
\hline Stauroneis borrichii (Petersen) Lund & 2 & & & & & & & \\
\hline Staurosira construens Ehrenberg & 2 & & & & & & & \\
\hline Stauroneis gracillor Reichardt & 2 & 9 & & 21 & 4 & 3 & 1 & \\
\hline Stauroneis cf. krigeri Patrick & 2 & 1 & & & & 6 & 2 & \\
\hline Stauroneis phoenicentron (Nitzsch) Ehrenberg & 2 & 23 & 23 & 4 & 8 & & & \\
\hline Stauroneis prominuta (Grunow) Hustedt & 2 & & & & & & 1 & \\
\hline Stauroneis reichardtii Lange-Bertalot, Cavacini, Tagliaventi and Al & 2 & 4 & & & & & & \\
\hline Stauroneis subgracilis Lange-Bertalot et Krammer & 2 & & & 2 & & & & \\
\hline Stephanodiscus cf. minutulus (Kützing) Cleve \& Möller & 3 & & & & & & & \\
\hline Stephanodiscus sp. & 3 & & & & & & & \\
\hline Ulnaria acus (Kützing) Aboal & 3 & & & & & & & \\
\hline Ulnaria cf. ulna (Nitzsch) Compère & 1 & & 1 & & & & 1 & \\
\hline pH tolerances $1=$ acidophilous, $2=$ circumneutral, 3=alkaliphilou & $u s, 4$ & 7=indiffere & ent, . =no in & & & & & \\
\hline count & & 600 & 600 & 600 & 600 & 600 & 600 & 600 \\
\hline species count & & 20 & 19 & 18 & 21 & 12 & 11 & 11 \\
\hline
\end{tabular}




\begin{tabular}{|c|c|c|c|c|c|c|c|c|c|}
\hline Sample \# & pH & 10 & 11 & 12 & 13 & 14 & 15 & 16 & 19 \\
\hline Sample ID & & BOL2.307 & BOL2.320 & BOL2.333 & BOL2.344 & TOV2.315 & TOV2.323 & TOV2.332 & BOL2_2.152 \\
\hline \multicolumn{10}{|c|}{\begin{tabular}{|l|l|l|l|l|} 
blue=benthic/aquatic species, light blue=cosmopolitan species, yellow=aerial/terrestrial & & & & \\
\end{tabular}} \\
\hline \begin{tabular}{|l|l|} 
Aulacosira italica (Ehrenberg) Simonsen \\
\end{tabular} & 3 & \begin{tabular}{|l} 
\\
\end{tabular} & 2 & & & & & & 15 \\
\hline Aulacosira sp. & 3 & & & & & 2 & & & \\
\hline Brevisira cf. arentii (Kolbe) Krammer & 4 & & & & & & & & 1 \\
\hline Cocconeis placentula Ehrenberg & 4 & & & & & & & & \\
\hline \multicolumn{10}{|l|}{ Craticula ambigua (Ehrenberg) D.G. Mann } \\
\hline Craticula cuspidata (Kützing) D.G. Mann & 3 & & & & & 2 & & & \\
\hline Cyclostephanos thioliformis Stoermer, Hakansson \& Theriot & 2 & & 3 & & & & & & \\
\hline Denticula kuetzingii Grunow & 3 & & & & & & & & \\
\hline Diadesmis contenta (Grunow ex Van Heurck) D.G. Mann & 4 & 2 & & & 21 & 4 & 14 & 20 & 6 \\
\hline \multicolumn{10}{|l|}{ Diploneis ovalis (Hilse) Cleve } \\
\hline Encyonema silesiacum (Bleisch) D.G. Mann & 2 & & 2 & & & & & & \\
\hline Eunotia cf. pectanalis (Kützing) Rabenhorst & 1 & & & & & & & & 2 \\
\hline Gomphonema angustum Agardh & 2 & & & & & & & & 2 \\
\hline Gomphonema parvulum (Kützing) Kützing & 2 & & 43 & & & & & & \\
\hline Gomphonema sarcophagus Gregory & 2 & & & & & 2 & 6 & & \\
\hline Hantzschia amphioxys (Ehrenberg) Grunow & 2 & 349 & 289 & 321 & 263 & 259 & 179 & 360 & 258 \\
\hline Luticola mutica (Kützing) D.G. Mann & 2 & 141 & 181 & 201 & 229 & 177 & 187 & 111 & 152 \\
\hline Luticola muticopsis (Van Heurck) D.G. Mann & 3 & 15 & 13 & 21 & 4 & 34 & 20 & 9 & 2 \\
\hline Luticola nivalis (Ehrenberg) D.G. Mann & 2 & & 2 & 2 & & 20 & 10 & 2 & 2 \\
\hline \multicolumn{10}{|l|}{ Meridion circulare (Greville) Agardh } \\
\hline \multicolumn{10}{|l|}{ Muelleria gibbula (Cleve) Spalding \& Stoermer } \\
\hline \multicolumn{10}{|l|}{ Navicula reichardtiana Lange-Bertalot } \\
\hline \multicolumn{10}{|l|}{ Neidium septentrionale Cleve-Euler } \\
\hline \multicolumn{10}{|l|}{ Nitzschia amphibia fo. rostrata Hustedt } \\
\hline Nitzschia fonticola (Grunow) Grunow & 2 & 2 & & & & & & & \\
\hline Nitzschia palea (Kützing) Smith & 2 & & & & & & 30 & & \\
\hline Nitzschia paleaceae Grunow & 3 & & & & & & & 8 & \\
\hline Nitzschia perminuta (Grun.) M. Pergallo & 4 & & 2 & & & & & & \\
\hline Pinnularia appendiculata (Agardh) Cleve & 1 & & & & & 6 & 2 & & \\
\hline Pinnularia borealis Ehrenberg & 2 & 85 & 30 & 46 & 78 & 22 & 31 & 52 & 146 \\
\hline Pinnularia brebissonii (Kützing) Rabenhorst & 3 & & & & & 17 & & & \\
\hline Pinnularia grunowii Krammer & 2 & & & & & & & & \\
\hline Pinnularia infirma Krammer & 2 & & & & & & & & \\
\hline Pinnularia intermedia (Lagerstedt) Cleve & 2 & & & & 1 & & & & \\
\hline Pinnularia microstauron (Ehrenberg) Cleve & 2 & & & & & 14 & & & \\
\hline Pinnularia obscura Krasske & 1 & & & & & 3 & & & \\
\hline Pinnularia simliformis Krammer & 2 & & & & & & 111 & & \\
\hline Pinnularia subcapitata Gregory & 1 & & & & & 1 & 1 & & 2 \\
\hline \multicolumn{10}{|l|}{\begin{tabular}{|l} 
Pinnularia viridis (Nitzsch) Ehrenberg \\
\end{tabular}} \\
\hline \multicolumn{10}{|l|}{ Planothidium frequentissimum (Lange-Bertalot) Lange-Bertald } \\
\hline \multicolumn{10}{|l|}{ Planothidium lanceolatum (Brébisson ex Kützing) Lange-Berta } \\
\hline Rhopalodia gibba (Ehrenberg) Müller & 3 & 2 & & & & & & & \\
\hline Rhopalodia sp. & 3 & 1 & & & & & & & \\
\hline Stauroneis anceps Ehrenberg & 2 & & & & & 7 & 3 & 18 & \\
\hline Stauroneis cf. bertrandii Van de Vijver \& Lange-Bertalot & 2 & & & & & & & 4 & \\
\hline Stauroneis borrichii (Petersen) Lund & 2 & & & 9 & & & & & \\
\hline \multicolumn{10}{|l|}{ Staurosira construens Ehrenberg } \\
\hline Stauroneis gracillor Reichardt & 2 & & & & & & & 13 & \\
\hline Stauroneis cf. krigeri Patrick & 2 & & 2 & & 4 & 27 & 5 & & \\
\hline \multicolumn{10}{|l|}{ Stauroneis phoenicentron (Nitzsch) Ehrenberg } \\
\hline Stauroneis prominuta (Grunow) Hustedt & 2 & & & & & & & & \\
\hline Stauroneis reichardtii Lange-Bertalot, Cavacini, Tagliaventi and & 2 & & & & & & & & \\
\hline Stauroneis subgracilis Lange-Bertalot et Krammer & 2 & & & & & & & & \\
\hline Stephanodiscus cf. minutulus (Kützing) Cleve \& Möller & 3 & 1 & & & & & & & \\
\hline Stephanodiscus sp. & 3 & & & & & 1 & & & \\
\hline Ulnaria acus (Kützing) Aboal & 3 & & 22 & & & & & & \\
\hline Ulnaria cf. ulna (Nitzsch) Compère & 1 & & & & & & & & 1 \\
\hline pH tolerances $1=$ acidophilous, $2=$ circumneutral, $3=$ alkaliph & nilous, $4=$ in & & $=$ no info & & & & & & \\
\hline count & & 600 & 600 & 600 & 600 & 600 & 600 & 600 & 600 \\
\hline species count & & 10 & 16 & 6 & 7 & 18 & 14 & 11 & 14 \\
\hline
\end{tabular}


TABLE 2

ECOLOGICAL CHARACTERISTICS OF JEMEZ MOUNTAIN RESERVOIR DIATOMS

\begin{tabular}{|c|c|}
\hline $\begin{array}{l}\text { DIATOM } \\
\text { NAME }\end{array}$ & DIATOM ECOLOGY \\
\hline $\begin{array}{l}\text { Achnantheiopsis } \\
\text { frequentissima }\end{array}$ & $\begin{array}{l}\text { aquatic, in oligotrophic water with moderate conductivity, similar } \\
\text { ecology to Achnantheiopsis lanceolata }\end{array}$ \\
\hline $\begin{array}{l}\text { Achnantheiopsis } \\
\text { lanceolata }\end{array}$ & $\begin{array}{l}\text { aquatic, high alkalinity, low to moderate conductivity, eutrophic, } \alpha- \\
\text { mesosaprobous, tolerant to organically bound nitrogen (OBN), } \\
\text { tolerates highly degraded conditions, tolerates }>50 \% \text { DO saturation, } \\
\text { alkaliphilous, fresh-brackish water, chloride optimum low ( }<15 \mathrm{mg} / \mathrm{L}) \text {, } \\
\text { benthic, non-motile }\end{array}$ \\
\hline $\begin{array}{l}\text { Aulacoseira } \\
\text { italica }\end{array}$ & $\begin{array}{l}\text { aquatic, meso- eutrophic, } \beta \text {-mesosaprobous, tolerant to organically } \\
\text { bound nitrogen (OBN), tolerates }>75 \% \text { DO saturation, alkaliphilous, } \\
\text { fresh-brackish water, planktonic, non-motile, dry soil, cosmopolitan }\end{array}$ \\
\hline Brevisira arentii & aquatic, planktonic in dystrophic to mesotrophic water \\
\hline $\begin{array}{l}\text { Cocconeis } \\
\text { placentula }\end{array}$ & aquatic, benthic, attached, shallow water, cosmopolitan \\
\hline $\begin{array}{l}\text { Craticula } \\
\text { ambigua }\end{array}$ & $\begin{array}{l}\text { aquatic, benthic, tolerates drying, cosmopolitan, found with Craticula } \\
\text { cuspidata }\end{array}$ \\
\hline $\begin{array}{l}\text { Craticula } \\
\text { cuspidata }\end{array}$ & $\begin{array}{l}\text { aquatic and aerial, cosmopolitan, waters with an average to higher } \\
\text { electrolyte content, even in brackish water, usually epipelic, eutrophic } \\
\text { and pollution tolerant, eutrophic, } \alpha \text {-mesosaprobous, tolerant to OBN, } \\
\text { tolerates degraded conditions, tolerates }>50 \% \text { DO saturation, } \\
\text { alkaliphilous, fresh-brackish water, benthic, motile, tolerates drying, } \\
\text { found in prairie soils }\end{array}$ \\
\hline $\begin{array}{l}\text { Cyclostephanos } \\
\text { tholiformis }\end{array}$ & aquatic, planktonic, fresh water \\
\hline $\begin{array}{l}\text { Denticula } \\
\text { kuetzingii }\end{array}$ & aquatic and aerial, waterfalls, dry moss and cliffs, cosmopolitan \\
\hline $\begin{array}{l}\text { Diadesmis } \\
\text { contenta }\end{array}$ & aerial, waterfalls, wet rocks and cliffs, moss, cosmopolitan \\
\hline Diploneis ovalis & aquatic, cosmopolitan in medium to high conductivity, brackish water \\
\hline $\begin{array}{l}\text { Encyonema } \\
\text { silesiacum }\end{array}$ & $\begin{array}{l}\text { aquatic, wide range of tolerance to nutrients, indicator of low total } \\
\text { nitrogen, } \alpha \text {-mesosaprobous, tolerant to OBN, tolerates }>50 \% \text { DO } \\
\text { saturation, circumneutral } \mathrm{pH} \text {, fresh-brackish water, conductivity } \\
\text { optimum low }(<200 \mu \mathrm{S} / \mathrm{cm}) \text {, chloride optimum low }(<15 \mathrm{mg} / \mathrm{L}) \text {, } \\
\text { benthic, non-motile, cosmopolitan }\end{array}$ \\
\hline $\begin{array}{l}\text { Eunotia cf } \\
\text { pectinalis }\end{array}$ & aquatic, benthic \\
\hline $\begin{array}{l}\text { Gomphonema } \\
\text { angustum }\end{array}$ & aquatic, benthic, cosmopolitan, oligotrophic \\
\hline $\begin{array}{l}\text { Gomphonema } \\
\text { parvulum }\end{array}$ & $\begin{array}{l}\text { aquatic, prefers nutrient-rich water, eutrophic, indicator of high total } \\
\text { nitrogen and total phosphorous, } \alpha \text {-meso/polysaprobous, requires } \\
\text { periodic elevated concentrations of OBN, tolerates extremely degraded } \\
\text { conditions, tolerates }>30 \% \text { DO saturation, circumneutral pH, fresh- }\end{array}$ \\
\hline
\end{tabular}




\begin{tabular}{|c|c|}
\hline & $\begin{array}{l}\text { brackish water, chloride optimum low }(<15 \mathrm{mg} / \mathrm{L}) \text {, benthic, non-motile, } \\
\text { silt and sand attached with stalk, cosmopolitan, an indicator of polluted } \\
\text { water }\end{array}$ \\
\hline $\begin{array}{l}\text { Gomphonema } \\
\text { sarcophagus }\end{array}$ & $\begin{array}{l}\text { aquatic, prefers nutrient-rich water, eutrophic, indicator of high total } \\
\text { nitrogen and total phosphorous, } \alpha \text {-meso/polysaprobous, requires } \\
\text { periodic elevated concentrations of OBN, tolerates extremely degraded } \\
\text { conditions, tolerates }>30 \% \text { DO saturation, circumneutral pH, fresh- } \\
\text { brackish water, chloride optimum low ( }<15 \mathrm{mg} / \mathrm{L}) \text {, benthic, non-motile, } \\
\text { silt and sand, attached with stalk, cosmopolitan, generally considered } \\
\text { aquatic but also found on mosses and liverworts above the water level. }\end{array}$ \\
\hline $\begin{array}{l}\text { Hantzschia } \\
\text { amphioxys }\end{array}$ & $\begin{array}{l}\text { aerial, wide range of tolerance to nutrients, indicator of high total } \\
\text { phosphorous, } \alpha \text {-mesosaprobous, tolerant to OBN, tolerates }>75 \% \text { DO } \\
\text { saturation, circumneutral } \mathrm{pH} \text {, fresh-brackish water, chloride optimum } \\
\text { low ( }<15 \mathrm{mg} / \mathrm{L}) \text {, benthic, motile, dry soil, survives prolonged dry } \\
\text { periods, cosmopolitan, one of the most common soil diatoms } \\
\text { worldwide }\end{array}$ \\
\hline Luticola mutica & $\begin{array}{l}\text { aerial, wide range of tolerance to nutrients, indicator of high total } \\
\text { phosphorous, } \alpha \text {-mesosaprobous, tolerant to OBN, tolerates }>75 \% \text { DO } \\
\text { saturation, circumneutral } \mathrm{pH} \text {, fresh-brackish water, chloride optimum } \\
\text { low ( }<15 \mathrm{mg} / \mathrm{L}) \text {, benthic, motile, dry soil, survives prolonged dry } \\
\text { periods, cosmopolitan, one of the most common soil diatoms } \\
\text { worldwide, on mosses, liverworts and lichens }\end{array}$ \\
\hline $\begin{array}{l}\text { Luticola } \\
\text { muticopsis }\end{array}$ & $\begin{array}{l}\text { aerial, benthic, motile, very widespread in the Antarctic and } \\
\text { Subantarctic Regions, high nutrient concentrations, chinstrap penguin } \\
\text { rookeries with pH } 8.2\end{array}$ \\
\hline Luticola nivalis & $\begin{array}{l}\text { aerial, aquatic, oligo-mesotrophic, tolerates somewhat degraded } \\
\text { conditions, circumneutral pH, brackish-freshwater, benthic, motile, in } \\
\text { soil, near gull nesting areas and fur seal wallows, on lichens, mosses } \\
\text { and liverworts, dry soil }\end{array}$ \\
\hline $\begin{array}{l}\text { Meridion } \\
\text { circulare }\end{array}$ & $\begin{array}{l}\text { aquatic, wide range of tolerance to nutrients, } \beta \text {-mesosaprobous, tolerant } \\
\text { to OBN, tolerates }>75 \% \text { DO saturation, alkaliphilous, fresh-brackish } \\
\text { water, conductivity optimum low }(<200 \mu \mathrm{S} / \mathrm{cm}) \text {, chloride optimum low } \\
\text { ( }<15 \mathrm{mg} / \mathrm{L}) \text {, planktonic, non-motile, tolerates drying, moss and } \\
\text { liverworts above water line }\end{array}$ \\
\hline $\begin{array}{l}\text { Muelleria } \\
\text { gibbula }\end{array}$ & cosmopolitan, a montaine species, on mosses, small pools, alpine tarns \\
\hline $\begin{array}{l}\text { Navicula } \\
\text { reichardtiana }\end{array}$ & $\begin{array}{l}\text { aquatic, cosmopolitan, eutrophic, moderately electrolyte rich water, } \\
\text { particularly those rich in calcium carbonate, rarely in brackish water, } \\
\text { pollution tolerant only to critical levels, good indicator of eutrophy and } \\
\beta \text {-mesosaprobity }\end{array}$ \\
\hline $\begin{array}{l}\text { Neidium } \\
\text { septentrionale }\end{array}$ & aquatic, nordic-alpine regions \\
\hline $\begin{array}{l}\text { Nitzschia } \\
\text { amphibia }\end{array}$ & $\begin{array}{l}\text { aquatic, cosmopolitan, springs, creeks, epipelic, prefers high } \\
\text { conductivity, eutrophic, indicator of high total nitrogen and total } \\
\text { phosphorous, } \alpha \text {-mesosaprobous, requires periodic elevated } \\
\text { concentrations of OBN, tolerates highly degraded conditions, tolerates }\end{array}$ \\
\hline
\end{tabular}




\begin{tabular}{|c|c|}
\hline & $\begin{array}{l}\text { >50\% DO saturation, fresh-brackish water, benthic, non-motile, } \\
\text { tolerant of a wide range from oligotrophic to eutrophic waters, } \\
\text { oligohalobous-indifferent, alkaliphilous to alkalibiontic, prefers } \\
\text { eutrophic waters, a widespread freshwater species, epipelic in the } \\
\text { littoral mud of freshwater lakes, can tolerate higher salt contents and } \\
\text { slight fluctuations in osmotic pressure, can thrive in a wide range of } \\
\text { chemical conditions, eurythermal, temperate, saprophilous, facultative } \\
\text { nitrogen heterotroph, can grow in low oxygen concentrations, } \\
\text { eurysaprobic, pH 7-8.6, on rock, wood, macroalgae, found snail } \\
\text { intestines, on wet concrete, moss, mud and floating cakes of algae. }\end{array}$ \\
\hline $\begin{array}{l}\text { Nitzschia } \\
\text { fonticola }\end{array}$ & $\begin{array}{l}\text { aquatic, cosmopolitan, low to high conductivity, oligotrophic to } \\
\text { mesotrophic, brackish water }\end{array}$ \\
\hline Nitzschia palea & $\begin{array}{l}\text { aquatic, tolerates a wide range of ecological conditions, a good } \\
\text { indicator of organic pollution, cosmopolitan, } \alpha \text {-mesosaprobous to } \\
\text { polysaprobous, indicator of high total nitrogen and total phosphorous, } \\
\text { indicative of elevated concentrations of OBN, tolerates extremely } \\
\text { degraded conditions, tolerates }>30 \% \text { DO saturation, circumneutral pH, } \\
\text { fresh-brackish water, benthic, non-motile, soils, pond margin mud, } \\
\text { survives dry periods, cosmopolitan }\end{array}$ \\
\hline $\begin{array}{l}\text { Nitzschia } \\
\text { paleaceae }\end{array}$ & $\begin{array}{l}\text { aquatic. cosmopolitan, benthic, more or less eutrophic water with } \\
\text { moderate to high conductivity, eutrophic, } \alpha \text {-mesosaprobous, indicative } \\
\text { of elevated concentrations of OBN, tolerates highly degraded } \\
\text { conditions, tolerates }>50 \% \text { DO saturation, alkaliphilous, fresh-brackish } \\
\text { water, chloride optimum low ( }<15 \mathrm{mg} / \mathrm{L} \text { ), benthic, motile; also in } \\
\text { periodic water and wet subaerial }\end{array}$ \\
\hline $\begin{array}{l}\text { Nitzschia } \\
\text { perminuta }\end{array}$ & $\begin{array}{l}\text { aquatic, cosmopolitan, benthic in oligotrophic water with moderate } \\
\text { conductivity }\end{array}$ \\
\hline $\begin{array}{l}\text { Pinnularia } \\
\text { appendiculata }\end{array}$ & $\begin{array}{l}\text { aquatic, cosmopolitan, prefers mineralized waters, salt-rich inland } \\
\text { waters, salines, soda lakes, generally in waters with an average to high } \\
\text { electrolyte content (1), oligo-mesotrophic, oligosaprobous, generally } \\
\text { intolerant to OBN, tolerates nearly } 100 \% \text { DO saturation, acidophilous, } \\
\text { freshwater, conductivity optimum low ( }<200 \mu \mathrm{S} / \mathrm{cm}) \text {, chloride } \\
\text { optimum low ( }<15 \mathrm{mg} / \mathrm{L}) \text {, benthic, motile, soil }\end{array}$ \\
\hline $\begin{array}{l}\text { Pinnularia } \\
\text { borealis }\end{array}$ & $\begin{array}{l}\text { aerial, soils, dry moss, wet and dry walls, and extremely dry habitats, } \\
\text { oligo-mesotrophic, } \beta \text {-mesosaprobous, tolerates OBN, high dissolved } \\
\text { oxygen, circumneutral pH, fresh and brackish water, benthic, motile, } \\
\text { cosmopolitan }\end{array}$ \\
\hline $\begin{array}{l}\text { Pinnularia } \\
\text { brebissonii }\end{array}$ & $\begin{array}{l}\text { aerial, soils, prairie swales, peat moors, acidic to neutral montane } \\
\text { waters, also in alkaline water, salt indifferent }\end{array}$ \\
\hline $\begin{array}{l}\text { Pinnularia } \\
\text { grunowii }\end{array}$ & $\begin{array}{l}\text { aquatic, cosmopolitan in cold regions, low to moderate conductivity, } \\
\text { pH over } 8 \text {, in organic muds, epilithic, epiphytic }\end{array}$ \\
\hline $\begin{array}{l}\text { Pinnularia } \\
\text { infirma }\end{array}$ & aquatic, no ecology available \\
\hline $\begin{array}{l}\text { Pinnularia } \\
\text { intermedia }\end{array}$ & aquatic, cosmopolitan, cold, oxygen rich water with low conductivity \\
\hline Pinnularia & aquatic, epipelic, cosmopolitan, oligotrophic, oligosaprobic waters with \\
\hline
\end{tabular}




\begin{tabular}{|c|c|}
\hline microstauron & $\begin{array}{l}\text { a low electrolyte content and } \mathrm{pH} \text { values, cool, oxygen-rich moorland } \\
\text { water with a very low electrolyte content, wide range of tolerance to } \\
\text { nutrients, } \beta \text {-mesosaprobous, tolerant to OBN, tolerates }>50 \% \text { DO } \\
\text { saturation, circumneutral } \mathrm{pH} \text {, fresh-brackish water, chloride optimum } \\
\text { low }(<15 \mathrm{mg} / \mathrm{L}) \text {, benthic, motile }\end{array}$ \\
\hline $\begin{array}{l}\text { Pinnularia } \\
\text { obscura }\end{array}$ & $\begin{array}{l}\text { aerial, cosmopolitan in nordic-alpine regions, particularly in moist and } \\
\text { occasionally moist mosses and liverworts above the water line, and on } \\
\text { wet and dry rocks and walls, one of the commonest soil diatoms, } \\
\text { oligosaprobous, generally intolerant to OBN, tolerates nearly } 100 \% \text { DO } \\
\text { saturation, circumneutral } \mathrm{pH} \text {, fresh-brackish water, conductivity } \\
\text { optimum low }(<200 \mu \mathrm{S} / \mathrm{cm}) \text {, chloride optimum low }(<15 \mathrm{mg} / \mathrm{L}) \text {, } \\
\text { benthic, motile }\end{array}$ \\
\hline $\begin{array}{l}\text { Pinnularia } \\
\text { similiformis }\end{array}$ & $\begin{array}{l}\text { aerial and aquatic, on mosses, oligotrophic, oxygen rich, electrolyte } \\
\text { poor moorland waters, mountain climates, cosmopolitan }\end{array}$ \\
\hline $\begin{array}{l}\text { Pinnularia } \\
\text { subcapitata }\end{array}$ & $\begin{array}{l}\text { aerial, aquatic, bogs, wet moss, oligotrophic, electrolyte-poor water, } \\
\text { oligo-mesotrophic, } \beta \text {-mesosaprobous, tolerant to OBN, tolerates }>50 \% \\
\text { DO saturation, acidophilous, fresh-brackish water, benthic, motile }\end{array}$ \\
\hline $\begin{array}{l}\text { Pinnularia } \\
\text { viridis }\end{array}$ & $\begin{array}{l}\text { aquatic, cosmopolitan, circumneutral } \mathrm{pH} \text {, oligo-mesotrophic water with } \\
\text { lower to average electrolyte content, wide range of tolerance to } \\
\text { nutrients, } \beta \text {-mesosaprobous, tolerant to OBN, tolerates }>50 \% \text { DO } \\
\text { saturation, fresh-brackish water, fresh-brackish water, conductivity } \\
\text { optimum low }(<200 \mu \mathrm{S} / \mathrm{cm}) \text {, chloride optimum low }(<15 \mathrm{mg} / \mathrm{L}) \text {, } \\
\text { benthic, motile, frequent at the margin of ponds and survives short } \\
\text { periods of drying, up to about a month }\end{array}$ \\
\hline $\begin{array}{l}\text { Rhopalodia } \\
\text { gibba }\end{array}$ & $\begin{array}{l}\text { aquatic, capable of fixing atmospheric nitrogen, eutrophic, indicator of } \\
\text { low total nitrogen and high total phosphorous, } \beta \text {-mesosaprobous, } \\
\text { generally intolerant to OBN, tolerates }>50 \% \text { DO saturation, } \\
\text { alkalibiontic, fresh-brackish water, chloride optimum low ( }<15 \mathrm{mg} / \mathrm{L}) \text {, } \\
\text { benthic, motile, cosmopolitan }\end{array}$ \\
\hline $\begin{array}{l}\text { Stauroneis } \\
\text { anceps }\end{array}$ & $\begin{array}{l}\text { aquatic and aerial, epipelic, high organic content, } \beta \text {-mesosaprobous, } \\
\text { tolerant to OBN, tolerates }>75 \% \text { DO saturation, circumneutral } \mathrm{pH} \text {, } \\
\text { fresh-brackish water, benthic, motile,abundant in ditches, brooks and } \\
\text { puddles, in sandy soils, on mosses near springs and in prairie swales }\end{array}$ \\
\hline $\begin{array}{l}\text { Stauroneis } c f \text {. } \\
\text { bertrandii }\end{array}$ & aquatic, shallow pools, pH 7.2, high conductivity \\
\hline $\begin{array}{l}\text { Stauroneis } \\
\text { borrichii }\end{array}$ & $\begin{array}{l}\text { aquatic and aerial, oligosaprobous, tolerates nearly } 100 \% \text { DO } \\
\text { saturation, circumneutral pH, freshwater, benthic, motile, soil, dry } \\
\text { rocks and walls }\end{array}$ \\
\hline $\begin{array}{l}\text { Stauroneis } \\
\text { gracillor }\end{array}$ & $\begin{array}{l}\text { aquatic, epipelic, high organic content, } \beta \text {-mesosaprobous, tolerant to } \\
\text { OBN, tolerates }>75 \% \text { DO saturation, circumneutral } \mathrm{pH} \text {, fresh-brackish } \\
\text { water, benthic, motile, small ponds with very low conductivity }\end{array}$ \\
\hline $\begin{array}{l}\text { Stauroneis } c f . \\
\text { krigeri }\end{array}$ & $\begin{array}{l}\text { aquatic and aerial, in moss and acidic to circumneutral soils, low } \\
\text { conductivity, cold water }\end{array}$ \\
\hline $\begin{array}{l}\text { Stauroneis } \\
\text { phoenicentron }\end{array}$ & $\begin{array}{l}\text { aquatic in brooks, ditches, puddles, on mosses and liverworts above the } \\
\text { water line }\end{array}$ \\
\hline Stauroneis & aquatic, cosmopolitan in standing and flowing water with moderate to \\
\hline
\end{tabular}




\begin{tabular}{|l|l|}
\hline prominula & high conductivity, brackish water \\
\hline $\begin{array}{l}\text { Stauroneis } \\
\text { reichardtii }\end{array}$ & $\begin{array}{l}\text { aquatic and aerial, in small pools and large lakes, } \mathrm{pH} \text { range 6.1 to 8.1, } \\
\text { low conductivity, nutrient and salinity levels, occasionally in moss and } \\
\text { soil }\end{array}$ \\
\hline $\begin{array}{l}\text { Stauroneis } \\
\text { subgracilis }\end{array}$ & $\begin{array}{l}\text { aquatic and aerial, shallow pools and large, deep lakes, pH 6 to 8.3, } \\
\text { conductivity low to moderate, oligotrophic to mesotrophic, wet and } \\
\text { occasionally dry moss and soils }\end{array}$ \\
\hline $\begin{array}{l}\text { Staurosira } \\
\text { construens }\end{array}$ & $\begin{array}{l}\text { aquatic, planktonic and benthic, in standing and flowing water, } \\
\text { oligosaprobic, wide ecological amplitude }\end{array}$ \\
\hline $\begin{array}{l}\text { Stephanodiscus } \text { minutulus } \\
\text { Ulnaria acus }\end{array}$ & $\begin{array}{l}\text { aquatic, planktonic } \\
\text { aquatic, tolerates a wide range of ecological conditions, eutrophic, } \alpha- \\
\text { mesosaprobous, tolerant to OBN, tolerates degraded conditions, } \\
\text { tolerates }>75 \% \text { DO saturation, alkaliphilous, fresh-brackish water, } \\
\text { chloride optimum low (<15 mg/L), benthic, non-motile, cosmopolitan }\end{array}$ \\
\hline Ulnaria cf. ulna & $\begin{array}{l}\text { aquatic, tolerates a wide range of ecological conditions, wide range of } \\
\text { tolerance to nutrients, indicator of low total nitrogen and total } \\
\text { phosphorous, } \alpha \text {-meso/polysaprobous, tolerant to OBN, tolerates } \\
\text { extremely degraded conditions, tolerates }>50 \% \text { DO saturation, } \\
\text { alkaliphilous, fresh-brackish water, chloride optimum low (<15 mg/L), } \\
\text { benthic, non-motile, cosmopolitan, temporarily wet settings, bar } \\
\text { ditches }\end{array}$ \\
\hline
\end{tabular}




\title{
DIATOM PALEOENVIRONMENTAL ANALYSIS OF SEDIMENTS
}

FROM ANCESTRAL PUEBLOAN WATER RESERVOIR FEATURES

AT LARGE VILLAGE SITES ON THE PAJARITO PLATEAU, AND ONE SAMPLE FROM THE SITE OF WABAKWA ON THE JEMEZ PLATEAU

NEW MEXICO

\author{
Prepared By: \\ Barbara Winsborough \\ Winsborough Consulting \\ 23606 Round Mountain Circle \\ Leander, Texas 78641 \\ July 2016
}

\author{
Prepared For: \\ Michael Aiuvalasit M.A., R.P.A. \\ PhD Candidate and Research Assistant \\ Department of Anthropology \\ Southern Methodist University \\ Campus PO Box 750336 \\ 3225 Daniel Ave., Heroy Hall \# 435 \\ Dallas, Texas 75275-0336
}




\section{INTRODUCTION}

This investigation is part of a larger research project reconstructing the use-life of Ancestral Puebloan water reservoir features at large village sites in the Jemez Mountains near Jemez Springs, New Mexico. The goal of this part of the project is to investigate the diatom content of core samples taken from the deep parts of the reservoirs and determine how much water present and how long it lasted. Previously, a set of 15 core samples was analyzed in detail. The goal was to identify wet and dry periods that reflect changes in the availability of water. This report details the results of a diatom paleoenvironmental analysis of an additional 16 samples (Table 1).

Diatoms are unicellular, eukaryotic algae that are distinguished by the presence of a silica cell wall. They live in a wide variety of habitats, including soil, rocks, moss, caves, rivers, streams, ponds, lakes, bogs, lagoons, marshes, swamps, mud flats, sandy and rocky beaches, estuaries, bays and oceans. Many species are cosmopolitan, found in different parts of the world under similar environmental conditions, making it possible to predict their environmental requirements and tolerances. While diatoms are often regarded as aquatic organisms, many species are capable of surviving and reproducing in a variety of non-aquatic, aerial (not submerged) habitats, including moist and dry substrates, These algae often derive their water from moisture in the air and rain.

Diatoms can be identified to species level and a large and growing body of information exists on the range and ecological tolerances of many of the common forms. Diatoms are good indicators of water chemistry, depth, $\mathrm{pH}$, salinity, habitat, substrate, nutrient concentrations and pollution levels. Because of their silica cell walls they are often preserved in sedimentary deposits, making them well-suited for use in paleoenvironmental reconstruction. 


\section{METHODS}

Approximately one $\mathrm{cm}^{3}$ of sediment was oxidized with $35 \% \mathrm{H}_{2} \mathrm{O}_{2}$ to remove organic material and decalcified with 31.45\% $\mathrm{HCl}$. After rinsing to a neutral $\mathrm{pH}$, the material was dried onto cover slips and mounted on glass slides with Naphrax ${ }^{\circledR}$. The slides were scanned at x1500 magnification, and the first 600 diatoms encountered in random fields were identified and recorded. If there were less than 600 diatoms on a slide, at least two slides were completely scanned and all diatoms recorded.

\section{RESULTS}

Overall, 7125 diatom valves were recorded during this investigation. Of the 16 samples, 11 were particularly diatomaceous and 600 valves were counted in each. Fewer total numbers of valves were found in the remaining samples (Table 1). Three species accounted for most of these numbers. Hantzschia amphioxys (Ehrenberg) Grunow (Plate 1 D, E), the overwhelming dominant in all samples except sample 17, represented 4186 of these valves. Luticola mutica (Kützing) D.G. Mann (Plate 1 C) was the next most abundant taxon with 1690 valves and there were 926 Pinnularia borealis Ehrenberg (Plate 1 A, B, Plate 4 I) valves. These species were present in varying amounts in all the samples except number 17, which had no Luticola mutica.

Four other taxa were common overall but less abundant and were not recorded from every sample. These diatoms are Stauroneis anceps Ehrenberg (71 valves), Craticula ambigua (Ehrenberg) D.G. Mann (65 valves), Stephanodiscus spp. fragments, and Luticola dismutica (Hustedt) D.G. Mann (41 valves). The ecological preferences of these common to abundant diatom species define the primary characteristics of the paleoenvironment. The preferences and tolerances of the rarer species that were recorded only a few times, or only in one or a few 
samples, are also important in providing information about the entire range of conditions represented by the assemblage, including short-term changes. The abundance data is tabulated on Table 1 and Table 2 is a summary of the ecological characteristics of each taxon. Unless specified, ecological information comes from a collection of sources including: Round 1981, Krammer and Lange-Bertalot 1988, Vos and de Wolf 1993, Van Dam et al. 1994, Stoermer and Smol 1999, Johansen 1999, Lange-Bertalot and Genkal 1999, Winter and Duthie 2000, Krammer 2001, Lange-Bertalot 2001, Van de Vijver et al. 2004, Potapova and Charles 2007, Van de Vijver and Mataloni 2008, Porter, 2008, and others.

\section{DISCUSSION}

The three most abundant taxa, Hantzschia amphioxys, Luticola mutica, and Pinnularia borealis are aerial forms that live on dry soil, moss, and a variety of damp settings (Table 2). They bloom after a rain but can survive for long periods of time under dry conditions. In addition to these taxa, Diadesmis contenta (Grunow) D.G. Mann, the other Luticola species and Pinnularia appendiculata (Agardh) Cleve (Plate $3 \mathrm{C}$ ) are also aerial forms. These diatoms reflect the baseline conditions that predominated during the deposition of most of the samples. It is assumed that they were growing under favorable conditions that reflect their ecological preferences and tolerances.

\section{Discussion of Individual Samples}

Sample 1 (LA3834_2.109, 16-18 cm) was not very diatomaceous. Two slides were scanned in their entirety and 82 diatoms were found. All species in this sample except two valves of the aquatic diatom Navicula cryptotenella Lange-Bertalot are aerial forms. It is unclear if this represents a brief aquatic episode or the diatoms were reworked or transported. 
Sample 2 (LA70790_2.225, 48-50 cm) was diatomaceous and 600 valves were counted. It contained exclusively aerial species, except for one valve of the extinct, heavily silicified, planktonic diatom Aulacoseira canadensis (Hustedt) Simonsen (Plate 4 B, C), that was probably transported to the site. It's presence can be explained by the erosion of diatomites into lakes and streams from shallow, softwater Miocene lakebed deposits, such as dry intermontane lakes in Nevada and elsewhere (Bahls et al. 2009). There was also one broken sponge spicule (Plate 4 A). This sample was full of phytoliths and vascular plant fragments, and also contained abundant statocysts, Statocysts or statospores are the siliceous resting stages of algae belonging to the Chrysophyceae and are preserved in lake sediments. Their production may have been prompted by drying conditions. There was enough water to support plant growth but not enough for diatoms, or there was too much shade, even if the soil was wet. The wet soil explains the abundant aerial diatoms. It is possible that this sample represents a moist period when the basin was not maintained clean of vegetation.

Sample 3 (LA70798_2.207, 12-14 cm) was diatomaceous and 600 valves were counted. There were only 4 taxa, Hantzschia amphioxys, Luticola mutica, Pinnularia appendiculata and Pinnularia borealis, all aerial forms. Because of the abundance of diatoms this sample probably represents a damp setting with no water on the surface.

Sample 4 (LA70798)_2.214, 26-26 cm) was diatomaceous and 600 valves were counted. There were 6 taxa, all aerial. Including the same 4 in the previous sample plus Diadesmis contenta (Grunow) D.G. Mann and Luticola dismutica (Hustedt) D.G. Mann. This sample probably represents a damp setting with no surface water. 
Sample 5 (SMG2.109, 16-18 cm) was diatomaceous and 600 valves were counted. There were 5 diatom taxa, all aerial forms as in the previous samples. There were no aquatic diatoms to suggest submerged conditions.

Sample 6 (TK1_2.214, 26-28 cm) was diatomaceous and 600 valves were counted. The 4 usual aerial diatoms were present, and one additional valve of the aquatic diatom Denticula sp. that was too corroded to identify to species and was probably a contaminant was also found. This sample represents damp or occasionally wetted conditions as the previous samples, with no indication of standing water.

Sample 7 (TK2_2.214, 26-28 cm) was not very diatomaceous and 88 valves were found in a scan of 2 entire slides. The diatoms are all the same aerial forms as in previous samples except for one corroded valve of Stephanodiscus or Cyclostephanos (Plate 3 E). Cyclostephanos is a new name for some Stephanodiscus species but the entire diatom needs to be seen and this one is missing it's critical edges. This is probably a wind blown contaminant from nearby Pleistocene dry lakes.

Sample 8 (TK3_2.207, 14-16 cm) was diatomaceous and 600 valves were counted. The overwhelming dominant is Hantzschia amphioxys, followed by Luticola mutica. There were only a few other species, all aerial except the aquatic, benthic, eutrophic Gomphonema parvulum (Kützing) Kützing (Plate $1 \mathrm{G}$ ). There was also one Stephanodiscus fragment that was transported to the site.

Sample 9 (TK3_2.212, 24-26 cm) was very diluted with clastic sediments and 114 valves were found in a scan of two slides. The most common species are aerial but there was also 3 aquatic species, Denticula cf kuetzingii Grunow and Epithemia turgida (Ehrenberg) Kützing (Plate 3 D) 
and Staurosirella pinnata (Ehrenberg) Williams and Round (Plate 3 B). These valves were whole and may indicate the presence of water. There were 3 centric, planktonic species including Stephanodiscus spp. fragments, Aulacoseira cf. italica (Ehrenberg) Simonsen (Plate 2 G), and Aulacoseira sp. (Plate 2 I). In addition to diatoms there was a sponge spicule (Plate $2 \mathrm{H}$ ) and chrysophyte statocysts. The abundance of centric diatoms probably represents a windy period.

Sample 10 (TSR2.115, 28-30 cm) was diatomaceous and 600 valves were counted. There were only three diatom species, and all were the same common aerial species as in other samples, suggesting that the setting was not as humid as the other samples.

Sample 11 (TSR2.128, 54-56) was diatomaceous and 600 valves were counted. Over half of these were Hantzschia amphioxys. Luticola mutica and Pinnularia borealis were also abundant. In addition there was 71 Stauroneis anceps valves. Stauroneis species tend to live in small, standing or slowly moving oligotrophic, circumneutral or slightly acidic, clean bodies of water, and are often associated with macrophytes, or on wet soils and moss, often in remote locations (Bahls, 2012). Also abundant was Craticula ambigua. This taxon has internal siliceous structures thought to be a response to some unfavorable environmental conditions such as desiccation, fluctuating salt content, nutritional deficiency, and a rather sudden increase in osmotic pressure. They are found in settings where strong evaporation over part of the year is a characteristic. Together these diatoms indicate that the site was submerged for some time but then dried out. They are a combination of aquatic species adapted to frequent drying and those typically associated with moss, springs, wet walls and soil, suggesting that the amount of water was variable and not very long lasting.

Sample 12 (TSR2.144, 86-88 cm) was sparsely diatomaceous and 184 valves were found. In addition to the aerial species there were 12 Craticula ambigua suggesting briefly submerged 
conditions. Statospores were also present supporting the interpretation of temporary submergence. There were also 33 Stephanodiscus fragments (Plate 3 F, G, H, I; Plate 4 D, E, F, $\mathrm{G}, \mathrm{H})$. These fragments are all broken, particularly around their rims, and indicate mechanical breakage due to transport to the site. Their abundance is suggestive of a dry, windy interval. The Stephanodiscus species probably were transported from the Pleistocene-early Holocene fossil lake beds in the San Augustin Basin in western New Mexico where Stephanodiscus species were abundant (Markgraf et al. 1984).

Sample 13 (YAP2.303, 4-6 cm) contained enough diatoms to count 600 valves. It was heavily dominated by aerial diatoms but there was also 5 intact valves of the common aquatic, benthic, epiphyte Encyonema silesiacum (Blesch) D.G. Mann (Plate 2 A, B) and two valves of the aquatic, benthic Rhopalodia $c f$. brebissonii Krammer. This suggests that there may have been a small amount of standing water associated with these sediments.

Sample 14 (YAP2.210, 18-20 cm) was diatomaceous and 600 valves were counted. There were only 4 diatoms, all the usual aerial species. There is no evidence of standing water.

Sample 15 (YAP2.231, 60-62 cm) was very diatomaceous and 600 valves were counted. Hantzschia amphioxys, Luticola spp. and Pinnularia borealis account for all but 2 valves. These are Rhopalodia gibba (Ehrenberg) Müller) (Plate 1 F), an aquatic, benthic, diatom with internal siliceous supports, often found in aquatic settings that dry out.

Sample 17 (WAB2.226_50-52 cm) was different from the others. Four slides were scanned completely and only 56 diatoms were found. Fifteen valves were aerial forms, and the rest were aquatic. There were 8 benthic, aquatic species including 25 valves of the shallow water epiphyte Gomphonema parvulum (Kützing) Kützing an indicator of eutrophic conditions (Porter 2008). 
There were 4 valves of Navicula reichardtiana Lange-Bertalot (Plate $1 \mathrm{H}$ ). This diatom is also found in eutrophic, moderately carbonate rich water and is a good indicator of eutrophy (LangeBertalot 2001). In addition, there was one fragment of Stephanodiscus sp. and a sponge spicule.

\section{$\underline{\text { Reasons for Lack of Diatoms in Some Samples }}$}

There were few diatoms in some samples and many in others. There are several reasons for this. The absence of diatoms may indicate an environment that was not conducive to diatom growth such as a dry or aeolian surface, or a setting in which diatoms were originally present but later removed by diagenetic and pedogenic processes. Poor diatom preservation may be explained by silica dissolution, frequent wind-induced resuspension cycles and grazing by benthic invertebrates that can cause breakage of diatom frustules (Bennion et al., 2010). In these samples the aerial diatoms were sometimes corroded and broken but the aquatic species were mostly whole.

Silica dissolution affects all siliceous microfossils, including diatoms, phytoliths, and sponge spicules, but diatoms are the group that is most sensitive to dissolution by oxidation and bacterial decay. While the diatom is alive there is an organic casing consisting of polysaccharides, proteins and lipids around the silica wall that protects it against dissolution. Dissolution of the siliceous exoskeleton is slow except in alkaline conditions or in the interstitial water of peat bogs (Round et al. 1990). In a setting with alternating wet and dry environments, a lowering of the water table, increases biological activity and decomposition processes, with diatoms rare in unsaturated soil environments and frequent in saturated conditions (Bouma et al 1990). 


\section{CONCLUSIONS}

These data illustrate a remarkable consistency in composition, with most of the diatoms being aerial species belonging to about a half dozen taxa, with three of them clear dominants. Assuming similar geology, topography, and hydrology at all sites, climate, including rain and wind appear to be the primary variables. These is no evidence of permanent water in most of the samples but several of them contain small numbers of aquatic taxa indicating temporary pools. The most common habitat suggested by the diatoms is one that was not submerged but often damp enough to support mosses. In contrast, one sample, number 17 , although it was very much diluted with sediment, contained mostly whole aquatic taxa indicating submerged but shallow conditions. This mixing of surface sediments could have been caused by activities associated with collecting water.

There were fragments of centric, planktonic diatoms in some of the samples. These diatoms grow in large, permanent lakes and because they are heavily silicified they are preserved when the lakes dry out. These were most likely aeolian, brought to the site by winds carrying diatoms from dry paleolake beds nearby. They are the same species as was reported from paleolakes in the lake basins on the San Augustin Plains about $90 \mathrm{~km}$ west of Soccoro, New Mexico that dried to ephemeral ponds by about 5000 yr B.P (Markgraf 1984).

\section{REFERENCES, INCLUDING THOSE USED IN ECOLOGICAL DESCRIPTIONS}

Bahls, Loren, 2012. Five new species of Stauroneis (Bacillariophyta, Stauroneidaceae) from the northern Rocky Mountains, USA. Phytotaxa 67: 1-8.

Bahls, Loren, Marina Potapova, Marie-Andrée Fallu, Reinhard Pienitz, 2009. Aulacoseira canadensis and Aulacoseira crassipunctata (Bacillariophyta) in North America. Nova Hedwigia 135, 167-184. 
Bennion, Helen, Carl D. Sayer, John Tibby and Hunter J. Carrick, 2010. Diatoms as indicators of environmental change in shallow lakes. In: The Diatoms: Applications for the Environmental and Earth Sciences, $2^{\text {nd }}$ edition, John P. Smol and Eugene F. Stoermer eds. Cambridge University Press, Cambridge, 152-173.

Bouma, J., C.A. Fox and R. Miedema, 1990. Micromorphology of hydromorphic soils: applications for soil genesis and land evaluation. In: Soil Micromorphology: A Basic and Applied Science. L.A. Douglass ed. Elsevier, Amsterdam, New York, 257-278.

Evans, John H., 1959. The survival of freshwater algae during dry periods, Part II, drying experiments, Part III, stratification of algae in pond margin litter and mud. J. Ecol. 47, 55-81.

Johansen, Jeffrey R., 1999. Diatoms in aerial habitats. In: The Diatoms: Applications for the Environmental and Earth Sciences, Eugene F. Stoermer and John P. Smol eds. Cambridge University Press, Cambridge, 264-273.

Krammer, Kurt, 2001. Diatoms of Europe 1, ed. by H. Lange-Bertalot. The Genus Pinnularia. A.R.G. Gantner Verlag K.G.

Krammer, Kurt and Horst Lange-Bertalot, 1988. Susswasserflora von Mitteleuropa 2/2 Bacillariophyceae 2 Teil: Bacillariaceae, Epithemiaceae, Surirellaceae. VEB Gustav Fischer Verlag, Jena.

Lange-Bertalot, Horst, 2001. Navicula sensu stricto, 10 Genera Separated from Navicula sensu lato, Frustulia. Diatoms of Europe 2, Horst Lange-Bertalot ed., A.R.G. Gantner Verlag K.G.

Lange-Bertalot, H and S.I. Genkal, 1999. Diatoms from Siberia. Iconographia Diatomologica 6, Koeltz Scientific Books, Koenigstein.

Markgraf, Vera, J. Platt Bradbury, R.M, Forester, G. Singh and R.S. Sternberg, 1984. San Augustin Plains, New Mexico: age and paleoenvironmental potential reassessed. Quaternary Research 22, 336-343.

Porter, Stephen D., 2008. Algal Attributes: An Autecological Classification of Algal Taxa Collected by the National Water-Quality Assessment Program. U.S. Geological Survey Data Series 329, http://pubs.usgs.gov/ds/ds329/

Potapova, M. \& D.F. Charles, 2007. Diatom metrics for monitoring eutrophication in rivers of the United States. Ecological indicators 7, 48-70.

Round, Frank E., 1981. The Ecology of Algae. Cambridge University Press, Cambridge.

Round, F.E., R.M. Crawford and D.G. Mann, 1990. The Diatoms, Biology and Morphology of the Genera. Cambridge University Press, Cambridge. 
Stoermer, Eugene F. and John P. Smol (eds.), 1999. The Diatoms: Applications for the Environmental and Earth Sciences. Cambridge University Press, Cambridge, 264-273.

Van Dam, Herman, Adrienne Mertens, and Jos Sinkeldam 1994. A coded checklist and ecological indicator values of freshwater diatoms from the Netherlands. Netherlands Journal of Aquatic ecology 28 (1), 117-133.

Van de Vijver, Bart, Louis Beyens and Horst Lange-Bertalot, 2004. The Genus Stauroneis in the Arctic and (Sub-) Antarctic Regions. Bibliotheca Diatomologica 51, J. Cramer, Berlin.

Van de Vijver, Bart \& Gabriella Mataloni, 2008. New and interesting species in the genus Luticola D.G. Mann (Bacillariophyta) from Deception Island (South Shetland Islands). Phycologia 47 (5), 451-467.

Vos, Peter and Hein de Wolf, 1993. Diatoms as a tool for reconstructing sedimentary environments in coastal wetlands: methodological aspects. Hydrobiologia 269/270, 285-296.

Winter, J.G. and H.C. Duthie, 2000. Epilithic diatoms as indicators of stream total N and total P concentration. J. N. Am. Benthol. Soc. 19 (1), 32-49.

\section{CAPTIONS FOR PHOTOMICROGRAPHS OF DIATOMS AND SPONGE SPICULES}

All images at x1000 magnification 

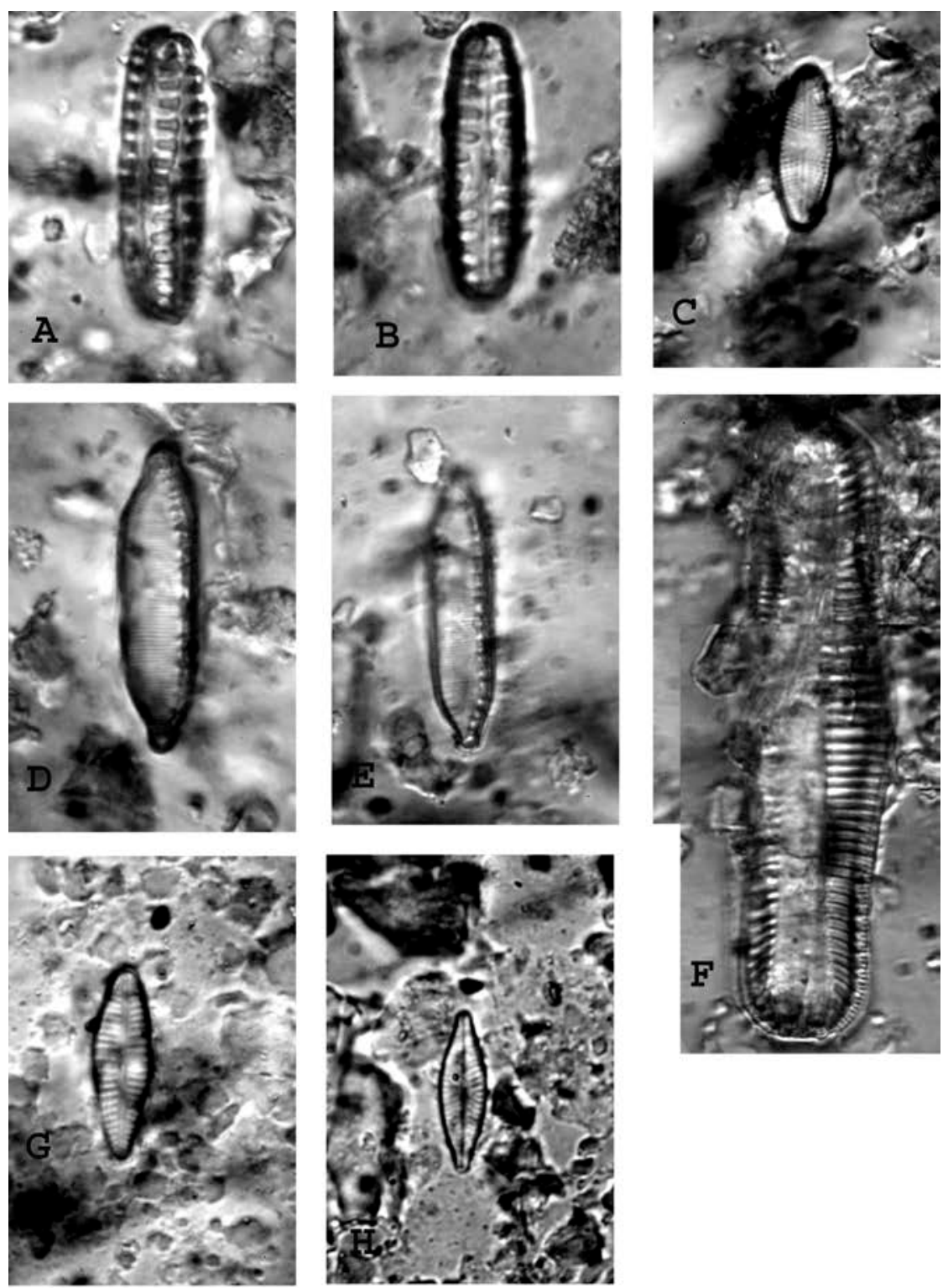

PLATE 1

Plate 1.

A, B. Pinnularia borealis Ehrenberg; C. Luticola mutica (Kützing) D.G. Mann; D, E. Hantzschia amphioxys (Ehrenberg) Grunow; F. Rhopalodia gibba (Ehrenberg) Müller; G. Gomphonema parvulum (Kützing) Kützing; H. Navicula reichardtiana Lange-Bertalot. 

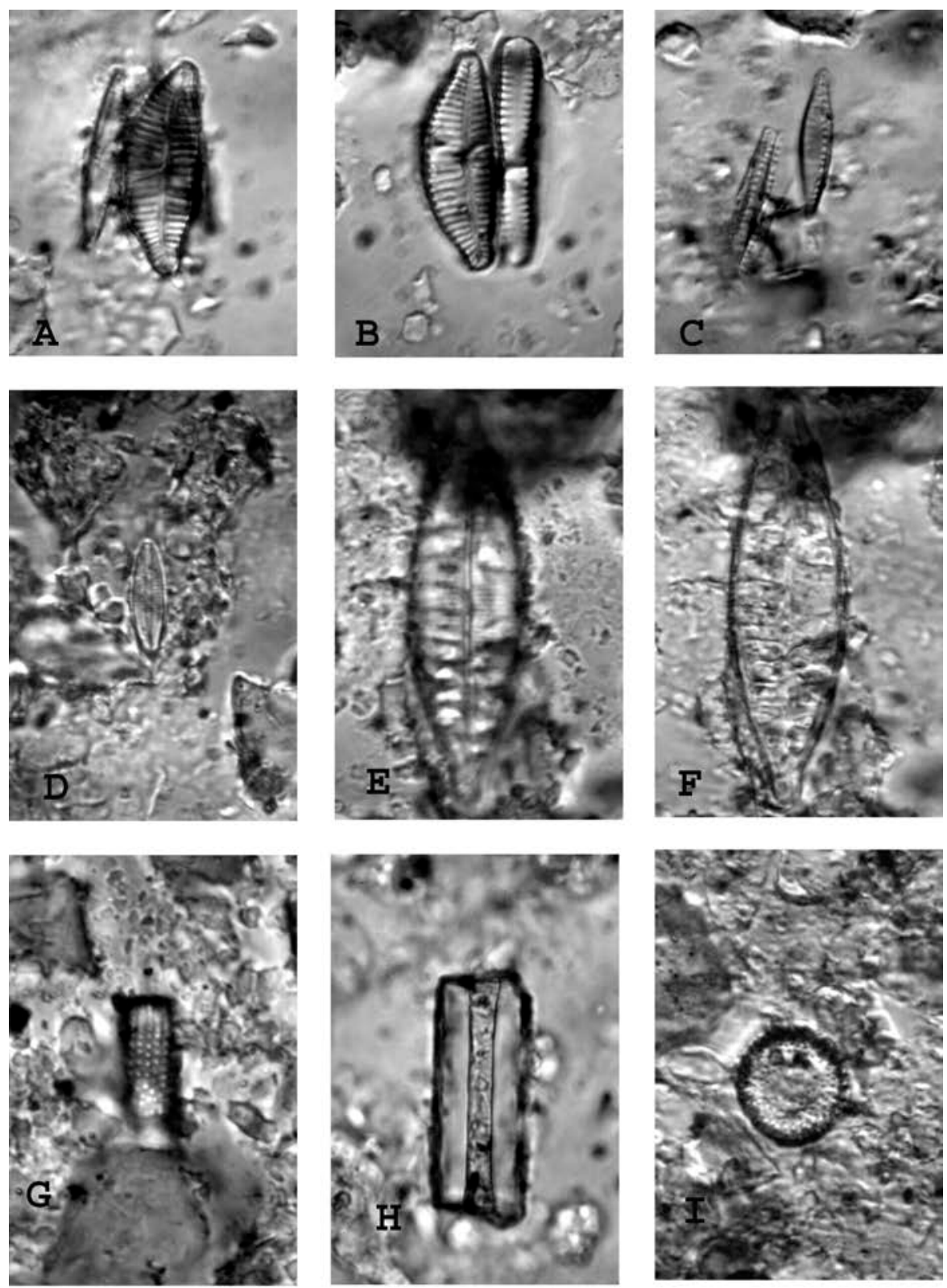

PLATE 2

Plate 2.

A, B. Cymbella excisa Kützing. C. Nitzschia fonticola (Grunow) Grunow. D. Achnanthidium pyrenaicum (Hustedt) Kobayashi; E, F. Different focal levels of Craticula cuspidata (Hustedt) Simonsen, E: high focus showing striae on surface, F: low focus showing internal craticula; G. Aulacoseira italica (Ehrenberg) Simonsen; H. Sponge spicule; I. Aulacoseira sp. (valve view). 

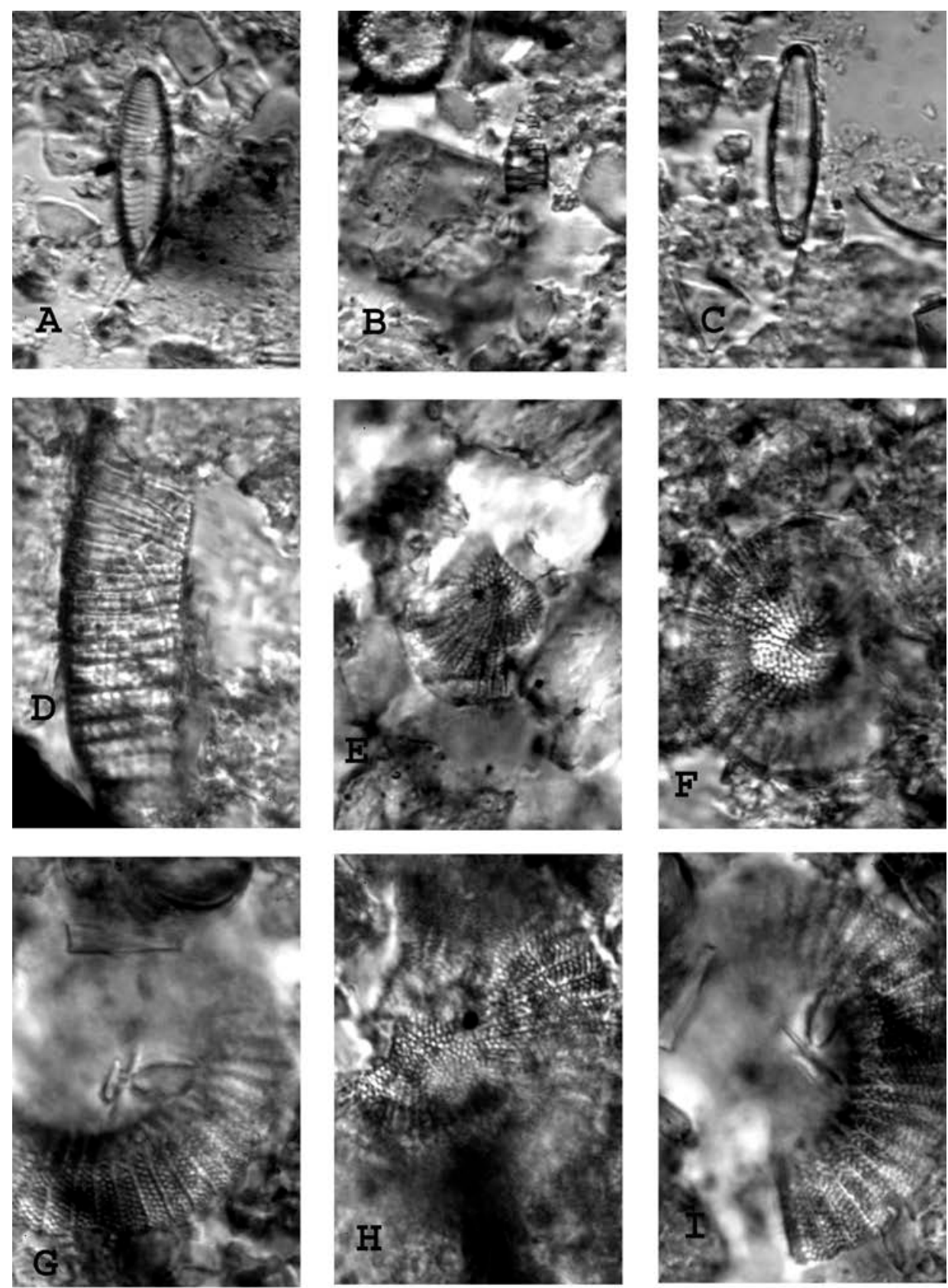

\section{PLATE 3}

Plate 3.

A. Gomphonema parvulum (Kützing) Kützing; B. Staurosirella pinnata (Ehrenberg) Williams and Round; C. Pinnularia appendiculata (Agardh) Cleve; D. Epithemia turgida (Ehrenberg) Kützing; E. Stephanodiscus sp. fragment; F. Stephanodiscus sp. fragment; G, H, I. Different focal levels of one specimen of Stephanodiscus sp. 

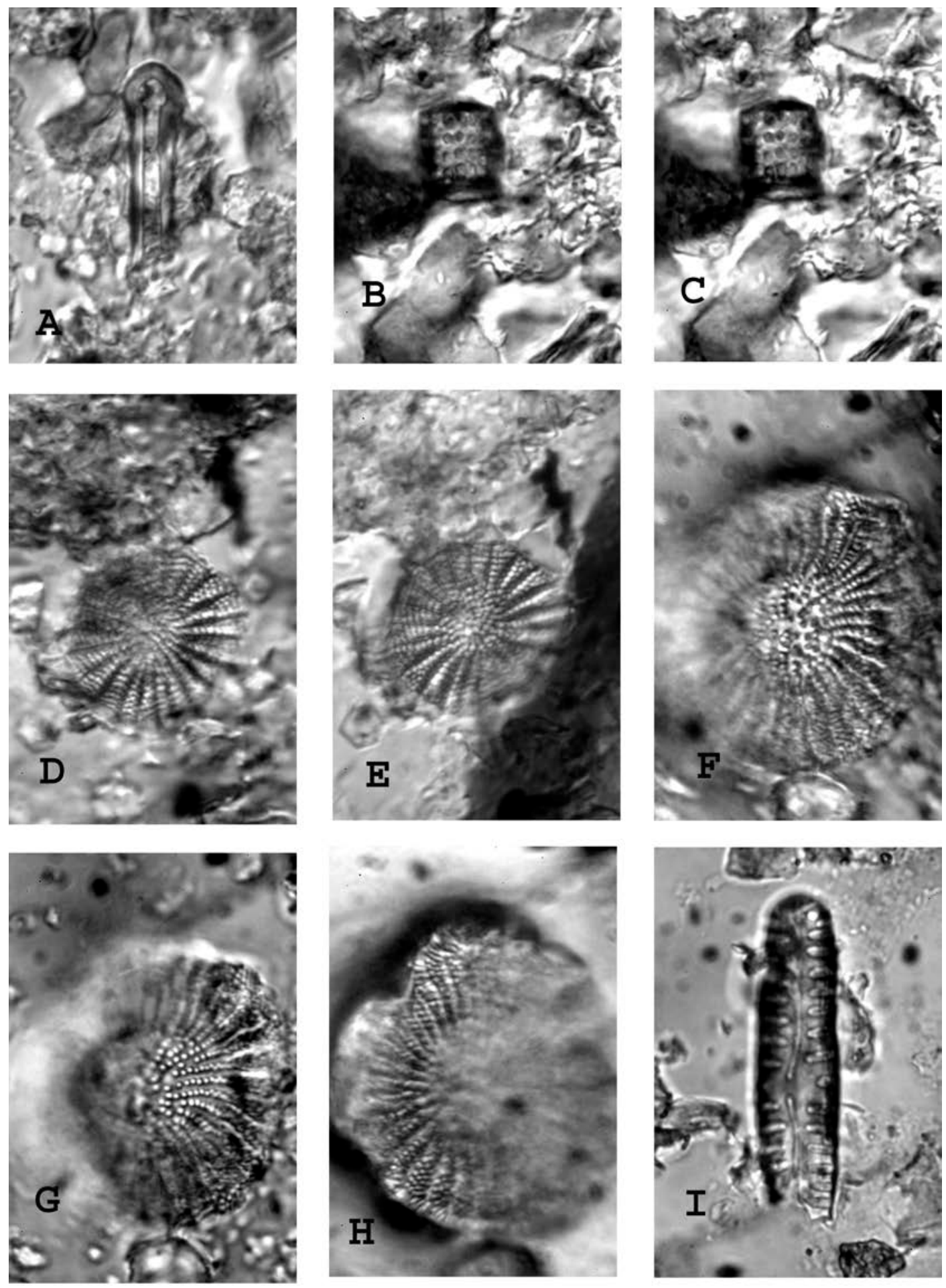

\section{PLATE 4}

Plate 4.

A. Sponge spicule; B, C. Different focal levels of Aulacoseira canadensis (Hustedt) Simonsen; D, E. Different focal levels of Stephanodiscus sp.; F, G, H. Different focal levels of Stephanodiscus sp.; I. Pinnularia borealis Ehrenberg. 
TABLE 1. LIST OF SAMPLES ANALYZED AND COUNTS

\begin{tabular}{|c|c|c|c|c|c|c|c|c|c|}
\hline Sample \# & & 1 & \begin{tabular}{|l|} 
\\
\end{tabular} & 3 & 4 & 5 & 6 & \begin{tabular}{|l|}
7 \\
\end{tabular} & 8 \\
\hline Sample ID & & LA3834_2.109 & LA70790_2.225 & LA70798_2.20 & LA70798_2.214 & SMG2.109 & TK1_2.214 & TK2_2.214 & TK3_2.207 \\
\hline Depth $(\mathrm{cm})$ & $\mathrm{pH}$ & $16-18$ & $48-50$ & $12-14$ & $26-28$ & $16-18$ & $26-28$ & $26-28$ & $14-16$ \\
\hline \multicolumn{10}{|c|}{ blue $=$ benthic/aquatic species, light blue=cosmopolitan species, yellow=aerial/terrestrial } \\
\hline \multicolumn{10}{|c|}{\begin{tabular}{|l|l|l|l|} 
Achnanthidium pyrenaicum (Hustedt) Kobayashi &. & & \\
\end{tabular}} \\
\hline \multicolumn{10}{|l|}{ Aulacoseira canadensis (Hustedt) Simonsen } \\
\hline Aulacoseira italica (Ehrenberg) Simonsen & 3 & & & & & & & & \\
\hline Aulacoseira $\mathrm{sp}$. & 3 & & & & & & & & \\
\hline Craticula ambigua (Ehrenberg) D.G. Mann & 3 & & & & & & & & \\
\hline \multicolumn{10}{|l|}{ Cymbella excisa Kützing } \\
\hline \multicolumn{10}{|l|}{ Denticula cf. kuetzingii Grunow } \\
\hline Denticula sp. & & & & & & & 1 & & \\
\hline Diadesmis contenta (Grunow ex Van Heurck) D.G. Mann & 4 & & 2 & & 2 & & & & \\
\hline Encyonema silesiacum (Bleisch) D.G. Mann & 2 & & & & & & & & \\
\hline Epithemia turgida (Ehrenberg) Kützing & 3 & & & & & & & & \\
\hline Gomphonema parvulum (Kützing) Kützing & 2 & & & & & & & & 2 \\
\hline Hantzschia amphioxys (Ehrenberg) Grunow & 2 & 61 & 318 & 305 & 315 & 312 & 411 & 80 & 461 \\
\hline Luticola dismutica (Hustedt) D.G.Mann & & 2 & 5 & & 16 & 8 & 8 & & 2 \\
\hline Luticola mutica (Kützing) D.G. Mann & 2 & 6 & 132 & 92 & 136 & 217 & 174 & 4 & 132 \\
\hline Luticola muticopsis (Van Heurck) D.G. Mann & 3 & & 2 & & & & & & \\
\hline \multicolumn{10}{|l|}{ Navicula cryptotenella Lange-Bertalot } \\
\hline Navicula reichardtiana Lange-Bertalot & 3 & & & & & & & & \\
\hline \multicolumn{10}{|l|}{ Navicula tripunctata (Müller) Bory } \\
\hline Nitzschia fonticola (Grunow) Grunow & 2 & & & & & & & & \\
\hline Nitzschia palea (Kützing) Smith & 2 & & & & & & & & \\
\hline Pinnularia appendiculata (Agardh) Cleve & 1 & & & 2 & 6 & 6 & & & \\
\hline Pinnularia borealis Ehrenberg & 2 & 11 & 140 & 201 & 125 & 57 & 6 & 3 & 2 \\
\hline \multicolumn{10}{|l|}{ Rhopalodia cf. brebissonii Krammer } \\
\hline Rhopalodia gibba (Ehrenberg) Müller & 3 & & & & & & & & \\
\hline \multicolumn{10}{|l|}{ Stauroneis anceps Ehrenberg } \\
\hline \multicolumn{10}{|l|}{ Staurosirella pinnata (Ehrenberg) Williams and Round } \\
\hline Fragments of Stephanodiscus sp. or Cyclostephanos sp. & & & & & & & & 1 & 1 \\
\hline \multicolumn{10}{|c|}{ pH tolerances $1=$ =acidophilous, $2=$ circumneutral, $3=$ =alkaliphilous, $4=$ =indifferent, . =no info } \\
\hline Total & & 82 & 600 & 600 & 600 & 600 & 600 & 88 & 600 \\
\hline Species Count & & 5 & 7 & 4 & 6 & 5 & 5 & 4 & \\
\hline
\end{tabular}




\begin{tabular}{|c|c|c|c|c|c|c|c|c|c|}
\hline Sample \# & & 9 & 10 & 11 & 12 & 13 & 14 & 15 & 17 \\
\hline Sample ID & & TK3_2.212 & TSR2.115 & TSR2.128 & TSR2.144 & YAP2.203 & YAP2.210 & YAP2.231 & WAB2.226 \\
\hline Depth $(\mathrm{cm})$ & $\mathrm{pH}$ & $24-26$ & $28-30$ & 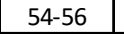 & $86-88$ & $4-6$ & $18-20$ & $60-62$ & $50-52$ \\
\hline \multicolumn{10}{|c|}{ blue =benthic/aquatic species, light blue =cosmopolitan species, yellow=aerial/terrestrial } \\
\hline \multicolumn{10}{|c|}{ 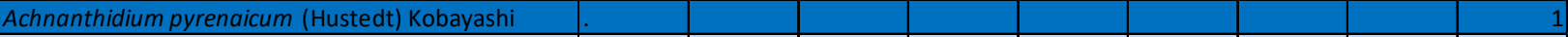 } \\
\hline \multicolumn{10}{|l|}{ Aulacoseira canadensis (Hustedt) Simonsen } \\
\hline Aulacoseira italica (Ehrenberg) Simonsen & 3 & 1 & & & & & & & \\
\hline Aulacoseira sp. & 3 & 2 & & & & & & & \\
\hline Craticula ambigua (Ehrenberg) D.G. Mann & 3 & & & 53 & 12 & & & & \\
\hline \multicolumn{10}{|l|}{ Cymbella excisa Kützing } \\
\hline Denticula cf. kuetzingii Grunow & 3 & 1 & & & & & & & \\
\hline \multicolumn{10}{|l|}{ Denticula sp. } \\
\hline Diadesmis contenta (Grunow ex Van Heurck) D.G. Man & 4 & & & 2 & & & & & \\
\hline Encyonema silesiacum (Bleisch) D.G. Mann & 2 & & & & & 5 & & & \\
\hline Epithemia turgida (Ehrenberg) Kützing & 3 & 1 & & & & & & & \\
\hline Gomphonema parvulum (Kützing) Kützing & 2 & & & & & & & & 25 \\
\hline Hantzschia amphioxys (Ehrenberg) Grunow & 2 & 61 & 378 & 346 & 120 & 290 & 342 & 384 & 2 \\
\hline \multicolumn{10}{|l|}{ Luticola dismutica (Hustedt) D.G.Mann } \\
\hline Luticola mutica (Kützing) D.G. Mann & 2 & 34 & 170 & 73 & 9 & 182 & 198 & 131 & \\
\hline \multicolumn{10}{|l|}{ Luticola muticopsis (Van Heurck) D.G. Mann } \\
\hline \multicolumn{10}{|l|}{ Navicula cryptotenella Lange-Bertalot } \\
\hline Navicula reichardtiana Lange-Bertalot & 3 & & & & & & & & \\
\hline \multicolumn{10}{|l|}{ Navicula tripunctata (Müller) Bory } \\
\hline Nitzschia fonticola (Grunow) Grunow & 2 & & & & & & & & \\
\hline Nitzschia palea (Kützing) Smith & 2 & & & & & & & & 4 \\
\hline Pinnularia appendiculata (Agardh) Cleve & 1 & & & & & 7 & 5 & & \\
\hline Pinnularia borealis Ehrenberg & 2 & 5 & 52 & 55 & 10 & 113 & 55 & 83 & 8 \\
\hline \multicolumn{10}{|l|}{ Rhopalodia cf. brebissonii Krammer } \\
\hline \multicolumn{10}{|l|}{ Rhopalodia gibba (Ehrenberg) Müller } \\
\hline \multicolumn{10}{|l|}{ Stauroneis anceps Ehrenberg } \\
\hline \multicolumn{10}{|l|}{ Staurosirella pinnata (Ehrenberg) Williams and Round| } \\
\hline Fragments of Stephanodiscus sp. or Cyclostephanos sp. & & 9 & & & 33 & 1 & & & \\
\hline \multicolumn{10}{|c|}{ pH tolerances 1=acidophilous, 2=circumneutral, 3=alkaliphilous, 4=indifferent, .=no info } \\
\hline Total & & 115 & 600 & 600 & 184 & 600 & 600 & 600 & 56 \\
\hline Species Count & & 9 & 3 & 6 & 5 & 7 & 4 & 4 & 11 \\
\hline
\end{tabular}

TABLE 2

ECOLOGICAL CHARACTERISTICS OF JEMEZ MOUNTAIN RESERVOIR DIATOMS

\begin{tabular}{|l|l|}
\hline $\begin{array}{l}\text { DIATOM } \\
\text { NAME }\end{array}$ & \multicolumn{1}{|c|}{ DIATOM ECOLOGY } \\
\hline $\begin{array}{l}\text { Achnanthidium } \\
\text { pyrenaicum }\end{array}$ & aquatic, benthic, freshwater, early colonizer in weakly alkaline water \\
\hline $\begin{array}{l}\text { Aulacoseira } \\
\text { canadensis }\end{array}$ & aquatic, planktonic, fossil, extinct Miocene species \\
\hline $\begin{array}{l}\text { Aulacoseira } \\
\text { italica }\end{array}$ & $\begin{array}{l}\text { aquatic, meso- eutrophic, } \beta \text {-mesosaprobous, tolerant to organically } \\
\text { bound nitrogen (OBN), tolerates }>75 \% \text { DO saturation, alkaliphilous, } \\
\text { fresh-brackish water, planktonic, non-motile, dry soil, cosmopolitan }\end{array}$ \\
\hline $\begin{array}{l}\text { Craticula } \\
\text { ambigua }\end{array}$ & $\begin{array}{l}\text { aquatic, benthic, tolerates drying, cosmopolitan, found with Craticula } \\
\text { cuspidata }\end{array}$ \\
\hline Cymbella excisa & aquatic, benthic, attached, sensitive to organic pollution \\
\hline $\begin{array}{l}\text { Denticula } \\
\text { kuetzingii }\end{array}$ & aquatic and aerial, waterfalls, dry moss and cliffs, cosmopolitan \\
\hline Diadesmis & aerial, waterfalls, wet rocks and cliffs, moss, cosmopolitan \\
\hline
\end{tabular}




\begin{tabular}{|c|c|}
\hline contenta & \\
\hline $\begin{array}{l}\text { Encyonema } \\
\text { silesiacum }\end{array}$ & $\begin{array}{l}\text { aquatic, wide range of tolerance to nutrients, indicator of low total } \\
\text { nitrogen, } \alpha \text {-mesosaprobous, tolerant to OBN, tolerates }>50 \% \text { DO } \\
\text { saturation, circumneutral } \mathrm{pH} \text {, fresh-brackish water, conductivity } \\
\text { optimum low }(<200 \mu \mathrm{S} / \mathrm{cm}) \text {, chloride optimum low }(<15 \mathrm{mg} / \mathrm{L}) \text {, } \\
\text { benthic, non-motile, cosmopolitan }\end{array}$ \\
\hline $\begin{array}{l}\text { Epithemia } \\
\text { turgida }\end{array}$ & $\begin{array}{l}\text { aquatic, epiphytic, oligohalobous-indifferent, alkaliphilous, meso- } \\
\text { eutrophic, attached }\end{array}$ \\
\hline $\begin{array}{l}\text { Gomphonema } \\
\text { angustatum }\end{array}$ & $\begin{array}{l}\text { aquatic, benthic, epiphytic, cosmopolitan, fresh-brackish water, } \\
\text { alkaliphilous, pH optimum between } 7.5 \text { and } 7.7 \text {, oligotrophic to } \\
\text { somewhat mesotrophic water, eurysaprobous, oligohalobous- } \\
\text { indifferent }\end{array}$ \\
\hline $\begin{array}{l}\text { Gomphonema } \\
\text { parvulum }\end{array}$ & $\begin{array}{l}\text { aquatic, benthic, epiphytic, prefers nutrient-rich water, eutrophic, } \\
\text { indicator of high total nitrogen and total phosphorous, } \alpha \text { - } \\
\text { meso/polysaprobous, requires periodic elevated concentrations of } \\
\text { OBN, tolerates extremely degraded conditions, tolerates }>30 \% \text { DO } \\
\text { saturation, circumneutral pH, fresh-brackish water, chloride optimum } \\
\text { low }(<15 \mathrm{mg} / \mathrm{L}) \text {, benthic, non-motile, silt and sand attached with stalk, } \\
\text { cosmopolitan, an indicator of polluted water }\end{array}$ \\
\hline $\begin{array}{l}\text { Hantzschia } \\
\text { amphioxys }\end{array}$ & $\begin{array}{l}\text { aerial, wide range of tolerance to nutrients, indicator of high total } \\
\text { phosphorous, } \alpha \text {-mesosaprobous, tolerant to OBN, tolerates }>75 \% \text { DO } \\
\text { saturation, circumneutral } \mathrm{pH} \text {, fresh-brackish water, chloride optimum } \\
\text { low ( }<15 \mathrm{mg} / \mathrm{L}) \text {, benthic, motile, dry soil, survives prolonged dry } \\
\text { periods, cosmopolitan, one of the most common soil diatoms } \\
\text { worldwide }\end{array}$ \\
\hline $\begin{array}{l}\text { Luticola } \\
\text { dismutica }\end{array}$ & aerial, benthic, periphytic \\
\hline Luticola mutica & $\begin{array}{l}\text { aerial, wide range of tolerance to nutrients, indicator of high total } \\
\text { phosphorous, } \alpha \text {-mesosaprobous, tolerant to OBN, tolerates }>75 \% \text { DO } \\
\text { saturation, circumneutral } \mathrm{pH} \text {, fresh-brackish water, chloride optimum } \\
\text { low ( }<15 \mathrm{mg} / \mathrm{L}) \text {, benthic, motile, dry soil, survives prolonged dry } \\
\text { periods, cosmopolitan, one of the most common soil diatoms } \\
\text { worldwide, on mosses, liverworts and lichens }\end{array}$ \\
\hline $\begin{array}{l}\text { Luticola } \\
\text { muticopsis }\end{array}$ & $\begin{array}{l}\text { aerial, benthic, motile, very widespread in the Antarctic and } \\
\text { Subantarctic regions, high nutrient concentrations, chinstrap penguin } \\
\text { rookeries with pH } 8.2\end{array}$ \\
\hline $\begin{array}{l}\text { Navicula } \\
\text { cryptotenella }\end{array}$ & $\begin{array}{l}\text { aquatic, benthic, shallow water, periphytic, oligohalobous-indifferent, } \\
\text { tolerant of a wide range from oligotrophic to eutrophic water without } \\
\text { discernable preference, tolerates brackish water, indifferent to organic } \\
\text { pollution }\end{array}$ \\
\hline $\begin{array}{l}\text { Navicula } \\
\text { reichardtiana }\end{array}$ & $\begin{array}{l}\text { aquatic, cosmopolitan, eutrophic, moderately electrolyte rich water, } \\
\text { particularly those rich in calcium carbonate, rarely in brackish water, } \\
\text { pollution tolerant only to critical levels, good indicator of eutrophy and } \\
\beta \text {-mesosaprobity }\end{array}$ \\
\hline $\begin{array}{l}\text { Navicula } \\
\text { tripunctata }\end{array}$ & $\begin{array}{l}\text { aquatic, a good indicator species for eutrophic waters with average to } \\
\text { high electrolyte content, healthy up to contamination levels of } \beta-\alpha-\end{array}$ \\
\hline
\end{tabular}




\begin{tabular}{|c|c|}
\hline & mesosaprobic \\
\hline $\begin{array}{l}\text { Nitzschia } \\
\text { fonticola }\end{array}$ & $\begin{array}{l}\text { aquatic, cosmopolitan, low to high conductivity, oligotrophic to } \\
\text { mesotrophic, brackish water }\end{array}$ \\
\hline Nitzschia palea & $\begin{array}{l}\text { aquatic, tolerates a wide range of ecological conditions, a good } \\
\text { indicator of organic pollution, cosmopolitan, } \alpha \text {-mesosaprobous to } \\
\text { polysaprobous, indicator of high total nitrogen and total phosphorous, } \\
\text { indicative of elevated concentrations of OBN, tolerates extremely } \\
\text { degraded conditions, tolerates }>30 \% \text { DO saturation, circumneutral pH, } \\
\text { fresh-brackish water, benthic, non-motile, soils, pond margin mud, } \\
\text { survives dry periods, cosmopolitan }\end{array}$ \\
\hline $\begin{array}{l}\text { Pinnularia } \\
\text { appendiculata }\end{array}$ & $\begin{array}{l}\text { aquatic, cosmopolitan, prefers mineralized waters, salt-rich inland } \\
\text { waters, salines, soda lakes, generally in waters with an average to high } \\
\text { electrolyte content (1), oligo-mesotrophic, oligosaprobous, generally } \\
\text { intolerant to OBN, tolerates nearly } 100 \% \text { DO saturation, acidophilous, } \\
\text { freshwater, conductivity optimum low }(<200 \mu \mathrm{S} / \mathrm{cm}) \text {, chloride } \\
\text { optimum low }(<15 \mathrm{mg} / \mathrm{L}) \text {, benthic, motile, soil }\end{array}$ \\
\hline $\begin{array}{l}\text { Pinnularia } \\
\text { borealis }\end{array}$ & $\begin{array}{l}\text { aerial, soils, dry moss, wet and dry walls, and extremely dry habitats, } \\
\text { oligo-mesotrophic, } \beta \text {-mesosaprobous, tolerates OBN, high dissolved } \\
\text { oxygen, circumneutral pH, fresh and brackish water, benthic, motile, } \\
\text { cosmopolitan }\end{array}$ \\
\hline $\begin{array}{l}\text { Rhopalodia } \\
\text { brebissonii }\end{array}$ & aquatic, fresh and brackish water with moderate to high conductivity \\
\hline $\begin{array}{l}\text { Rhopalodia } \\
\text { gibba }\end{array}$ & $\begin{array}{l}\text { aquatic, capable of fixing atmospheric nitrogen, eutrophic, indicator of } \\
\text { low total nitrogen and high total phosphorous, } \beta \text {-mesosaprobous, } \\
\text { generally intolerant to OBN, tolerates }>50 \% \text { DO saturation, } \\
\text { alkalibiontic, fresh-brackish water, chloride optimum low ( }<15 \mathrm{mg} / \mathrm{L}) \text {, } \\
\text { benthic, motile, cosmopolitan }\end{array}$ \\
\hline $\begin{array}{l}\text { Stauroneis } \\
\text { anceps }\end{array}$ & $\begin{array}{l}\text { aquatic and aerial, epipelic, high organic content, } \beta \text {-mesosaprobous, } \\
\text { tolerant to OBN, tolerates }>75 \% \text { DO saturation, circumneutral } \mathrm{pH} \text {, } \\
\text { fresh-brackish water, benthic, motile,abundant in ditches, brooks and } \\
\text { puddles, in sandy soils, on mosses near springs and in prairie swales }\end{array}$ \\
\hline $\begin{array}{l}\text { Staurosirella } \\
\text { pinnata }\end{array}$ & $\begin{array}{l}\text { aquatic fresh-brackish water, tychoplanktonic with benthic origins, in } \\
\text { mud from shallow lakes and rivers, able to survive variations in } \\
\text { osmotic pressure, circumneutral to slightly alkaline } \mathrm{pH} \text {, oligohalobous }\end{array}$ \\
\hline
\end{tabular}




\title{
APPENDIX D: STRATIGRAPHIC DESCRIPTIONS
}

\section{Jemez Plateau Reservoirs}

\section{Site: Amoxiumqua (LA481)}

\author{
Amoxiumqua Locality: Control
}

$1.1,1.2$

\begin{tabular}{|l|l|l|}
\hline $\begin{array}{l}\text { Soil } \\
\text { Horizon }\end{array}$ & Depth & Description \\
\hline A1 & $0-4$ & $\begin{array}{l}\text { Brown (7.5YR4/2)(d), dark brown (3/2)(w), sandy loam, soft, single grained, 5\% partially to } \\
\text { undecayed fine organic fragments, very few fine roots, abrupt lower boundary }\end{array}$ \\
\hline A2 & $4-16$ & $\begin{array}{l}\text { Brown (7.5YR5/2)(d), dark brown (3/2)(w), loamy sand to sandy clay loam with depth, } \\
\text { medium sands and few fine to medium tuff pebbles, soft, weak fine to medium play to weak } \\
\text { fine granular structure, few fine charcoal fragments, common fine roots, clear lower boundary }\end{array}$ \\
\hline BC & $16-24$ & $\begin{array}{l}\text { Strong brown (7.5YR4/6)(d), dark brown (7.5YR3/3)(w), loamy sand, 5-10\% fine to medium } \\
\text { angular tuff pebbles which increase to 15\% medium subangular to subrounded tuff fragments } \\
\text { with depth, slightly hard, very weak medium platy to single grained structure, very few fine } \\
\text { to medium roots, abrupt lower boundary }\end{array}$ \\
\hline C/R & $24-42$ & $\begin{array}{l}\text { Light brown (7.5YR6/4)(d), brown (4/3)(w), extremely gravelly sandy clay, fine to medium } \\
\text { angular tuff fragments in a sandy clay matrix become soft to very weakly cemented white tuff } \\
\text { bedrock by 30 cm depth }\end{array}$ \\
\hline
\end{tabular}

Amoxiumqua Locality: Basin

2.1[Seds], 2.2[Microfossils], 2.3[Char]

\begin{tabular}{|c|c|c|}
\hline $\begin{array}{l}\text { Soil } \\
\text { Horizon }\end{array}$ & Depth & Description \\
\hline $\mathrm{AC}$ & $0-20$ & $\begin{array}{l}\text { Reddish brown }(7.5 \mathrm{YR} 5 / 3)(\mathrm{d}) \text {, dark reddish gray }(4 / 2)(\mathrm{w}) \text { sandy loam, weak medium to fine } \\
\text { play to granular structure, with depth fines to sandy clay loam with very weak fine } \\
7.5 \mathrm{YR} 5 / 4(\mathrm{~d}) \text { redox surface coats on plate faces, slightly firm, few fine open pores, clear lower } \\
\text { boundary }\end{array}$ \\
\hline C1 & $20-45$ & $\begin{array}{l}\text { Dark gray }(7.5 Y R 4 / 1)(d) \text {, very dark gray }(3 / 1)(w) \text { sandy clay to clay loam, firm, weak fine to } \\
\text { medium platy to moderate fine granular structure, poorly sorted coarse sand to very few } \\
\text { pebble sized tuff fragments, very few fine roots, sherd frag } 30-32 \text {, tuff frag } 32-34 \text {, sherd frag } \\
\text { 34-36, large root } 42-44,44-45 \text { sandy clay loam with charcoal and root frags, abrupt lower } \\
\text { boundary }\end{array}$ \\
\hline tuff & $45-47$ & Large white tuff rock fragment \\
\hline $\mathrm{C} 2$ & $47-50$ & $\begin{array}{l}\text { Dark gray }(7.5 Y R 4 / 1)(d) \text {, very dark gray }(3 / 1)(w) \text { sandy clay loam with } 10 \% \text { coarse sand to } \\
\text { medium pebble sized tuff fragments, moderate fine to medium roots, weak fine to medium } \\
\text { platy to moderate fine granular structure, angular medium tuff fragment at base (bedrock) }\end{array}$ \\
\hline $\mathrm{R}$ & 50 & Top of white tuff bedrock \\
\hline
\end{tabular}


Amoxiumqua Locality: Berm

3.1[Microfossils], 3.2[Seds], 3.3[MM], 3.4[Char]

\begin{tabular}{|c|c|c|}
\hline $\begin{array}{l}\text { Soil } \\
\text { Horizon }\end{array}$ & Depth & Description \\
\hline A1 & $0-6$ & $\begin{array}{l}\text { Brown }(7.5 Y R 5 / 2)(d) \text {, dark brown }(3 / 2)(w) \text {, sandy loam, slightly hard, weak fine granular to } \\
\text { single grained structure, common fine roots, clear lower boundary }\end{array}$ \\
\hline$\wedge \mathrm{C} 1$ & $6-30$ & $\begin{array}{l}\text { Brown }(7.5 Y R 4 / 2)(d) \text {, dark brown }(3 / 3)(w) \text {, sandy clay loam to clay loam, common coarse } \\
\text { sand with few very fine gravel sized tuff fragments, slightly hard, massive structure, few fine } \\
\text { roots, few to common fine charcoal fragments, clear lower boundary }\end{array}$ \\
\hline$\wedge \mathrm{C} 2$ & $30-72$ & $\begin{array}{l}\text { Brown }(7.5 Y R 5 / 4)(d) \text {, brown } 4 / 4(w) \text {, sandy loam, very few fine gravel sized tuff, moderately } \\
\text { hard, very few open fine pores, possibly very fine calcium carbonate soft masses on pores and } \\
\text { roots, ( } 44-46 \text { burned sherd, } 46-48 \text { medium tuff gravel, } 64-66 \text { sherd fragment) } 72-74 \text { increase } \\
\text { in charcoal concentrations, clear lower boundary }\end{array}$ \\
\hline$\wedge \mathrm{C} 3$ & $72-126$ & $\begin{array}{l}\text { Light brown }(7.5 Y R 6 / 4)(d),(5 / 4)(w) \text {, sandy loam, few fine tuff fragments, soft to slightly } \\
\text { hard, single grained, few fine charcoal, abrupt lower boundary }\end{array}$ \\
\hline $2 \mathrm{Ab}$ & $126-134$ & $\begin{array}{l}\text { White tuff rock from 126-130, Dark brown }(7.5 \mathrm{YR} 3 / 3)(\mathrm{d}),(\mathrm{w}) \text {, clay loam, common coarse } \\
\text { sands to very fine sized tuff pebbles, weak fine subangular bocky to granular structure, } \\
\text { common fine charcoal, abrupt lower boundary }\end{array}$ \\
\hline $2 \mathrm{Cb}$ & $134-178$ & $\begin{array}{l}\text { Brown }(7.5 Y R 5 / 4)(d) \text {, brown }(4 / 4)(w) \text { loamy sand, common fine gravel tuff fragments, } \\
\text { moderately hard, massive to weak fine platy structure, few to common light brown } \\
(7.5 Y R 6 / 3)(d), 5 / 3(w) \text { redox concentrations (masses) on ped interiors and roots casts, faint to } \\
\text { becoming prominent with depth, few very fine open pores, few fine to medium roots, few fine } \\
\text { charcoal decreasing in concentration with depth, tuff rock 142-144, occasional burned pine } \\
\text { needle 158-160, abrupt lower boundary }\end{array}$ \\
\hline 2BCb & $178-188$ & $\begin{array}{l}\text { Dark reddish brown }(5 \mathrm{YR} 3 / 3)(\mathrm{d}),(3 / 2)(\mathrm{w}) \text { clay loam, weak moderate subangular blocky } \\
\text { structure partly to weak fine platy-single grained, common light reddish brown } \\
(5 \mathrm{YR} 6 / 4)(\mathrm{d} / \mathrm{w}) \text {, fine distinct redox concentrations, few fine roots, abrupt lower boundary }\end{array}$ \\
\hline $\mathrm{R}$ & $188-190$ & White tuff bedrock \\
\hline
\end{tabular}

\section{Site: Boletsakwa (LA136)}

\section{Boletsakwa Locality: Control}

1.1, 1.2

\begin{tabular}{|l|l|l|}
\hline $\begin{array}{l}\text { Soil } \\
\text { Horizon }\end{array}$ & Depth & Description \\
\hline A & $0-38$ & $\begin{array}{l}\text { Brown (7.5YR5/3)(d), very dark gray (3/1)(w) very gravelly loamy sand, 30-35\% very coarse } \\
\text { sand to medium gravels, loose, single grained, common roots and very fine plant tissues, } \\
\text { decreasing in frequency with depth, clear lower boundary }\end{array}$ \\
\hline Bk & $38-53$ & $\begin{array}{l}\text { Strong brown (7.54/6)(d), dark brown (3/3)(w) very gravelly loamy sand, 40\% angular fine to } \\
\text { medium tuff gravels, hard, massive to single grained, common prominent fine carbonate } \\
\text { threads on faces of tuff gravels and adhering matrix, abrupt lower boundary }\end{array}$ \\
\hline 2CR1 & $53-67$ & $\begin{array}{l}\text { Pinkish gray (7.5YR6/2)(d), brown 4/3(w) extremely gravelly loamy sand, 80\% angular fine } \\
\text { to medium white tuff gravels, loose, single grained, abrupt lower boundary }\end{array}$ \\
\hline 2CR2 & $67-105$ & $\begin{array}{l}\text { White (7.5YR8/1)(d), pink (7/3)(w) gravel, very coarse sand to fine angular tuff gravels with } \\
\text { few medium gravels }\end{array}$ \\
\hline
\end{tabular}


Boletsakwa Locality: Basin

$2.1,2.2,2.3,2.4$

\begin{tabular}{|c|c|c|}
\hline $\begin{array}{l}\text { Soil } \\
\text { Horizon }\end{array}$ & Depth & Description \\
\hline $\mathrm{AC}$ & $0-8$ & $\begin{array}{l}\text { Dark brown }(7.5 Y R 3 / 2)(w) \text {, brown }(4 / 2)(d) \text { very gravelly loamy sand, 35\% very fine } \\
\text { subangular to subrounded tuff gravels, loose, single grained, 5-10\% very fine plant tissues, } \\
\text { roots, and grass fragments, abrupt lower boundary }\end{array}$ \\
\hline A & $8-12$ & $\begin{array}{l}\text { Black }(7.5 Y R 2.5 / 1)(w) \text {, dark brown }(3 / 2)(d) \text { loam to sandy loam, } 10 \% \text { very fine angular to } \\
\text { subrounded tuff gravels, soft, single grained, common fine roots, sooty silt fraction, abrupt } \\
\text { lower boundary }\end{array}$ \\
\hline AC1 & $12-40$ & $\begin{array}{l}\text { Brown }(7.5 Y R 5 / 2)(d) \text {, dark brown }(3 / 2)(w) \text { gravelly loamy sand, } 30 \% \text { very coarse sand to } \\
\text { fine subrounded to subangular tuff gravels, loose, single grained, very few fine roots, few } \\
\text { rotting tree roots }(22-24 \mathrm{~cm}) \text {, clear lower boundary }\end{array}$ \\
\hline AC2 & $40-60$ & $\begin{array}{l}\text { Brown }(7.5 Y R 5 / 3)(d) \text {, dark brown }(3 / 3)(w) \text { gravelly sandy loam to gravelly sandy clay loam, } \\
30 \% \text { fine subrounded tuff gravels, soft to slightly firm, weak fine granular to single grained, } \\
\text { very few very fine roots, large rock frag at } 60 \mathrm{~cm} \text { is possibly abrupt lower boundary, however } \\
\text { uncertain boundary because of break between cores }\end{array}$ \\
\hline $2 \mathrm{CA}$ & $60-75$ & $\begin{array}{l}\text { Brown (7.5YR4/3)(d), dark brown (3/2)(w) interbedded sandy clay to clay loam, } 10-15 \% \\
\text { very coarse sand to fine subangular tuff gravels, with a large rock fragment at top, friable } \\
\text { (slightly moist) weak medium platy parting to single grained, few fine to medium roots, } \\
\text { between } 66-76 \mathrm{~cm} \text { increasingly distinct } 0.5-1.0 \mathrm{~cm} \text { thick } 3 / 2(\mathrm{w}) \text { clay loam with a decreasing } \\
\text { gravel content ( } 2 \% \text { fine gravels) interbedded with dark brown }(7.5 \mathrm{YR} / 4)(\mathrm{w}) \text {, strong brown } \\
(4 / 6)(\mathrm{d}) \text { sandy clay loam with } 5-10 \% \text { fine gravels, abrupt lower boundary }\end{array}$ \\
\hline $2 \mathrm{C}$ & $75-87$ & $\begin{array}{l}\text { Dark brown }(7.5 \mathrm{YR} 3 / 4)(\mathrm{w}) \text {, brown }(4 / 4)(\mathrm{d}) \text { gravelly sandy clay loam, } 15-20 \% \text { fine } \\
\text { subrounded tuff gravels, slighty firm (moist), weak medium subangular blocky structure } \\
\text { parting to single grained, no roots, abrupt lower boundary }\end{array}$ \\
\hline 3CR & $87-155$ & $\begin{array}{l}\text { Light brown }(7.5 Y R 6 / 3)(d),(6 / 4)(w) \text { fine to medium subangular to angular white tuff gravels } \\
\text { with minor medium to coarse sand fraction }\end{array}$ \\
\hline
\end{tabular}

\section{Boletsakwa Locality: Berm}

3.1, 3.3

\begin{tabular}{|l|l|l|}
\hline $\begin{array}{l}\text { Soil } \\
\text { Horizon }\end{array}$ & Depth & Description \\
\hline A & $0-16$ & $\begin{array}{l}\text { Brown 7.5YR5/2(d)(3/2)(w) loamy fine sand, 10\% very fine gravel, loose, single grained, } \\
\text { common fine roots, few very large tuff fragments, abrupt lower boundary }\end{array}$ \\
\hline$\wedge$ AC & $16-24$ & $\begin{array}{l}\text { Brown 7.5YR4/3(d)(3/2)(w) very gravelly sandy loam, 20\% very fine to fine gravels, slightly } \\
\text { hard, weak fine granular to single grained, very few fine roots, large rotting tree root fragment } \\
\text { at top of horizon (16-17 cm), abrupt lower boundary }\end{array}$ \\
\hline Ab? & $24-28$ & $\begin{array}{l}\text { Dark brown (7.5YR3/2)(d), very dark gray (3/1)(w) very gravelly sandy loam, 20\% very fine } \\
\text { to fine gravels, soft, weak fine granular to single grained, clear lower boundary }\end{array}$ \\
\hline 2C1(b?) & $28-167$ & $\begin{array}{l}\text { Brown (7.5YR4/3)(d), dark brown (3/2)(w) gravelly fine sandy loam to fine sandy loam, 10- } \\
\text { 15\% very fine subrounded gravels decreasing in \% to 5\% with depth, slightly hard, single } \\
\text { grained, very few fine to no roots with depth, }\end{array}$ \\
\hline 2C2(b?) & $167-177$ & $\begin{array}{l}\text { Brown (7.5YR4/3)(d), dark brown (3/3)(w) gravelly fine sandy loam, 10-15\% very fine to } \\
\text { fine subrounded to subangular tuff gravels, slightly hard, single grained, no roots }\end{array}$ \\
\hline
\end{tabular}




\section{Site: Boletsakwa-2 (LA25092)}

\section{LA25092 Locality: Control}

\section{Core \#1.1}

\begin{tabular}{|l|l|l|}
\hline $\begin{array}{l}\text { Soil } \\
\text { Horizon }\end{array}$ & Depth & Description \\
\hline AC1 & $0-12$ & $\begin{array}{l}\text { Pinkish gray (7.5YR6/2)(d) dark brown (3/3)(w) very fine sandy loam, loose, single grained, } \\
\text { 1-5\% fine subangular to rounded tuff gravels, very few medium and fine roots, abrupt lower } \\
\text { boundary }\end{array}$ \\
\hline Ab2 & $12-24$ & $\begin{array}{l}\text { Light brown (7.5YR6/3)(d) dark brown (3/3)(w) gravelly silt loam, 30\% gravels fine to } \\
\text { medium tuff fragments from 12-16 cm, very firm, moderate medium blocky angular parting } \\
\text { to single grained structure, many medium roots }\end{array}$ \\
\hline BC & $24-64 ?$ & $\begin{array}{l}\text { Light brown 7.5YR6/3(d), brown (4/2)(w) very fine sandy loam, slightly hard, massive to } \\
\text { single grained, undetermined lower boundary, may include slump, sediments missing at lower } \\
\text { boundary }\end{array}$ \\
\hline 2CR1 & $76-130$ & $\begin{array}{l}\text { Brown (7.5YR5/3)(d), dark brown (3/4)(w) very gravelly fine sandy loam, loose, 40\% very } \\
\text { fine to fine angular to subangular tuff gravels, clear lower boundary }\end{array}$ \\
\hline 2CR2 & $130-132$ & $\begin{array}{l}\text { Pinkish white (7.5YR8/2)(d), dark brown (3/4)(w) extremely gravelly fine sandy loam, loose, } \\
\text { 80\% fine with occasional medium angular to subangular white tuff gravels }\end{array}$ \\
\hline
\end{tabular}

\section{LA25092 Locality: Basin}

Core \#2.1, 2.2

\begin{tabular}{|l|l|l|}
\hline $\begin{array}{l}\text { Soil } \\
\text { Horizon }\end{array}$ & Depth & Description \\
\hline AC & $0-14$ & $\begin{array}{l}\text { Light brown (7.5YR6/3)(d) dark brown (3/3)(w) very fine sandy loam, very few fine tuff } \\
\text { gravels, massive to single grained structure, slightly hard, few to common fine roots, abrupt } \\
\text { lower boundary }\end{array}$ \\
\hline C1 & $14-28$ & $\begin{array}{l}\text { Brown (7.5YR4/2)(d) dark brown (3/3)(w) clay loam, slightly hard, moderate fine platy } \\
\text { parting to moderate fine subangular blocky to single grained, occasional fine root on ped face, } \\
\text { occasional fine charcoal fragments, clear lower boundary }\end{array}$ \\
\hline C2 & $28-44$ & $\begin{array}{l}\text { Reddish brown (5YR5/3)(d), reddish brown (4/3)(w) silty clay loam, weak medium platy to } \\
\text { weak fine subangular blocky structure, few to common fine roots, very few fine charcoal } \\
\text { fragments, clear lower boundary }\end{array}$ \\
\hline C3 & $44-56$ & $\begin{array}{l}\text { Reddish brown (5YR4/3)(d), dark reddish gray (4/2)(w) gravelly sandy clay loam, 15\% very } \\
\text { fine to fine tuff gravels decrease to 5\% with depth, weak fine subangular blocky structure, } \\
\text { few fine to medium roots, clear lower boundary }\end{array}$ \\
\hline C4 & $56-108$ & $\begin{array}{l}\text { Brown (7.5YR5/4)(d) (4/3)(w) loam, very few fine gravels, slightly hard, weak medium } \\
\text { subangular blocky to single grained becoming massive with depth, many to few (with depth) } \\
\text { fine roots, occasional charcoal fragment, abrupt lower boundary }\end{array}$ \\
\hline C5 & $108-144$ & $\begin{array}{l}\text { Brown (7.5YR4/4)(d)(4/3)(w) very fine sandy loam, 5-10\% very fine to fine tuff gravels } \\
\text { increasing to 30\% at base (140-144 cm), slightly hard, massive to single grained structure, } \\
\text { few to medium fine roots, occasional fine charcoal fragments, clear lower boundary }\end{array}$ \\
\hline 2CR & $144-205$ & $\begin{array}{l}\text { Pink (7.5YR7/3)(d,w) extremely gravelly fine sandy loam to gravel, 75-90\% fine to medium } \\
\text { angular to subangular tuff gravels }\end{array}$ \\
\hline
\end{tabular}




\section{LA25092 Locality: Berm}

\section{Core \#3.1}

\begin{tabular}{|c|c|c|}
\hline $\begin{array}{l}\text { Soil } \\
\text { Horizon }\end{array}$ & Depth & Description \\
\hline A & $0-12$ & $\begin{array}{l}\text { Brown }(7.5 Y R 5 / 3)(d) \text {, dark brown }(3 / 2)(w) \text { very gravelly loamy sand, } 40 \% \text { very coarse sand } \\
\text { to fine angular to subangular tuff gravels, loose, single grained, } 10 \% \text { very fine roots and } \\
\text { decayed organic tissues, clear lower boundary }\end{array}$ \\
\hline$\wedge \mathrm{CA}$ & $12-30$ & $\begin{array}{l}\text { Brown }(7.5 \mathrm{YR} 5 / 3)(\mathrm{d}) \text {, dark brown }(3 / 3)(\mathrm{w}) \text { extremely gravelly loamy sand, } 70 \% \text { very coarse } \\
\text { sand to fine angular to subangular tuff gravels, loose, single grained, few to common medium } \\
\text { roots, abrupt lower boundary }\end{array}$ \\
\hline$\wedge \mathrm{C}$ & $30-57$ & $\begin{array}{l}\text { Brown }(7.5 Y R 4 / 4)(d) \text {, dark brown }(3 / 3)(w) \text { very gravelly sandy loam, } 30 \% \text { very fine angular } \\
\text { to subangular tuff gravels, loose, single grained, very occasional medium tree roots, abrupt } \\
\text { lower boundary }\end{array}$ \\
\hline $2 \mathrm{Ab}$ & $57-73$ & $\begin{array}{l}\text { Brown }(7.5 Y R 4 / 3)(d) \text {, dark brown }(3 / 3)(w) \text { very fine sandy clay loam, slightly hard to soft, } \\
\text { massive to single grained, very few fine open pores, very few fine roots, uncertain lower } \\
\text { boundary/thickness because of loss at core contact, }\end{array}$ \\
\hline $2 \mathrm{Bwb}$ & $73-87$ & $\begin{array}{l}\text { Brown }(7.5 Y R 5 / 4)(d) \text {, dark brown (3/4)(w) clay loam, moderately hard, moderate medium } \\
\text { subangular blocky structure, few faint fine carbonate threads, filaments, and soft masses on } \\
\text { ped faces, increasing with depth to common medium soft masses, abrupt lower boundary }\end{array}$ \\
\hline $2 \mathrm{CBb}$ & $87-93$ & $\begin{array}{l}\text { Brown (7.5YR5/4(d), brown (4/3)(w) loam, moderately hard, massive to single grained, } \\
\text { abrupt lower boundary }\end{array}$ \\
\hline $2 \mathrm{CBkb}$ & $93-111$ & $\begin{array}{l}\text { Dark brown }(7.5 Y R 3 / 4)(d)(w) \text { clay loam, moderately hard, moderate medium subangular } \\
\text { blocky structure, common prominent fine carbonate soft masses on ped faces and few } \\
\text { prominent carbonate filaments(threads) both on and within peds, clear lower boundary }\end{array}$ \\
\hline $2 \mathrm{Cb}$ & 111-135 & $\begin{array}{l}\text { Light brown }(7.5 Y R 6 / 4(d), \text { brown }(4 / 4)(w) \text { gravelly sandy loam, } 5-10 \% \text { fine rounded to } \\
\text { subangular tuff gravels, loose, single grained, undetermined lower boundary because of poor } \\
\text { recovery in cores }\end{array}$ \\
\hline $2 \mathrm{CR}$ & $135-155$ & Light brown (7.5YR6/3)(d), brown (5/4)(w) fine angular to subangular white tuff gravels \\
\hline
\end{tabular}

\section{Site: Kwastiyukwa (LA482)}

\section{Kwastiyukwa Locality: Control}

Core \#1.1

\begin{tabular}{|l|l|l|}
\hline $\begin{array}{l}\text { Soil } \\
\text { Horizon }\end{array}$ & Depth & Description \\
\hline A & $0-6$ & $\begin{array}{l}\text { Brown (10YR4/3)(w) fine sandy loam, weak fine platy to massive, loose, common fine roots, } \\
\text { clear lower boundary }\end{array}$ \\
\hline BC1 & $6-42$ & $\begin{array}{l}\text { Brown (7.5YR4/3)(w) clay loam, moderate medium platy parting to moderate fine blocky } \\
\text { subangular structure, weak clay films on ped faces, slightly hard, few medium roots, few fine } \\
\text { charcoal and fine partially decayed organics, clear lower boundary }\end{array}$ \\
\hline BC2 & $42-59$ & $\begin{array}{l}\text { Brown (7.5YR4/4)(w) poorly sorted (fine to coarse) sandy clay loam, moderate medium platy } \\
\text { structure, slightly hard, open and filled fine pores, abrupt lower boundary }\end{array}$ \\
\hline R & $59-60$ & White tuff bedrock \\
\hline
\end{tabular}


Kwastiyukwa Locality: Basin

Core \#2.1[seds], 2.2[char], 2.3[microfossils]

\begin{tabular}{|l|l|l|}
\hline $\begin{array}{l}\text { Soil } \\
\text { Horizon }\end{array}$ & Depth & Description \\
\hline A & $0-6$ & $\begin{array}{l}\text { Dark grayish brown (10YR4/2) (d), very dark grayish brown (3/2)(w), sandy loam, weak very } \\
\text { fine single grained to loose, 5\% undecayed to partially decayed plant tissues, roots, pine } \\
\text { needles, clear abrupt lower boundary }\end{array}$ \\
\hline BC & $6-42$ & $\begin{array}{l}\text { Brown (7.5YR4/2)(d), dark brown (3/3)(w) silty clay loam to silty clay, moderate fine } \\
\text { subangular blocky structure with weak slickensides on ped faces, hard, few fine roots on ped } \\
\text { faces and within peds, few very fine open pores in ped interiors, few fine charcoal, 36-38 cm } \\
\text { silty clay with common 10\% fine angular tuff pebbles, 38-40 cm silty clay with common } \\
\text { (20\%) fine to medium angular tuff pebbles and small sherd fragment, 40-42 cm silty clay } \\
\text { with common medium decaying roots, smooth to clear lower boundary }\end{array}$ \\
\hline CB & $42-59$ & $\begin{array}{l}\text { Bedded brown (7.5YR4/3)(d), dark brown (3/3)(w) silty clay and light brown (7.5YR6/4)(d), } \\
\text { brown (5/4)(w) very fine sand, moderately hard, weak to moderate thin to medium platy } \\
\text { structure, with less pronounced fine to medium subangular blocky at top, common small to } \\
\text { medium tree roots along platy horizontal beds, 2-5\% very fine subangular tuff pebbles, few to } \\
\text { common charcoal, fines upward from thin to medium sand beds at base with bioturbation } \\
\text { (roots) to medium to continuous clay beds, abrupt lower boundary }\end{array}$ \\
\hline R & $59-60$ & \begin{tabular}{l} 
White tuff bedrock with thin mantling root mat \\
\hline
\end{tabular}
\end{tabular}

Kwastiyukwa Locality: Berm

Core \#3.1[microfossils], 3.2[seds], 3.3[MM], 3.4[char]

\begin{tabular}{|l|l|l|}
\hline $\begin{array}{l}\text { Soil } \\
\text { Horizon }\end{array}$ & Depth & Description \\
\hline Oe/A & $0-8$ & $\begin{array}{l}\text { Brown (7.5YR4/3)(d), dark brown (3/4)(w), 30\% partially to undecayed very fine roots and } \\
\text { pine needles in sandy loam, loose, friable, dry, abrupt lower boundary }\end{array}$ \\
\hline$\wedge$ CA1 & $8-22$ & $\begin{array}{l}\text { Light brown (7.5YR6/4)(d), brown (5/4)(w), sandy loam, slightly firm, structureless, 2\% fine } \\
\text { to partially decayed organics decreasing with depth, very few fine charcoal, few very fine } \\
\text { roots with depth, very occasional small tuff pebble, clear lower boundary }\end{array}$ \\
\hline$\wedge$ CA2 & $22-32$ & $\begin{array}{l}\text { Brown (7.5YR4/4)(d), dark brown (3/4)(w), sandy clay loam, firm, slight increase in clay, } \\
\text { weak fine blocky subangular to massive structure, very fine open pores, very occasional very } \\
\text { coarse sand to very small pebbles, very few fine roots, abrupt lower boundary }\end{array}$ \\
\hline$\wedge \mathrm{C}$ & $32-60$ & $\begin{array}{l}\text { Pinkish gray (7.5YR6/2)(d), brown (4/2)(w) loamy sand, between 32-38 cm rotten tuff, 15\% } \\
\text { broken tuff gravels, abrupt contact with 38-44 cm tuff fragment, 44-46 cm 7.5YR6/4(d), } \\
\text { 5/4(w) silty loam with medium partially decayed root (poss. mud between rocks?), 46-52 tuff } \\
\text { fragment in mud, 52-54 cm 7.5YR4/4(d), 5/4(w) loam, 54-60 cm tuff fragment, abrupt lower } \\
\text { boundary }\end{array}$ \\
\hline $2 \mathrm{Ab}$ & $60-70$ & $\begin{array}{l}\text { Brown (7.5YR5/4)(d), brown (4/3)(w) clay loam, weak fine blocky angular parting to } \\
\text { granular/single grained, slightly firm to firm, few fine open pores, very few fine charcoal, } \\
\text { abrupt lower boundary }\end{array}$ \\
\hline R & $74-85$ & $\begin{array}{l}\text { Brown (7.5YR5/4)(d), brown (4/3)(w) fine sandy loam, weak to moderate fine platy structure, } \\
\text { slightly firm to loose, few fine root casts, organic stains, large charcoal fragment 72-72 cm, } \\
\text { abrupt lower boundary }\end{array}$ \\
White-gray tuff bedrock
\end{tabular}




\section{Site: Reservoir near Tovakwa (LA61641)}

\section{LA61641 Locality: Control}

1.1, 1.2

\begin{tabular}{|l|l|l|}
\hline $\begin{array}{l}\text { Soil } \\
\text { Horizon }\end{array}$ & Depth & Description \\
\hline A1 & $0-8$ & $\begin{array}{l}\text { Brown (7.5YR5/2)(d), dark brown (3/2)(w) silt loam, loose, single grained, 5\% very fine } \\
\text { organic tissues (duff and pine needle fragments), abrupt lower boundary }\end{array}$ \\
\hline A2 & $8-14$ & $\begin{array}{l}\text { Pinkish gray (7.5YR7/2)(d), brown (4/2)(w) coarse sandy loam, loose, single grained, few } \\
\text { very fine roots and pine needle fragments, abrupt lower boundary }\end{array}$ \\
\hline C1 & $14-42$ & $\begin{array}{l}\text { Pinkish gray (7.5YR7/2)(d), brown (5/3)(w), loamy coarse sand, fragmented white tuff } \\
\text { boulder from 14-30 cm, loose, single grained, occasional medium roots on faces of rock } \\
\text { fragments, abrupt lower boundary }\end{array}$ \\
\hline C2 & $42-52$ & $\begin{array}{l}\text { Brown (7.5YR4/3)(w/d) gravelly sandy clay, moderately hard, 30\% very fine to medium tuff } \\
\text { pebbles, including medium tuff gravel from 42-46 cm, moderate fine granular structure, 2 cm } \\
\text { thick root mat at base, abrupt lower boundary }\end{array}$ \\
\hline R & $52-57$ & Fragmented white tuff bedrock \\
\hline
\end{tabular}

\section{LA61641 Locality: Basin}

2.1, 2.2, 2.3, 2.4

\begin{tabular}{|c|c|c|}
\hline $\begin{array}{l}\text { Soil } \\
\text { Horizon }\end{array}$ & Depth & Description \\
\hline A & $0-8$ & $\begin{array}{l}\text { Brown }(7.5 Y R 5 / 2)(d) \text {, dark brown }(3 / 2)(w) \text { silt loam, loose, single grained, few to many very } \\
\text { fine roots, increasing with depth, few fine charcoal decreasing with depth, abrupt lower } \\
\text { boundary }\end{array}$ \\
\hline $\mathrm{Bw} / \mathrm{Bg}$ & $8-32$ & $\begin{array}{l}\text { Light gray }(7.5 Y R 7 / 1)(d) \text {, pinkish gray }(6 / 2)(w) \text { silt loam, loose, very weak fine to medium } \\
\text { platy parting to single grained, few to common brown }(7.5 Y R 4 / 2)(d) \text {, dark brown }(3 / 2)(w) \\
\text { sharp faint to distinct medium iron-manganese concentrations infused on ped faces becoming } \\
\text { distinct with depth, common fine open pores, few fine roots and root casts, clear lower } \\
\text { boundary }\end{array}$ \\
\hline $\mathrm{C}$ & $32-40$ & $\begin{array}{l}\text { Light gray (7.5YR7/1)(d), dark gray (4/1)(w) silt loam, loose, single grained, very occasional } \\
\text { fine to medium tuff pebble, abrupt lower boundary }\end{array}$ \\
\hline Bg' & $40-52$ & $\begin{array}{l}\text { Brown }(7.5 Y R 5 / 2)(d),(4 / 2)(w) \text { silty clay loam, loose, weak fine to medium platy parting to } \\
\text { single grained, common fine brown }(7.5 Y R 4 / 2)(d) \text {, dark brown }(3 / 2)(w) \text { sharp faint to distinct } \\
\text { medium iron-manganese concentrations, soft masses, and hypocoats infused on platy ped } \\
\text { faces and around closed and open pores, possible fine manganese nodules few fine open } \\
\text { pores, few fine roots, abrupt lower boundary }\end{array}$ \\
\hline $\mathrm{BC}$ & $52-60$ & $\begin{array}{l}\text { Brown }(7.5 Y R 4 / 2)(d)(3 / 2)(w) \text { silty clay loam to loam with increase in medium to coarse sand } \\
\text { with depth, loose, weak fine subangular blocky parting to single grained, few brown } \\
(7.5 Y R 4 / 2)(d)(3 / 2)(w) \text { faint to distinct medium iron-manganese concentrations decreasing in } \\
\text { frequency and prominence with depth, very occasional fine charcoal and fine roots with } \\
\text { depth, abrupt lower boundary }\end{array}$ \\
\hline $\mathrm{B} / \mathrm{R}$ & $60-70$ & $\begin{array}{l}\text { Brown (7.5YR5/2)(d), dark brown (3/2)(w) silty clay loam, firm, moderate medium } \\
\text { subangular blocky structure, few to common medium tree roots increasing in size and } \\
\text { frequency along ped faces with depth, fine gravel tuff fragments become increasingly larger } \\
\text { white tuff gravels with consolidated white tuff bedrock at base }\end{array}$ \\
\hline
\end{tabular}




\section{LA61641 Locality: Berm}

3.1, 3.2, 3.3

\begin{tabular}{|c|c|c|}
\hline $\begin{array}{l}\text { Soil } \\
\text { Horizon }\end{array}$ & Depth & Description \\
\hline A & $0-12$ & $\begin{array}{l}\text { Brown }(7.5 Y R 4 / 2)(d) \text {, very dark gray }(3 / 1)(w) \text { very fine sandy loam, loose, weak fine to } \\
\text { medium granular parting to single grained, occasional fine to medium tuff fragment, } \\
\text { occasional fine to medium root, clear lower boundary }\end{array}$ \\
\hline$\wedge \mathrm{B} / \mathrm{C}$ & $12-20$ & $\begin{array}{l}\text { Dark brown }(7.5 Y R 3 / 2)(d) \text {, very dark brown }(2.5 / 2)(w) \text { sandy clay, slightly hard, moderate } \\
\text { fine to medium granular structure, poorly sorted with occasional (5-10\%) tuff gravels and } \\
\text { occasional angular blocky fine gravel sized clay masses, few to many fine to medium roots, } \\
\text { clear lower boundary }\end{array}$ \\
\hline$\wedge^{\wedge} \mathrm{C} 1$ & $20-28$ & $\begin{array}{l}\text { Brown }(7.5 Y R 5 / 2)(d) \text {, dark brown }(3 / 3)(w) \text { sandy clay loam, loose, } 10 \% \text { fine to medium tuff } \\
\text { rock fragments, occasional fine to medium roots }\end{array}$ \\
\hline$\wedge \mathrm{C} 2$ & $28-54$ & $\begin{array}{l}\text { Pinkish gray }(7.5 Y R 6 / 2)(d) \text {, brown }(4 / 2)(w) \text { sandy loam to gravelly sandy loam, loose, } 10- \\
20 \% \text { fine to medium tuff gravels with occasional large tuff rock fragments, occasional } \\
\text { angular blocky fine gravel sized dark brown }(7.5 \mathrm{YR} 3 / 3)(\mathrm{d}) \text {, very dark brown }(2.5 / 3)(\mathrm{w}) \\
\text { sandy clay loam masses, large tuff rock fragment at base, abrupt lower boundary }\end{array}$ \\
\hline$\wedge \mathrm{C} 3$ & $54-108$ & $\begin{array}{l}\text { Pinkish gray }(7.5 Y R 6 / 2)(d) \text {, brown }(7.5 Y R 4 / 2)(w) \text { sandy loam to sandy clay loam, soft, } \\
\text { massive to single grained, very few fine to medium tuff gravels, possible charcoal observed } \\
98-100 \mathrm{~cm} \text {, abrupt lower boundary }\end{array}$ \\
\hline Bss(b?) & $108-114$ & $\begin{array}{l}\text { Reddish brown } 5 \text { YR4/3(d), dark reddish brown }(3 / 4)(\text { w) clay, extremely hard, } 5 \% \text { coarse } \\
\text { sand, fine angular blocky structure with slickensides on ped faces, very few fine roots, } \\
\text { abrupt lower boundary }\end{array}$ \\
\hline C(b) & $114-122$ & $\begin{array}{l}\text { Gray }(7.5 Y R 6 / 1)(d)(3 / 2)(w) \text { very fine sandy loam, loose, single grained, very few fine tuff } \\
\text { gravels, abrupt lower boundary }\end{array}$ \\
\hline R1 & $122-138$ & Consolidated white tuff rock \\
\hline R2 & $138-148$ & $\begin{array}{l}\text { Pinkish gray }(7.5 Y R 6 / 2)(d) \text { brown }(4 / 3)(w) \text { gravelly silt loam, loose, } 60 \% \text { white tuff angular } \\
\text { rock fragments }\end{array}$ \\
\hline
\end{tabular}

\section{Site: Wabakwa (LA478)}

\section{Wabakwa Locality: Control}

1.1, 1.2

\begin{tabular}{|l|l|l|}
\hline $\begin{array}{l}\text { Soil } \\
\text { Horizon }\end{array}$ & Depth & Description \\
\hline A & $0-14$ & $\begin{array}{l}\text { Brown (7.5YR5/3)(d), dark brown (3/2)(w) very gravelly loamy sand to sandy loam, soft to } \\
\text { loose, 20-40\% fine to medium angular to subangular tuff fragments, few to many fine organic } \\
\text { roots and plant tissues, abrupt lower boundary }\end{array}$ \\
\hline C1 & $14-24$ & $\begin{array}{l}\text { Brown (7.5YR4/3)(d),(4/4)(w) extremely gravelly coarse sandy loam, loose, single grained, } \\
\text { very fine to medium subangular to angular tuff gravels few fine roots, clear lower boundary }\end{array}$ \\
\hline C2 & $24-92$ & $\begin{array}{l}\text { Pinkish gray (7.5YR7/2)(d), light brown (6/3)(w), very fine to medium subangular to angular } \\
\text { tuff gravel, occasional 2 cm thick bedding of coarser and finer gravel lenses throughout, } \\
\text { occasional very fine roots decrease to no roots by 40 cm, abrupt lower boundary }\end{array}$ \\
\hline C3 & $92-94$ & $\begin{array}{l}\text { Light brown (7.5YR6/3)(d), brown (4/3)(w) silt loam, loose to single grained, few coarse } \\
\text { sand sized tuff fragments, common very fine roots forming a 0.5 cm thick root mat, possibly } \\
\text { above bedrock? }\end{array}$ \\
\hline
\end{tabular}


Wabakwa Locality: Basin

2.1, 2.2, 2.3, 2.4

\begin{tabular}{|c|c|c|}
\hline $\begin{array}{l}\text { Soil } \\
\text { Horizon }\end{array}$ & Depth & Description \\
\hline A & $0-8$ & $\begin{array}{l}\text { Brown }(7.5 Y R 4 / 2)(d) \text {, dark brown }(3 / 2)(w) \text { sandy loam, mantled by angular to subrounded } \\
\text { medium tuff gravels at surface, loose, single grained, few fine organic fragments and few fine } \\
\text { roots, clear lower boundary }\end{array}$ \\
\hline $\mathrm{AC}$ & $8-22$ & $\begin{array}{l}\text { Pinkish gray }(7.5 Y R 6 / 2)(d) \text {, brown }(5 / 2)(w) \text { sandy loam, } 5-20 \% \text { fine to medium tuff gravels, } \\
\text { soft to slightly hard, very weak fine granular structure, few very fine roots few to many fine } \\
\text { charcoal fragments, clear lower boundary }\end{array}$ \\
\hline $\mathrm{BC}$ & $22-34$ & $\begin{array}{l}\text { Pinkish gray }(7.5 Y R 7 / 2)(d) \text {, brown }(4 / 3)(w) \text { gravelly sandy clay loam, moderately hard, } 15 \% \\
\text { very coarse sand to very fine tuff gravels, faint diffuse brown }(7.5 \mathrm{YR} / 4)(\mathrm{d}),(4 / 4)(\mathrm{w}) \text { soft } \\
\text { masses throughout, moderate fine subangular blocky structure, few fine open pores, common } \\
\text { fine to medium roots and root casts on ped faces, clear lower boundary }\end{array}$ \\
\hline C1 & $34-52$ & $\begin{array}{l}\text { Light brown }(7.5 Y R 6 / 4)(w) \text {, brown }(4 / 4)(d) \text { very gravelly sandy loam to sandy clay loam at } \\
\text { base, } 40 \% \text { fine tuff gravels, loose, weak medium platy parting to single grained structure, } \\
\text { very few open fine pores, common medium roots, abrupt lower boundary }\end{array}$ \\
\hline $\mathrm{C} 2$ & $52-62$ & Gray (burned?) tuff fragment from 52-56 cm, white tuff fragment 56-62 cm \\
\hline $2 \mathrm{C} 1$ & $62-86$ & $\begin{array}{l}\text { Light brown }(7.5 Y R 6 / 3)(d) \text {, brown }(4 / 3)(w) \text { very gravelly loam to extremely gravelly loam, } \\
\text { common medium to fine gravel tuff, loose, few fine to medium roots and few fine plant } \\
\text { fragments, abrupt lower boundary }\end{array}$ \\
\hline $2 \mathrm{C} 2$ & 86-106 & $\begin{array}{l}\text { Light brown }(7.5 Y R 6 / 3)(d) \text {, brown }(4 / 4)(w) \text { very gravelly sandy loam, 30\% fine to very fine } \\
\text { angular tuff fragments, loose, single grained, very occasional medium to fine roots }\end{array}$ \\
\hline
\end{tabular}

Wabakwa Locality: Berm

3.1, 3.2, 3.3

\begin{tabular}{|l|l|l|}
\hline $\begin{array}{l}\text { Soil } \\
\text { Horizon }\end{array}$ & Depth & Description \\
\hline A1 & $0-10$ & $\begin{array}{l}\text { Brown (7.5YR5/2)(d), dark brown (3/2)(w) gravelly loamy sand, 20\% fine rounded to } \\
\text { subrounded tuff gravels, loose, single grained, common fine roots, abrupt lower boundary }\end{array}$ \\
\hline A2 & $10-16$ & $\begin{array}{l}\text { Light brown (7.5YR6/3)(d), brown (4/3)(w) fine sandy loam to loam, 5\% fine rounded to } \\
\text { subangular tuff gravels, loose, single grained, few fine roots and plant tissues, abrupt lower } \\
\text { boundary }\end{array}$ \\
\hline BC1 & $16-22$ & $\begin{array}{l}\text { Reddish brown (5YR4/3)(d)(w) clay loam, moderately hard, moderate medium platy parting } \\
\text { to moderate fine blocky angular structure, common partially decayed roots and plant tissues } \\
\text { at top (16-20cm), few fine open pores, few fine roots on ped faces, abrupt lower boundary }\end{array}$ \\
\hline BC2 & $22-34$ & $\begin{array}{l}\text { Brown (7.5YR4/3)(d), dark brown (3/3)(w) loam to clay loam, moderately hard, increase (to } \\
5 \%) \text { in coarse sand to fine pebble sizes angular to subangular gravels with depth, moderate } \\
\text { medium platy parting to weak fine single grained structure, very few fine open pores, } \\
\text { common fine to medium roots on platy ped faces, clear lower boundary }\end{array}$ \\
\hline 2C1 & $34-80$ & $\begin{array}{l}\text { Light brown (7.5YR6/3)(d), brown (4/4)(w) gravelly loamy sand, 20-30\% coarse sand to fine } \\
\text { to medium subangular tuff pebbles, loose, single grained, few fine roots, occasional medium } \\
\text { roots, uncertain lower boundary }\end{array}$ \\
\hline 2C2 & $80-170$ & $\begin{array}{l}\text { Light brown (7.5YR6/3)(d), (5/3)(w) extremely gravelly loamy coarse sand to fine gravel, } \\
\text { fine to medium angular to subangular tuff pebbles, loose, some bedding, very occasional root } \\
\text { between 80-110 cm, no roots below, abrupt lower boundary }\end{array}$ \\
\hline 3C & $170-173$ & $\begin{array}{l}\text { Light brown (7.5YR6/4)(d), (4/4)(w) silt loam, loose, single grained structure 5\% fine angular } \\
\text { tuff gravels }\end{array}$ \\
\hline
\end{tabular}




\title{
Pajarito Plateau Reservoirs
}

\section{Site: Haatse/San Miguel (LA370)}

\author{
Haatse/San Miguel Locality: Basin
}

Core \#2.1 (Samples 2.101-2.125)

\begin{tabular}{|l|l|l|}
\hline $\begin{array}{l}\text { Soil } \\
\text { Horizon }\end{array}$ & Depth & Description \\
\hline AC & $0-10$ & $\begin{array}{l}\text { Dark brown [7.5YR3/4(d), 3/2(w)] poorly sorted gravelly sandy loam to gravelly sandy clay } \\
\text { loam, 15\% fine gravels, very slightly firm, very weak medium platy to weak fine granular } \\
\text { structure, few very fine roots, with increase in frequency with depth, abrupt lower boundary }\end{array}$ \\
\hline Ab & $10-16$ & $\begin{array}{l}\text { Dark brown [7.5YR3/3(d)],black 2.5/2(w) gravelly sandy clay loam, 15-20\% very fine to fine } \\
\text { gravels, massive to weak fine granular structure, few very fine roots, abrupt lower boundary }\end{array}$ \\
\hline Cb1 & $16-36$ & $\begin{array}{l}\text { Brown [7.5YR4/3(d)], dark brown [3/2(w)] extremely gravelly sandy clay loam, loose, 20- } \\
\text { 40\% poorly sorted very fine to medium tuff gravels, very few fine roots, abrupt lower } \\
\text { boundary }\end{array}$ \\
\hline Cb2 & $36-50$ & $\begin{array}{l}\text { Brown [7.5YR4/4(d)], dark brown [3/3(w)] extremely gravelly sandy loam, loose, poorly } \\
\text { sorted fine to coarse sand fraction, 10-20\% very fine to fine tuff gravel, single grained, few } \\
\text { fine roots, 40-44 cm sandy clay loam }\end{array}$ \\
\hline
\end{tabular}

Haatse/San Miguel Locality: Basin

Core \#2.2 (Samples 2.201-2.231)

\begin{tabular}{|l|l|l|}
\hline $\begin{array}{l}\text { Soil } \\
\text { Horizon }\end{array}$ & Depth & Description \\
\hline AC1 & $0-8$ & $\begin{array}{l}\text { Dark brown [7.5YR3/4(d), 3/2(w)] poorly sorted gravelly sandy loam to gravelly sandy loam, } \\
\text { 15\% fine gravels, very slightly firm, very weak medium platy to weak fine granular structure, } \\
\text { few very fine roots, with increase in frequency with depth, clear lower boundary }\end{array}$ \\
\hline AC2(b) & $8-16$ & $\begin{array}{l}\text { Brown [7.5YR4/3(d)], dark brown [3/2(w)] gravelly sandy clay loam, 10-15\% very fine to } \\
\text { fine gravel, very few fine roots, abrupt lower boundary }\end{array}$ \\
\hline Cb1 & $16-36$ & $\begin{array}{l}\text { Brown [7.5YR4/3(d)], dark brown [3/2(w)] extremely gravelly sandy clay loam, loose, 20- } \\
\text { 40\% poorly sorted very fine to medium tuff gravels, very few fine roots with large root 30-32 } \\
\text { cm, abrupt lower boundary }\end{array}$ \\
\hline Cb2 & $36-64$ & $\begin{array}{l}\text { Brown [7.5YR4/4(d)], dark brown [3/3(w)] extremely gravelly sandy loam, loose, poorly } \\
\text { sorted fine to coarse sand fraction, 10-20\% very fine to fine tuff gravel, single grained, few } \\
\text { fine roots, 40-44 cm sandy clay loam }\end{array}$ \\
\hline
\end{tabular}

Haatse/San Miguel Locality: Berm

Core \#3.1 (Sample Numbers 3.101-3.131)

\begin{tabular}{|l|l|l|}
\hline $\begin{array}{l}\text { Soil } \\
\text { Horizon }\end{array}$ & Depth & Description \\
\hline AC & $0-14$ & $\begin{array}{l}\text { Brown [7.5YR4/3(d)], dark brown [3/2(w)] gravelly fine sandy loam, loose, 20-40\% fine to } \\
\text { medium rounded tuff gravels, single grained, few to common fine roots, gradual lower } \\
\text { boundary }\end{array}$ \\
\hline C1 & $14-38$ & $\begin{array}{l}\text { Brown [7.5YR4/2(d)], dark brown [3/2(w)] extremely gravelly loamy sand, loose, 20-40\% } \\
\text { fine to medium rounded tuff gravels, single grained, few to common fine roots, gradual lower } \\
\text { boundary }\end{array}$ \\
\hline C2 & $38-62$ & $\begin{array}{l}\text { Brown [7.5YR5/3(d)], dark brown [3/3(w)] extremely gravelly loamy sand, loose, 40-60\% } \\
\text { fine to medium with few coarse angular and rounded tuff gravels, single grained }\end{array}$ \\
\hline
\end{tabular}




\section{Site: LA3834}

LA3834 Locality: basin

Core \#2.1 (Samples 2.101-2.112)

\begin{tabular}{|l|l|l|}
\hline $\begin{array}{l}\text { Soil } \\
\text { Horizon }\end{array}$ & Depth & Description \\
\hline AC & $0-6$ & $\begin{array}{l}\text { Brown [7.5YR4/3(d)], dark brown [3/2(w)] loamy fine sand, few medium to coarse sands, } \\
\text { loose, single grained, few fine roots, abrupt lower boundary }\end{array}$ \\
\hline C1 & $6-16$ & $\begin{array}{l}\text { Brown [7.5YR4/3(d)], dark brown [3/3(w)] clay loam, slightly firm, weak medium platy } \\
\text { parting to weak fine subangular blocky/single grained, few fine roots, some possible fine } \\
\text { charcoal }\end{array}$ \\
\hline C2 & $16-24$ & $\begin{array}{l}\text { Brown [7.5YR4/3(d)], dark brown [3/3(w)] clay loam, loose, moderate medium granular } \\
\text { structure, occasional fine gravels, common medium roots, abrupt lower boundary }\end{array}$ \\
\hline
\end{tabular}

\section{LA3834 Locality: basin}

Core \#2.2 (Samples 2.201-2.218)

\begin{tabular}{|l|l|l|}
\hline $\begin{array}{l}\text { Soil } \\
\text { Horizon }\end{array}$ & Depth & Description \\
\hline AC & $0-6$ & $\begin{array}{l}\text { Brown [7.5YR4/3(d), dark brown [3/2(w)] loamy fine sand, few medium to coarse sands, } \\
\text { loose, single grained, few fine roots, abrupt lower boundary }\end{array}$ \\
\hline C1 & $6-16$ & $\begin{array}{l}\text { Brown [7.5YR4/3(d)], dark brown [3/3(w)] clay loam, slightly firm, weak medium platy } \\
\text { parting to weak fine subangular blocky/single grained, few fine roots, some possible fine } \\
\text { charcoal }\end{array}$ \\
\hline C2 & $16-26$ & $\begin{array}{l}\text { Brown [7.5YR4/3(d)], dark brown [3/3(w)] clay loam, loose, moderate medium granular } \\
\text { structure, occasional fine gravels, common medium roots, abrupt lower boundary }\end{array}$ \\
\hline C3 & $26-36$ & $\begin{array}{l}\text { Brown [7.5YR4/2(d), dark brown [3.5/3(w)] gravelly clay loam, 5-10\% fine to medium } \\
\text { gravel, weak medium platy parting to weak fine subangular blocky structure, few fine roots, } \\
\text { 30-32 may be slump }\end{array}$ \\
\hline
\end{tabular}

\section{LA3834 Locality: berm}

Core \#3.1 (Samples 3.101-3.110)

\begin{tabular}{|l|l|l|}
\hline $\begin{array}{l}\text { Soil } \\
\text { Horizon }\end{array}$ & Depth & Description \\
\hline$\wedge \mathrm{AC}$ & $0-6$ & $\begin{array}{l}\text { Brown [7.5YR4/3(d)], dark brown [3/2(w)] loam to fine sandy loam, massive to single } \\
\text { grained structure, few fine roots, clear lower boundary }\end{array}$ \\
\hline 2Bw & $6-20$ & $\begin{array}{l}\text { Brown [7.5YR5/4(d)], 4/3(w)] loam to clay loam, firm to slightly firm, weak fine subangular } \\
\text { blocky parting to weak fine granular and single grained structure, few fine roots, charcoal } \\
\text { observed 8-10 cm (3.105) }\end{array}$ \\
\hline
\end{tabular}




\section{Site: Tsankawi (LA211) TK1}

Tsankawi (LA211) TK1 Locality: Basin

Core \#2.1 (Samples 2.101-2.118)

\begin{tabular}{|l|l|l|}
\hline $\begin{array}{l}\text { Soil } \\
\text { Horizon }\end{array}$ & Depth & Description \\
\hline AC & $0-40$ & $\begin{array}{l}\text { Brown [7.5YR4/2(d), very dark gray 3/1(w)] loam, loose, 1-5\% very fine tuff gravels, single } \\
\text { grained, few very fine roots, possible loose slump at top of second core collected (36-40 cm) }\end{array}$ \\
\hline
\end{tabular}

Tsankawi (LA211) TK1 Locality: Basin

Core \#2.2 (Samples 2.201-2.221)

\begin{tabular}{|l|l|l|}
\hline $\begin{array}{l}\text { Soil } \\
\text { Horizon }\end{array}$ & Depth & Description \\
\hline AC & $0-42$ & $\begin{array}{l}\text { Brown [7.5YR4/2(d), very dark gray 3/1(w)] loam, loose, 1-5\% very fine tuff gravels, single } \\
\text { grained, few very fine roots, medium tuff gravel at 12 cm }\end{array}$ \\
\hline
\end{tabular}

Tsankawi (LA211) TK1 Locality: Basin

Core \#2.3 (Samples 2.301-2.319)

\begin{tabular}{|l|l|l|}
\hline $\begin{array}{l}\text { Soil } \\
\text { Horizon }\end{array}$ & Depth & Description \\
\hline AC & $0-39$ & $\begin{array}{l}\text { Brown [7.5YR4/2(d), very dark gray 3/1(w)] loam, loose, 1-5\% very fine tuff gravels, single } \\
\text { grained, few very fine roots, large white tuff rocks 24-26 cm, 30-32 cm, and at base 36-39 cm }\end{array}$ \\
\hline
\end{tabular}

\section{Tsankawi (LA211) TK1 Locality: Basin}

Core \#2.4 (Samples 2.401-2.421)

\begin{tabular}{|l|l|l|}
\hline $\begin{array}{l}\text { Soil } \\
\text { Horizon }\end{array}$ & Depth & Description \\
\hline AC & $0-42$ & $\begin{array}{l}\text { Brown [7.5YR4/2(d), very dark gray 3/1(w)] loam to very fine sandy loam, loose, 1-5\% very } \\
\text { fine tuff gravels with slight increase in coarse sand tuff fragments towards base, single } \\
\text { grained, few very fine roots }\end{array}$ \\
\hline
\end{tabular}

\section{Tsankawi (LA211) TK1 Locality: Berm}

Core \#3.1 (Samples 3.101-3.113

\begin{tabular}{|l|l|l|}
\hline $\begin{array}{l}\text { Soil } \\
\text { Horizon }\end{array}$ & Depth & Description \\
\hline AC & $0-8$ & $\begin{array}{l}\text { Brown [7.5YR5/2(d), dark brown 3/2(w)] loam to very fine sandy loam, loose, 5\% very fine } \\
\text { gravels to coarse tuff sand, single grained, 10\% very fine root and undecayed to partially } \\
\text { decayed fine plant tissues, clear lower boundary }\end{array}$ \\
\hline CA & $8-28$ & $\begin{array}{l}\text { Brown [7.5YR5/2(d), dark brown 3/2(w)] medium to fine sandy loam, loose, single grained, } \\
1-3 \% \text { fine roots and partially decayed organics, abrupt lower boundary }\end{array}$ \\
\hline
\end{tabular}


Tsankawi (LA211) TK1 Locality: Berm

Core \#3.2 (Samples 3.201-3.216)

\begin{tabular}{|l|l|l|}
\hline $\begin{array}{l}\text { Soil } \\
\text { Horizon }\end{array}$ & Depth & Description \\
\hline AC & $0-10$ & $\begin{array}{l}\text { Brown [7.5YR5/2(d), dark brown 3/2(w)] loam to very fine sandy loam, loose, 5\% very fine } \\
\text { gravels to coarse tuff sand, single grained, 10\% very fine root and undecayed to partially } \\
\text { decayed fine plant tissues, clear lower boundary }\end{array}$ \\
\hline$\wedge$ CA & $10-27$ & $\begin{array}{l}\text { Brown [7.5YR5/2(d), dark brown 3/2(w)] medium to fine sandy loam, loose, single grained, } \\
1-3 \% \text { fine roots and partially decayed organics , tuff rock fragment 18-20 cm, rock with } \\
\text { charcoal 22-24 cm, many rock fragments at base 24-27 cm, abrupt lower boundary }\end{array}$ \\
\hline 2 CAb & $27-32$ & $\begin{array}{l}\text { Brown [7.5YR5/2(d), dark brown 3/4(w)] loam to silt loam, loose, few medium tuff gravels, } \\
\text { single grained, very few fine roots, charcoal observed 27-29 cm, abrupt lower boundary }\end{array}$ \\
\hline $\mathrm{R}$ & $32-39$ & White tuff rock fragments \\
\hline
\end{tabular}

\section{Tsankawi (LA211) TK1 Locality: Berm}

Core \#3.3 (Samples 3.301-3.320)

\begin{tabular}{|l|l|l|}
\hline $\begin{array}{l}\text { Soil } \\
\text { Horizon }\end{array}$ & Depth & Description \\
\hline AC & $0-10$ & $\begin{array}{l}\text { Brown [7.5YR5/2(d), dark brown 3/2(w)] loam to very fine sandy loam, loose, 5\% very fine } \\
\text { gravels to coarse tuff sand, single grained, 10\% very fine root and undecayed to partially } \\
\text { decayed fine plant tissues, clear lower boundary }\end{array}$ \\
\hline CA & $10-20$ & $\begin{array}{l}\text { Brown [7.5YR5/2(d), dark brown 3/2(w)] medium to fine sandy loam, loose, single grained, } \\
1-3 \% \text { fine roots and partially decayed organics, charcoal observed 14-16 cm, abrupt lower } \\
\text { boundary }\end{array}$ \\
\hline R & $20-28$ & White tuff rock fragments, abrupt lower boundary \\
\hline 2ACb & $28-40$ & $\begin{array}{l}\text { Brown [7.5YR5/4(d), dark brown 3/3(w)] gravelly medium to fine sandy loam, loose, 5-10\% } \\
\text { poorly sorted fine to medium tuff rock fragments, single grained, very few fine roots, rock } \\
\text { fragment 30-32 cm, tuff rock at base }\end{array}$ \\
\hline
\end{tabular}

Tsankawi (LA211) TK1 Locality: Berm

Core \#3.4 (Samples 3.401-3.418)

\begin{tabular}{|l|l|l|}
\hline $\begin{array}{l}\text { Soil } \\
\text { Horizon }\end{array}$ & Depth & Description \\
\hline AC & $0-8$ & $\begin{array}{l}\text { Brown [7.5YR5/2(d), dark brown 3/2(w)] loam to very fine sandy loam, loose, 5\% very fine } \\
\text { gravels to coarse tuff sand, single grained, 10\% very fine root and undecayed to partially } \\
\text { decayed fine plant tissues, clear lower boundary }\end{array}$ \\
\hline CA & $8-16$ & $\begin{array}{l}\text { Brown [7.5YR5/2(d), dark brown 3/2(w)] medium to fine sandy loam, loose, single grained, } \\
1-3 \% \text { fine roots and partially decayed organics, abrupt lower boundary }\end{array}$ \\
\hline R & $16-19$ & White tuff rock fragments, abrupt lower boundary \\
\hline 2ACb & $19-37$ & $\begin{array}{l}\text { Brown [7.5YR5/4(d), dark brown 3/3(w)] gravelly medium to fine sandy loam, loose, 5-10\% } \\
\text { poorly sorted fine to medium tuff rock fragments, single grained, very few fine roots, tuff } \\
\text { rock at base }\end{array}$ \\
\hline
\end{tabular}


Tsankawi (LA211) TK2 Locality: Control

Core \#1.1 (Samples 1.101-1.110

\begin{tabular}{|l|l|l|}
\hline $\begin{array}{l}\text { Soil } \\
\text { Horizon }\end{array}$ & Depth & Description \\
\hline A & $0-10$ & $\begin{array}{l}\text { Brown [7.5YR4/3(d), dark brown 3/3(w)] fine sandy loam, loose, 5\% fine tuff gravels, single } \\
\text { grained, 5-10\% undecayed plant tissues and roots, abrupt lower boundary }\end{array}$ \\
\hline A/R & $10-20$ & $\begin{array}{l}\text { Brown [7.5YR4/3(d), dark brown 3/3(w)] extremely gravelly fine sandy loam, loose, } ~ 80 \% \\
\text { fractured white tuff rock fragments, few fine roots }\end{array}$ \\
\hline
\end{tabular}

\section{Tsankawi (LA211) TK2 Locality: Control}

Core \#1.2 (Samples 1.201-1.209)

\begin{tabular}{|l|l|l|}
\hline $\begin{array}{l}\text { Soil } \\
\text { Horizon }\end{array}$ & Depth & Description \\
\hline A & $0-10$ & $\begin{array}{l}\text { Brown [7.5YR4/3(d), dark brown 3/3(w)] fine sandy loam, loose, 5\% fine tuff gravels, single } \\
\text { grained, 5-10\% undecayed plant tissues and roots, abrupt lower boundary }\end{array}$ \\
\hline BC & $10-14$ & $\begin{array}{l}\text { Brown [7.5YR4/4(d), 5/4(w)] loamy sand, loose, 10\% fine tuff gravels, abrupt lower } \\
\text { boundary }\end{array}$ \\
\hline R & $14-20$ & White tuff bedrock fragments \\
\hline
\end{tabular}

\section{Tsankawi (LA211) TK2 Locality: Basin}

Core \#2.1 (Sample 2.101-2.114)

\begin{tabular}{|l|l|l|}
\hline $\begin{array}{l}\text { Soil } \\
\text { Horizon }\end{array}$ & Depth & Description \\
\hline CA & $0-28$ & $\begin{array}{l}\text { Brown [7.5YR4/3(d), dark brown 3/2(w)] loam, loose, 2-5\% very fine to medium white tuff } \\
\text { gravel, sand becomes medium to coarse with depth, massive structure, very few very fine } \\
\text { roots }\end{array}$ \\
\hline
\end{tabular}

\section{Tsankawi (LA211) TK2 Locality: Basin}

Core \#2.2 (Samples 2.201-2.220)

\begin{tabular}{|l|l|l|}
\hline $\begin{array}{l}\text { Soil } \\
\text { Horizon }\end{array}$ & Depth & Description \\
\hline CA & $0-8$ & $\begin{array}{l}\text { Brown [7.5YR4/2(d) dark brown 3/2(w)] loam to fine sandy loam, loose, 2-5\% fine to } \\
\text { medium white tuff gravels, weak medium platy to single grained structure, very few very fine } \\
\text { roots, abrupt lower boundary }\end{array}$ \\
\hline C1 & $8-30$ & $\begin{array}{l}\text { Brown [7.5YR5/3(d), brown 4/2(w)] gravelly fine sandy loam, loose, 10-15\% medium to fine } \\
\text { white rounded tuff gravels, massive structure, very few very fine roots, large tuff fragment } \\
\text { 20-22 cm, uncertain lower boundary because transition at top of second core }\end{array}$ \\
\hline C2 & $30-40$ & $\begin{array}{l}\text { Light brown [7.5YR6/3(d), brown 5/4(w)] gravelly sandy clay loam, loose, 10-15\% white tuff } \\
\text { rock-bedrock fragments, single grained structure }\end{array}$ \\
\hline
\end{tabular}


Tsankawi (LA211) TK2 Locality: Basin

Core \#2.3 (Samples 2.301-2.319)

\begin{tabular}{|l|l|l|}
\hline $\begin{array}{l}\text { Soil } \\
\text { Horizon }\end{array}$ & Depth & Description \\
\hline CA & $0-6$ & $\begin{array}{l}\text { Brown [7.5YR4/2(d) dark brown 3/2(w)] loam to fine sandy loam, loose, 2-5\% fine to } \\
\text { medium white tuff gravels, weak medium platy to single grained structure, very few very fine } \\
\text { roots, abrupt lower boundary }\end{array}$ \\
\hline C1 & $6-26$ & $\begin{array}{l}\text { Brown [7.5YR5/3(d), brown 4/2(w)] gravelly fine sandy loam, loose, 10-15\% medium to fine } \\
\text { white rounded tuff gravels, massive structure, very few very fine roots, large tuff fragment } \\
\text { 20-22 cm, very fine charcoal present, uncertain lower boundary because transition at top of } \\
\text { second core }\end{array}$ \\
\hline C2 & $26-34$ & $\begin{array}{l}\text { Brown [7.5YR5/4(d), brown 4/2(w)] gravelly sandy clay loam, loose, 10-15\% white tuff } \\
\text { rock-bedrock fragments, weak medium platy to massive structure, abrupt lower boundary }\end{array}$ \\
\hline C3 & $34-38$ & $\begin{array}{l}\text { Light brown [7.5YR6/3(d), brown 5/4(w)] gravelly sandy clay loam, loose, 5-10\% white tuff } \\
\text { rock-bedrock fragments, single grained structure }\end{array}$ \\
\hline
\end{tabular}

Tsankawi (LA211) TK2 Locality: Basin

Core \#2.4 (Samples 2.401-2.414)

\begin{tabular}{|l|l|l|}
\hline $\begin{array}{l}\text { Soil } \\
\text { Horizon }\end{array}$ & Depth & Description \\
\hline CA & $0-6$ & $\begin{array}{l}\text { Brown [7.5YR4/2(d) dark brown 3/2(w)] loam to fine sandy loam, loose, 2-5\% fine to } \\
\text { medium white tuff gravels, weak medium platy to single grained structure, very few very fine } \\
\text { roots, abrupt lower boundary }\end{array}$ \\
\hline C1 & $6-30$ & $\begin{array}{l}\text { Brown [7.5YR5/3(d), brown 4/2(w)] fine sandy loam, loose, 5-10\% medium to fine white } \\
\text { rounded tuff gravels, massive structure, very few very fine roots, large tuff fragments 18-20, } \\
\text { 20-22, 26-30 cm, uncertain lower boundary because transition at top of second core }\end{array}$ \\
\hline C2 & $30-35$ & $\begin{array}{l}\text { Brown [7.5YR5/4(d), brown 4/2(w)] gravelly sandy clay loam, loose, 10-15\% white tuff } \\
\text { rock-bedrock fragments, weak medium platy to massive structure }\end{array}$ \\
\hline
\end{tabular}

Tsankawi (LA211) TK2 Locality: Berm

Core \#3.1 (Samples 3.101-3.120)

\begin{tabular}{|l|l|l|}
\hline $\begin{array}{l}\text { Soil } \\
\text { Horizon }\end{array}$ & Depth & Description \\
\hline AC1 & $0-4$ & $\begin{array}{l}\text { Brown [7.5YR4/3(d), dark brown 3/2(w)] loam to sandy clay loam, soft, weak medium platy } \\
\text { to massive structure, very few roots, abrupt lower boundary }\end{array}$ \\
\hline AC2 & $4-38$ & $\begin{array}{l}\text { Brown [7.5YR5/3(d), dark brown 3/2(w)] loam to gravelly loam soft-loose, 3-5\% very fine } \\
\text { to fine gravels increasing to 10-15\% between 16-20 cm, single grained structure, large tuff } \\
\text { rock fragments 26-28, 36-38 cm, abrupt lower boundary }\end{array}$ \\
\hline 2BC & $38-40$ & $\begin{array}{l}\text { Brown [7.5YR5/4(d), strong brown 4/6(w)] extremely gravelly sandy clay loam, slightly } \\
\text { firm, 40-60\% medium to fine tuff gravels, moderate medium platy structure, very few open } \\
\text { pores, rock at base }\end{array}$ \\
\hline
\end{tabular}


Tsankawi (LA211) TK2 Locality: Berm

Core \#3.2 (Samples 3.201-3.222)

\begin{tabular}{|l|l|l|}
\hline $\begin{array}{l}\text { Soil } \\
\text { Horizon }\end{array}$ & Depth & Description \\
\hline AC1 & $0-4$ & $\begin{array}{l}\text { Brown [7.5YR4/3(d), dark brown 3/2(w)] loam to sandy clay loam, soft, weak medium platy } \\
\text { to massive structure, very few roots, abrupt lower boundary }\end{array}$ \\
\hline AC2 & $4-34$ & $\begin{array}{l}\text { Brown [7.5YR5/3(d), dark brown 3/2(w)] loam to gravelly loam, soft-loose, 3-5\% very fine } \\
\text { to fine gravels increasing to 10-15\% single grained structure, abrupt lower boundary }\end{array}$ \\
\hline 2Ab & $34-36$ & $\begin{array}{l}\text { Brown [7.5YR5/4(d), 4/3(w)] clay loam, slightly firm, weak medium platy to weak fine } \\
\text { granular structure, very few fine roots, abrupt lower boundary }\end{array}$ \\
\hline 2BC & $36-44$ & $\begin{array}{l}\text { Brown [7.5YR4/3(d), 3/2(w)] gravelly sandy clay loam, firm, 20-40\% fine to medium tuff } \\
\text { gravels, moderate medium platy structure, very few open pores, few very fine roots, some } \\
\text { fine charcoal observed 40-42 cm, rock at base }\end{array}$ \\
\hline
\end{tabular}

\section{Tsankawi (LA211) TK2 Locality: Berm}

Core \#3.3 (Samples 3.301-3.318)

\begin{tabular}{|l|l|l|}
\hline $\begin{array}{l}\text { Soil } \\
\text { Horizon }\end{array}$ & Depth & Description \\
\hline AC1 & $0-4$ & $\begin{array}{l}\text { Brown [7.5YR4/3(d), dark brown 3/2(w)] loam to sandy clay loam, soft, weak medium platy } \\
\text { to massive structure, very few roots, abrupt lower boundary }\end{array}$ \\
\hline AC2 & $4-18$ & $\begin{array}{l}\text { Brown [7.5YR5/3(d), dark brown 3/2(w)] loam to gravelly loam, soft-loose, 3-5\% very fine } \\
\text { to fine gravels increasing to 10-15\% single grained structure, abrupt lower boundary }\end{array}$ \\
\hline Ab & $18-30$ & $\begin{array}{l}\text { Brown [7.5YR5/4(d), dark brown 3/3(w)] clay loam, slightly firm to firm, weak medium } \\
\text { platy to massive structure, fine charcoal observed 18-20 cm, abrupt lower boundary }\end{array}$ \\
\hline 2BC & $30-36$ & $\begin{array}{l}\text { Brown [7.5YR4/3(d), 3/2(w)] gravelly sandy clay loam, firm, 20-40\% fine to medium tuff } \\
\text { gravels, moderate medium platy structure, very few open pores, few very fine roots, some } \\
\text { fine charcoal observed 40-42 cm, rock at base }\end{array}$ \\
\hline
\end{tabular}

Tsankawi (LA211) TK2 Locality: Berm

Core \#3.4 (Samples 3.401-3.419)

\begin{tabular}{|l|l|l|}
\hline $\begin{array}{l}\text { Soil } \\
\text { Horizon }\end{array}$ & Depth & Description \\
\hline AC1 & $0-6$ & $\begin{array}{l}\text { Brown [7.5YR4/3(d), dark brown 3/2(w)] loam to sandy clay loam, soft, weak medium platy } \\
\text { to massive structure, very few roots, abrupt lower boundary }\end{array}$ \\
\hline AC2 & $6-32$ & $\begin{array}{l}\text { Brown [7.5YR5/3(d), dark brown 3/2(w)] loam to gravelly loam, soft-loose, 3-5\% very fine } \\
\text { to fine gravels increasing to 10-15\% single grained structure, large white tuff rock 22-26 cm, } \\
\text { possible slump 26-32 cm abrupt lower boundary }\end{array}$ \\
\hline 2Ab & $32-38$ & $\begin{array}{l}\text { Brown [7.5YR5/4(d), 4/3(w)] clay loam, slightly firm, weak medium platy to weak fine } \\
\text { granular structure, very few fine roots, abrupt lower boundary }\end{array}$ \\
\hline 2BC & $38-42$ & $\begin{array}{l}\text { Brown [7.5YR4/3(d), 3/2(w)] gravelly sandy clay loam, firm, 20-40\% fine to medium tuff } \\
\text { gravels, moderate medium platy structure, very few open pores, few very fine roots, rock at } \\
\text { base }\end{array}$ \\
\hline
\end{tabular}


Tsankawi (LA211) TK2 Locality: Berm

Core \#3.5 (Samples 3.501-3.522)

\begin{tabular}{|c|c|c|}
\hline $\begin{array}{l}\text { Soil } \\
\text { Horizon }\end{array}$ & Depth & Description \\
\hline $\mathrm{C}^{\wedge}$ & $0-16$ & $\begin{array}{l}\text { Light brown [7.5YR6/3, brown } 5 / 4(\mathrm{w})] \text { extremely gravelly sandy loam to sandy clay loam, } \\
\text { loose, single grained, } 40-60 \% \text { medium to large white tuff rock fragments, abrupt lower } \\
\text { boundary }\end{array}$ \\
\hline $\mathrm{AC}^{\wedge}$ & $16-22$ & $\begin{array}{l}\text { Brown [7.5YR5/3(d), dark brown 3/2(w)] loam to gravelly loam, soft-loose, } 3-5 \% \text { very fine } \\
\text { to fine tuff gravels increasing to } 10-15 \% \text { single grained structure, abrupt lower boundary }\end{array}$ \\
\hline $\mathrm{C}^{\wedge}$ & $22-28$ & $\begin{array}{l}\text { Pinkish gray [7.5YR6/2(d), brown 4/2(w)] extremely gravelly sandy loam, loose, single } \\
\text { grained, } 20-30 \% \text { medium fine white tuff gravels, clear lower boundary }\end{array}$ \\
\hline $\mathrm{R}$ & $28-34$ & Rotting white tuff rock fragments, abrupt lower boundary \\
\hline 2BC & $34-44$ & $\begin{array}{l}\text { Brown }[7.5 Y R 4 / 4(d),(w)] \text { clay loam, firm, } 5 \% \text { fine white tuff gravels, strong medium platy } \\
\text { parting to weak fine granular structure }\end{array}$ \\
\hline
\end{tabular}

\section{Tsankawi (LA211) TK3 Locality: Basin}

Core \#2.1 (2.101-2.122)

\begin{tabular}{|l|l|l|}
\hline $\begin{array}{l}\text { Soil } \\
\text { Horizon }\end{array}$ & Depth & Description \\
\hline AC1 & $0-14$ & $\begin{array}{l}\text { Brown [7.5YR5/2(d), dark brown 3/2(w)] loamy very sand, soft, well sorted, single grained to } \\
\text { very weak fine platy structure, few to many very fine open pores, few to common fine roots, } \\
\text { clear lower boundary }\end{array}$ \\
\hline AC2 & $14-42$ & $\begin{array}{l}\text { Brown [7.5YR4/2(d), very dark gray 3/1(w)] sandy loam to loam, slightly firm,1-3\% fine tuff } \\
\text { rock fragments, weak medium platy structure, few fine open pores, few fine roots, possibly } \\
\text { fine charcoal throughout, large white rock fragments 24-28, 30-32, 34-36 cm, slump at top of } \\
2^{\text {nd }} \text { core not collected, some sample loss }\end{array}$ \\
\hline
\end{tabular}

Tsankawi (LA211) TK3 Locality: Basin

Core \#2.2 (Samples 2.201-2.225)

\begin{tabular}{|l|l|l|}
\hline $\begin{array}{l}\text { Soil } \\
\text { Horizon }\end{array}$ & Depth & Description \\
\hline AC1 & $0-16$ & $\begin{array}{l}\text { Brown [7.5YR5/2(d), dark brown 3/2(w)] loamy very fine to medium sand, soft, well sorted, } \\
\text { single grained to very weak fine platy structure, few to many very fine open pores, few to } \\
\text { common fine roots, clear lower boundary }\end{array}$ \\
\hline AC2 & $16-52$ & $\begin{array}{l}\text { Brown [7.5YR4/2(d), very dark gray 3/1(w)] sandy loam to loam, slightly firm,1-3\% fine tuff } \\
\text { rock fragments, weak medium platy structure, few fine open pores, few fine roots, possibly } \\
\text { fine charcoal throughout, large white rock fragment with charcoal 26-28 cm, uncertain of } \\
\text { integrity (slump) 30-38 cm, large tuff rock 46-48 cm, large roots at base 50-52 cm overlying } \\
\text { white tuff bedrock }\end{array}$ \\
\hline
\end{tabular}


Tsankawi (LA211) TK3 Locality: Basin

Core \#2.3 (Samples 2.301-2.318)

\begin{tabular}{|l|l|l|}
\hline $\begin{array}{l}\text { Soil } \\
\text { Horizon }\end{array}$ & Depth & Description \\
\hline AC1 & $0-16$ & $\begin{array}{l}\text { Brown [7.5YR5/2(d), dark brown 3/2(w)] loamy very fine to medium sand, soft, well sorted, } \\
\text { single grained to very weak fine platy structure, few to many very fine open pores, few to } \\
\text { common fine roots, clear lower boundary }\end{array}$ \\
\hline AC2 & $16-40$ & $\begin{array}{l}\text { Brown [7.5YR4/2(d), very dark gray 3/1(w)] sandy loam to loam, slightly firm,1-3\% fine tuff } \\
\text { rock fragments, weak medium platy structure, few fine open pores, few fine roots, possibly } \\
\text { fine charcoal throughout, large roots at base overlying white tuff bedrock }\end{array}$ \\
\hline
\end{tabular}

Tsankawi (LA211) TK3 Locality: Basin

Core \#2.4 (Samples 2.401-2.422)

\begin{tabular}{|l|l|l|}
\hline $\begin{array}{l}\text { Soil } \\
\text { Horizon }\end{array}$ & Depth & Description \\
\hline AC1 & $0-18$ & $\begin{array}{l}\text { Brown [7.5YR5/2(d), dark brown 3/2(w)] loamy sand to very fine loamy sand, soft, well } \\
\text { sorted, single grained to very weak fine platy structure, few to many very fine open pores, } \\
\text { few to common fine roots, clear lower boundary }\end{array}$ \\
\hline AC2 & $18-46$ & $\begin{array}{l}\text { Brown [7.5YR4/2(d), very dark gray 3/1(w)] loam to silt loam, slightly firm,1-3\% fine tuff } \\
\text { rock fragments, weak medium platy structure, few fine open pores, few fine roots, possibly } \\
\text { fine charcoal throughout, large tuff rock 36-40 cm, large roots at base overlying white tuff } \\
\text { bedrock }\end{array}$ \\
\hline
\end{tabular}

\section{Tsankawi (LA211) TK3 Locality: Berm}

Core \#3.1 (Samples 3.101-3.119)

\begin{tabular}{|l|l|l|}
\hline $\begin{array}{l}\text { Soil } \\
\text { Horizon }\end{array}$ & Depth & Description \\
\hline AC & $0-14$ & $\begin{array}{l}\text { Brown [7.5YR5/3(d), dark brown 3/3(w)] fine sandy loam, loose, single grained, 5-15\% fine } \\
\text { partially decayed plant tissues, few very fine roots, few fine tuff rocks at base, clear lower } \\
\text { boundary }\end{array}$ \\
\hline CA & $14-40$ & $\begin{array}{l}\text { Brown [7.5YR5/2(d), dark brown 3/2(w)] very fine sandy loam to loam, very soft to loose, } \\
\text { single grained, 1-5\% very fine white tuff rock fragments, 5\% very fine roots and partially } \\
\text { decayed plant tissues, large tree root 28-30 cm, large white tuff rock fragments 24-28 cm, and } \\
\text { at base }\end{array}$ \\
\hline
\end{tabular}

\section{Tsankawi (LA211) TK3 Locality: Berm}

Core \#3.2 (Samples 3.201-3.217)

\begin{tabular}{|l|l|l|}
\hline $\begin{array}{l}\text { Soil } \\
\text { Horizon }\end{array}$ & Depth & Description \\
\hline AC & $0-32$ & $\begin{array}{l}\text { Brown [7.5YR5/3(d), very dark gray 3/1(w)] very fine sandy loam to loam, loose, single } \\
\text { grained, 5\% very fine roots and partially decayed plant tissues, tuff rock 6-8 cm, charcoal } \\
\text { observed 16-18 cm, large root 24-26 cm, 5\% fine tuff rock fragments and few medium roots } \\
\text { at base }\end{array}$ \\
\hline
\end{tabular}


Tsankawi (LA211) TK3 Locality: Berm

Core \#3.3 (Samples 3.301-3.317)

\begin{tabular}{|l|l|l|}
\hline $\begin{array}{l}\text { Soil } \\
\text { Horizon }\end{array}$ & Depth & Description \\
\hline AC & $0-10$ & $\begin{array}{l}\text { Brown [7.5YR5/3(d), dark brown 3/3(w)] fine sandy loam, loose, single grained, 10-20\% fine } \\
\text { partially decayed plant tissues, few very fine roots, few fine tuff rocks at base, abrupt lower } \\
\text { boundary }\end{array}$ \\
\hline CA & $10-34$ & $\begin{array}{l}\text { Brown [7.5YR5/2(d), dark brown 3/2(w)] very fine sandy loam to loam, very soft to loose, } \\
\text { single grained, 1-5\% very fine white tuff rock fragments, 5\% very fine roots and partially } \\
\text { decayed plant tissues, large tree root 28-30 cm, large white tuff rock fragments 24-28 cm, and } \\
\text { at base }\end{array}$ \\
\hline
\end{tabular}

\section{Tsankawi (LA211) TK3 Locality: Berm}

Core \#3.4 (Samples 3.401-3.413)

\begin{tabular}{|l|l|l|}
\hline $\begin{array}{l}\text { Soil } \\
\text { Horizon }\end{array}$ & Depth & Description \\
\hline AC & $0-6$ & $\begin{array}{l}\text { Brown [7.5YR5/3(d), dark brown 3/3(w)] fine sandy loam, loose, single grained, 5-15\% fine } \\
\text { partially decayed plant tissues, few very fine roots, few fine tuff rocks at base, clear lower } \\
\text { boundary }\end{array}$ \\
\hline CA & $6-26$ & $\begin{array}{l}\text { Brown [7.5YR5/2(d), dark brown 3/2(w)] very fine sandy loam to loam, very soft to loose, } \\
\text { single grained, 1-5\% very fine white tuff rock fragments, 5\% very fine roots and partially } \\
\text { decayed plant tissues, large white tuff rock fragments 16-18, 18-20, 20-24 cm, and at base }\end{array}$ \\
\hline
\end{tabular}

\section{Tsankawi (LA211) TK3 Locality: Berm}

Core \#3.5 (Samples 3.501-3.514)

\begin{tabular}{|l|l|l|}
\hline $\begin{array}{l}\text { Soil } \\
\text { Horizon }\end{array}$ & Depth & Description \\
\hline AC & $0-12$ & $\begin{array}{l}\text { Brown [7.5YR5/3(d), dark brown 3/3(w)] fine sandy loam, loose, single grained, 5-15\% fine } \\
\text { partially decayed plant tissues, few very fine roots, few fine tuff rocks at base, abrupt lower } \\
\text { boundary }\end{array}$ \\
\hline CA & $12-34$ & $\begin{array}{l}\text { Brown [7.5YR5/2(d), dark brown 3/2(w)] very fine sandy loam to loam, very soft to loose, } \\
\text { single grained, 1-5\% very fine white tuff rock fragments, 5\% very fine roots and partially } \\
\text { decayed plant tissues, large white tuff rock fragments 14-16, 16-18 cm, and at base }\end{array}$ \\
\hline
\end{tabular}

\section{Site: Tsirege (LA170)}

\section{Tsirege Locality: Control}

\section{2, 1.1-MM}

\begin{tabular}{|l|l|l|}
\hline $\begin{array}{l}\text { Soil } \\
\text { Horizon }\end{array}$ & Depth & Description \\
\hline CA & $0-22$ & $\begin{array}{l}\text { Brown (7.5YR5/3)(d), dark brown (3/2)(w) loamy sand to sand, very few fine subangular to } \\
\text { angular quartzite gravels with occasional medium tuff gravels, 10-20 cm coarse sand, loose, } \\
\text { single grained, few fine roots, abrupt lower boundary }\end{array}$ \\
\hline Ab & $22-38$ & $\begin{array}{l}\text { Light brown (7.5YR6/4)(d), brown (4/3)(w) fine sandy loam, loose, weak medium platy } \\
\text { parting to single grained, few to common fine roots, few fine open pores and root channels, } \\
\text { abrupt lower boundary }\end{array}$ \\
\hline
\end{tabular}




\begin{tabular}{|l|l|l|}
\hline Bw & $38-42$ & $\begin{array}{l}\text { Dark brown (7.5YR3/4(d)(w) clay loam to gravely clay loam, hard, moderate fine angular } \\
\text { blocky structure, 10-20\% fine to medium angular tuff gravels, few fine roots on ped faces and } \\
\text { ped core interiors, large tuff gravel at base (42-44 cm) abrupt lower boundary }\end{array}$ \\
\hline $\mathrm{Cr}$ & $42-64$ & $\begin{array}{l}\text { Dark brown 7.5YR3/4(d)(w) extremely gravelly clay loam to extremely gravelly sandy loam, } \\
60-80 \% \text { tuff rock fragments, few medium to fine roots (incl. tree), matrix between rocks and } \\
\text { roots is loose, becoming coarser (sandy loam) with depth }\end{array}$ \\
\hline
\end{tabular}

Tsirege Locality: Basin

2.2, 2.3-MM

\begin{tabular}{|l|l|l|}
\hline $\begin{array}{l}\text { Soil } \\
\text { Horizon }\end{array}$ & Depth & Description \\
\hline CA1 & $0-38$ & $\begin{array}{l}\text { Brown (7.5YR5/3)(d), (4/2)(w) silt loam, slightly firm, well sorted, weak medium platy to } \\
\text { single grained, few fine open pores, few fine roots increasing in size to fine to medium with } \\
\text { depth, clear lower boundary }\end{array}$ \\
\hline CA2 & $38-48$ & $\begin{array}{l}\text { Pinkish gray (7.5YR6/2)(d), brown (4/3)(w) silt loam, slighty firm, moderate medium platy } \\
\text { partying to weak fine granular and single grained, few very fine roots, common very fine } \\
\text { open pores, abrupt lower boundary }\end{array}$ \\
\hline C & $48-62$ & $\begin{array}{l}\text { Brown (7.5YR5/2)(d), dark brown (7.5YR3/2)(w) gravelly silty clay loam, slightly firm, 10- } \\
\text { 15\% medium pink tuff angular gravels, moderate fine granular structure, few fine roots, } \\
\text { abrupt lower boundary }\end{array}$ \\
\hline 2C1 & $62-84$ & $\begin{array}{l}\text { Brown (7.5YR5/2(d),(4/2)(w) extremely gravelly loam, common medium pink tuff rock } \\
\text { fragments, loose, massive to single grained, abrupt lower boundary }\end{array}$ \\
\hline 2C3 & $84-102$ & $\begin{array}{l}\text { Brown (7.5YR5/3)(d), dark brown (7.5YR3/2)(w) gravelly coarse sandy loam, loose, 10-15\% } \\
\text { medium tuff gravels, single grained, few fine roots, sherd fragment 94-96 cm, abrupt lower } \\
\text { boundary }\end{array}$ \\
\hline
\end{tabular}

Tsirege Locality: Berm

3.1, 3.3-MM

\begin{tabular}{|l|l|l|}
\hline $\begin{array}{l}\text { Soil } \\
\text { Horizon }\end{array}$ & Depth & Description \\
\hline CA & $0-12$ & $\begin{array}{l}\text { Brown [7.5YR5/3(d)], dark brown [3/3(w)], Fine sandy loam, 5\% fine angular tuff gravels, } \\
\text { very weak fine granular to single grained structure, few fine roots, clear lower boundary }\end{array}$ \\
\hline$\wedge \mathrm{C} 1$ & $12-18$ & $\begin{array}{l}\text { Brown [7.5YR5/3(d)], brown [4/3(w)], medium to coarse sandy loam to loamy sand, 5-10\% } \\
\text { very fine gravels, loose, single grained, very few very fine roots, clear lower boundary }\end{array}$ \\
\hline$\wedge \mathrm{C} 2$ & $18-30$ & $\begin{array}{l}\text { Brown [7.5YR5/2(d)], dark brown [3/2(w)], gravelly sandy loam to loam, 15-20\% fine } \\
\text { gravels, loose, single grained, pink tuff fragment from 24-28 cm, clear lower boundary }\end{array}$ \\
\hline$\wedge \mathrm{CA}$ & $30-38$ & $\begin{array}{l}\text { Brown [7.5YR5/2(d)], dark brown [3/2(w)], gravelly loam, 10-15\% very fine gravels, dry, } \\
\text { slightly firm, weak very fine subangular blocky structure parting to single grained, very few } \\
\text { very fine roots, clear lower boundary }\end{array}$ \\
\hline$\wedge \mathrm{C} 3$ & $38-84$ & $\begin{array}{l}\text { Brown [7.5YR5/3(d)], dark brown [3/3(w)], gravelly loamy sand, 15\% fine to very fine } \\
\text { gravels that decrease in percentage with depth below 76 cm, loose, single grained, very few } \\
\text { very fine roots, few open pores, white tuff frag 56-58 cm, charcoal observed 72-74 cm }\end{array}$ \\
\hline
\end{tabular}




\section{Site: Yapashi (LA250)}

\section{Yapashi Locality: Control}

Core \#1.1 (Samples 1.101-1.110)

\begin{tabular}{|l|l|l|}
\hline $\begin{array}{l}\text { Soil } \\
\text { Horizon }\end{array}$ & Depth & Description \\
\hline AC1 & $0-6$ & $\begin{array}{l}\text { Brown [7.5YR4/3(d), 4/2(w)] sandy loam to sandy clay loam, slightly firm, 5\% poorly sorted } \\
\text { fine gravel, weak medium platy parting to single grained structure, very few fine roots, clear } \\
\text { lower boundary }\end{array}$ \\
\hline AC2 & $6-14$ & $\begin{array}{l}\text { Brown [7.5YR4/2(d), dark brown 3/4(w)] coarsening upward from gravelly loamy sand to } \\
\text { sandy loam, 10\% fine with few medium tuff gravels, very weak fine platy to massive } \\
\text { structure, very few fine roots, abrupt lower boundary }\end{array}$ \\
\hline Bw & $14-20$ & $\begin{array}{l}\text { Brown [7.5YR4/4(d), dark brown 3/4(w)] loam to clay loam, very slightly firm, 2\% fine tuff } \\
\text { gravels, massive parting to weak fine subangular blocky structure, very few fine roots with } \\
\text { increase to medium size roots at base and at contact with white tuff bedrock at base }\end{array}$ \\
\hline
\end{tabular}

Yapashi Locality: Control

Core \#1.2 (Samples 1.201-1.210)

\begin{tabular}{|l|l|l|}
\hline $\begin{array}{l}\text { Soil } \\
\text { Horizon }\end{array}$ & Depth & Description \\
\hline AC1 & $0-6$ & $\begin{array}{l}\text { Brown [7.5YR4/3(d), 4/2(w)] sandy loam to sandy clay loam, slightly firm, 5\% poorly sorted } \\
\text { fine gravel, weak medium platy parting to single grained structure, very few fine roots, clear } \\
\text { lower boundary }\end{array}$ \\
\hline AC2 & $6-11$ & $\begin{array}{l}\text { Brown [7.5YR4/2(d), dark brown 3/4(w)] coarsening upward from gravelly loamy sand to } \\
\text { sandy loam, 10\% fine with few medium tuff gravels, very weak fine platy to massive } \\
\text { structure, very few fine roots, abrupt lower boundary }\end{array}$ \\
\hline Bw & $11-18$ & $\begin{array}{l}\text { Brown [7.5YR4/4(d), dark brown 3/4(w)] loam to clay loam, very slightly firm, 2\% fine tuff } \\
\text { gravels, massive parting to weak fine subangular blocky structure, very few fine roots with } \\
\text { increase to medium size roots at base, abrupt lower boundary }\end{array}$ \\
\hline R & $18-20$ & White tuff bedrock \\
\hline
\end{tabular}

\section{Yapashi Locality: Basin}

Core \#2.1 (Samples 2.101-2.138)

\begin{tabular}{|l|l|l|}
\hline $\begin{array}{l}\text { Soil } \\
\text { Horizon }\end{array}$ & Depth & Description \\
\hline CA & $0-6$ & $\begin{array}{l}\text { Very dark gray [7.5YR3/1(d),black 2.5/1(w)] loam, soft, very few medium tuff rock } \\
\text { fragments, massive, common very fine silt black charcoal towards base, very few fine roots, } \\
\text { abrupt lower boundary }\end{array}$ \\
\hline C1 & $6-16$ & $\begin{array}{l}\text { Brown [7.5YR5/2(d), dark gray 4/1(w)] loam to silt loam, soft, 5\% fine white tuff gravel, } \\
\text { massive, few very fine roots, clear lower boundary }\end{array}$ \\
\hline C2 & $16-26$ & $\begin{array}{l}\text { Brown [7.5YR4/3(d), dark brown 3/2(w)] gravelly silt loam to loam, soft, 5-10\% fine to } \\
\text { medium white tuff gravels, massive structure, few fine roots, uncertain lower boundary } \\
\text { because contact at top of second core }\end{array}$ \\
\hline C3 & $26-34$ & $\begin{array}{l}\text { Brown [7.5YR5/3(d), dark brown 3/2(w)] loam, soft, 5\% fine to medium white tuff gravels, } \\
\text { massive common fine roots, clear lower boundary }\end{array}$ \\
\hline C4 & $34-50$ & $\begin{array}{l}\text { Brown [7.5YR5/2(d), dark brown 3/2(w)], gravelly silt loam, soft, } 10-15 \% \text { white tuff } \\
\text { gravels fining upward from medium to fine gravels, massive parting to single grained } \\
\text { structure, common very fine roots, uncertain lower boundary because slump between bottom } \\
\text { of second and top of third core }\end{array}$ \\
\hline C5 & $50-62$ & $\begin{array}{l}\text { Brown [7.5YR5/2(d), very dark gray 3/1(w)] gravelly silt loam, slightly firm, 10-15\% fine to } \\
\text { medium white tuff gravels, weak medium platy parting to weak fine subangular blocky to }\end{array}$ \\
\hline
\end{tabular}




\begin{tabular}{|l|l|l|}
\hline C6 & 62-70 & $\begin{array}{l}\text { single grained structure, few fine open pores, few fine roots, gradual lower boundary } \\
\text { medium white tuff gravels, massive to single grained structure, few fine roots, abrupt lower } \\
\text { boundary }\end{array}$ \\
\hline C7 & $70-77$ & $\begin{array}{l}\text { Brown [7.5YR5/2(d), very dark gray 3/1(w)] silt loam, very slightly firm, 5\% fine with very } \\
\text { few medium white tuff rock fragments, poorly sorted fine to medium sand, fine medium platy } \\
\text { structure, very few very fine roots, medium tuff rock fragment at base }\end{array}$ \\
\hline
\end{tabular}

\section{Yapashi Locality: Basin}

Core \#2.2

\begin{tabular}{|l|l|l|}
\hline $\begin{array}{l}\text { Soil } \\
\text { Horizon }\end{array}$ & $\begin{array}{l}\text { Depth } \\
(\mathrm{cm})\end{array}$ & Description \\
\hline CA & $0-6$ & $\begin{array}{l}\text { Very dark gray [7.5YR3/1(d),black 2.5/1(w)] loam, soft, very few medium tuff rock } \\
\text { fragments, massive, common very fine silt black charcoal towards base, very few fine roots, } \\
\text { abrupt lower boundary }\end{array}$ \\
\hline C1 & $6-18$ & $\begin{array}{l}\text { Brown [7.5YR5/2(d), dark gray 4/1(w)] loam to silt loam, soft, 5\% medium to fine white tuff } \\
\text { gravel, massive, few very fine roots, clear lower boundary }\end{array}$ \\
\hline C2 & $18-24$ & $\begin{array}{l}\text { Brown [7.5YR4/3(d), dark brown 3/2(w)] gravelly silt loam to silt loam, soft, 5-7\% fine to } \\
\text { medium white tuff gravels, massive structure, few fine roots, clear lower boundary }\end{array}$ \\
\hline C3 & $24-36$ & $\begin{array}{l}\text { Brown [7.5YR5/3(d), dark brown 3/2(w)] loam, soft, 5\% fine to medium white tuff gravels, } \\
\text { massive common fine roots, clear lower boundary }\end{array}$ \\
\hline C4 & $36-54$ & $\begin{array}{l}\text { Brown [7.5YR5/2(d), dark brown 3/2(w)], gravelly silt loam, soft, } 10-15 \% \text { white tuff } \\
\text { gravels fining upward from medium to fine gravels with lenses of 5\% and 15\%, massive } \\
\text { parting to single grained structure, common very fine roots, uncertain lower boundary } \\
\text { because slump between bottom of second and top of third core }\end{array}$ \\
\hline C5 & $54-64$ & $\begin{array}{l}\text { Brown [7.5YR5/2(d), very dark gray 3/1(w)] very gravelly silt loam, slightly firm, 10-15\% } \\
\text { fine to medium white tuff gravels, weak medium platy parting to weak fine subangular blocky } \\
\text { to single grained structure, few fine open pores, few fine roots, abrupt lower boundary }\end{array}$ \\
\hline C6 & $64-75$ & $\begin{array}{l}\text { Brown [7.5YR4/2(d), very dark gray 3/1(w)] very gravelly loam, loose, 15-25\% fine with few } \\
\text { medium white tuff gravels, massive to single grained structure, few fine roots, abrupt lower } \\
\text { boundary }\end{array}$ \\
\hline
\end{tabular}

Yapashi Locality: Basin

Core \#2.3 (Samples 2.301-2.336)

\begin{tabular}{|l|l|l|}
\hline $\begin{array}{l}\text { Soil } \\
\text { Horizon }\end{array}$ & Depth & Description \\
\hline CA & $0-6$ & $\begin{array}{l}\text { Very dark gray [7.5YR3/1(d),black 2.5/1(w)] loam, soft, very few medium tuff rock } \\
\text { fragments, massive, common very fine silt black charcoal towards base, very few fine roots, } \\
\text { abrupt lower boundary }\end{array}$ \\
\hline C1 & $6-12$ & $\begin{array}{l}\text { Brown [7.5YR5/2(d), dark gray 4/1(w)] loam to silt loam, soft, 5\% medium to fine white tuff } \\
\text { gravel, massive to single grained, few very fine roots, clear lower boundary }\end{array}$ \\
\hline C2 & $12-22$ & $\begin{array}{l}\text { Brown [7.5YR4/3(d), dark brown 3/2(w)] gravelly silt loam to silt loam, soft, 5-7\% fine to } \\
\text { medium white tuff gravels, massive structure, few fine roots, clear lower boundary }\end{array}$ \\
\hline C3 & $22-32$ & $\begin{array}{l}\text { Brown [7.5YR5/3(d), dark brown 3/2(w)] loam, soft, 5\% fine to medium white tuff gravels, } \\
\text { massive common fine roots, clear lower boundary }\end{array}$ \\
\hline C4 & $32-46$ & $\begin{array}{l}\text { Brown [7.5YR5/2(d), dark brown 3/2(w)], gravelly silt loam, soft, } 10-15 \% \text { white tuff } \\
\text { gravels fining upward from medium to fine gravels with lenses of 5\% and 15\%, massive } \\
\text { parting to single grained structure, common very fine roots, uncertain lower boundary } \\
\text { because slump between bottom of second and top of third core }\end{array}$ \\
\hline C5 & $46-60$ & $\begin{array}{l}\text { Brown [7.5YR5/2(d), very dark gray 3/1(w)] very gravelly silt loam, slightly firm, 10-15\% } \\
\text { fine to medium white tuff gravels, weak medium platy parting to weak fine subangular blocky }\end{array}$ \\
\hline
\end{tabular}




\begin{tabular}{|l|l|l|}
\hline C6 & to single grained structure, few fine open pores, few fine roots, abrupt lower boundary \\
\hline C7 & $\begin{array}{l}\text { Brown [7.5YR4/2(d), very dark gray 3/1(w)] silt loam to very gravelly silt loam, loose, 15- } \\
\text { 25\% fine with few medium white tuff gravels, massive to single grained structure, few fine } \\
\text { roots, white tuff rock fragment 70-73 cm abrupt lower boundary }\end{array}$ \\
\hline
\end{tabular}

\section{Yapashi Locality: Basin}

Core \#2.4 (Samples 2.401-2.438)

\begin{tabular}{|l|l|l|}
\hline $\begin{array}{l}\text { Soil } \\
\text { Horizon }\end{array}$ & Depth & Description \\
\hline CA & $0-6$ & $\begin{array}{l}\text { Very dark gray [7.5YR3/1(d),black 2.5/1(w)] loam, soft, very few medium tuff rock } \\
\text { fragments, massive, common very fine silt black charcoal towards base, very few fine roots, } \\
\text { abrupt lower boundary }\end{array}$ \\
\hline C1 & $6-10$ & $\begin{array}{l}\text { Brown [7.5YR5/2(d), dark gray 4/1(w)] loam to silt loam, soft, 5\% fine white tuff gravel, } \\
\text { massive, few very fine roots, clear lower boundary }\end{array}$ \\
\hline C2 & $10-16$ & $\begin{array}{l}\text { Brown [7.5YR4/3(d), dark brown 3/2(w)] gravelly silt loam to loam, soft, 5-10\% fine to } \\
\text { medium white tuff gravels, massive structure, few fine roots, gradual lower boundary }\end{array}$ \\
\hline C3 & $16-32$ & $\begin{array}{l}\text { Brown [7.5YR5/3(d), dark brown 3/2(w)] loam, soft, 5\% fine to medium white tuff gravels, } \\
\text { massive common fine roots, clear lower boundary }\end{array}$ \\
\hline C4 & $32-46$ & $\begin{array}{l}\text { Brown [7.5YR5/2(d), dark brown 3/2(w)], gravelly silt loam, soft, 10-15\% white tuff } \\
\text { gravels fining upward from medium to fine gravels with lenses of 5\% and 15\%, massive } \\
\text { parting to single grained structure, common very fine roots, uncertain lower boundary } \\
\text { because slump between bottom of second and top of third core }\end{array}$ \\
\hline C6 & $46-62$ & $\begin{array}{l}\text { Brown [7.5YR5/2(d), very dark gray 3/1(w)] very gravelly silt loam, slightly firm, 10-15\% } \\
\text { fine to medium white tuff gravels, weak medium platy parting to weak fine subangular blocky } \\
\text { to single grained structure, few fine open pores, few fine roots, gradual lower boundary }\end{array}$ \\
\hline C7 & $\begin{array}{l}\text { Brown [7.5YR4/2(d), very dark gray 3/1(w)] very gravelly loam, loose, 15-25\% fine with few } \\
\text { medium white tuff gravels, massive to single grained structure, few fine roots, 70-74 cm } \\
\text { white tuff rock fragment, abrupt lower boundary }\end{array}$ \\
\hline
\end{tabular}

\section{Yapashi Locality: Berm}

Core \#3.1 (Samples 3.101-3.127)

\begin{tabular}{|l|l|l|}
\hline $\begin{array}{l}\text { Soil } \\
\text { Horizon }\end{array}$ & Depth & Description \\
\hline $\mathrm{A}^{\wedge}$ & $0-10$ & $\begin{array}{l}\text { Very dark gray [7.5YR3/1(d), black 2.5/1(w)] gravelly clay loam, slightly firm, 10-15\% } \\
\text { poorly sorted tuff gravel with few medium fragments of redware ceramics, fine charcoal, few } \\
\text { fine roots, abrupt lower boundary }\end{array}$ \\
\hline $\mathrm{C} 1 \wedge$ & $10-26$ & $\begin{array}{l}\text { Brown [7.5YR4/3(d), dark brown 3/2(w)] gravelly sandy clay loam, very slightly firm, 10- } \\
15 \% \text { fine to medium white tuff gravels, massive parting to single grained structure, very few } \\
\text { to no roots, abrupt lower boundary }\end{array}$ \\
\hline $\mathrm{C} 2^{\wedge}$ & $26-54$ & $\begin{array}{l}\text { Brown [7.5YR5/2(d), dark brown 3/2(w)] gravelly loamy sand, loose, 15-20\% fine to } \\
\text { medium white tuff gravel, massive to single grained, very few very fine roots, few medium } \\
\text { charcoal fragments }\end{array}$ \\
\hline
\end{tabular}


Yapashi Locality: Berm

Core \#3.2 (Samples 3.201-3.236)

\begin{tabular}{|l|l|l|}
\hline $\begin{array}{l}\text { Soil } \\
\text { Horizon }\end{array}$ & Depth & Description \\
\hline $\mathrm{A}^{\wedge}$ & $0-12$ & $\begin{array}{l}\text { Very dark gray [7.5YR3/1(d), black 2.5/1(w)] gravelly clay loam, slightly firm, 10-15\% } \\
\text { poorly sorted tuff gravel with medium fragment of redware ceramics, fine charcoal, few fine } \\
\text { roots, clear lower boundary }\end{array}$ \\
\hline $\mathrm{C} 1 \wedge$ & $12-40$ & $\begin{array}{l}\text { Brown [7.5YR4/3(d), dark brown 3/2(w)] gravelly sandy clay loam, very slightly firm, 10- } \\
15 \% \text { fine to medium white tuff gravels, including tuff rock 40-42 at base, massive parting to } \\
\text { single grained structure, very few to no roots, uncertain lower boundary, 50-56 cm may be } \\
\text { slump at top of 3d }\end{array}$ \\
\hline $\mathrm{C} 2 \wedge$ & $40-78$ & $\begin{array}{l}\text { Brown [7.5YR5/2(d), dark brown 3/2(w)] gravelly loamy sand, loose, 15-20\% fine to } \\
\text { medium white tuff gravel, massive to single grained, very few very fine roots }\end{array}$ \\
\hline
\end{tabular}

\section{Yapashi Locality: Berm}

Core \#3.3 (Samples 3.301-3.329)

\begin{tabular}{|l|l|l|}
\hline $\begin{array}{l}\text { Soil } \\
\text { Horizon }\end{array}$ & Depth & Description \\
\hline $\mathrm{AC} \wedge$ & $0-18$ & $\begin{array}{l}\text { Very dark gray [7.5YR3/1(w),(d)] clay loam, slightly firm, 5-10\% fine tuff gravel increasing } \\
\text { to 15\% at depth, weak medium platy parting to weak fine granular structure, very few very } \\
\text { fine roots, charcoal, abrupt lower boundary }\end{array}$ \\
\hline $\mathrm{C1 \wedge}$ & $18-58$ & $\begin{array}{l}\text { Brown [7.5YR5/2(d), dark brown 3/2(w)] gravelly sandy loam to sandy clay loam, loose, 10- } \\
\text { 20\% very coarse sand to fine white tuff gravels, massive structure, very few very fine roots, } \\
\text { charcoal, 1 medium root 36-38 cm, between 54-56 cm is a 2 cm thick lens of brown } \\
\text { [7.5YR4/2(d), very dark gray 3/1(w)] gravelly sandy loam, below is sandy clay loam, abrupt } \\
\text { lower boundary }\end{array}$ \\
\hline
\end{tabular}

Yapashi Locality: Berm

Core \#3.4 (Samples 3.401-3.426)

\begin{tabular}{|l|l|l|}
\hline $\begin{array}{l}\text { Soil } \\
\text { Horizon }\end{array}$ & Depth & Description \\
\hline AC1^ & $0-6$ & $\begin{array}{l}\text { Very dark gray [7.5YR3/1(w),(d)] clay loam, slightly firm, 5-10\% fine tuff gravel increasing } \\
\text { to 15\% at depth, weak medium platy parting to weak fine granular structure, very few very } \\
\text { fine roots, charcoal, abrupt lower boundary }\end{array}$ \\
\hline $\mathrm{AC2}^{\wedge}$ & $6-14$ & $\begin{array}{l}\text { Dark brown [7.5YR3/2(w),(d)] gravelly clay loam, slightly firm, 10-15\% fine white tuff } \\
\text { gravels, weak medium platy to moderate fine granular structure, abrupt lower boundary }\end{array}$ \\
\hline $\mathrm{C}^{\wedge}$ & $14-50$ & $\begin{array}{l}\text { Brown [7.5YR4/3(d), dark brown 3/2(w) gravelly sandy loam, loose, 5-15\% very coarse to } \\
\text { fine tuff gravels, 36-39 cm large white tuff rock, large rooting root 30-36 cm, uncertain } \\
\text { recovery because core depth } 67 \mathrm{~cm} \text {, yet only 50 cm recovery }\end{array}$ \\
\hline
\end{tabular}

\section{Site: LA70790}

\section{LA70790 Locality: Control}

Core \#1.1 (Samples 1.101-1.105)

\begin{tabular}{|l|l|l|}
\hline $\begin{array}{l}\text { Soil } \\
\text { Horizon }\end{array}$ & Depth & Description \\
\hline AC & $0-10$ & $\begin{array}{l}\text { Dark brown [7.5YR3/2(w),(d)] sandy loam, soft, weak medium granular parting to single } \\
\text { grained structure, very few fine roots, large tuff rock at base }\end{array}$ \\
\hline
\end{tabular}




\section{LA70790 Locality: Control}

Core \#1.2 (Samples 1.201-1.208)

\begin{tabular}{|l|l|l|}
\hline $\begin{array}{l}\text { Soil } \\
\text { Horizon }\end{array}$ & Depth & Description \\
\hline AC & $0-8$ & $\begin{array}{l}\text { Dark brown [7.5YR3/2(w),(d)] sandy loam to loamy sand, slightly firm, weak medium } \\
\text { granular parting to single grained, few fine roots, abrupt lower boundary }\end{array}$ \\
\hline Bt & $8-12$ & $\begin{array}{l}\text { Dark brown [7.5YR3/3(w),(d)] silty clay, firm, weak medium subangular blocky structure, } \\
\text { few fine roots, abrupt lower boundary }\end{array}$ \\
\hline C/R & $12-18$ & Dark brown [7.5YR3/3(w),(d)] gravelly silty clay,60\% large tuff rock fragments \\
\hline
\end{tabular}

\section{LA70790 Locality: Basin}

Core \#2.1 (Samples 2.101-2.128)

\begin{tabular}{|l|l|l|}
\hline $\begin{array}{l}\text { Soil } \\
\text { Horizon }\end{array}$ & Depth & Description \\
\hline AC & $0-8$ & $\begin{array}{l}\text { Dark brown [7.5YR3/3(d), 3/2(w)] sandy loam to sandy clay loam, soft, fine granular to } \\
\text { single grained structure, very few fine roots, clear lower boundary }\end{array}$ \\
\hline C1 & $8-38$ & $\begin{array}{l}\text { Brown [7.5YR5/3(d), dark brown 3/2(w)] gravelly sandy loam, loose, 40\% fine to medium } \\
\text { rounded to subrounded white tuff gravels, massive to single grained structure, very few } \\
\text { medium roots, abrupt lower boundary }\end{array}$ \\
\hline C2 & $38-44$ & $\begin{array}{l}\text { Light brown [7.5YR6/3(d), brown 4/3(w)] extremely gravelly sandy loam, 60-80\% fine with } \\
\text { few medium rounded white tuff gravels, single grained structure, very few medium roots, } \\
\text { clear lower boundary }\end{array}$ \\
\hline C3 & $44-56$ & $\begin{array}{l}\text { Brown [7.5YR4/3(d), dark brown 3/2(w) fine to medium sandy loam, loose, 5-10\% fine to } \\
\text { medium tuff gravels, single grained structure, few medium roots }\end{array}$ \\
\hline
\end{tabular}

\section{LA70790 Locality: Basin}

Core \#2.2 (Samples 2.201-2.228)

\begin{tabular}{|l|l|l|}
\hline $\begin{array}{l}\text { Soil } \\
\text { Horizon }\end{array}$ & Depth & Description \\
\hline AC & $0-8$ & $\begin{array}{l}\text { Dark brown [7.5YR3/3(d), 3/2(w)] sandy loam to sandy clay loam, soft, fine granular to } \\
\text { single grained structure, very few fine roots, clear lower boundary }\end{array}$ \\
\hline C1 & $8-36$ & $\begin{array}{l}\text { Brown [7.5YR5/3(d), dark brown 3/2(w)] gravelly sandy loam, loose, 40\% fine to medium } \\
\text { rounded to subrounded white tuff gravels, massive to single grained structure, very few } \\
\text { medium roots, abrupt lower boundary }\end{array}$ \\
\hline C2 & $36-46$ & $\begin{array}{l}\text { Light brown [7.5YR6/3(d), brown 4/3(w)] extremely gravelly sandy loam, 60-80\% fine with } \\
\text { few medium rounded white tuff gravels, single grained structure, very few medium roots, } \\
\text { clear lower boundary }\end{array}$ \\
\hline C3 & $46-56$ & $\begin{array}{l}\text { Brown [7.5YR4/3(d), dark brown 3/2(w) fine to medium sandy loam, loose, 5-10\% fine to } \\
\text { medium tuff gravels, single grained structure, few medium roots }\end{array}$ \\
\hline
\end{tabular}

\section{LA70790 Locality: Basin}

Core \#2.3 (Samples 2.301-2.325)

\begin{tabular}{|l|l|l|}
\hline $\begin{array}{l}\text { Soil } \\
\text { Horizon }\end{array}$ & Depth & Description \\
\hline AC & $0-10$ & $\begin{array}{l}\text { Dark brown [7.5YR3/3(d), 3/2(w)] sandy loam to sandy clay loam, soft, fine granular to } \\
\text { single grained structure, very few fine roots, clear lower boundary }\end{array}$ \\
\hline C1 & $10-36$ & $\begin{array}{l}\text { Brown [7.5YR5/3(d), dark brown 3/2(w)] gravelly sandy loam, loose, 40\% fine to medium } \\
\text { rounded to subrounded white tuff gravels, massive to single grained structure, very few } \\
\text { medium roots, abrupt lower boundary }\end{array}$ \\
\hline
\end{tabular}




\begin{tabular}{|l|l|l|}
\hline C2 & $36-50$ & $\begin{array}{l}\text { Light brown [7.5YR6/3(d), brown 4/3(w)] extremely gravelly sandy loam, 60-80\% fine with } \\
\text { few medium rounded white tuff gravels, single grained structure, very few medium roots, } \\
\text { clear lower boundary }\end{array}$ \\
\hline C3 & $50-57$ & $\begin{array}{l}\text { Brown [7.5YR4/3(d), dark brown 3/2(w) fine to medium sandy loam, loose, 5-10\% fine to } \\
\text { medium tuff gravels, single grained structure, few medium roots, charcoal present 50-52 cm, } \\
52-54 \mathrm{~cm}\end{array}$ \\
\hline
\end{tabular}

\section{LA70790 Locality: Berm}

Core \#3.1 (Samples 3.101-3.108)

\begin{tabular}{|l|l|l|}
\hline $\begin{array}{l}\text { Soil } \\
\text { Horizon }\end{array}$ & Depth & Description \\
\hline A & $0-10$ & $\begin{array}{l}\text { Dark brown [7.5YR3/2(w),(d)] silt loam to loam, soft, weak medium granular structure, 5\% } \\
\text { fine rounded white tuff gravels, 10-15\% fine partially decayed duff, few very fine roots, } \\
\text { abrupt lower boundary }\end{array}$ \\
\hline Bt & $10-16$ & $\begin{array}{l}\text { Brown [7.5YR4/4(d) dark brown 3/4(w)] gravelly clay loam, very firm, 10\% very coarse sand } \\
\text { to fine white tuff gravels, moderate medium subangular blocky partying to weak fine granular } \\
\text { structure, fine medium roots on ped faces }\end{array}$ \\
\hline
\end{tabular}

\section{LA70790 Locality: Berm}

Core \#3.2 (Samples 3.201-3.205)

\begin{tabular}{|l|l|l|}
\hline $\begin{array}{l}\text { Soil } \\
\text { Horizon }\end{array}$ & Depth & Description \\
\hline A & $0-7$ & $\begin{array}{l}\text { Dark brown [7.5YR3/2(w),(d)] silt loam to loam, soft, weak medium granular structure, 5\% } \\
\text { fine rounded white tuff gravels, 10-15\% fine partially decayed duff, few very fine roots, } \\
\text { abrupt lower boundary }\end{array}$ \\
\hline Bt/C & $7-12$ & $\begin{array}{l}\text { Brown [7.5YR4/4(d) dark brown 3/4(w)] gravelly clay loam to sandy loam, very firm, 10\% } \\
\text { very coarse sand to fine white tuff gravels, moderate medium subangular blocky partying to } \\
\text { weak fine granular structure, fine medium roots on ped faces and large well decayed root }\end{array}$ \\
\hline
\end{tabular}

\section{LA70790 Locality: Berm}

Core \#3.3 (Samples 3.301-3.321)

\begin{tabular}{|l|l|l|}
\hline $\begin{array}{l}\text { Soil } \\
\text { Horizon }\end{array}$ & Depth & Description \\
\hline AC & $0-12$ & $\begin{array}{l}\text { Dark brown [7.5YR3/3(d), very dark brown 2.5/3(w)] gravelly sandy clay, slightly firm, 10- } \\
15 \% \text { fine to medium rounded white tuff gravels, moderate medium granular structure, few } \\
\text { fine roots, clear lower boundary, possibly welded A at base }\end{array}$ \\
\hline CB & $12-42$ & $\begin{array}{l}\text { Brown [7.5YR4/3(d), dark brown 3/3(w) sandy clay loam to sandy loam with depth (below } \\
26 \mathrm{~cm}), \text { loose, 5-10\% fine to medium white tuff gravel, massive structure, few very fine roots, } \\
\text { large tuff rock fragment 32-36 cm }\end{array}$ \\
\hline
\end{tabular}

\section{LA70790 Locality: Berm}

Core \#3.4 (Samples 3.401-3.419)

\begin{tabular}{|l|l|l|}
\hline $\begin{array}{l}\text { Soil } \\
\text { Horizon }\end{array}$ & Depth & Description \\
\hline AC & $0-10$ & $\begin{array}{l}\text { Dark brown [7.5YR3/3(d), very dark brown 2.5/3(w)] gravelly sandy clay, slightly firm, 10- } \\
\text { 15\% fine to medium rounded white tuff gravels, moderate medium granular structure, few } \\
\text { fine roots, clear lower boundary poss. welded A at base? }\end{array}$ \\
\hline CB1 & $10-30$ & Brown [7.5YR4/3(d), dark brown 3/3(w) sandy clay loam to sandy loam, loose, 5-10\% fine to \\
\hline
\end{tabular}




\begin{tabular}{|l|l|l|}
\hline & & $\begin{array}{l}\text { medium white tuff gravel, massive structure, charcoal observed 12-14, 14-16 cm, few very } \\
\text { fine roots }\end{array}$ \\
\hline CB2 & $30-42$ & $\begin{array}{l}\text { Brown [7.5YR4/3(d), dark brown 3/3(w) gravelly sandy loam, loose, 10-20\% fine to medium } \\
\text { white tuff gravel, massive structure, few very fine roots }\end{array}$ \\
\hline
\end{tabular}

\section{Site: LA70798}

\section{LA70798 Locality: Control}

Core \#1.1 (Samples 1.101-1.114)

\begin{tabular}{|l|l|l|}
\hline $\begin{array}{l}\text { Soil } \\
\text { Horizon }\end{array}$ & Depth & Description \\
\hline A & $0-20$ & $\begin{array}{l}\text { Brown [7.5YR4/2(d), 4/3(w)] sandy loam to silt loam, slightly firm to soft, 2-5\% fine } \\
\text { rounded tuff gravels, massive parting to weak fine granular structure, few fine roots, clear } \\
\text { lower boundary }\end{array}$ \\
\hline Bt & $20-28$ & $\begin{array}{l}\text { Brown [7.5YR4/4(d), 4/3(w)] clay, firm moderate fine blocky subangular structure, few fine } \\
\text { roots }\end{array}$ \\
\hline
\end{tabular}

\section{LA70798 Locality: Control}

Core \#1.2 (Samples 1.201-1.212)

\begin{tabular}{|l|l|l|}
\hline $\begin{array}{l}\text { Soil } \\
\text { Horizon }\end{array}$ & Depth & Description \\
\hline A & $0-18$ & $\begin{array}{l}\text { Brown [7.5YR4/2(d), 4/3(w)] sandy loam to silt loam, slightly firm to soft, 2-5\% fine } \\
\text { rounded tuff gravels, massive parting to weak fine granular structure, few fine roots, clear } \\
\text { lower boundary }\end{array}$ \\
\hline Bt & $18-24$ & $\begin{array}{l}\text { Brown [7.5YR4/4(d), 4/3(w)] clay, firm moderate fine blocky subangular structure, few fine } \\
\text { roots }\end{array}$ \\
\hline
\end{tabular}

\section{LA70798 Locality: Basin}

Core \#2.1 (Samples 2.101-2.121)

\begin{tabular}{|l|l|l|}
\hline $\begin{array}{l}\text { Soil } \\
\text { Horizon }\end{array}$ & Depth & Description \\
\hline CA & $0-12$ & $\begin{array}{l}\text { Dark brown [7.5YR3/2(w),(d)] gravelly sandy clay loam, slightly firm, 40\% fine rounded } \\
\text { white tuff gravels, moderate medium granular structure, many to few fine roots with depth, } \\
\text { abrupt lower boundary }\end{array}$ \\
\hline $\mathrm{C1}$ & $12-20$ & $\begin{array}{l}\text { Brown [7.5YR5/2(d), dark brown 3/2(w)] silt loam, very firm, 5-10\% medium rounded tuff } \\
\text { gravels, massive to weak fine subangular blocky structure, abrupt lower boundary }\end{array}$ \\
\hline $\mathrm{Ab}$ & $20-26$ & $\begin{array}{l}\text { Pinkish gray [7.5YR6/2(d), very dark brown 2.5/2] silty clay loam, slightly firm, 10-15\% fine } \\
\text { to medium rounded tuff gravels, weak fine granular structure, common fine roots, abrupt } \\
\text { lower boundary }\end{array}$ \\
\hline $\mathrm{BCb}$ & $26-34$ & $\begin{array}{l}\text { Pinkish gray [7.5YR6/2(d), brown 4/2(w)] silty clay loam, slightly firm, 10-15\% fine to } \\
\text { medium tuff gravels, weak fine granular parting to single grained, few fine open pores with } \\
\text { faint very fine dark brown (7.5YR3/4) iron concentrations on pore walls, few fine roots, } \\
\text { abrupt lower boundary }\end{array}$ \\
\hline $\mathrm{Cb}$ & $34-42$ & $\begin{array}{l}\text { Brown [7.5YR5/2(d), 4/2(w)] gravelly clay loam, loose, 20\% fine to medium rounded tuff } \\
\text { gravel, weak medium granular parting to single grained, few fine to medium roots, maybe } \\
\text { some very fine charcoal }\end{array}$ \\
\hline
\end{tabular}




\section{LA70798 Locality: Basin}

Core \#2.2 (Samples 2.201-2.220)

\begin{tabular}{|l|l|l|}
\hline $\begin{array}{l}\text { Soil } \\
\text { Horizon }\end{array}$ & Depth & Description \\
\hline $\mathrm{CA}$ & $0-8$ & $\begin{array}{l}\text { Dark brown [7.5YR3/2(w),(d)] gravelly clay loam, slightly firm, 40\% fine rounded white tuff } \\
\text { gravels, moderate medium granular structure, many to few fine roots with depth, abrupt lower } \\
\text { boundary }\end{array}$ \\
\hline $\mathrm{C1}$ & $8-24$ & $\begin{array}{l}\text { Brown [7.5YR5/2(d), dark brown 3/2(w)] silt loam, very firm, 5-10\% medium rounded tuff } \\
\text { gravels, massive to weak fine subangular blocky structure, abrupt lower boundary }\end{array}$ \\
\hline $\mathrm{Ab}$ & $24-28$ & $\begin{array}{l}\text { Pinkish gray [7.5YR6/2(d), very dark brown 2.5/2] silty clay loam, slightly firm, 10-15\% fine } \\
\text { to medium rounded tuff gravels, weak fine granular structure, common fine roots, abrupt } \\
\text { lower boundary }\end{array}$ \\
\hline $\mathrm{CBb}$ & $28-36$ & $\begin{array}{l}\text { Pinkish gray [7.5YR6/2(d), brown 4/2(w)] silty clay loam, slightly firm, 10-15\% fine to } \\
\text { medium tuff gravels, weak fine granular parting to single grained, few fine open pores, few } \\
\text { fine roots, abrupt lower boundary }\end{array}$ \\
\hline $\mathrm{Cb}$ & $36-40$ & $\begin{array}{l}\text { Brown [7.5YR5/2(d), 4/2(w)] gravelly clay loam, loose, 20\% fine to medium rounded tuff } \\
\text { gravel, weak medium granular parting to single grained, few fine to medium roots, maybe } \\
\text { some very fine charcoal }\end{array}$ \\
\hline
\end{tabular}

\section{LA70798 Locality: Basin}

Core \#2.3 (Samples 2.301-2.315)

\begin{tabular}{|l|l|l|}
\hline $\begin{array}{l}\text { Soil } \\
\text { Horizon }\end{array}$ & Depth & Description \\
\hline CA & $0-10$ & $\begin{array}{l}\text { Dark brown [7.5YR3/2(w),(d)] gravelly clay loam, slightly firm, 40\% fine rounded white tuff } \\
\text { gravels, moderate medium granular structure, many to few fine roots with depth, abrupt lower } \\
\text { boundary }\end{array}$ \\
\hline C1 & $10-26$ & $\begin{array}{l}\text { Brown [7.5YR5/2(d), dark brown 3/2(w)] silt loam, very firm, 5-10\% medium rounded tuff } \\
\text { gravels, massive to weak fine subangular blocky structure, abrupt lower boundary }\end{array}$ \\
\hline CB(b) & $26-30$ & $\begin{array}{l}\text { Pinkish gray [7.5YR6/2(d), brown 4/2(w)] silty clay loam, slightly firm, 10-15\% fine to } \\
\text { medium tuff gravels, weak fine granular parting to single grained, few fine open pores, few } \\
\text { fine roots, abrupt lower boundary }\end{array}$ \\
\hline
\end{tabular}

\section{LA70798 Locality: Basin}

Core \#2.4 (Samples 2.401-2.417)

\begin{tabular}{|l|l|l|}
\hline $\begin{array}{l}\text { Soil } \\
\text { Horizon }\end{array}$ & Depth & Description \\
\hline CA & $0-10$ & $\begin{array}{l}\text { Dark brown [7.5YR3/2(w),(d)] gravelly clay loam, slightly firm, 40\% fine rounded white tuff } \\
\text { gravels, moderate medium granular structure, many to few fine roots with depth, abrupt lower } \\
\text { boundary }\end{array}$ \\
\hline C1 & $10-22$ & $\begin{array}{l}\text { Brown [7.5YR5/2(d), dark brown 3/2(w)] silt loam, very firm, 5-10\% medium rounded tuff } \\
\text { gravels, massive to weak fine subangular blocky structure, abrupt lower boundary }\end{array}$ \\
\hline Ab & $22-28$ & $\begin{array}{l}\text { Pinkish gray [7.5YR6/2(d), very dark brown 2.5/2] silty clay loam, slightly firm, 10-15\% fine } \\
\text { to medium rounded tuff gravels, weak fine granular structure, common fine roots, abrupt } \\
\text { lower boundary }\end{array}$ \\
\hline CBb & $28-37$ & $\begin{array}{l}\text { Pinkish gray [7.5YR6/2(d), brown 4/2(w)] silty clay loam, slightly firm, 10-15\% fine to } \\
\text { medium tuff gravels, weak fine granular parting to single grained, few fine open pores with } \\
\text { faint very fine dark brown (7.5YR3/4) iron concentrations on pore walls, few fine roots, } \\
\text { abrupt lower boundary }\end{array}$ \\
\hline
\end{tabular}




\section{LA70798 Locality: Berm}

Core \#3.1 (Samples 3.101-3.116)

\begin{tabular}{|c|c|c|}
\hline $\begin{array}{l}\text { Soil } \\
\text { Horizon }\end{array}$ & Depth & Description \\
\hline $\mathrm{AB}$ & $0-16$ & $\begin{array}{l}\text { Dark brown [7.5YR3/2(d),(w)] sandy clay loam to gravelly sandy clay loam, slightly firm, } \\
10-20 \% \text { fine rounded tuff gravels, medium to coarse sand, moderate medium platy parting to } \\
\text { moderate fine granular structure, lens of very fine, well decayed charcoal } 6-7 \mathrm{~cm} \text { and some } \\
\text { charcoal } 4-6 \mathrm{~cm} \text {, few fine roots, possible charcoal and a very fine redware sherd fragment } 14- \\
16 \mathrm{~cm} \text {, abrupt lower boundary }\end{array}$ \\
\hline $\mathrm{R}$ & $16-22$ & Dark gray ashy tuff rock fragment (possibly burned?) \\
\hline Bw & $22-34$ & $\begin{array}{l}\text { Brown }[7.5 Y R 4 / 3(d),(w)] \text { sandy clay loam to clay loam, slightly firm, } 5-10 \% \text { fine to medium } \\
\text { tuff gravels increasing to } 15 \% \text { with depth, moderate medium platy parting to single grained } \\
\text { structure, common faint fine brown }(7.5 Y R 4 / 4) \text { mottles, few medium charcoal fragments }\end{array}$ \\
\hline
\end{tabular}

\section{LA70798 Locality: Berm}

Core \#3.2 (Samples 3.201-3.218)

\begin{tabular}{|l|l|l|}
\hline $\begin{array}{l}\text { Soil } \\
\text { Horizon }\end{array}$ & Depth & Description \\
\hline R/C & $0-4$ & White tuff rock with very fine charcoal matrix at abrupt lower boundary \\
\hline AB & $4-22$ & $\begin{array}{l}\text { Dark brown [7.5YR3/2(d),(w)] sandy clay loam to gravelly sandy clay loam, slightly firm, } \\
10-20 \% \text { fine rounded tuff gravels, medium to coarse sand, moderate medium platy parting to } \\
\text { moderate fine granular structure, few fine roots, abrupt lower boundary }\end{array}$ \\
\hline R & $22-25$ & tuff rock fragment \\
\hline Bw & $25-33$ & $\begin{array}{l}\text { Brown [7.5YR4/3(d),(w)] sandy clay loam to clay loam, slightly firm, 5-10\% fine to medium } \\
\text { tuff gravels increasing to 15\% with depth, moderate medium platy parting to single grained } \\
\text { structure, common faint fine brown (7.5YR4/4) mottles }\end{array}$ \\
\hline
\end{tabular}

\section{LA70798 Locality: Berm}

Core \#3.3 (Samples 3.301-3.315)

\begin{tabular}{|l|l|l|}
\hline $\begin{array}{l}\text { Soil } \\
\text { Horizon }\end{array}$ & Depth & Description \\
\hline AB & $0-20$ & $\begin{array}{l}\text { Dark brown [7.5YR3/2(d),(w)] sandy clay loam to gravelly sandy clay loam, slightly firm, } \\
10-20 \% \text { fine rounded tuff gravels, medium to coarse sand, moderate medium platy parting to } \\
\text { moderate fine granular structure, lens of very fine charcoal 4-6 cm, few fine roots, abrupt } \\
\text { lower boundary }\end{array}$ \\
\hline Bw & $20-34$ & $\begin{array}{l}\text { Brown [7.5YR4/3(d),(w)] sandy clay loam to clay loam, slightly firm, 5-10\% fine to medium } \\
\text { tuff gravels increasing to 15\% with depth, moderate medium platy parting to single grained } \\
\text { structure, common faint fine brown (7.5YR4/4) mottles }\end{array}$ \\
\hline
\end{tabular}


APPENDIX E: RESULTS OF RESERVOIR HYDROLOGICAL ANALYSES

\begin{tabular}{|c|c|c|c|c|c|c|c|c|}
\hline \multirow[b]{2}{*}{ Site } & \multirow[b]{2}{*}{$\begin{array}{c}\text { Catchment } \\
\text { Area }\left(\mathrm{m}^{2}\right)\end{array}$} & \multirow{2}{*}{$\begin{array}{c}\text { Basin } \\
\text { Max } \\
\text { Storage } \\
\text { Volume } \\
\left(\mathbf{m}^{3}\right)\end{array}$} & \multicolumn{6}{|c|}{ Runoff Estimates $\left(\mathrm{m}^{3}\right)$} \\
\hline & & & $\begin{array}{c}1 \text { yr max } \\
\text { event } \\
(\mathrm{CN}=87)\end{array}$ & $\begin{array}{c}1 \text { yr max } \\
\text { event } \\
(\mathrm{CN}=93)\end{array}$ & $\begin{array}{c}10 \mathrm{yr} \\
\text { max } \\
\text { event } \\
(\mathrm{CN}=87)\end{array}$ & $\begin{array}{c}10 \mathrm{yr} \\
\text { max } \\
\text { event } \\
(\mathrm{CN}=93)\end{array}$ & $\begin{array}{c}50 \text { yr } \\
\text { max } \\
\text { event } \\
(\mathrm{CN}=97)\end{array}$ & $\begin{array}{c}50 \text { yr max } \\
\text { event } \\
(\mathrm{CN}=93)\end{array}$ \\
\hline $\begin{array}{l}\text { Amoxiumqua } \\
\text { (LA481) }\end{array}$ & 7205 & 1261.03 & 91.65 & 150.55 & 256.82 & 344.55 & 389.46 & 489.79 \\
\hline $\begin{array}{l}\text { Boletsakwa } \\
\text { (LA136) }\end{array}$ & 2160 & 132.90 & 27.29 & 44.83 & 76.47 & 102.59 & 115.96 & 145.84 \\
\hline $\begin{array}{l}\text { Boletsakwa-2 } \\
\text { (LA25092) }\end{array}$ & 6253 & 717.35 & 79.81 & 131.10 & 223.63 & 300.03 & 339.14 & 426.50 \\
\hline $\begin{array}{l}\text { Kwastiyukwa } \\
\text { (LA482) }\end{array}$ & 1120 & 318.87 & 14.42 & 23.68 & 40.40 & 54.20 & 61.26 & 77.05 \\
\hline $\begin{array}{l}\text { Tovakwa } \\
\text { (LA61641) }\end{array}$ & 100566 & 729.85 & 1279.53 & 2101.82 & 3585.37 & 4810.19 & 5437.10 & 6837.78 \\
\hline $\begin{array}{l}\text { Wabakwa } \\
\text { (LA478) }\end{array}$ & 1108 & 307.88 & 13.90 & 22.84 & 38.96 & 52.26 & 59.08 & 74.29 \\
\hline $\begin{array}{l}\text { Haatse/San } \\
\text { Miguel (LA370) }\end{array}$ & 2318 & 64.80 & 26.59 & 44.68 & 73.40 & 100.40 & 113.75 & 144.99 \\
\hline $\begin{array}{l}\text { Haatse/San } \\
\text { Miguel ( LA3834) }\end{array}$ & 494 & 41.47 & 5.60 & 9.41 & 15.45 & 21.14 & 23.95 & 30.52 \\
\hline $\begin{array}{l}\text { Tsankawi-1 } \\
\text { (LA211) }\end{array}$ & 3535 & 189.67 & 40.59 & 68.20 & 112.03 & 153.24 & 173.62 & 221.30 \\
\hline $\begin{array}{l}\text { Tsankawi-2 } \\
\text { (LA211) }\end{array}$ & 2406 & 150.80 & 27.53 & 46.25 & 75.98 & 103.92 & 117.74 & 150.08 \\
\hline $\begin{array}{l}\text { Tsankawi-3 } \\
\text { (LA211) }\end{array}$ & 6242 & 95.43 & 71.85 & 120.72 & 198.31 & 271.26 & 307.32 & 391.72 \\
\hline Tsirege( LA170) & 37075 & 399.00 & 427.34 & 718.03 & 1179.56 & 1613.47 & 1827.97 & 2329.99 \\
\hline Yapashi (LA250) & 8834 & 526.22 & 101.70 & 170.88 & 280.72 & 383.99 & 435.04 & 554.52 \\
\hline $\begin{array}{l}\text { Yapashi } \\
\text { (LA70790) }\end{array}$ & 5646 & 176.71 & 65.31 & 109.74 & 180.28 & 246.60 & 279.38 & 356.11 \\
\hline $\begin{array}{l}\text { Yapashi } \\
\text { (LA70798) }\end{array}$ & 1587 & 70.87 & 18.19 & 30.57 & 50.22 & 68.70 & 77.83 & 99.20 \\
\hline
\end{tabular}




\section{APPENDIX F: RESULTS OF RESERVOIR SEDIMENTOLOGY}

\begin{tabular}{|c|c|c|c|c|c|c|c|c|c|c|}
\hline Site & \# & depth (cm) & pH & $\begin{array}{l}\text { SOM } \\
\%\end{array}$ & $\begin{array}{l}\text { Gr } \\
\%\end{array}$ & S\% & $\mathrm{Si} \%$ & $\mathrm{C} \%$ & USDA Texture & $\begin{array}{l}\text { Sat. } \\
\text { Hydr. } \\
\text { Cond. } \\
\text { mm/hr }\end{array}$ \\
\hline AMO & 1.203 & 4-6 & 6.1 & 1.8 & 6.1 & 55.2 & 31.2 & 13.6 & Sandy Loam & 28.33 \\
\hline AMO & 2.103 & $4-6$ & 5.4 & 3.4 & 0.5 & 13.3 & 57.2 & 29.5 & $\begin{array}{c}\text { Silty Clay } \\
\text { Loam }\end{array}$ & 6.91 \\
\hline AMO & 2.109 & $16-18$ & 5.7 & 2.5 & 3.2 & 15.8 & 53.9 & 30.3 & $\begin{array}{l}\text { Silty Clay } \\
\text { Loam }\end{array}$ & 6.84 \\
\hline AMO & 2.112 & $22-24$ & 6 & 2.0 & 2.0 & 17.9 & 49.5 & 32.6 & $\begin{array}{c}\text { Silty Clay } \\
\text { Loam }\end{array}$ & 5.72 \\
\hline AMO & 2.118 & $34-36$ & 6.2 & 1.4 & 13.0 & 12.4 & 58.8 & 28.8 & $\begin{array}{c}\text { Silty Clay } \\
\text { Loam }\end{array}$ & 4.05 \\
\hline AMO & 2.123 & $44-45$ & 6 & 1.9 & 2.1 & 20.5 & 48 & 31.5 & Clay Loam & 4.34 \\
\hline AMO & 3.116 & $32-34$ & 7.2 & 1.6 & 4.5 & 15.4 & 50.5 & 34.1 & $\begin{array}{l}\text { Silty Clay } \\
\text { Loam }\end{array}$ & 3.55 \\
\hline AMO & 3.154 & $118-120$ & 6.5 & 0.7 & 11.5 & 32 & 41.4 & 26.6 & Loam & 4.25 \\
\hline $\mathrm{BOL}$ & 2.306 & $10-12$ & 6.2 & 3.2 & 24.1 & 80 & 14.3 & 5.75 & Loamy Sand & 83.04 \\
\hline BOL & 2.320 & $38-40$ & 6.8 & 0.7 & 44.0 & 76.3 & 17.3 & 6.43 & Loamy Sand & 65.5 \\
\hline BOL & 2.340 & $78-80$ & 6.9 & 1.8 & 21.9 & 57.4 & 29.1 & 13.5 & Sandy Loam & 25.34 \\
\hline BOL & 2.347 & $92-94$ & 8.3 & 1.4 & 24.2 & 55.2 & 32.7 & 12.1 & Sandy Loam & 26.98 \\
\hline BOL & $\begin{array}{c}3.110- \\
112\end{array}$ & $18-20,22-24$ & 7 & 1.8 & 16.6 & 58.9 & 30.7 & 10.4 & Sandy Loam & 36.8 \\
\hline BOL2 & 1.109 & $16-18$ & . & 1.7 & 0.4 & 38.7 & 49.6 & 11.7 & Silt Loam & 22.89 \\
\hline BOL2 & 2.120 & $38-40$ & . & 2.0 & 0.0 & 8.64 & 61.8 & 29.6 & $\begin{array}{l}\text { Silty Clay } \\
\text { Loam }\end{array}$ & 5.68 \\
\hline BOL2 & 2.130 & $58-60$ & . & 1.7 & 7.5 & 20.4 & 60.1 & 19.5 & Silt Loam & 8.97 \\
\hline BOL2 & 2.161 & $120-122$ & . & 1.4 & 10.3 & 26 & 54 & 20 & Silt Loam & 8.99 \\
\hline BOL2 & 2.170 & $138-140$ & . & 1.3 & 15.9 & 31.6 & 50.2 & 18.2 & Silt Loam & 11.29 \\
\hline KWA & 2.302 & $2-4$ & 6.2 & 2.6 & 0.2 & 14.2 & 52.8 & 33 & $\begin{array}{l}\text { Silty Clay } \\
\text { Loam }\end{array}$ & 6.2 \\
\hline KWA & 2.314 & $27-29$ & 6.4 & 2.3 & 0.0 & 11 & 54.7 & 34.3 & $\begin{array}{l}\text { Silty Clay } \\
\text { Loam }\end{array}$ & 5.43 \\
\hline
\end{tabular}




\begin{tabular}{|c|c|c|c|c|c|c|c|c|c|c|}
\hline KWA & 2.321 & $41-43$ & 6.6 & 1.3 & 0.0 & 14.9 & 56.9 & 28.2 & $\begin{array}{l}\text { Silty Clay } \\
\text { Loam }\end{array}$ & 7.09 \\
\hline KWA & 2.329 & $57-59$ & 6.6 & 1.5 & 4.8 & 10.8 & 59 & 30.2 & $\begin{array}{l}\text { Silty Clay } \\
\text { Loam }\end{array}$ & 4.54 \\
\hline KWA & 3.129 & $60-62$ & 7.6 & 1.0 & 0.0 & 19.9 & 58.7 & 21.4 & Silt Loam & 6.29 \\
\hline TOV & 2.303 & $4-6$ & 6 & 3.6 & 0.0 & 12.9 & 54.7 & 32.4 & $\begin{array}{l}\text { Silty Clay } \\
\text { Loam }\end{array}$ & 3.33 \\
\hline TOV & 2.321 & $40-42$ & 6.7 & 1.5 & 0.2 & 10.7 & 56.7 & 32.6 & $\begin{array}{l}\text { Silty Clay } \\
\text { Loam }\end{array}$ & 4.03 \\
\hline TOV & 2.330 & $58-60$ & 6.9 & 1.7 & 0.9 & 19.2 & 48.1 & 32.7 & $\begin{array}{l}\text { Silty Clay } \\
\text { Loam }\end{array}$ & 4.23 \\
\hline TOV & 2.333 & $64-66$ & 7 & 2.0 & 28.9 & 15.6 & 57.9 & 26.5 & Silt Loam & 6.58 \\
\hline TOV & $\begin{array}{c}3.150- \\
151\end{array}$ & $110-114$ & 6.3 & 2.4 & 8.9 & 37.6 & 43.6 & 18.8 & Loam & 15.14 \\
\hline WAB & 1.203 & $4-6$ & . & 4.2 & 28.4 & 54.3 & 31.5 & 14.2 & Sandy Loam & 37.10 \\
\hline WAB & 1.207 & $12-14$ & . & 3.0 & 37.7 & 62.4 & 27.6 & 10 & Sandy Loam & 47.44 \\
\hline WAB & 2.103 & $4-6$ & . & 4.7 & 26.0 & 26.1 & 52.4 & 21.5 & Silt Loam & 20.35 \\
\hline WAB & 2.109 & $16-18$ & . & 3.4 & 35.0 & 21.5 & 52.6 & 25.9 & Silt Loam & 10.9 \\
\hline WAB & 2.115 & $28-30$ & . & 2.3 & 8.4 & 7.64 & $\begin{array}{c}69.4 \\
6\end{array}$ & 22.9 & Silt Loam & 7.85 \\
\hline WAB & 2.121 & $40-42$ & . & 5.6 & 47.4 & 23.9 & 59 & 17.1 & Silt Loam & 35.05 \\
\hline WAB & 2.328 & $56-58$ & . & 1.2 & 19.7 & 19.9 & 66.5 & 13.6 & Silt Loam & 10.19 \\
\hline WAB & 2.334 & $68-70$ & . & 1.7 & 39.8 & 20.4 & 65.7 & 13.9 & Loam & 12.57 \\
\hline SMG & 2.102 & $2-4$ & . & 1.6 & 13.0 & 54.3 & 31 & 14.7 & Sandy Loam & 24.06 \\
\hline SMG & 2.207 & $12-14$ & . & 1.2 & 8.5 & 75.4 & 15.6 & 9 & Sandy Loam & 52.69 \\
\hline SMG & 2.216 & $32-34$ & . & 1.5 & 25.2 & 49.8 & 33.8 & 16.4 & Loam & 15.64 \\
\hline SMG & 2.228 & $56-58$ & . & 1.4 & 16.8 & 41.5 & 39.1 & 19.4 & Loam & 13.23 \\
\hline
\end{tabular}




\begin{tabular}{|c|c|c|c|c|c|c|c|c|c|c|}
\hline LA3834 & 2.202 & $2-4$ & . & 2.7 & 8.5 & 58.1 & 29.9 & 12 & Sandy Loam & 36.41 \\
\hline LA3834 & 2.211 & $20-22$ & . & 2.3 & 3.1 & 12.3 & 58.2 & 29.5 & $\begin{array}{l}\text { Silty Clay } \\
\text { Loam }\end{array}$ & 6.29 \\
\hline LA3834 & 2.217 & $32-34$ & . & 1.9 & 14.5 & 8.77 & $\begin{array}{c}65.8 \\
3\end{array}$ & 25.4 & Silt Loam & 5.76 \\
\hline TK1 & 2.102 & $2-4$ & . & 3.2 & 0.7 & 48.9 & 33.1 & 11.4 & Loam & 40.31 \\
\hline TK1 & 2.107 & $12-14$ & . & 2.6 & 18.5 & 22.3 & 47.1 & 30.6 & Clay Loam & 5.56 \\
\hline TK1 & 2.116 & $32-34$ & . & 2.1 & 1.2 & 25.7 & 47 & 27.3 & Clay Loam & 7.2 \\
\hline TK2 & 1.202 & $2-4$ & . & 2.2 & 2.9 & 41.8 & 40.2 & 18 & Loam & 16.93 \\
\hline TK2 & 1.205 & $10-12$ & . & 2.3 & 1.9 & 25.7 & 55.9 & 18.4 & Silt Loam & 13.75 \\
\hline TK2 & 2.202 & $2-4$ & . & 2.3 & 5.5 & 40 & 39.1 & 20.9 & Loam & 12.95 \\
\hline TK2 & 2.210 & $18-20$ & . & 1.9 & 24.1 & 42.2 & 39.7 & 18.1 & Loam & 12.79 \\
\hline TK2 & 2.219 & $36-38$ & . & 1.5 & 22.2 & 64.8 & 28.2 & 7.0 & Sandy Loam & 46.63 \\
\hline TK3 & 2.404 & $6-8$ & . & 7.3 & 0.0 & 11.3 & 51 & 37.7 & $\begin{array}{l}\text { Silty Clay } \\
\text { Loam }\end{array}$ & 19.36 \\
\hline TK3 & 2.411 & $20-22$ & . & 2.8 & 6.5 & 27.5 & 41.8 & 30.7 & Clay Loam & 6.36 \\
\hline TK3 & 2.421 & $42-44$ & . & 3.2 & 10.3 & 16.7 & 48.8 & 34.5 & Silt Loam & 6.22 \\
\hline TSR & 2.101 & $0-2$ & . & 1.5 & 3.4 & 29 & 50.6 & 20.4 & Silt Loam & 9.63 \\
\hline TSR & 2.127 & $52-54$ & . & 2.0 & 2.6 & 10.9 & 61 & 28.1 & $\begin{array}{l}\text { Silty Clay } \\
\text { Loam }\end{array}$ & 6.03 \\
\hline TSR & 2.136 & 70-72 & . & 2.0 & 31.0 & 12.7 & 59.6 & 27.7 & $\begin{array}{l}\text { Silty Clay } \\
\text { Loam }\end{array}$ & 6.08 \\
\hline TSR & 2.146 & 90-92 & . & 1.5 & 34.7 & 29 & 46.3 & 24.7 & Loam & 4.84 \\
\hline TSR & 3.437 & $72-74$ & . & 0.9 & 3.1 & 59.5 & 26.8 & 13.7 & Sandy Loam & 26.09 \\
\hline YAP & 1.202 & $2-4$ & . & 3.6 & 13.9 & 46.1 & 36.9 & 17 & Loam & 25.34 \\
\hline
\end{tabular}




\begin{tabular}{|c|c|c|c|c|c|c|c|c|c|c|}
\hline YAP & 1.205 & $10-12$ & . & 2.0 & 13.7 & 50.7 & 39.6 & 9.74 & Loam & 32.28 \\
\hline YAP & 1.207 & $16-18$ & . & 2.5 & 11.5 & 22 & 63.1 & 14.8 & Silt Loam & 15.13 \\
\hline YAP & 2.302 & $2-4$ & . & 5.7 & 14.6 & 9.19 & 66.3 & 24.5 & Silt Loam & 26.04 \\
\hline YAP & 2.307 & $14-16$ & . & 3.9 & 20.3 & 9.54 & 59.7 & 31.1 & $\begin{array}{l}\text { Silty Clay } \\
\text { Loam }\end{array}$ & 9.62 \\
\hline YAP & 2.315 & $30-32$ & . & 3.6 & 18.7 & 15.6 & 58.7 & 25.7 & Silt Loam & 10.78 \\
\hline YAP & 2.326 & $54-56$ & . & 3.1 & 23.1 & 7.75 & 64.3 & 28 & $\begin{array}{l}\text { Silty Clay } \\
\text { Loam }\end{array}$ & 8.02 \\
\hline YAP & 2.332 & $66-68$ & . & 2.3 & 46.0 & 16.3 & 55 & 28.7 & $\begin{array}{l}\text { Silty Clay } \\
\text { Loam }\end{array}$ & 4.08 \\
\hline YAP & 2.335 & $73-75$ & . & 2.1 & 21.5 & 18.3 & 51.2 & 30.5 & $\begin{array}{l}\text { Silty Clay } \\
\text { Loam }\end{array}$ & 4.59 \\
\hline LA70790 & 1.202 & $2-4$ & . & 1.8 & 5.8 & 40.8 & 42.4 & 16.8 & Loam & 15.93 \\
\hline LA70790 & 1.205 & $10-12$ & . & 2.2 & 12.4 & 3.97 & 71.3 & 24.7 & Silt Loam & 6.56 \\
\hline LA70790 & 2.303 & $2-4$ & . & 1.1 & 5.0 & 64.6 & 25.2 & 10.2 & Sandy Loam & 40.75 \\
\hline LA70790 & 2.311 & $22-24$ & . & 1.3 & 24.1 & 43.8 & 45.2 & 11 & Loam & 19.82 \\
\hline LA70790 & 2.317 & $36-38$ & . & 1.6 & 38.4 & 14.1 & 60.3 & 25.6 & Silt Loam & 4.61 \\
\hline LA70790 & 2.324 & $52-54$ & . & 1.6 & 13.9 & 10.6 & 62.8 & 26.6 & $\begin{array}{l}\text { Silty Clay } \\
\text { Loam }\end{array}$ & 4.29 \\
\hline LA70798 & 2.203 & $4-6$ & . & 2.9 & 24.8 & 19.2 & 58.4 & 22.4 & Silt Loam & 10.3 \\
\hline LA70798 & 2.206 & $10-12$ & . & 2.7 & 34.8 & 6.61 & 74.3 & 19.1 & Silt Loam & 9.34 \\
\hline LA70798 & 2.210 & $18-20$ & 5.7 & 2.4 & 3.8 & 10.3 & 65.1 & 24.6 & Silt Loam & 8.03 \\
\hline LA70798 & 2.215 & $28-30$ & 5.6 & 1.3 & 19.0 & 13.8 & 55.6 & 30.6 & $\begin{array}{c}\text { Silty Clay } \\
\text { Loam }\end{array}$ & 3.38 \\
\hline LA70798 & 2.216 & $30-32$ & . & 2.4 & 27.0 & 10.9 & 63.6 & 25.5 & Silt Loam & 6.25 \\
\hline LA70798 & 2.219 & $36-38$ & 5.6 & 1.7 & 10.4 & 28.8 & 44.4 & 26.8 & Clay Loam & 5.94 \\
\hline LA70798 & 3.203 & $6-8$ & 6.9 & 2.3 & 25.7 & 23.3 & 51.4 & 25.3 & Silt Loam & 6.82 \\
\hline LA70798 & 3.209 & $18-20$ & 7 & 1.0 & 15.4 & 43.2 & 43.2 & 13.6 & Loam & 15.72 \\
\hline
\end{tabular}




\section{APPENDIX G: SOIL MICROMORPHOLOGY SAMPLE INVENTORY}

\begin{tabular}{|c|c|c|c|}
\hline Site & Core \# & $\begin{array}{l}\text { Sample } \\
\text { Depth (cm) }\end{array}$ & Pedological Context \\
\hline \multirow{11}{*}{ Amoxiumqua } & AMO1.1 & $1-5$ & A horizon \\
\hline & AMO2 & $3-7$ & A horizon (top) \\
\hline & $\mathrm{AMO} 2$ & $16-20$ & A horizon (bottom) \\
\hline & AMO2 & $20.5-24.5$ & C1 horizon (top) \\
\hline & AMO2 & $33-37$ & C1 horizon (bottom, above rock) \\
\hline & $\mathrm{AMO} 2$ & $42.5-46.5$ & C2 horizon (bottom, below rock) \\
\hline & AMO3.3 & $19-23$ & $\wedge \mathrm{C} 1$ horizon \\
\hline & AMO3.3 & $34-38$ & $\wedge \mathrm{C} 2$ horizon \\
\hline & AMO3.3 & $86-90$ & $\wedge \mathrm{C} 3$ horizon \\
\hline & AMO3.3 & $120-124$ & 2Ab horizon \\
\hline & AMO3.3 & $129-133$ & 2Cb horizon \\
\hline \multirow{8}{*}{ Boletsakwa } & BOL1.2 & $9-13$ & A horizon \\
\hline & BOL2.5 & $16-20$ & AC horizon \\
\hline & BOL2.5 & $65-69$ & AC3 horizon \\
\hline & BOL2.5 & $85.5-89.5$ & 2CA horizon (interbedded) \\
\hline & BOL2.5 & $96-100$ & 2CA-C horizon, interbedded (poorly) at base \\
\hline & BOL3.2 & $5-9$ & A horizon w/rock frags at bottom of sample \\
\hline & BOL3.2 & $26-30$ & Ab? Interbedded dark gray fines and brown fines with gravels \\
\hline & BOL3.2 & $65-69$ & Rep of C1 horizon, medium gravels \\
\hline \multirow{10}{*}{ Kwastiyukwa } & KWA1.1 & $14-18$ & Bottom A horizon, transition to B horizon \\
\hline & KWA1.1 & $57-61$ & Bedded BC horizon \\
\hline & KWA2 & 6-Feb & A horizon \\
\hline & KWA2 & $16.5-20.5$ & Top of BC horizon \\
\hline & KWA2 & $27-31$ & Base of BC horizon \\
\hline & KWA2 & $31-35$ & Bedded CB horizon, contact with bedrock \\
\hline & KWA3.3 & $13-17$ & ^CA1 horizon (2-microfacies observed) \\
\hline & KWA3.3 & $29-33$ & $\wedge$ CA2 horizon \\
\hline & KWA3.3 & $52-56$ & 2Ab horizon \\
\hline & KWA3.3 & $66-70$ & 2Cb horizon (bedding features) \\
\hline \multirow{4}{*}{$\begin{array}{l}\text { Tovakwa } \\
\text { (LA 61641) }\end{array}$} & TOV1.2 & $4-8$ & A horizon \\
\hline & TOV1.2 & $34-38$ & B horizon w/gravels \\
\hline & TOV2.2 & $13-17$ & A/Bw-Bg horizon \\
\hline & TOV2.2 & $30-34$ & Bw-Bg horizon \\
\hline
\end{tabular}




\begin{tabular}{|c|c|c|c|}
\hline & TOV2.2 & $66-70$ & C horizon w/ bedding at base of basin fill \\
\hline & TOV3.2 & $28-32$ & $\begin{array}{l}\wedge \mathrm{C} \text { horizon, poorly sorted sandy clay fill w/clay nodules and } \\
\text { sand }\end{array}$ \\
\hline & TOV3.2 & $88-92$ & $\begin{array}{l}\wedge \mathrm{C} 3 \text { horizon, bottom of fine grained fill at contact with rocks } \\
\text { and possible bone }\end{array}$ \\
\hline \multirow{8}{*}{ Wabakwa } & WAB1.1 & $0-4$ & A horizon \\
\hline & WAB1.1 & $22-26$ & C horizon \\
\hline & WAB2.4 & $16-20$ & Transition AC-B horizons \\
\hline & WAB2.4 & $37-41$ & Transition between high gravel BC and lower C horizon \\
\hline & WAB2.4 & $48-52$ & Transition C-2C horizons \\
\hline & WAB3.1 & $13-17$ & A2 horizon \\
\hline & WAB3.1 & 31-35 & BC horizon \\
\hline & WAB3.1 & $42-46$ & Possible buried A horizon \\
\hline San Miguel & SMG2.2 & $24-28$ & Cb1 horizon - bottom-most strata of gravelly basin fill \\
\hline \multirow{6}{*}{ Tsankawi } & TK1_2.1 & $36-40$ & Base of AC horizon \\
\hline & TK1_3.2 & $29-33$ & Base of 2Cab-natural buried (truncated?) soil horizon \\
\hline & TK2_1.2 & $4-8$ & Rep of natural AC horizon \\
\hline & TK2_2.4 & $30-35$ & C3 horizon \\
\hline & TK3_2.3 & $8-12$ & Rep AC1 horizon \\
\hline & TK3_2.3 & $20-24$ & Rep AC2 horizon \\
\hline \multirow{6}{*}{ Tsirege } & TSR1.1 & $43-47$ & B horizon \\
\hline & TSR2.3 & $15-19$ & Upper basin fill, fines w/few $\mathrm{f}$ gr \\
\hline & TSR2.3 & $68-72$ & Bedded fines below red tuff \\
\hline & TSR2.3 & $94-98$ & Fines with gravels and sherds at base \\
\hline & TSR3.3 & $28-32$ & Sandy loam with fine gravels above red tuff \\
\hline & TSR3.3 & $85.5-89.5$ & Contact between coarse seds and intact buried surface \\
\hline \multirow{7}{*}{ Yapashi } & YAP1.2 & $6-10$ & AC horizon \\
\hline & YAP1.2 & $12-16$ & Bw horizon \\
\hline & YAP2.3 & $10-14$ & Contact between C1-C2 \\
\hline & YAP2.3 & $48-52$ & Contact/top of C5 \\
\hline & YAP2.3 & $75-78$ & C7-base of basin fill \\
\hline & YAP3.2 & $8-12$ & Base of AC horizon with sherd and boundary with C1 \\
\hline & YAP3.2 & $22-26$ & Rep of C1 \\
\hline \multirow{2}{*}{ LA70790 } & 70790_2.3 & $8-12$ & top of basin fill \\
\hline & 70790_2.3 & $54-57$ & Base of basin fill \\
\hline \multirow{3}{*}{ LA70798 } & 70798_2.4 & $22-26$ & Ab horizon \\
\hline & 70798_3.3 & $14-18$ & Overthickened A horizon? \\
\hline & 70798_3.3 & $22-26$ & Bw horizon \\
\hline
\end{tabular}


APPENDIX H: RESERVOIR RADIOCARBON DATING REPORTS

Amoxiumqua [LA 481] (n=6)

\begin{tabular}{|c|c|c|c|c|c|}
\hline $\begin{array}{l}\text { KECK } \\
\text { Lab \# }\end{array}$ & Sample ID & $\begin{array}{c}\text { Context \& } \\
\text { depth below } \\
\text { surface (cm) }\end{array}$ & Material dated & $\begin{array}{l}{ }^{14} \mathrm{C} \text { age } \\
\text { (BP) }\end{array}$ & $\begin{array}{c}2-\sigma \text { calibrated dates } \\
(\text { OxCal 4.2) }\end{array}$ \\
\hline 161827 & AMO 2.310 & basin (19) & woody twig & $265 \pm 20$ & $\begin{array}{c}1526-1557,1631- \\
1667,1784-1796\end{array}$ \\
\hline 172749 & AMO2.313 & basin (25) & $\begin{array}{l}\text { needle bundle and seed } \\
\text { frags }\end{array}$ & $475+15$ & $1420-1446$ \\
\hline 161826 & AMO 2.216 & basin (31) & needle & $545 \pm 35$ & $1310-1360,1386-1438$ \\
\hline 165051 & AMO 2.125 & basin (41) & angio leaf tissue & $600+25$ & 1299-1370, 1380-1407 \\
\hline 170990 & AMO3.211 & berm (21) & needle and twig xylum & $685 \pm 15$ & 1276-1300, 1368-1382 \\
\hline 165068 & AMO3.152 & berm (115) & angio leaf and axis & $935+25$ & $1031-1157$ \\
\hline
\end{tabular}

Boletsakwa [LA 136] (n=7)

\begin{tabular}{|c|c|c|c|c|c|}
\hline $\begin{array}{l}\text { KECK } \\
\text { Lab \# }\end{array}$ & Sample ID & $\begin{array}{l}\text { Context \& } \\
\text { depth below } \\
\text { surface (cm) }\end{array}$ & Material dated & $\begin{array}{l}{ }^{14} \mathrm{C} \text { age } \\
\text { (BP) }\end{array}$ & $\begin{array}{c}2-\sigma \text { calibrated dates } \\
(\text { OxCal 4.2) }\end{array}$ \\
\hline 172750 & BOL2.408 & $\begin{array}{c}\text { basin } \\
(14-16)\end{array}$ & $\begin{array}{l}\text { charred angio xylum } \\
\text { fragments }\end{array}$ & $175 \pm 15$ & $\begin{array}{l}\text { 1667-1684, 1734- } \\
\text { 1784, 1796-1807, } \\
\text { 1929-modern }\end{array}$ \\
\hline 165050 & BOL 2.421 & $\begin{array}{l}\text { basin } \\
(40-42)\end{array}$ & Charred needle bundle base & $485 \pm 15$ & $1417-1444$ \\
\hline 172751 & BOL2.434 & $\begin{array}{l}\text { basin } \\
(62-68)\end{array}$ & $\begin{array}{l}\text { charred angio xylum } \\
\text { fragments }\end{array}$ & $865 \pm 20$ & 1056-1076, 1153-1222 \\
\hline 161823 & BOL 2.441 & $\begin{array}{l}\text { basin } \\
(80-82)\end{array}$ & charred woody twig & $780 \pm 25$ & $1218-1277$ \\
\hline 161822 & BOL 2.444 & $\begin{array}{l}\text { basin } \\
(86-88)\end{array}$ & charred forb axes & $780 \pm 30$ & $1210-1281$ \\
\hline 165048 & BOL 3.110A & $\begin{array}{l}\text { berm } \\
(18-20)\end{array}$ & Charred xylum and stem & $425 \pm 20$ & $1433-1483$ \\
\hline 165049 & BOL 3.110B & $\begin{array}{l}\text { berm } \\
(18-20)\end{array}$ & $\begin{array}{l}\text { Charred xylem (exterior } \\
\text { ring?) }\end{array}$ & $335 \pm 15$ & $1486-1636$ \\
\hline
\end{tabular}


Boletsakwa-2 [LA 25092] (n=3)

\begin{tabular}{|c|c|c|c|c|c|}
\hline $\begin{array}{l}\text { KECK } \\
\text { Lab \# }\end{array}$ & Sample ID & $\begin{array}{l}\text { Context \& } \\
\text { depth below } \\
\text { surface (cm) }\end{array}$ & Material dated & $\begin{array}{l}{ }^{14} \mathrm{C} \text { age } \\
\text { (BP) }\end{array}$ & $\begin{array}{c}2-\sigma \text { calibrated dates } \\
(\text { OxCal 4.2) }\end{array}$ \\
\hline 170991 & BOL2 2.129 & $\begin{array}{c}\text { basin } \\
(56-58)\end{array}$ & charred bark scale fragment & $315 \pm 20$ & 1493-1602, 1615-1645 \\
\hline 168921 & $\begin{array}{c}\text { BOL2 } \\
2.165-166\end{array}$ & $\begin{array}{c}\text { basin (128- } \\
132)\end{array}$ & charred angio wood xylum & $485+35$ & 1331-1338, 1397-1461 \\
\hline 165052 & $\begin{array}{c}\text { BOL2 } \\
3.129-132\end{array}$ & $\begin{array}{c}\text { berm } \\
(57-65)\end{array}$ & Charred needle fragment & $720 \pm 25$ & 1256-1299, 1371-1379 \\
\hline
\end{tabular}

\section{Kwastiyukwa [LA 482] (n=5)}

\begin{tabular}{|c|c|c|c|c|c|}
\hline $\begin{array}{l}\text { KECK } \\
\text { Lab \# }\end{array}$ & Sample ID & $\begin{array}{c}\text { Context \& } \\
\text { depth below } \\
\text { surface (cm) }\end{array}$ & Material dated & $\begin{array}{l}{ }^{14} \mathrm{C} \text { age } \\
\text { (BP) }\end{array}$ & $\begin{array}{c}2-\sigma \text { calibrated dates } \\
\text { (OxCal 4.2) }\end{array}$ \\
\hline 165053 & KWA 2.109 & $\begin{array}{c}\text { basin } \\
(16-18)\end{array}$ & Charred wood xylum & $280+15$ & 1523-1559, 1631-1658 \\
\hline 172753 & KWA2.319 & $\begin{array}{c}\text { basin } \\
(33-39)\end{array}$ & $\begin{array}{l}\text { aggregated charred cuticle, } \\
\text { needle bundle, microchar of } \\
\text { xylum and cuticle }\end{array}$ & $490 \pm 15$ & $1415-1442$ \\
\hline 165054 & KWA 2.227 & $\begin{array}{l}\text { basin } \\
(52-54)\end{array}$ & $\begin{array}{l}\text { Charred wood xylum } \\
\text { fragments }\end{array}$ & $575+15$ & 1316-1355, 1388-1412 \\
\hline 165057 & KWA 2.232 & $\begin{array}{l}\text { basin } \\
(62-65)\end{array}$ & Charred wood xylum & $890 \pm 15$ & $\begin{array}{l}\text { 1048-1086, 1123- } \\
1138,1149-1210\end{array}$ \\
\hline 165058 & KWA 3.130 & $\begin{array}{l}\text { berm } \\
(62-64)\end{array}$ & $\begin{array}{l}\text { Charred wood xylum } \\
\text { fragments }\end{array}$ & $920 \pm 15$ & $1040-1110,1116-1161$ \\
\hline
\end{tabular}

Haatse/San Miguel [LA370] (n=4)

\begin{tabular}{|c|c|c|c|c|c|}
\hline $\begin{array}{l}\text { KECK } \\
\text { Lab \# }\end{array}$ & Sample ID & $\begin{array}{l}\text { Context \& } \\
\text { depth below } \\
\text { surface (cm) }\end{array}$ & Material dated & $\begin{array}{l}{ }^{14} \mathrm{C} \text { age } \\
\text { (BP) }\end{array}$ & $\begin{array}{c}2-\sigma \text { calibrated dates } \\
\text { (OxCal 4.2) }\end{array}$ \\
\hline 170999 & SMG 2.107 & $\begin{array}{l}\text { basin } \\
(10-14)\end{array}$ & $\begin{array}{l}\text { aggregated charred bark } \\
\text { scale and base of leaf } \\
\text { bundle }\end{array}$ & Modern & $x_{2}$ \\
\hline 172757 & SMG2.108 & $\begin{array}{l}\text { basin } \\
(10-16)\end{array}$ & $\begin{array}{l}\text { aggregated charred cuticle, } \\
\text { angio bark scales, and } \\
\text { xylum }\end{array}$ & $475 \pm 15$ & $1420-1446$ \\
\hline 172758 & SMG2.231 & $\begin{array}{l}\text { basin } \\
(60-64)\end{array}$ & $\begin{array}{l}\text { aggregated microchar of } \\
\text { angio twig and wood xylum }\end{array}$ & $615 \pm 15$ & 1297-1330, 1338-1398 \\
\hline 172759 & SMG_3.109 & $\begin{array}{c}\text { berm } \\
(12-18)\end{array}$ & $\begin{array}{l}\text { aggregated charred cuticle } \\
\text { and angio xylum }\end{array}$ & $740 \pm 25$ & $1225-1233,1243-1290$ \\
\hline
\end{tabular}

Haatse/San Miguel [LA3834] $(n=3)$

\begin{tabular}{|c|c|c|c|c|c|}
\hline $\begin{array}{l}\text { KECK } \\
\text { Lab \# }\end{array}$ & Sample ID & $\begin{array}{c}\text { Context \& } \\
\text { depth below } \\
\text { surface (cm) }\end{array}$ & Material dated & $\begin{array}{l}{ }^{14} \mathrm{C} \text { age } \\
\text { (BP) }\end{array}$ & $\begin{array}{l}2-\sigma \text { calibrated dates } \\
\text { (OxCal 4.2) }\end{array}$ \\
\hline 172754 & LA3834_2.208 & $\begin{array}{c}\text { basin } \\
(10-16)\end{array}$ & $\begin{array}{l}\text { aggregated charred cuticle } \\
\text { and xylum fragments }\end{array}$ & $470+20$ & $1418-1450$ \\
\hline 170993 & LA3834 2.218 & $\begin{array}{c}\text { basin } \\
(34-36)\end{array}$ & $\begin{array}{l}\text { aggregated charred cuticle } \\
\text { and angio xylum }\end{array}$ & $585+20$ & 1306-1364, 1385-1411 \\
\hline 172755 & LA3834_3.105 & $\begin{array}{l}\text { berm } \\
(4-10)\end{array}$ & $\begin{array}{l}\text { aggregated micro char of } \\
\text { cuticle and xylum frags }\end{array}$ & $\begin{array}{c}1115 \pm \\
45\end{array}$ & $\begin{array}{l}\text { 777-793, 802-846, } \\
\text { 856-1017 }\end{array}$ \\
\hline
\end{tabular}




\begin{tabular}{|c|c|c|c|c|c|}
\hline $\begin{array}{l}\text { KECK } \\
\text { Lab \# }\end{array}$ & Sample ID & $\begin{array}{c}\text { Context \& } \\
\text { depth below } \\
\text { surface (cm) }\end{array}$ & Material dated & $\begin{array}{l}{ }^{14} \mathrm{C} \text { age } \\
\text { (BP) }\end{array}$ & $\begin{array}{c}2-\sigma \text { calibrated dates } \\
\text { (OxCal 4.2) }\end{array}$ \\
\hline 165060 & TOV2.509-510 & $\begin{array}{c}\text { basin } \\
(16-20)\end{array}$ & charred needle & $790 \pm 30$ & $1190-1279$ \\
\hline 161824 & TOV 2.121 & $\begin{array}{c}\text { basin } \\
(40-42)\end{array}$ & charred needle & Modern & - \\
\hline 161825 & TOV2.128 & $\begin{array}{c}\text { basin } \\
(54-56)\end{array}$ & charred needle & Modern & - \\
\hline 168922 & TOV2.331-332 & $\begin{array}{c}\text { basin } \\
(60-64)\end{array}$ & aggregated wood xylum & $805 \pm 25$ & $1189-1271$ \\
\hline 165059 & TOV3.150 & $\begin{array}{c}\text { berm (110- } \\
112)\end{array}$ & charred needle & $\begin{array}{c}1100 \pm \\
20\end{array}$ & $892-990$ \\
\hline
\end{tabular}

Tsankawi [LA 211] (n=11)

\begin{tabular}{|c|c|c|c|c|c|}
\hline $\begin{array}{l}\text { KECK } \\
\text { Lab \# }\end{array}$ & Sample ID & $\begin{array}{c}\text { Context \& } \\
\text { depth below } \\
\text { surface (cm) }\end{array}$ & Material dated & $\begin{array}{l}{ }^{14} \mathrm{C} \text { age } \\
\text { (BP) }\end{array}$ & $\begin{array}{c}2-\sigma \text { calibrated dates } \\
(\text { OxCal 4.2) }\end{array}$ \\
\hline 172760 & TK1_2.207 & $\begin{array}{l}\text { basin } \\
(8-14)\end{array}$ & $\begin{array}{l}\text { aggregated microchar of } \\
\text { cuticle and needle frags }\end{array}$ & $495+15$ & $1413-1440$ \\
\hline 171000 & TK1_2.221 & $\begin{array}{l}\text { basin } \\
(36-42)\end{array}$ & $\begin{array}{l}\text { aggregated charred cuticles, } \\
\text { bark scales, and pine needle } \\
\text { fragment }\end{array}$ & $470 \pm 15$ & $1422-1448$ \\
\hline 172763 & TK1_3.412 & $\begin{array}{l}\text { berm } \\
(19-25)\end{array}$ & $\begin{array}{l}\text { aggregated microchar of } \\
\text { cuticle, needle frag, } \\
\text { cambium, bark scale }\end{array}$ & $650 \pm 15$ & 1285-1316, 1355-1390 \\
\hline 172764 & TK2_2.405 & $\begin{array}{l}\text { basin } \\
(6-10)\end{array}$ & $\begin{array}{l}\text { aggregated charred angio } \\
\text { wood xylum }\end{array}$ & $535 \pm 15$ & $1330-1340,1396-1431$ \\
\hline 172765 & TK2_2.412 & $\begin{array}{l}\text { basin } \\
(24-26)\end{array}$ & $\begin{array}{l}\text { aggregated charred angio } \\
\text { wood xylum }\end{array}$ & $485 \pm 20$ & 1414-1445 \\
\hline 171003 & TK2_2.319 & $\begin{array}{c}\text { basin } \\
(34-38)\end{array}$ & $\begin{array}{l}\text { aggregated charred bark } \\
\text { scales, cuticle fragments, } \\
\text { and xylum/bark scale }\end{array}$ & $930 \pm 15$ & $1039-1155$ \\
\hline 171004 & TK2_3.310 & $\begin{array}{l}\text { basin } \\
(18-24)\end{array}$ & $\begin{array}{l}\text { aggregated charred twig } \\
\text { xylum, cuticle and seed } \\
\text { fragments }\end{array}$ & $675+15$ & 1278-1305, 1365-1385 \\
\hline 171005 & TK3_2.410 & $\begin{array}{l}\text { basin } \\
(18-20)\end{array}$ & $\begin{array}{l}\text { aggregated charred pine } \\
\text { needle frag, cuticle, and } \\
\text { leaf bundle fragment }\end{array}$ & $580 \pm 15$ & $1313-1358,1387-1410$ \\
\hline 171006 & TK3_2.316 & $\begin{array}{c}\text { basin } \\
(34-36)\end{array}$ & $\begin{array}{l}\text { aggregated charred seed } \\
\text { and needle fragments }\end{array}$ & $550 \pm 15$ & 1324-1345, 1392-1423 \\
\hline 171007 & TK3_3.209 & $\begin{array}{l}\text { berm } \\
(16-18)\end{array}$ & charred bark scale fragment & $335 \pm 20$ & $1481-1639$ \\
\hline 172766 & TK3_3.217 & $\begin{array}{l}\text { berm } \\
(28-34)\end{array}$ & $\begin{array}{l}\text { aggregated microchar of } \\
\text { angio wood xylum and } \\
\text { cuticle }\end{array}$ & $425+15$ & $1436-1472$ \\
\hline
\end{tabular}


Tsirege [LA 170] (n=4)

\begin{tabular}{|c|c|c|c|c|c|}
\hline $\begin{array}{l}\text { KECK } \\
\text { Lab \# }\end{array}$ & Sample ID & $\begin{array}{l}\text { Context \& } \\
\text { depth below } \\
\text { surface (cm) }\end{array}$ & Material dated & $\begin{array}{l}{ }^{14} \mathrm{C} \text { age } \\
\text { (BP) }\end{array}$ & $\begin{array}{c}2-\sigma \text { calibrated dates } \\
\text { (OxCal 4.2) }\end{array}$ \\
\hline 171008 & TSR2.117 & $\begin{array}{c}\text { basin } \\
(30-34)\end{array}$ & aggregated charred xylum & $535 \pm 15$ & 1330-1340, 1396-1431 \\
\hline 171009 & TSR2.140 & $\begin{array}{l}\text { basin } \\
(74-80)\end{array}$ & $\begin{array}{l}\text { aggregated charred cuticle, } \\
\text { twig xylum, poss. needle } \\
\text { bundle }\end{array}$ & $455 \pm 15$ & $1427-1451$ \\
\hline 171010 & TSR2.251 & $\begin{array}{c}\text { basin } \\
(96-102)\end{array}$ & $\begin{array}{l}\text { aggregated charred cuticle, } \\
\text { stem, possible needle } \\
\text { bundle fragment }\end{array}$ & $545+15$ & $1325-1345,1393-1426$ \\
\hline 171011 & TSR3.139 & $\begin{array}{l}\text { berm } \\
(76-80)\end{array}$ & $\begin{array}{l}\text { aggregated charred seed } \\
\text { and cuticle }\end{array}$ & $600 \pm 15$ & 1304-1365, 1383-1403 \\
\hline
\end{tabular}

Wabakwa [LA 478] $(n=2)$

\begin{tabular}{|c|c|c|c|c|c|}
\hline $\begin{array}{l}\text { KECK } \\
\text { Lab \# }\end{array}$ & Sample ID & $\begin{array}{c}\text { Context \& } \\
\text { depth below } \\
\text { surface (cm) }\end{array}$ & Material dated & $\begin{array}{l}{ }^{14} \mathrm{C} \text { age } \\
\text { (BP) }\end{array}$ & $\begin{array}{c}2-\sigma \text { calibrated dates } \\
(\text { OxCal 4.2) }\end{array}$ \\
\hline 172767 & WAB2.309 & $\begin{array}{c}\text { basin } \\
(16-18)\end{array}$ & $\begin{array}{l}\text { aggregated charred needle } \\
\text { and cuticle fragments }\end{array}$ & Modern & 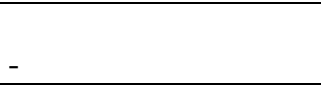 \\
\hline 172768 & WAB2.318 & $\begin{array}{l}\text { basin } \\
(34-36)\end{array}$ & $\begin{array}{l}\text { charred bark scale-twig } \\
\text { fragment }\end{array}$ & $795+15$ & $1219-1265$ \\
\hline
\end{tabular}

Yapashi [LA 250] (n=5)

\begin{tabular}{|c|c|c|c|c|c|}
\hline $\begin{array}{l}\text { KECK Lab } \\
\#\end{array}$ & Sample ID & $\begin{array}{l}\text { Context \& } \\
\text { depth below } \\
\text { surface }(\mathbf{c m})\end{array}$ & Material dated & $\begin{array}{l}{ }^{14} \mathrm{C} \text { age } \\
\text { (BP) }\end{array}$ & $\begin{array}{c}2-\sigma \text { calibrated dates } \\
(\text { OxCal 4.2) }\end{array}$ \\
\hline 172769 & YAP2.408 & $\begin{array}{l}\text { basin } \\
(10-16)\end{array}$ & $\begin{array}{l}\text { aggregated microchar of } \\
\text { charred cuticle and angio } \\
\text { wood xylum fragments }\end{array}$ & $510 \pm 15$ & $1409-1436$ \\
\hline 171012 & YAP2.118 & $\begin{array}{l}\text { basin } \\
(30-36)\end{array}$ & $\begin{array}{l}\text { aggregated wood xylum, } \\
\text { cuticles, and possible bark } \\
\text { scale }\end{array}$ & $590+20$ & 1304-1365, 1384-1409 \\
\hline 171013 & YAP2.137 & $\begin{array}{l}\text { basin } \\
(68-74)\end{array}$ & $\begin{array}{l}\text { aggregated wood xylum, } \\
\text { cuticle, and possible needle } \\
\text { bundle fragment }\end{array}$ & $585 \pm 15$ & $1310-1360,1386-1409$ \\
\hline 172770 & YAP3.311 & $\begin{array}{l}\text { berm } \\
(20-22)\end{array}$ & charred angio xylum & $540 \pm 15$ & $1328-1342,1395-1428$ \\
\hline 172771 & YAP3.327 & $\begin{array}{l}\text { berm } \\
(52-54)\end{array}$ & charred angio twig xylum & $665 \pm 15$ & 1281-1308, 1361-1387 \\
\hline
\end{tabular}


Yapashi [LA70790] (n=3)

\begin{tabular}{|c|c|c|c|c|c|}
\hline $\begin{array}{l}\text { KECK } \\
\text { Lab \# }\end{array}$ & Sample ID & $\begin{array}{l}\text { Context \& } \\
\text { depth below } \\
\text { surface (cm) }\end{array}$ & Material dated & $\begin{array}{l}{ }^{14} \mathrm{C} \text { age } \\
\text { (BP) }\end{array}$ & $\begin{array}{c}2-\sigma \text { calibrated dates } \\
\text { (OxCal 4.2) }\end{array}$ \\
\hline 170994 & $\begin{array}{c}\text { LA70790 } \\
2.118 \\
\end{array}$ & $\begin{array}{c}\text { basin } \\
(32-36)\end{array}$ & $\begin{array}{l}\text { aggregated charred needle } \\
\text { fragment, bark scales, and } \\
\text { cuticle }\end{array}$ & $685 \pm 15$ & $1276-1300,1368-1382$ \\
\hline 170995 & $\begin{array}{c}\text { LA70790 } \\
2.128 \\
\end{array}$ & $\begin{array}{c}\text { basin } \\
(50-56)\end{array}$ & $\begin{array}{l}\text { aggregated charred bark } \\
\text { scales, cuticle, twig xylum } \\
\text { fragments }\end{array}$ & $770 \pm 25$ & $1220-1280$ \\
\hline 172756 & $\begin{array}{c}\text { LA70790 } \\
3.306 \\
\end{array}$ & $\begin{array}{l}\text { basin } \\
(8-12)\end{array}$ & $\begin{array}{l}\text { aggregated microchar of } \\
\text { leaf cuticle and angio wood } \\
\text { xylum fragments }\end{array}$ & $630 \pm 15$ & 1293-1322, 1348-1393 \\
\hline
\end{tabular}

\section{Yapashi [LA70798] $(n=3)$}

Context \&

KECK depth below

Lab \# $\quad$ Sample ID surface $(\mathbf{c m})$

\begin{tabular}{|c|c|c|l|c|c|}
\hline 170996 & $\begin{array}{c}\text { LA70798 } \\
2.114\end{array}$ & $\begin{array}{c}\text { basin } \\
(22-28)\end{array}$ & $\begin{array}{l}\text { aggregated charred cuticle, } \\
\text { fine twig xylum, and poss. } \\
\text { leaf bundle fragments }\end{array}$ & $650 \pm 30$ & $1280-1326,1343-1395$ \\
\hline & $\begin{array}{c}\text { LA70798 } \\
2.121\end{array}$ & $\begin{array}{c}\text { basin } \\
(36-42)\end{array}$ & $\begin{array}{l}\text { aggregated charred cuticle, } \\
\text { seeds, and poss. cambium } \\
\text { fragment }\end{array}$ & $605 \pm 15$ & $1301-1368,1381-1401$ \\
\hline 170997 & $\begin{array}{c}\text { LA70798 } \\
\text { berm }\end{array}$ & $\begin{array}{l}\text { charred xylum } \\
\text { (18-20) }\end{array}$ & $865 \pm 20$ & $1056-1076,1153-1222$ \\
\hline
\end{tabular}

